\title{
The School Environment in Egypt. A Situation Analysis of Public Preparatory Schools [Arabic]
}

Sahar El Tawila

Cynthia B. Lloyd

Population Council

Barbara Mensch

Population Council

Hind Wassef

Zeinab Gamal

See next page for additional authors

Follow this and additional works at: https://knowledgecommons.popcouncil.org/departments_sbsr-pgy How does access to this work benefit you? Let us know!

\section{Recommended Citation}

El Tawila, Sahar, Cynthia B. Lloyd, Barbara Mensch, Hind Wassef, Zeinab Gamal, Wesley H. Clark, and Rania Sakr. 2000. "The School Environment in Egypt. A Situation Analysis of Public Preparatory Schools [Arabic]." Cairo: Population Council. 


\section{Authors}

Sahar El Tawila, Cynthia B. Lloyd, Barbara Mensch, Hind Wassef, Zeinab Gamal, Wesley H. Clark, and Rania Sakr 


$$
\begin{aligned}
& \text { مجلس السكان الدولى الدى } \\
& \text { نديورك - الولايات المتحدة الأمريكية } \\
& \text { يسعى مجلس السكان إلى تحسين رفاهية الأجيال الحالية } \\
& \text { والقادمة وصحتها الإنجابية فى كل أنحاء العالم. } \\
& \text { كما يسعى إلى تحقيق توازن إنسانى ومذصف ومستديم بين السكان والموارد . }
\end{aligned}
$$

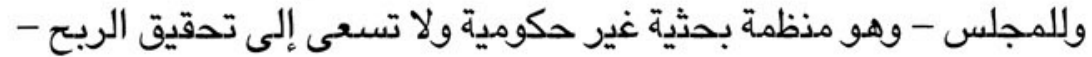

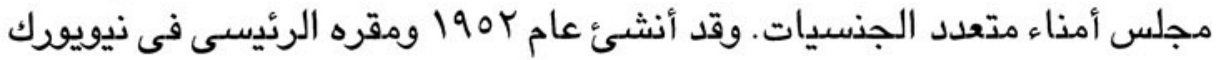

$$
\begin{aligned}
& \text { وله شبكة عالمية من المكاتب الإقليمية والقطرية. }
\end{aligned}
$$

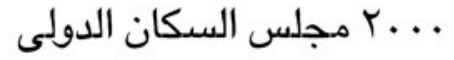

$$
\begin{aligned}
& \text { هذا الكتاب عمل مشترك بين مركز البحوث الإجتماعية } \\
& \text { بالجامعة الأمريكية بالقاهرة }
\end{aligned}
$$

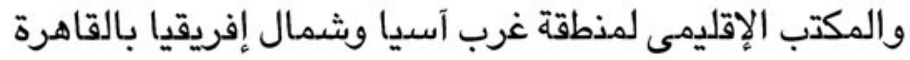

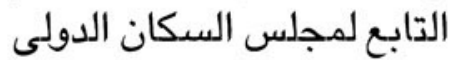

$$
\begin{aligned}
& \text { لمزيد من المعلومات عن الدراسة الرجاء الإتصال } \\
& \text { بالدكتورة سحر الطويلة }
\end{aligned}
$$

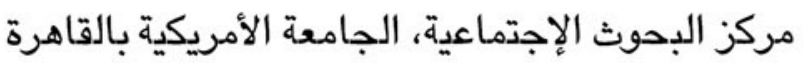

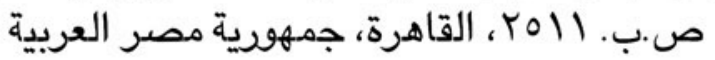

$$
\begin{aligned}
& \text { فاكس رقم: Y. T)VOOVY } \\
& \text { لمزيد من المعلومات والذستخ } \\
& \text { رجاء الاتصال بمجلس السكان الدولى من فولى } \\
& \text { مذطقة غرب آسيا وشمال أفريقيا } \\
& \text { ص.ب. } 110 \text { - الدقى - الجيزة - جمهورية مصر العربية } \\
& \text { تليفون: Y.r) Or00970) } \\
& \text { فاكس:Y } \\
& \text { بريد الكترونى:pccairo.org } \\
& \text { تصديم وطباعة } \\
& \text { دار النخيل للنشر والطباعة } \\
& \text { ع المذصور محمد - الزمالك }
\end{aligned}
$$

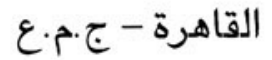

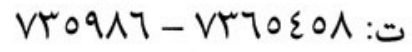

$$
\begin{aligned}
& \text { فاكس : ن : }
\end{aligned}
$$




\section{البيئة المدرسية في مصر: \\ تحليل حالة المدارس الإعدادية الحكومية}

سحر الطويلة، مركز البحوث الاجتماعية بالجامعة الأمريكية بالقاهرة

$$
\text { سينثيا لويد، مجلس السكان }
$$

زينب جمال، مركز البحوث الاجتماعية بالجامعة الأمريكية بالقاهرة

$$
\text { مع: ويسلي كلارك }
$$

الترجمة الى العربية: عمر الشافعى

$$
\text { ديسمبر • r... }
$$


الفصل الاول: تجرية التعليم: رؤية لانتقال النشء إلى مرحلة النضج ا الملفية

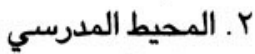

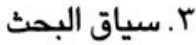
الفصل الثاني: تصميم و منهج الدراسة

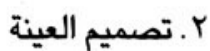 r. أدوات ومنهج الدراسة ع ـ مقدمة للجداول والنتائج

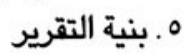

19

19

r.

YI

YY

rE

rV

$r$.

rI

rr

ro

ro

हr

$\varepsilon 0$

$\varepsilon 7$

$\varepsilon 9$

«q

01

or

or

or

०ᄉ

09

09

الفصل الثالث: حياة الطالب

$$
\text { ا } 1 \text { المقدمة }
$$

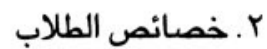

ז. العبء الدراسيى على الطلاب

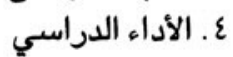

ه ـ الأنشطة غير الدراسية الدية

7 ـ تثبيط همة الطلاب في المدرسة الأنيطة

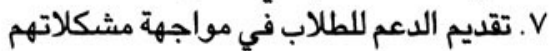

^. دعم احتياجات الطلاب من المعلومات

9. التطلعات والتوقعات الشخصية الطية للطلاب

. 1. الاستنتاجات التوات

الفصل الرابع: الصحة والنظافة العامة

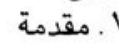

r r r r الخدمات الصحية المدرسية r. الصالة الصحية للطلاب والنظافة العامة في المدارس المس المبل ع. التواصل مـع الطلاب

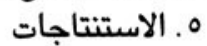

\footnotetext{
الفصل الخامس: الابعاد المتصلة بالنوع في البيئة المدرسية

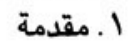

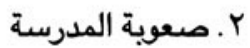
r. آراء العاملين حول قضايا مختارة تتصل بالسياسات

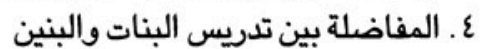

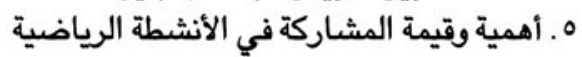

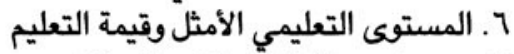

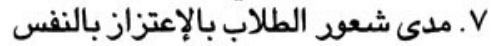

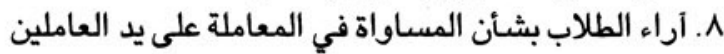

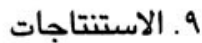




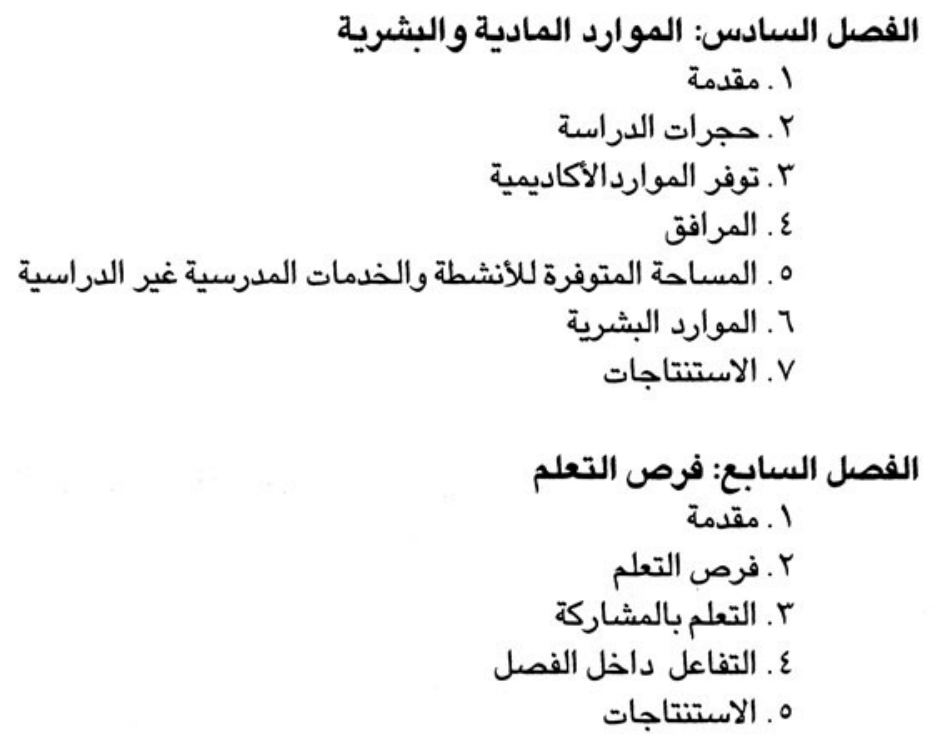

الفصل الثامن: القيادة المدرسية ودور أولياء الأمور

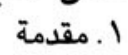
r r إدارة المدرسة: مدير المدرسة والدعم الإداري r. r. النظام والانضباط النداط ع. الرضا عن حالة المدرسة الناطية ه ـ دود أولياء الأمود والمجتمع المحلي 7. الاستنتاجات الملحق الأول: حساب أوزان العينة الملحق الثاني: الجداول الملحق الثالث: فريق جمع وإدارة البيانات

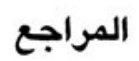
المؤلفون 


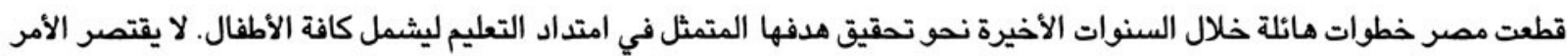

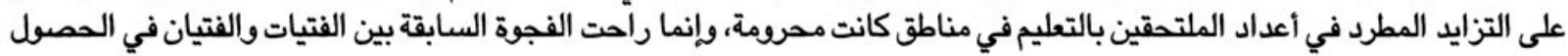

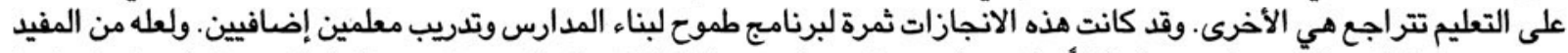

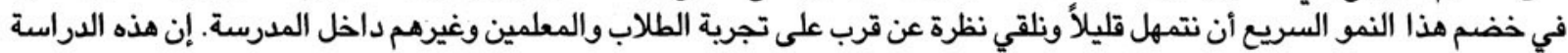

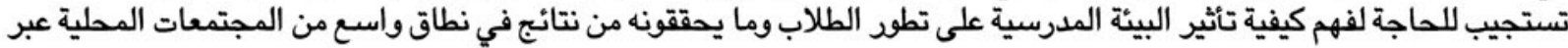

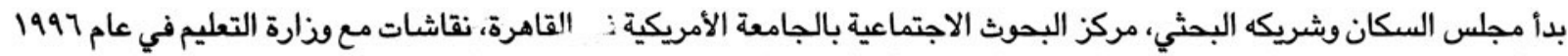

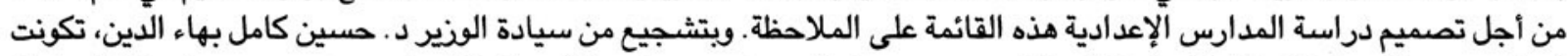

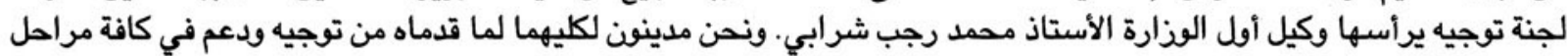

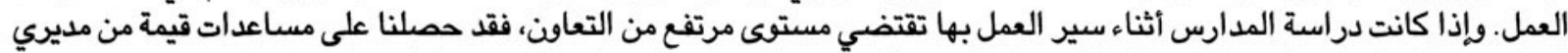

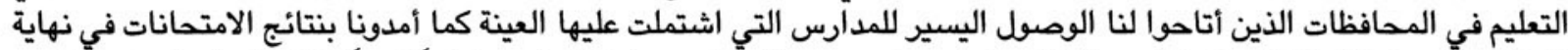

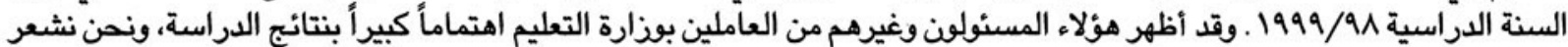

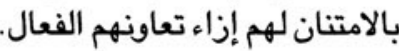

أسهه في هذهالدراسة العديد من الشركاء المانحين بالأفكار والموارد. ونود أن نعرب عن الامتنان لوكالة التنمية الدولية الكندية وهيئة

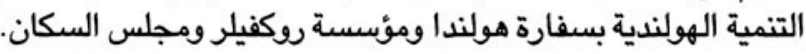

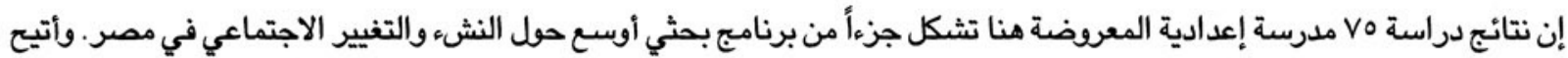

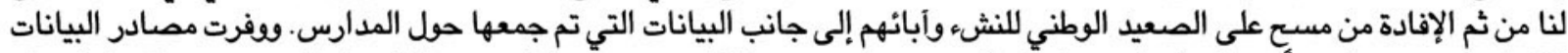

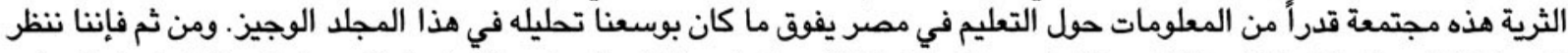

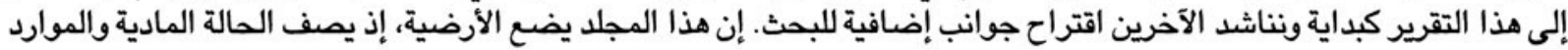

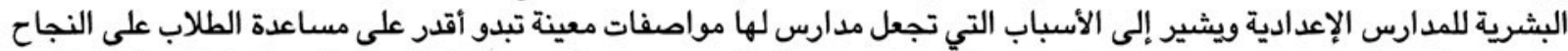

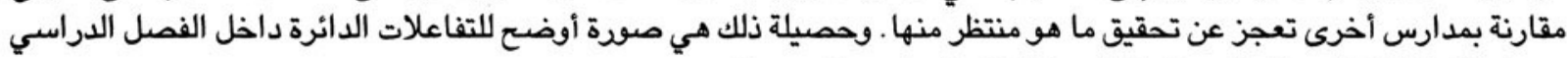

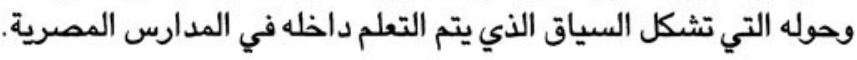

باريارا إبراهيم

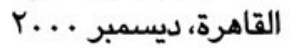




\section{شكر وتقدير}

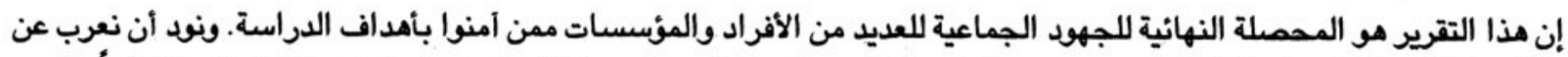

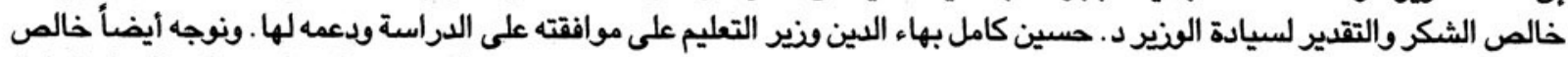

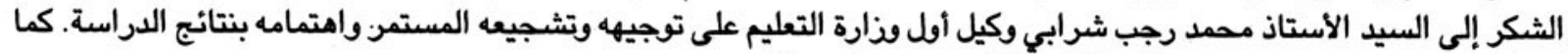

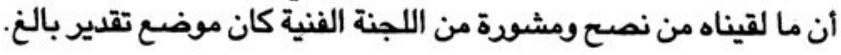

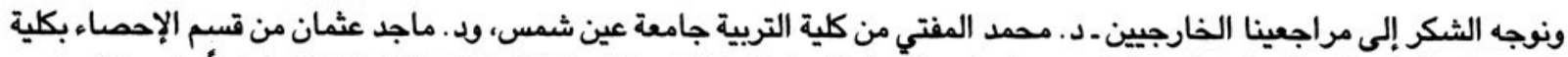

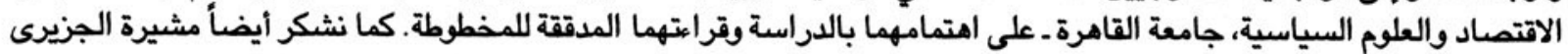
على القراءة والتحرير المدققين للتقرير النهاني.

ونود أن نعرب عن الامتنان للدكتو زكريا عبد السميع والأستاذة إقبال سامع إزاء ما قدماه من اسهامات وتعليقات قيمة فضلأ عن الدعم

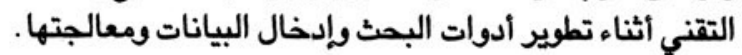

تولى الأستاذ عصمت خير ـ جنباً إلى جنب مع الأستاذة زينب جمال، مديرة العمل الميداني ـ الرقابة والإشراف العام على كافة العمليات الميدانية. وكان لإسهاماته دود حيوي في التنفيذ الناجح للمستح

ويبقى أن نعرب عن عميق تقديرنا للذين أجروا المقابلات، إذ أن تحقيق المهمة المنوطة بنا ما كان ليتم دون جهودهم المخلمة. 


\section{قائمة الأشكال}

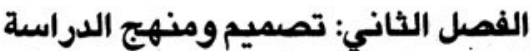

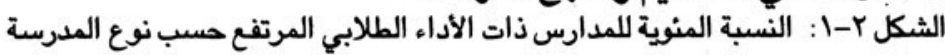

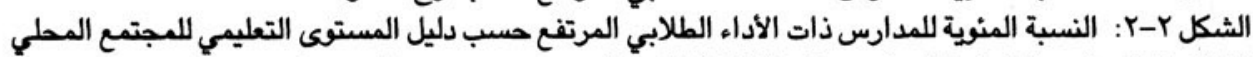
الشكل Y-T: النسبة المنوية للمدارس ذات الأداء الطلابي المرتفع حسب حجم المدرسة

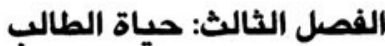

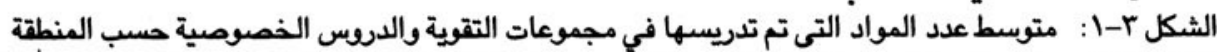

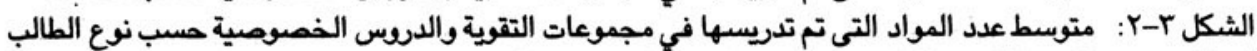

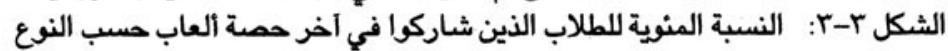

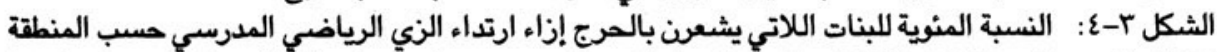

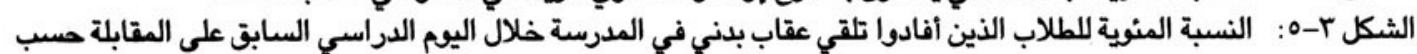
نوع الطالبة البرية

الشكل r-T: النسبة المنوية للطلاب الذين يعتقدن أن العاملين يمينغن في المعاملة بين الطلاب حسب المنطفة

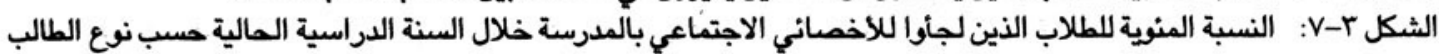

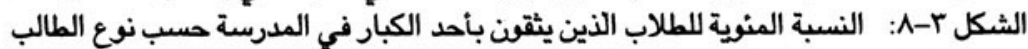

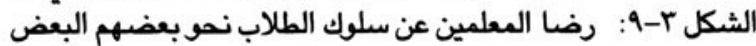

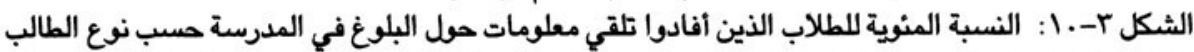

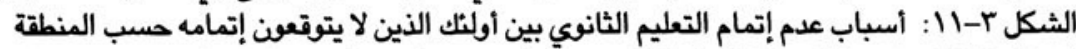
الشكل r-1 ا : النسبة المنوية للبنات اللاتي يرغبن/يتوقعن أن يعملن بعد إتمام الدراسة حسب المنطقة

الفصل الرابع: الصحة والنظافة العامة

الشكل ع-1 : : نسب التوزيع المنوية للمدارس حسب توفر الخدمات الطبية ومقدم الذدمات الطبية (طبيب/ممرضة)

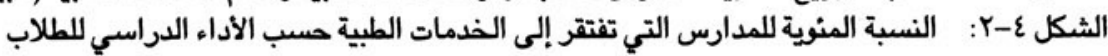

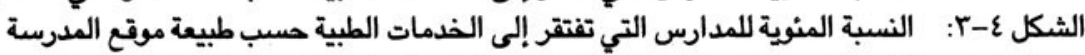

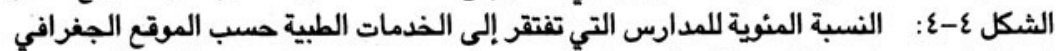

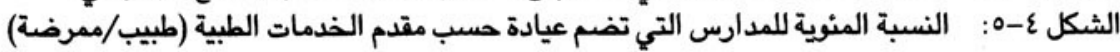

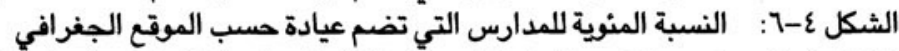

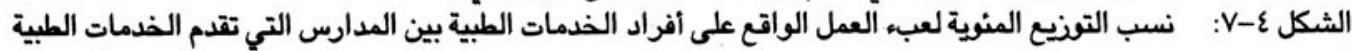

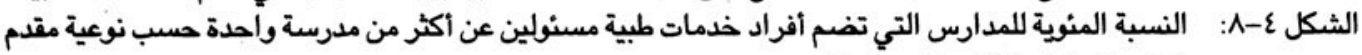
الخدمات الطبية (طبيب/ممرضة)

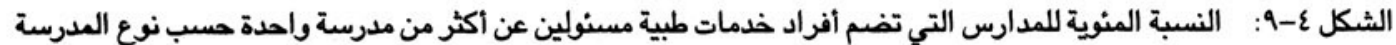

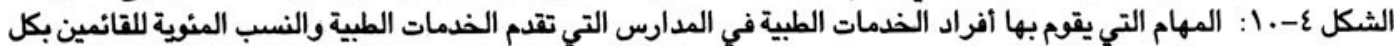

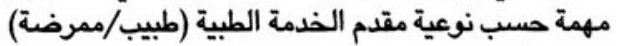

الشكل ع-1): النسبة المنوية للمدارس التي تضم أفراد خذمات طبية غير راضين بالكامل عن ساعات عملهم حسب الموقع

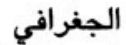

الشكل ع-1 ا : النسبة المئوية للمدارس التي تضم أفراد خدمات طبية غير راضين بالكامل عن المكان المخمص لعملهم حسب نوعية مقدم الخذمة الطبية (طبيب/ممرضية)

الشكل ع-1 : استذام الذذمات الطبية المدرسية من جانب الطلاب الذين شعروا بالمرض خلال الفصل الدراسي الألل ونسب توزيعهم المنوية في العدارس التي تقدم الخدمات الطبية الطبية

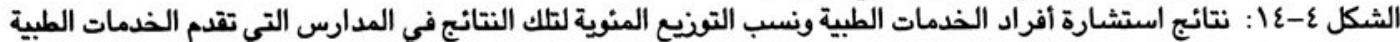

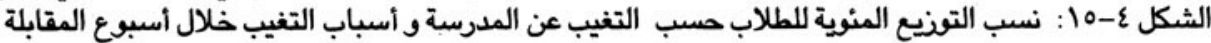

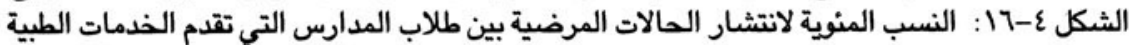

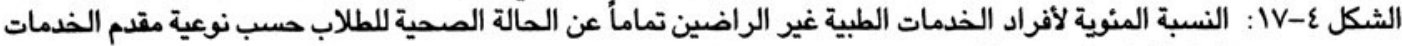

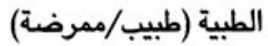

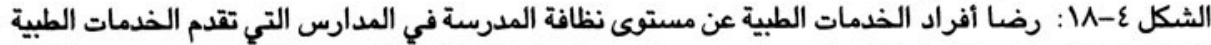

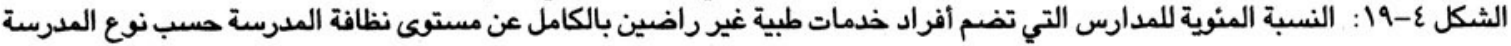

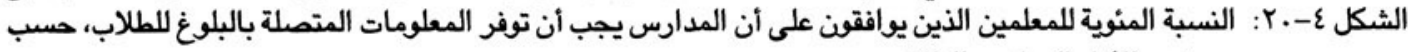

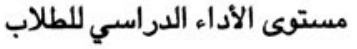
الشكل ع-Y1: النسبة المنوية للمعلمين الذين يوافقن على أن المدارس يجب أن توفر المعلومات المتملة بالبلوغ للطلاب، حسب

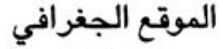




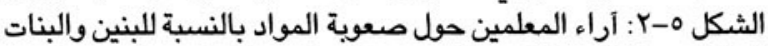

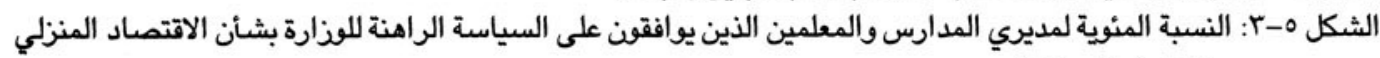
والزراعة والمناعة المبرية

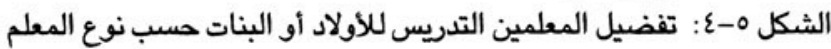

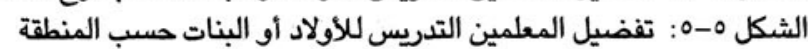
الشكل ه-1: النسبة المئوية لمديري المدارس والمعلمين الذينين أعربوا عن الدعم غير المشروط للمشاركة في الأنشطة الرياضية

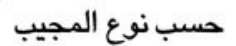
الشكل ه-V النسبة المئوية لمديري المدارس الذين أعربوا عن الدعم غير المشروط للمشاركة في الأنشطة الرياضية حسب المنطقة النمبة

الشكل ه-1: النسبة المئوية للمعلمين الذين أعربوا عن الدعم غير المشروط للمشاركة في الأنشطة الرياضية حسب المنطقة

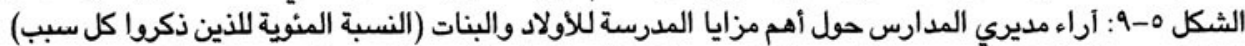

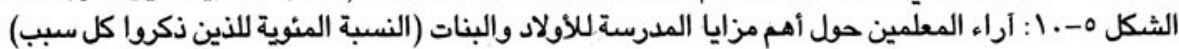

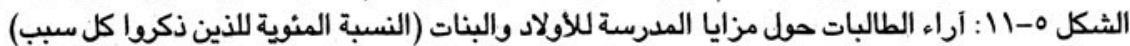

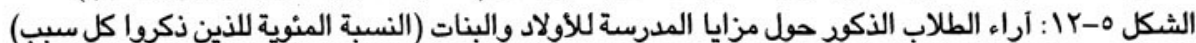

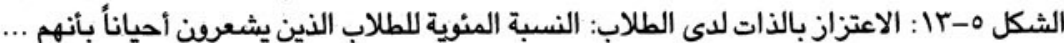

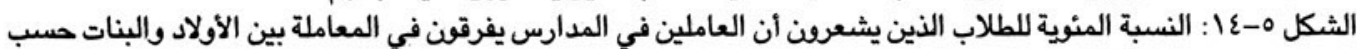

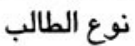
الشكل ه-10 : أراء الطلاب حول أي من الجنسين يتم تفضيله حسب نوع الطالب

الفصل السادس: الموارد المادية والبشرية

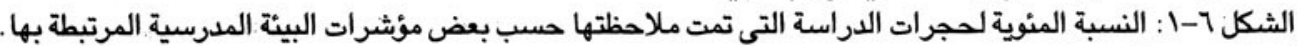

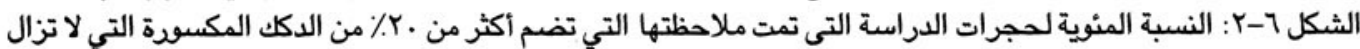

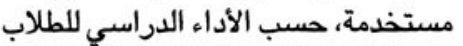

الشكل 1-r: النسبة المنوية لحجرات الدراسة التى تمت ملاحظتها والتى تتميز بالكثافة العالية (.7 V Vالب في الفمل)

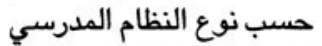

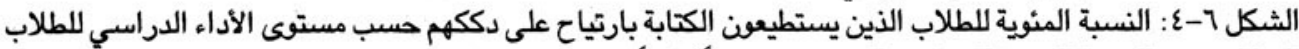

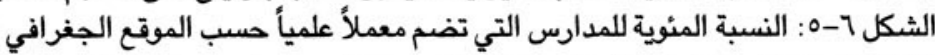

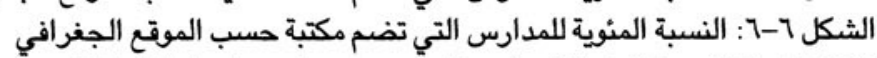

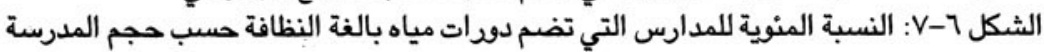
الشكل 1-A النسبة المئوية للطلاب الذين استخدموا دورة المياه المدرسية في يوم المقابلة أو اليوم السابق عليه حسب نوع

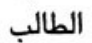
الشكل 1-9: النسبة المئوية للطلاب الذين يشعرون أن دورات المياه المدرسية تكفل الخصوصية حسب النوع

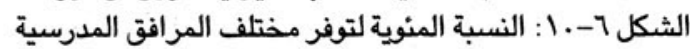

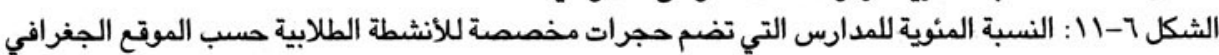

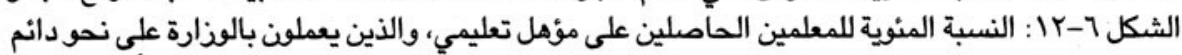

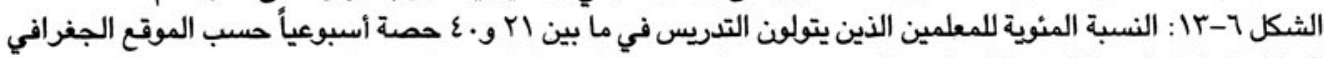

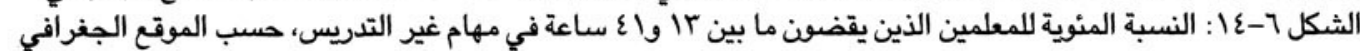

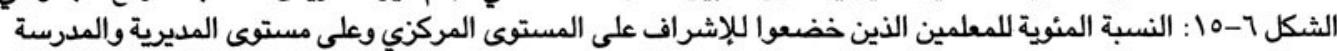

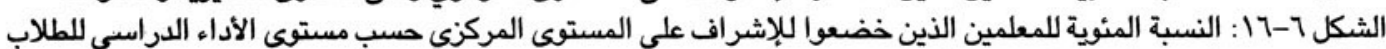

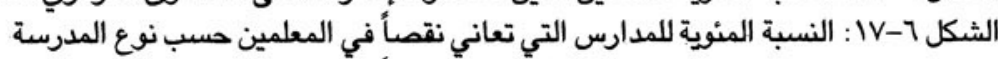

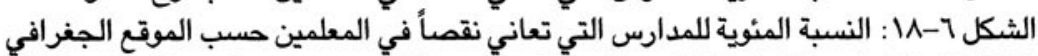

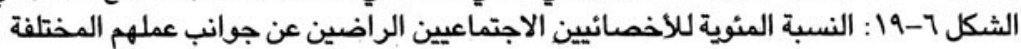
الشكل 1- -r: النسبة المئوية للأخصائيين الاجتماعيين الراضين الأين عن ظروف عملهم، حسب مستوى الأداء الدراسي للطلاب

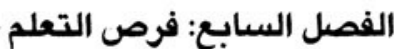

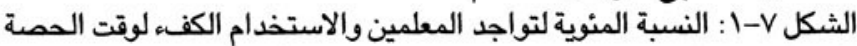

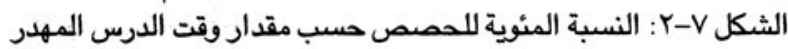

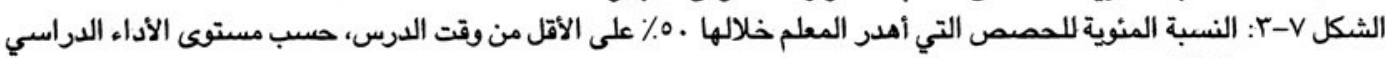

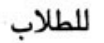
الشكل V-ع: النسبة المئوية للطلاب المتغييين ليوم واحد على الأقل خلال الأسبوع السابق على المقابلة حسب النوع 
$\wedge$.

^.

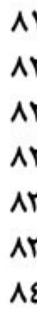

9.

9.

91

ar

ar

ar

वह

वह

90

90

90

97

97

$9 v$

av

91

91

99

99

I..

I..

1.1

1.1

I.Y

I.Y

I.Y
الشكل V-0 : النسبة المنوية للطلاب المتغيبين ليوم واحد على الأقل خلال الاسبوع السابق، على المقابلة حسب مستوى الأداء. الدراسي للطلاب المبلاب

الشكل V-7: النسبة المنوية للمعلمين المتغيبين ليوم واحد على الأقل خلال الأسبوع السابق، على المقابلة حسب مستوى الأداء الدراسي للطلاب المبليب

الشكل V-V: النسبة المنوية للطلاب الذين شاركوا في أنشطة خارج المقرد الدراسي خلال أسبوع المقابلة، حسب النظام

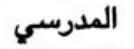

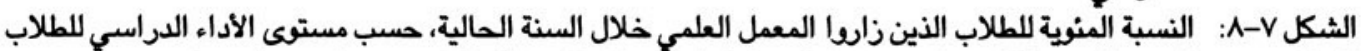

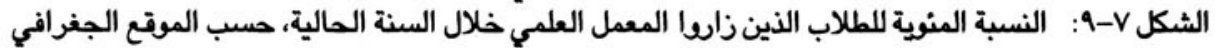

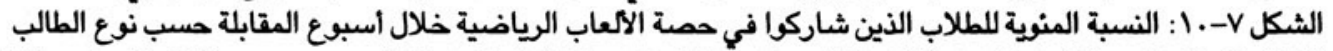

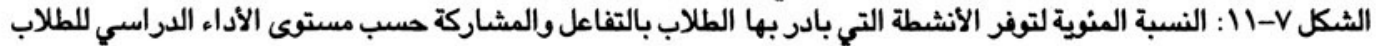

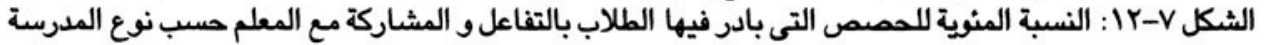

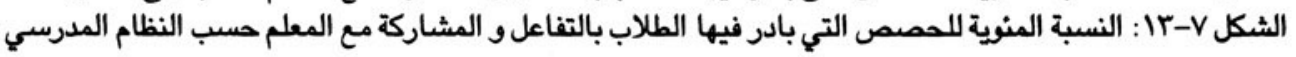

الفصل الثامن: القيادة المدرسية ودود أولياء الامور

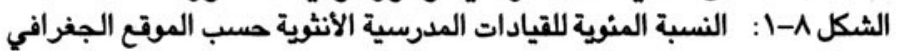

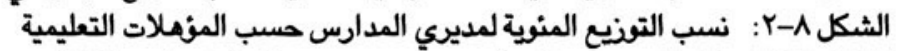

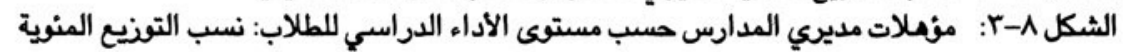

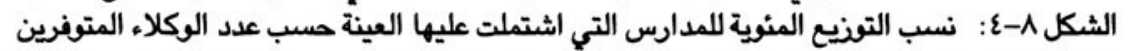

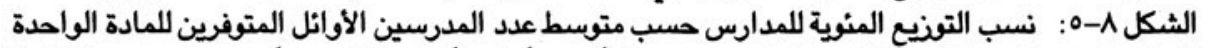

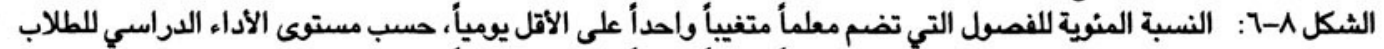

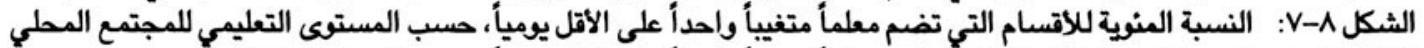

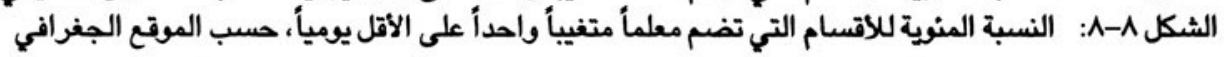

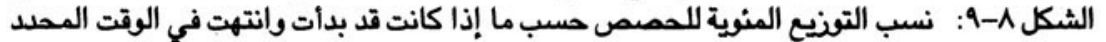

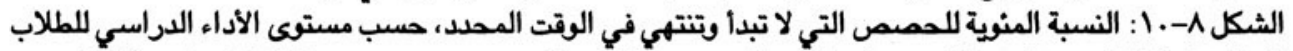

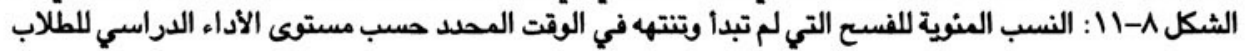

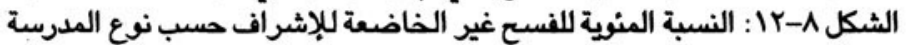

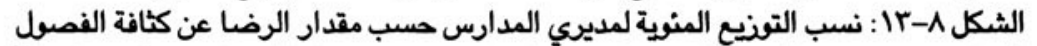

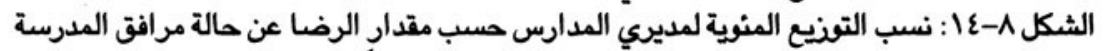

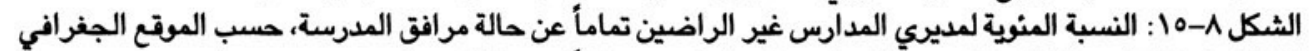

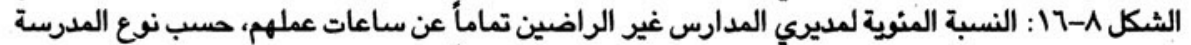

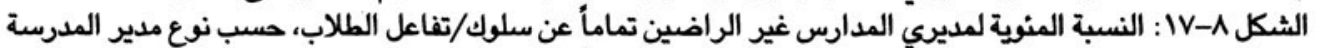

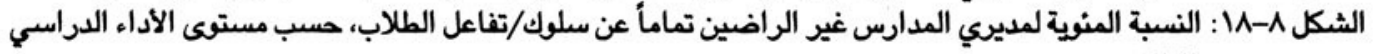
للطلاب

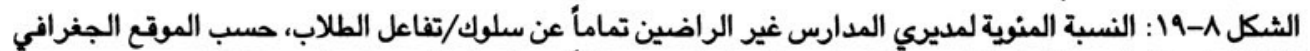

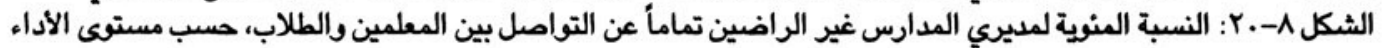

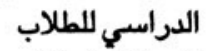

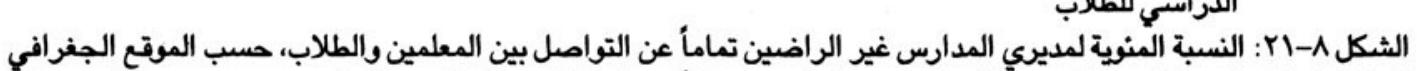

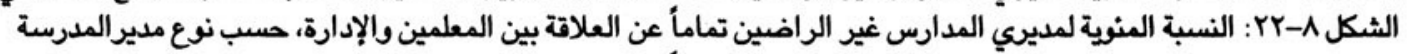

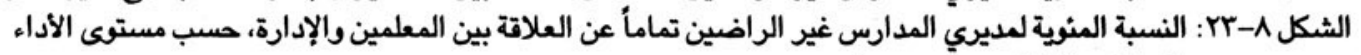

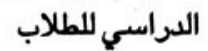

الشكل ^-^؟Y : نسب التوزيع المنوية للمدارس حسب ما إذا كانت قد تلقت إسهامات من المجتمع المحلي

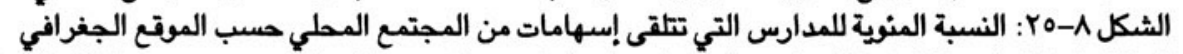

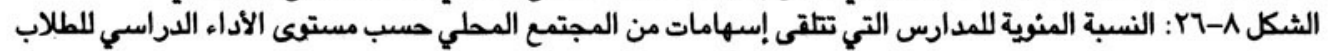




\section{قائمة الجداول}

1.

11

ir

I\&

10

IIr

IIr

IIE

IIE

110

117

117

IIV

111

119

119

ir.

$|r|$

IrT

ITr

ITE

iro

IYT

IrT

IrV

IrV

IKA
الفصل الثاني: تصميم و منهج الدراسة الداسة

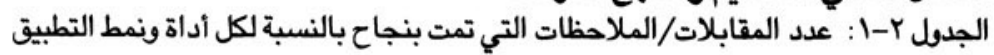

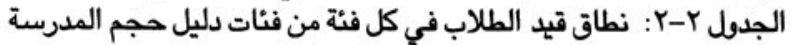

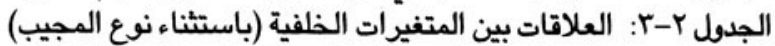

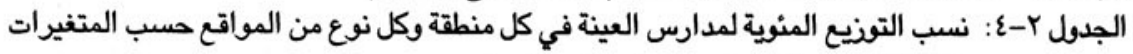

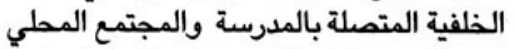

الجدول r-0: نسب التونيع المنوية لمستويات الأداء الدراسي المحلي للطلاب حسب المتغيرات الخلفية

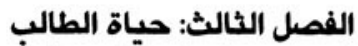

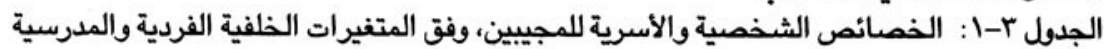

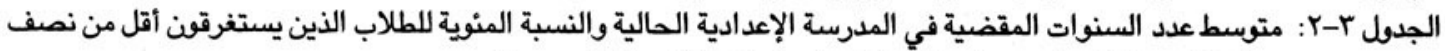

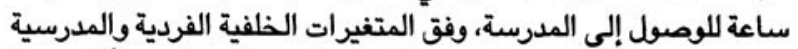

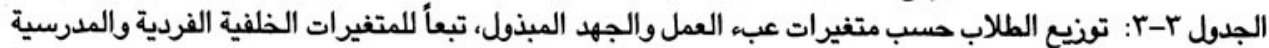

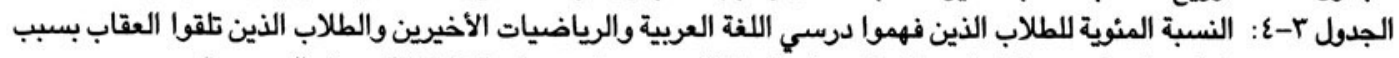

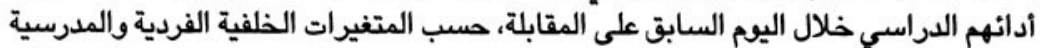

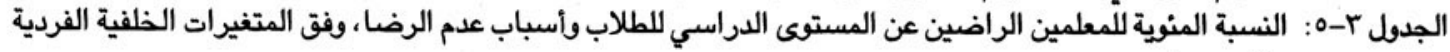
والمدرسية الجدول r-7: مقدار مشاركة الطلاب في الأنشطة غير الدراسية والنسبة المنوية للمشاركة في الأنشطة الاكثر شيوعاً، وفق المتغيرات الخلفية الفردية والمدرسية

الجدول r-r: النسبة المثوية للطلاب الذي تتوافر لهم حصص الألعاب الرياضية والذين شاركوا في حصص الألعاب الرياضية،

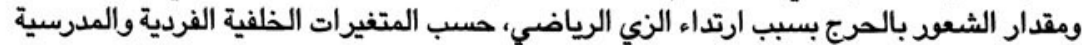

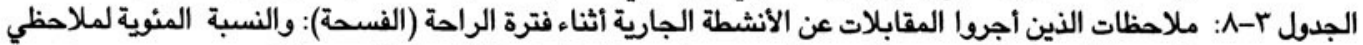

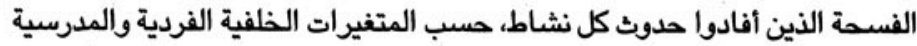

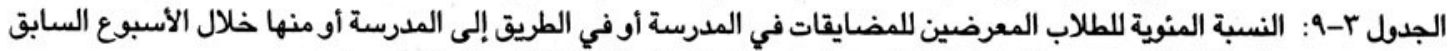

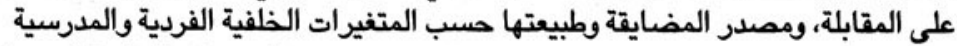

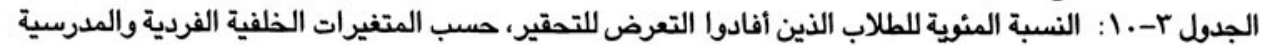

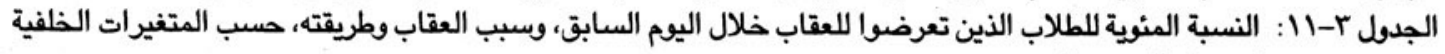
الفردية والمدرسية الفية الفية الفية

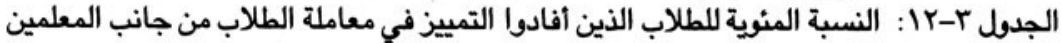

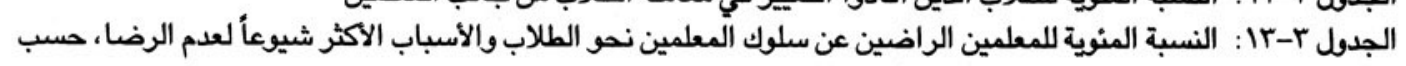

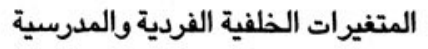

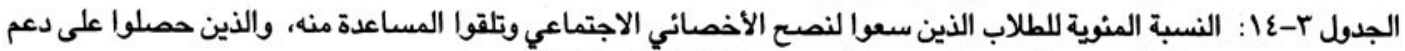

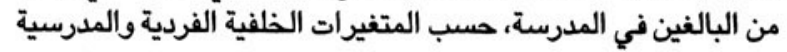

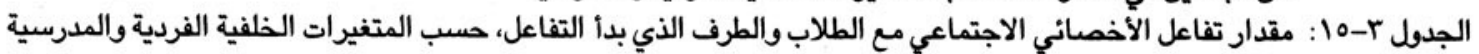

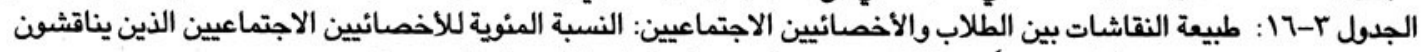

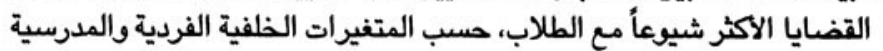

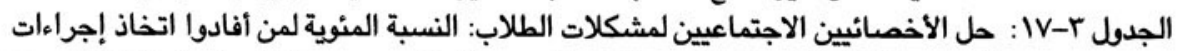

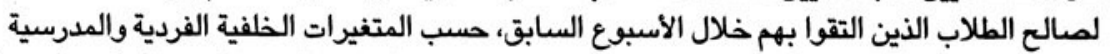

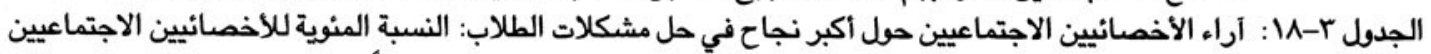

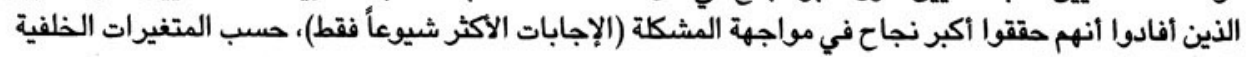

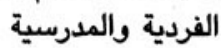

الجدول r-19: اراء الأخصانيين الاجتماعيين حل أخطر المشكلات الخاصة بالطلاب في المدرسة: النسبة المنوية لمن ذكروا كل

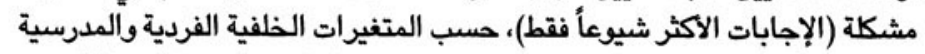

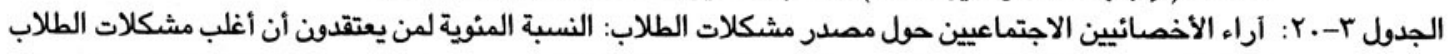

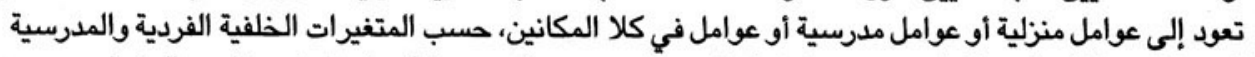

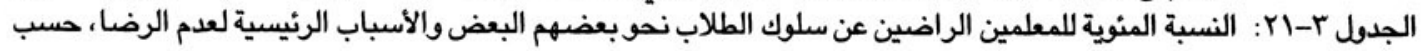

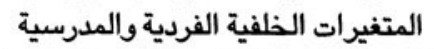
الجدول r-rr: النسبة المنوية للطلاب الذين يتلقون معلومات حل الفية التغيرات المصاحبة للنضوج أو الحيض والشئون الصحية المتصلة

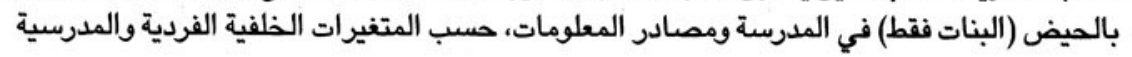


179

Irr

IT

IrE

ITE

iro

Iro

IrT

IrT

IrV

IrV

IrA

ITA

179

ira

$1 \varepsilon$.

الجدول r Tr-r : تطلعات الطلاب وتوقعاتهم بشأن مواصلة التعليم والعمل، والنسبة المنوية لمن يتوقعون مواصلة التعليم الثانوي، وأسباب توقع التوقف عن التعليم، و(بين البنات) التوقعات المتعلقة بالعمل، حسب المتغيرات التئرات الخلفية الفردية والمدرسية

الفصل الرابع: الصحة والنظافة العامة الجدول ع-1: نسب التوزيع المئوية للمدارس حسب توافر الخدمات المبات الصحية ونوعية مقدم الخدمات الطبية (طبيب/ ممرضة)، حسب

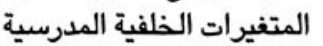
الجدول ع-r- توافر مقدمي الخدمات الطبية في مدارس العينة: نسب التوزيع المنوية بين المدارس التي تقدم الخدمات الصحية، حسب

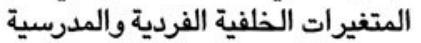
الجدول ع-r: نسب التوزيع المئوية لمقدمي الخدمات الطبية حسب النوع والمؤهلات والمتغيرات الخلفية المدرسية، بين المدارس التي تقدم الخدمات الصدية الجدول ع-ع: الوقت الذي يستغرقه مقدم الخدمات الطبية للوصول إلى المدرسة: نسب التوزيع المنوية بين العاملين بالمدارس التي

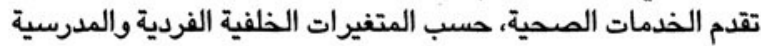

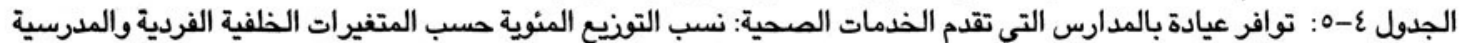

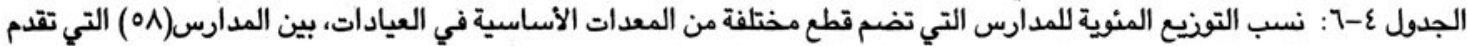
الخدمات الصحية

الجدول ع-V: نسب التوزيع المئوية لعبه العمل الواقع على مقدمي الخدمات الطبية بين المدارس التي تقدم الخدمات الطبية، حسب المتغيرات الخلفية الفردية والمدرسية المبية

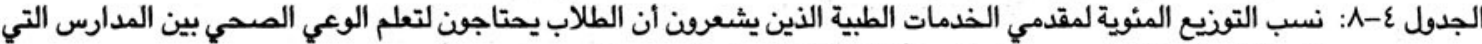

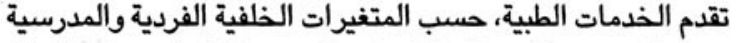
الجدول ع-9: مشاركة مقدمي الخدمات الطبية في التدريب أثناء الخدمة خلال السنتين السابقتين، بين المدارس التي تقدم الخدمات الصحية

الجدول ع-ـ 1: رضا مقدمي الخدمات الطبية عن واجباتهم ومسنولياتهم، وساعات عملهم، والمكان المخصص لعملهم: نسب التونيع

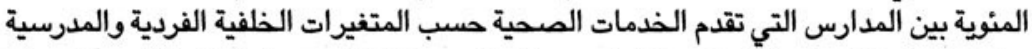

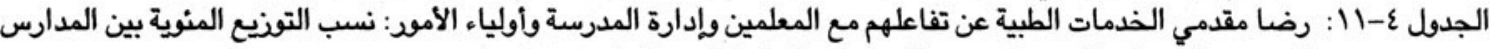

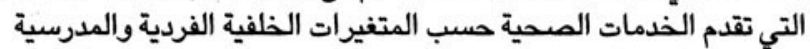

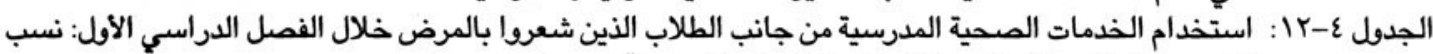

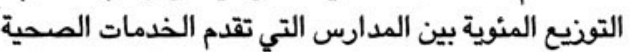

الجدول ع-rا: نتيجة استشارة الطلاب لمقدمي الخدمات الطبية في المدرسة: النسبة المنوية بين المدارس التي تقدم الخدمات الصحية حسب المتغيرات الخلفية الفردية والمدربية الفرمات المبية الجدول ع-ع : رضا مقدمي الخدمات الطبية عن الحالة الصحية للطلاب: نسب التوزيع المنوية بين المدارس التي تقدم الخدمات

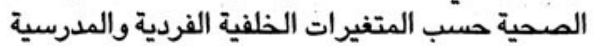
الجدول ع-10: رضا مقدمي الخدمات الطبية عن مستوى النظافة في المدرسة: نسب التونيع المنية الفية الفية بين المدارس

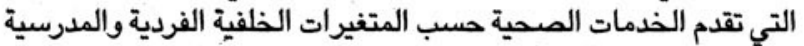

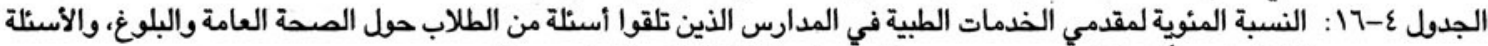

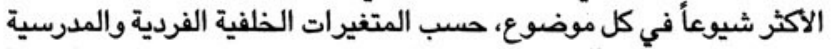

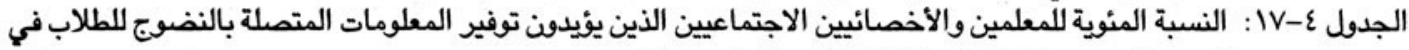
المدرسة، حسب المتغيرات الخلفية الفردية والمدرسية المائين

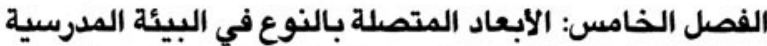
الجدول ه-1 : النسبة المنوية لمديري المدارس الذين يعتقدون أن بعض المواد أصعب المبل بالنسبة لأحد الجنسين أكثر من الآخر، حسب المتغيرات الخلفية الفردية والمدرسية الجدول ه-Y: النسبة المنوية للمعلمين الذين يعتقدون أن بعض المواد أصعب بالنسبة لأحد الجنسين أكثر من الآخر، حسب المتغيرات

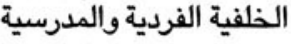

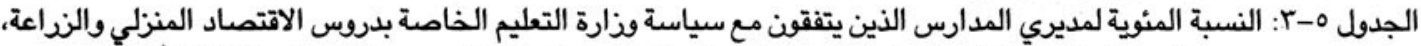

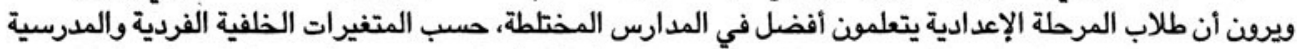

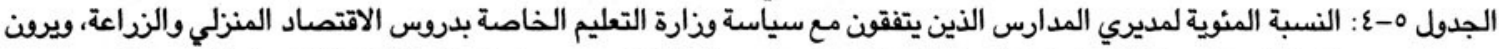

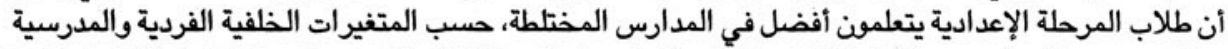

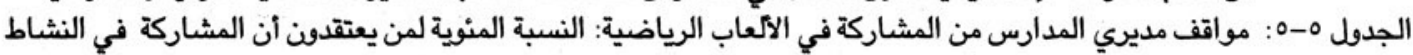

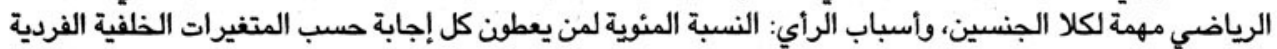
والمدرسية

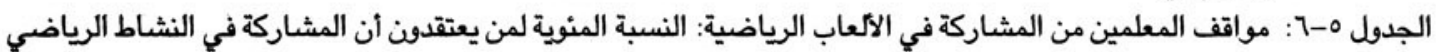

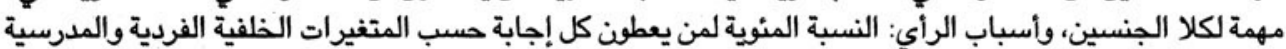

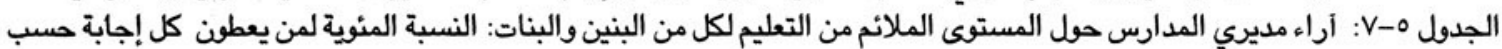


الجدول ه-1: آراء المعلمين حول المستوى الملائم من التعليم لكل من البنين والبنات: النسبة المنوية لمن يعطون كل إجابة حسب

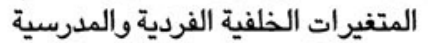
الجدول ه-9: مواقف الطلاب حل المستوى الملانم من التعليم لكل من البنين والبنات: النسبة المنوية لمن يعطون كل إجابة حسب المتغيرات الخلفية الفردية والمدرسية

الجدول هـ ـ 1 : مواقف مديري المدارس حل مزية اتيا التعليم للبنين: النسبة المئوية لمن يعطون كل إجابة حسب المتغيرات الخلفية الفردية والمدرسية

الجدول ه-11/ : مواقف مديري المدارس حول مزايا التعليم للبنات: النسبة المئوية لمن يعطون كل إجابة حسب المتغيراتالخلفية الفردية والمدرسية

الجدول ه- Y ا : مواقف المعلمين حول مزايا التعليم للبنين: النسبة المنوية لمن يعطون كل إجابة حسب المتغيرات الخلفية الفردية والمدرسية الجدول ه-r| : مواقف المعلمين حل مزايا التعليم للبنات: النسبة المنوية لمن يعطون كل إجابة حسب المتغيرات الخلفية الفردية والمدرسية الجدول ه-ع ا : مواقف الطلاب حول مزايا التعليم للبنين: النسبة المنوية لمن يعطون كل إجابة حسب المتغيرات الخلفية الفردية والمدرسية الجدول ه-10: مواقف الطلاب حول مزايا التعليم للبنات: النسبة المئوية لمن يعطون كل إجابة حسب المتغيرات الخلفية الفردية والمدرسية الجدول ه-17 : قياسات لشعود الطلاب بالاعتزاز بالذات: النسبة المئوية للطلاب الذين يتفقون مع الجمل المتصلة

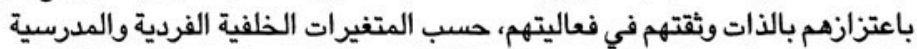

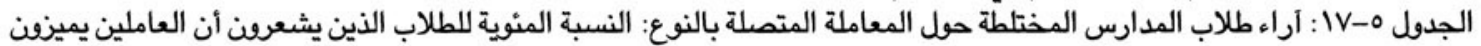

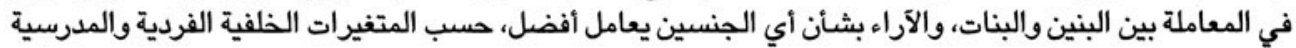

الفصل السادس: الموارد المادية والبشرية

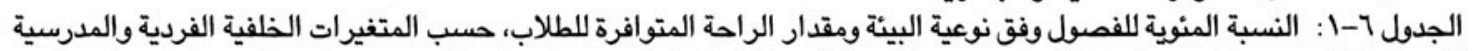

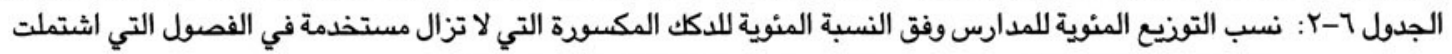

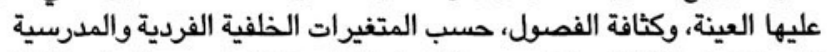

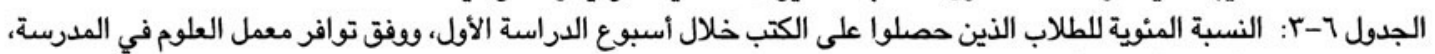

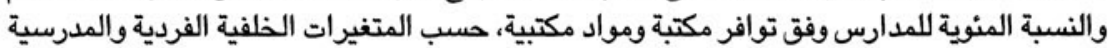
الجدول 7-ع: النسبة المئوية للمدارس وفق توافر واستخدام الموارد والمرافق الدراسية وغير الدراسية واسية، حسب المتغيرات الفية الخلفية الفردية والمدرسية المبية

الجدول 1-ه : النسبة المنوية للمدارس وفق توافر الصنابير والمراحيض ونظافة المراحيض، حسب المتغيرات الخلفية الفردية والمدرسية الجدول 1-7 : استخدام الطلاب لمراحيض المدرسة وتصورهم للخصوصية داخل دورات المياه: النسبة المئوية حسب المتغيرات الخلفية الفردية والمدرسية الطرابية المبنية

الجدول 1V- النسبة المنوية للمدارس وفق توافر حجرات الأنشطة والحجرات المخصصة للأخصائيين الاجتماعيين والحديقة،

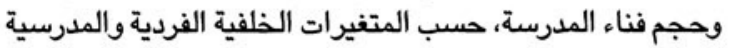
الجدول 1-1: نسب التوزيع المئوية للمعلمين من الذكود والإناث، والمعلمين ذوي المؤهية الميلات التعليمية، والذين يعدون موظفين دائمين

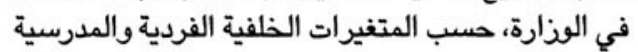
الجدول 1-9: نسب التوزيع المنوية للمعلمين وفق العمر والخبرة المهنية، والنسبة المنوية لمن تلقوا التدريب مؤخراً، حسب المتغيرات الخلفية الفردية والمدرسية المبنية الجدول 1- ـ ا : نسب التوزيع المنوية للمعلمين وفق مقدار التدريس والمسئوليات الأخرى، والرضا عن عبء العمل، حسب المتغيرات الخلفية الفردية والمدرسية المبنية الجدول 1-11 : مقدار الإشراف على المعلم: النسبة المنوية للمعلمين الذين يخضعون للإشراف المركزي والإشراف على مستوى المئي

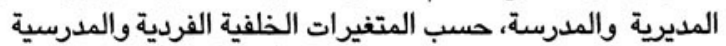
الجدول 1 1 ا : النسبة المنوية للمدارس التي تعاني نقصاً عاماً في المعلمين ونقص المعلمين وفق المادة، حسب المتغيرات الخلفية الفردية والمدرسية المنوبة لمبية الجدول 1-با : النسبة المئوية للأخصائيين الاجتماعيين الذين أفادوا وجود آخرين يساعدونهم بشأن مشكلات الطلاب، ومسئولياتهم

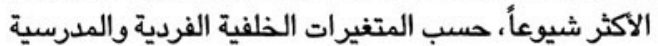

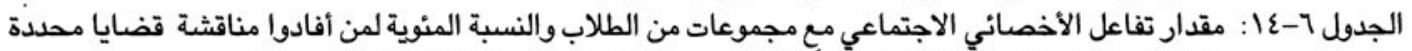

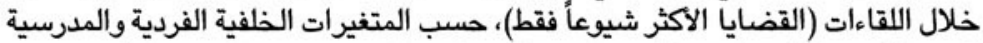

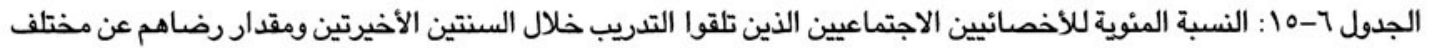

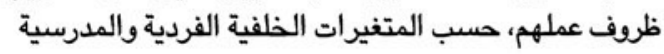




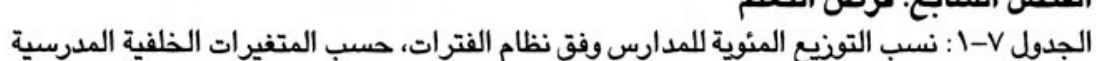

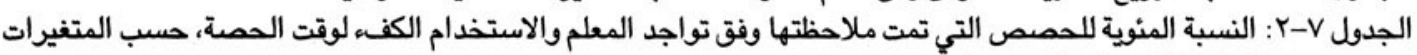
الخلفية الفردية والمدرسية النية النية الجدول V-r: النسبة المئوية لتفيب الطلاب ومتوسط عدد الأيام التي تغيكب فيها الطالب خلال الأسبوع الأخير، حسب المتغيرات

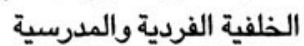
الجدول V-ع: مقدار توافر فرص التعلم التطبيقية: النسبة المنوية للطلاب الذين أفادوا المشاركة في أنشطة متنوعة وتلقي دربس الفيس

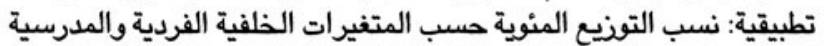

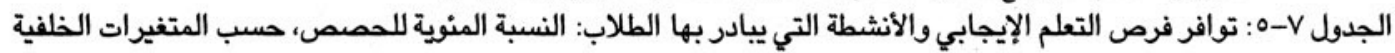
الفردية والمدرسية

الفصل الثامن: القيادة المدرسية ودور أولياء الأمور

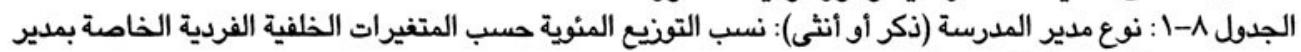
المدرسة والمدرسية

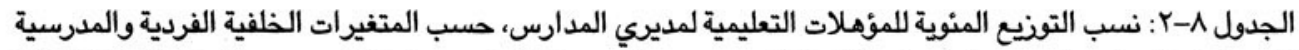
الجدول ^-r: متوسط عدد سنوات خبرة العمل كمدير مدرسة ومدير لهذه المدرسة بالذات، حسب المبرية المتغيرات الخلفية الفردية والمدرسية الجدول ^-عأ: نسب التوزيع المنوية لمديري المدارس الذين تلقوا تدريباً أثناء الخدمة خلال السنتين الأخيرتين، حسب المتغيرات الخلفية الفردية والمدرسية المتية

الجدول ^-عب: نسب التونيع المنوية لمديري المدارس فيما يتلعق برضاهم عن التدريب أثناء الخدمة الذي تلقوه خلال السنتين الأخيرتين الجدول ^-01: نسب التوزيع المنوية لمتوسط عدد المدرسين الأوائل لكل مادة، حسب المتفيرات الخلفية الفردية الخاصة بمدير المدرسة والمدرسية المتوبة المبرية

الجدول ^-0ب: نسب التونيع المنوية لمدارس العينة وفق عدد الوكلاء المتوافرين، حسب المتفيرات الخلفية الفردية والمدرسية

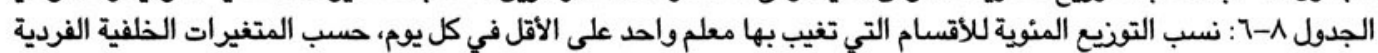

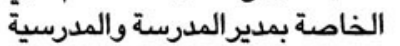
الجدول ^-V: نسب التوزيع المئوية للاقتسام وفق عدد محاولات ملاحظة الفصول الفاشلة، حسب المتغيرات الخلفية الفردية الخاصة بمدير المدرسة والمدرسية الموبة المبية الجدول ^-^: نسب التوزيع المنوية للحصص التي تمت ملاحظتها وفق ما إذا كانت قد بدأت وانتهت في موعدها المحدد، حسب

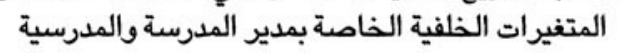

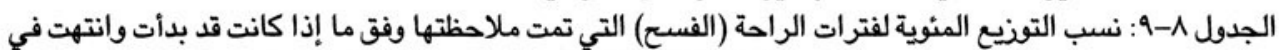

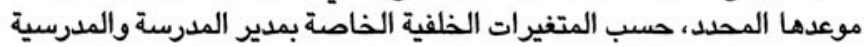
الجدول ^-ـ ـ : نسب التوزيع المئوية لفترات الراحة التي لم يتم الإشراف عليها، حسب المتغيرات الخلفية الخاصة

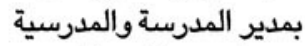
الجدول ^-11| : نسب التوزيع المئوية لمديري المدارس وفق مستوى رضاهم عن كثافة الفصول، حسب المتغيرات الخلفية الفردية والمدرسية الموية الجدول ^-1 | : نسب التوزيع المئوية لمديري المدارس وفق مستوى رضاهم عن حالة مرافق المدرسة، حسب المتغيرات الخلفية الفردية والمدرية المبية المدراية

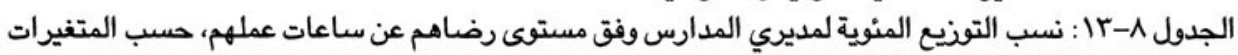
الخلفية الفردية والمدرسية المبوية الجدول ^-ع | : نسب التوزيع المنوية لمديري المدارس وفق مستوى رضاهم عن سلوك الطلاب فيما بينهم، حسب المتغيرات الخلفية الفردية والمدرية المدية الجدول ^-10 : نسب التوزيع المنوية لمديري المدارس وفق مستوى رضاهم عن التفاعل بين المعلمين والطلاب،

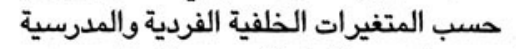
الجدول ^-17 : نسب التوزيع المئوية لمديري المدارس وفقت مستوى رضاهم عن العلاقة بين المعلمين وإدارة المدرسة، حسب المتغيرات الخلفية الفردية والمدربية التربية الجدول IV-1 : نسب التوزيع المنوية لمديري المدارس الذين يشجعون الوالدين على المشاركة في الأنشطة المدرسية، حسب المتغيرات الخلفية الفردية والمدربية المبرية المبرية الجدول ^-^| : النسبة المنوية للمدارس التي تحصل على مساهمات من المجتمع المحلي، حسب المتغيرات الخلفية الفردية والمدرسية الجدول 1-19 : نسب التوزيع المئوية لمديري المدارس وفق مستوى رضاهم عن علاقتهم بالوالدين 


\section{ملخص}

شهد العقدان الأخيران اهتماماً غير مسبوق من جانب الحكومة المصرية بقطاع التعليم. فحتى أوائل الثمانينات، كانت إمكانية الحصول

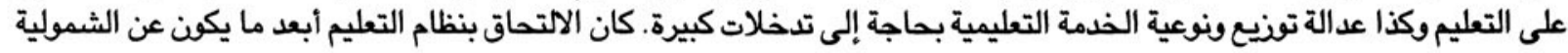

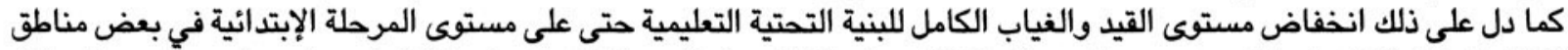

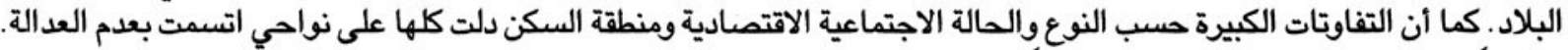

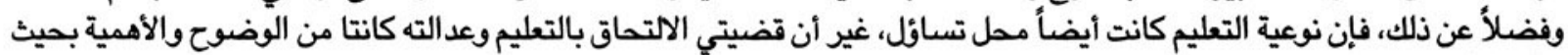

غطيتا على ما سواهما.

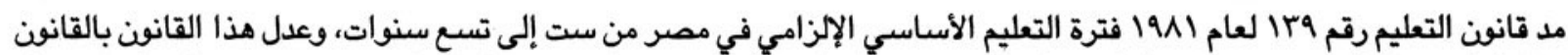

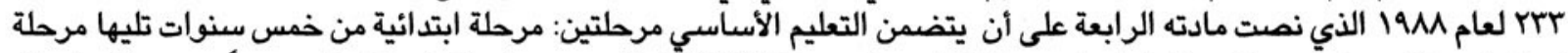

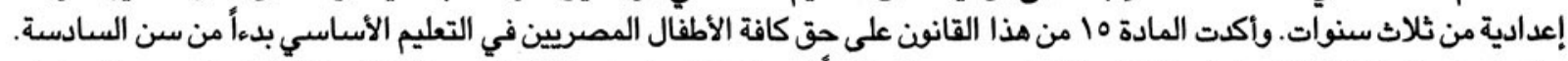

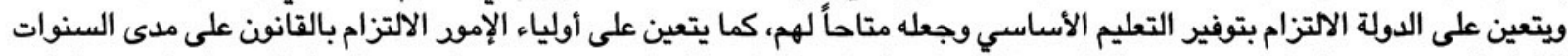

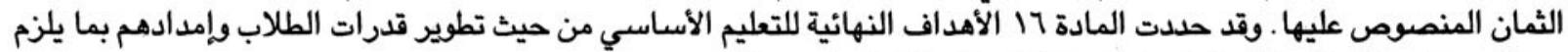

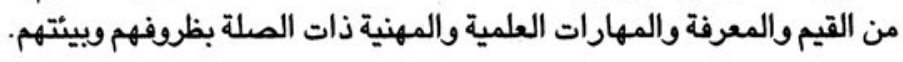

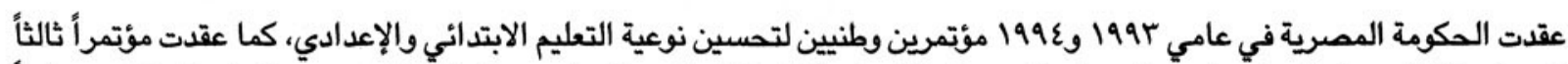

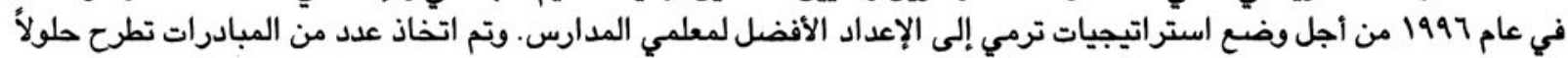

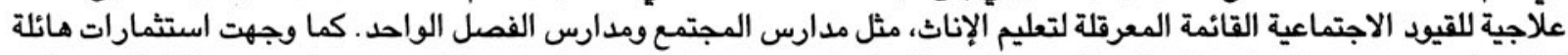

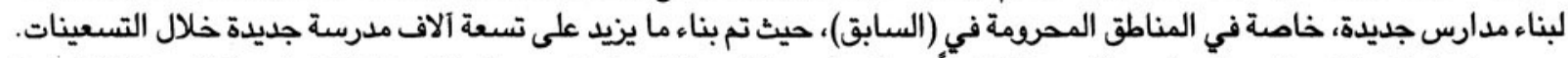

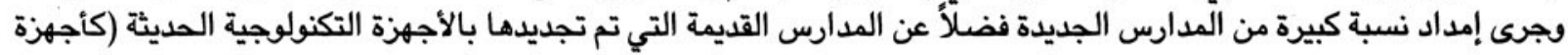

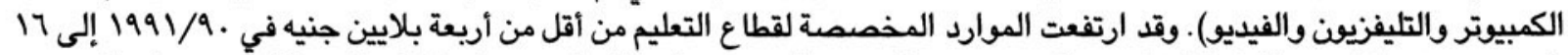

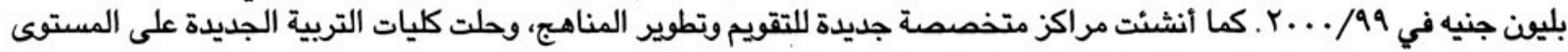
الجامعي محل مدارس المعلمين القديمة التي تعادل المستوى الثانوي.

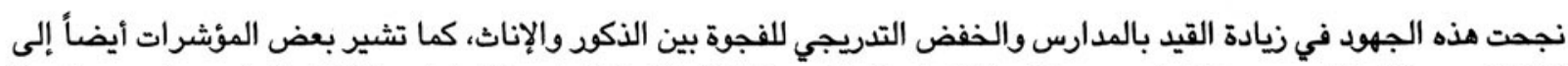

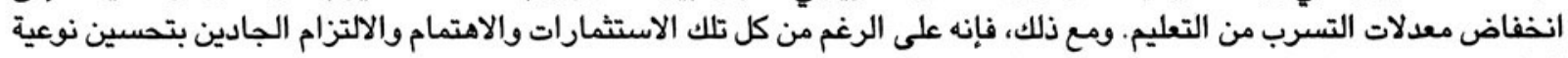

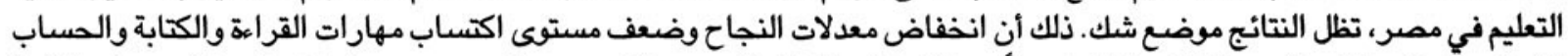

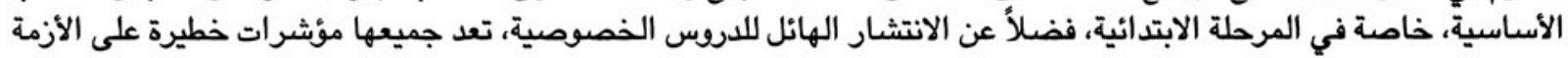
التعليمية في مصر . وقد آن الأوان لمناقشة ما يكتبه الطلاب من المدارس من حيث تطود المدارك والمعرفة العلمية والمهارات الحئ الحياتية

والقيم.

تواجه المؤسسة التعليمية في مصر في الوقت الراهن تحديات عديدة:

- الظروف العالمية ذات الأبعاد الاقتصادية والتي تقتضي الإعداد الجاد للأجيال الشابة وإمدادها بالمهارات اللازمة للمنافسة في الأسواق العالمية.

- فرص العمل المتاحة على الصعيد المحلي والمتوفرة أمام الأجيال الشابة عند إتمام تعليمها (وقبل إتمامه)، وهو الأمر الذي يؤثر بقوة في مدى التزام أبناء هذه الأجيال وآبائهم بالتعليم.

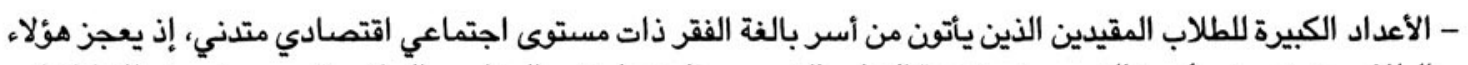

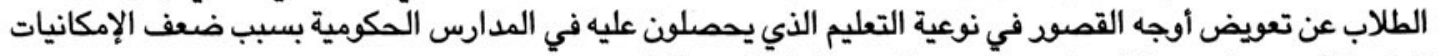
المادية لأسرهم أونتيجة انخفاض مستوى التحصيل التعليمي لآبائهم.

- التعرض غير المسبوق لصغار السن لوسائل الإعلام العالمية، وما يرتبط بذلك من تعرض كبير لأعراف وأنساق جديدة من القيم.

ليست المؤسسة التعليمية في مصر مسئولة عن خلق هذه الظروف، بيد أنها قد تكون مسئولة عن مواجهتها بحسم والتعامل معها بالجدية 


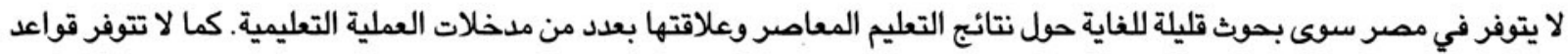

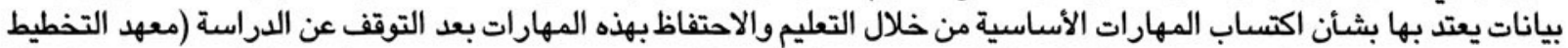

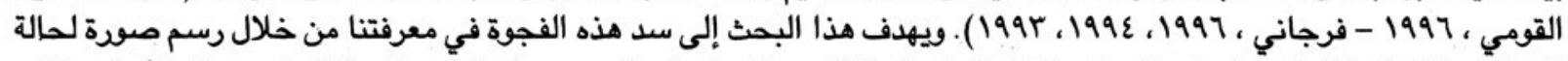

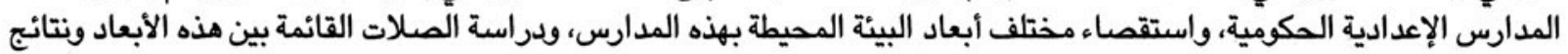

تعليمية محددة.

\section{نطاق وأهمية الدراسة}

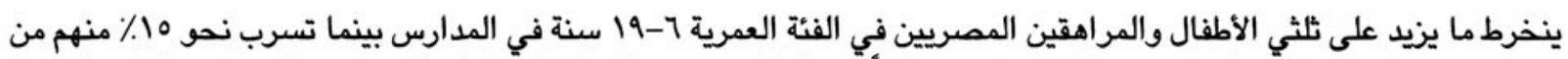

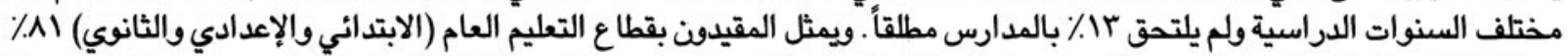

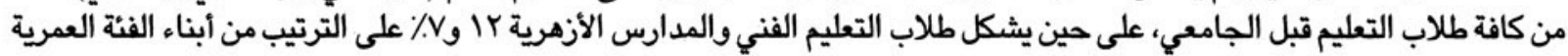

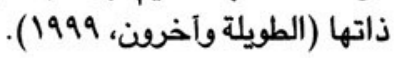

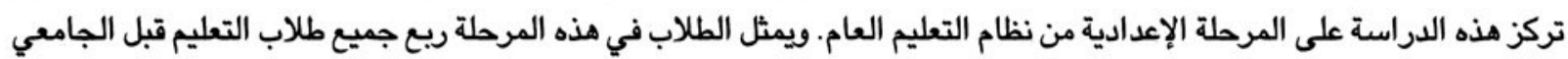

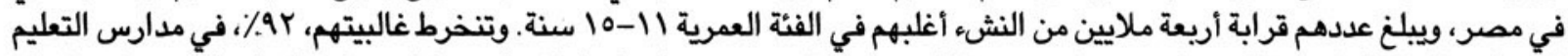

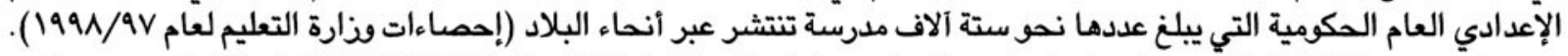

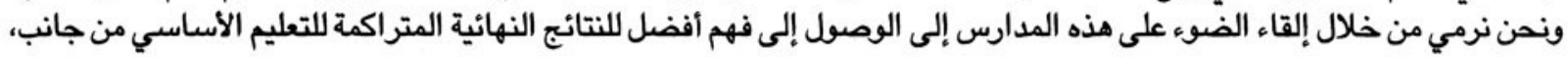

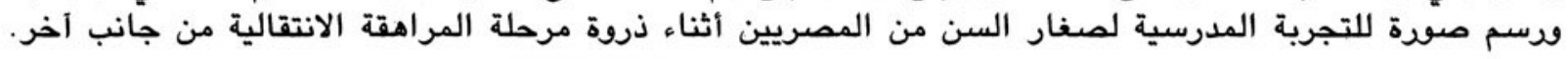

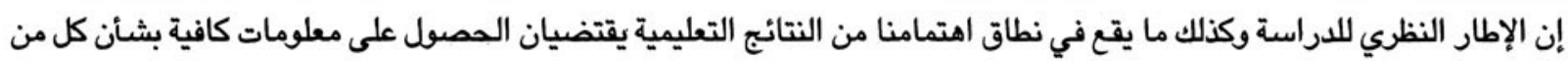

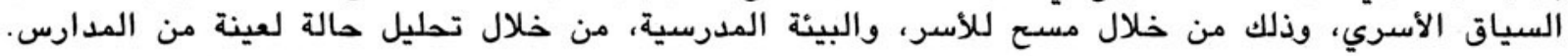




\section{الإطار النظري للدراسة}

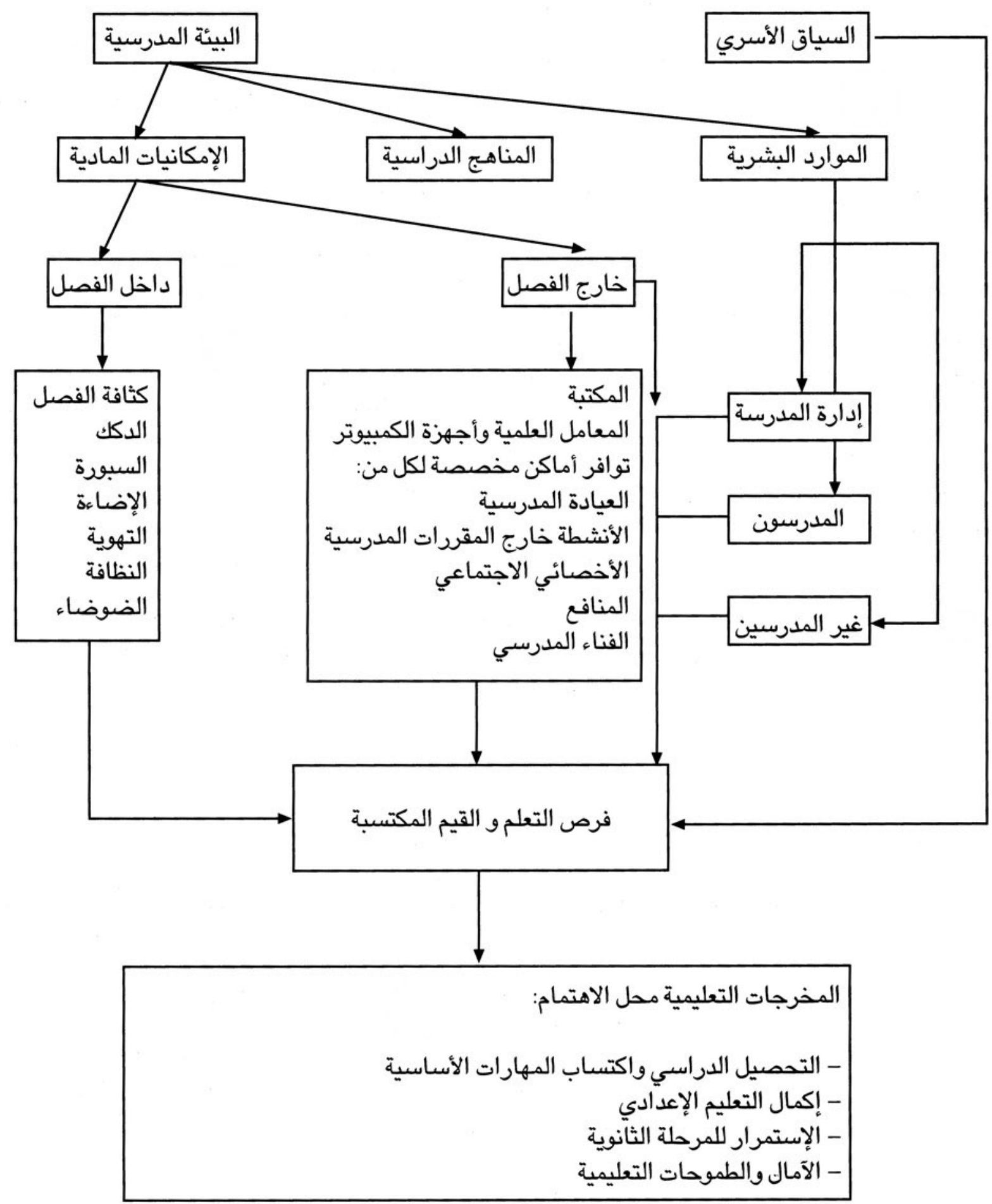




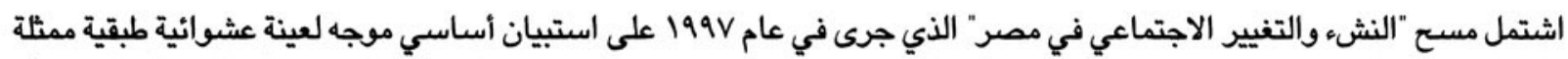

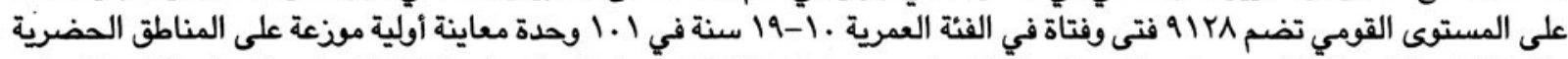

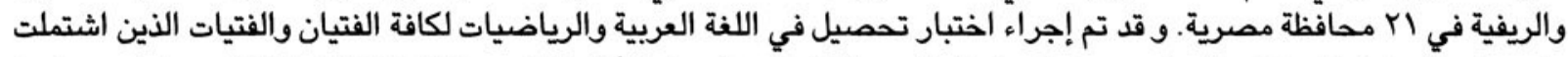

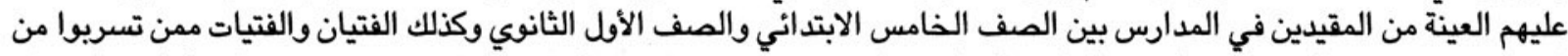

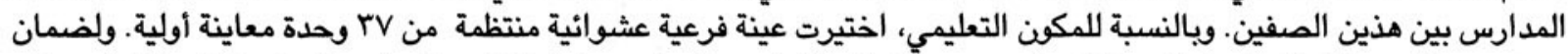

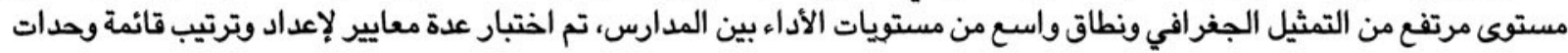

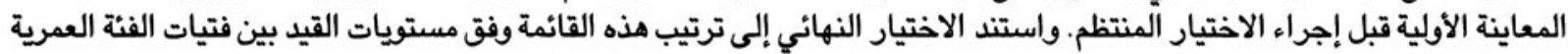

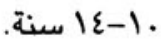

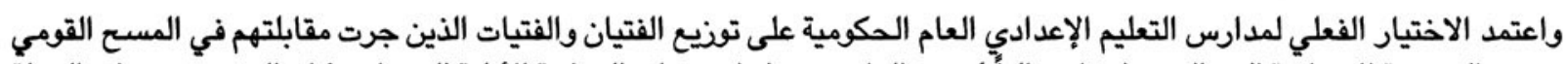

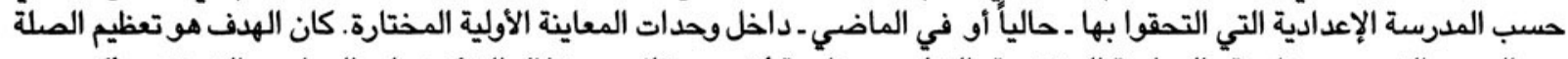

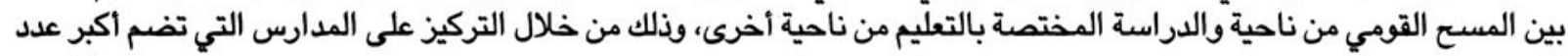

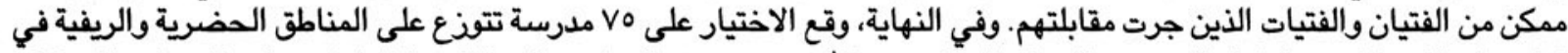

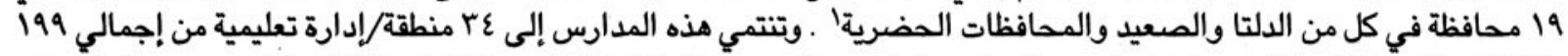

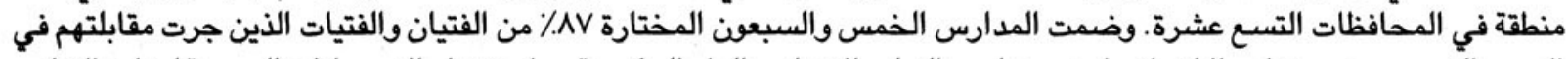

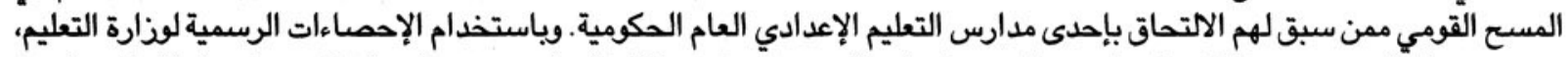

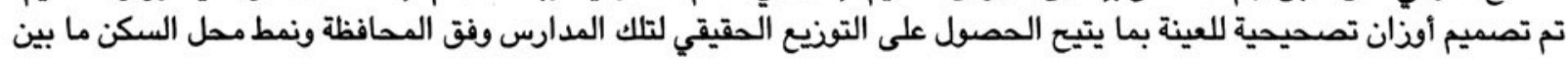

حضري وريفي.

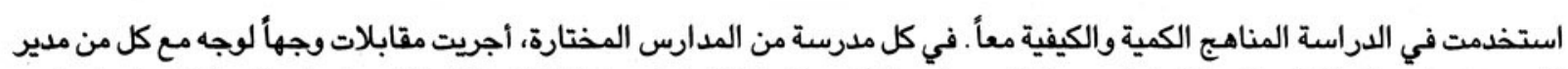

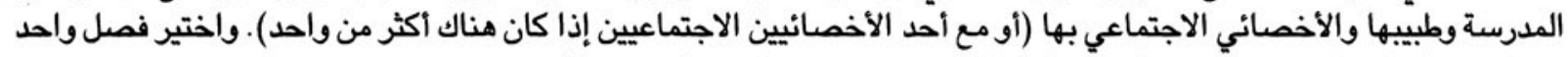
في الصف الثالث الإعدادي وخضي لالمي الإنلاعظة خلال ست حصص أحص دراسية على مدى الأسبوع.

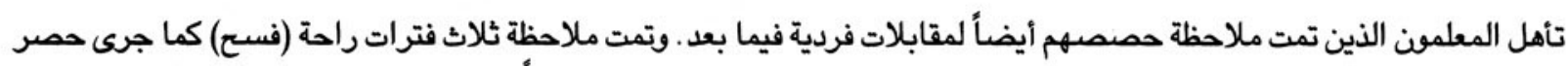

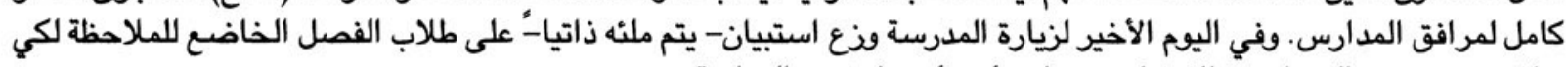

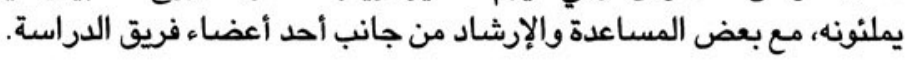

الأداء الدراسي للطلاب

استناداً إلى احصاءات وذارة التعليم ويمعزل عن تصميم الدراسة، كان مطمئناً أن نرى مستويات الأداء الدراسي للطلاب كما التها دلت عليه

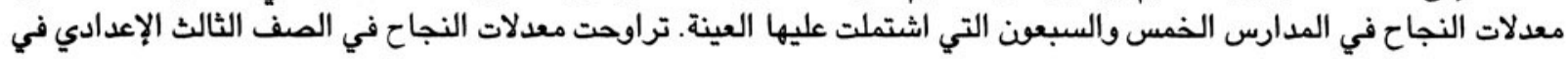

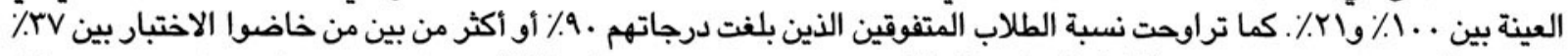

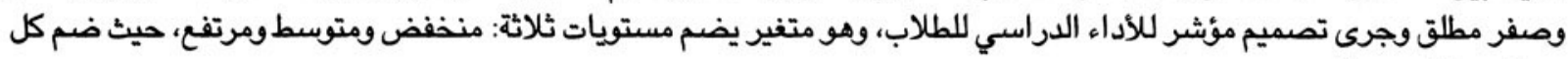

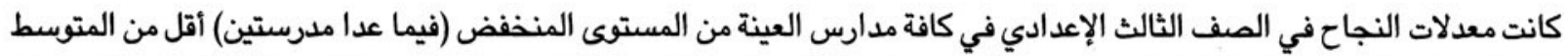

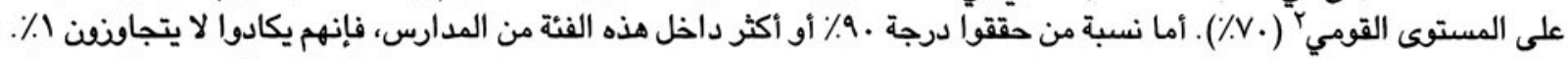

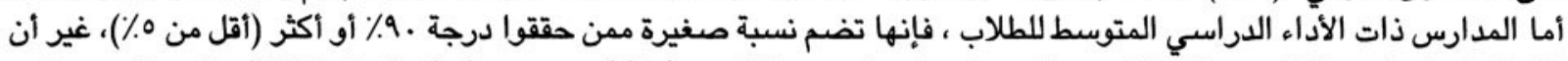

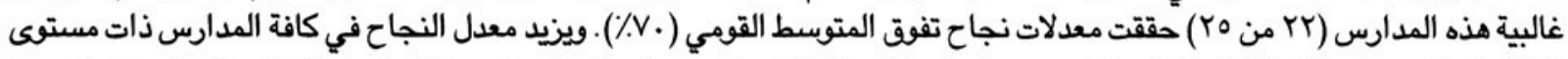

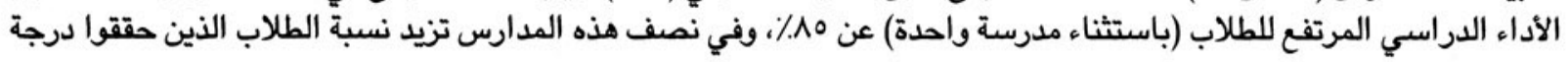

ا تم تنفيذ الدراسة في المحافظات التالية: القاهرة ، الاسكندرية ، بورسعيد ، دمياط ، الدقهلية ، الشرقية ، الغربية ، كفر الشيخ ، البحيرة، المنوفية ، القليويية ، الجيرة ،

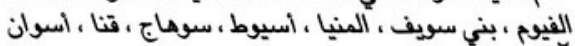

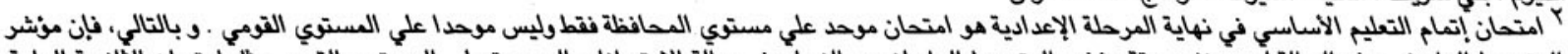

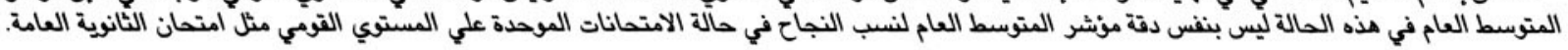


تندرجمدارس التعليم الإعدادي العام الحكومية الحضرية بالأساس داخل فئة الأداء الطلابي الدراسي المرتفع ويليها فئة الأداء المتوسط، بينما تصنف مثيلاتها الريفية كمدارس ذات أداء طلابي منففض أو متوسط.

ويسود الأداء الطلابي المتوسط إلى المرتفع بين مدارس التعليم الإعدادي العام الحكومية في المحافظات الحضرية وفي الدلتا ـ أما في الصعيد، فتتركز هذه المدارس اكثر في فنة الأداء الطلابي المنخفض الطئ.

وتقع كافة المدارس الحضرية تقريباً المصنفة باعتبارها ذات أداء طلابي منففض في المناطق شبه الحضرية على أطراف المراكز

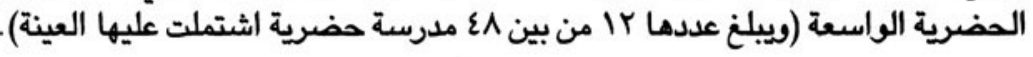

ويندرج نصف إجمالي مدارس العينة في ريف الدلا والصعيد داخل فئة الدارس ذات الأداء الطلابي المنففض (rV من Tد مدرسة ريفية اشتملت عليها العينة).

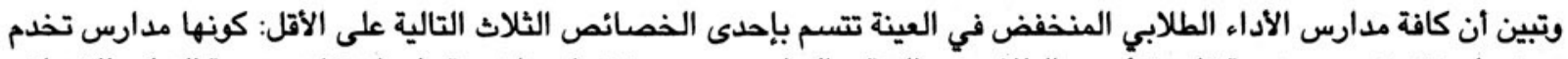

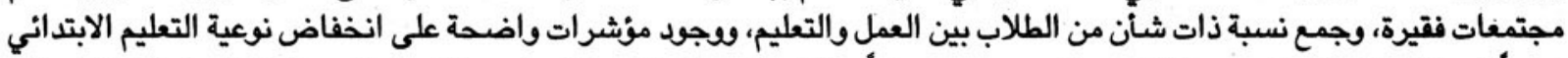

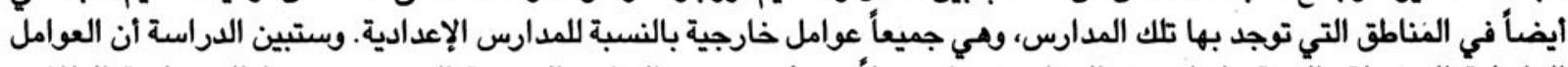

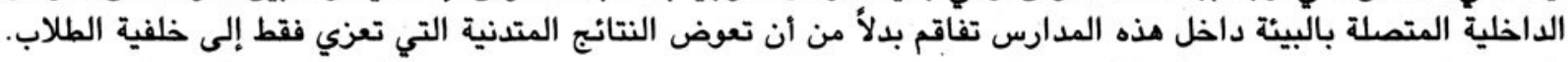

وتندرج كافة المدارس الواقعة في المناطق الأفضل حالأو التي تخدم طلاباً ميسورين في فئة الدارس ذات الات الأداء الطلابي المرتفع، بيد

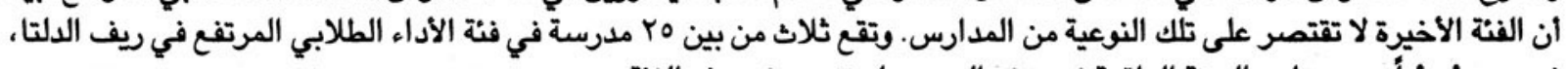

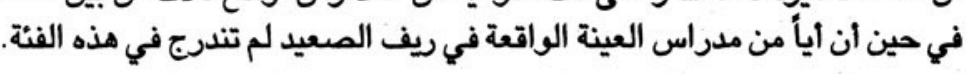

وتقل نسبة المدارس ذات الأداء الطلابي المرتفع في المدارس الإعدادية العامة الحكومية الصغيرة من حيث عداد الطلاب المقيدين بها،

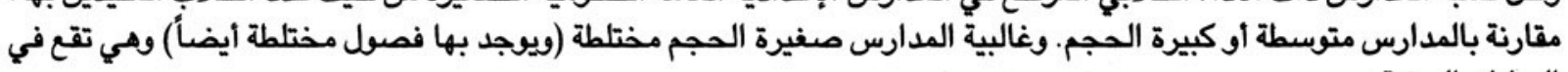

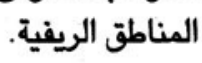

ويرتبط كلا من المستوي التعليمي للاباء من ناحية و مستوي الأداء الطلابي في المدرسة من ناحية اخري بصورة معنوية موجبة.

النتائج الأساسية للدراسة

(1) - (التجربة المدرسية للطلبة

- تستغرق الأغلبية (ب^٪) من طلاب المرحلة الإعدادية في مصر ما يقل عن نصف ساعة للوصول إلى المدرسة.

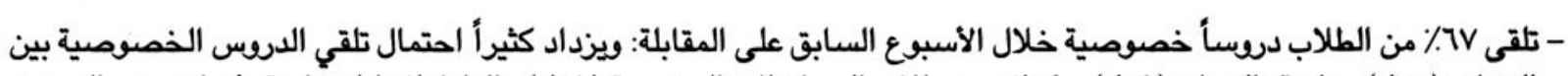

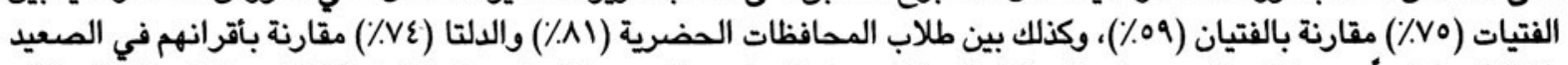

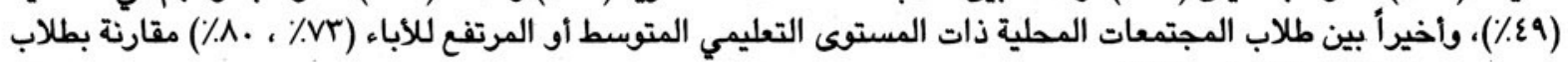

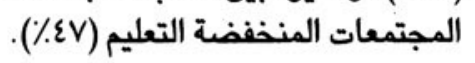

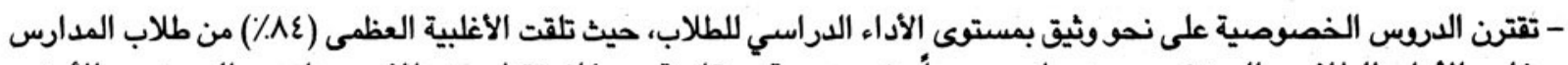

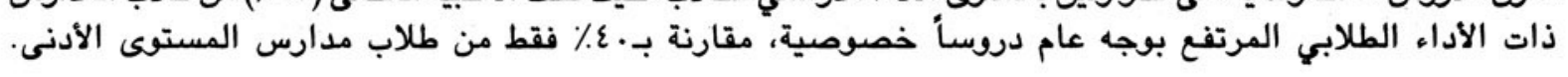
- لا يرضى بr/ من المعلمين عن المستوى الاكاديمي للطلاب. ويرتبط رضا المعلمين ارتباطأ عكسياً بالمستوى التعليمي للمجتمعات

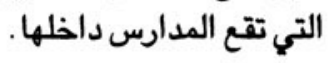




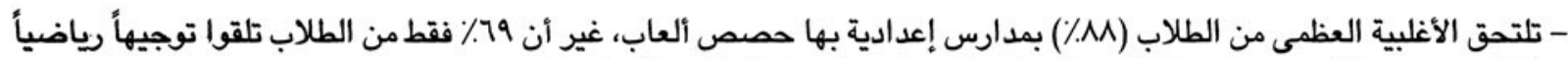

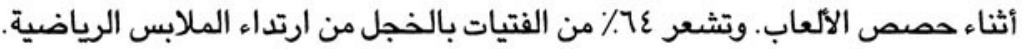

- تعرض ^^^٪ من الطلاب لمضايقات في طريق الذهاب إلى المدرسة أو العودة منها أثناء الأسبوع السابق على زيارة المدرسة.

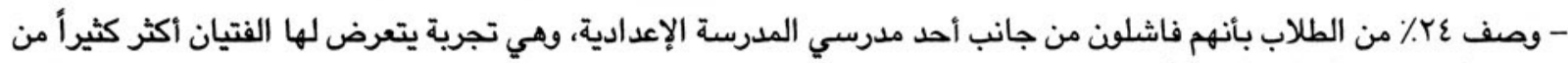

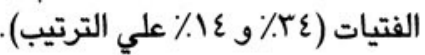

- كما تلقى זr٪٪ من الطلاب العقاب خلال اليوم السابق على المقابلة، وهو الأمر الاكثر شيوعاً بكثير بين الفتيان (rr٪) مقارنة بالفتيات

- يشعر هو٪ من الطلاب بأن ثُمة تفاوت في معاملة المعلمين للطلاب، وهو الأمر الذي ينسبه قرابة الريع إلى ما إذا كان الطلاب يتلقون

دروساً خصوصية من المعلم.

- لا يطلب أغلب الطلاب (rی^٪) النصح من الأخصائيين الاجتماعيين بالمدرسة، إذ يبدو أنهم يميلون أكثر لطلب النصح من معلميهم.

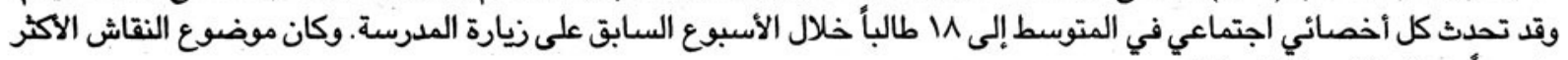
شيوعاً هو السلوك والآنضباط.

- يتوقع • ٪\% من الفتيات و٪\% من الفتيان أن يواصلوا التعليم الثانوي. وتعد التكلفة هي السبب الأساسي لتوقع عدم مواصلة التعليم.

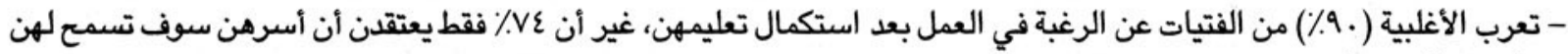
بذلك في المستقبل.

r) (r) النظافة والحالة الصحية

- تفتقر عr٪ من المدارس إلى وجود ممرضة أو طبيب، وهو الأمر الأكثر شيوعاً في مدارس الصعيد (عه٪). - ^عء من الممرضات والأطباء الذين تمت مقابلتهم يتحملون مسئولية الرعاية الطبية للطلاب في ثلاث مدارس علي الأقل.

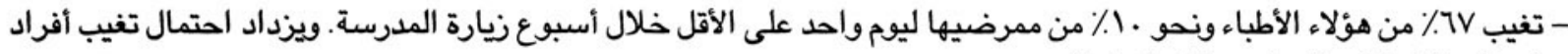
الهيئات الطبية في المدارس الإعدادية بالصعيد.

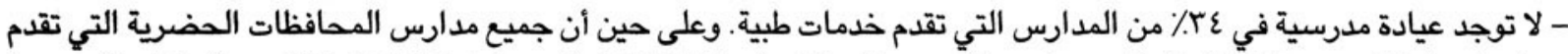

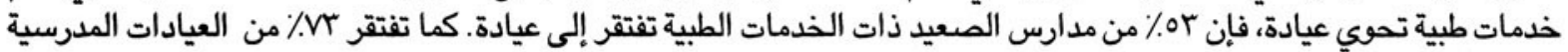

إلى مصدر مياه.

- تشعر الأغلبية العظمى من مقدمي الخدمات الطبية بالمدارس (AT٪) أن الطلاب بحاجة إلى التثقيف الصحي. - لا يرضى بحז٪ من أفراد الهيئات الطبية بالمدارس عن مستوى النظافة في المدرسة.

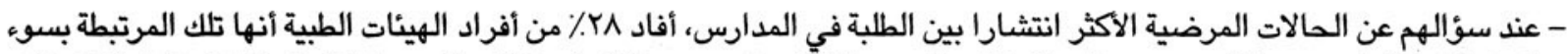

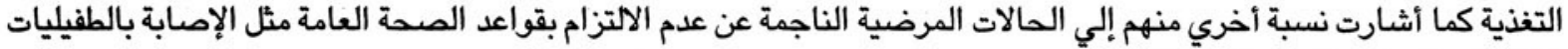

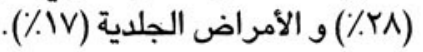

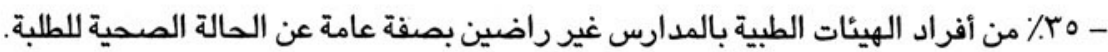

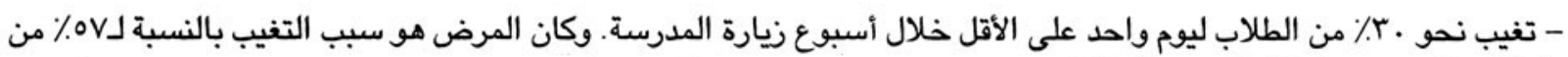
الطلاب الذين تغييوا خلال أسبوع الزيارة. 
- لم يلجأ للخدمات الطبية المدرسية ما يقرب من نصف طلاب المدارس (1\%) التي تقدم تلك الخدمات، ممن أصابهم المرض خلال

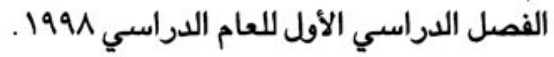

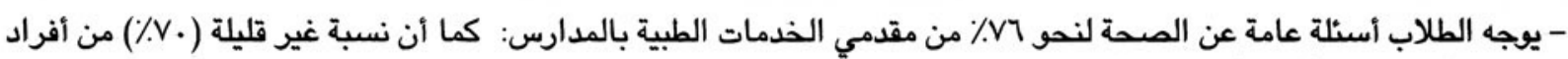

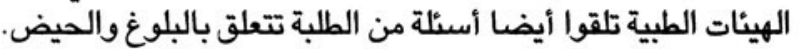

- تلقى 17٪ من الفتيات و. r٪ من الفتيان معلومات حول التغيرات المرتبطة بالبلوغ في المدارس، وكانت تلك المعلومات متاحة أكثر

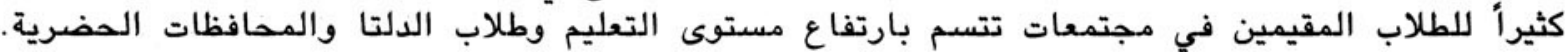

\section{r) الجوانب المتعلقة بالنوع و الأدوار المستقبلية المتوقعة للطالبات والطلبة}

- بمقدار ما أن المعلمين والنظار يرون أن بعض المواد الدراسية تمثل صعوبة أكـــــ النسبة لأحد الجنسين، فإن الاعتقاد السائد هو

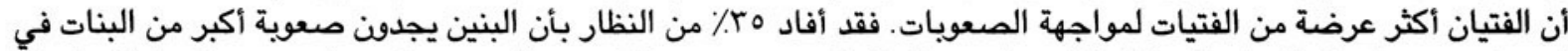

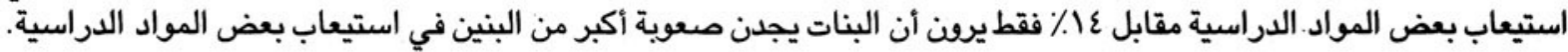

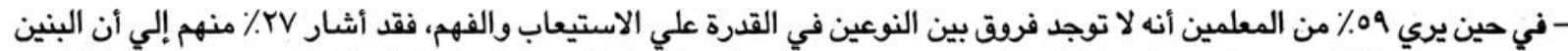

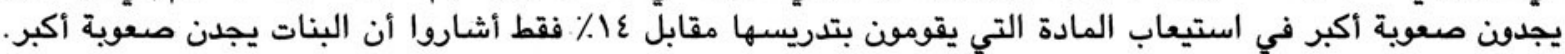

- من بين غالبية المعلمين الذين يفضلون التدريس لأحد الجنسين أكثر من الآخر، تفضل جميع المعلمات تقريباً التدريس للبنات أكثر البرات من البنين، بينما ينقسم المعلمون الذكود بالتساوي بين من يفضلون التين التدريس للبنين أو البنات.

- في المدارس المختلط، يعتقد كل من البنين والبنات أن البنات يلقين معاملة أفضل.

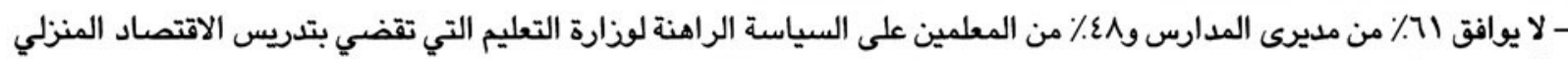
للفتيات فقط، بينما يقتصر تدريس الزراعة واريس والصناعة على الفتيان.

- بينما يؤكد أغلب المديرين والمعلمين أهمية الرياضة للبنين والبنات معاً، فإن 77٪ من المعلمين يعتقدون أنها مهمة للبنات، في حين

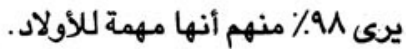

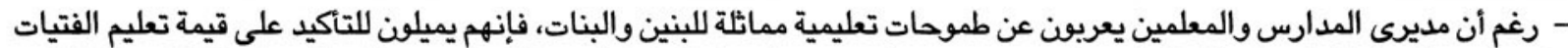

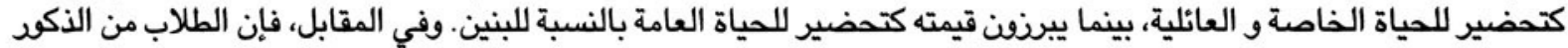
والإناث يؤكدون بالقدر نفسه أهمية تعليم الأولاد من أجل أن يصبحوا آباء جيدين ويحصلوا على عمل محترم.

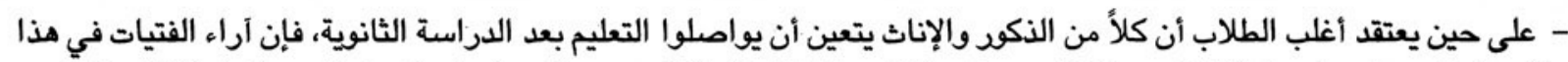

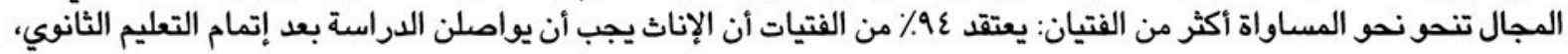

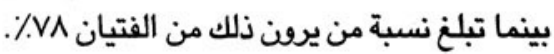

\section{ع) الإمكانيات المادية والموارد البشرية في المدارس الإعدادية}

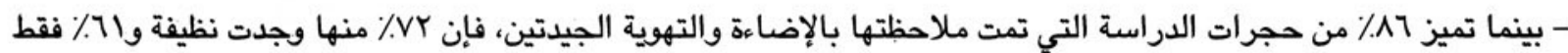

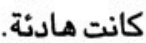

- في حين أن الغالبية الواسعة من الطلاب (19\%) كان بوسعها سماع المعلم بوضوح، فإن 70٪ كان بوسعهم رؤية الكتابة على السبورة و 00\% فقط كانوا قادرين على الكتابة على نحو مريح.

- لوحظ أن أكثر من ـ 1٪ من الدكل مكسورة في نحو عץ\% من حجرات الدراسة التي تمت ملاحظتها.

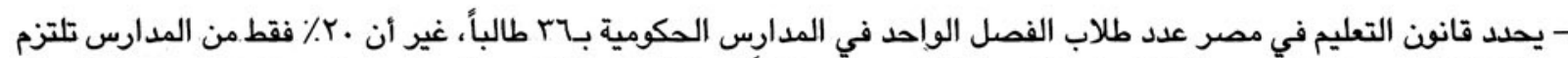

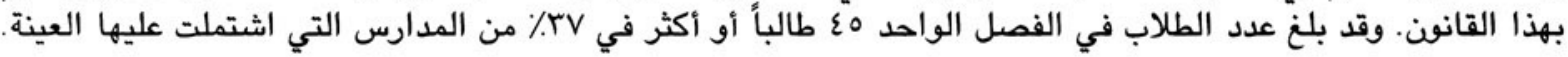


- ويشمل •v٪ من مدارس العينة فترة دراسية واحدة، بينما توجد أكثر من فترة دراسية في .r٪ منها.

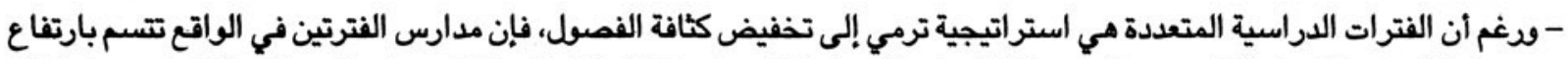

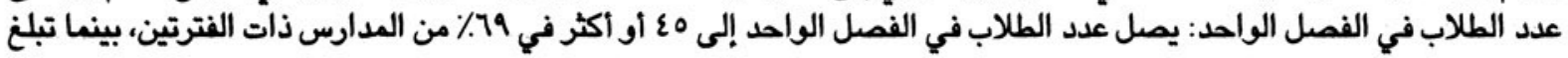

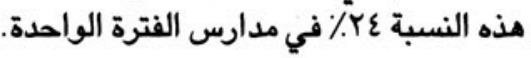

- يضم ما يقرب من ـ ؟ ٪ من المدارس معملاً علميأ ومكتبة. وكما هو متوقع، يزداد احتمال توفر مذه المرافق في مدارس المجتمعات المحلية التي تتميز بالمستويات التعليمية المرتفعة.

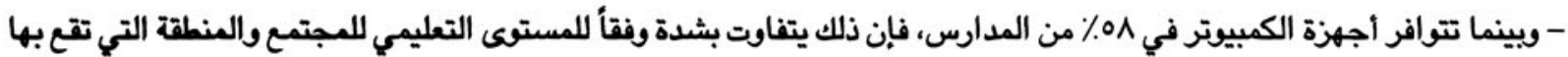

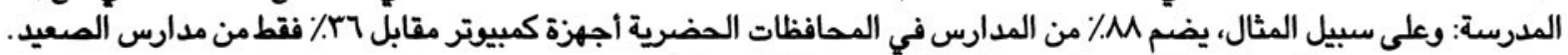

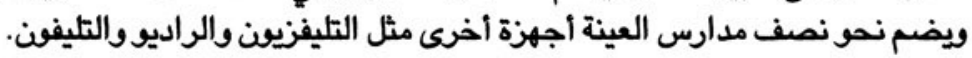

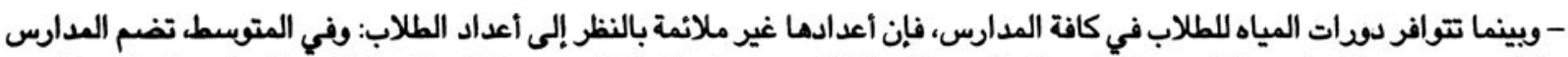

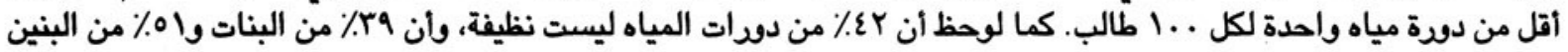

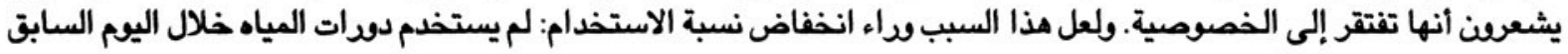

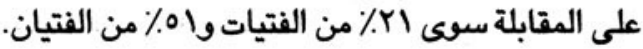

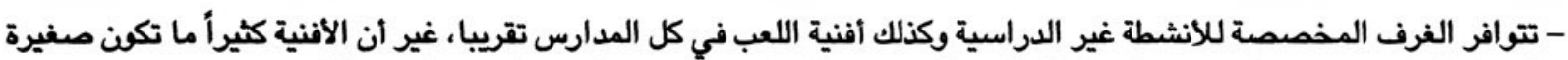

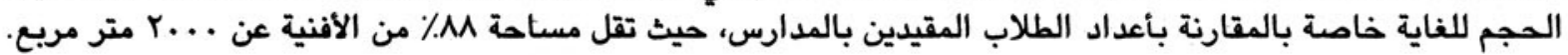

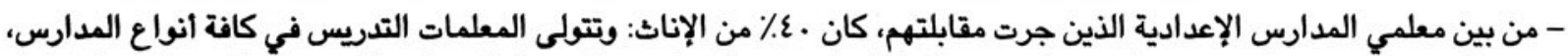

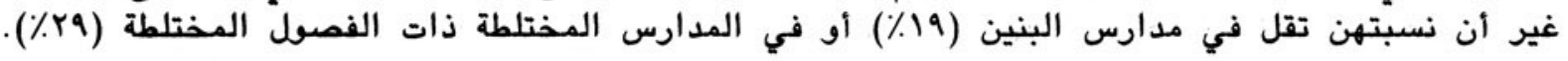

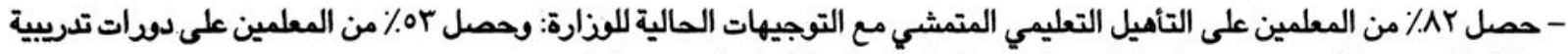

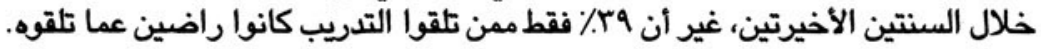

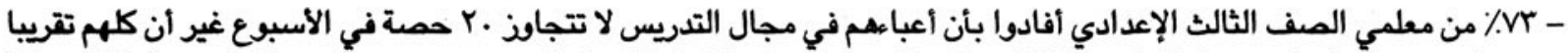

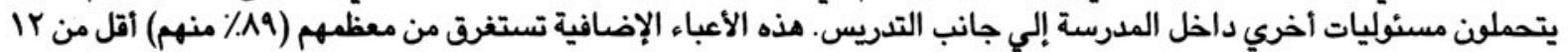
ساعة في الأسبوع.

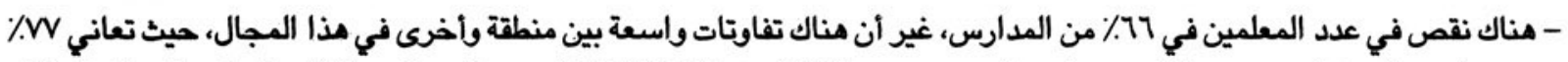

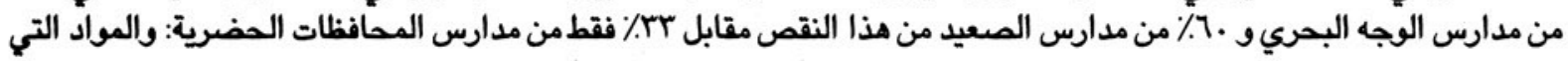

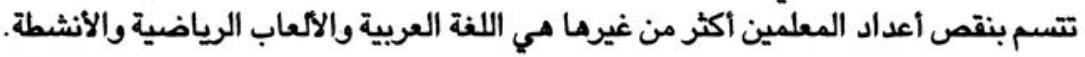

- أعرب مجمل مديرى المدارس ذات الأداء الطلابي المنففض عن عدم الرضا عن حالة المرافق المادية في مدارسهم ـ إلا انهم عبرا

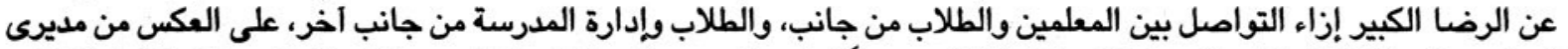

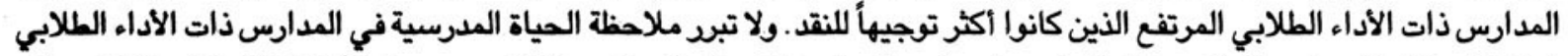

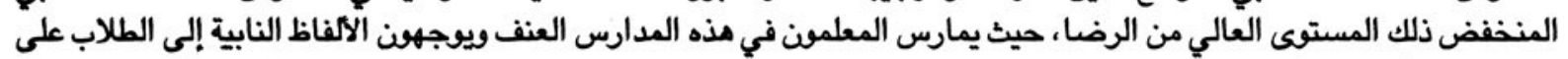
نحوشديد القسوة والوضوح.

- إن ما يقرب من • ^٪ من مديرى المدارس من الذكود. والمدارس الوحيدة في العينة التي تضم ناظرات أو مديرات مي مدارس البنات، حيث توجد مديرات في ما يقرب من نصف من مداري من من الذكر البنات.

- تلقى نحو . ٪\% من مديرى المدارس تدريباً أثناء الخدمة خلال السنتين الاخيرتين: وترتفع معدلات تلقي التدريب أثناء الخدمة كثيراً في الصعيد. - أفاد حوالي نصف مديرى المدارس أنهم تلقوا مساهمات من المجتمع المحلي. 


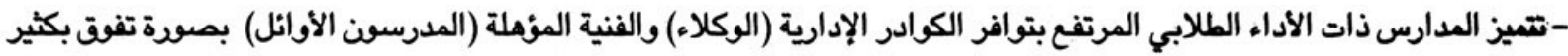

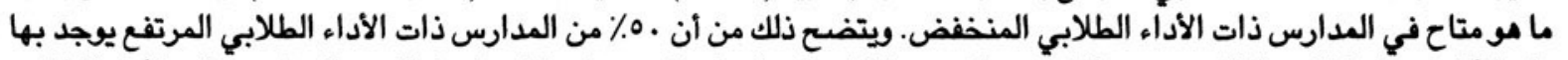

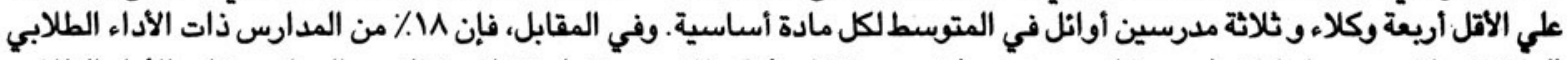

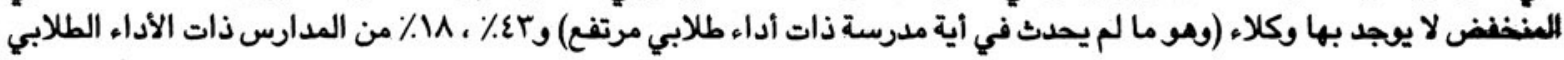

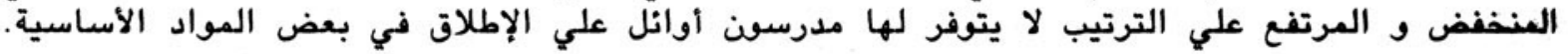

- ععم العدالة في توزيع الموارد البشرية المزٔملة داخل المؤسسة التعليمية لا يرتبط بنظام الدراسة في المدرسة (فترة واحدة أوفترتئين)

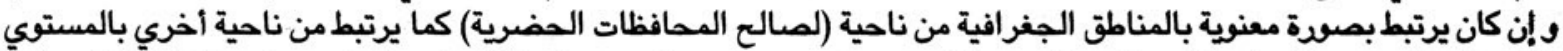

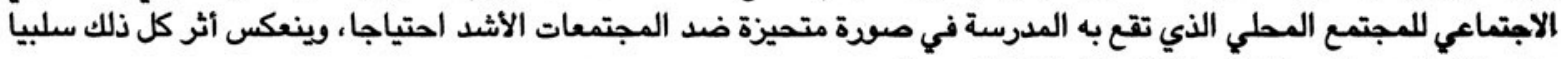

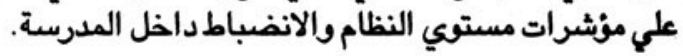

•) فرص التعلم داخل المدرسة

- من المفترض أن يرتبط امتداد اليوم الدراسي لفترة زمنية أطول بزيادة فرص التعلم الاكاديمي وغير الاكاديمي المتاحة للطلاب والتي التمابي

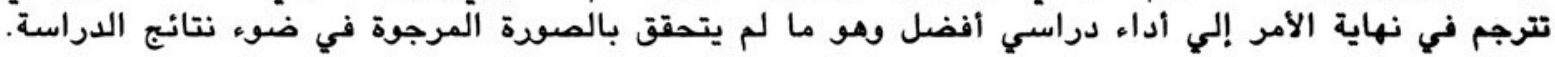

- الشارت النتانج إلي عدم وجود فرق معنوية بين مدارس الفترة الواحدة و المدارس متعددة الفترات من ناحية مستوي الأداء الدراسي للطلاب تبعا لمعياري نسبة النجاح في امتحان الشهادة الإعدادية ونسبة الطلبة المتفوقين في في المدرسة الطية.

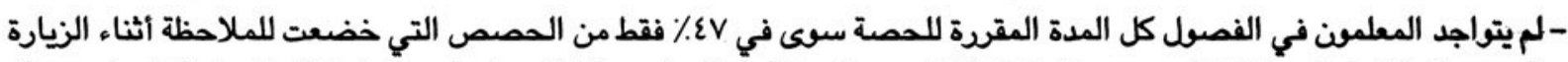
الدرسية، التي امتدت لفترة أسبوع، و قد ارتبط ذلك بمستوي الأداء الدراسي للطلاب وإن لم يرتبط بنظام الدراسة في المدرسة.

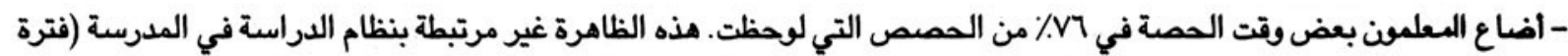

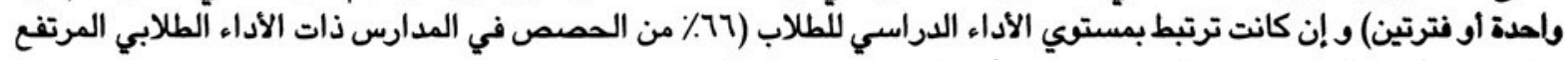

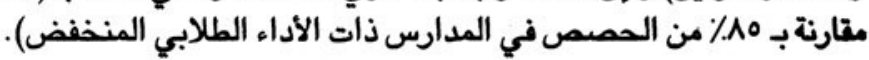

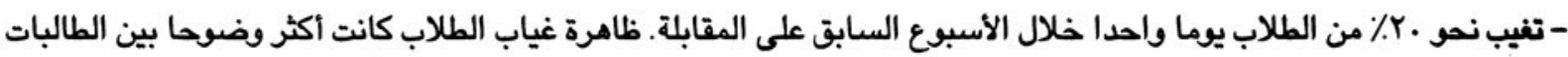

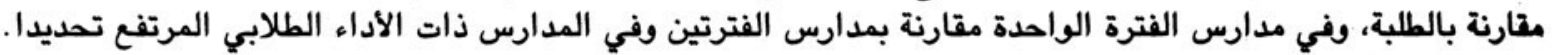

- في بr٪ من فمبل الصف الثالث الإعدادي التي تمت متابعتها تغيب أحد المعلمين على الأقل في كافة أيام الأسبوع السابق

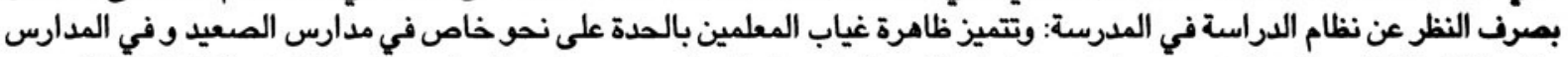

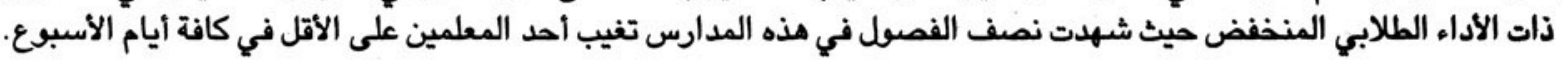

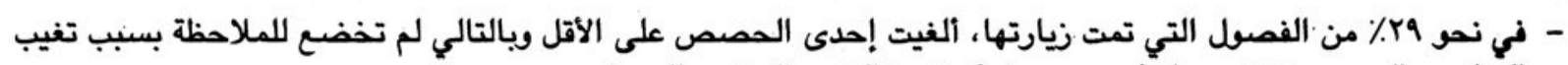

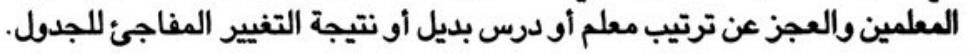

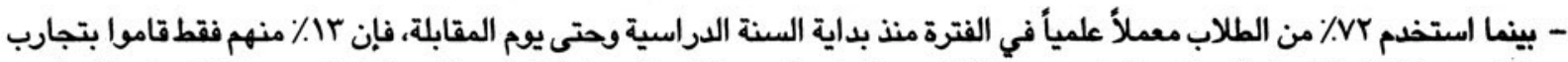

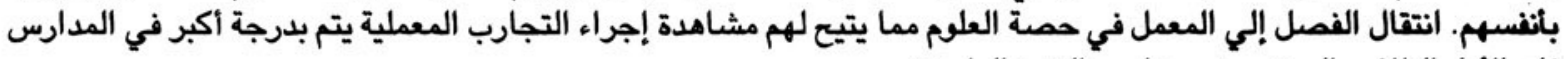
ذات الاداء الطلابي المرتفع وفي مدارس الفئري الفعل فئرة الواحدة.

- بينما امتوت 19٪ من المدارس على حجرة مكتبة، لم يذهب سوى ربع الطلاب إلى المكتبة خلال الأسبوع السابق على المقابلة دون ان يرتبط ذلك بنظام الدراسة في المدرسة المدرس

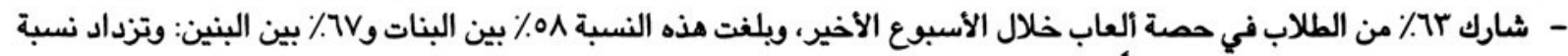

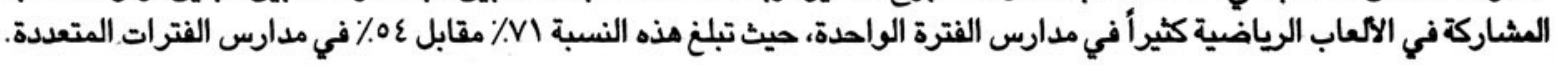

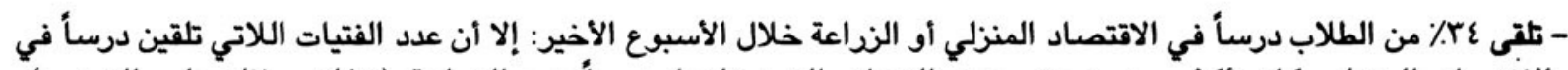

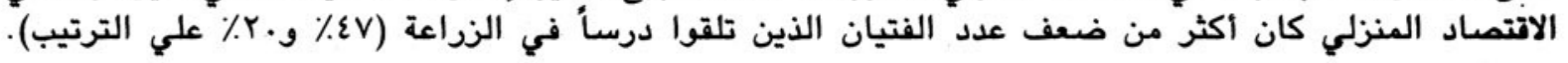




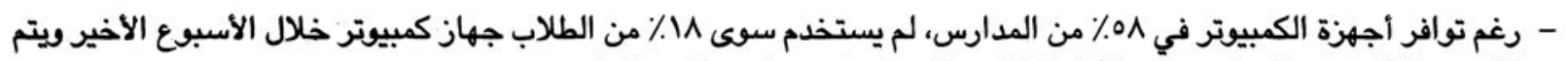
ذلك بدرجة أكبر في المدارس ذأت الأداء الطلابي المرتفع وفي مدارس الفي الفترة الواحدة.

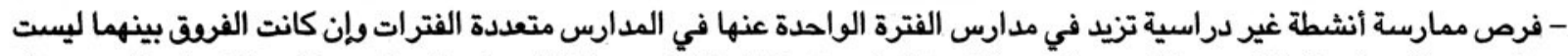

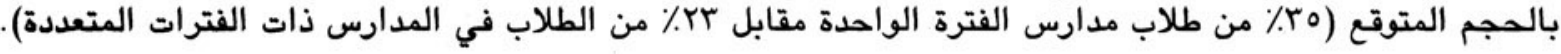

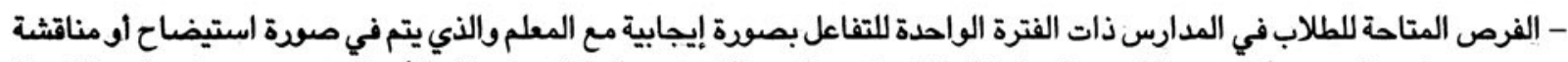

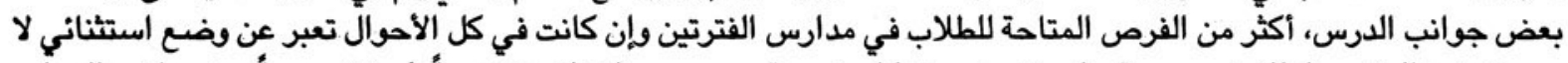

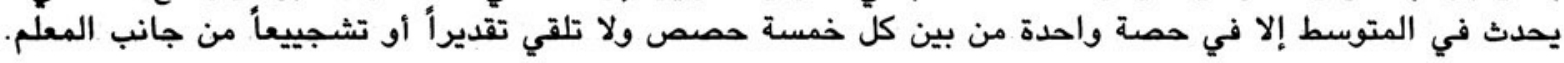




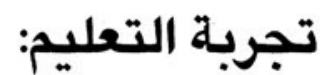 رؤية لانتقال النشء إلى مرحلة النضج}

ا الخلفية

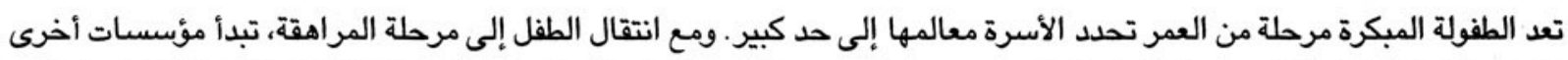

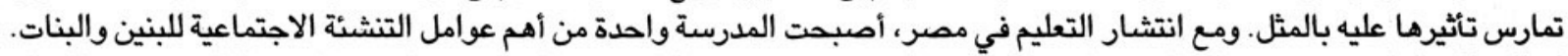

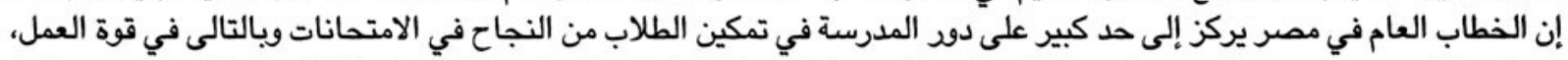

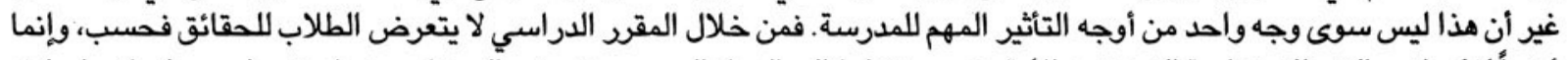

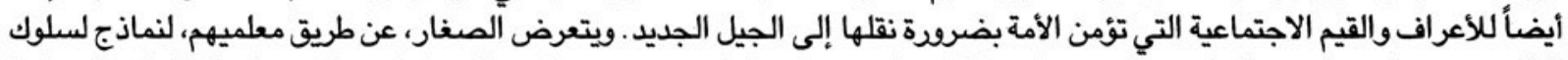

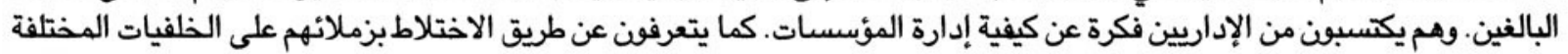
وكيفية التفاهم مع الآخرين داخل ثقافتهم.

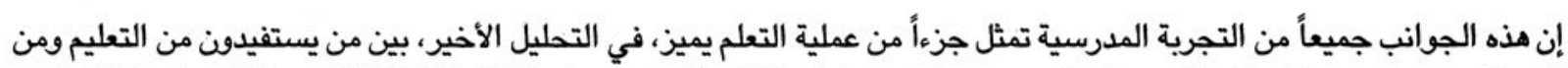

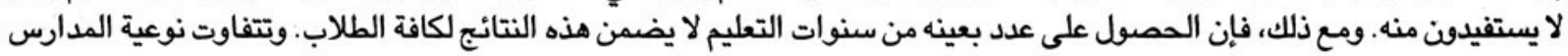

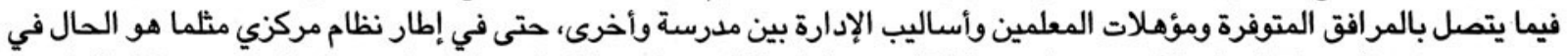

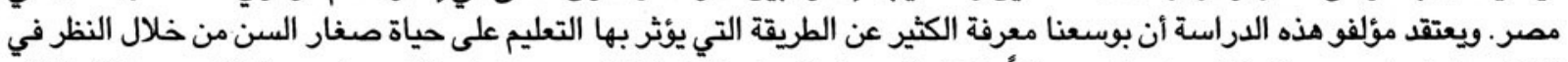

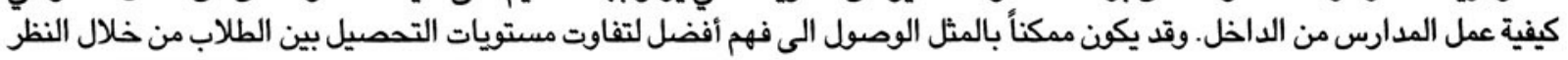

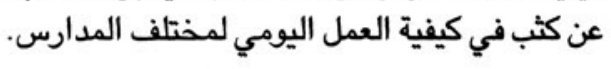

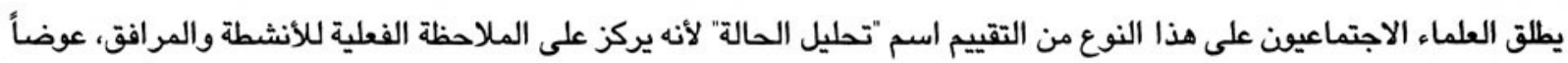

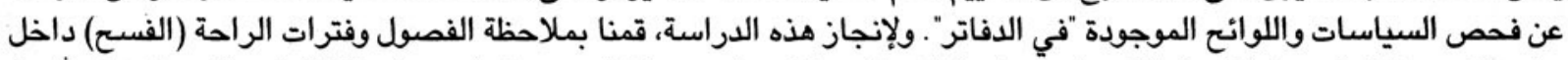

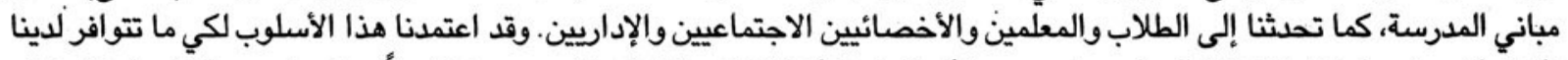

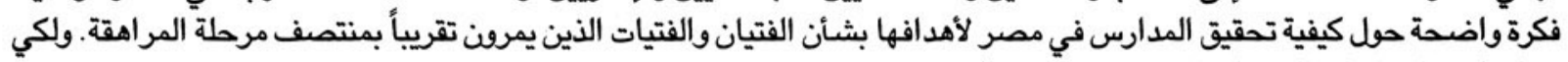

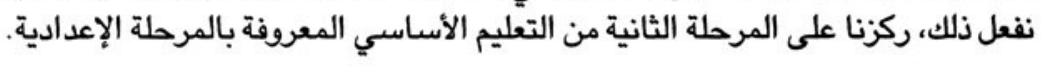

r. المحيط المدرسي

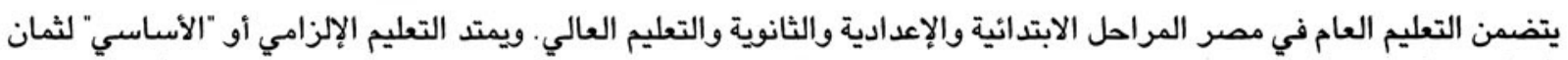

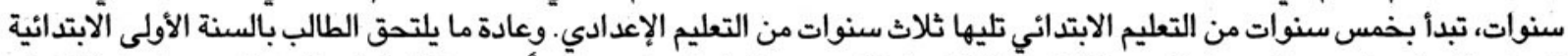

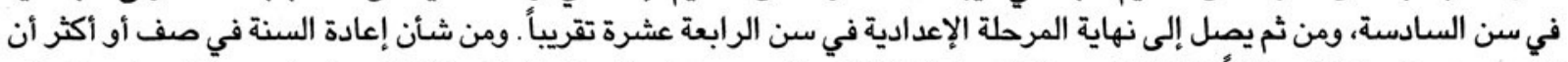

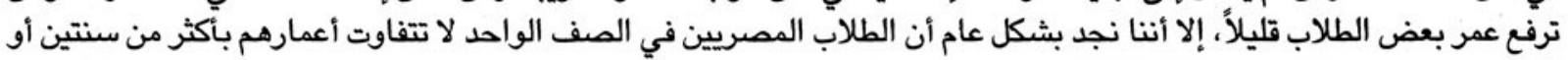

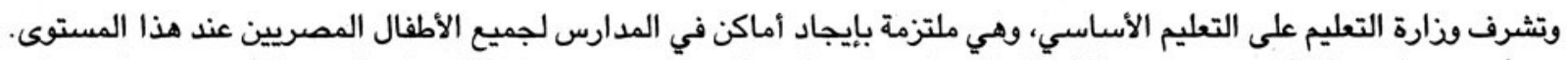

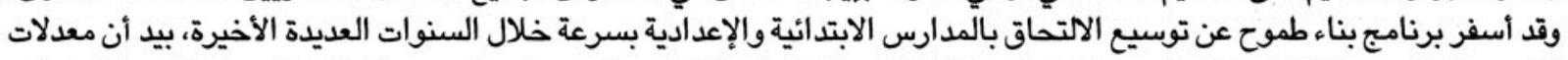

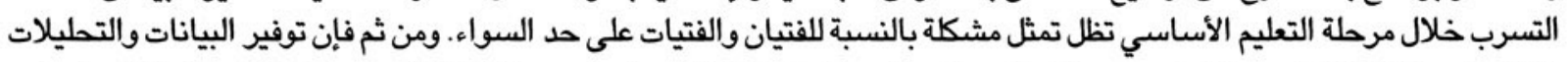

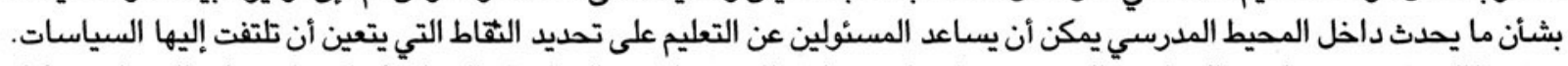

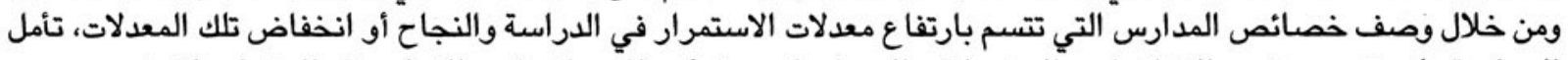

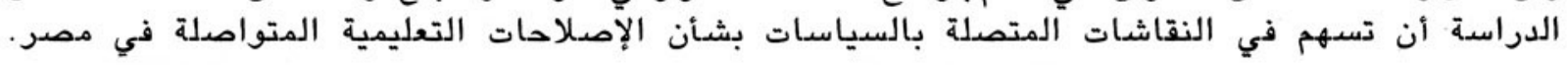

المدارس الحكومية مختلطة في المرحلة الابتدائية، وقد تكون مختلطة أو تقتصر على جنس واحد في المرحلة الإعدادية. ومن ناحية

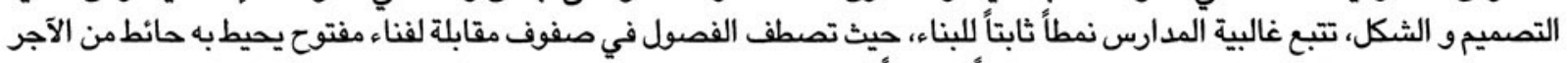

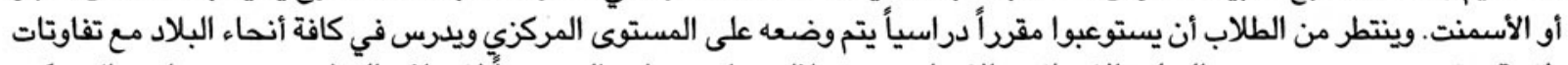

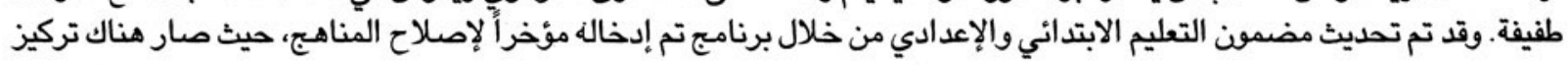




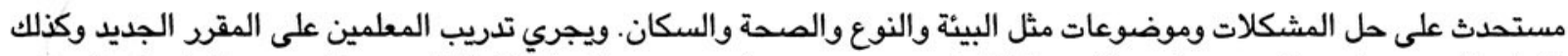

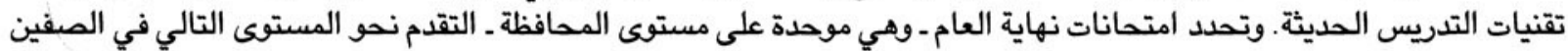
الثالث والخامس الابتدائيين والصف الثالث الإعدادي. أما في السنوات الأخرى، فتصمم كل مدرسة الامتحانات الخآصة التها بها.

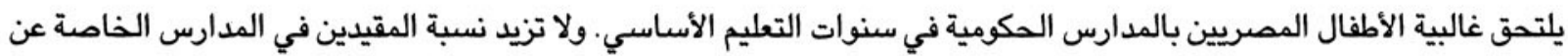

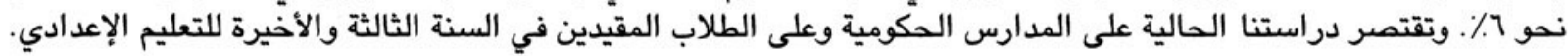

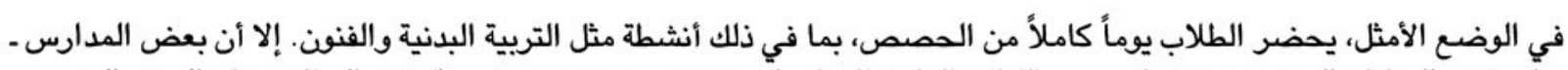

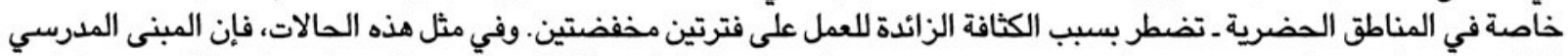

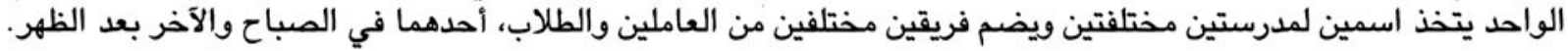

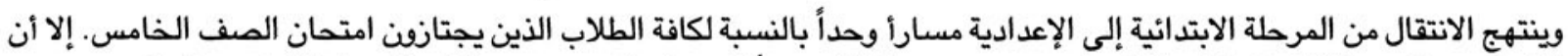

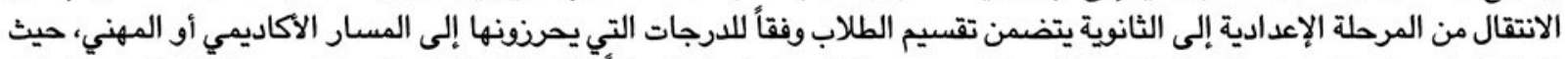

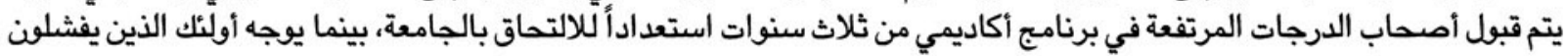

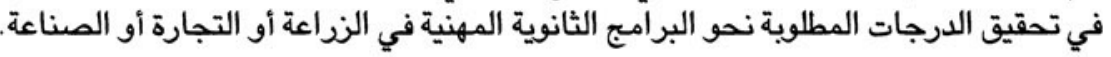

ومن هنا فإن نتائج امتحان الصف الثالث الإعدادي تعد جوهرية في تحديد مستقبل الطلاب، وتستثمر العائلات بكثافة في هذه السنة

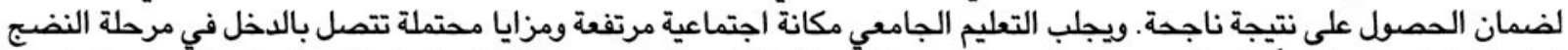

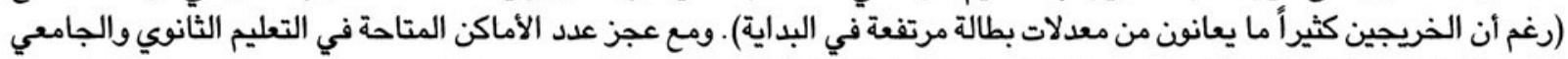

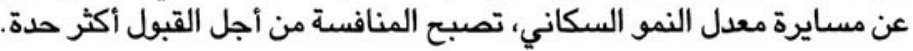

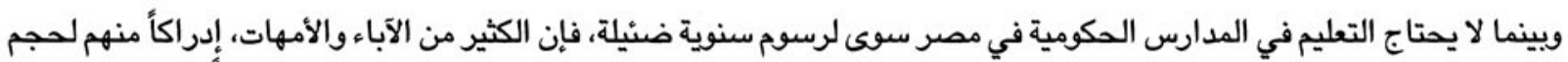

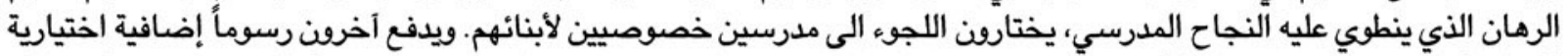

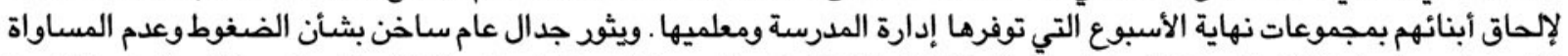

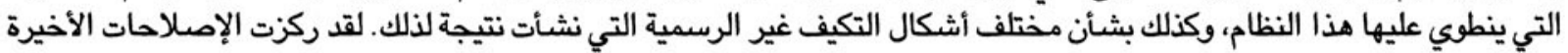

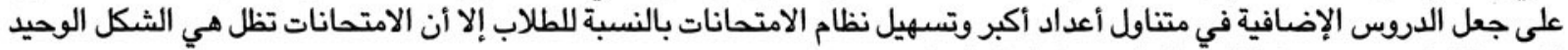

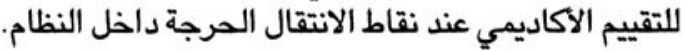

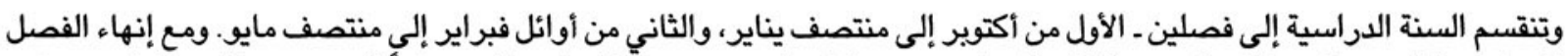

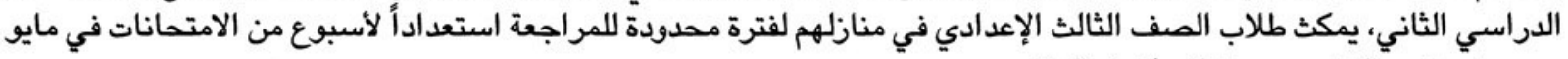
يجري في نفس الوقت عبر مختلف أنحاء البلاد.

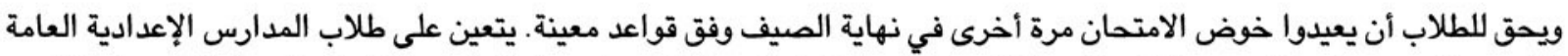

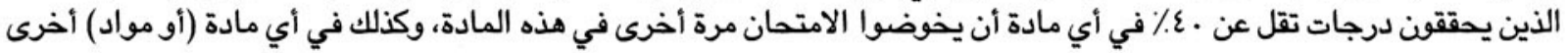

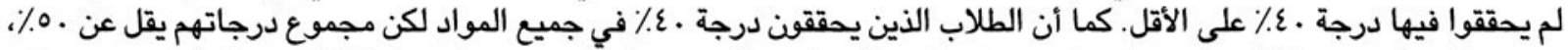

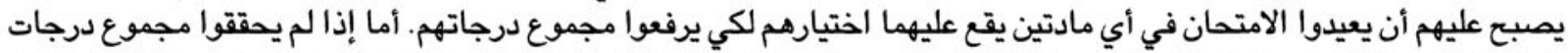

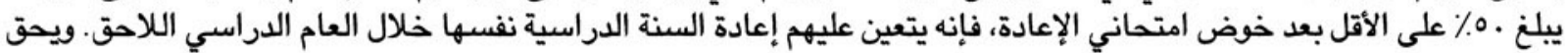

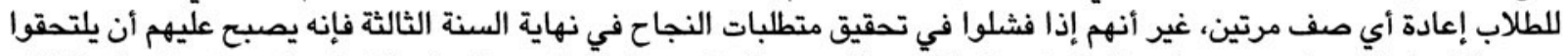

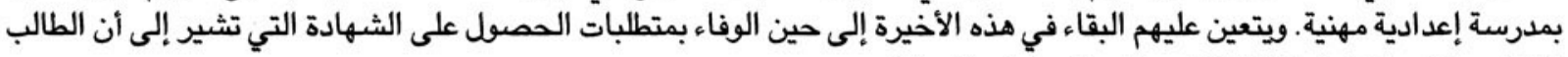
المتخرج تعلم القراءة والكتابة إلى جانب المهارات المئهية المذية.

تسري هذه القواعد بدءأ من الصف الخامس ـ السنة الأخيرة للتعليم الابتدائي. بيد أنه لما كان كل من التعليم الابتدائي (خمس سنوات التمات)

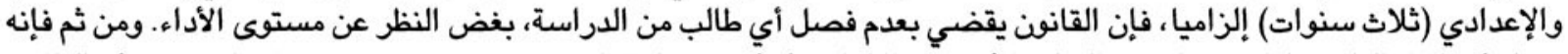

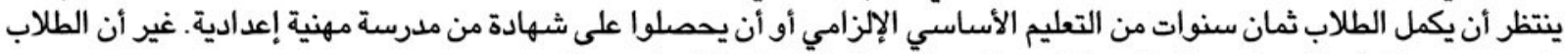

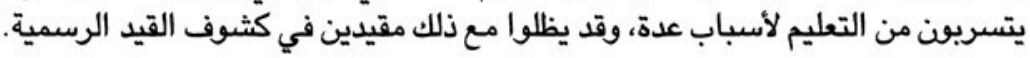

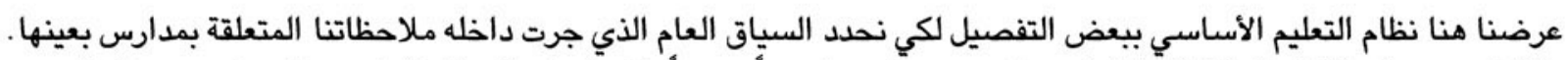

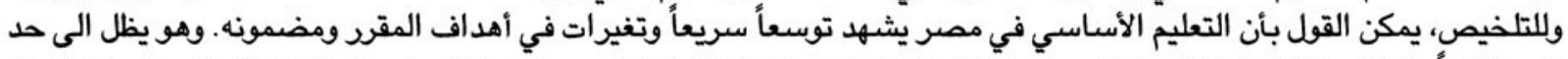

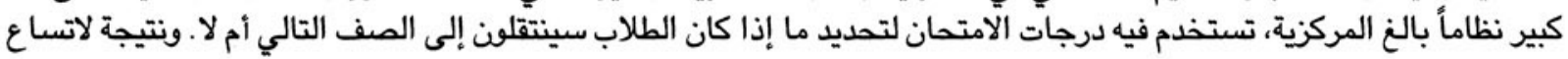


الطلب على أماكن الدرس، تضطر بعض المدارس لاستخدام مرافقها على فترات، الأمر الذي يقلل الوقت الذي يقضيه الطلاب في التعلم

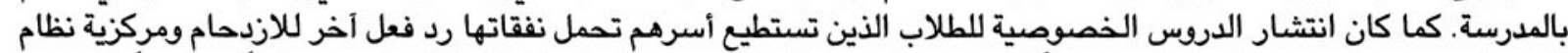
الامتحان. وقد مثلت هذه التطورات تحدياً لجهود وذارة التعليم المضنية لجعل التعليم الأساسي متاحاً وميسراً للجميع.

يلتحق بالتعليم الأساسي اليوم عدد من الطلاب يفوق أي وقت مضى. وينصب تركيز هذه الدراسة على خبرتهم اليومية في المدرسة مع بلوغهم نهاية المستوى الإعدادي.

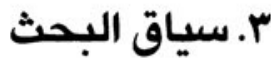

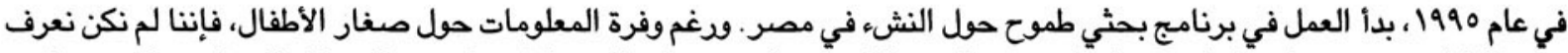

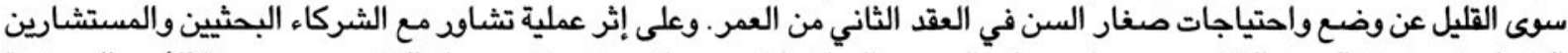

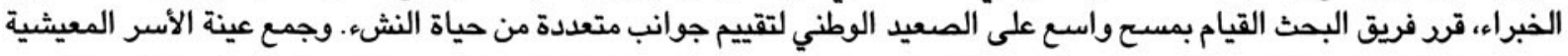

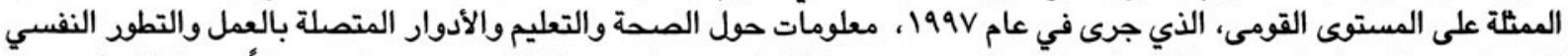

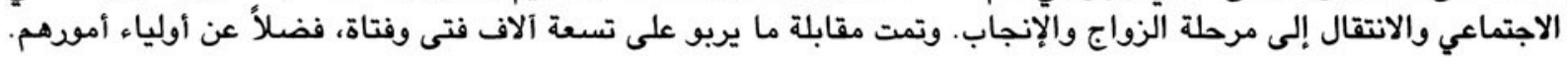

في الوقت ذاته، كان هناك إدراك أن المسوح القائمة على أساس الأسرة توفر صورة غير مكتملة لعمليات الانتقال المهمة في حياة النشء.

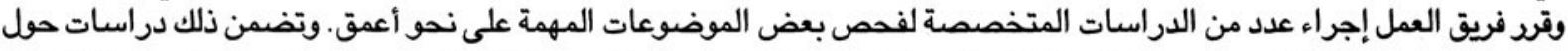

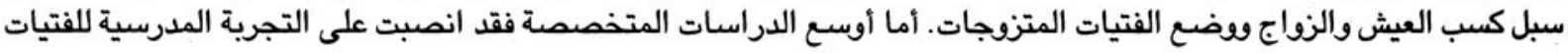

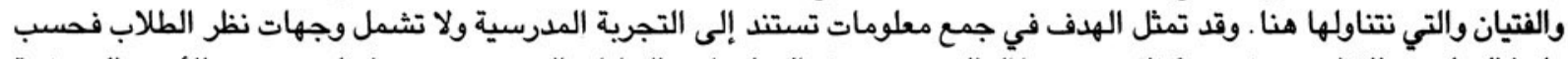

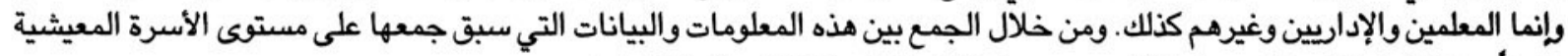
فضلأ عن نتانج اختبار التحصيل (الذي يرد وصفي والارين أدناه) تتاح إمكانيات ثرية للتحليل.

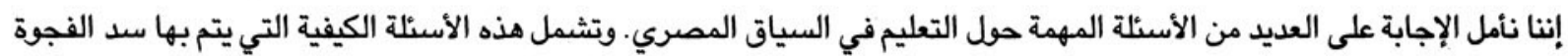

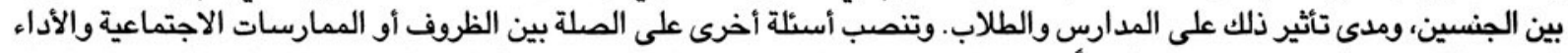

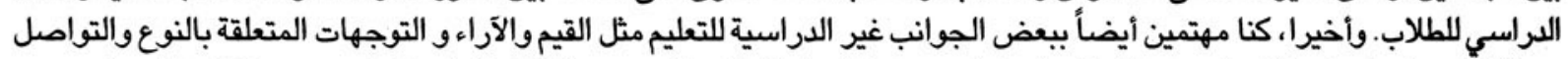

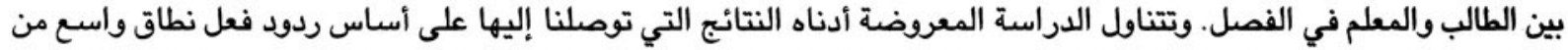

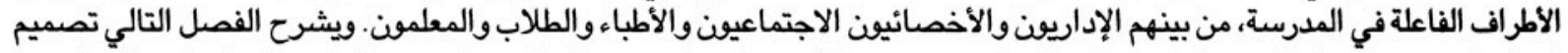
الدراسة ومنهج إعداد العينة كما يتناول الصلة بين مسح الأسر على الصعيد الوطني والمسح القائم الائم على أساس المدارسي. 


\section{تصميمجو منهج الدراسة}

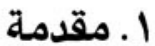

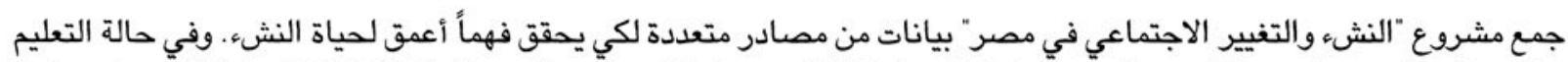

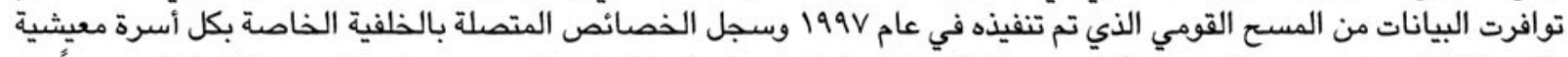

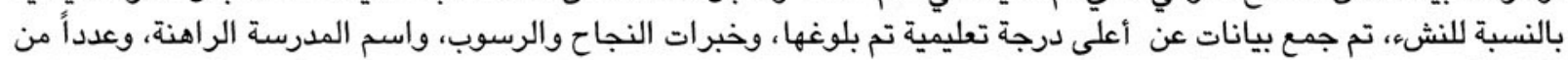

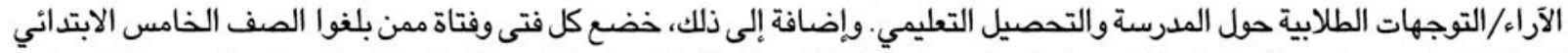

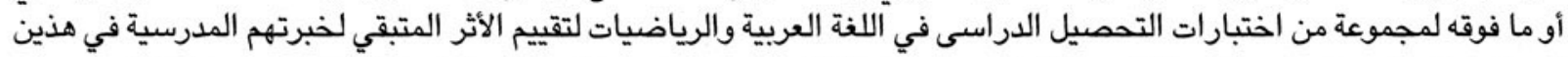

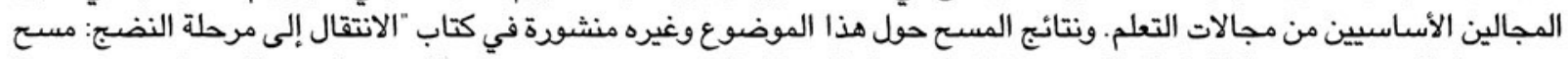

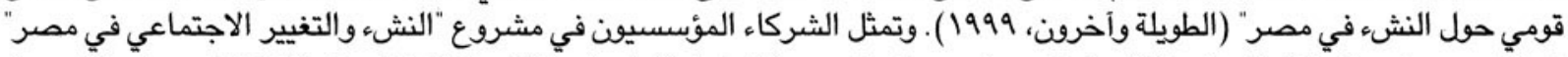

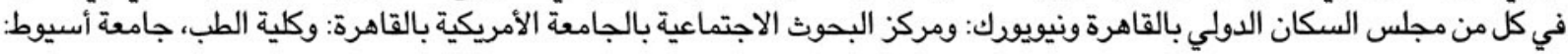
والمعهد العالي للصحة العامة، جامعة الإسكندرية.

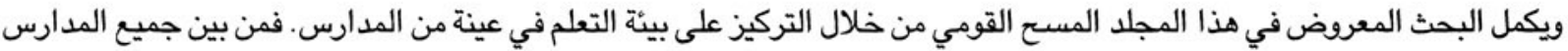

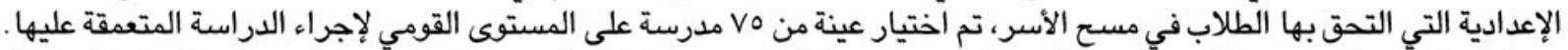

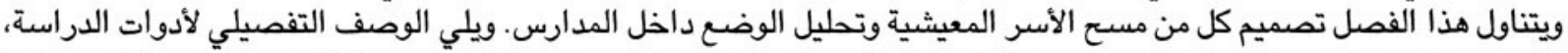

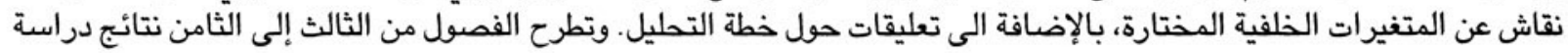
المدارس وتقدم اقتراحات تتصل بالمشروعات التفات التجريبية وتحليلات أخرى.

\section{Y r r r تصميم العينة}

\section{أ. تصميم عينة المسح القومي}

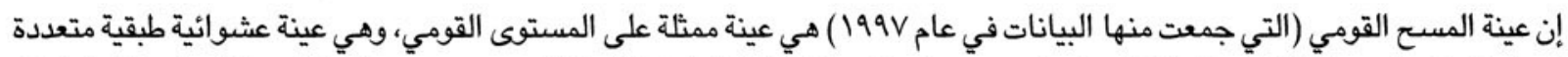

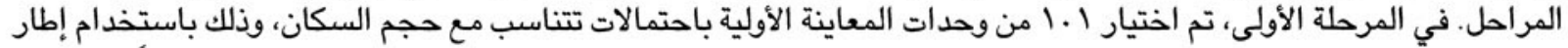

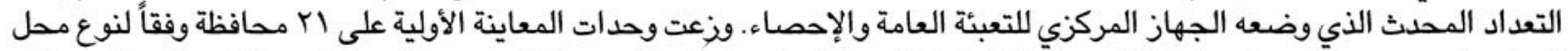

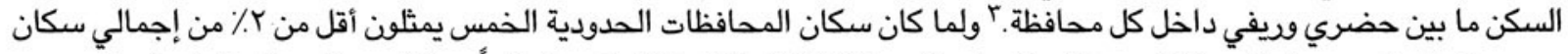

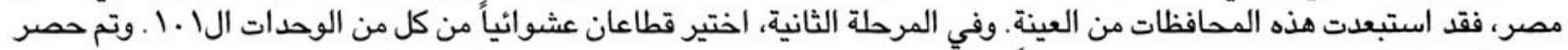

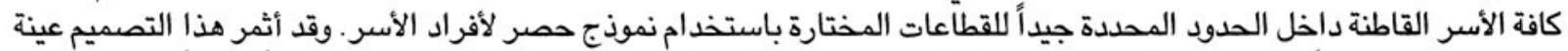

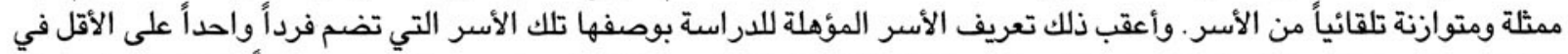

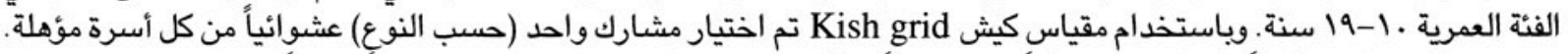

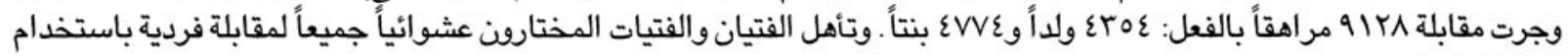

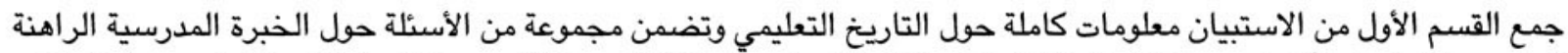

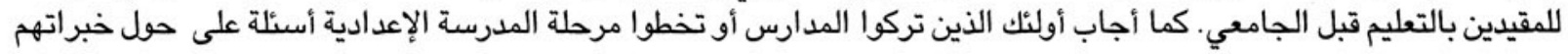

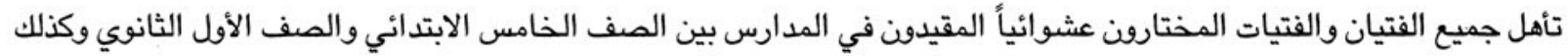

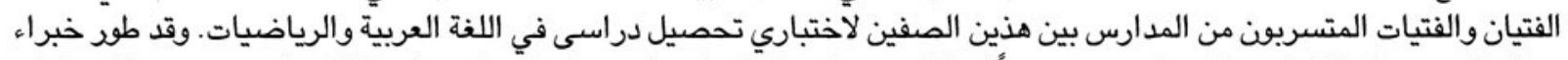

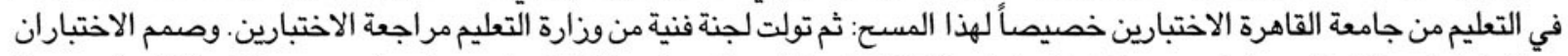

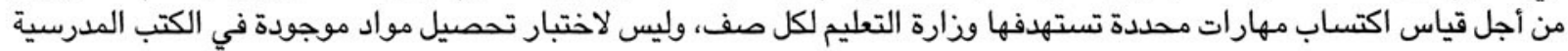

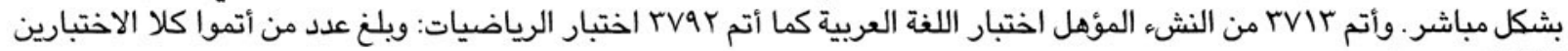

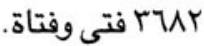

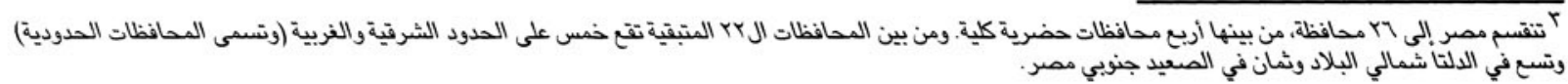




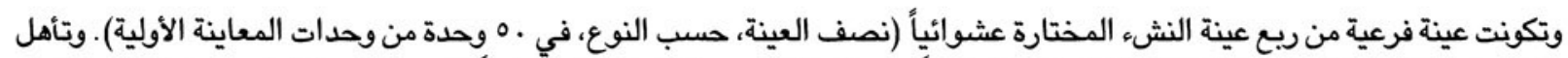
النشء في هذه العينة الفرعية لمقابلة ثانية ركزت أساساً على قضايا الصحة. كما تأهلوا أيضاً لفحص طبي الفي شامل وتحاليل للدم والبول

لمزيد من المعلومات حول نتائج المسح القومي، أنظر "الطويلة وآخرون، 1999".

ب. تصميم عينة الدراسة المتخصصة حول المدارس الإعدادية

استخدم الباحثن تصميم العينة والمعلومات التي تم جمعها في المسح القومي لاختيار عينة ممثلة من المدارس الإعدادية العامة الحكومية.

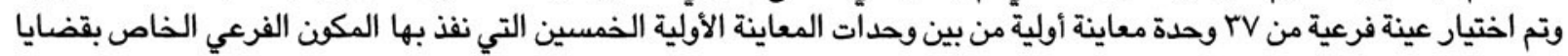

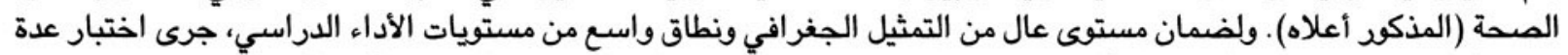

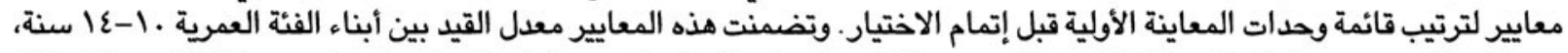

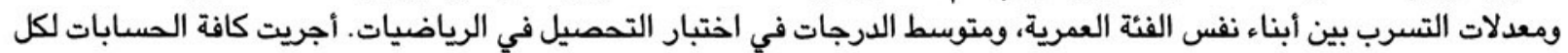

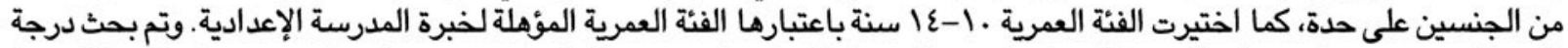

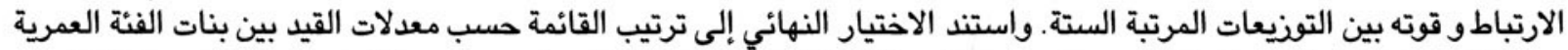

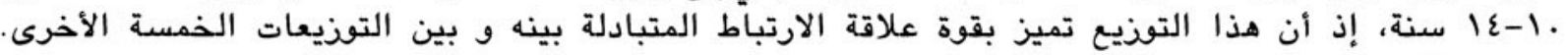

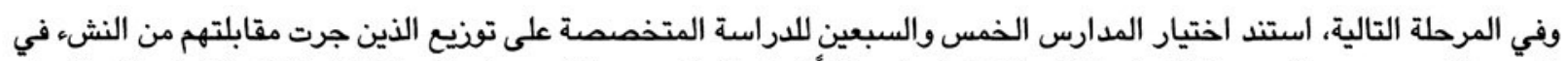

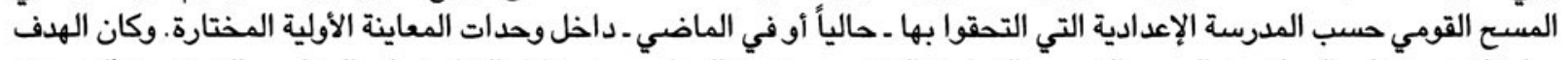

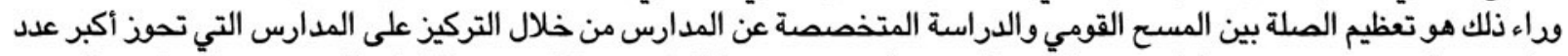

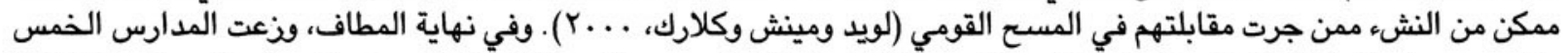

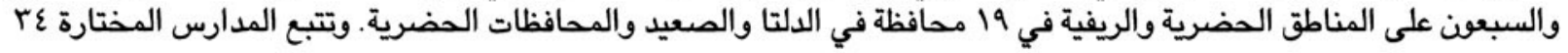
إدارة تعليمية من بين عدد إجمالي يبلغ المبرية 199 إدارة في المحافظاًت التسع عشرة.

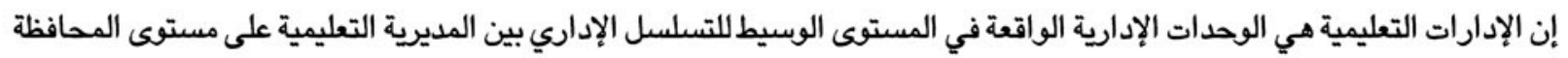

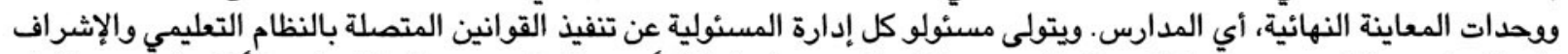

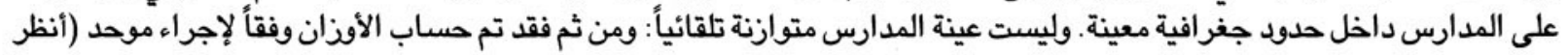
الملحق الأول للتعرف على تفاصيل هذه الحسابات).

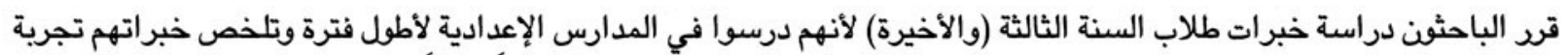

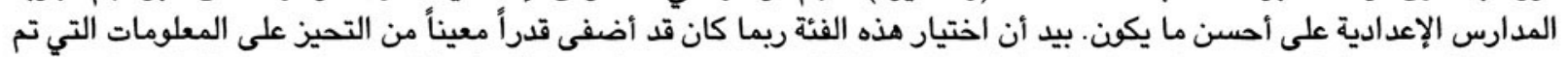

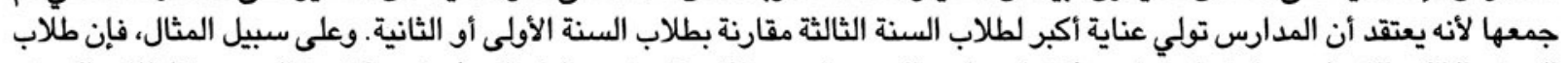

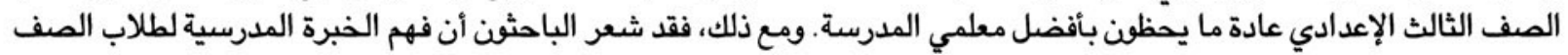
الثالث الإعدادي يمثل خطوة أولى مهمة نحو فهم مجمل خبرة الأفل معلى المدارس الإعدادية.

\section{r. أدوات و منهج الدراسة}

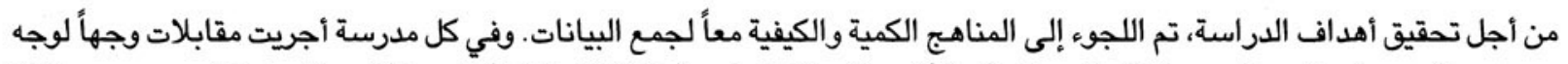

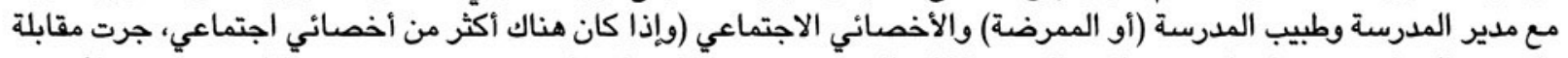

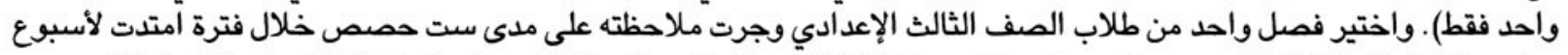

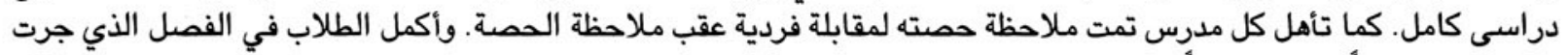

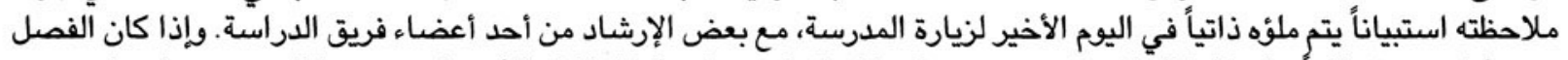

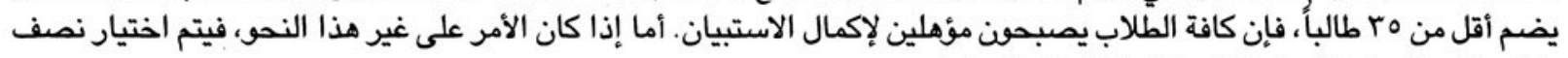
طلاب الفصل بطريقة عشوائية منتظمة لإكمال الاستبيان.

إضافة إلى ذلك، أجرى فريق الدراسة جرداً لمعدات المدرسة ومرافقها ولاحظوا ثلاث فترات راحة الإدة (فسح) في أيام مختلفة. كما جمعوا

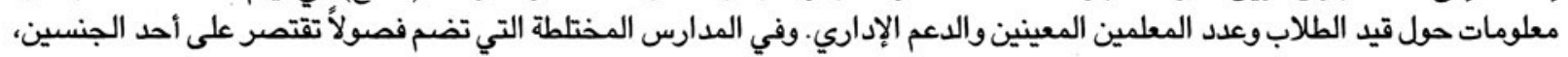
جرى اختيار فصل من الأولاد وآخر من البنات وتمت ملاحظظة الحصص المص والمارين المقابِلات مع المعلمين والطلاب مرتين. 


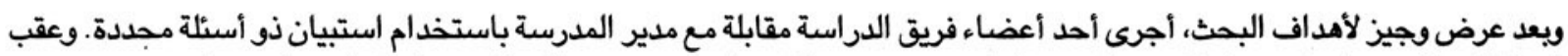

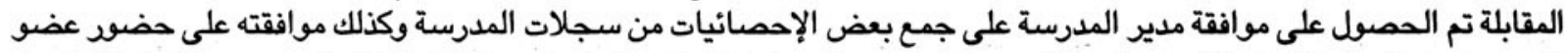

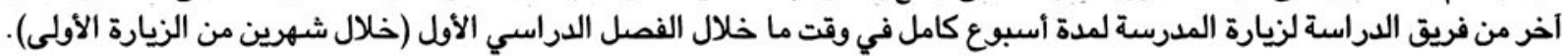

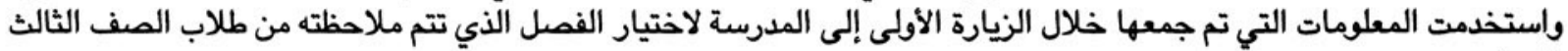

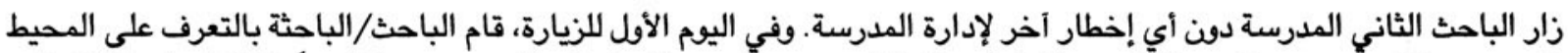

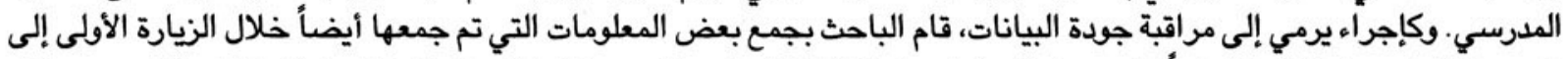

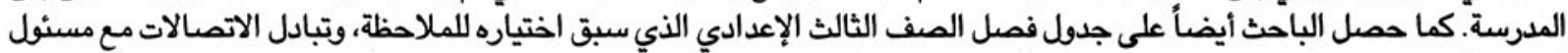
المسح الميداني المركزي حمل توزيع العمل المطلوب على أيام الدئ المراسة الستة.

وخلال الأيام الثلاثة التالية، لاحظ الباحث ثلاث فسح وست حصص للفصل المختار من طلاب الصف الثالث الإعدادي. كان الباحث

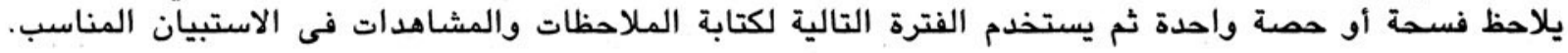

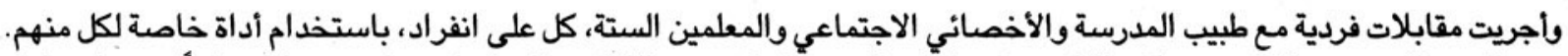

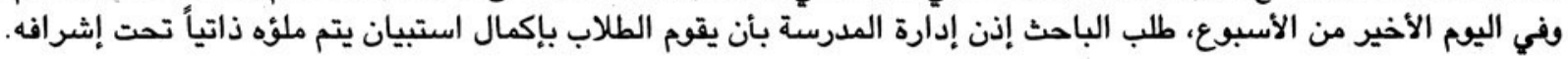

أ. أدوات الدراسة

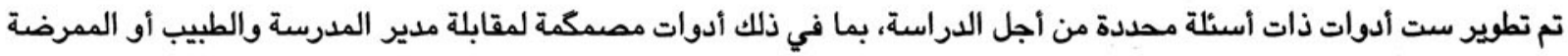

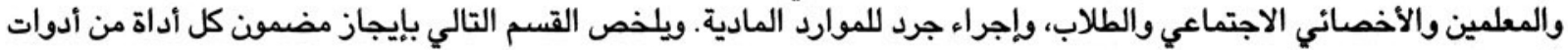

المسح. والمعين

اداة مدير المدرسة

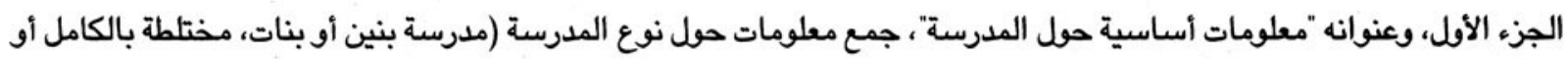

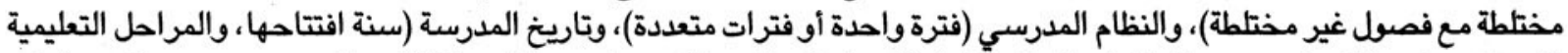

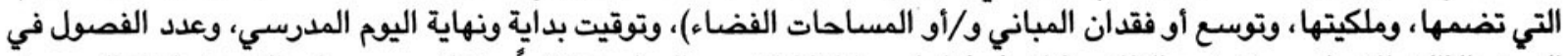

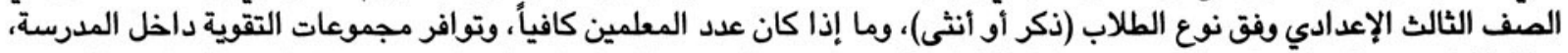

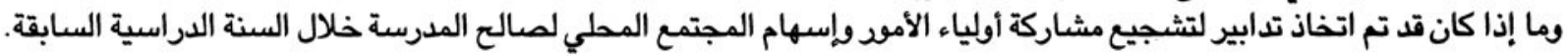

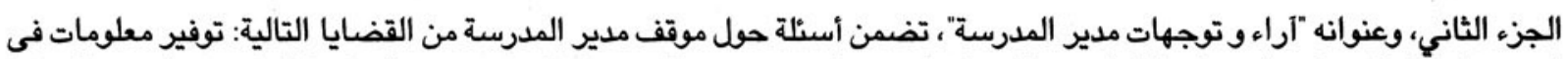

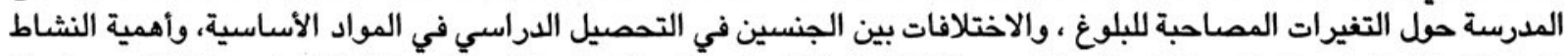

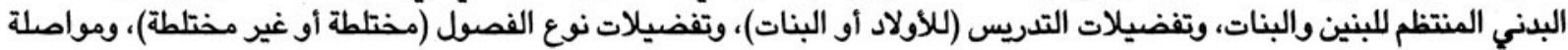
التعليم للاولاد والبنات، والتوجهات نخو الأدوار المتصلة بالنوع.

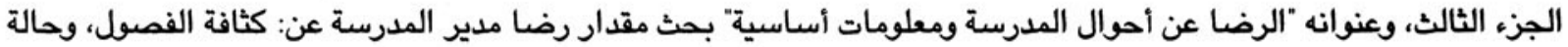

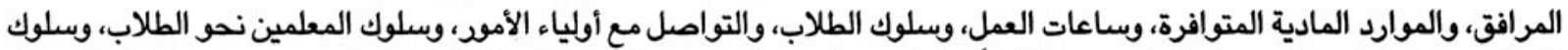

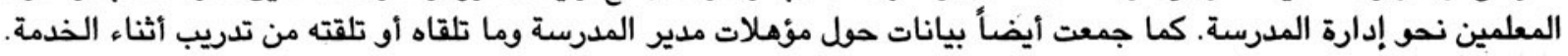

إضافة إلى ذلل، حصل فريق الدراسة على بعض الإحصائيات من سجلات المدارس حمل معدلات قيد الطلاب ونجاحهم، والعدد الإجمالي

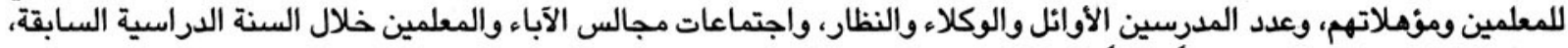

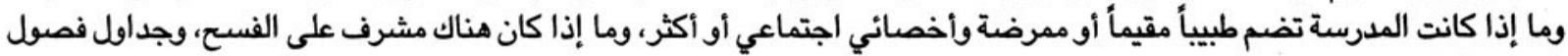
الصف الثالث الإعدادي.

\section{استبيان مقدمي الخدمة الطبية}

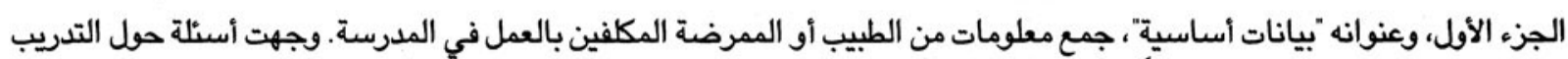

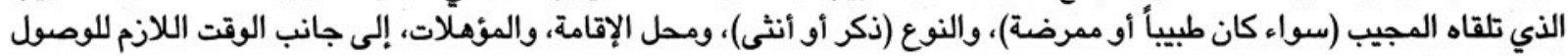
إلى المدرسة. 


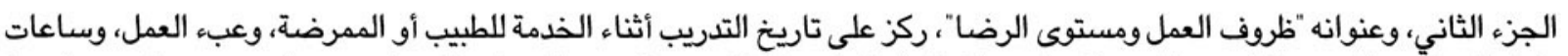

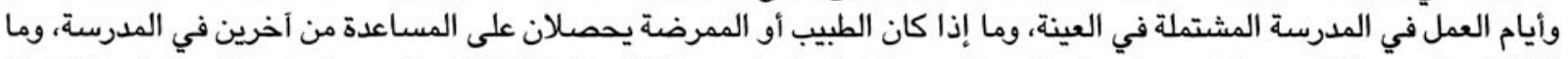

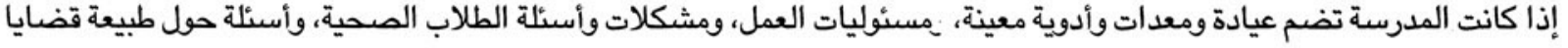

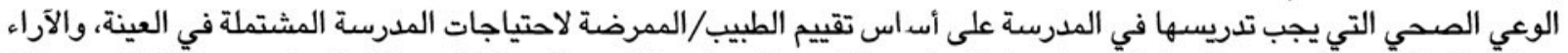

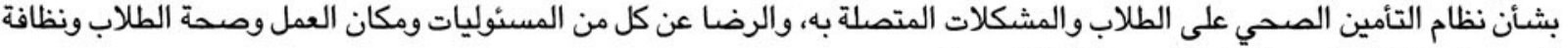
المدرسة، والتواصل مع أولياء الأمود وإدارة المدرسة.

\section{استبيان الأخصائي الاجتماعي}

الجزء الأول، وعنوانه "بيانات أساسية" جمع معلومات حول نوع وعمر ومحل إقامة وخبرة ومؤهلات الأخصائي الاجتماعي وما تلقاه

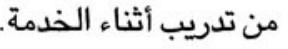

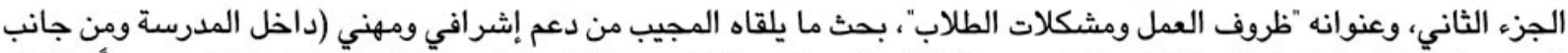

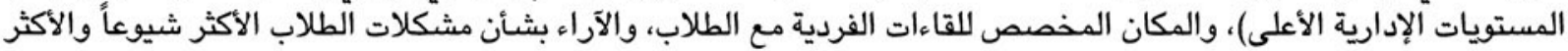

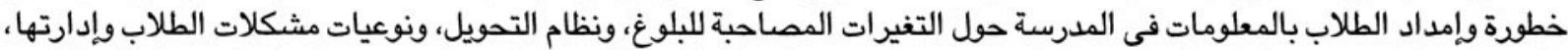

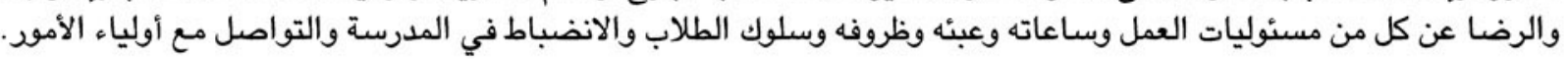

أداة المعلمين

الجزء الأول، وعنوانه "معلومات أساسية"، جمع معلومات حول نوع وعمر ومحل سكن ومؤهلات المعلم وما تلقاه من تدريب أثناء الخدمة ومقدار الوقت الذي يستغرقه للوصول إلى المعان المدرسة.

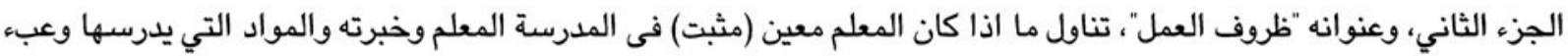

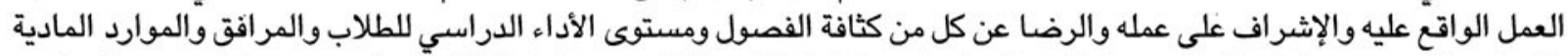
والمناهج المقررة وساعات العمل ومسئولياته والتواصل مع الإت أولياء الأمود الوالدين وسلوك الطلاب فيما بينهم وسلوكهم نحو المعلمين وسلوك المعلمين نحو الطلاب وسلوك المعلمين.

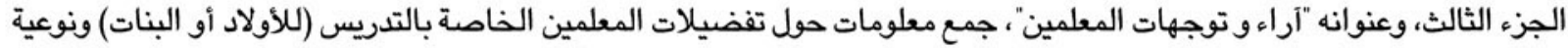

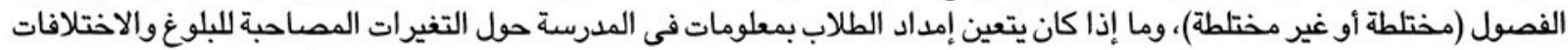

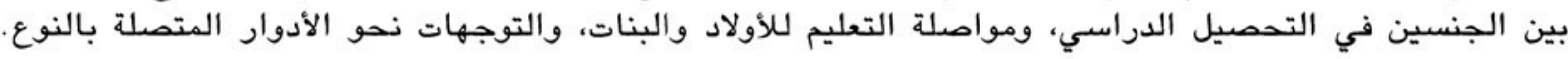

استبيان الطلاب (يملاً ذاتياً)

الجزء الأول، وعنوانه "بيانات أساسية"، جمع معلومات حول نوع وعمر الطالب، وما إذا كان يقطن مع الأب والأم، وتعليم الأب، وتعليم

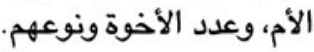

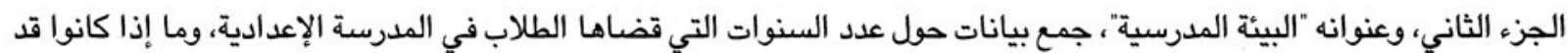

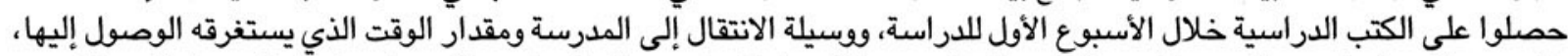

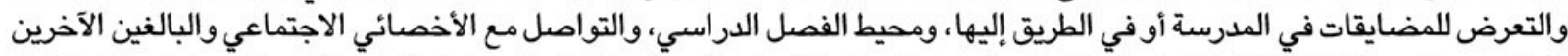

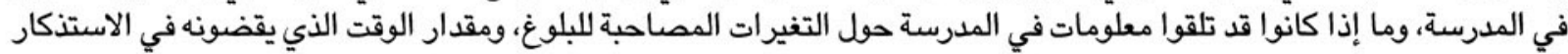

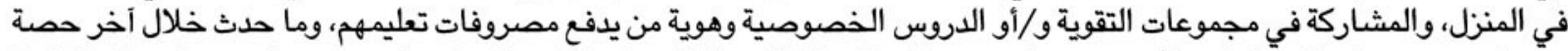

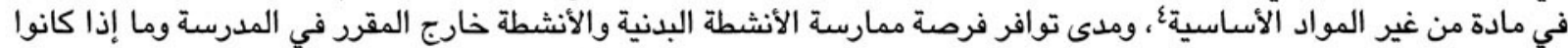

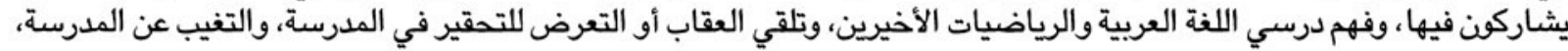
والتمييز في المعاملة في المدرسة على أساس النوعة أوراض أي أساس آخر.

الجزء الثالث، وعنوانه "آراء و توجهات الطلاب"، بحث آراء الطلاب نحو الأدوار المتصلة بالنوع، وتوجهاتهم إزاء مواصلة التعليم بالنسبة للأولاد والبنات، وفوائد مواصلة التعليم لكل منهما.

ع تشمل هذه المواد، الإقتماد المنزلى والزر اعةو الصناعة والنجارة والصيانة ومواد أخرى 
الجزء الرابع، وعنوانه "التطلعات والتوقعات والخصائص الشخصية"، ركز على ما إذا كان الطالب ينوي مواصلة التعليم حتى نهاية

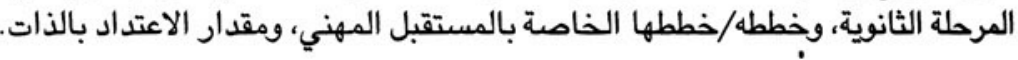

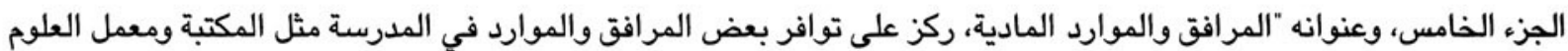

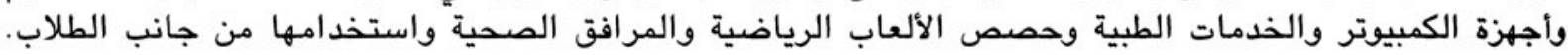

جرد الموارد المادية

أكمل الباحث هذه الأداة بعد فحص كل بند بنفسه.

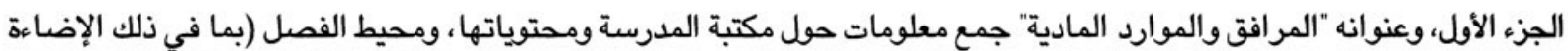

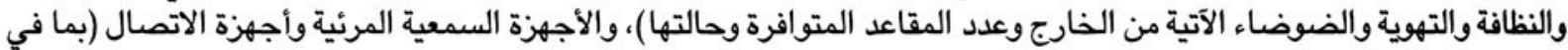

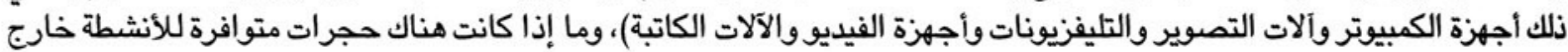

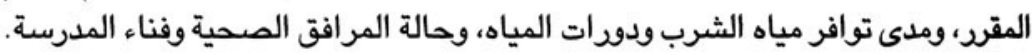

الجزء الثاني، وعنوانه "الانتظام والتغيب"، بحث معدل التغيب بين الطلاب والمعلمين وطبيب أو ممرضة المدرسة والأخصائي الاجتماعي

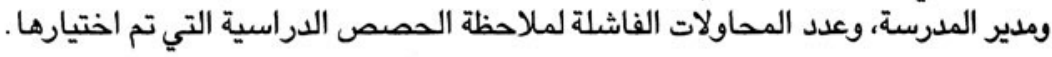

ب. أدوات الملاحظة المستخدمة فى الدراسة أكمل الباحثن أداتين شبه منظمتين لملاحظة الفسحة والحصة. وشملت كل أداة عدداً من الأسئلة ، المحددة الإجابات، فضلاً عن مساحة لتسجيل ملاحظاتهم في صيغة مكتوية.

ملاحظة الفسحة

جمعت هذه الأداة معلومات حول توقيت بدء ونهاية الفسحة، والتوقيت الذي يتعين أن تبدأ وتنتهي فيه وفق الجدول، والإشراف خلال فترة الفسحة، وما إذا كانت أية أنشطة قد وقعت خلال الفوة ونهاية الفحة وطبيعة هذه الأنشطة.

ملاحظة الحصة

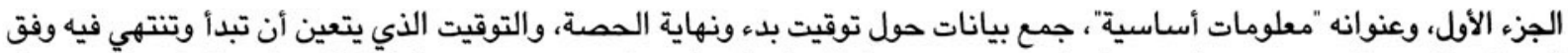

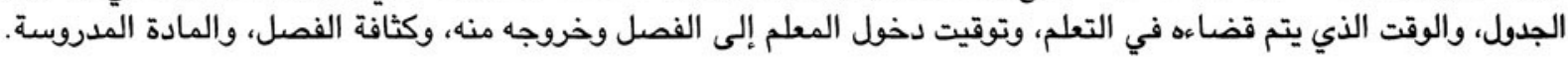

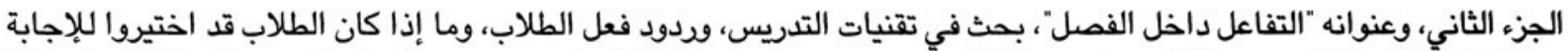

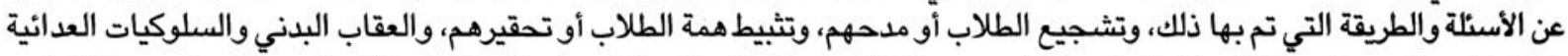

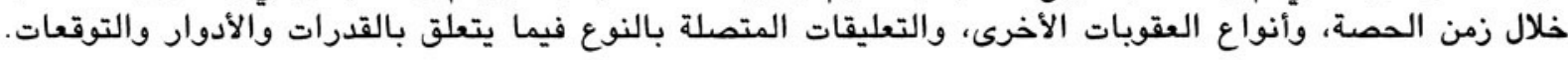

حاول فريق الدراسة جاهداً تقديم تقييم واقعي وغير متحيز للتجرية المدرسية داخل المدارس التي اشتملت عليها العينة. غير أن النتائج

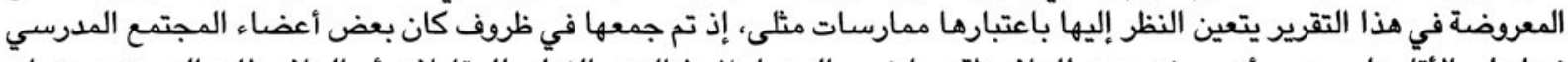

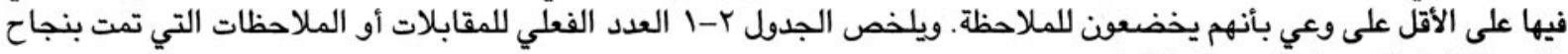
بالنسبة لكل أداة ونمط تطبيق هذه الأدوات 
الجدول r - 1: عدد المقابلات/الملاحظات التي تمت بنجاح بالنسبة لكل أداة ونمط التطبيق

\begin{tabular}{|c|c|c|}
\hline نمط التطبيق & العدد الذي تم إتمامه بنجاح & عنوان الأداة \\
\hline مقابلة & vo & مدير المدرسة \\
\hline مقابلة & i^o & الأخصائي الاجتماعي \\
\hline مقابلة مقابة & 10 10ب & مقدمو الخدمات الطبية \\
\hline مقابلة & ج^. & المعلمون \\
\hline أداة تملأ ذاتياً & $r \varepsilon 90$ & الطلاب \\
\hline الملاحظة وسجلات المدرسة & $د \wedge \varepsilon$ & جرد المدرسة \\
\hline الملاحظة & $\varepsilon \vee q$ & ملاحظة الحصص \\
\hline الملاحظة & ArrV & ملاحظة الفسح \\
\hline سجلات المدرسة & vo & القيد والعاملون \\
\hline
\end{tabular}

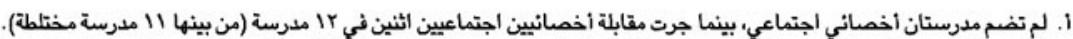

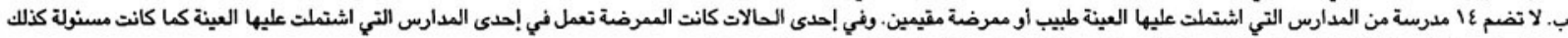

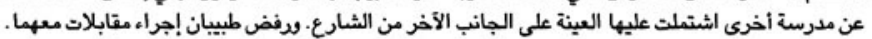

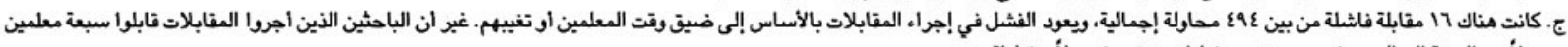

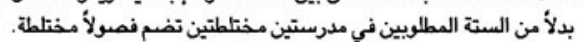

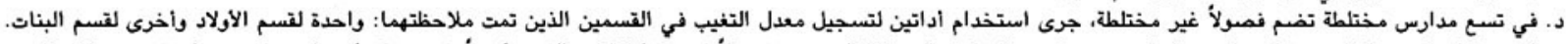

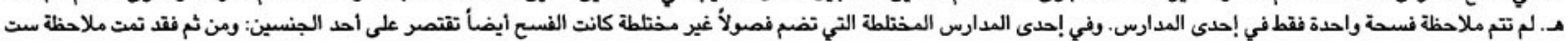

\section{ع. مقدمة للجداول و النتائج}

إن كافة الجداول والنتائج في هذا التقرير معروضة وفقاً لثلاثة متغيرات خلفية أساسية: (أ) نوع المجيب، (ب) المستوى الإجمالي للأداء

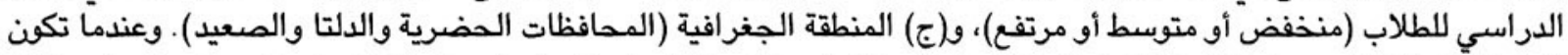

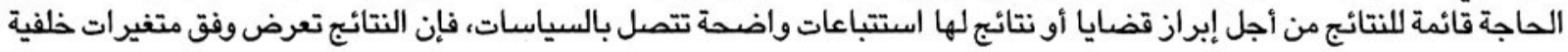

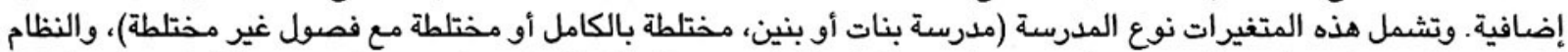

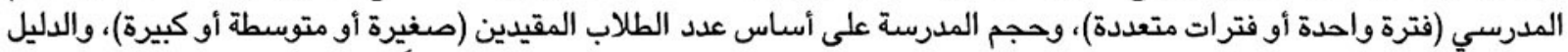

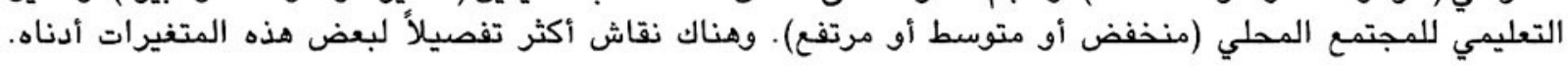

أ. متغير ات خلفية مختارة

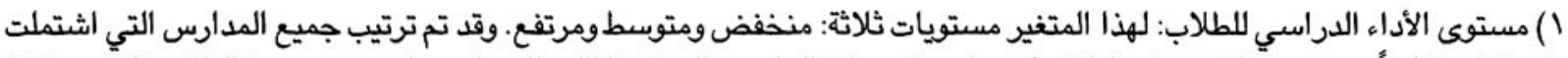

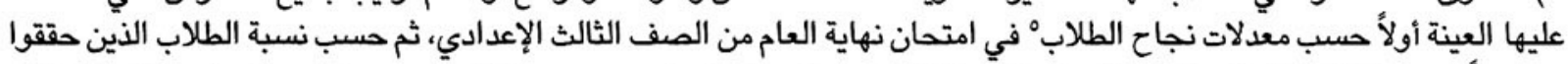

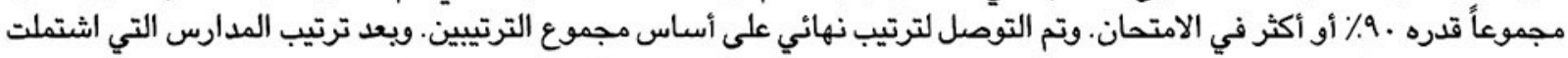

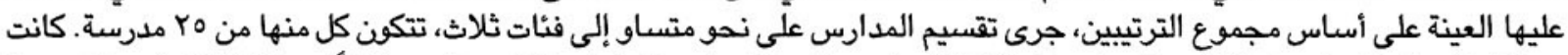

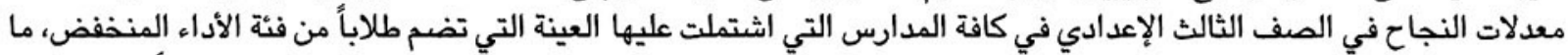

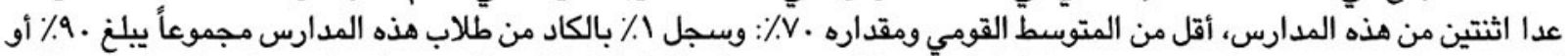

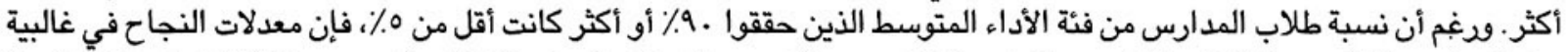

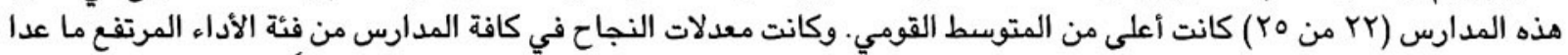

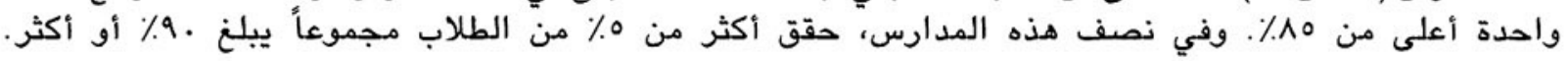

يستند هذا المؤشر للأداء الدراسي للطلاب على إحصائيات من وذارة التعليم (199V-1991) وهو مستقل تماماً عن تصميم الدراسة.

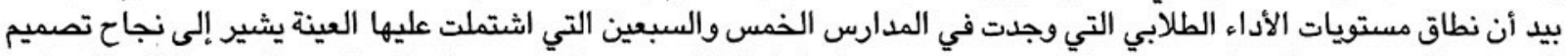

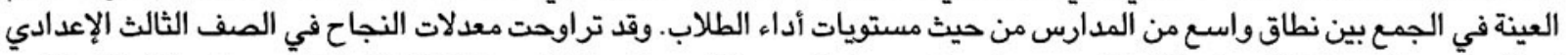

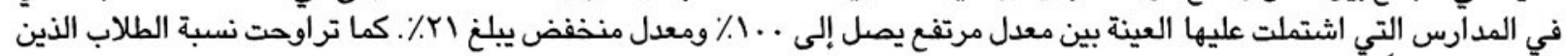

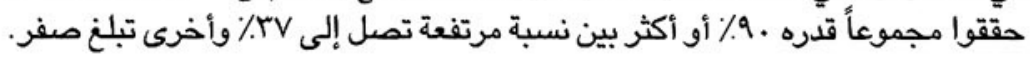

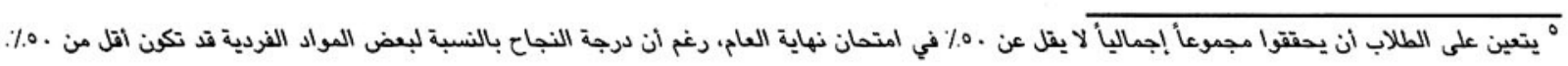




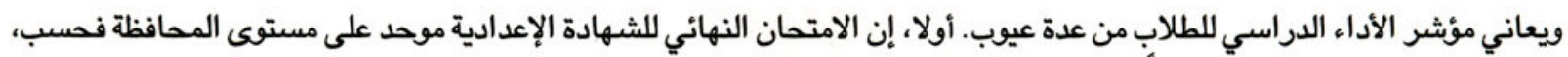

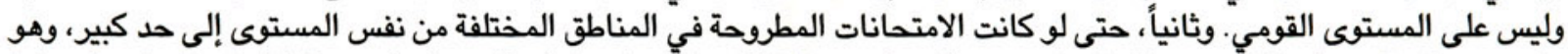

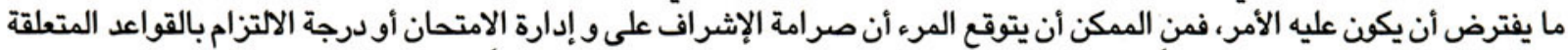

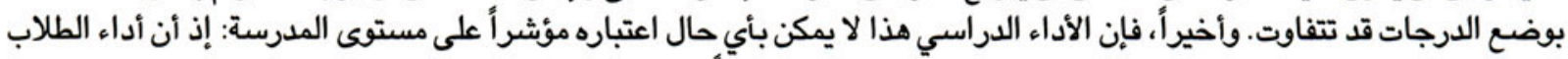

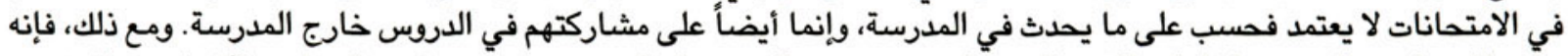

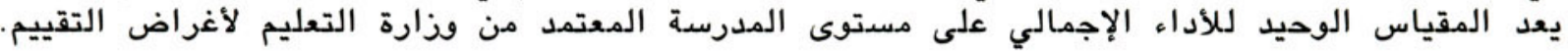

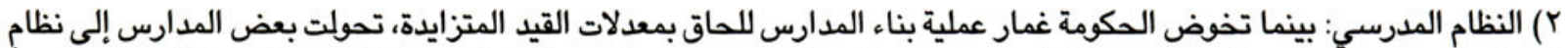

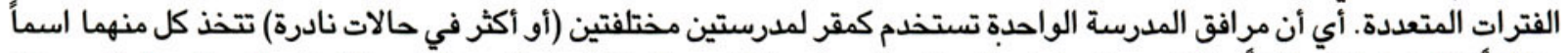

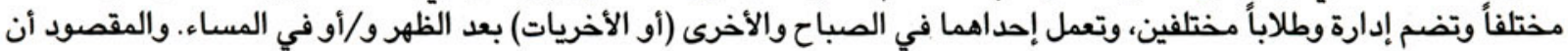

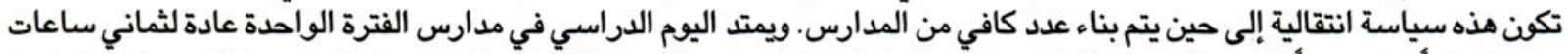

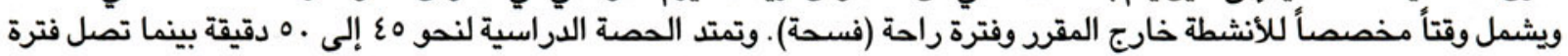

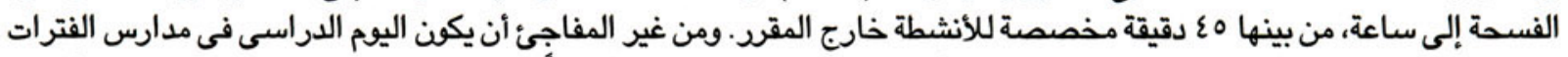

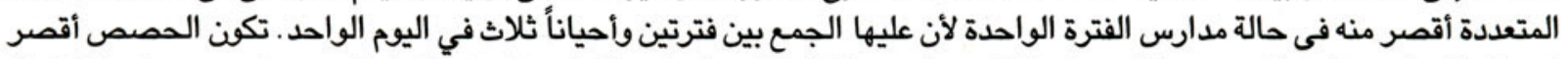

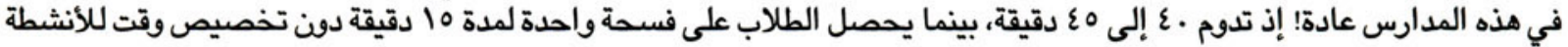

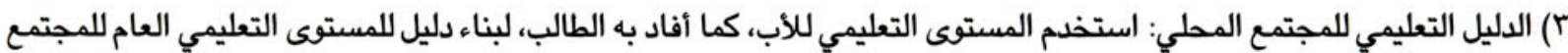

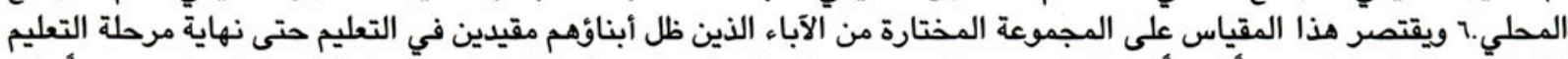

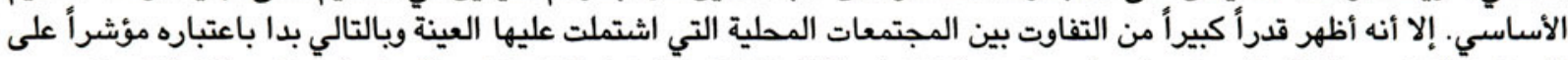

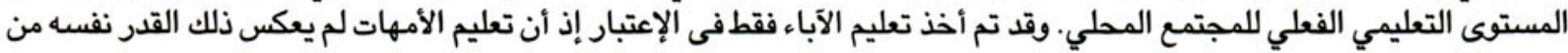
التفاوت بين وحدات المعاينة الأولية.

بالنسبة لكل وحدة من وحدات المعاينة الأولية، تم حساب قياس كمى مستمر على أساس: ه, . * ( ا - النسبة المئوية للآباء غير المتعلمين) + ه . .* (النسبة المئوية للآباء الحاصلين على شهادة جامعية) صنفت جميع وحدات المعاينة الأولية بترتيب متصاعد وفقاً للقيمة الناتجة عن هذا المقياس ثم تم جمعها في فئات ثلاث: منخفضة ومتوسطة ومرتفعة.

ع) حجم المدرسة: استخدم معدل القيد الإجمالي في كل مدرسة مشتملة في العينة لبناء دليل لحجم المدرسة يتضمن ثلاث فئات: صغيرة

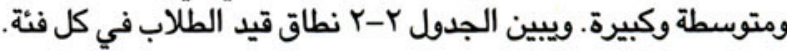

الجدول Y-ץ: نطاق قيد الطلاب في كل فئة من فئات دليل حجم المدرسة

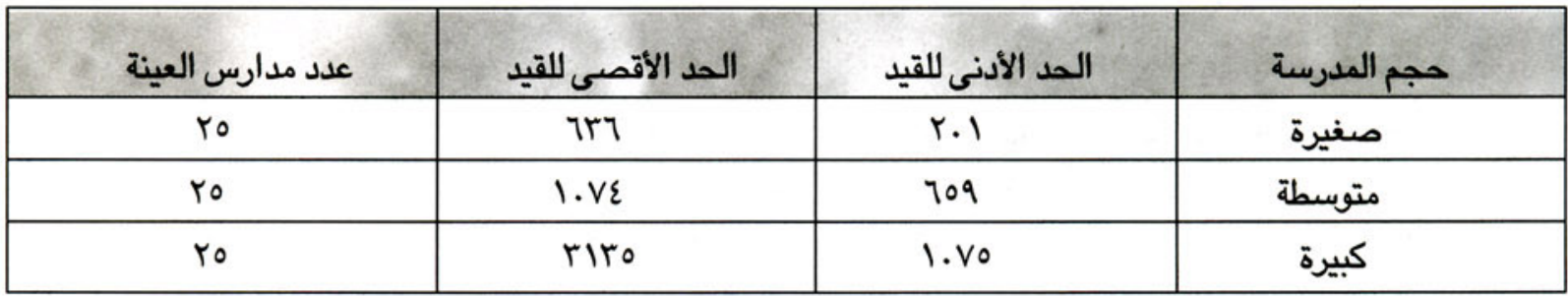

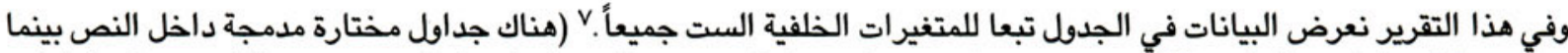

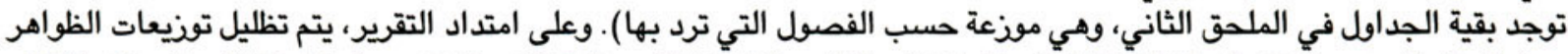

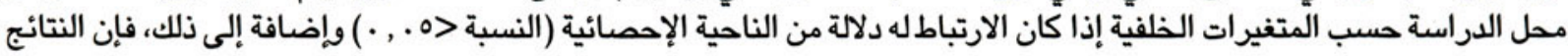

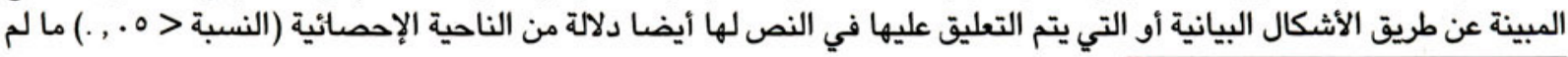

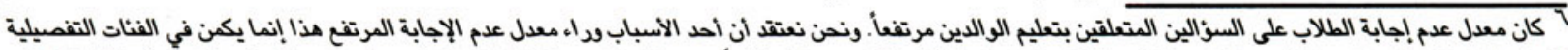

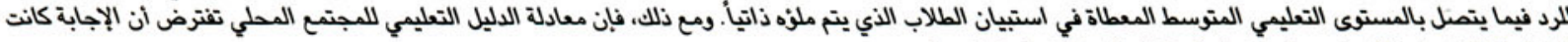

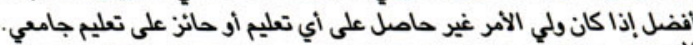

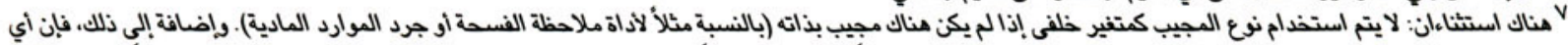

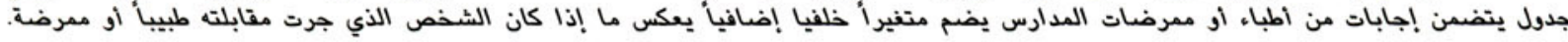


يذكر غير ذلك. وجميع النسب المنوية المذكوة محسوبة باستخدام الأوذان الترجيحية للعينة.

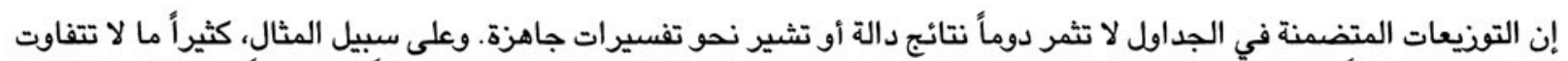

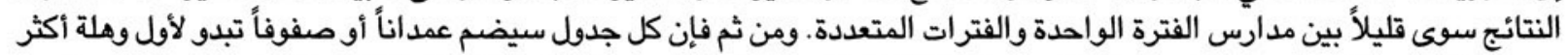

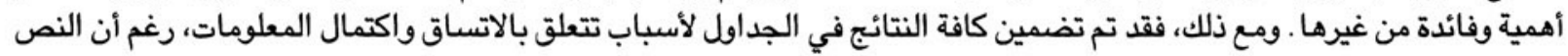
لا يتضمن تعليقات على كافة النتائج.

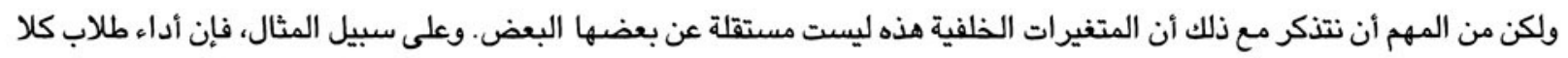

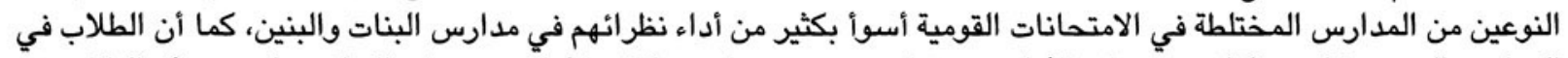

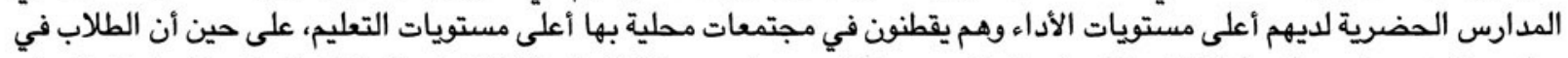

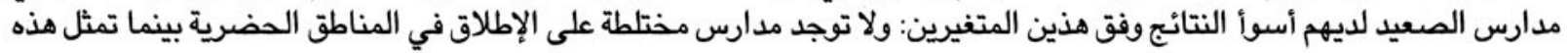

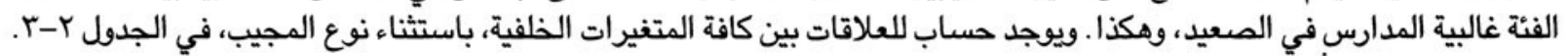

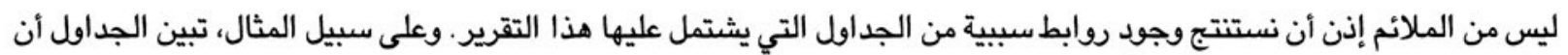

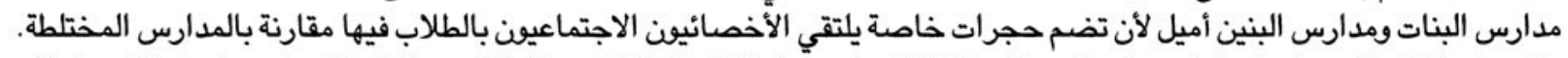

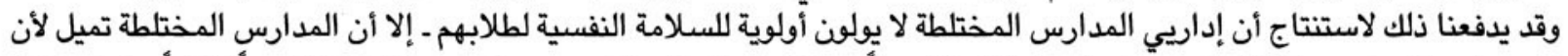

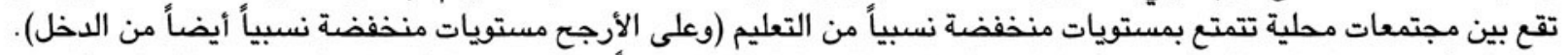

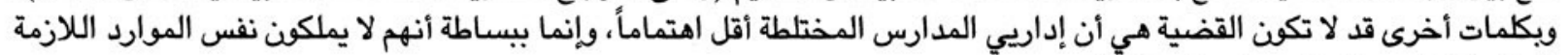
المتاحة لإداريي المدارس غير لانكن المختلطة. 


\section{الجدول ץ-r: العلاقات بين المتغيرات الخلفية (باستثناء نوع المجيب)}

نوع المدرسة ومستوى الأداء الدراسي للطلاب: توجد أعلى مستويات الأداء بين طالبات مدارس البنات،

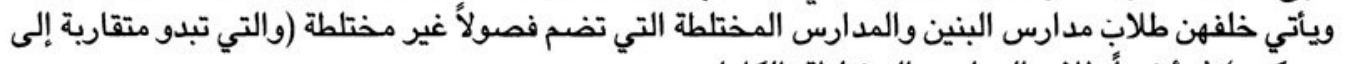
حد كبير) ثم أخيراً طلاب المدارس المختلطة بالكامل.

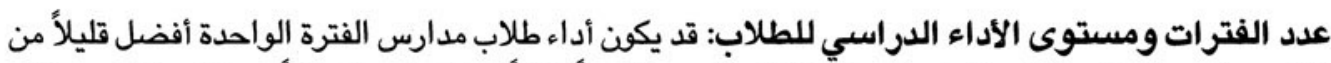

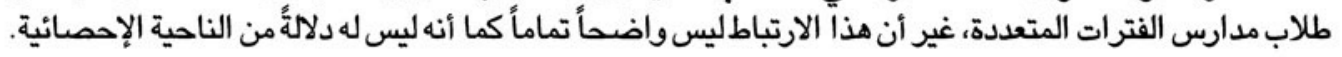
المنطقة ومستوى الأداء الدراسي للطلاب: توجد أعلى مستويات الأداء بين طلاب المدارس الحضرية يليهم طلاب مدارس الدلتا ثم طلاب مدارس الصعيد. لمعيد.

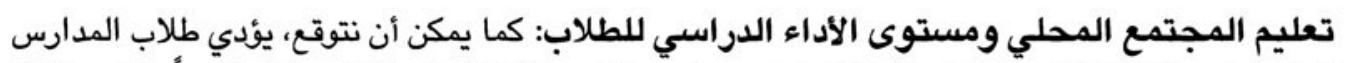

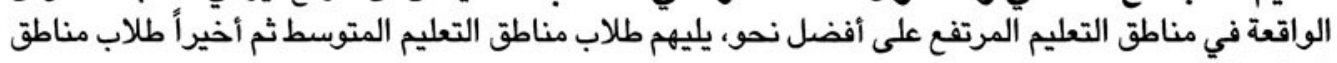
التعليم المنخفض.

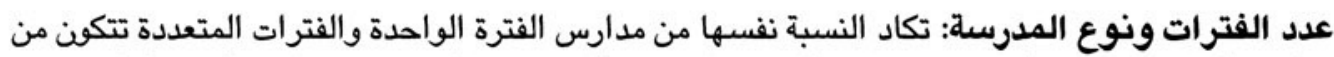

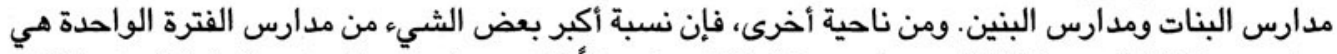

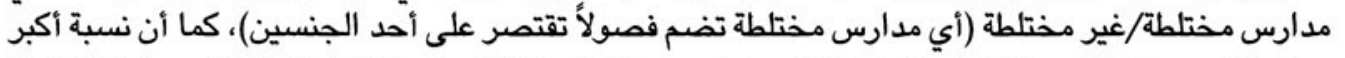

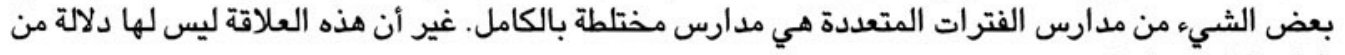
الناحية الإحصائية.

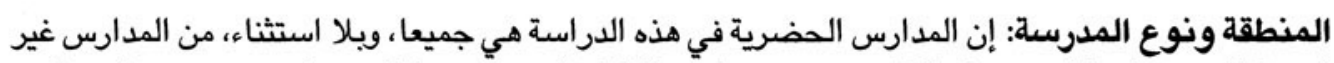

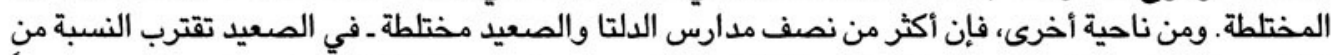

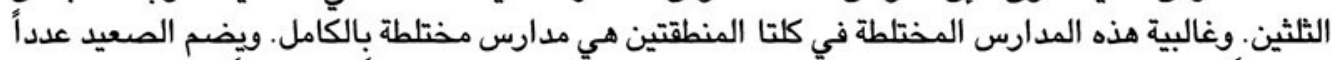

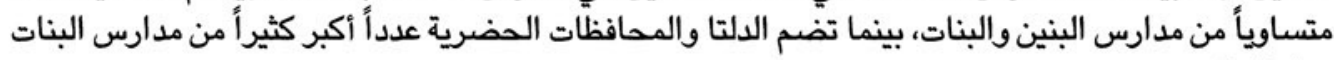
مقارنة بالبنين.

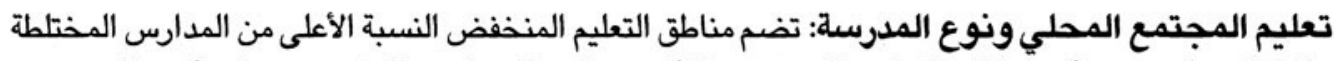

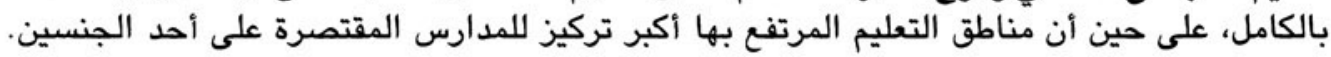

المنطقة وعدد الفترات: تضم المناطق الحضرية نسبة أعلى من مدارس الفترة الواحدة مقارنة بكل من الدلتا والصعيد (الذين يضمان نسباً متقاربة)، رغم أن العلاقة ليس لها دلإل دلالة من الناحية الإحصائية.

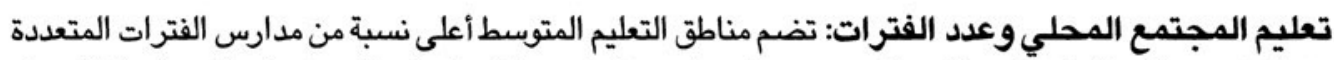

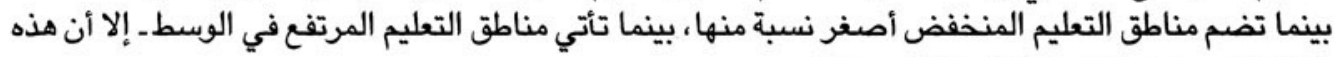
العلاقة ليس لها دلالة من الناحية الإحصائية.

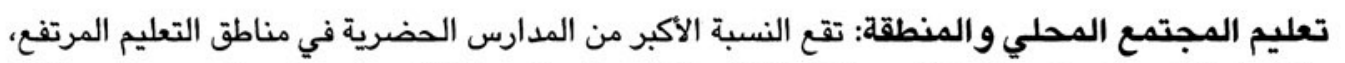

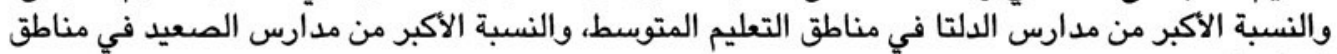
التعليم المنخفض.

ب. تعليقات ونتائج عامة

يبين الجدول r-ع النسب المئوية لتوزيع المدارس التي اشتملت عليها العينة في المناطق الثلاث وفي المناطق الحضرية والريفية حسب جميع المتغيرات الخلفية الأخرى.

تكاد كافة المدارس الحضرية التي تضم طلاباً منخفضي الأداء (Y من بين ^ع مدرسة حضرية في العينة) تقع في المناطق شبه الحضرية 


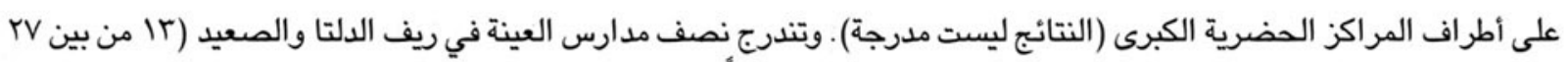

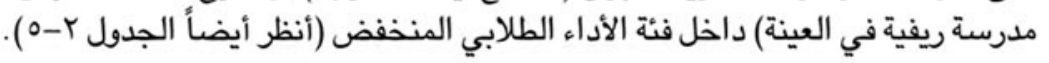

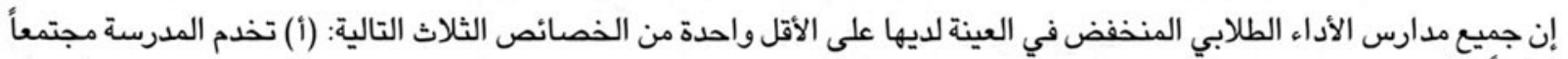

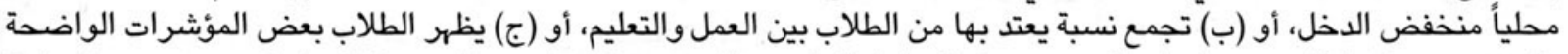

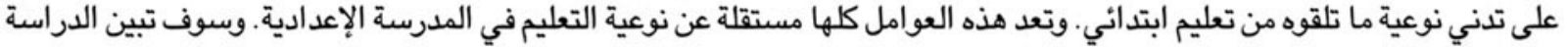

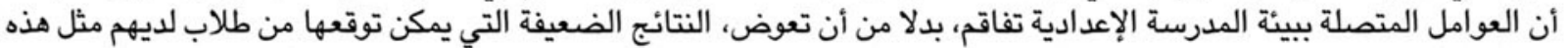
الخلفية.

الجدول ب-\{: نسب التوزيع المئوية لمدارس العينة في كل منطقة وكل نوع من المواقع حسب المتغيرات الخلفية المتصلة بالمدرسة والمجتمع المحلي المئوية

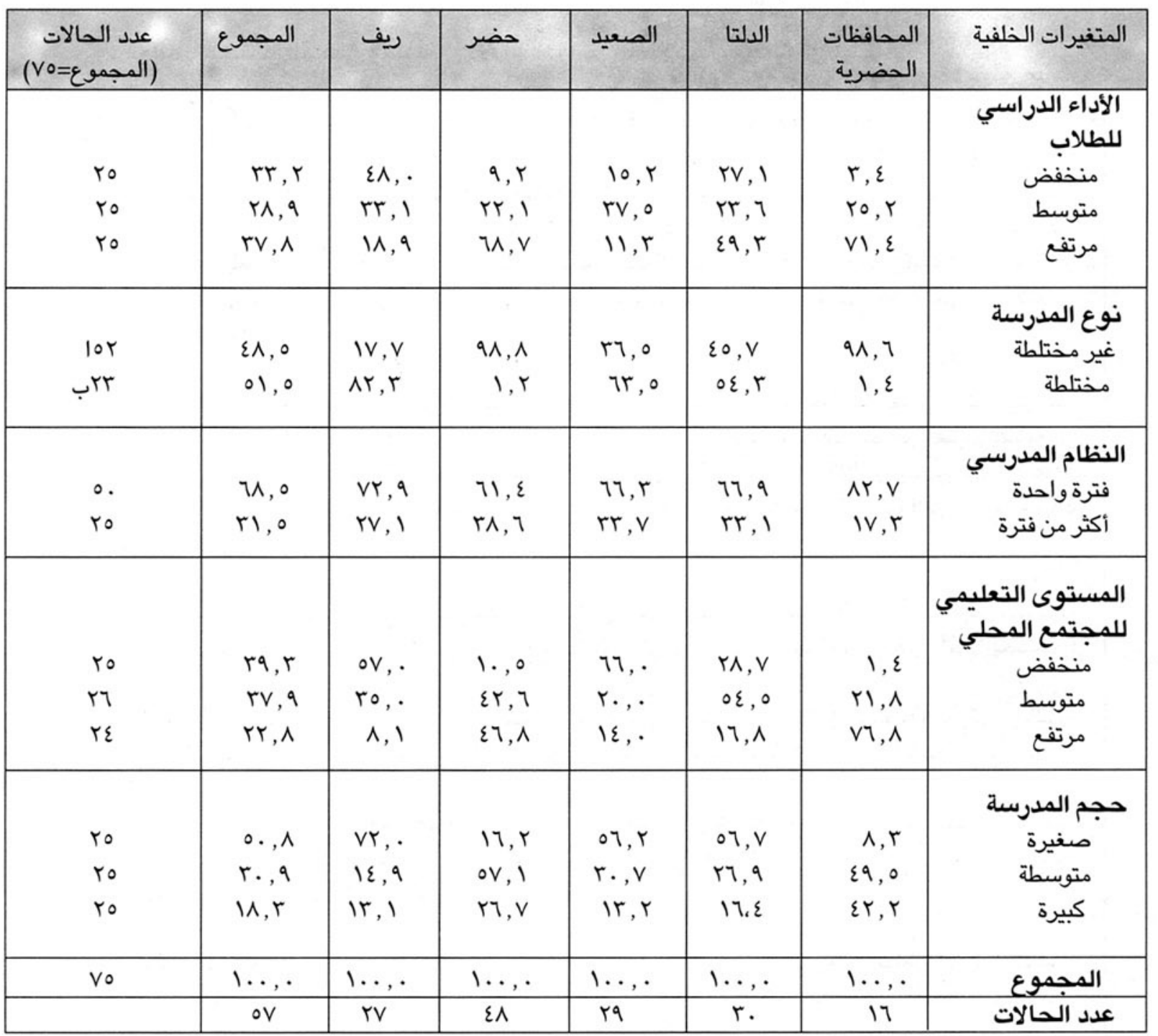

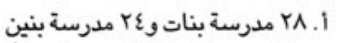
ب. ع ا مدرسة مختلطة تضم فصورلأ مختلطة و و مدارس مختلطة تضم فصولأ غير مختلطة.

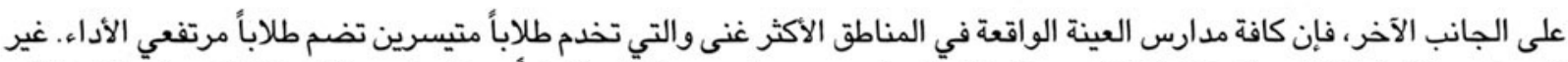

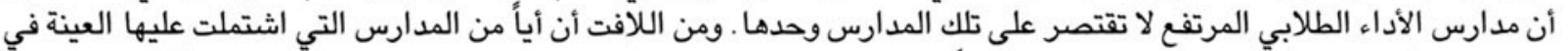

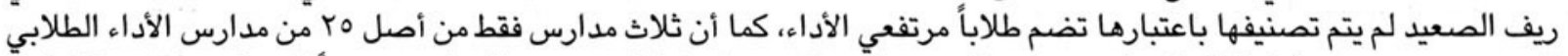

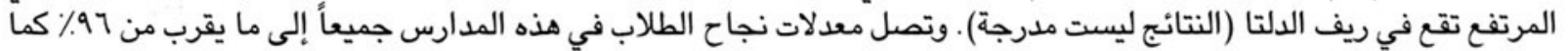

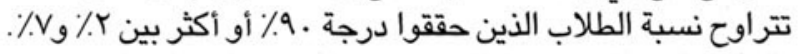




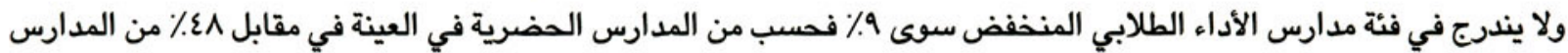

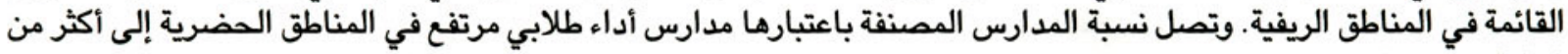
ثلاثة أضعاف النسبة المقابلة في المناطق الريفية (79٪ مقابل المبل 19٪).

ويمثل الأداء المتوسط إلى المرتفع المعدل المعتاد بين طلاب مدارس التعليم الإعدادي العام الحكومية في المحافظات الحضرية والدلتا،

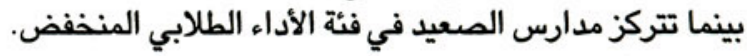

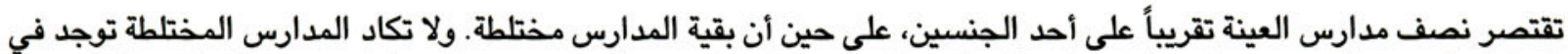

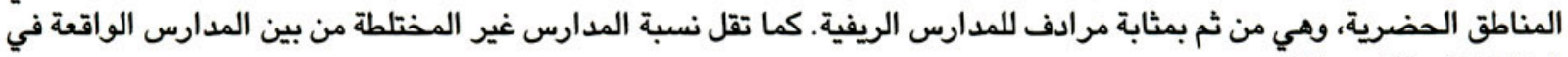

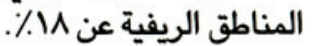

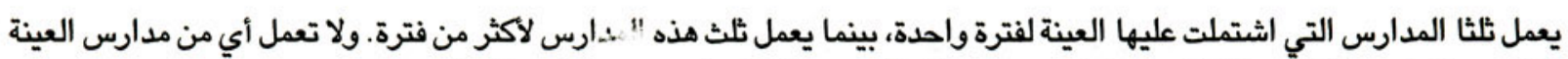

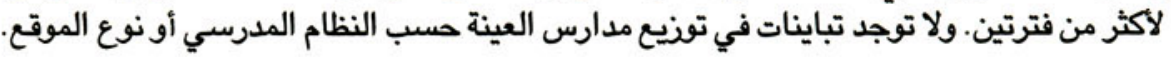

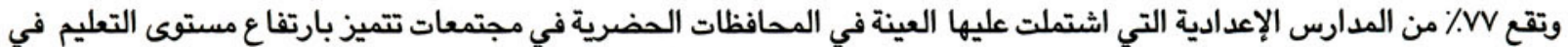

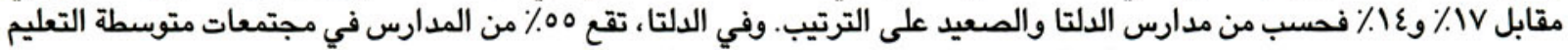
بينما تقع 77\% من مدارس الصعيد في مجتمعات منففضة التعليم.

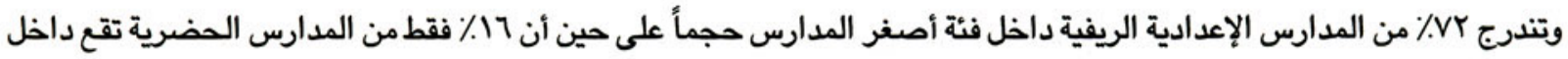
هذه الفئة.

الجدول Y-ه: نسب التوزيع المئوية لمستويات الأداء الدراسي للطلاب حسب المتغيرات الخلفية

\begin{tabular}{|c|c|c|c|c|}
\hline المجموع & أداء طلابي مرتفع & أداء طلابي متوسط & أداء طلابي منففض & المتغيرات الخلفية \\
\hline & & & & نوع المدرسة \\
\hline rA & Vr,o & $17,$. & 11,0 & بنات \\
\hline$r \varepsilon$ & ru, r & $\varepsilon r, v$ & $r \cdot, l$ & بنين \\
\hline $1 \varepsilon$ & 7,7 & $r v,$. & $07, \varepsilon$ & مختلطة بالكامل \\
\hline 9 & $\varepsilon 0, r$ & IV, 9 & $\mathrm{rl}, \Lambda$ & مختلطة مع فصبل غير مختلطة \\
\hline & & & & النظام المدرسي \\
\hline 0. & $\varepsilon ., \Lambda$ & rr, I & rv, & فترة واحدة \\
\hline ro & $r, r$ & $\varepsilon r, v$ & ro,. & أكثر من فترة \\
\hline & & & & المستوى التعليمي للمجتمع المحلي \\
\hline ro & Ir, & ir, 1 & 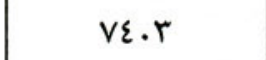 & 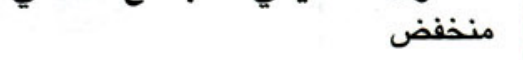 \\
\hline r & $r q, r$ & 01,9 & $\wedge, \wedge$ & متوسط متو \\
\hline$r \varepsilon$ & $v a, v$ & $\mathrm{IV}, \mathrm{r}$ & $r,$. & مرتفع \\
\hline & & & & المنطقة \\
\hline 17 & $\vee 1, \varepsilon$ & Yo,, & $r, \varepsilon$ & المحافظات الحضرية \\
\hline$r$. & $\varepsilon q, r$ & $r r, T$ & TV, I & الدلتا \\
\hline rq & $11, r$ & rv, o & $01, r$ & الصعيد \\
\hline & & & & الموقع الحضري-الريفي \\
\hline$\varepsilon \wedge$ & $\mathrm{u}, \mathrm{v}$ & $r, 1$ & $9, r$ & حضري \\
\hline rV & 11,9 & $r r, 1$ & $\varepsilon \wedge,$. & ريفي \\
\hline & & & & حجم المدرسة \\
\hline ro & IV,o & rר, I & $\varepsilon\urcorner, \varepsilon$ & صغيرة \\
\hline ro & $70,$. & $1 \wedge, \Lambda$ & $17, r$ & متوسطة \\
\hline ro & $\varepsilon \wedge, \varepsilon$ & rT, $r$ & $r_{0, \varepsilon}$ & كبيرة \\
\hline Vo & $r v, \Lambda$ & YA, 9 & $r r, r$ & المجموع \\
\hline
\end{tabular}




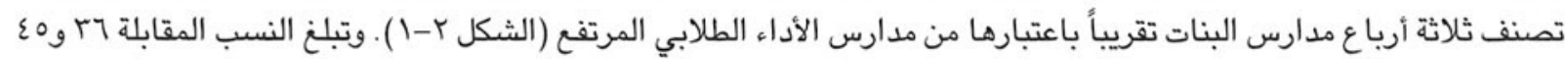

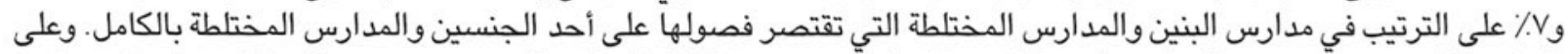

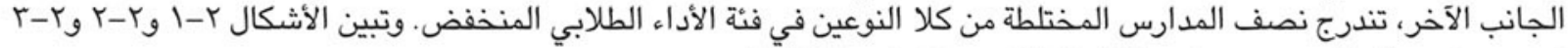
توزيع مدارس العينة حسب مستوى الأداء الطلابي ومتغيرات خلفية أُخرى.

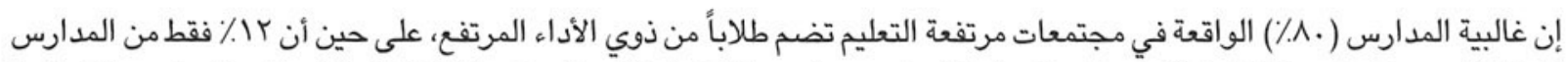

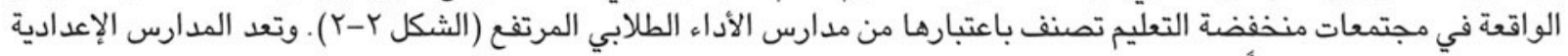

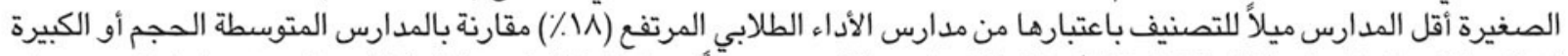

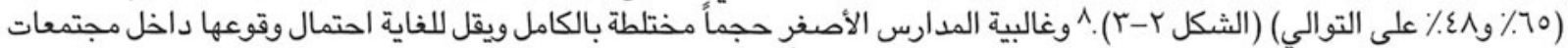
تتمتع بمستوى تعليم مرتفع. كما أن غالبية المدارس الأبرالبة الصغر حجماً تعمل لفترة واحدة فقط.

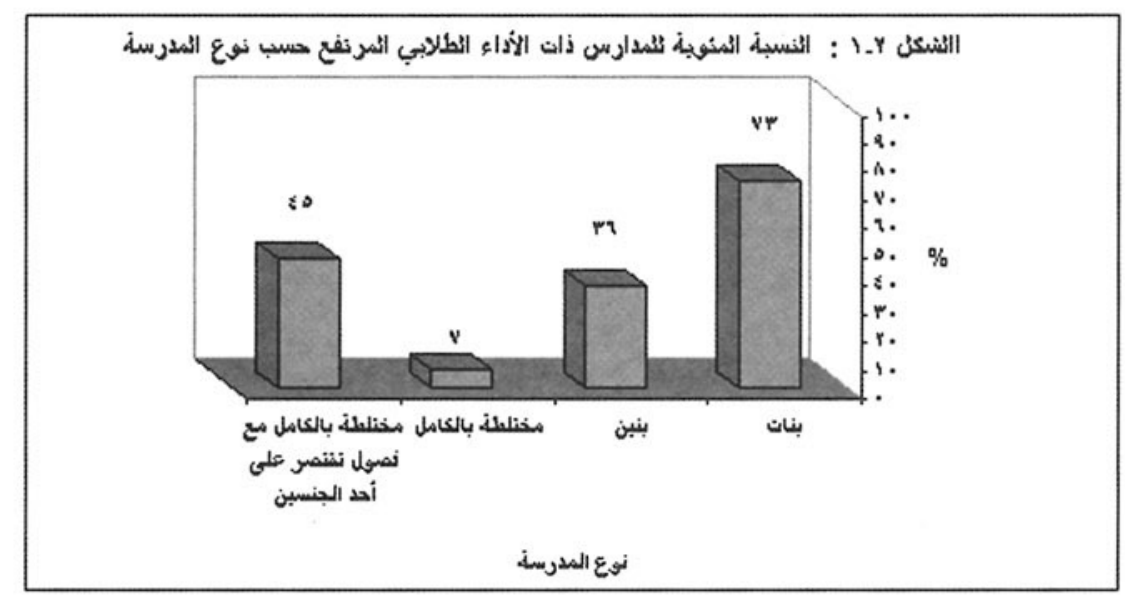

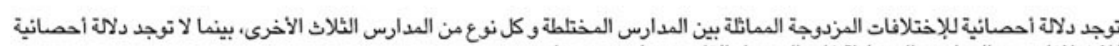

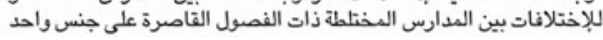

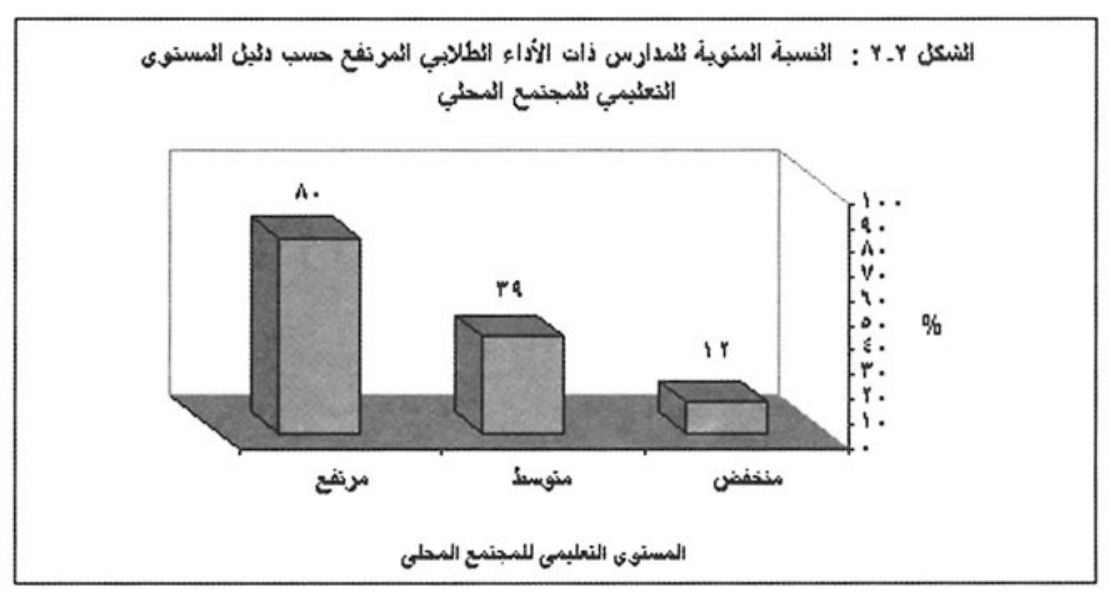

كل الإختلافات المزدوجة المهاثلة لها دلالة إحصانية

يعد الافتقار إلى ارتباط دال بين مستوى الأداء الدراسي للطلاب والنظام المدرسي (فترة واحدة أو أكثر من فترة) من الأمود اللافتة حقاً.

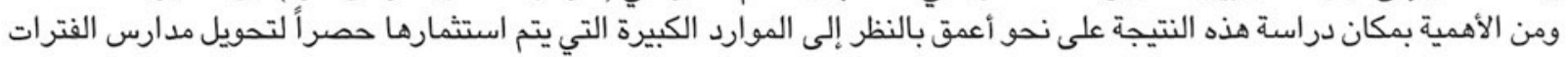
المتعددة إلى نظام الفترة الواحدة.

وتوجد ارتباطات لها دلالة احصائية بين نوع المدرسة وحجمها، وبين نوع المدرسة والدليل التعليمي للمجتمع المحلي، وكذلك بين حجم المدرسة والنظام المدرسي.

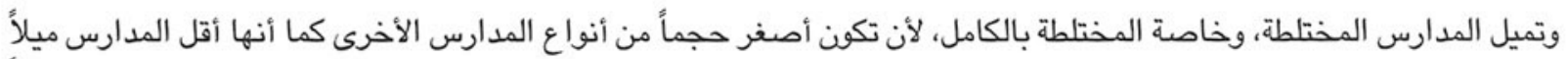

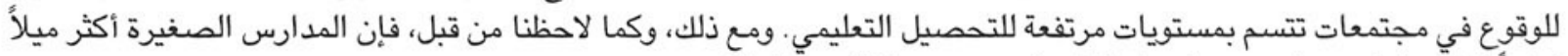

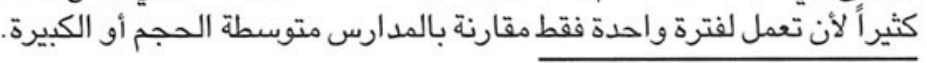
^ غير أن الفارق بين المدارس المتوسطة الحجم والكبيرة ليس دالأمن الناحية الإحصانية. 


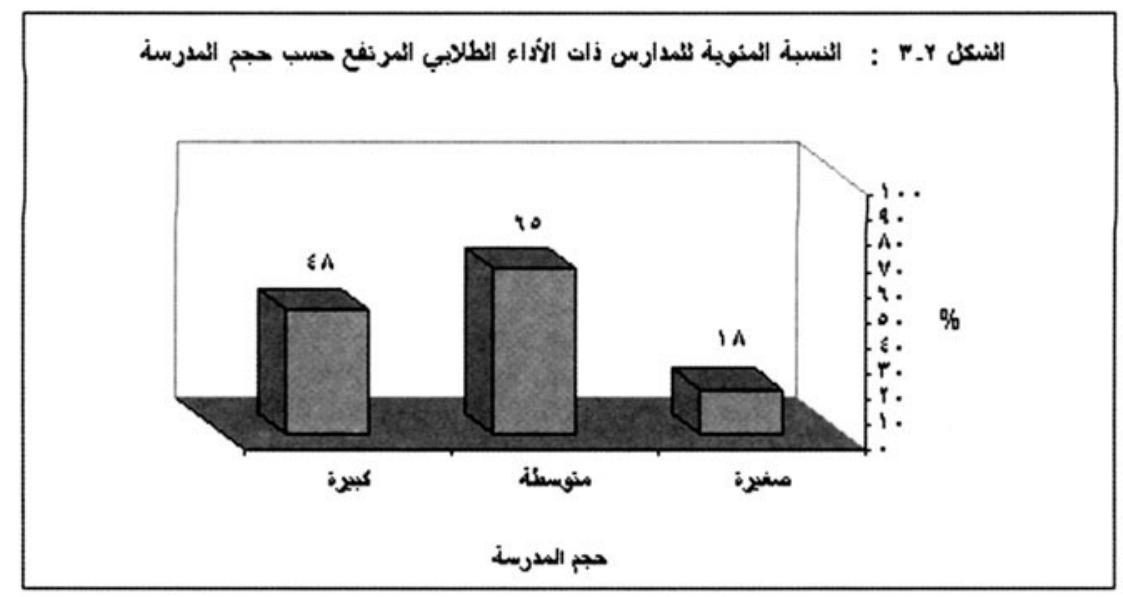

๑. بنية التقرير

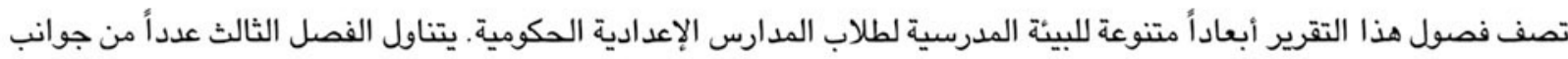

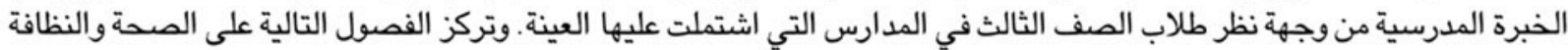
العامة في المدرسة، وقضايا النوع، والموارد المادية والبشرية، وفرص الثرالتية التعلم، والقيادات المدرسية.

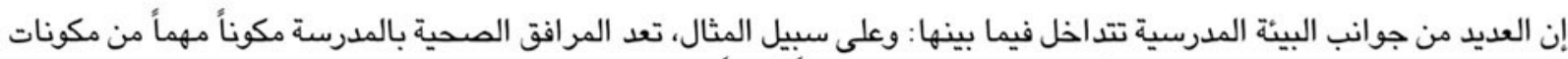

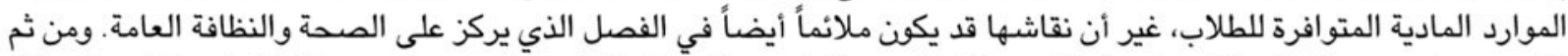

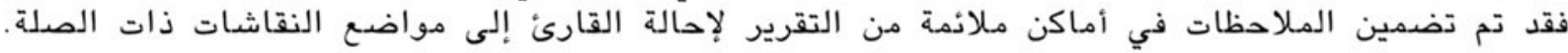

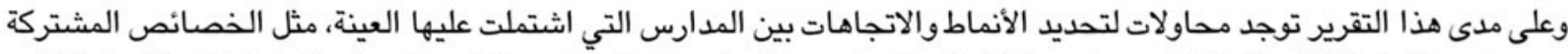

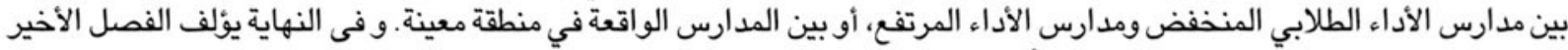

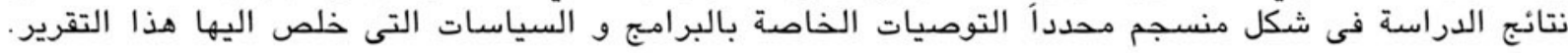




\section{حياة الطالب}

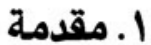

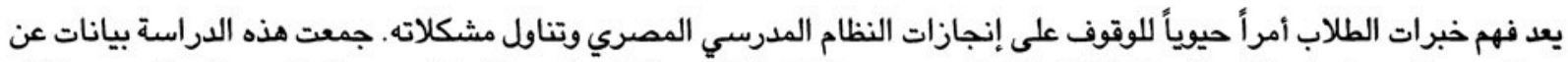

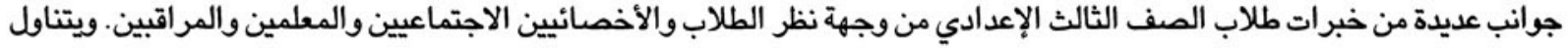

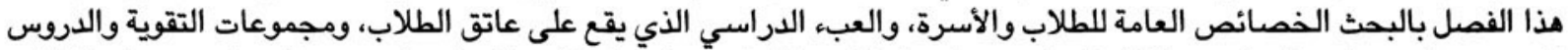

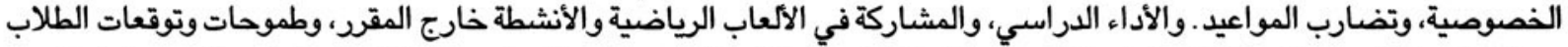

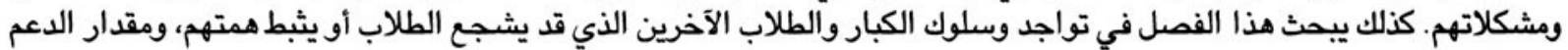
الذي يقدمه الكبار للطلاب في المدرسة ودوية المعلمين لسلوك الطلاب.

يمكن القول بأن كافة الموضوعات التى نفحصها هنا جديرة بالاهتمام في ظل أي نظام مدرسي في جميع أنحاء العالم . إلا أن هذا الفصل

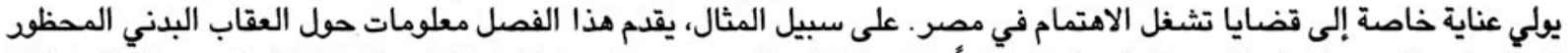

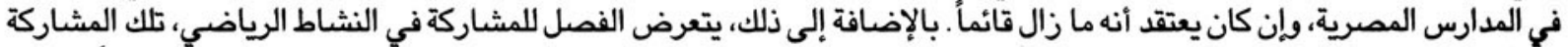

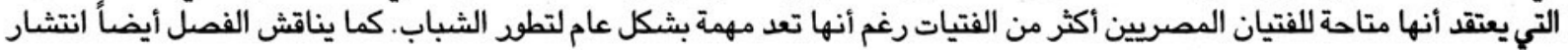

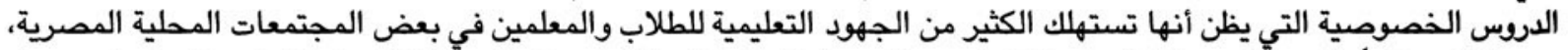

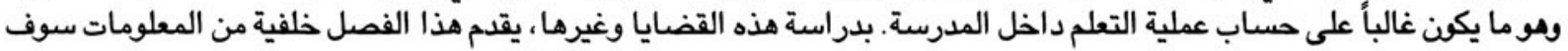

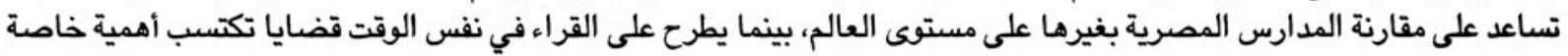

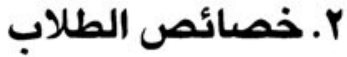

1. خلفية

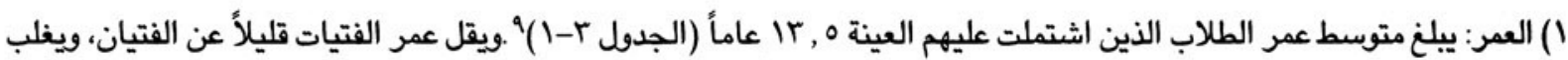

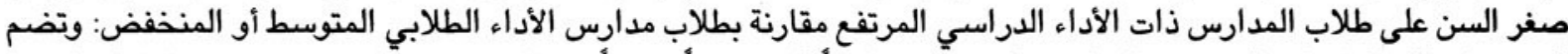

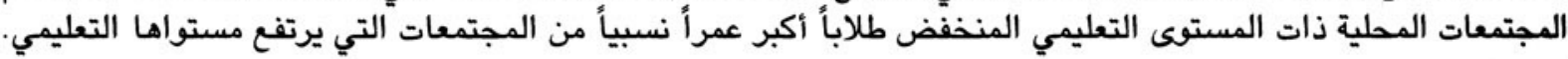

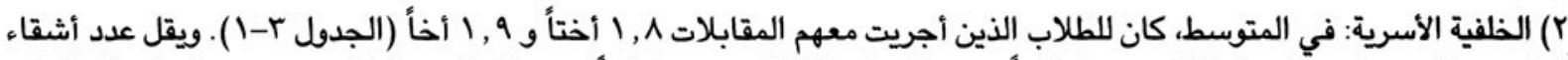

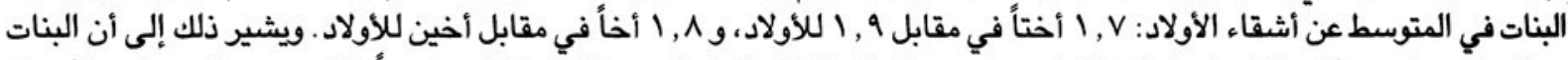

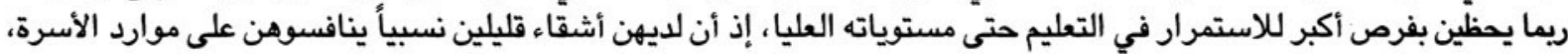
على حين أن تعليم الأولاد قد يحظى بالأولوية حتى في الأسر الكبيرة.

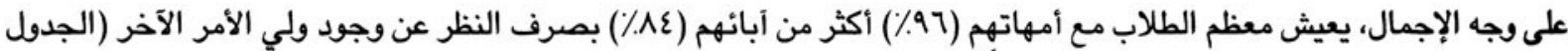

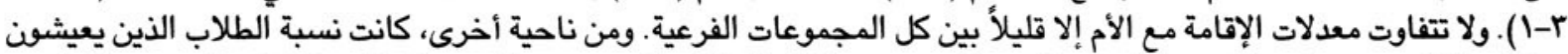

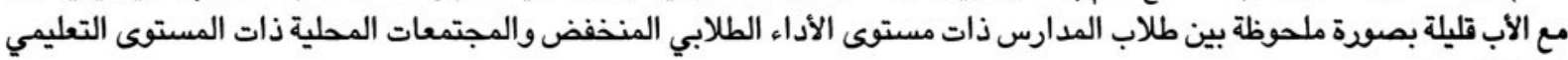
المنففض والصعيد.

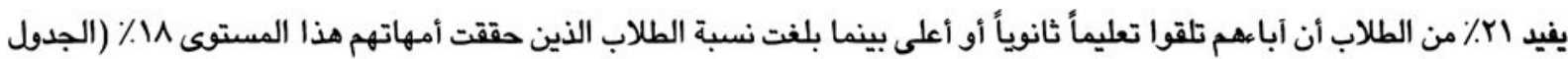

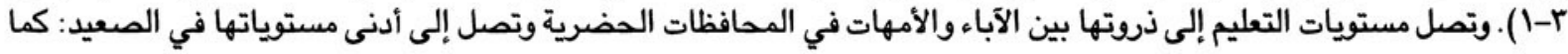

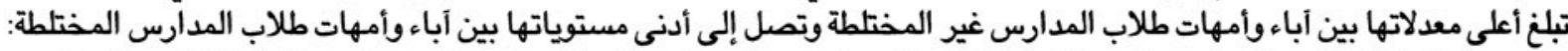

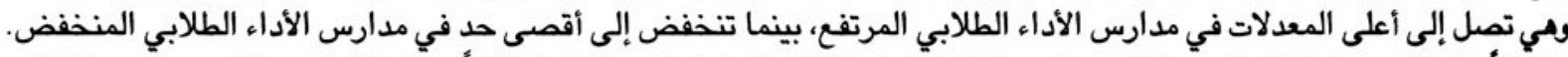

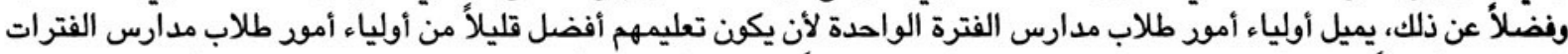

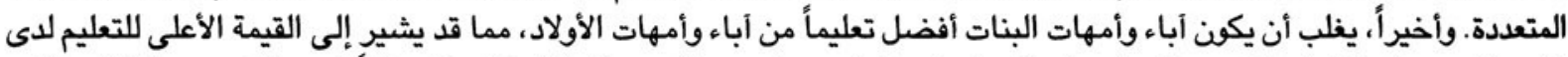

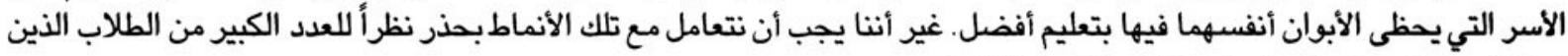

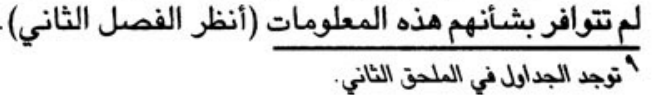




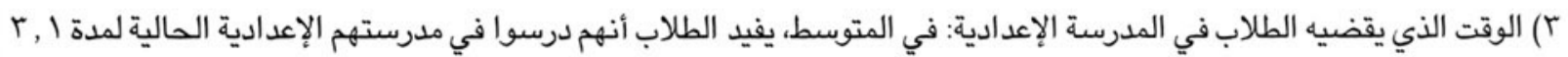

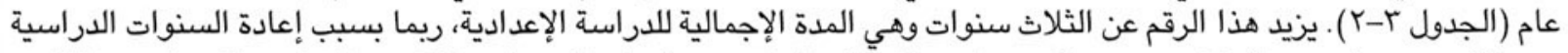

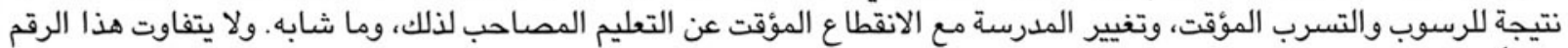

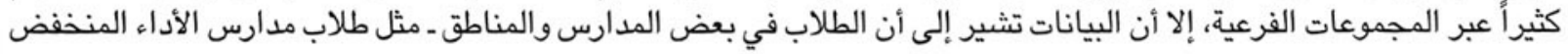

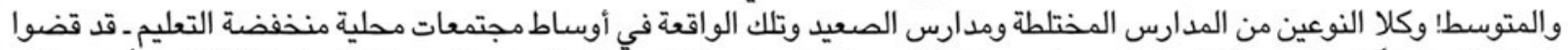

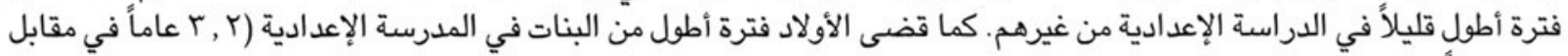

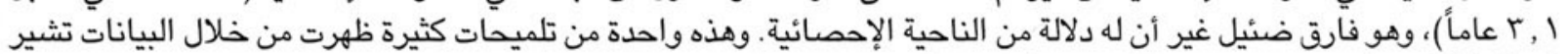

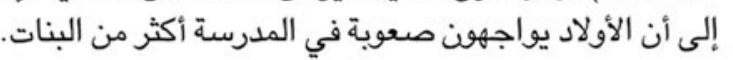

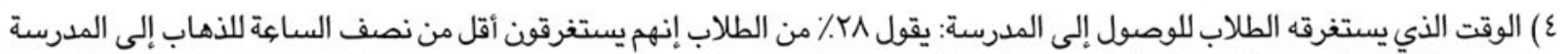

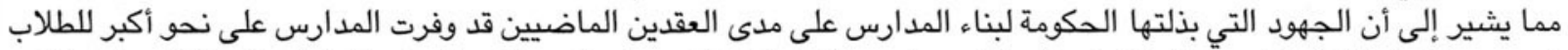

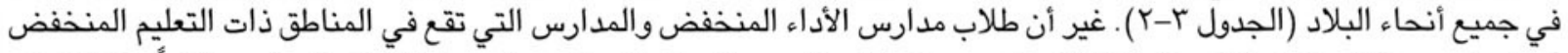

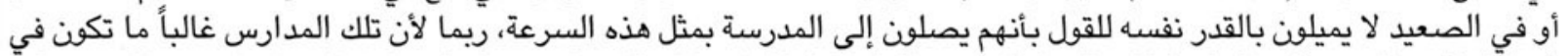

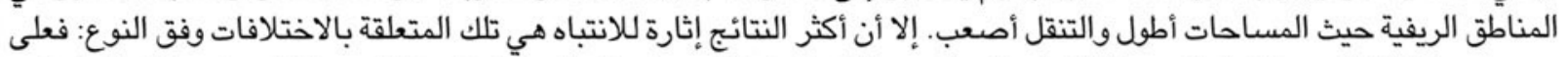

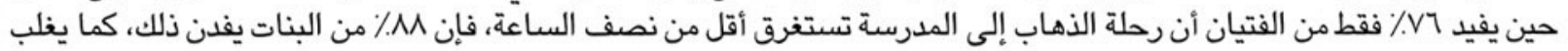

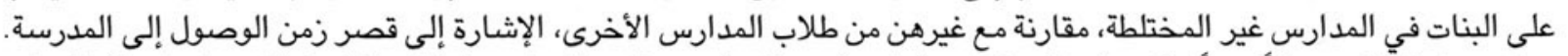

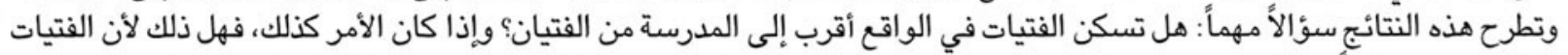

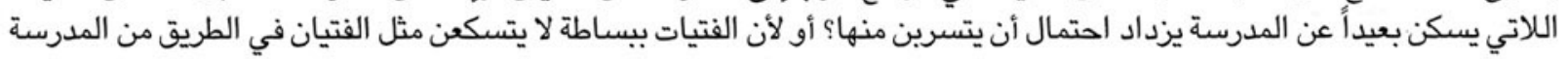

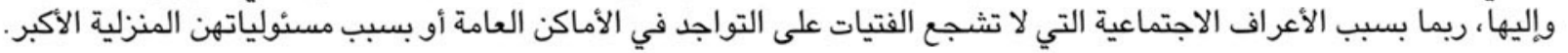

\section{r. - م. العبء الدراسي على الطلاب}

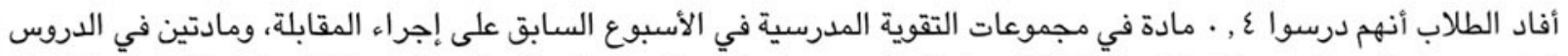

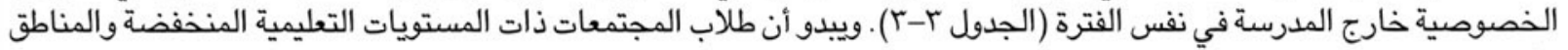

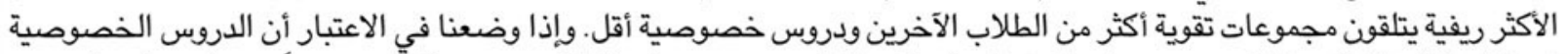

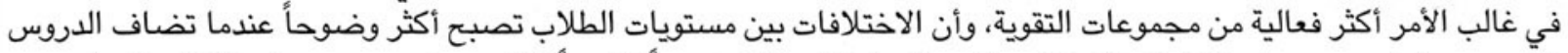

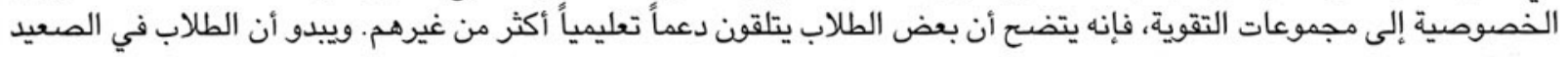

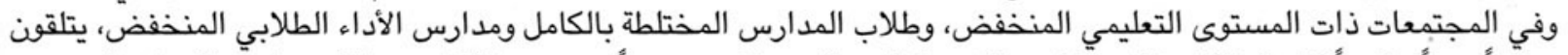

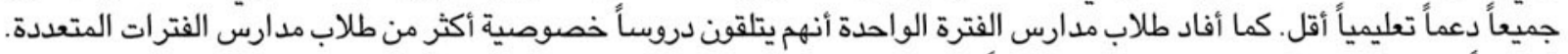

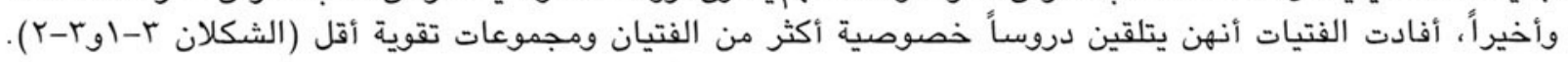

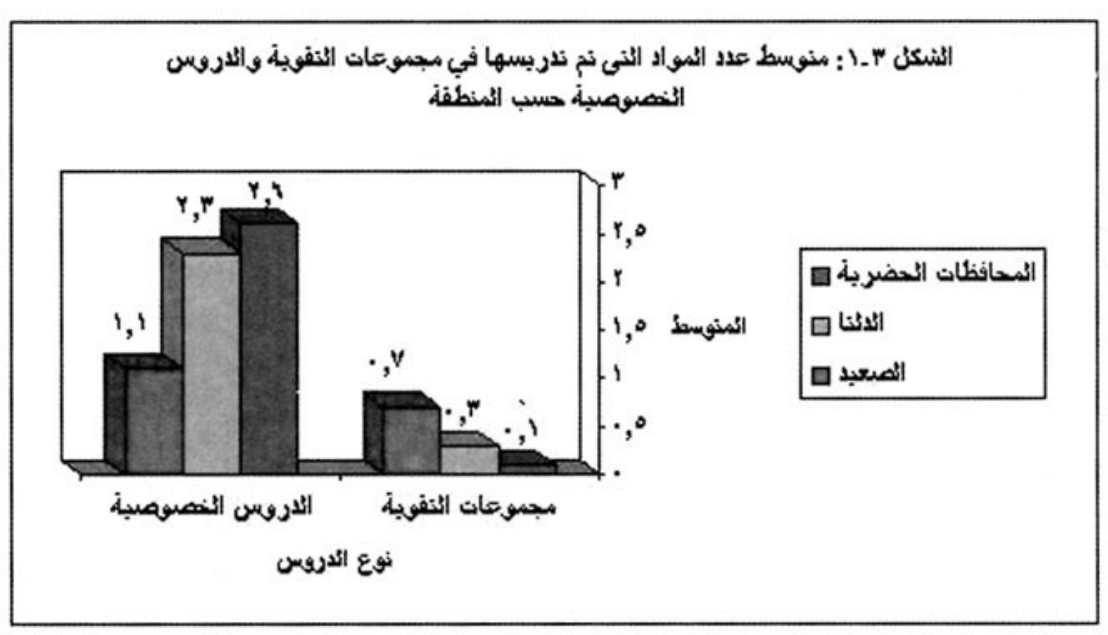




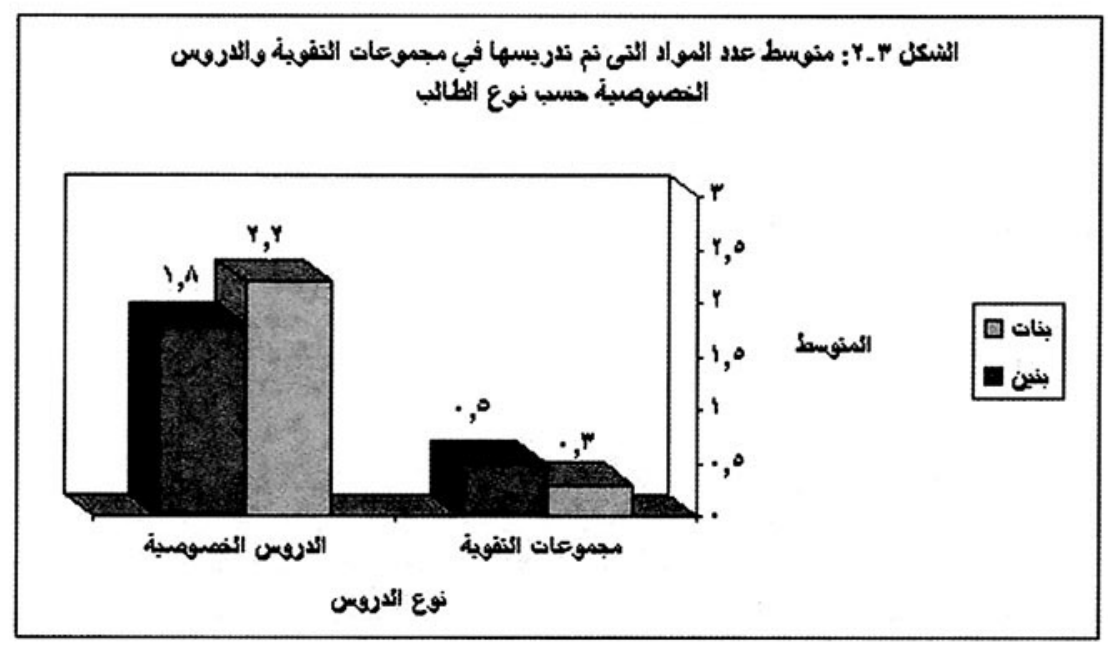

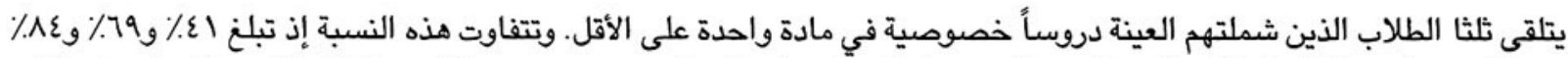

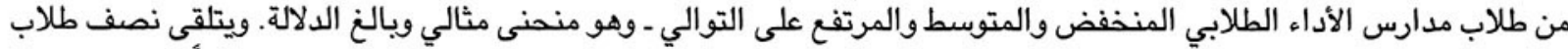

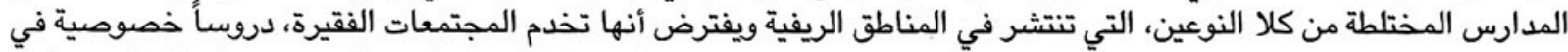

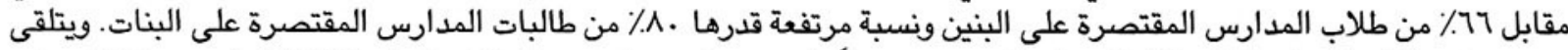

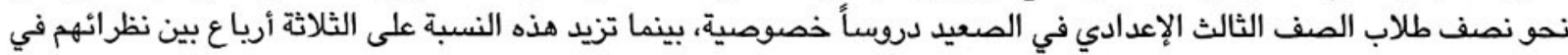

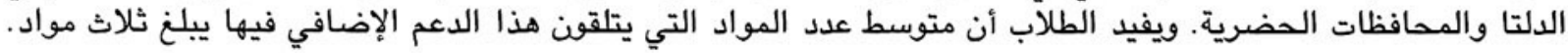

ب. الواجبات المنزلية

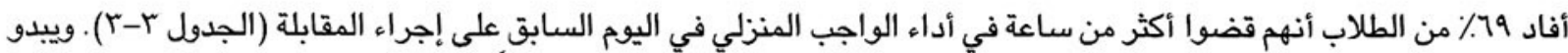

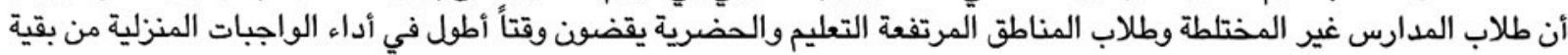

\section{ج. تضارب المطالب على وقت الطلاب}

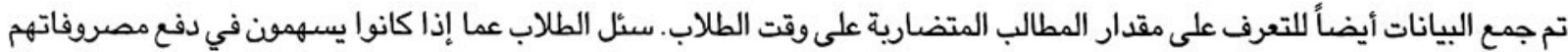

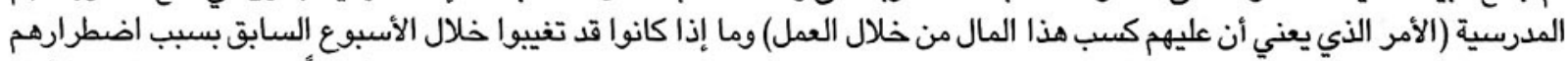

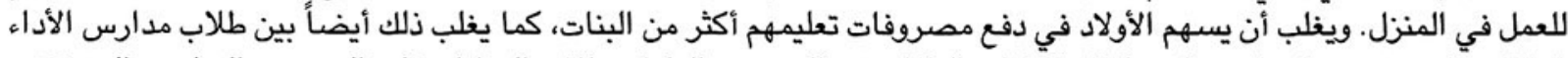

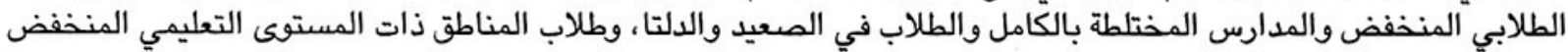

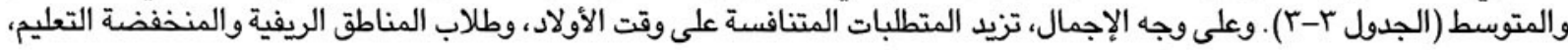
وطلاب الصعيد، وطلاب مدارس الأداء الطلابي المنخفض أكثر من غيرهم من الطلاب.

ع. الأداء الدراسي

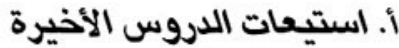

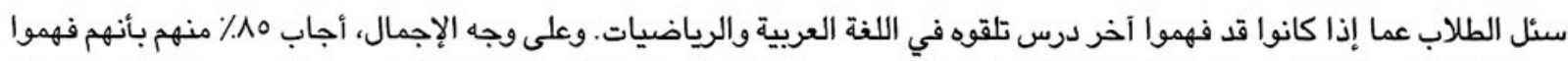

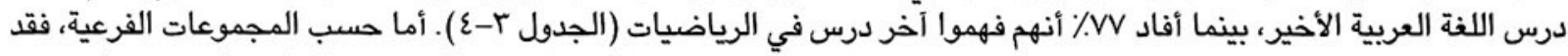

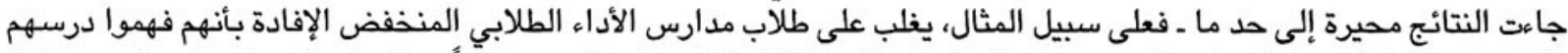

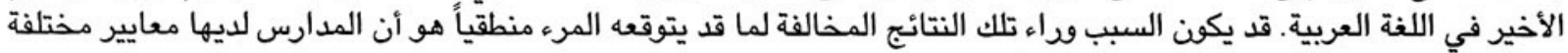

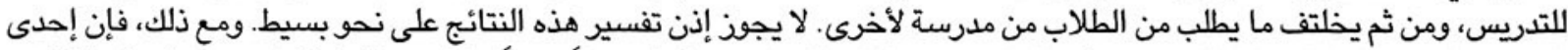

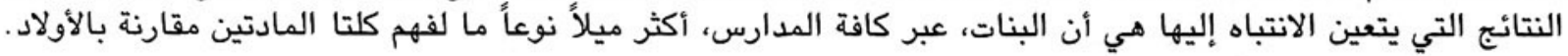




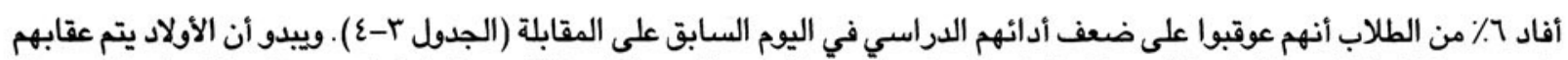

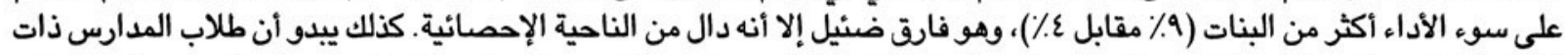

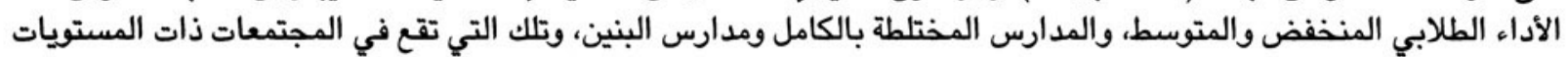

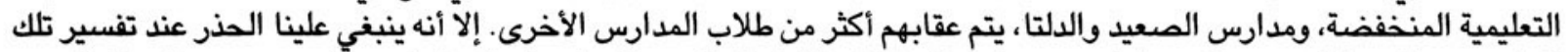

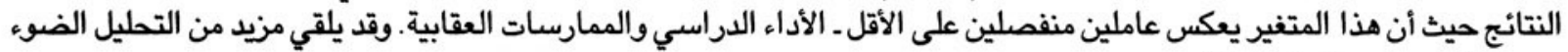

بصورة أكبر على هذه القضايا.

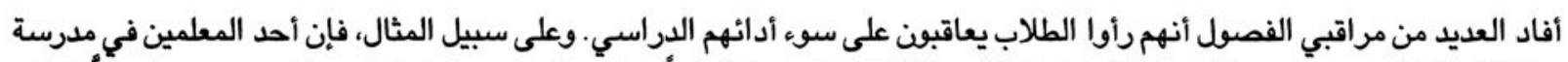

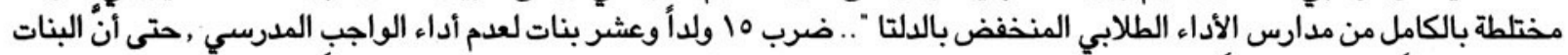

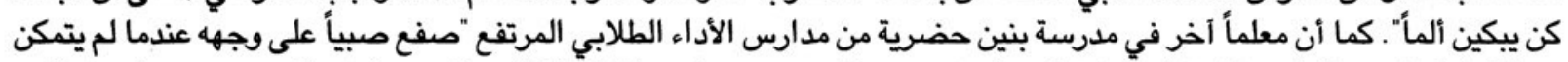

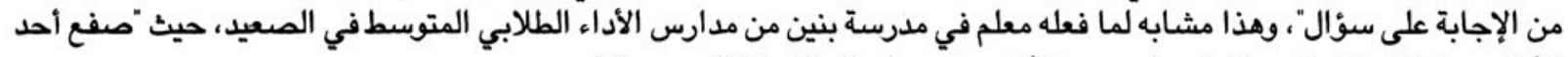

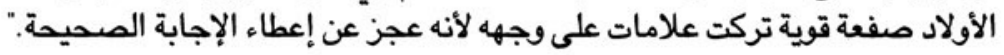

\section{ج. رضا المعلمين عن المستوى الدراسي للطلاب}

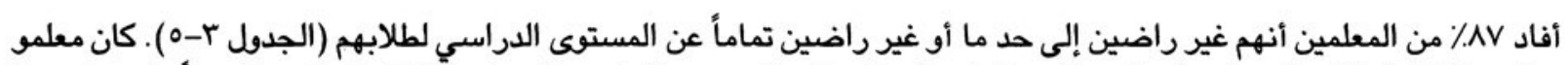

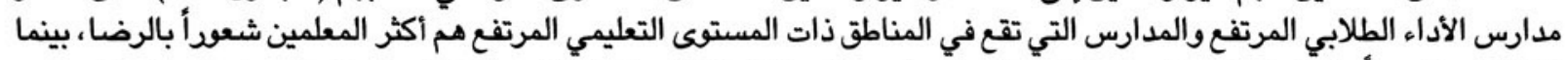

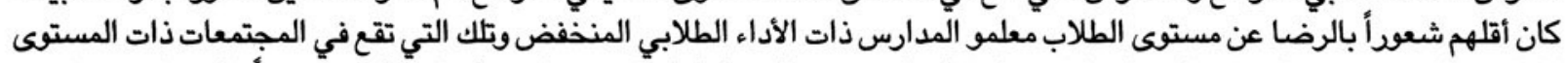

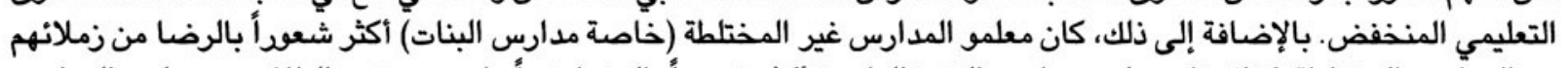

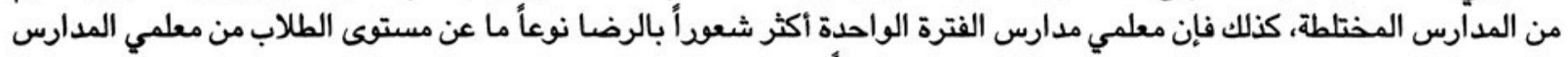

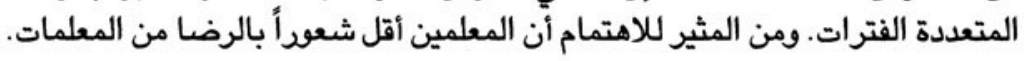

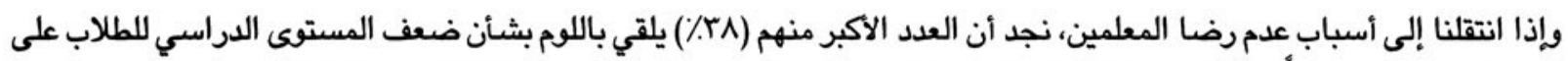

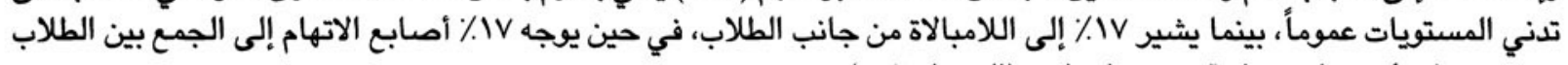

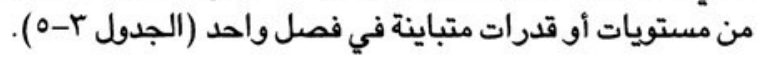

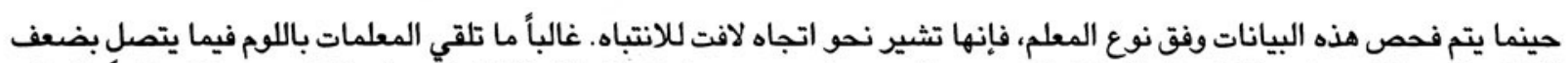

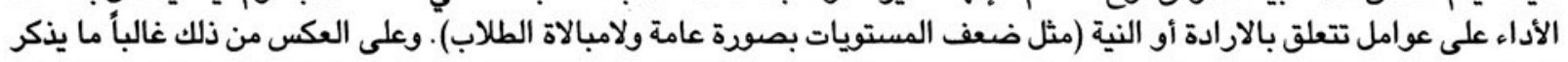

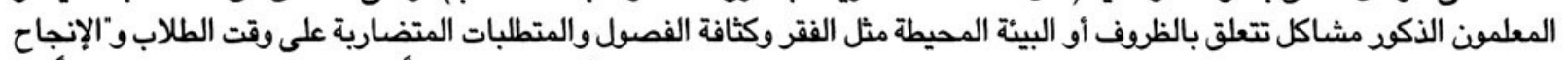

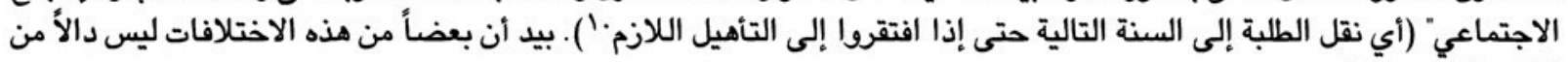

الناحية الإحصائية.

\section{ه. الأنشطة غير الدراسية}

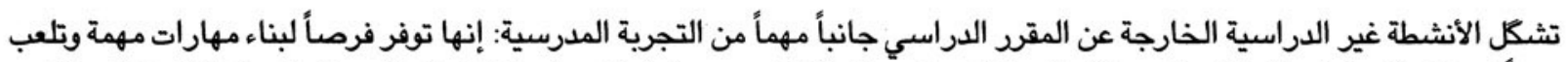

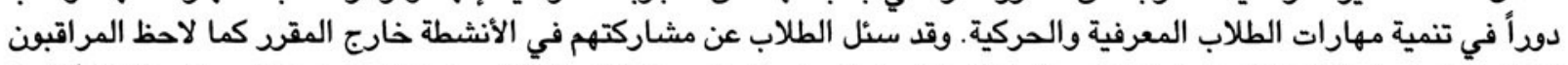

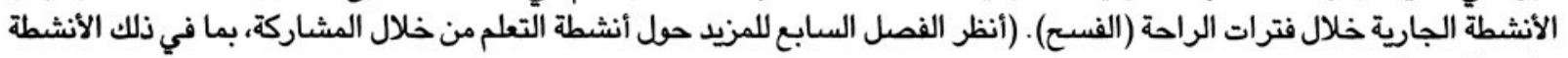

خارج المقرد).

\section{أ. الانشطة خارج المقرد}

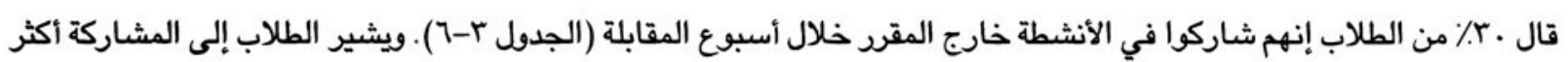

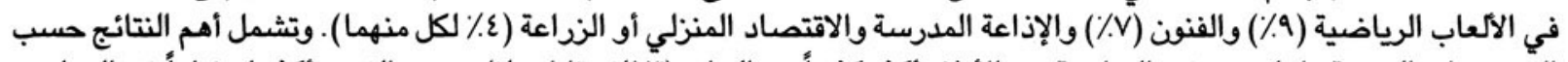

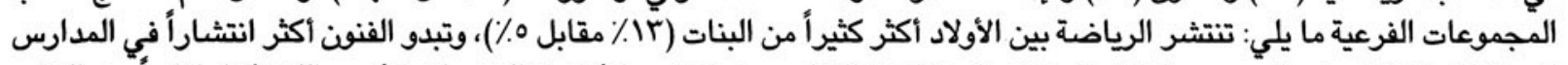

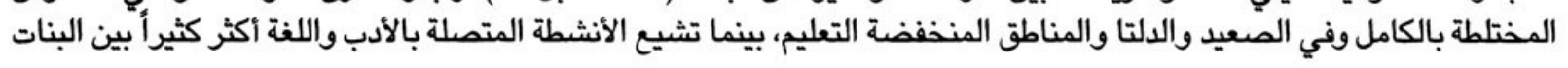

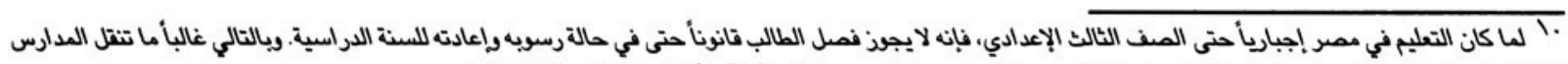

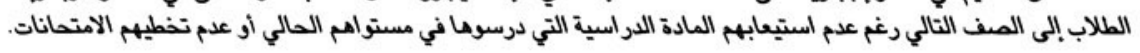


وفي مدارس البنات والمدارس الواقعة في المناطق المرتفعة التعليم والمناطق الحضرية.

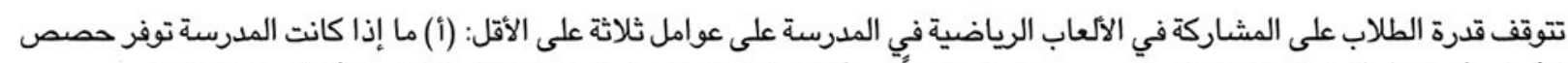

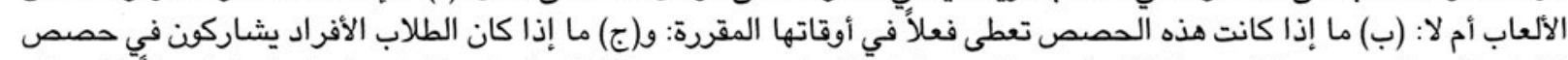

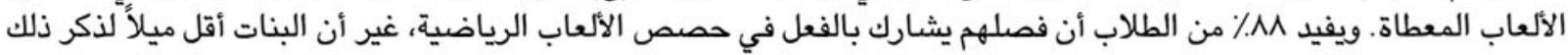

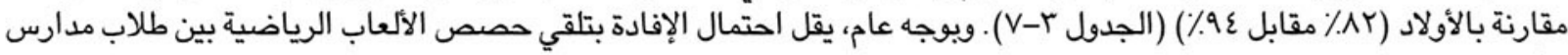

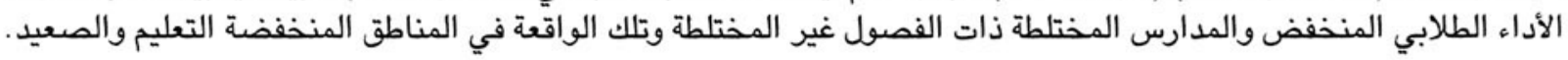

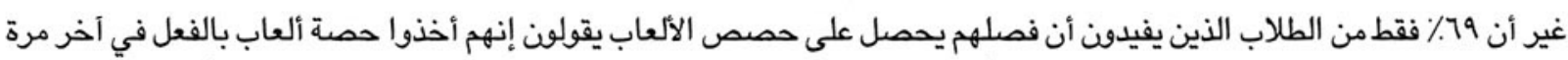

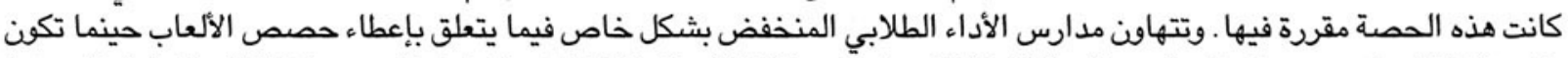

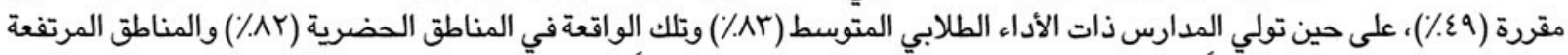

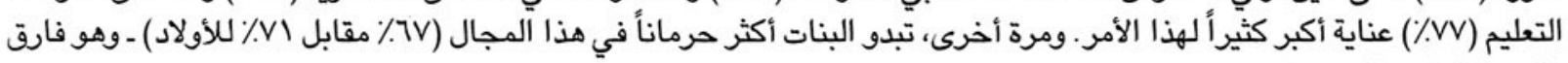

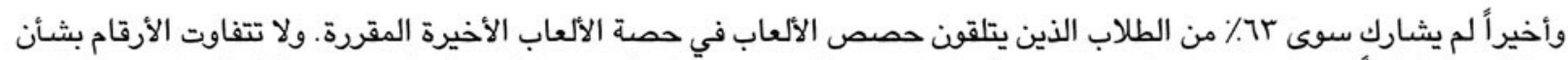

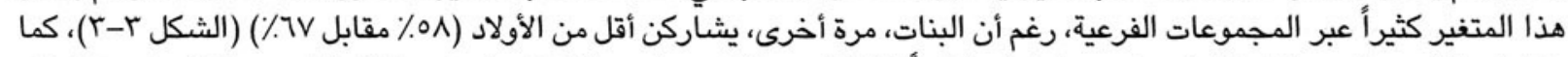

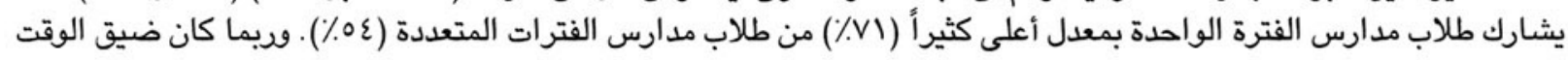

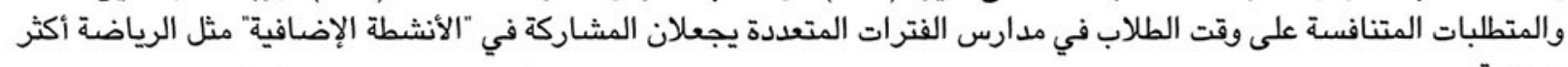

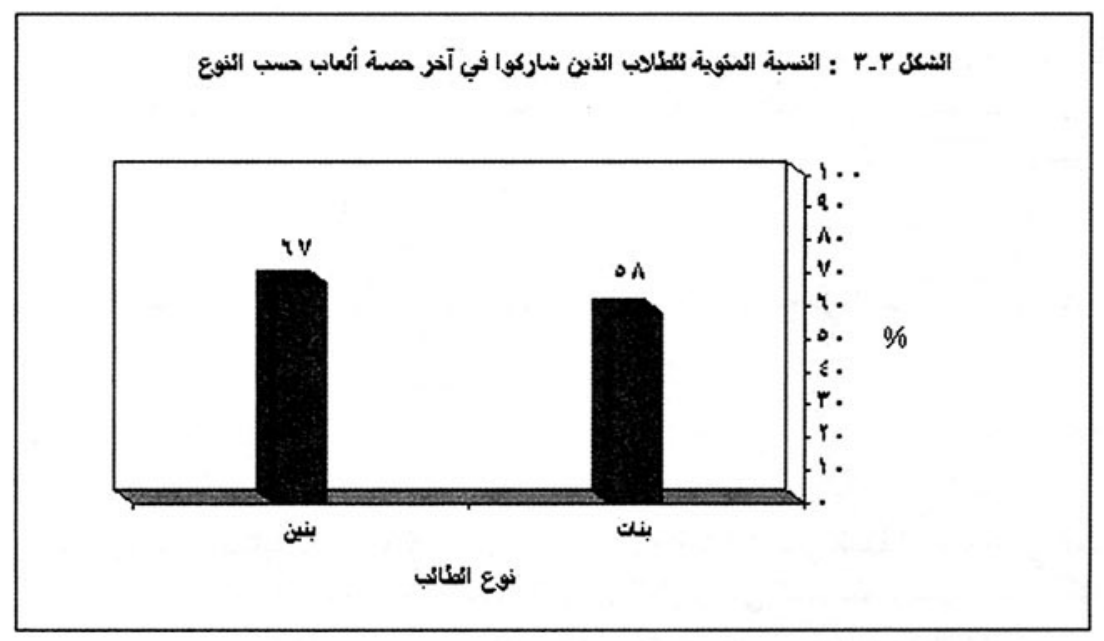

كل الإختلافات بين الهجموعات الخاصة بالمتغيرين لها دلالة إحصانية عند النسبة >0 . . .

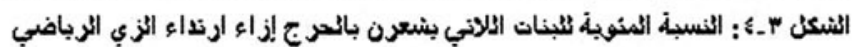

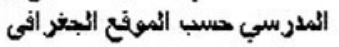

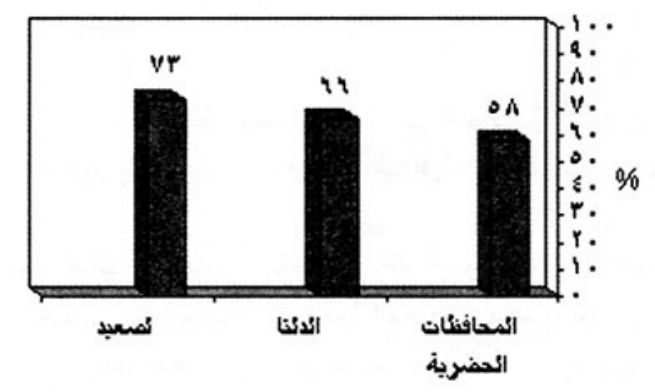

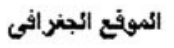

للإختلافات بين المحافظات الحضرية ورجيى قبلى وبحرى دلالة إحصانية عند >ه . . . ولا توجد دلالة إحصانية للإختلافات بين وجهى 


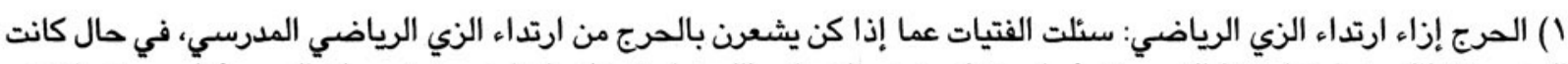

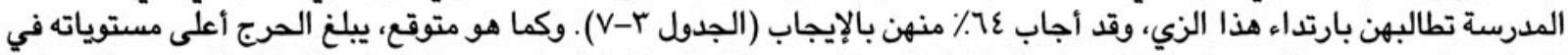

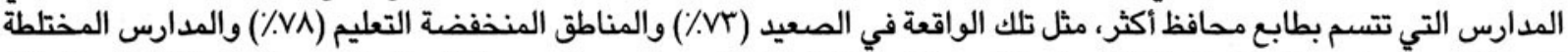
ذات الفصل غير المختلطة (V0٪ وإن كان هذا الارتباط الأخير غير دال من الناحية الإحصائية) (الشكل rالعالع).

ج. الأنشطة خلال الفسح

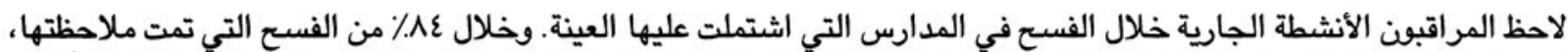

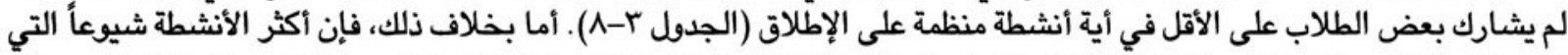

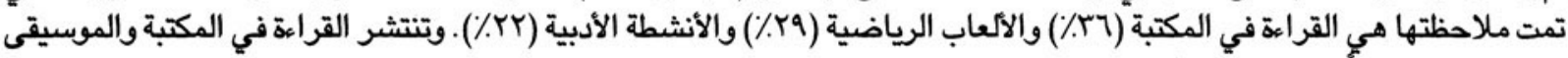

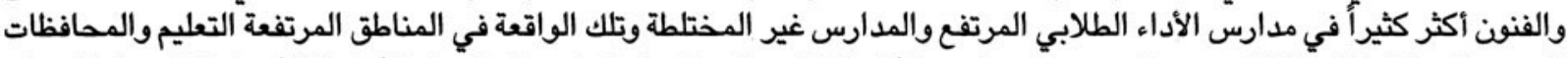

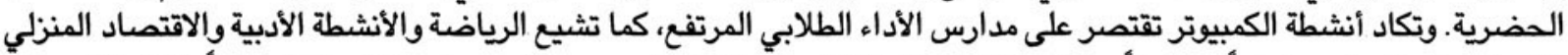

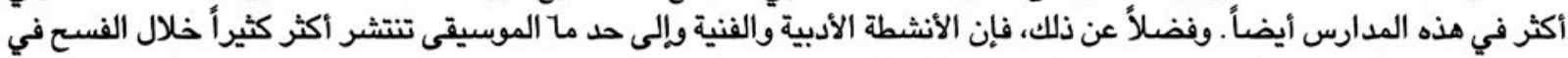

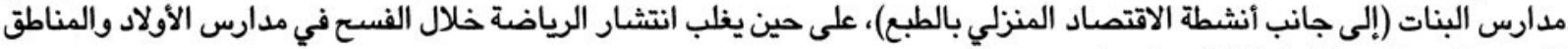

الحضرية ومدارس الأداء الطلابي المرتفع.

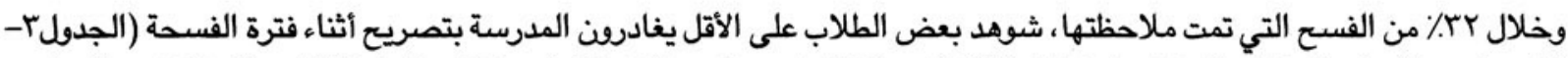

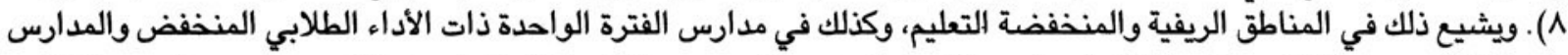

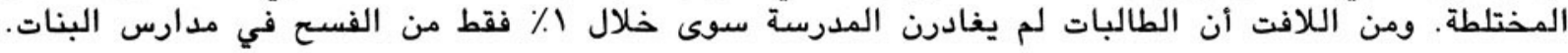

\section{T. تثبيط همة الطلاب في المدرسة}

يمكن أن يكون للمدرسة تأثير مهم على النجاح الدراسي للطلاب وفرصهم المستقبلية، وكذلك على مواقفهم تجاه التعلم والتعليم والاستمرار

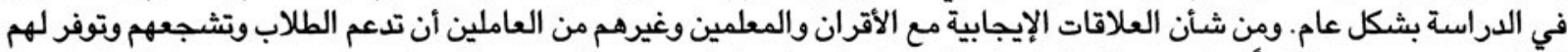

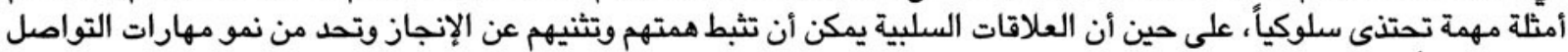

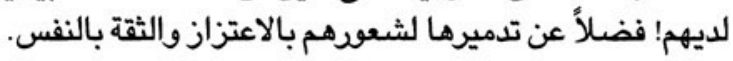

ومن ثم فقد تم توجيه سلسلة من الأسئة إلى الطلاب حول مقدار ما يلقون من دعم وتشجيع في المدرسة، وأنواع التواصل بينهم وبين الكبار والطلاب الآخرين في المدرسة.

أ. المضايقات و المعاكسات

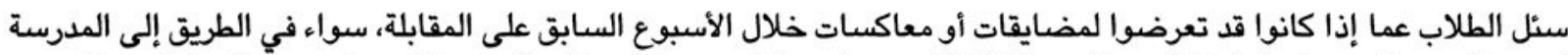

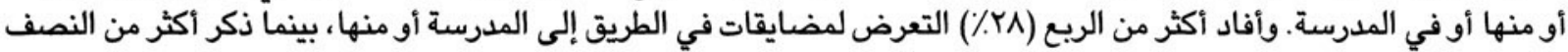

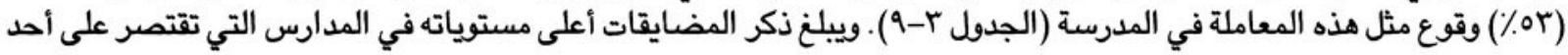

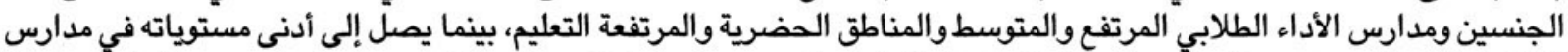

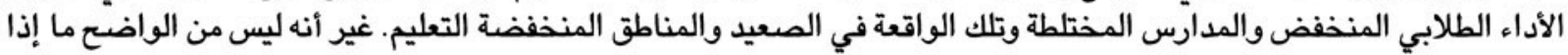

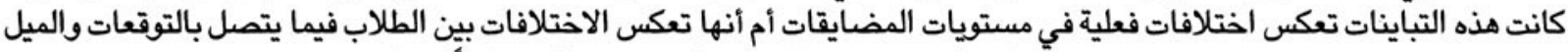

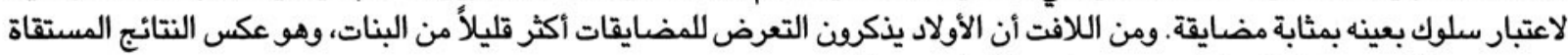

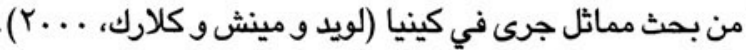

وجدير بالملاحظة أن ابr٪ يلقون باللوم بشأن هذه المضايقات على العاملين بالمدرسة. ويميل الأولاد أكثر كثيراً من البنات للإفادة

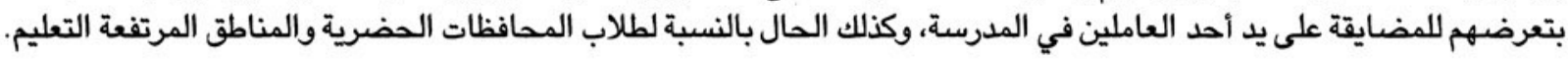

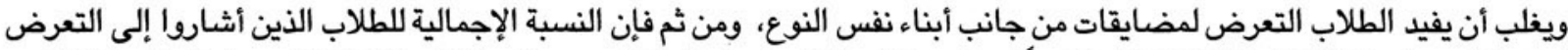

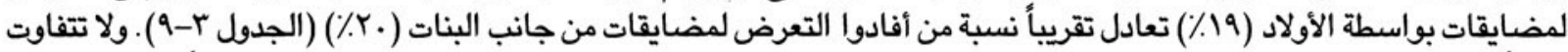

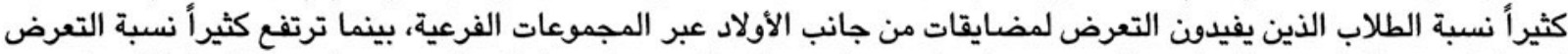

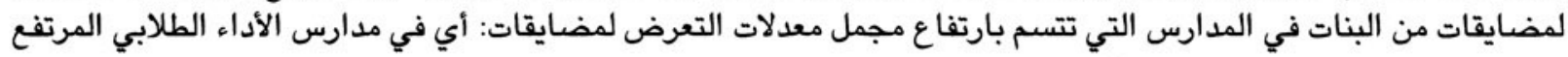


والمتوسطوتلك الواقعة في المناطق المرتفعة والمتوسطة التعليم ومدارس المناطق الحضرية والصعيد ـ ومن شبه المؤكد أن هذا الأمر

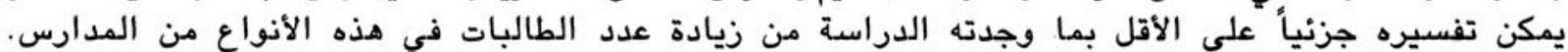

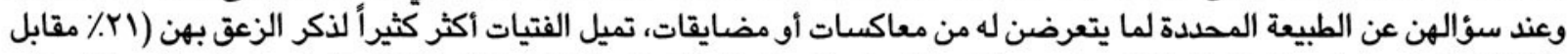

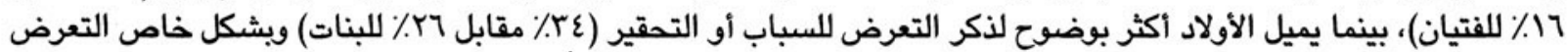

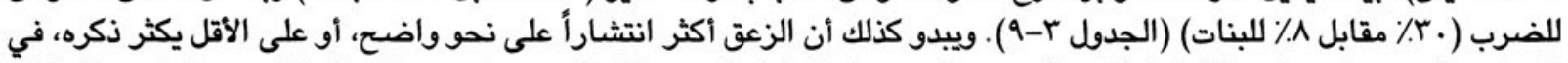

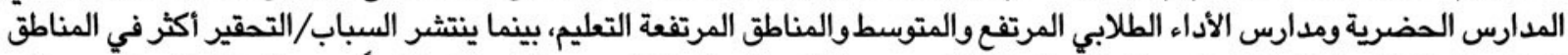

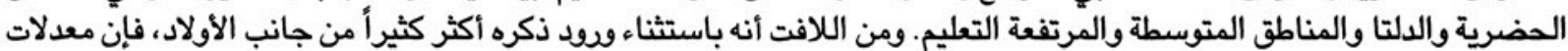
التعرض للضرب لا تتفاوت كثيراً وفق المجموعات الفرتفعة التعلية.

ب. تحقير الطلاب من جانب العاملين

يقول عَ٪ من الطلاب إن معلماً في المرحلة الإعدادية قد سبق له تحقير قدراتهم، واصفاً إياهم بالفشل أو متنبئاً برسوبهم في المدرسة

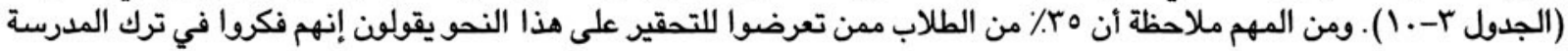
نتيجة لهذه التعليقات.

وقد لاحظ الذين أجروا المقابلات حوادث عديدة من هذا النوع أثناء ملاحظتهم للفصول. وعلى سبيل المثال، لاحظ مراقب لإحدى مدارس

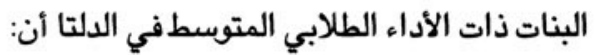

إحدى الفتيات...قالت للمعلم إنها لم تفهم شيئاً شرحه. أعاد المعلم الشرح، وقالت مرة أخرى إنها لم تفهم. فقال لها المعلم: "انتى دايما

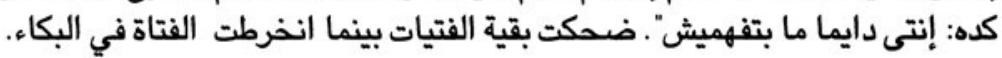

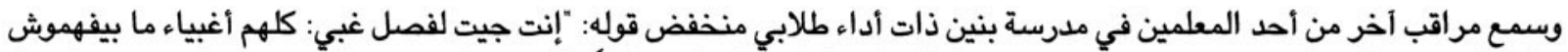

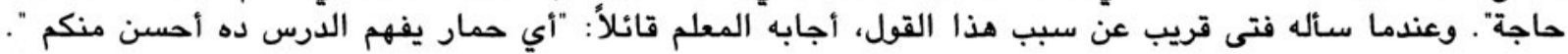

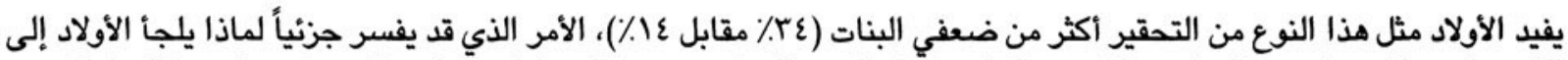

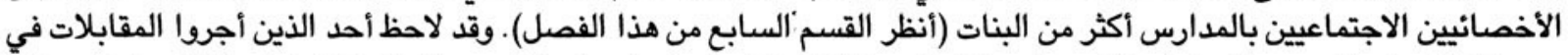

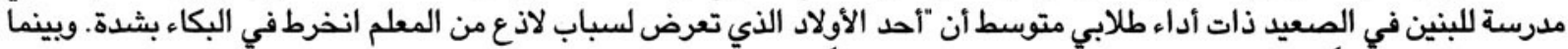

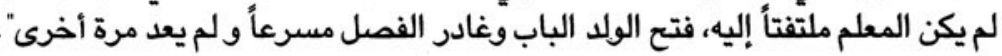

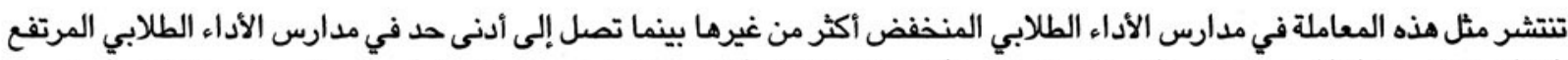

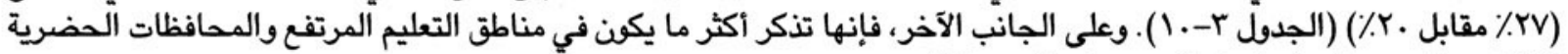

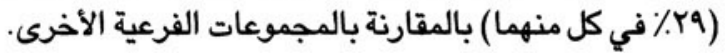

وعند فحص ما إذا كان الطلاب الذين تم تحقيرهم قد فكروا في التسرب من المدرسة، فإن نمطاً مماثلاً للنتائج السابقة يتضح (الجدول

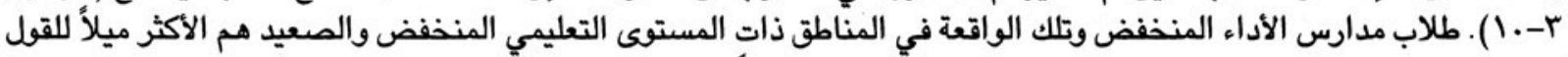

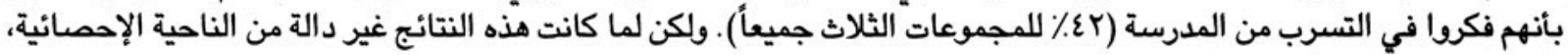
فإنه يتعين اعتبارها تأشيرية وليس حاسمة.

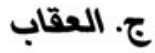

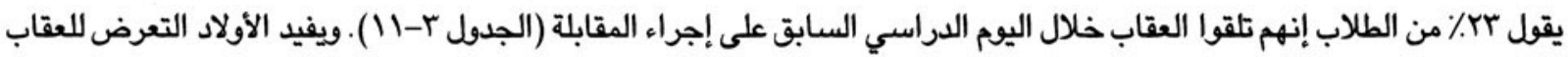

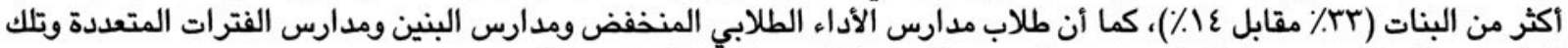

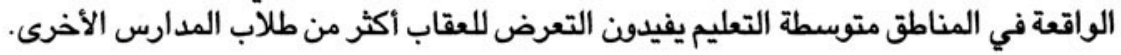

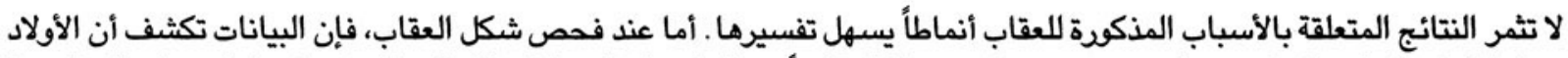

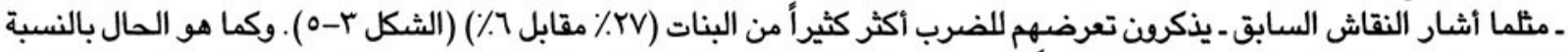

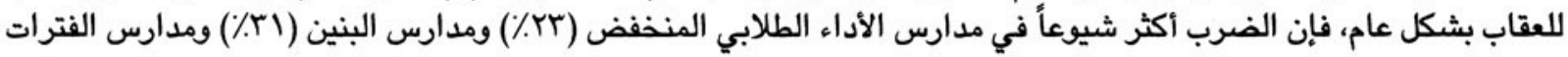

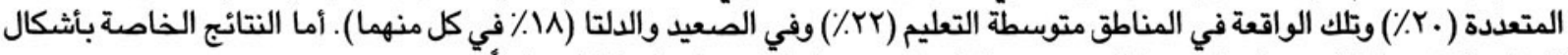

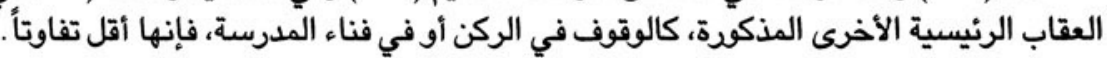




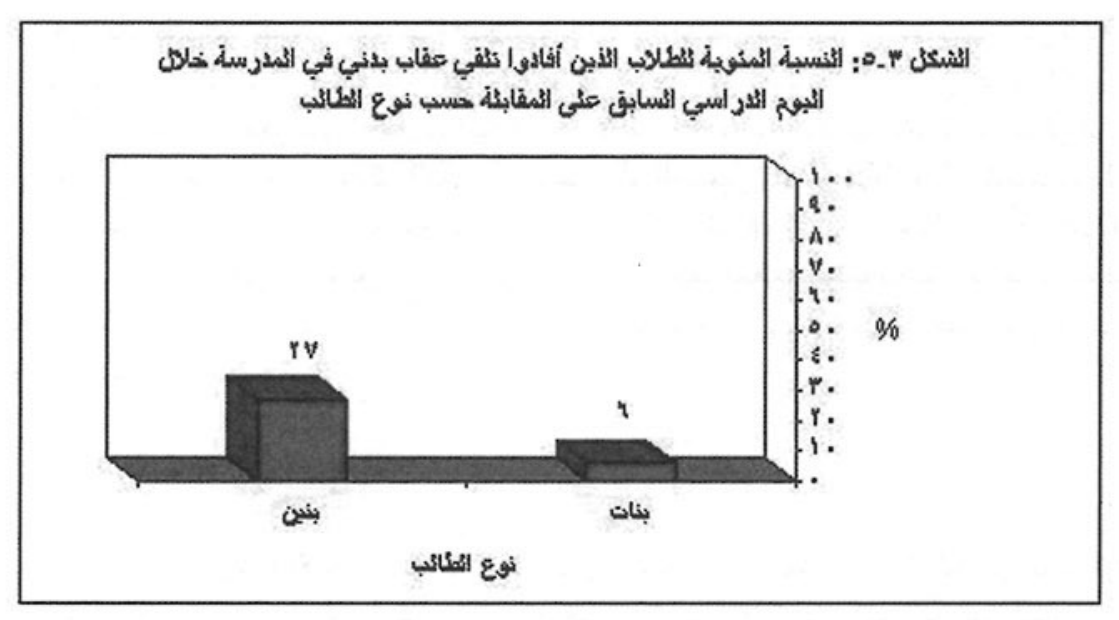

د. التمييز في المعاملة على يد العُاملين

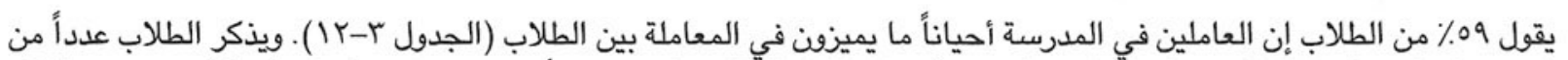

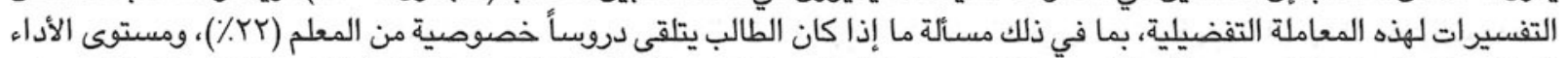

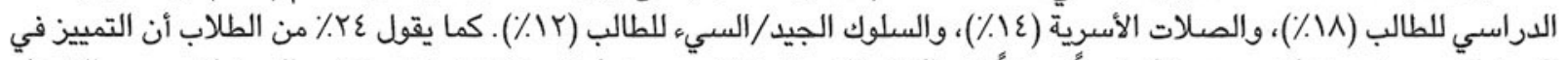
المعاملة يحدث دون أن يحددوا أساساً معيناً له. (أنظر الفصل الخامس من أجل مناقشة التمييز في المعاملة حسب النول النوع).

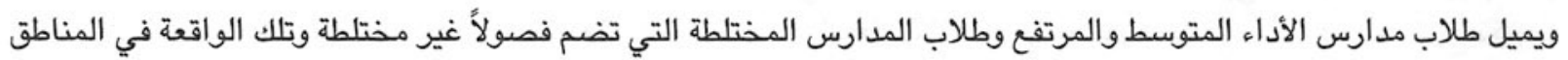

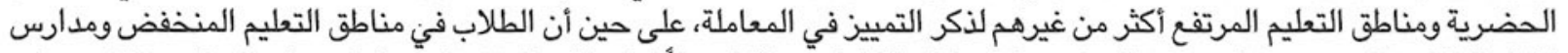

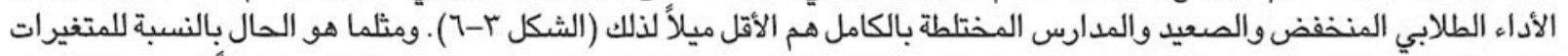

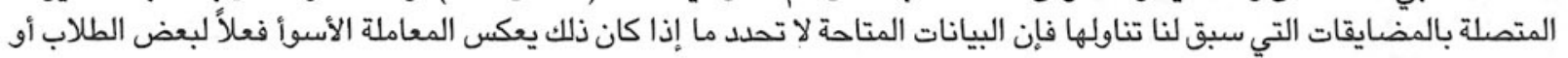

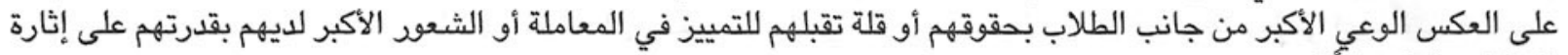

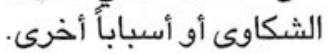

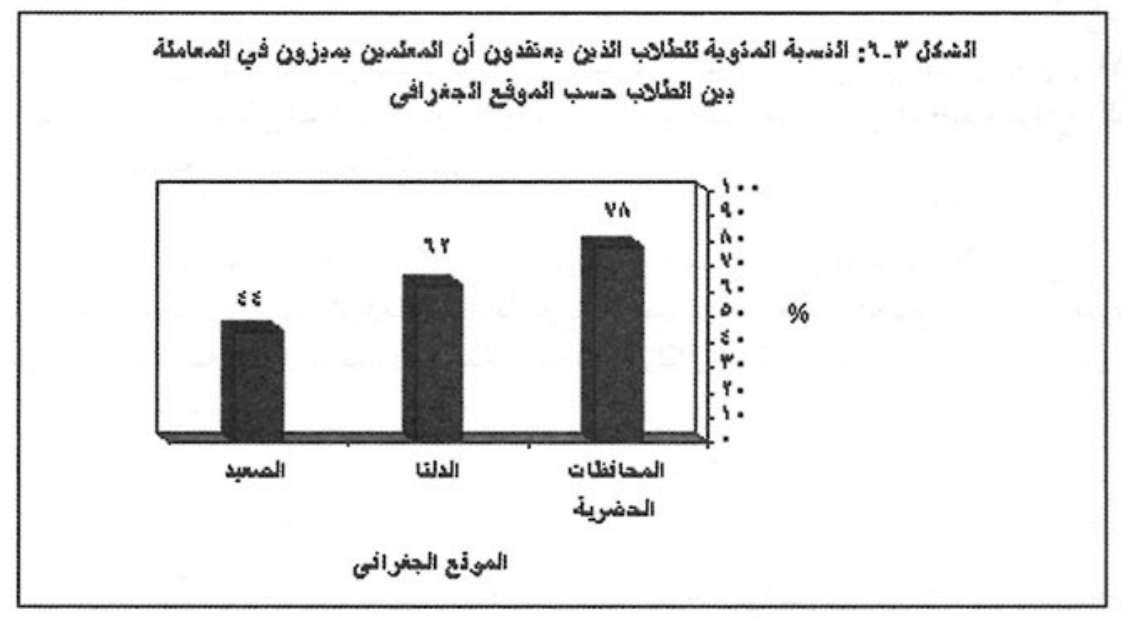

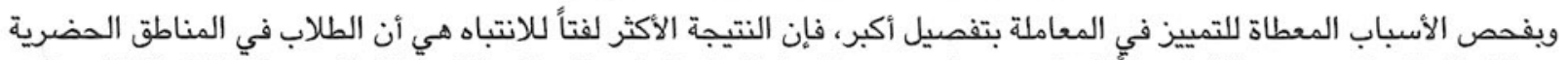

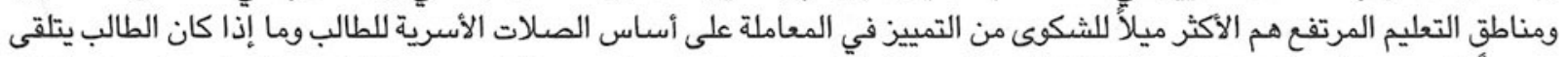

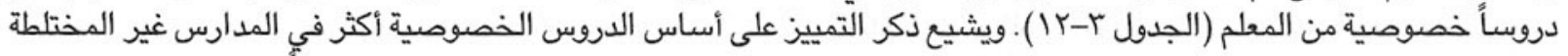

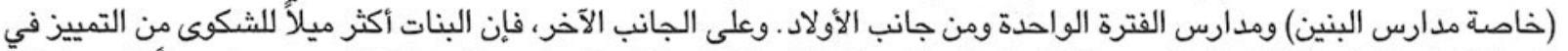

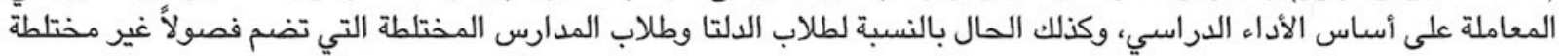
وطلاب المناطق متوسطة التعليم. 


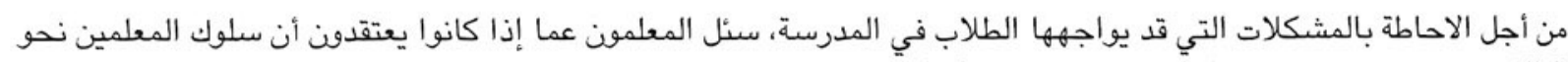

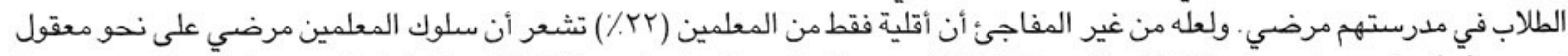

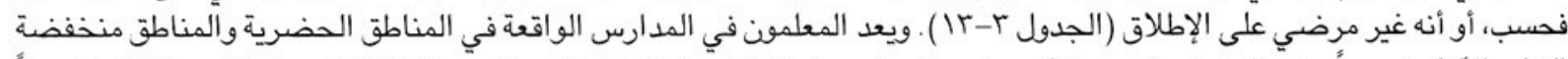

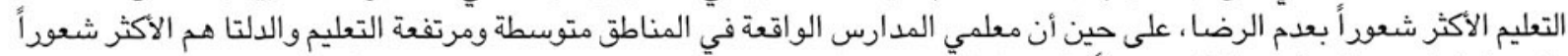

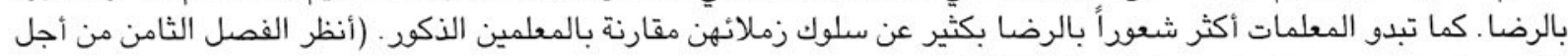
التعرف على آراء مديري المدارس بشأن هذا التفاعل).

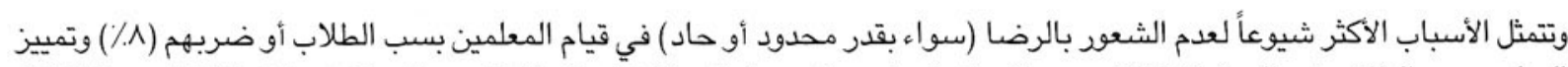

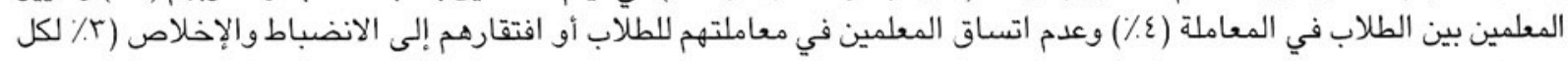

\section{V. تقديم الدعم للطلاب في مواجهة مشكلاتهم}

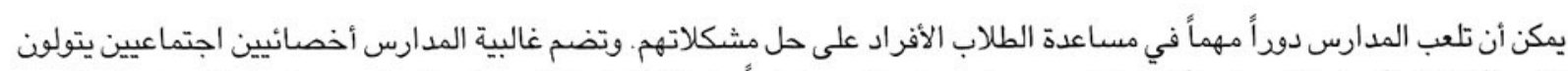

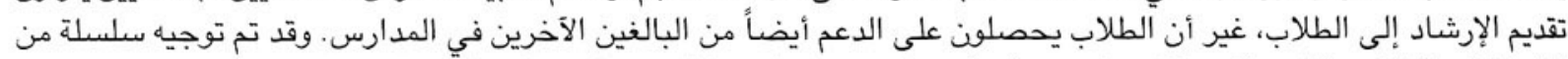

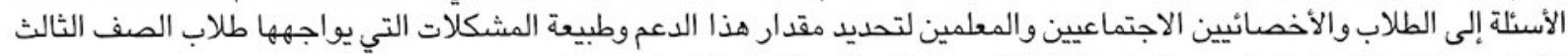

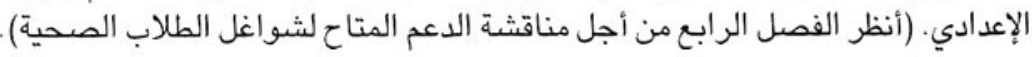

أ. دعم البالغين

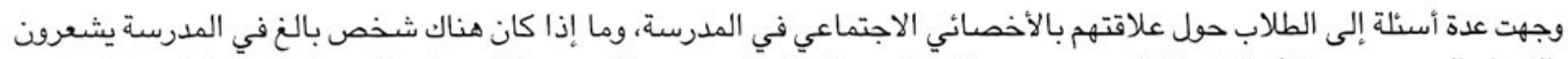

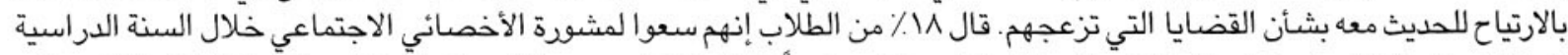

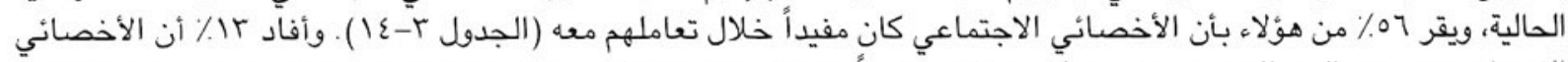

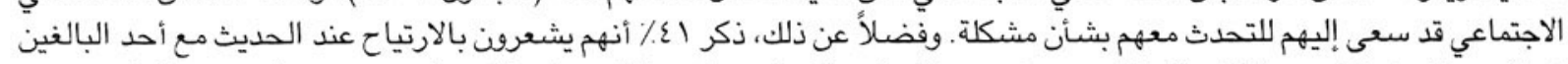

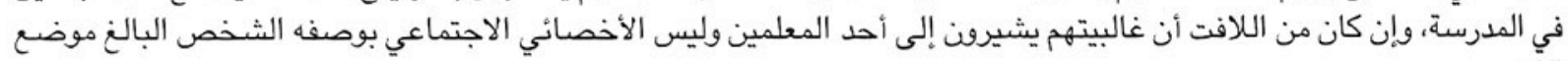

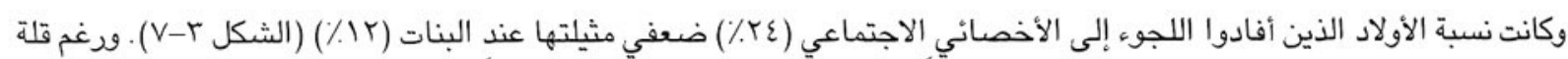

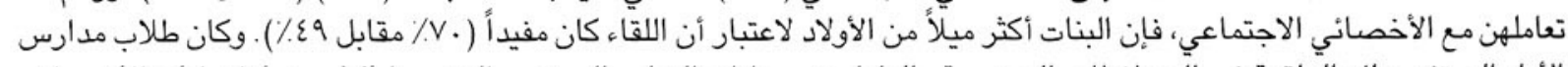

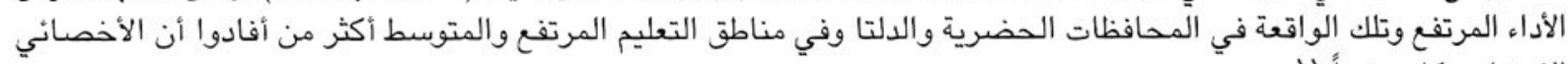

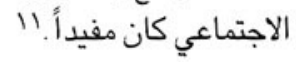

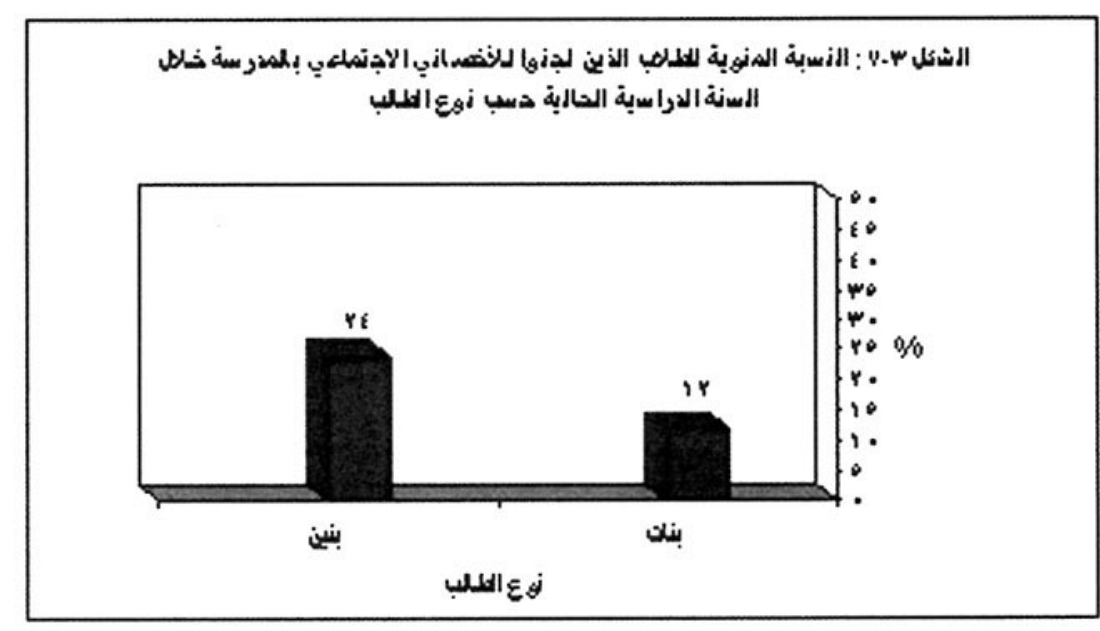

" ومي ذلك فان الارتباطات بين الستوى التطيمي للمجتمع المحلي والمنظقة من جانب ومقدار الاستفادة من الأخصاني الاجتماعي من جانب أخر ليست دالة من الناحبة الإحصانية. 


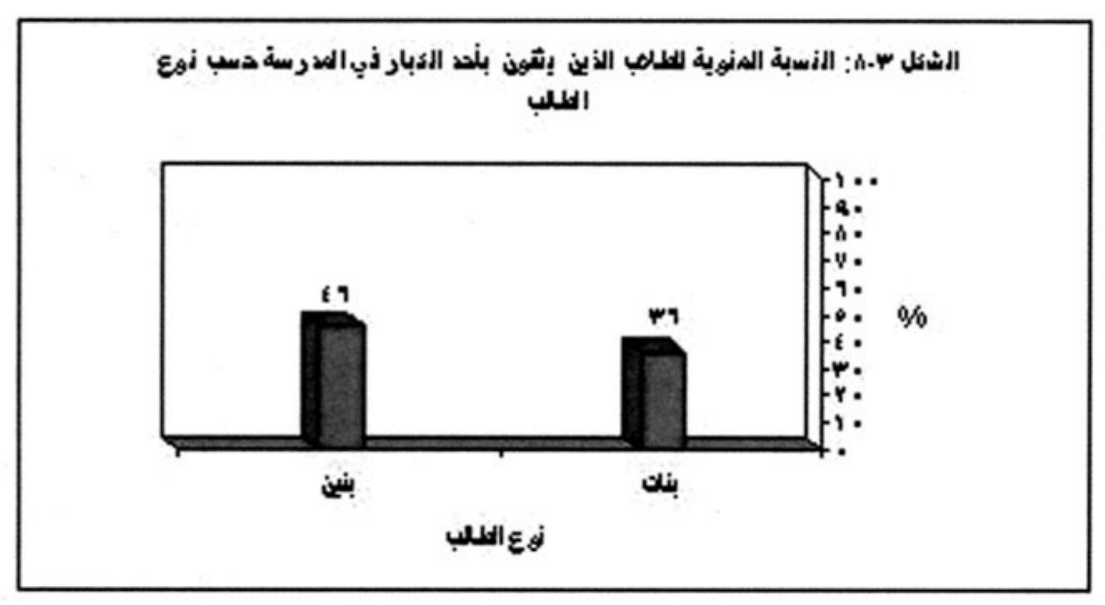

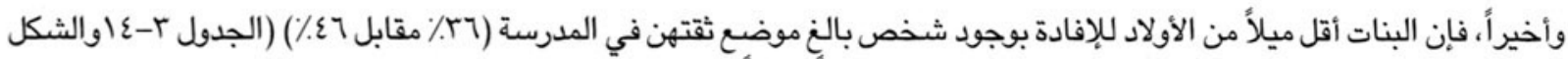

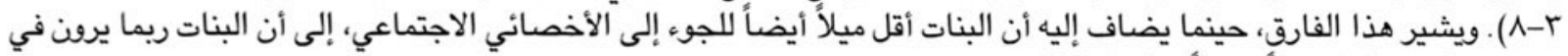
المدارس أماكن أقل دعماً نسبياً مقارنة بالأولاد.

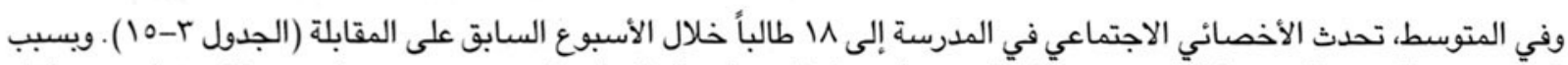

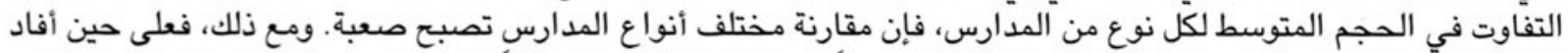

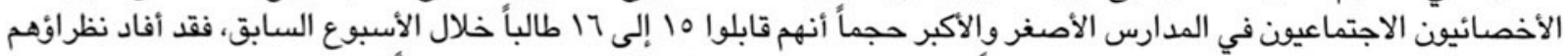

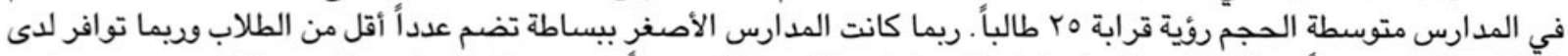

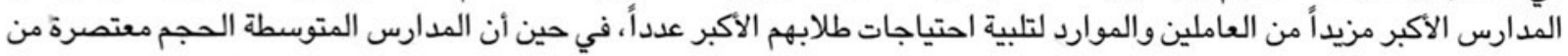

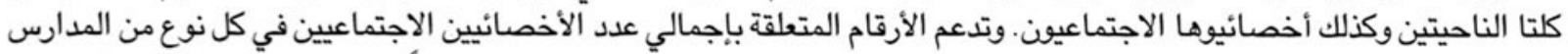

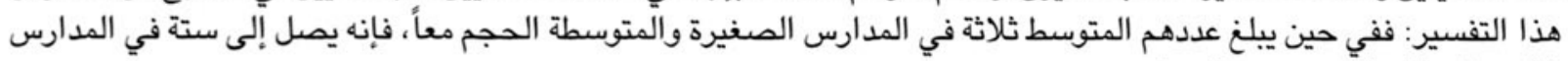

الأكبر (البيانات ليست مدرجة).

تم جمع بيانات أيضاً حول نسبة زيارات الطلاب التي جاءت بمبادرة من الطلاب أنفسهم أو الإدارة أو الأسر أو الأخصائيين الاجتماعيين.

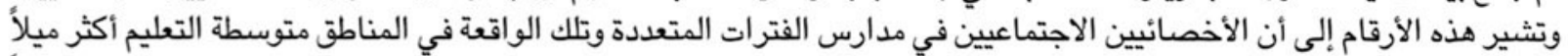

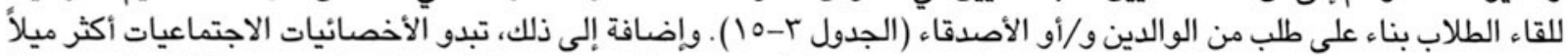

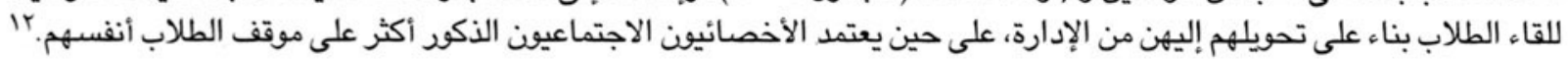

\section{ب. التو اصل مع الأخصائيين الاجتماعيين}

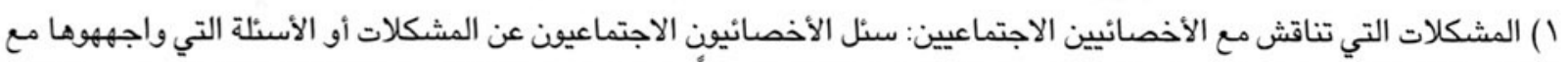

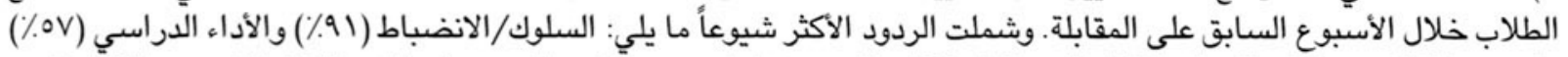

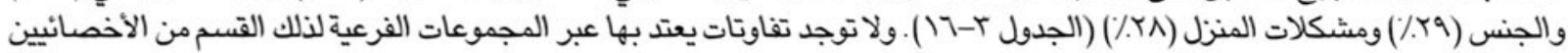

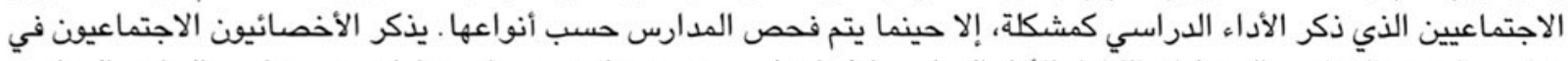

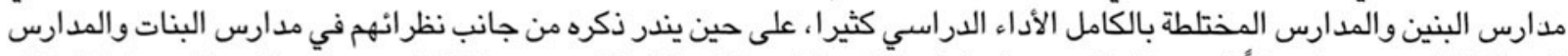

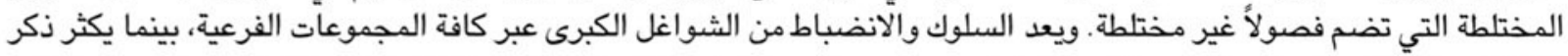

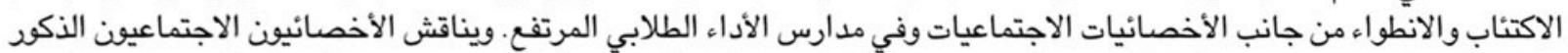

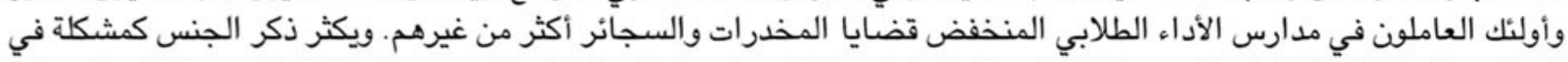

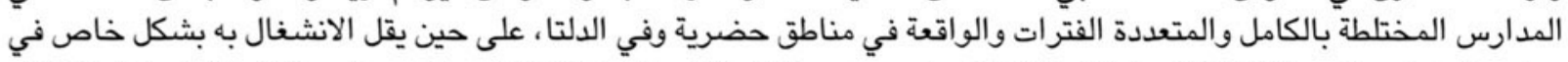

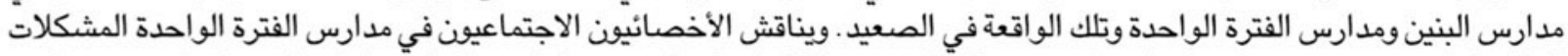

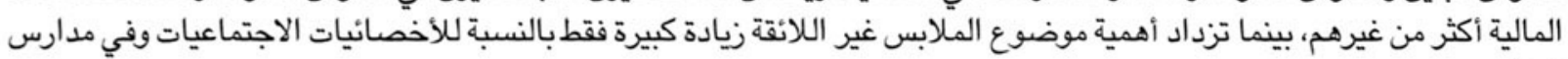




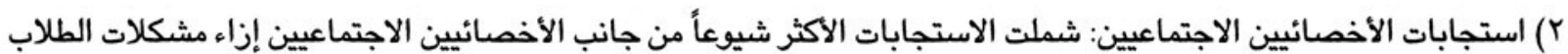

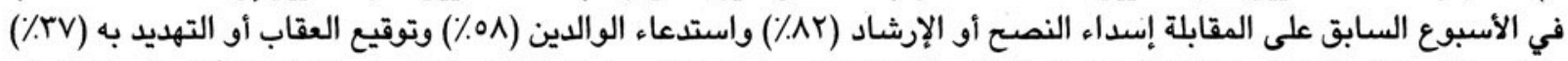

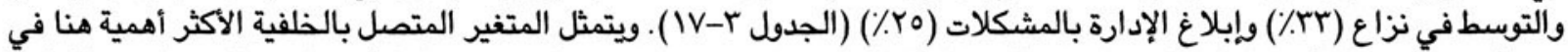

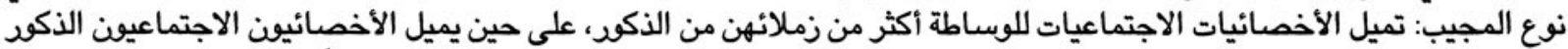

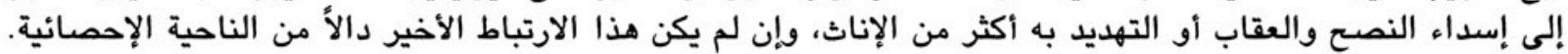

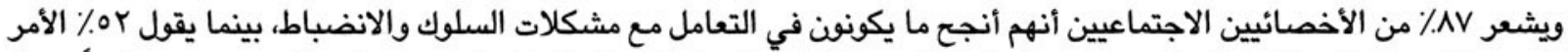

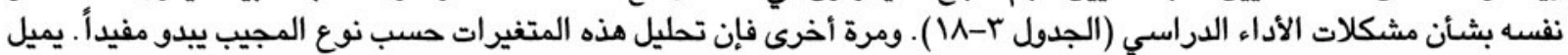

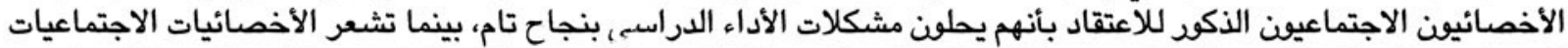

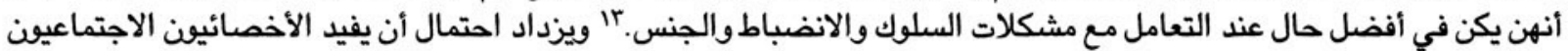

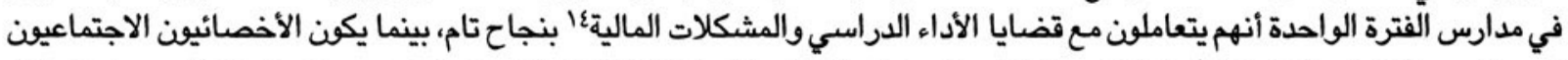

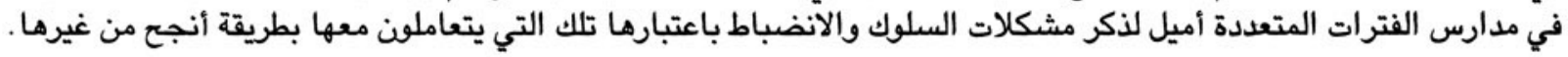

\section{ج· رؤى أخرى حول مشكلات الطلاب}

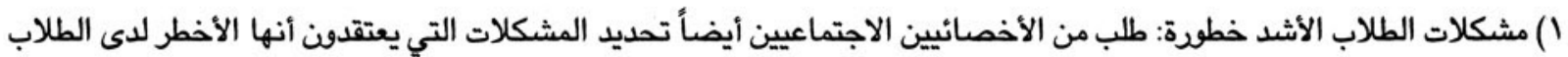

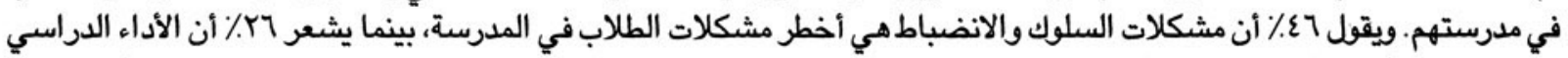

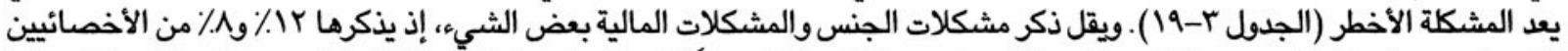

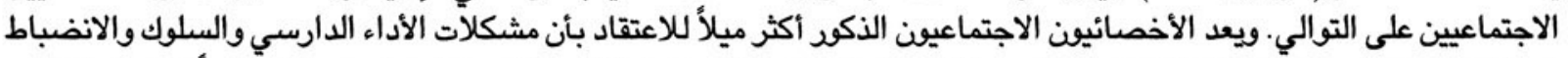

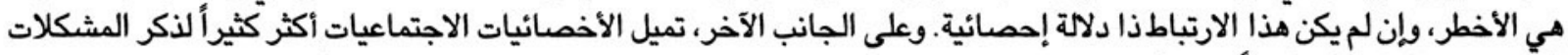

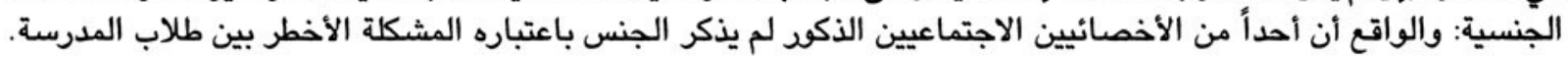

r) مصدر مشكلات الطلاب: سئل الأخصائيون الاجتماعيون حل ما ما إذا كانوا يعتقدون أن مشكلات الطلاب ألاب تنبع أساساً من المنزل

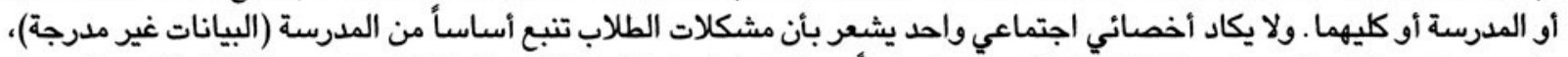

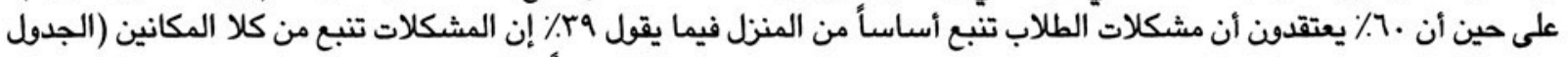

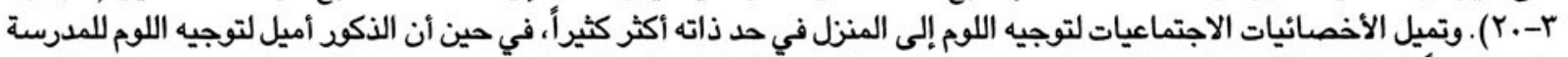

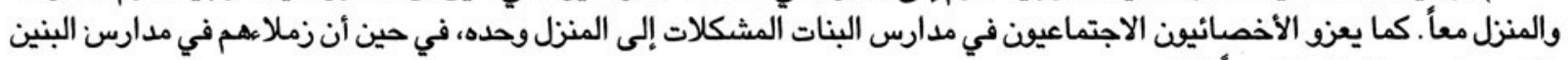
يذكرون المدرسة والمنزل معاً أكثر.

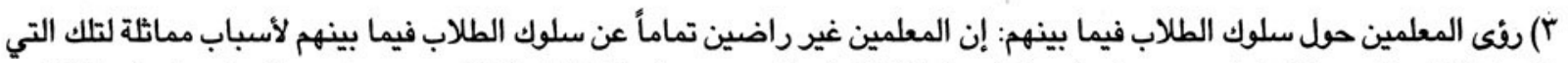

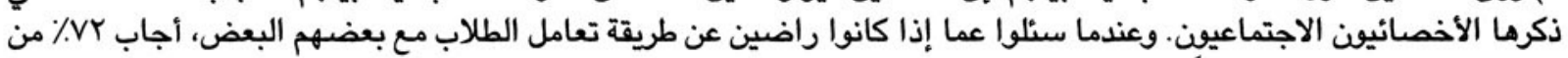

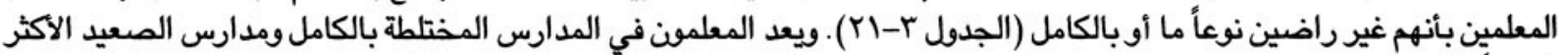

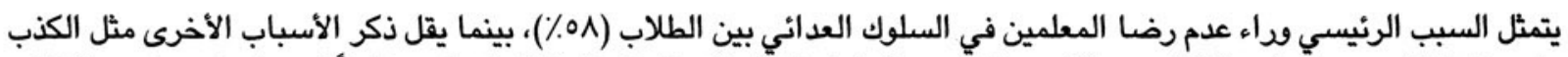

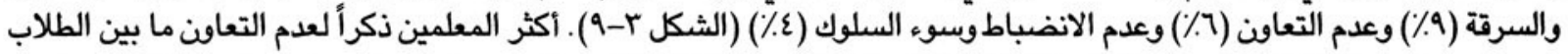

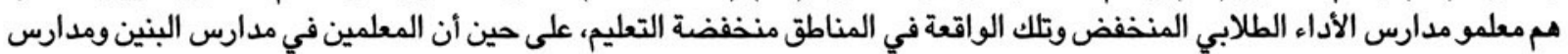

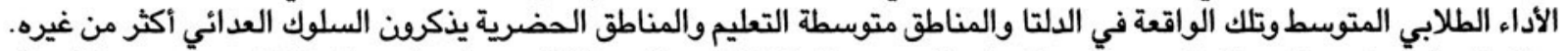

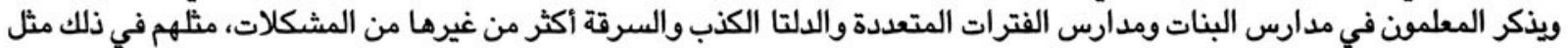
الأخصائيات الاجتماعيات.

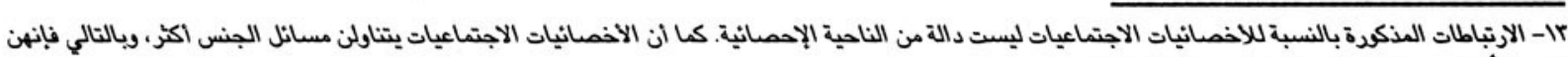

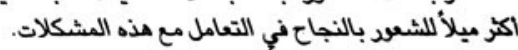
عا- يفيد عدد أكبر كثيراً من الأخمانئين الاجنماعيين في مدارس الفترة الواحدة أنهم يسالون حل المشكلات المالية، وهو الأمر الذي قد يفسر هذه النتجة. 


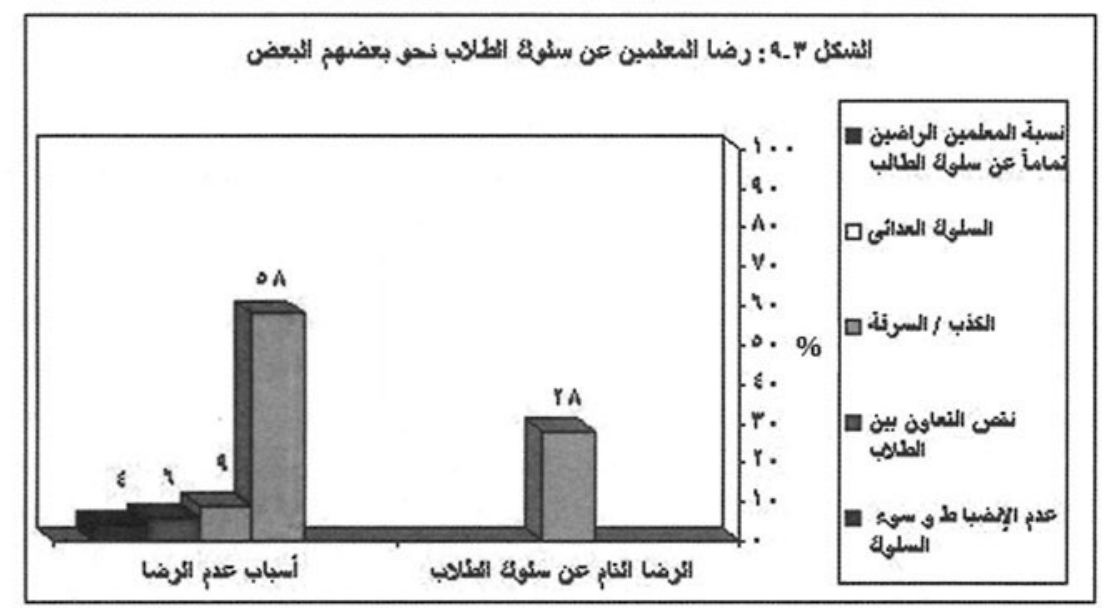

\section{^. دعم احتياجـات الطلاب من المعلومات}

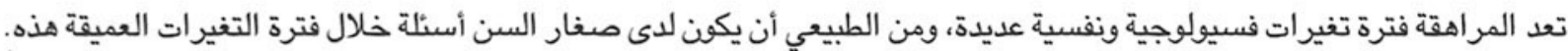

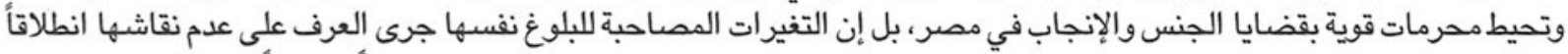

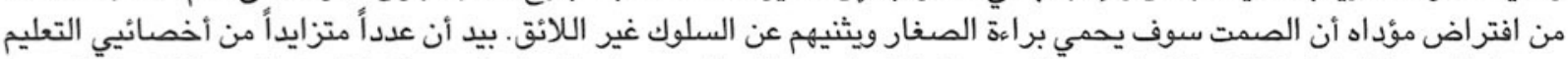

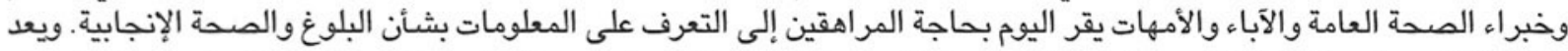

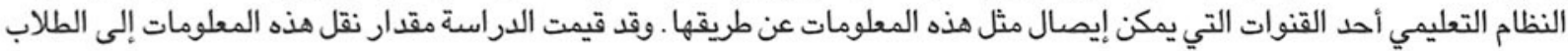

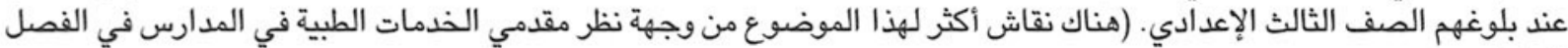

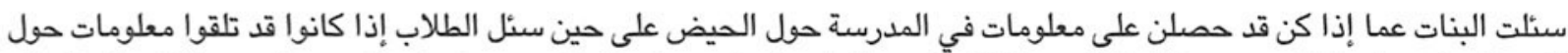

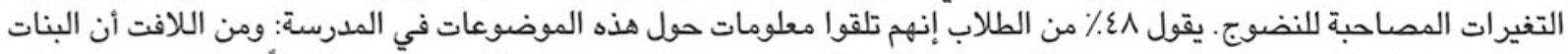

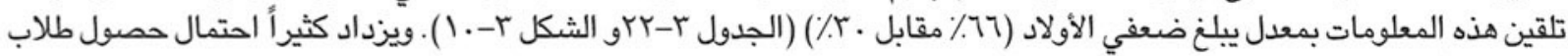

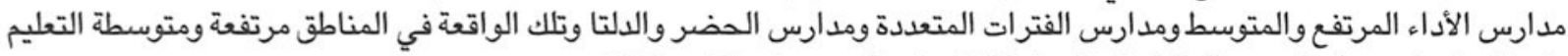
على المعلومات حول الحيض أو البلوغ مقارنة بالطلاب في المجموعات الفترد الفرعية الأخرى.

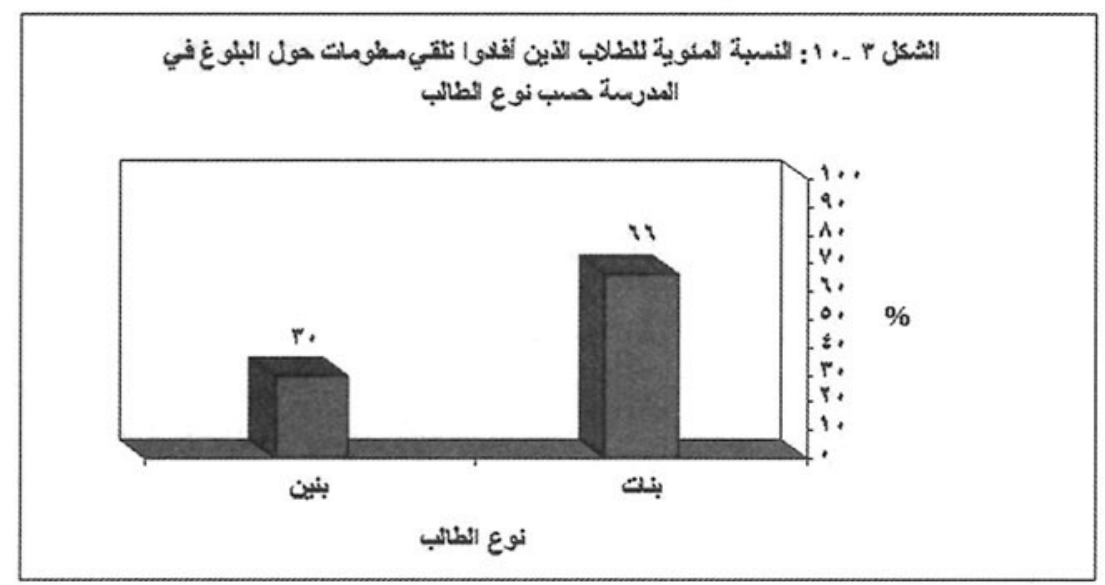

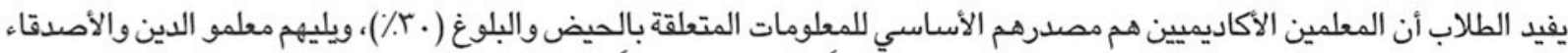

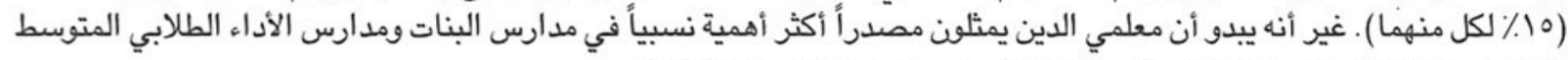
والفترات المتعددة وتلك الواقعة في المحأفظات الحضرية والمناطق مرتفعة التعليم.

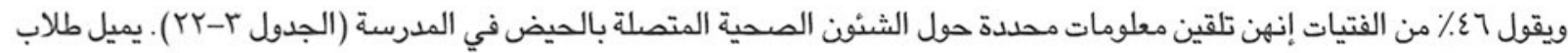
مدارس الأداء المتوسطومد الفتيات إنس البنات والفترات المتعددة وتلك الواقعة في المناطق مرتفعة التعليم والمحافظات الحضرية نحو إفادة 
الحصول على مثل هذه المعلومات أكثر من غيرهم، بينما يقل هذا الميل إلى أدنى حد بالنسبة لطلاب مدارس الأداء المنخفض والصئ الصعيد

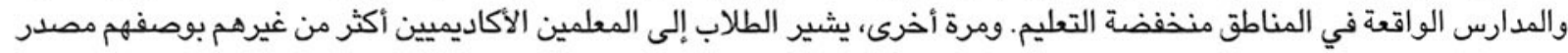

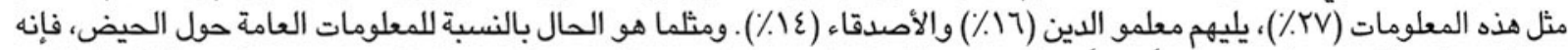

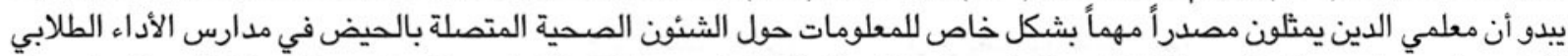

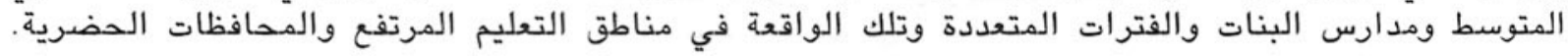

\section{9. التطلعات والتوقعات الشخصية للطلاب}

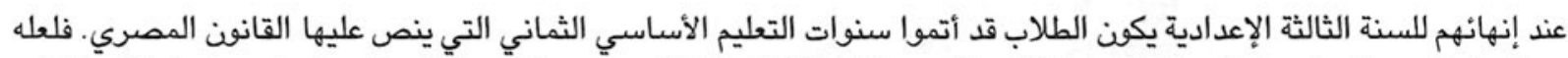

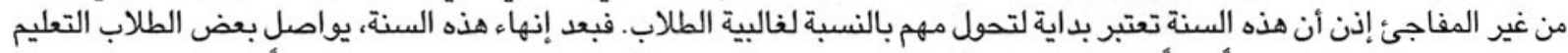

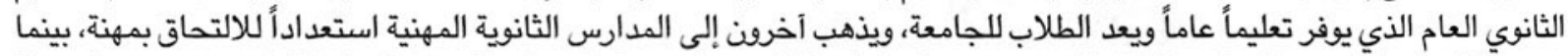

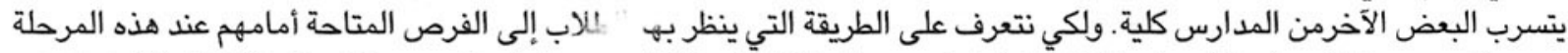
من حياتهم، وجهنا إليهم أسئلة حول ما إذا كانوا يتوقعن مواصلة التعليم الثانوي وحول أسباب عدم توقع ذلك إذا كانوا لإنا لا يتوقعونه.

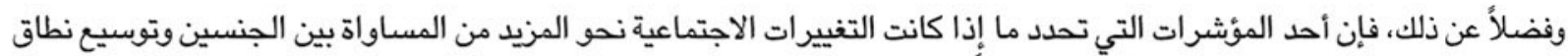

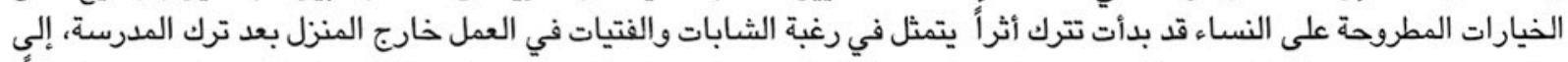

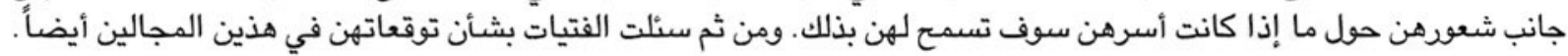

أ. التطلعات التعليمية

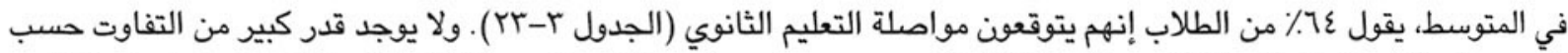
المجموعات الفرعية وإن كان الأولاد، وخاصة أولئك الذين يدرسون في مدارس البنين، لديهم توقعات أقل بشأن الاستمرار في التعليم التئ.

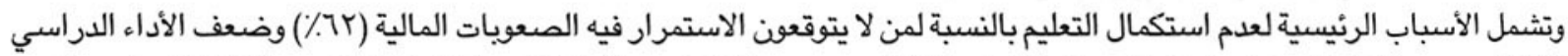

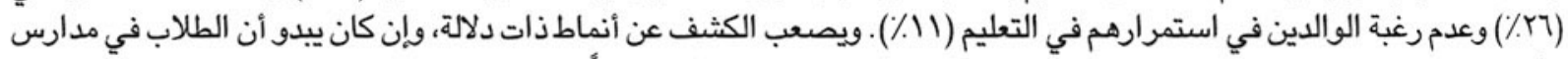

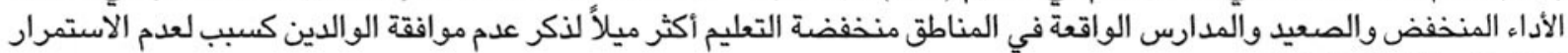

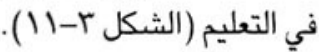

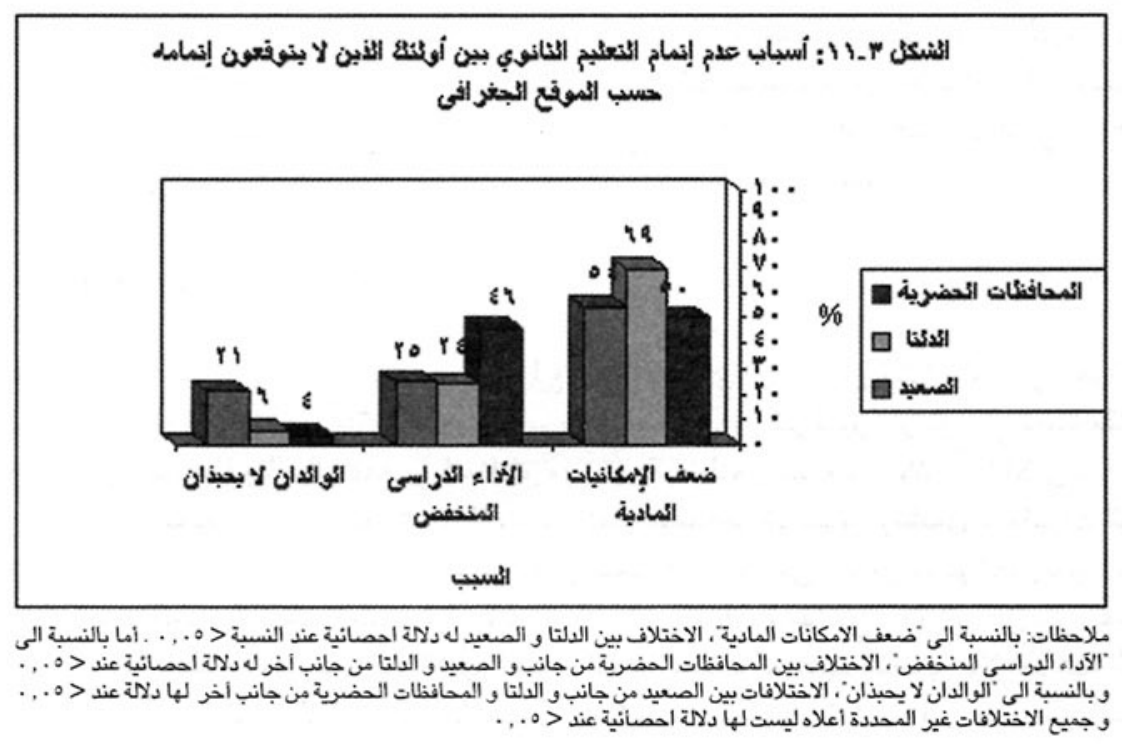

ب. تطلعات البنات بشأن العمل

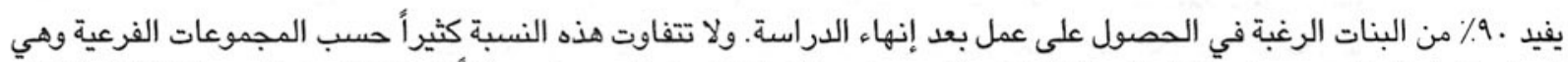

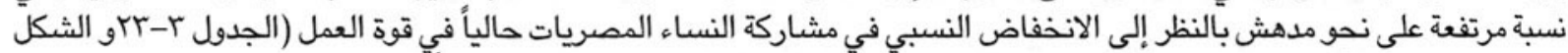

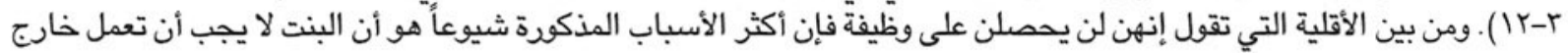


المنزل (1^^). ويعد الشعود بعدم جواز العمل للنساء أكثر انتشاراً في الصعيد والدلتا وفي مدارس المستويات التعليمية المنففضة و المتوسطة.

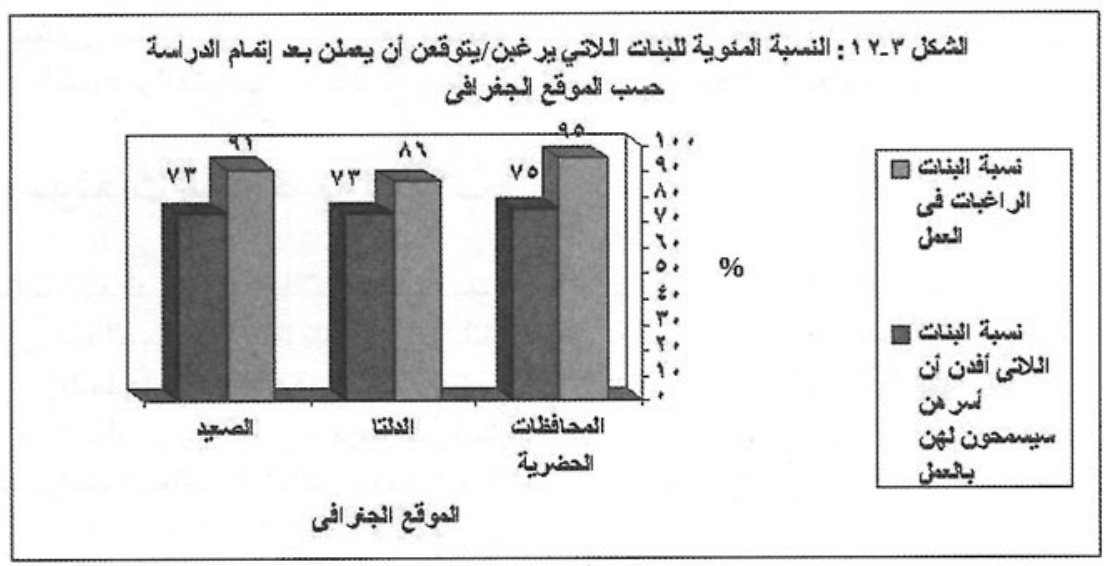

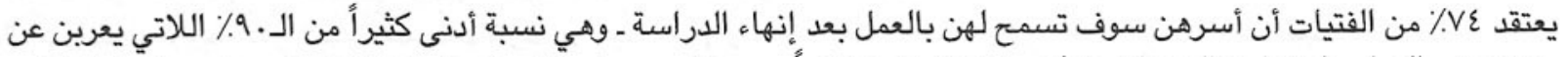

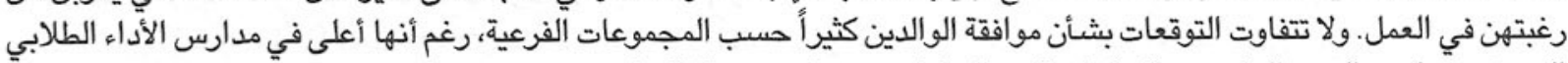
المرتفع ومدارس الفترة الواحدة وتلك الواقعة في المناطق مرتفعة ومتوسطة التعليم.

1. 1. 1. 1.

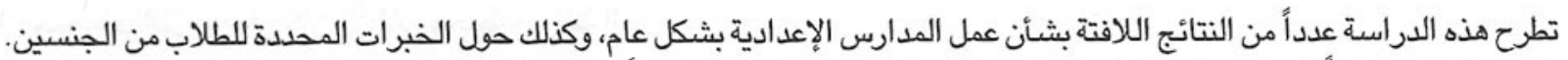

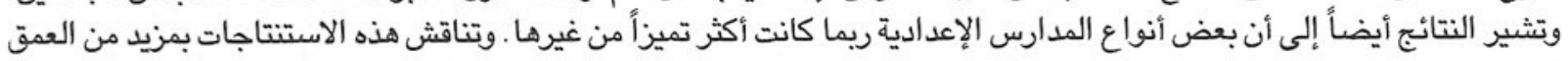

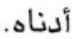

أ. المدارس إجمالاً

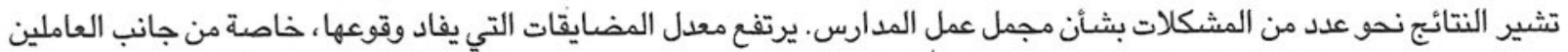

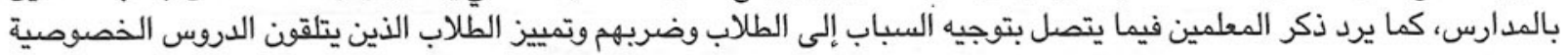

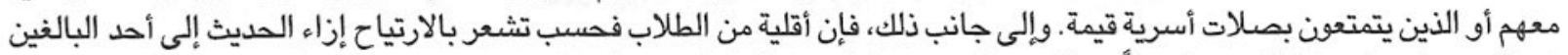

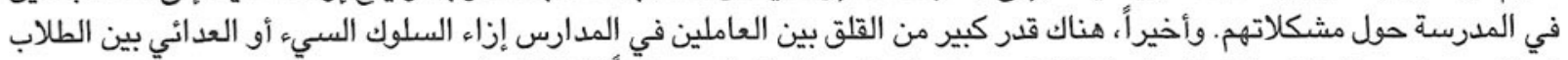

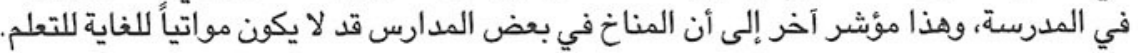

\section{ب. المدارس المتميزة في مقابل المدارس الأقل تميزاً}

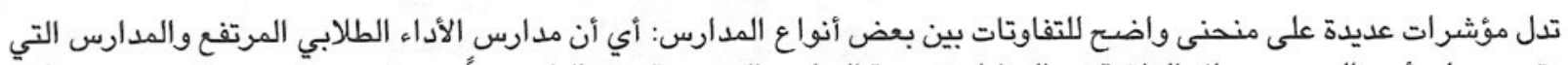

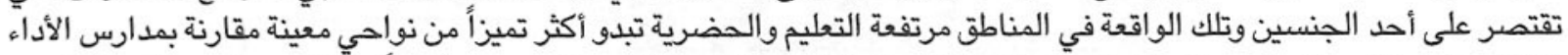

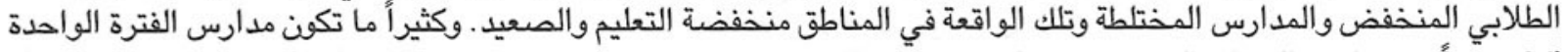

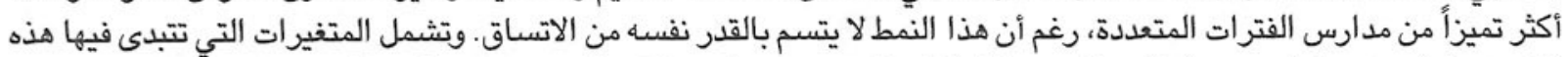

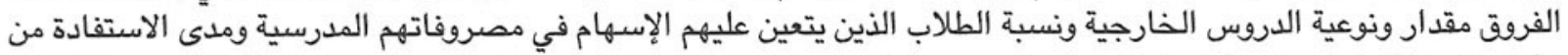

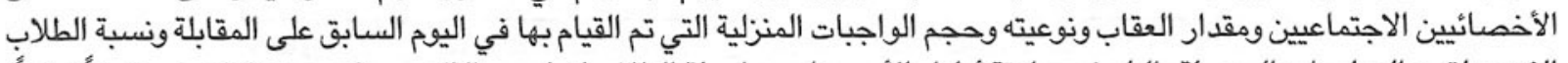

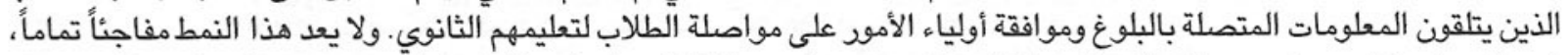

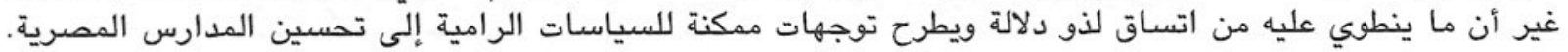

ومن جانب آخر، يلاحظ أن المدارس المتميزة من النواحي التي ناقشناها للتو مؤشراتها أسوأ فيما يتعلق بعدد من المتغيرات الأخرى.

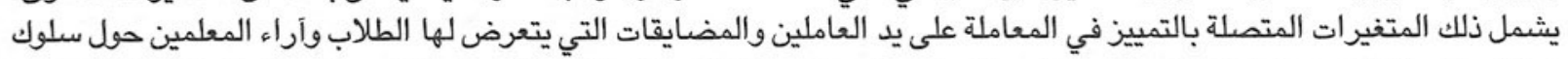

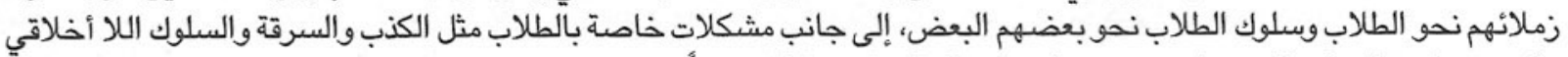

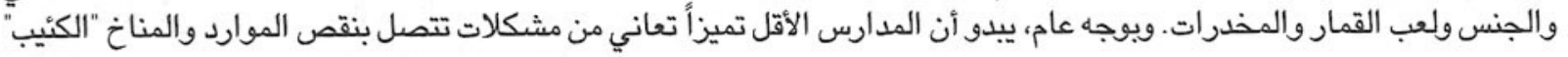


عموماً، غير أنها قد تكون أماكن أكثر انتظاماً من الناحية الاجتماعية، على حين أن المدارس الاكثر تميزاً تعاني من مشكلات اجتماعية ترتبط بشكل عام بالحياة العصرية الحضرية.

$$
\text { ج. الخبرات حسب النوع }
$$

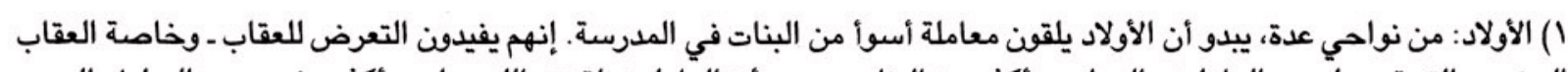

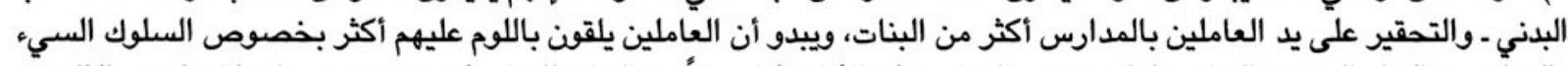

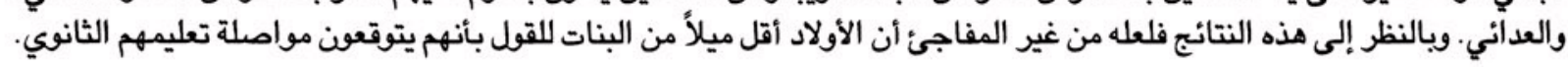

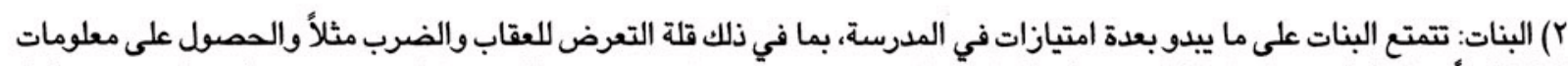

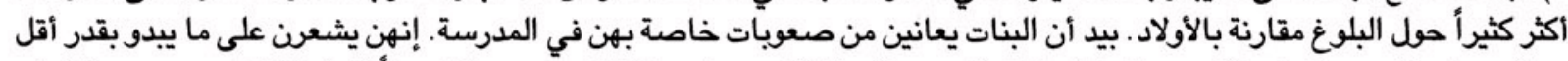

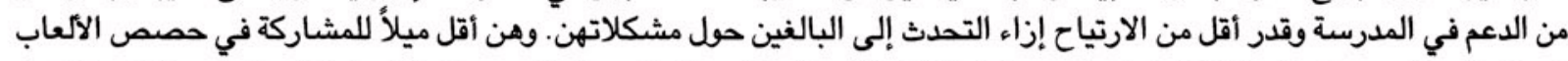

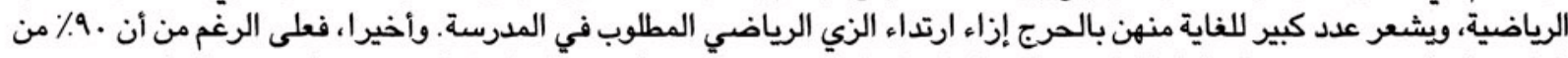

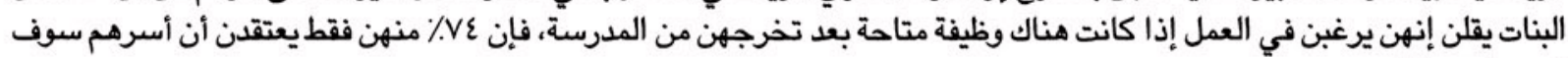
تسمح لهن بذلك.

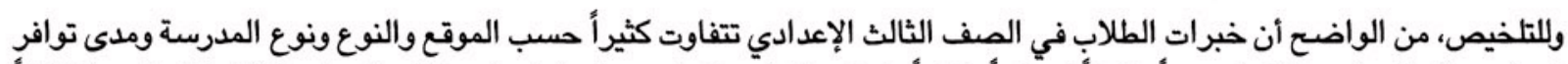

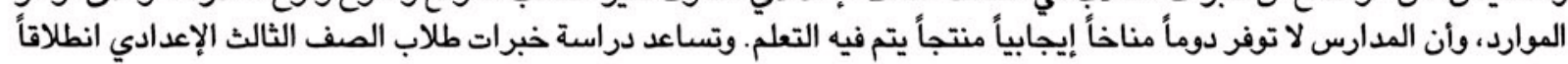

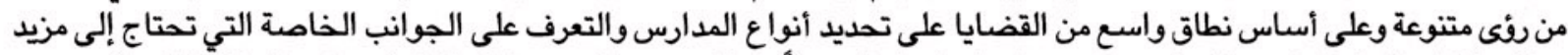

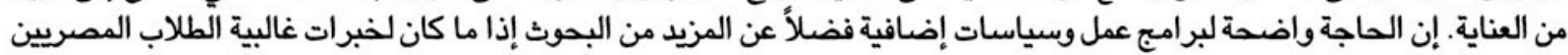




\section{الصحة و النظافة العامة}

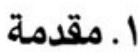

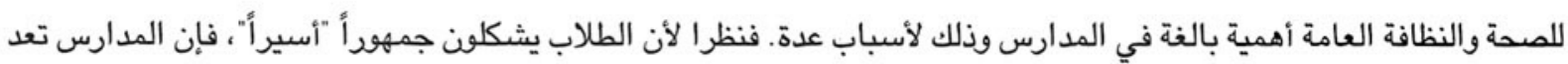

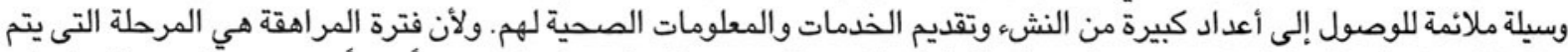

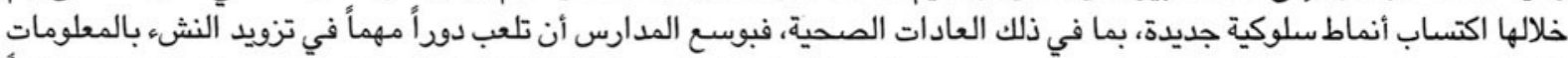

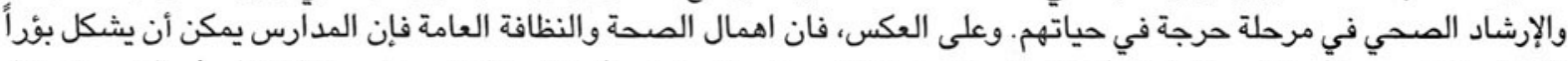

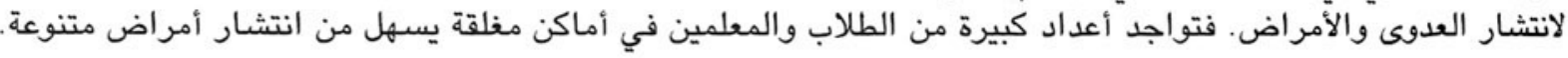

ورغم أن البيانات المتاحة من هذه الدراسة لن تمكننا من التعمق على نحو واف في شئون الصحة والنظافة العامة في المدارس الإعدادية،

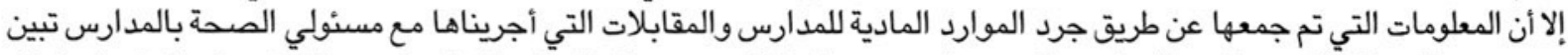

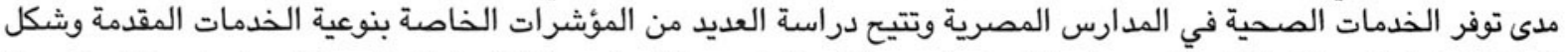

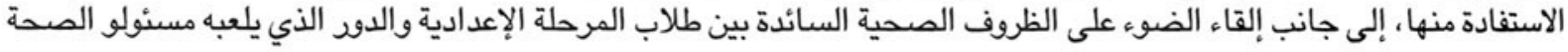
في تلل المدارس بصدد مساعدة الطلاب على فهم التغيرات المصاحبة للبلوغ. الفئ.

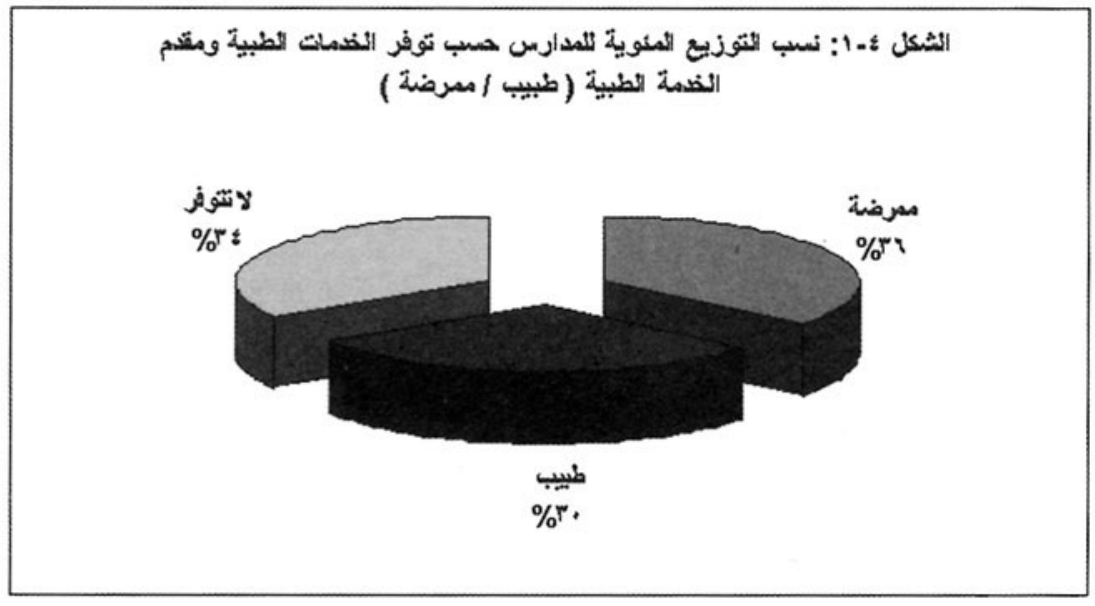

ب. ب الخدمات الصحية المدرسية

أ.توفر الخدمات الصحية المدرسية

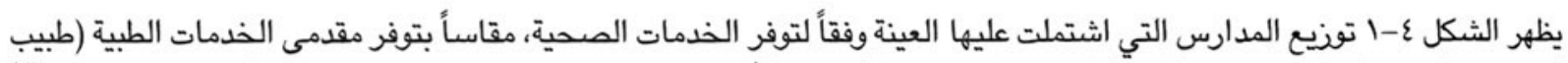

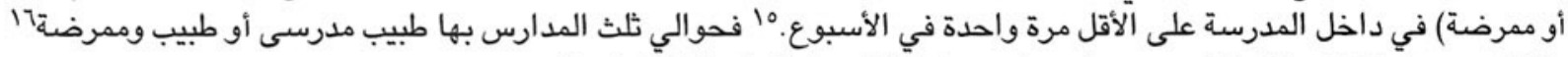

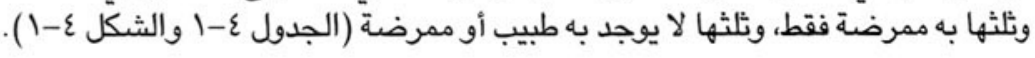

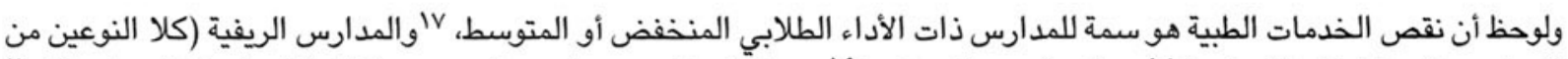

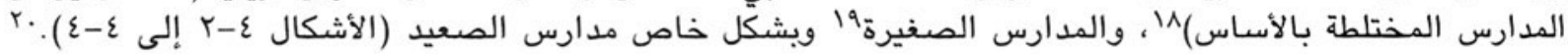

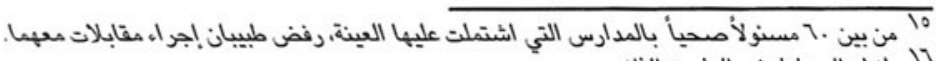

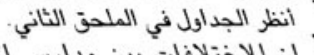

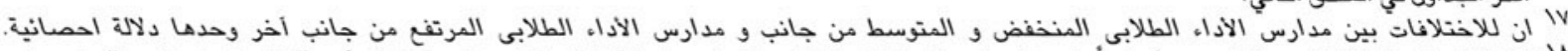

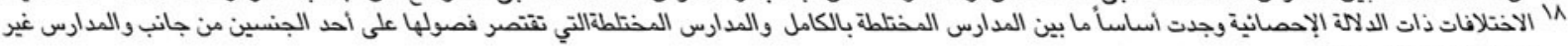

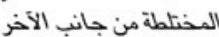

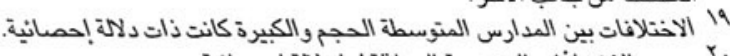
r. جميع الاختبار"ات المزدوجة المماثلة لهان دلالة الحصائية. 

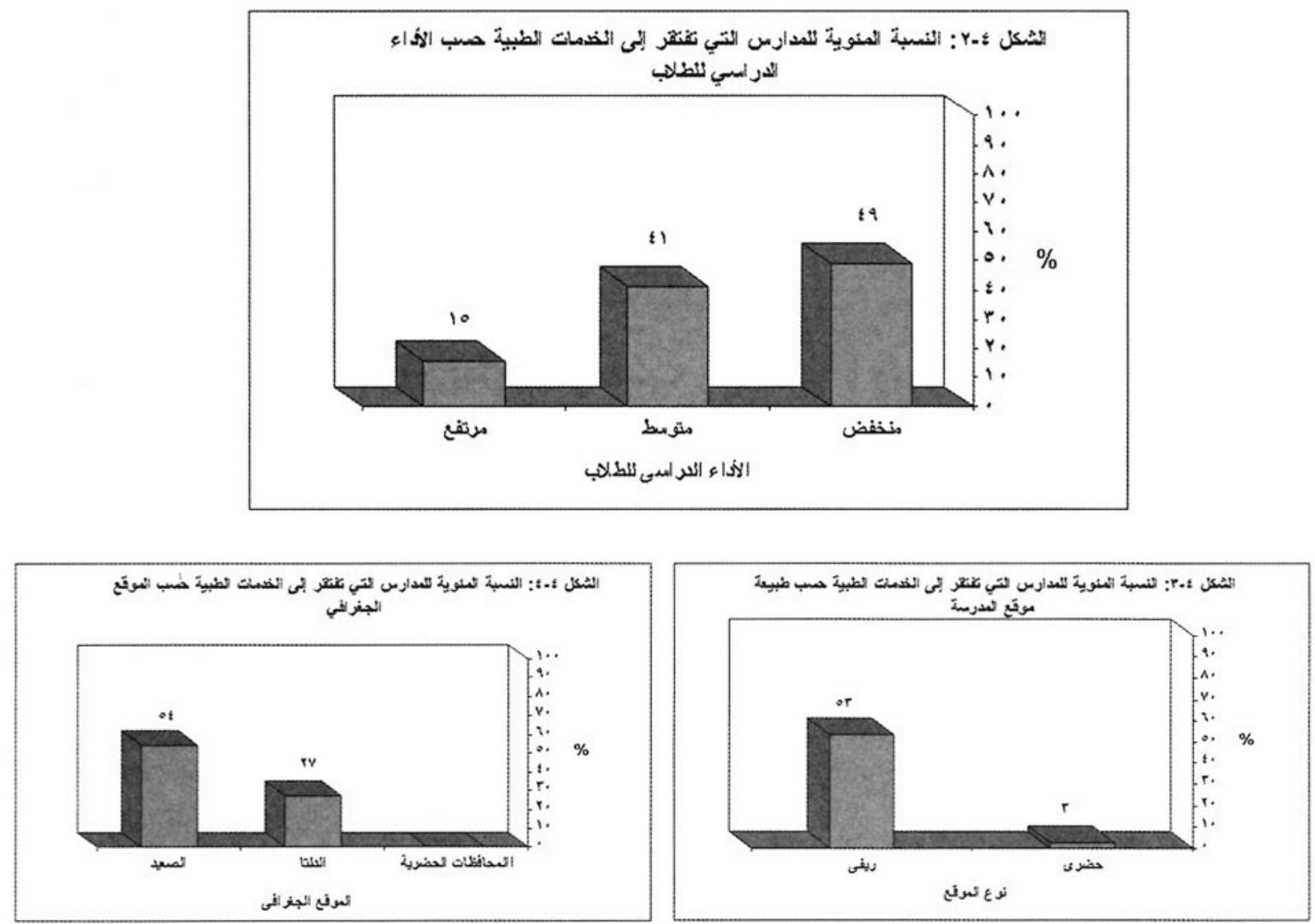

وجدير بالذكر أن تواجد مسئول طبي في مدرسة معينة لا يعنى بالضرورة أنه يعمل بتلك المدرسة فحسب أو يتواجد بها كل يوم. فبين

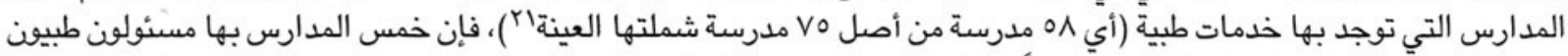

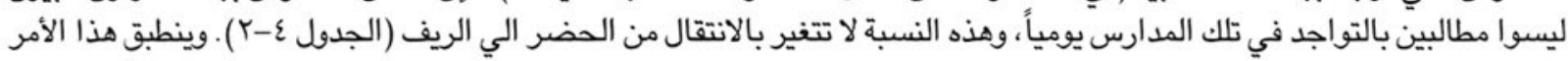

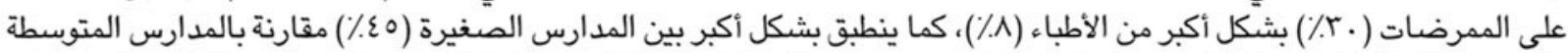

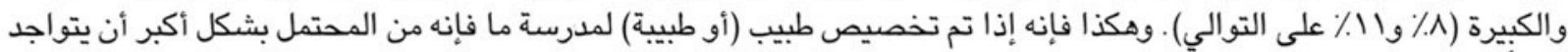
يومياً في تلل المدرسة عما إذا تم تخصيص ممرضة.

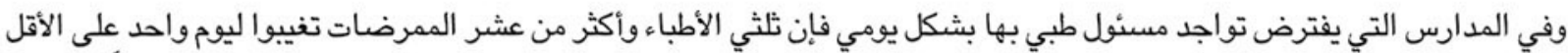

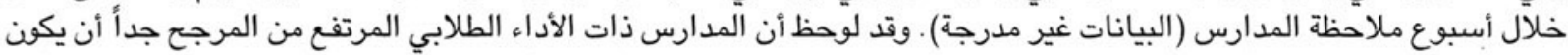

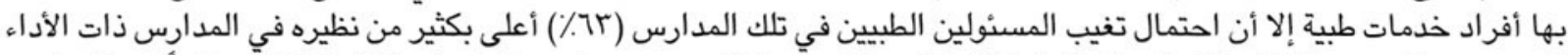

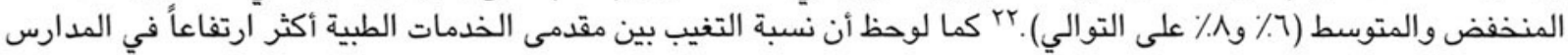

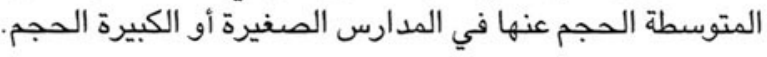

\section{ب. خلفية العاملين بالخدمات الطبية بالمدارس}

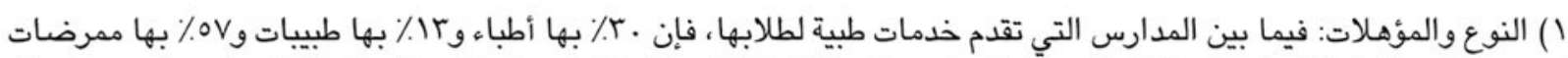

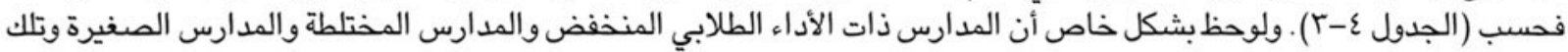

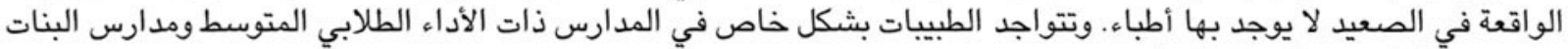
والمدارس الواقعة في المحافظات الحضرية.

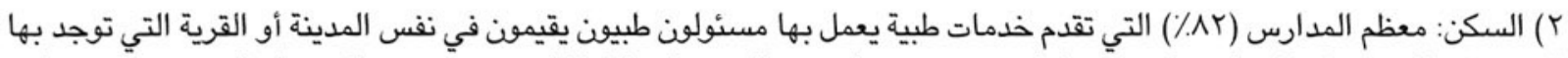

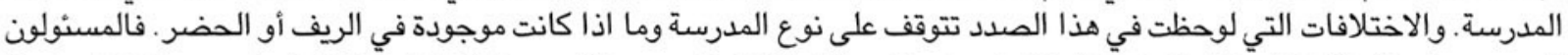

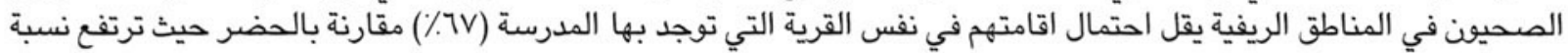

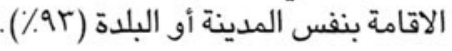

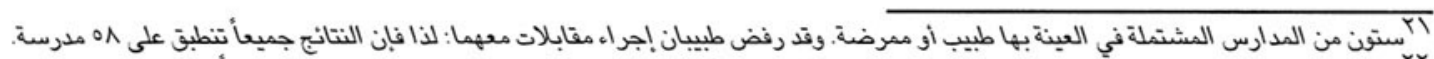

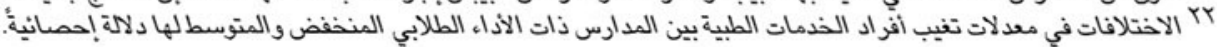




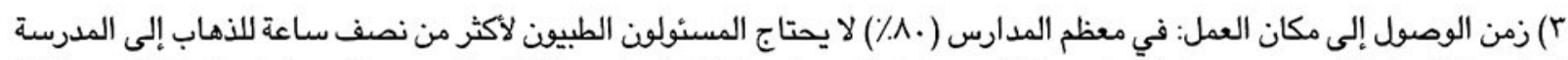

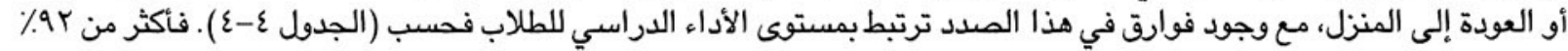

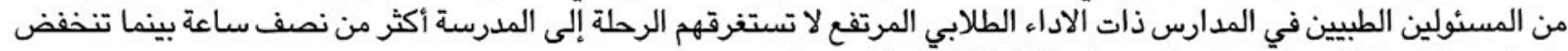

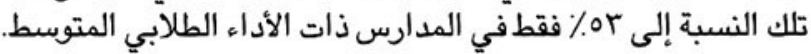

ج. نوعية الخدمات الصحية المقدمة بالمدارس

يتم تقييم الخدمات الصحية المدرسية هنا على أساس كل من التجهيزات المادية (مثل وجود عيادة تتوافر بها المعدات والمواد الطبية الأساسية) والكوادر الطبية (كوجود مسئولين طبيين، والعبء الملقى عليهم، ومستوى تدريبهم).

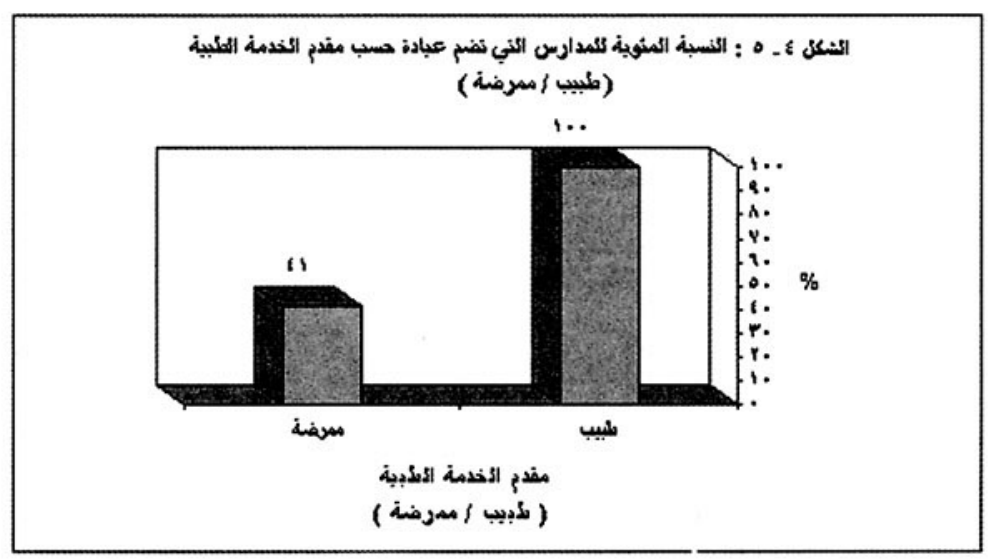

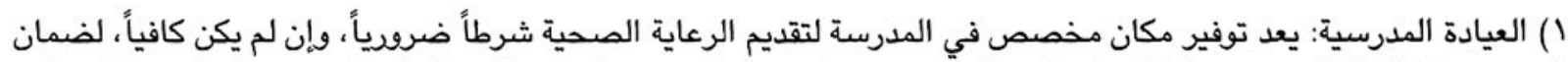

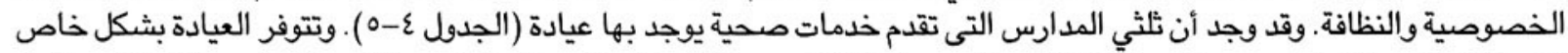

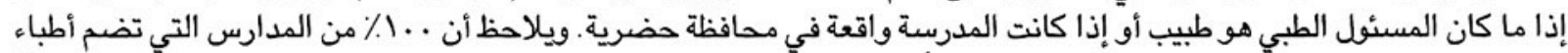

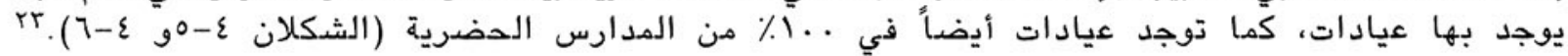

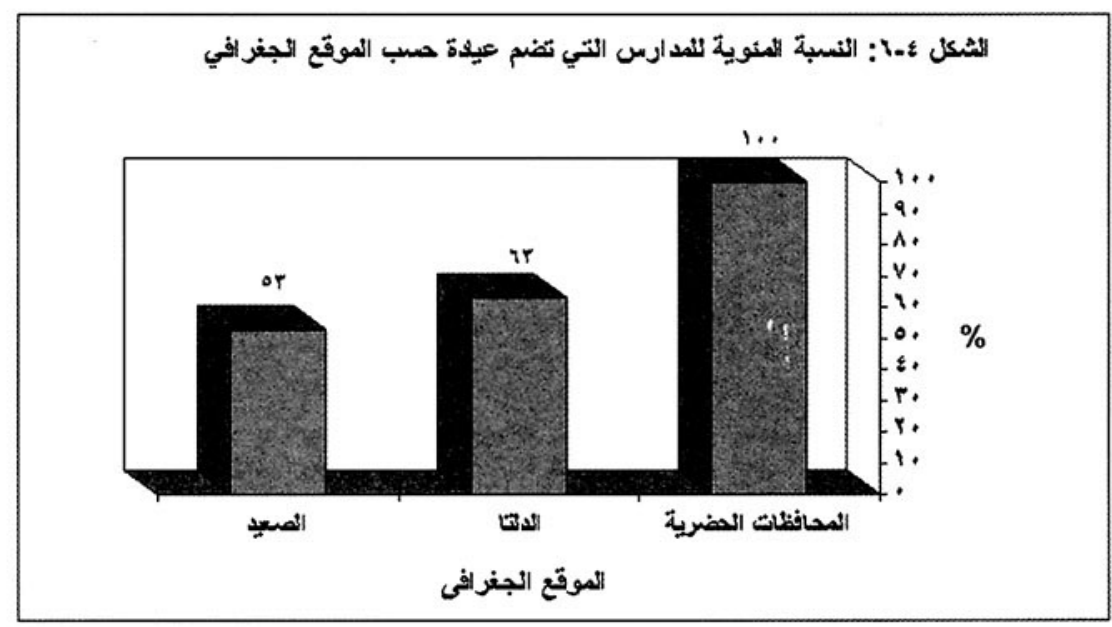

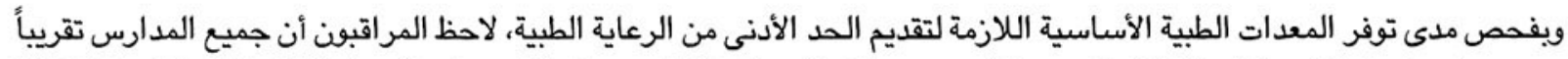

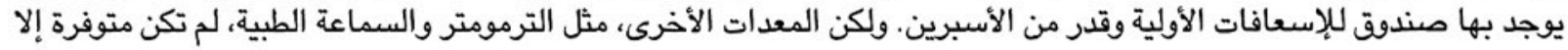

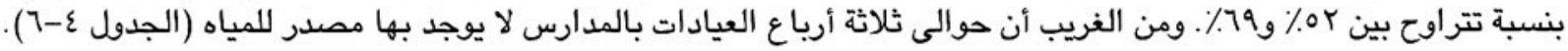

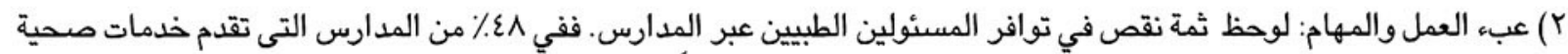

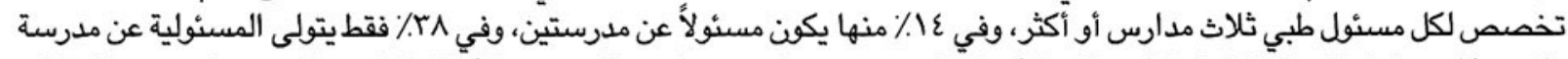

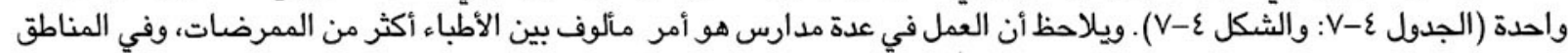

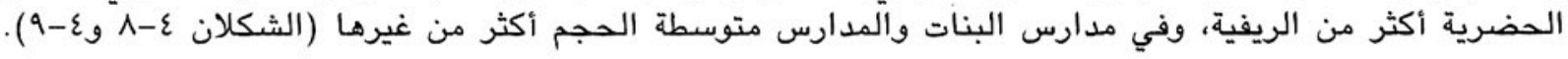



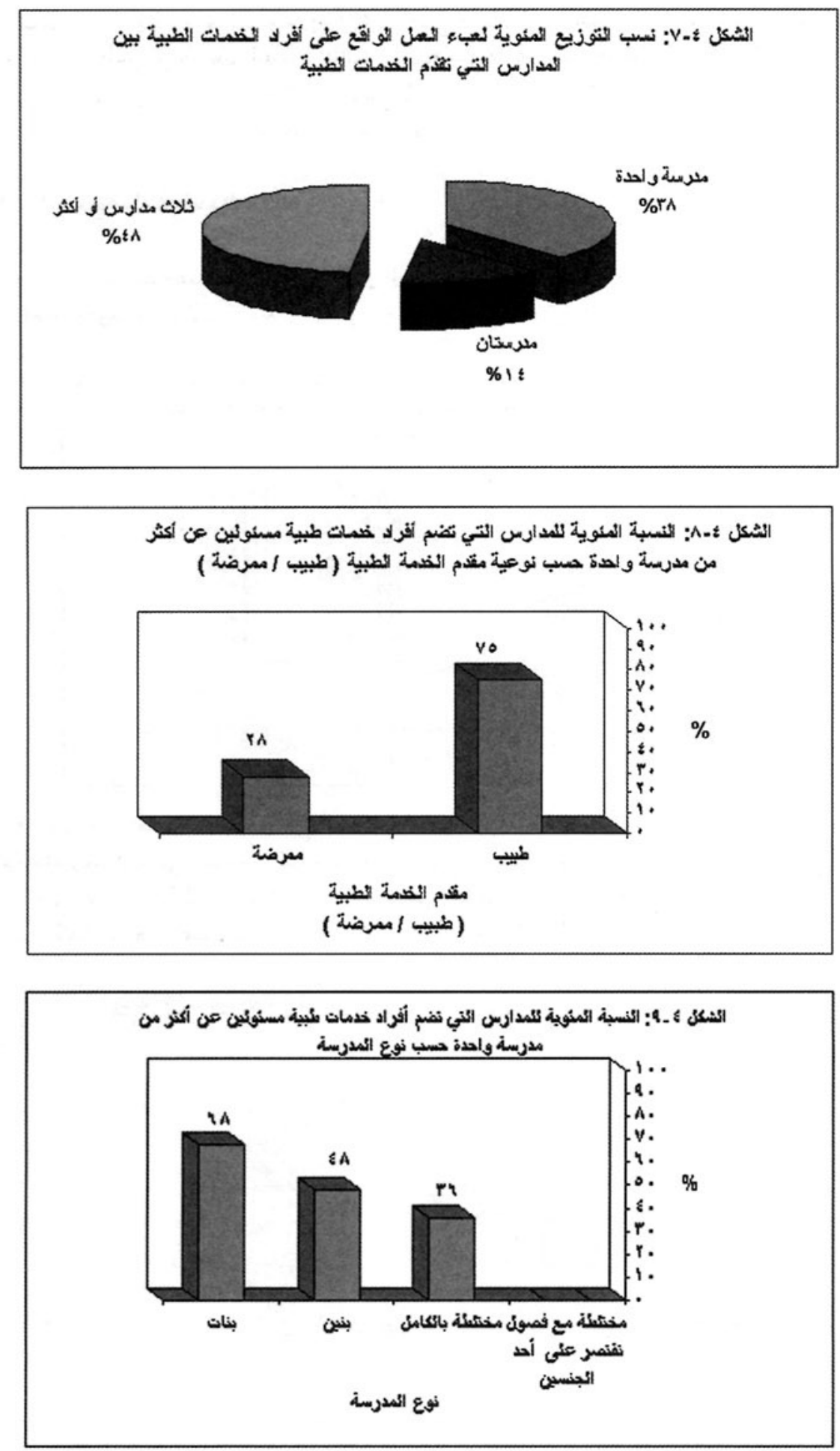

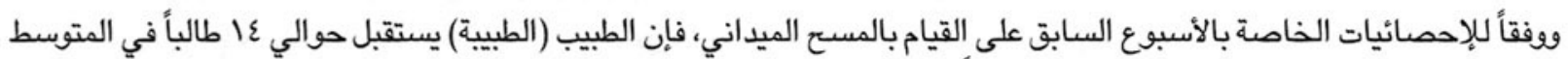

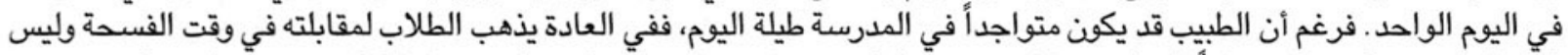

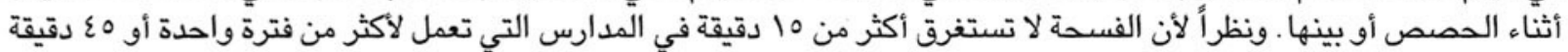

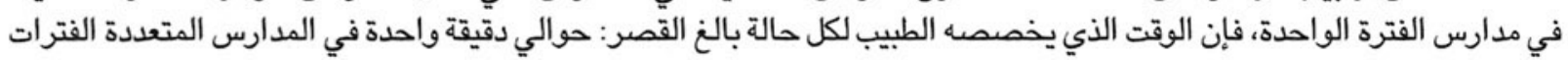

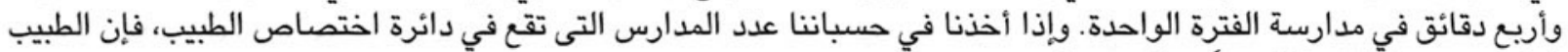

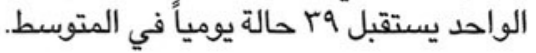

r) المهام والمسئوليات: تم سؤال أفراد الخدمات الصحية أيضاً عن المهام الفعلية التي يقومون بها في المدارس. وتم تصنيف الإجابات 


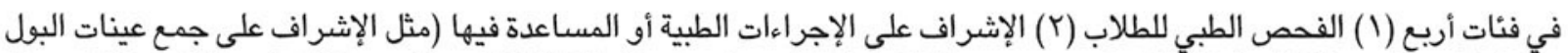
والبراز أو مساعدة الأطباء وأطباء الأسنان في فحص الطلاب) (r) الإشراف على النظافة العامة في المدرسة (ع) أنشطة التوعية الصحية.

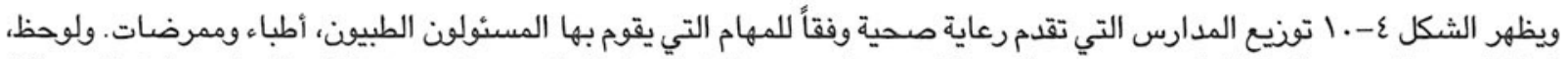

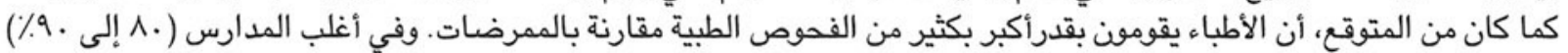
يقوم المسئولون الطبيون بالاشراف على الإنجراء يقون بقرات الطبية والنظافة العامة في المدارس.

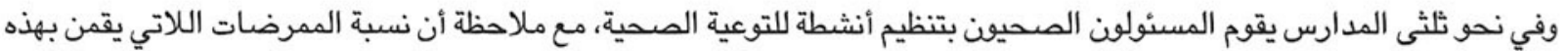

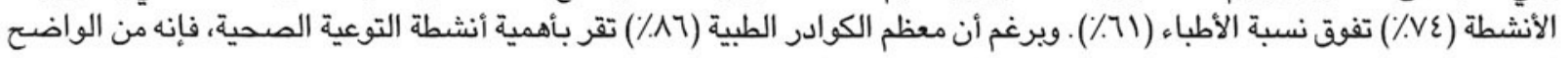

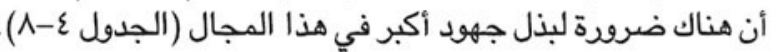

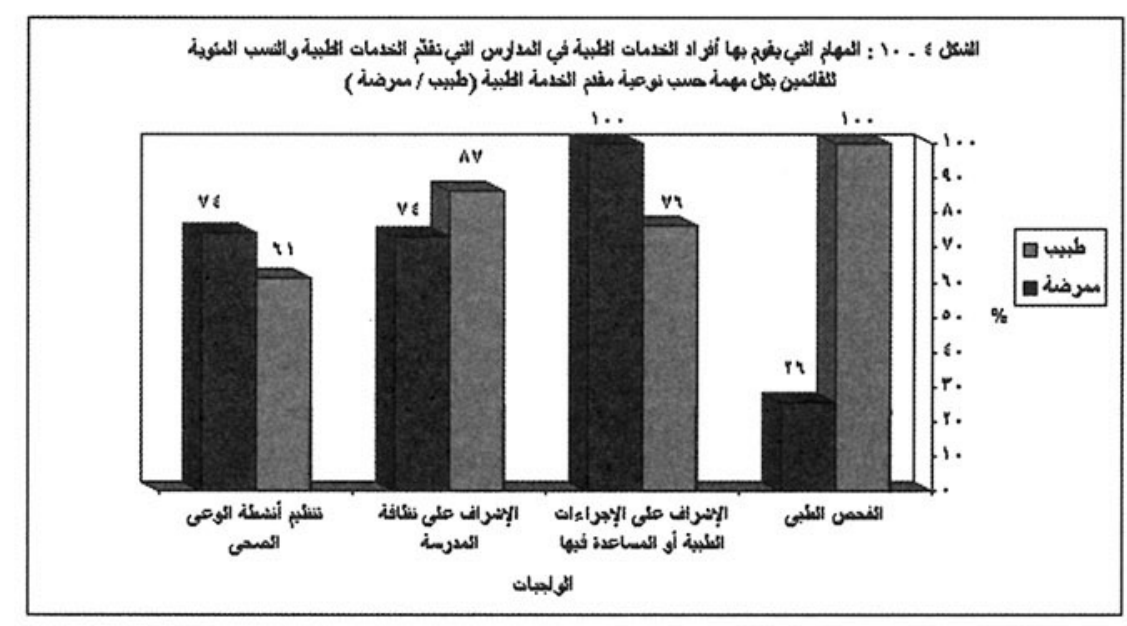

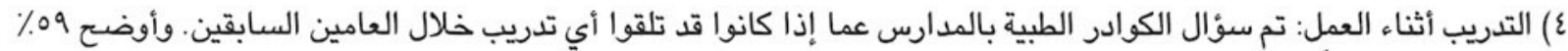

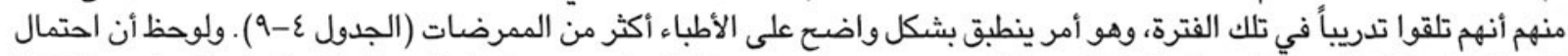

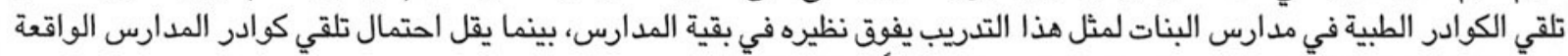
في ألمناطق الريفية (في المدارس المختلطة بنوعيها أساساً) لمثل هذا التدريب.

\section{د. الرضا عن ظروف العمل}

1) المهام والمسئوليات: أفاد ثلاثة أرباع المسئولون الطبيون أنهم راضون جداً عن مهامهم ومسئولياتهم. ولم توجد فوارق إحصائية

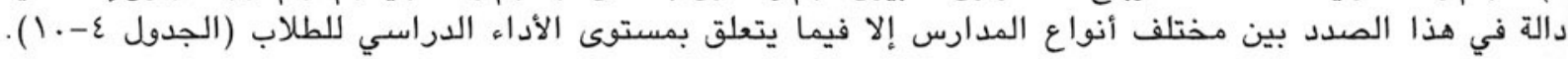

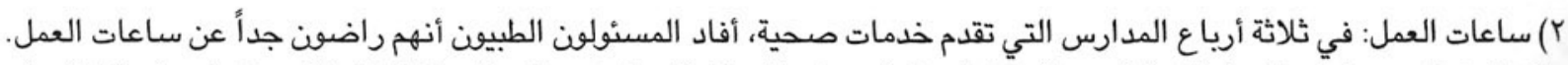

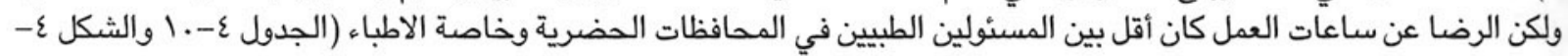




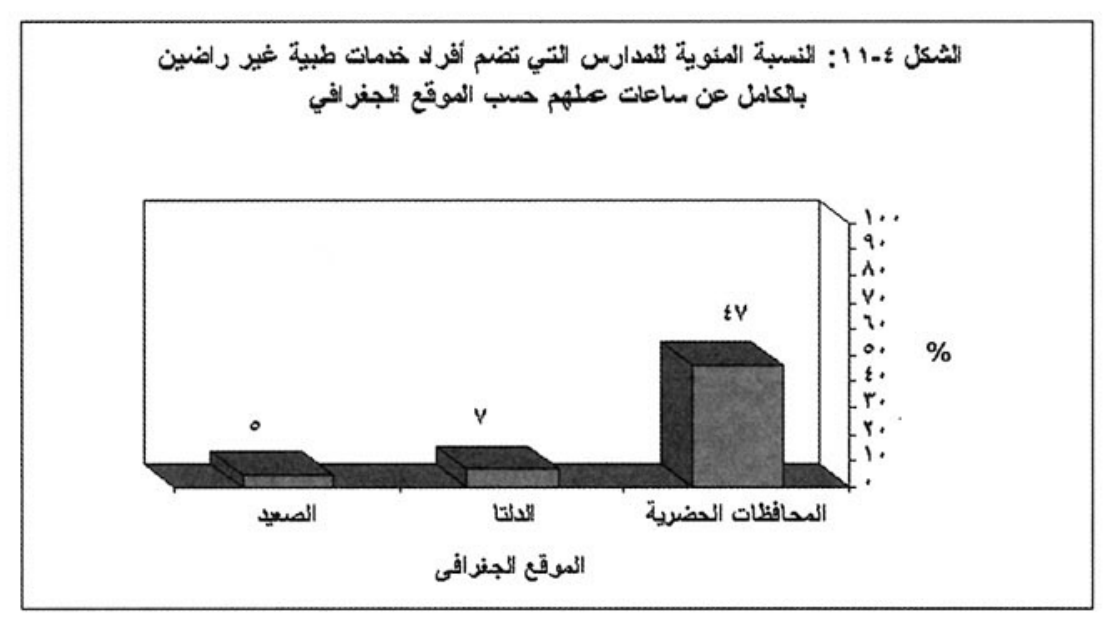

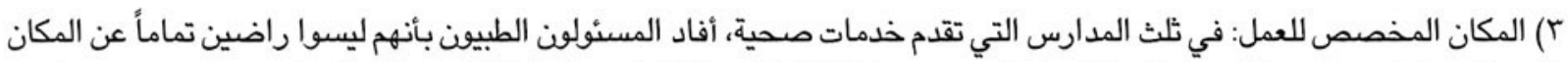

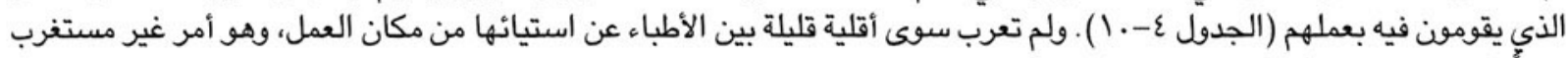

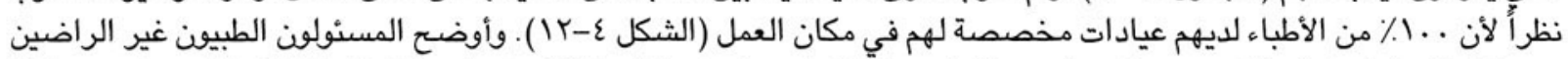

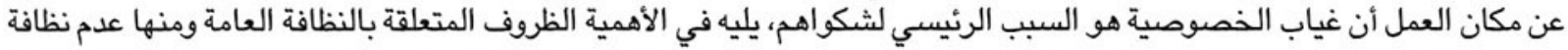

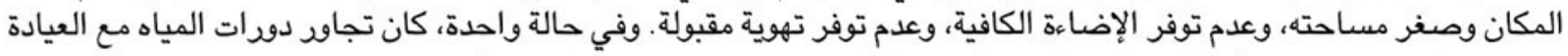

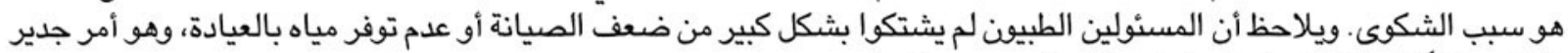
بالذكر نظراً لأن ثلاثة أرباع العيادات تفتقر إلى مصدر للمياه.

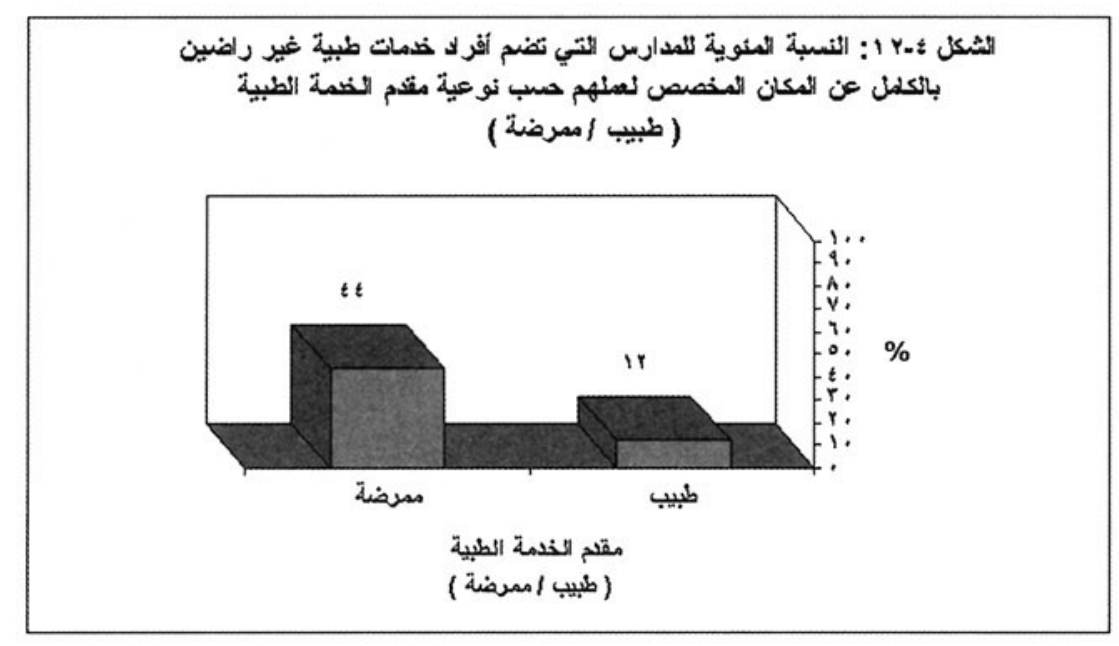

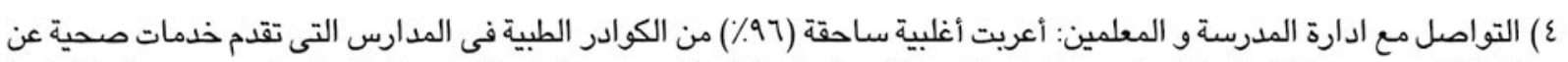

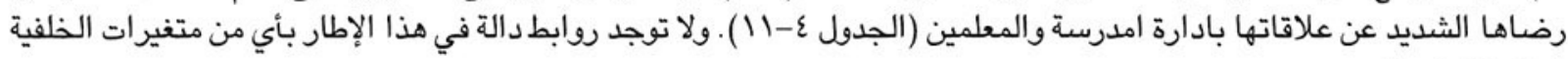
المتصلة بالمدارس.

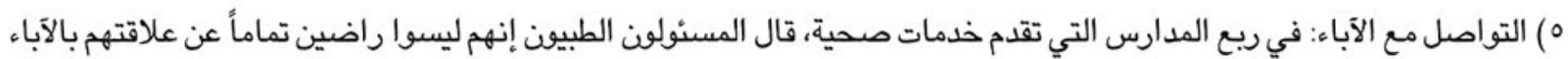

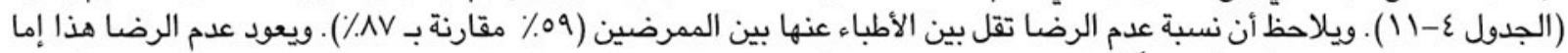

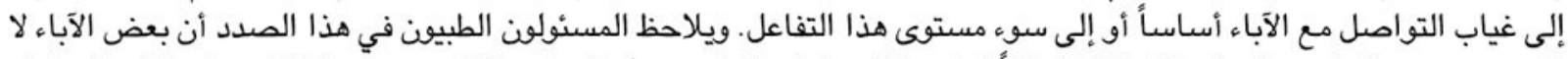

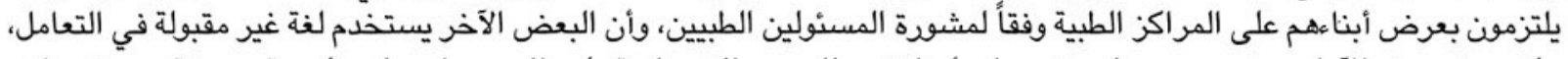

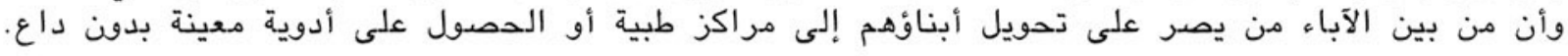




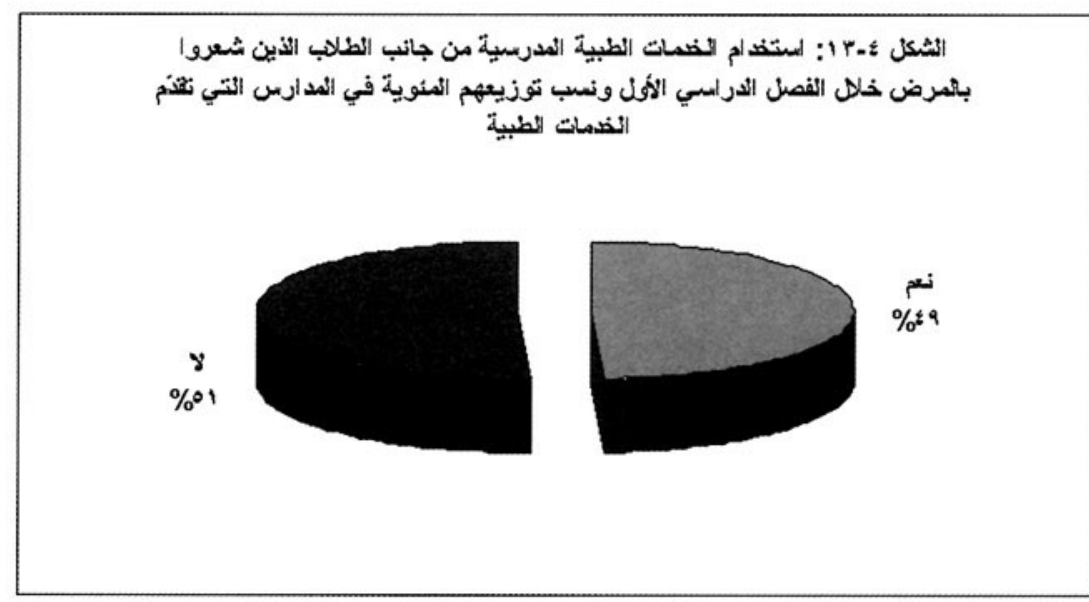

هـ. الانتفاع بالخدمات الصحية في المدارس

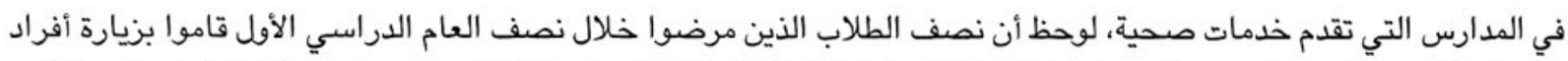

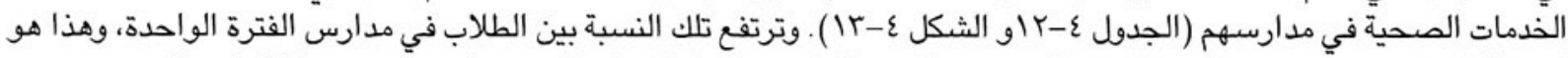

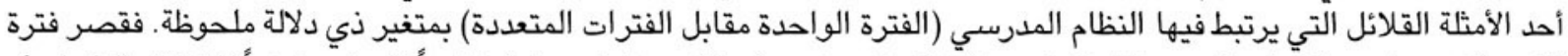

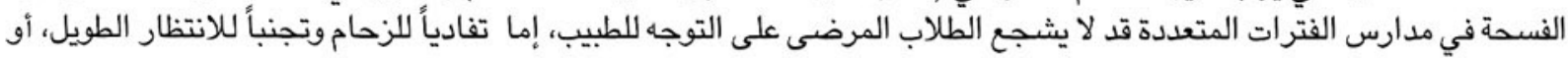
بسبب عدم الرضا عن مقدار الوقت الذي يمكن للمسئول الطبي أن يمنحه لهم. لهن.

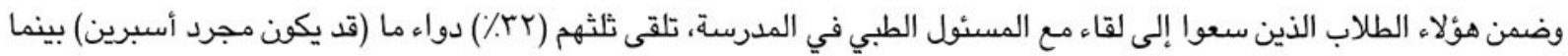

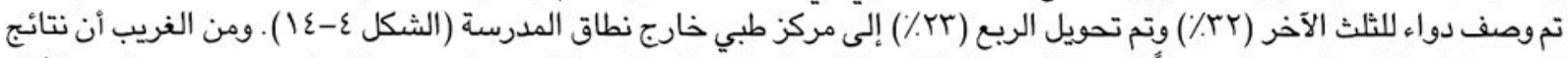

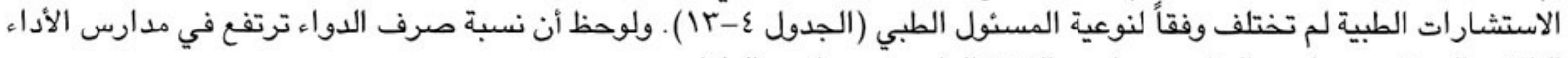

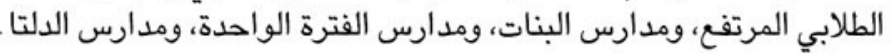

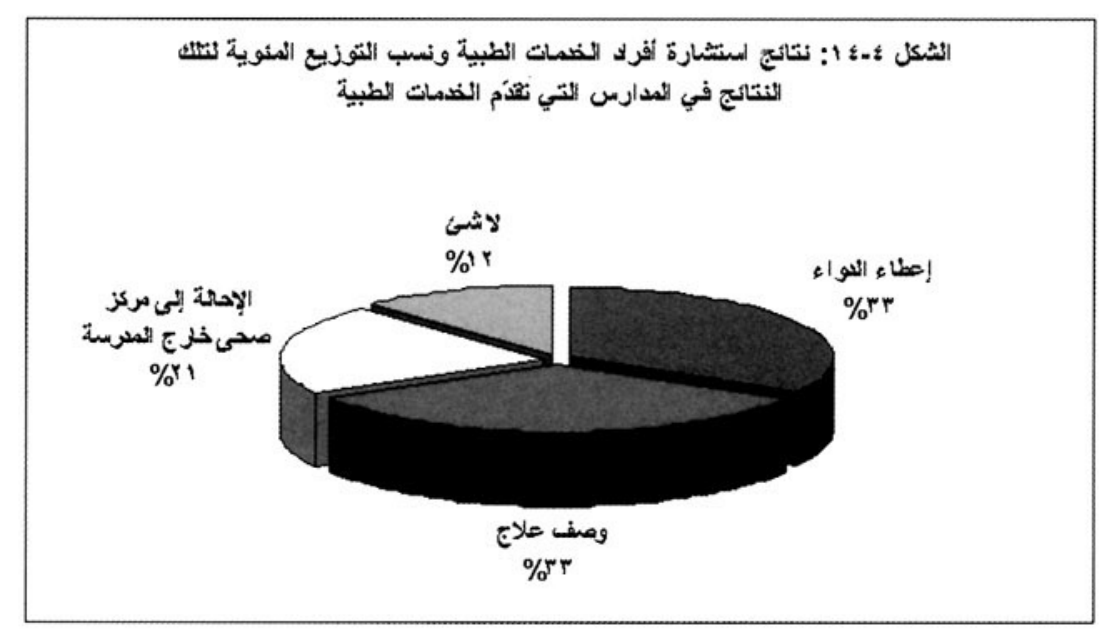

و. نظام التأمين الصحي المدرسي

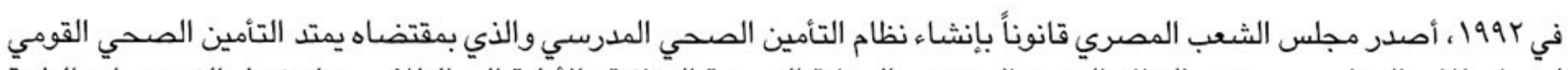

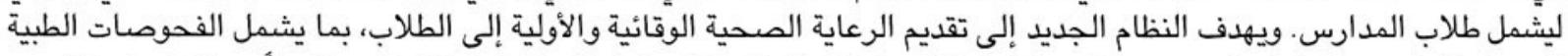

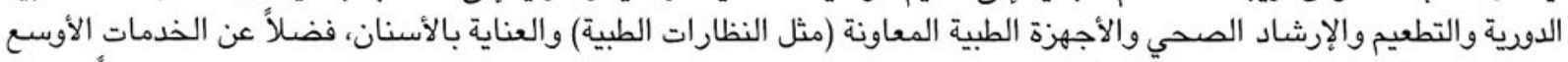

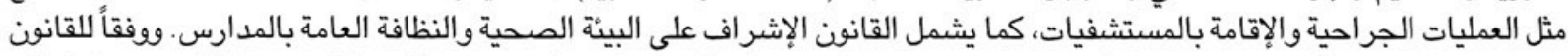

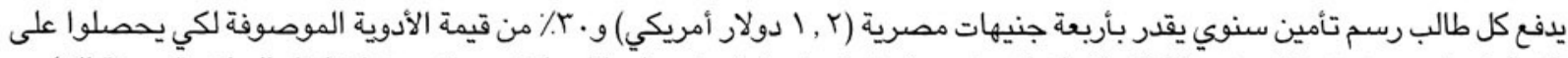

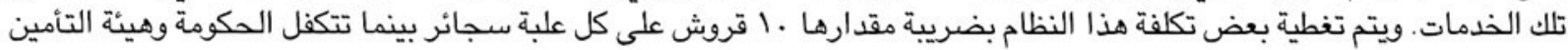

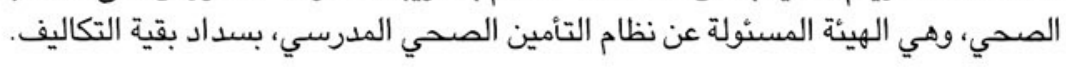


مثل أي نظام جديد، كان لنظام التأمين الصحي المدرسي صعوياته: ذلك أن تغطية الجمهور المستهدف وهو ـ ـ أملايين من طلاب المدارس

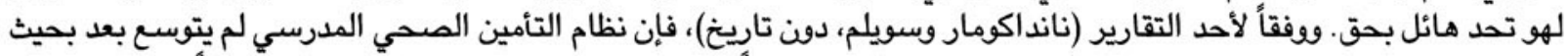

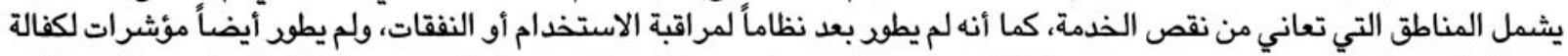

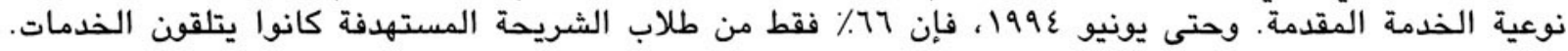

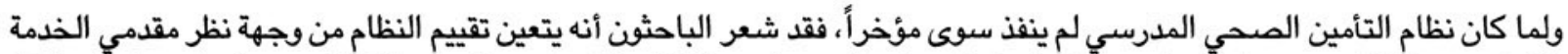

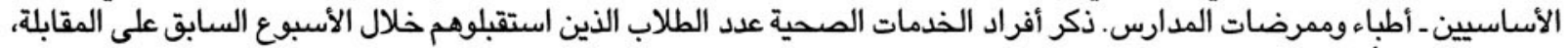

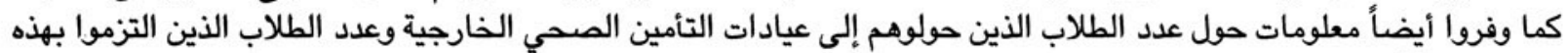

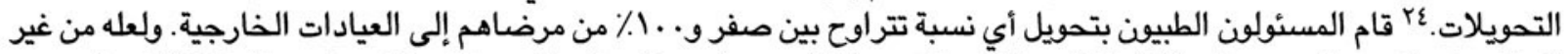

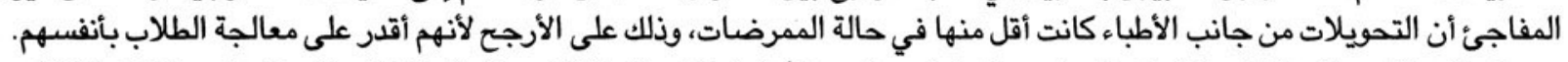

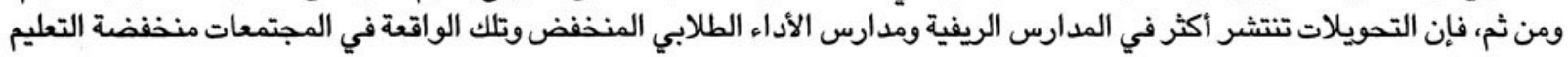

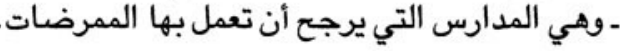

ويعطي المسئول الطبي بالمدرسة خطاب تحويل لكل طالب يعتقد أنه بحاجة للفحص في عيادة خارجية. ويكتب طبيب العيادة الخارجية

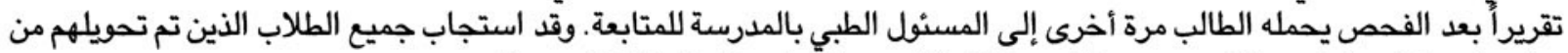
جانب المسئولين الطبيين الذين جرت مقابلتهم خلال الأسبوع السابق على على المقابلة للتحويلات.

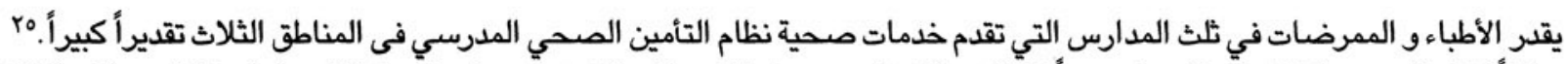

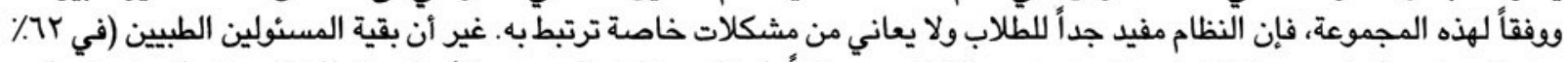
من المدارس) لديهم انتقادات قوية ضد النظام. وفوفقاً لهؤلا،، فإن العيوب الأساسية للنظام تتمثل فيما يلي:

• • إن نسبة كبيرة من المدارس لا يوجد بها بعد طبيب أو ممرضة مقيمين.

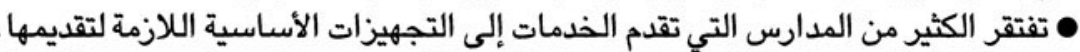

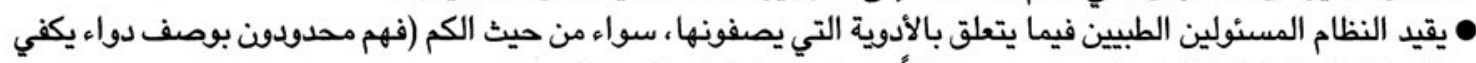

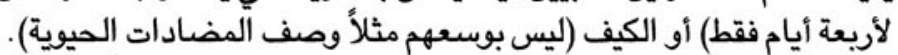

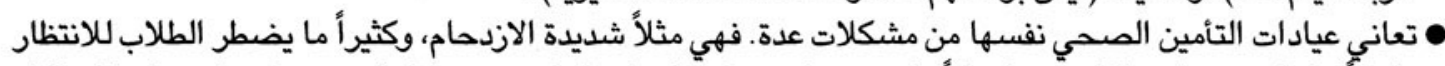

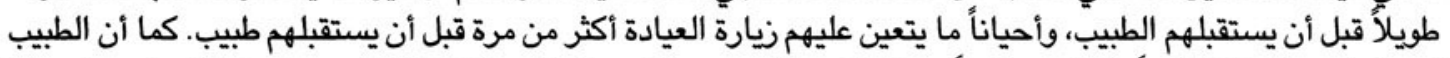

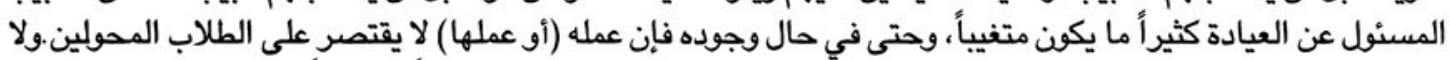

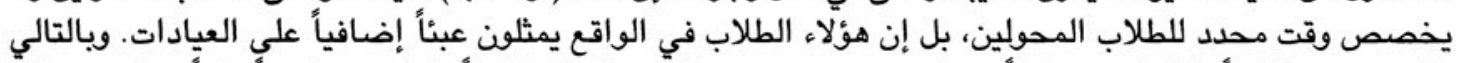

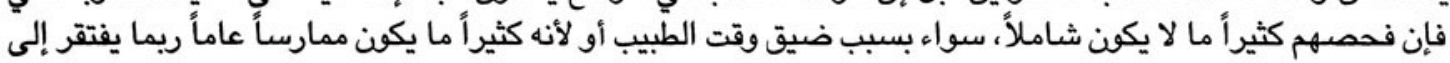

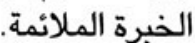
• يحتاج أفراد الخدمات الصحية بالمداد الضدارس لمزيد من التدريب، سواء فيما يتعلق بالمشكلات الصحية الاكثر شيوعاً بين

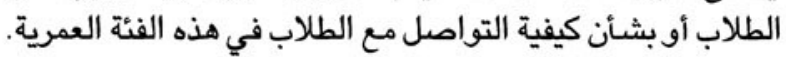

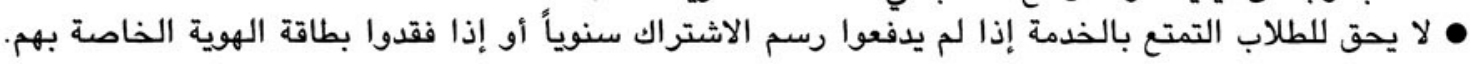

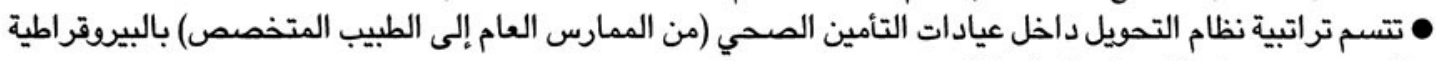
الشديدة، ويحتاج الأمر إلى أوداق كثيرة. • أولياء الأمود غير راضين مطلقاً عن الخدمات الفيرة المقدمة، لأنهم لا يتفهمون القواعد التي تحكم النظام.والقيود التي يفرضها

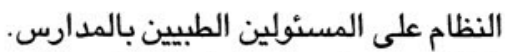

• الطلاب يسيئن استخدام النظام، وذلك عندما يدعون المرض أو يستبدلون الأدوية الموصوفة لهم في الصيدلية بغيرها.

\section{r. الحالات المرضية بين الطلاب والنظافة العامة في المدارس}

أ. تغيب الطلاب بسبب المرض

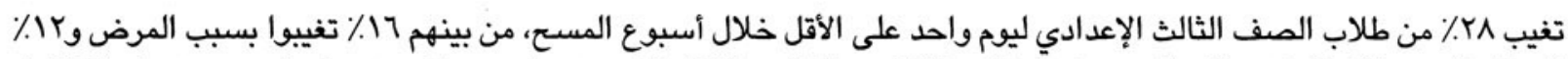

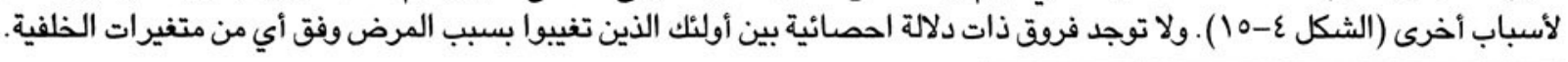




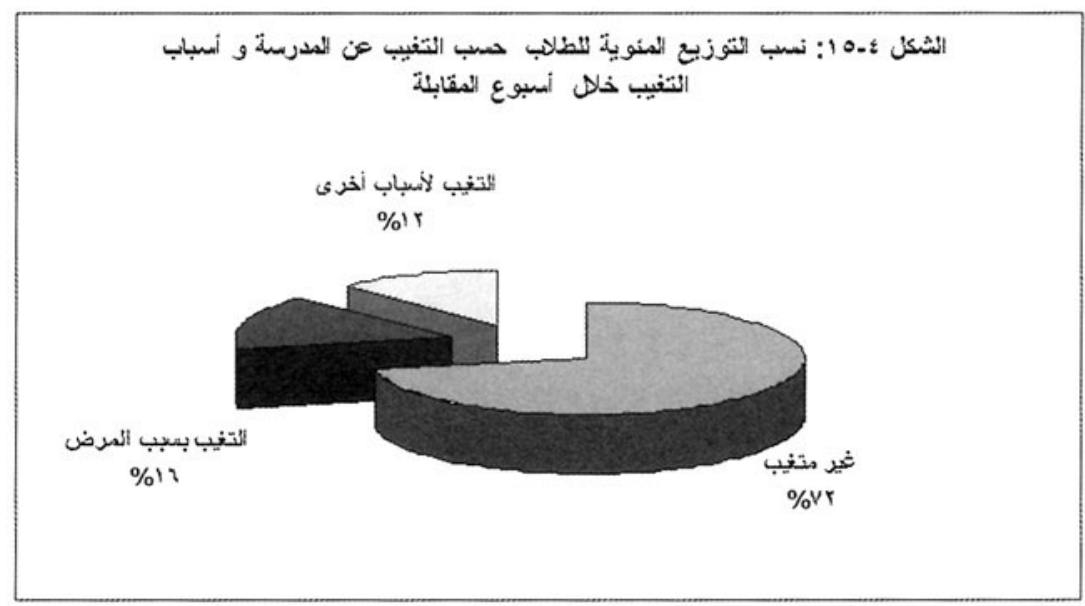

ب. الحالات المرضية الشائعة بين الطلاب

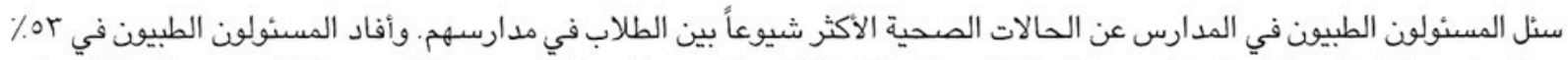

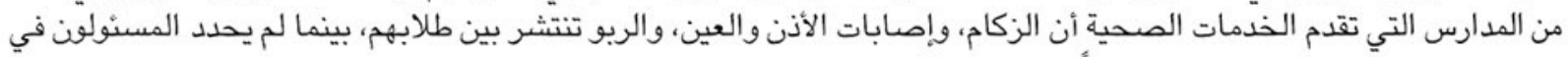

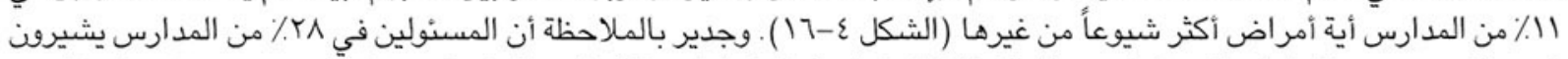

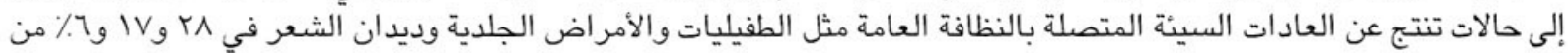

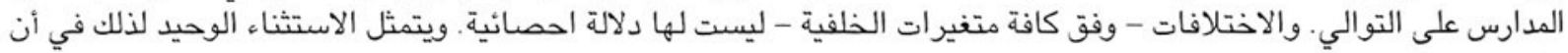

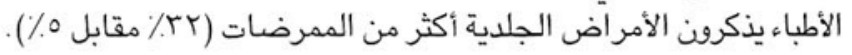

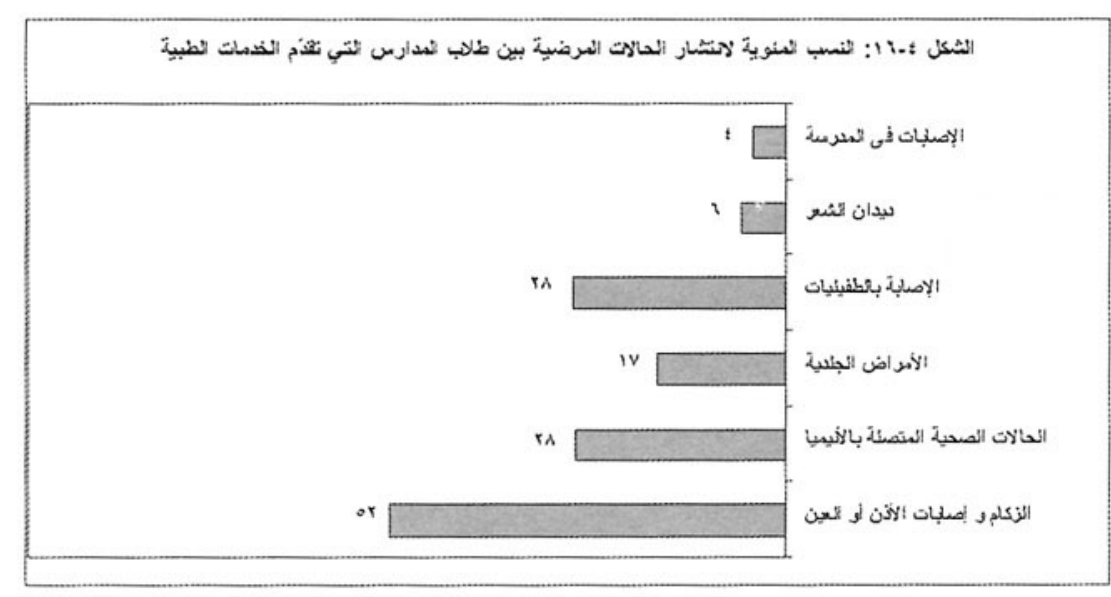

ج. المرافق الصحيدة

يناقش الفصل السادس بالتفصيل المرافق الصحية في المدرسة، وخاصة هدى توافر مياه الشرب والمراحيض. د. الرضا عن الحالة الصحية للطلاب و الصحة العامة في المدرسة

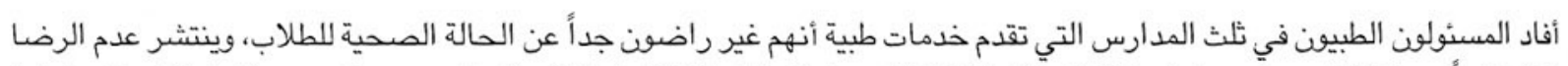

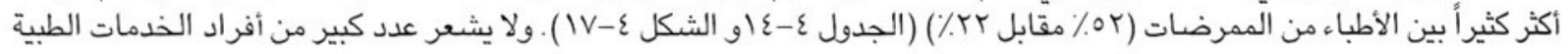

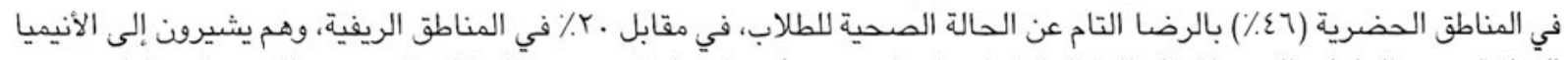

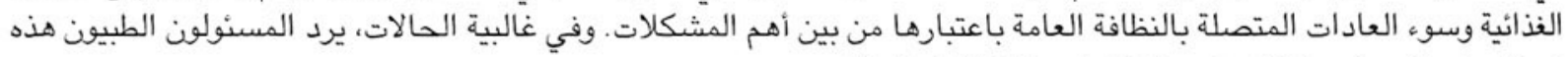

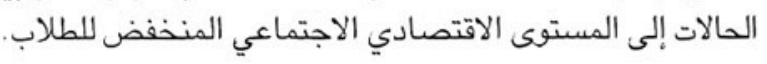




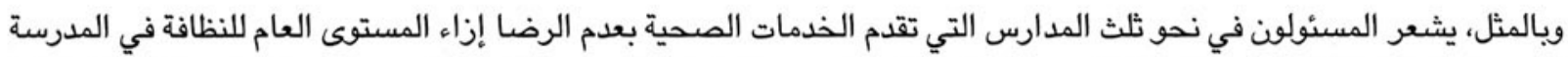

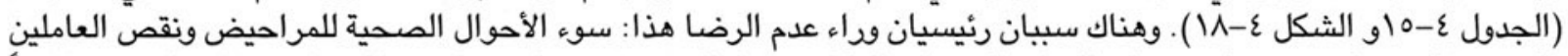

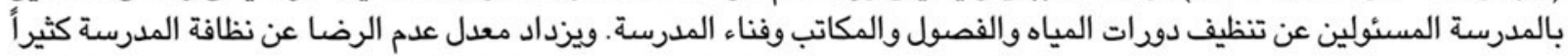

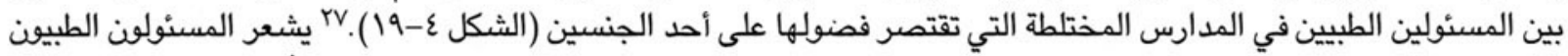

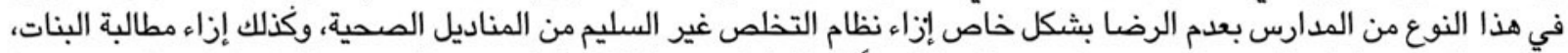

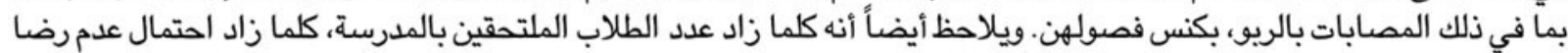

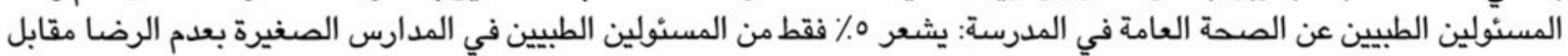

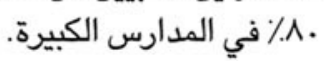
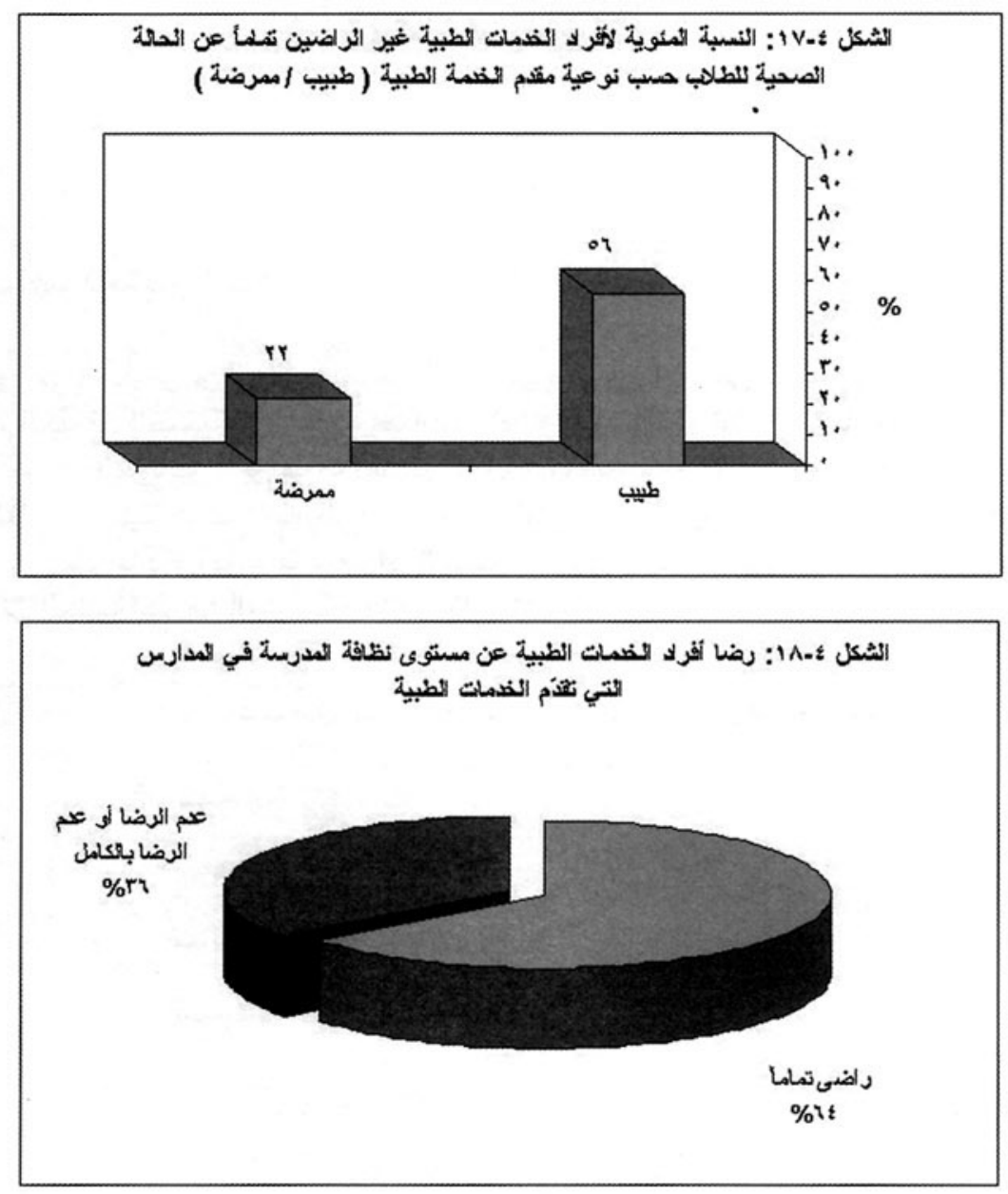

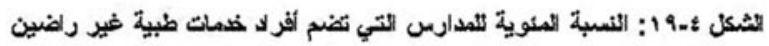

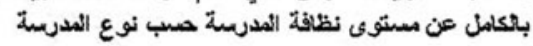

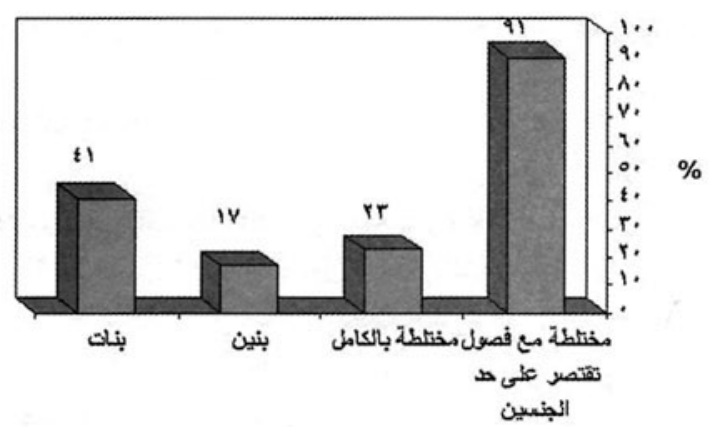

نوع المدرسة 


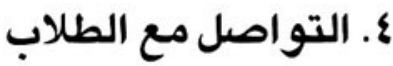

أ. أسئلة الطلاب حول الصحة العامة

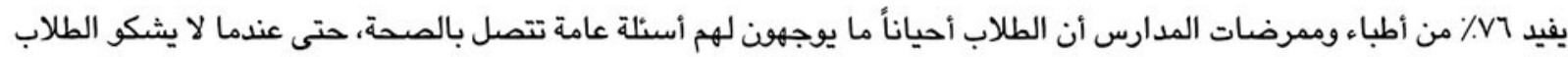

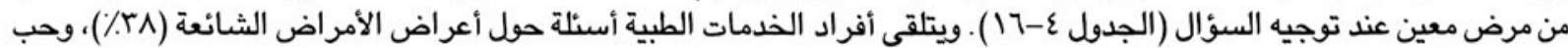

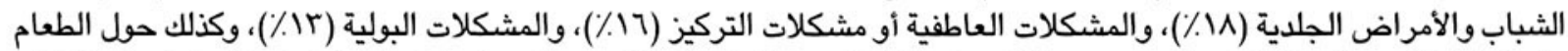

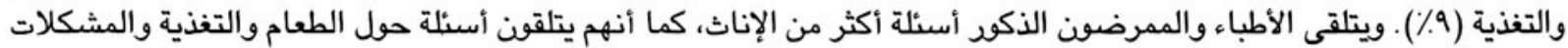
العاطفية/مشكلات التركيز أكثر من زملائهم من الإناث.

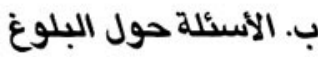

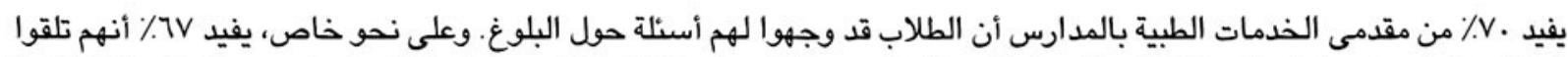

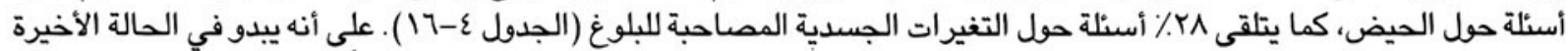

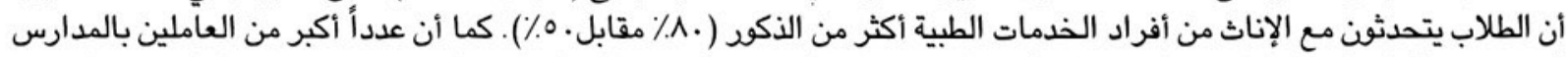

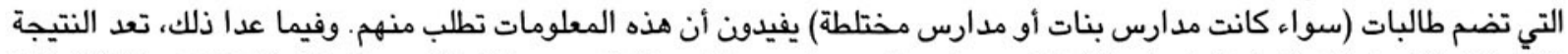

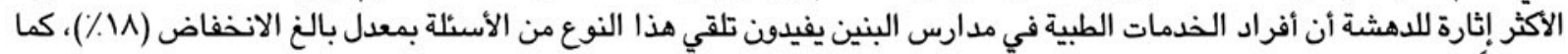

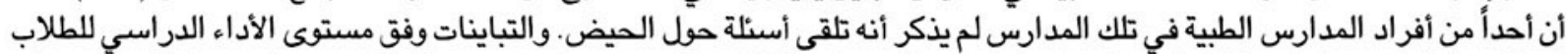

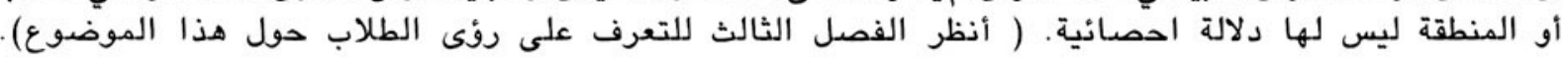

ج. الحاجة للإرشاد بشأن الحيض

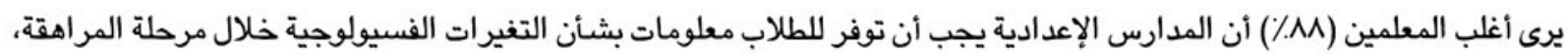

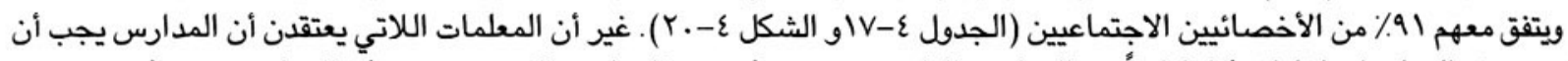

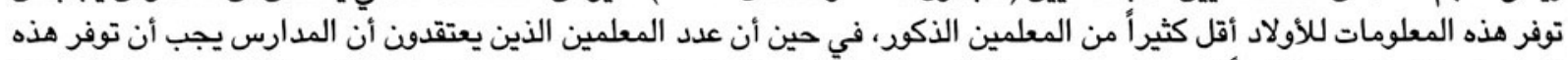

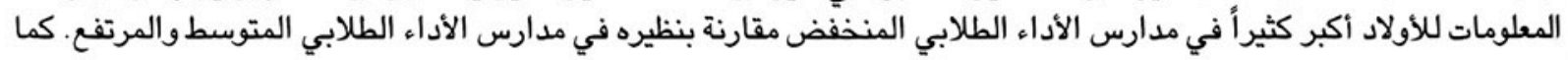

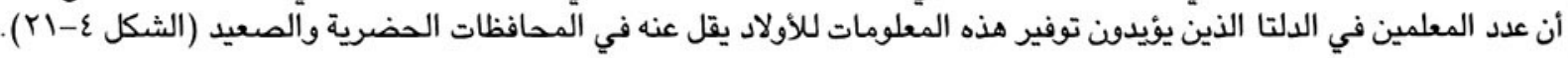

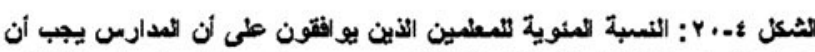

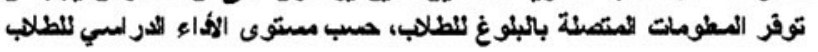

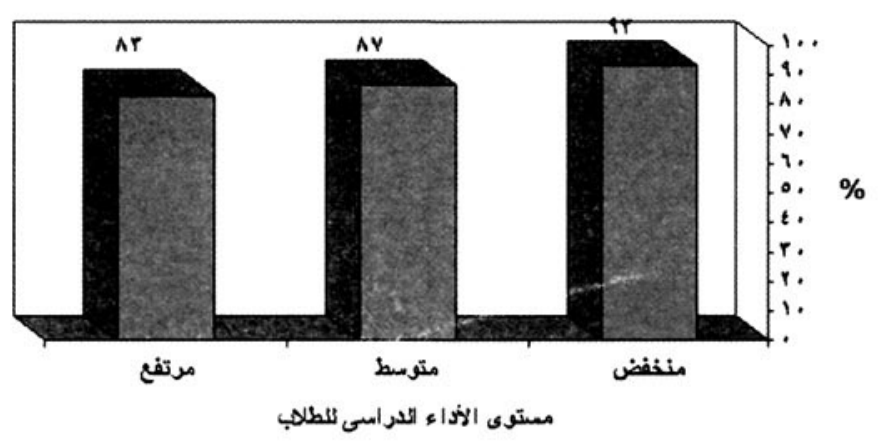




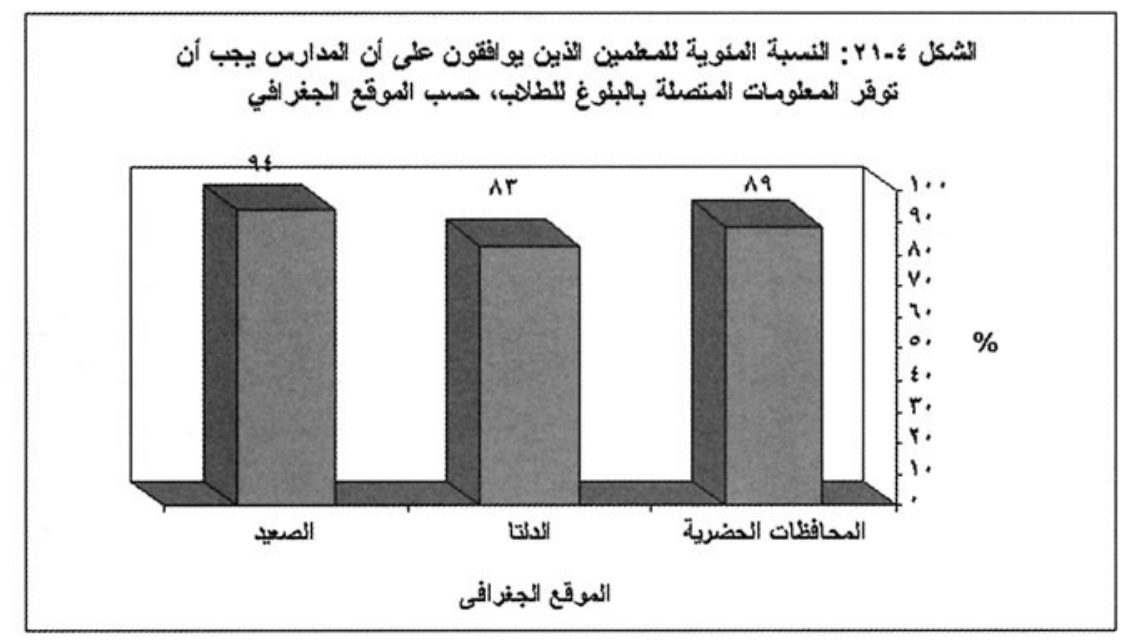

يخشى المعارضون لتوفير هذه المعلومات للطلاب أنها قد تشجعهم، وخاصة الأولاد منهم، على تعلم المزيد (من خلال الكتب أو أفلام

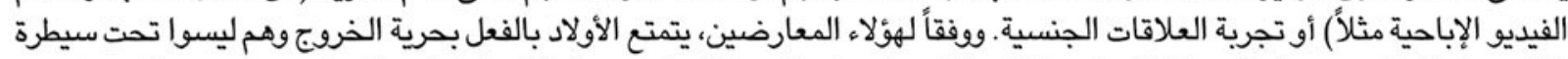

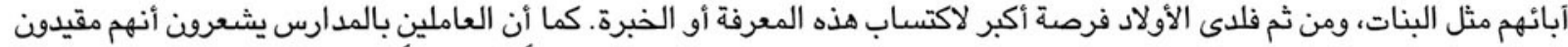

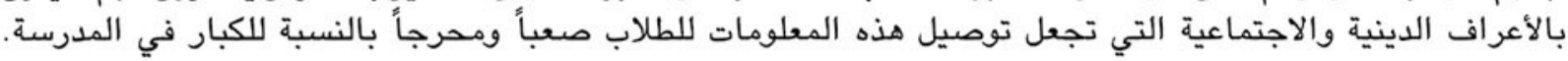

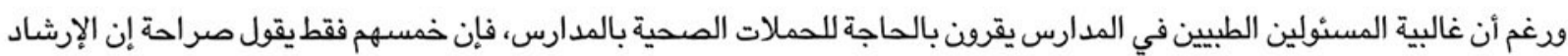

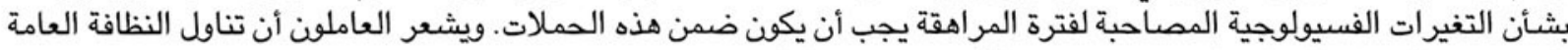
الشخصية والعادات الغذائية الصحية يفوق في الأهمية موضوع البرات البلوغ.

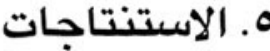

تظهر البيانات الحاجة الواضحة لحملات التوعية الصحية في المدارس. إن غلبة الممارسات الصحية السيئة (العادات الغذائية والممارسات

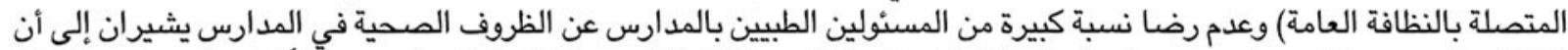

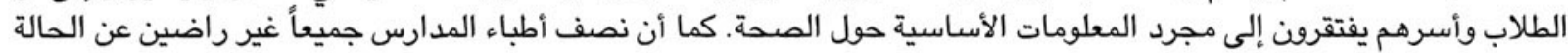

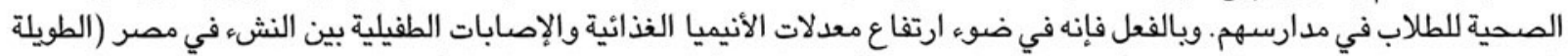

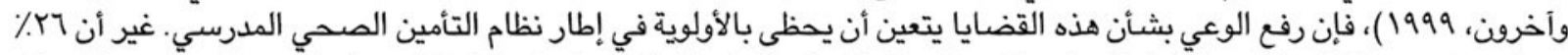

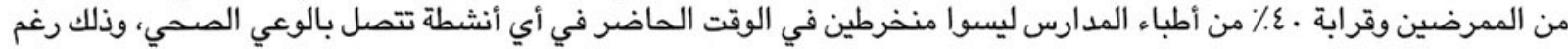
أن الغالبية الواسعة من المسئولين الطبيين يعتقدون أن الحاجة قائمة لتلك الأنشطة.

لا يستفيد جميع الطلاب من المسئولين الطبيين المتوفرين في المدرسة، كما أن أولئل الذين يلجأون إليهم ريما لا يحظون بعناية كبيرة.

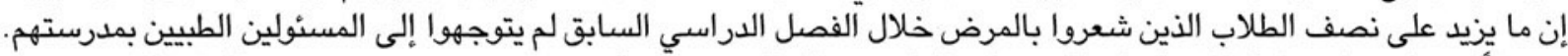

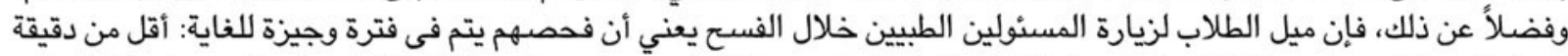

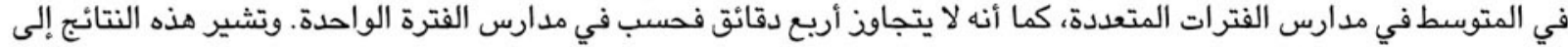

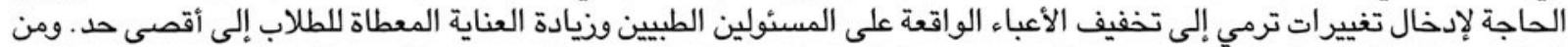
الواضح أن ثمة حاجة لمزيد من البحث من أجل زيادة هذا المورد المدرسي القيم إلى أقصى القيى حد ممكن.

يشعر المسئولون الطبيون في ثلث المدارس التي تقدم الخدمات الصحية بالرضا عن نظام التأمين الصحي المدرسي الذي ألفام أدخل مؤخراً

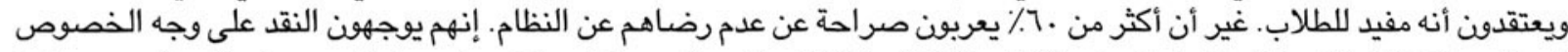

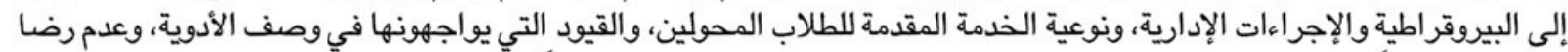

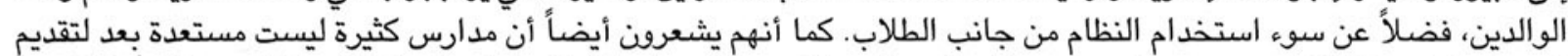

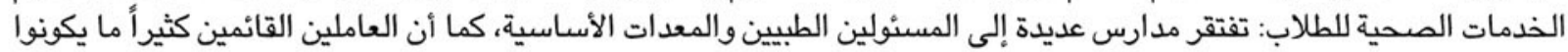

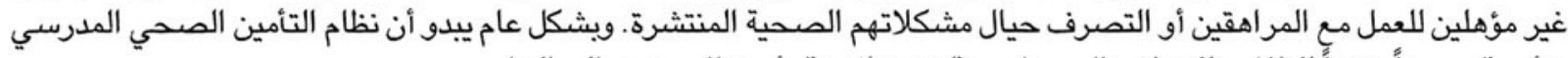
بدأ يمثل مورداً مفيداً للطلاب، لكنه لا يزال يحتاج، مثله في ذلك مثل أي نظام جديد، إلى التطوير. 
وتعكس البيانات المتوفرة بالفعل بعض هذه الانتقادات الموجهة للمرافق المدرسية والعاملين بها . فثلث المدارس لا لا تضم مسئولاً طبياً

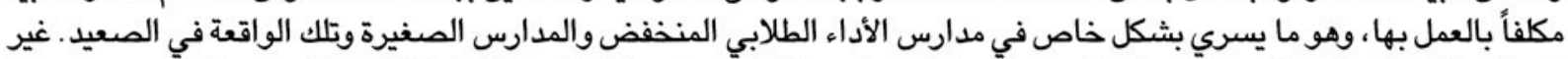

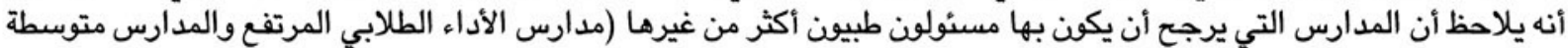
الحجم وتلك الواقعة في المحافظات الحضرية) تعاني من ارتفاع معدل الحيرنا التغيب بين هؤلاء المسئولين الطبيين.

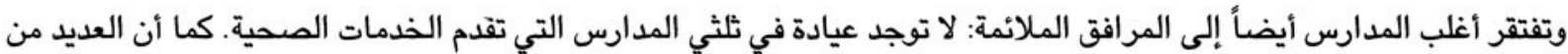

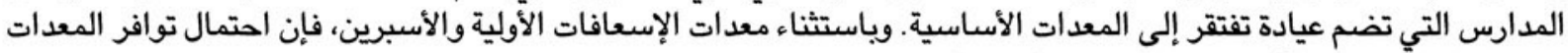

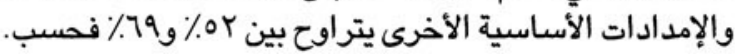

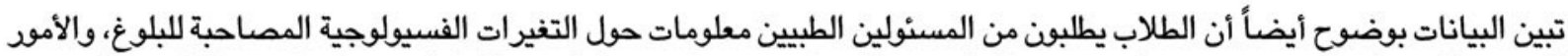

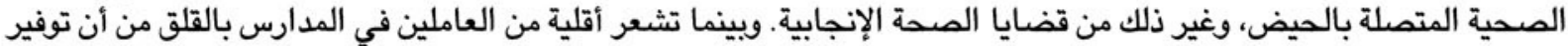

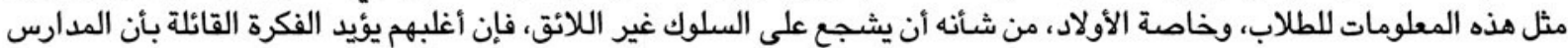

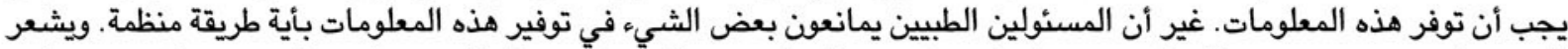

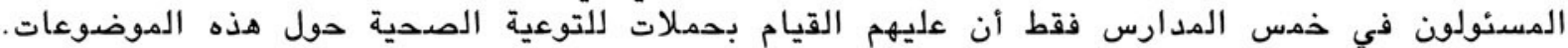




\section{الأبعاد المتصلة بالنوع في البيئة المدرسية}

1 ا مقدمة

يعرف كل الذين التحقوا بالمدارس أن النوع واحد من أهم المحاور التي تنظم وتتميز حولها هذه التجرية. فعلى أكثر المستويات أولية،

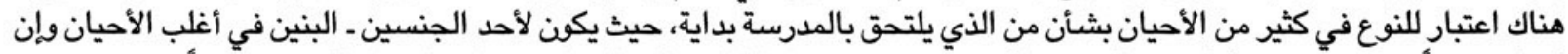

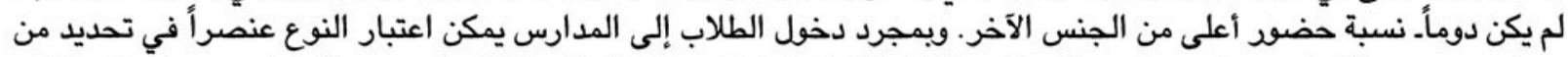
سيتسرب من التعليم ومتى، ونوع المواد والأنشطة المتوفرة، وطريقة المعاملة على يد العاملئ العتين، وما إلى ذلك الك.

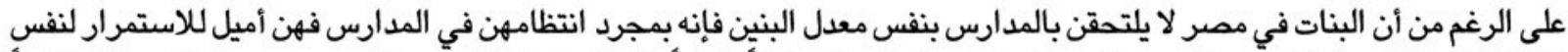

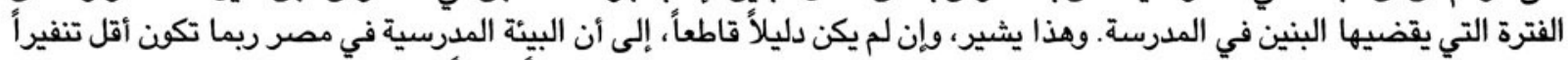

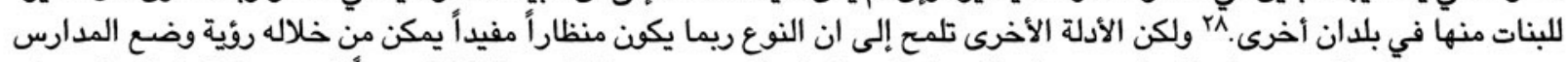

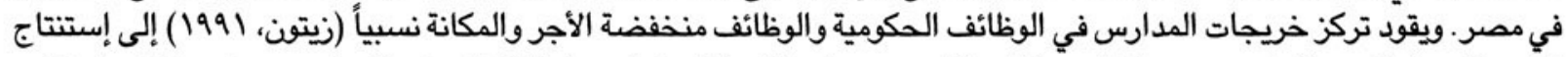

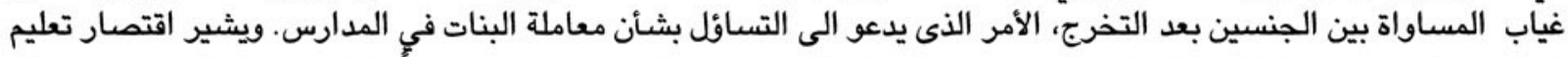

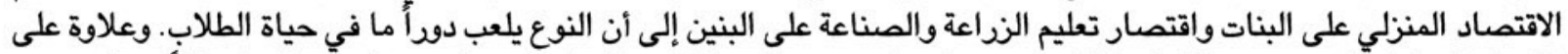

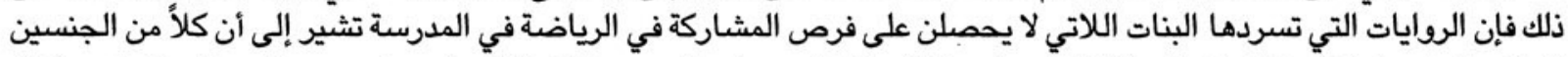

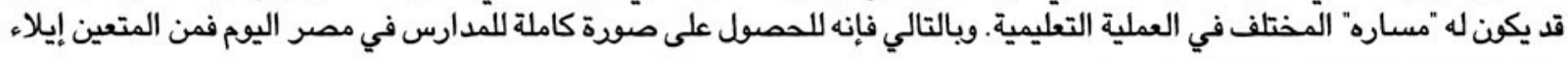
بعض الاهتمام للنوع في البيئة المدرسية.

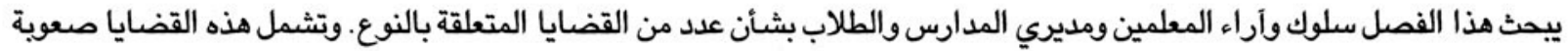

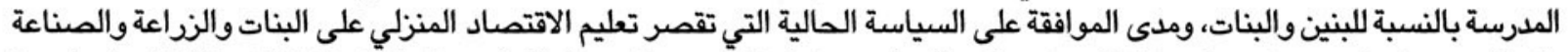

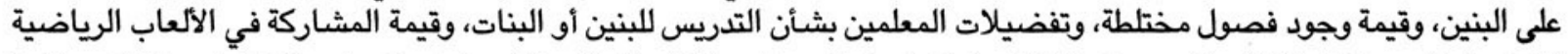

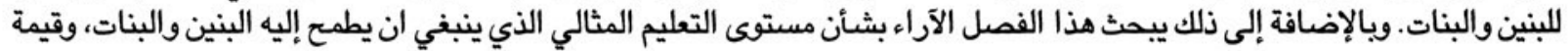

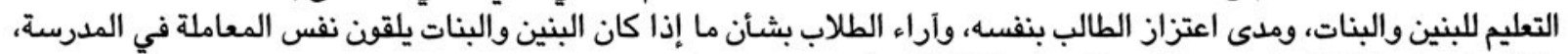
وإذا لم يكن الحال كذلك فمن هم الذين يلقون المعاملة الأفضل.

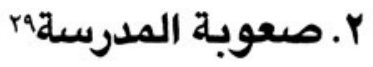

أ. مديرو المدارس

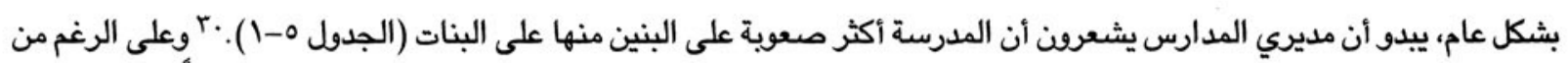

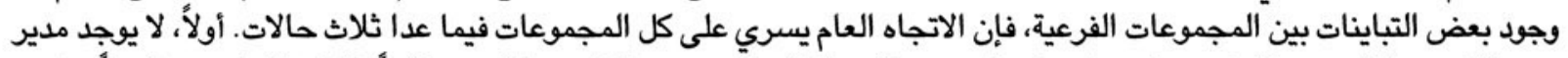

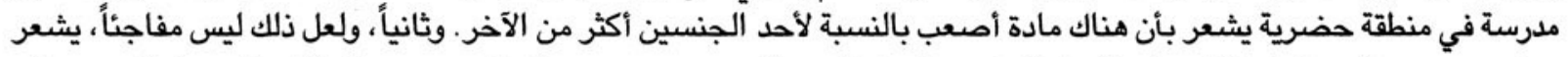

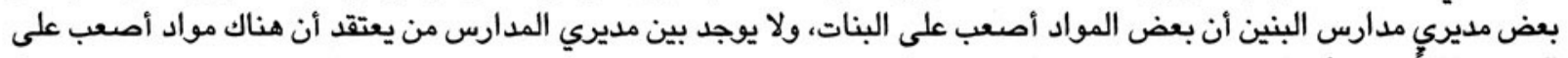

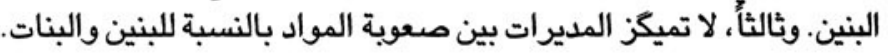

وسئل المديرون الذين يعتقدون ان المدرسة أصعب بالنسبة لأحد الجنسين مقارنة بالآخر عن المواد التي يشعرون أنها الأصعب ولأي الماني

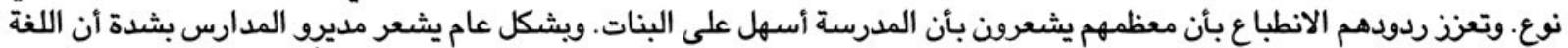

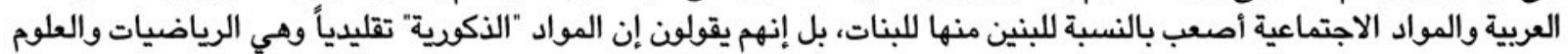

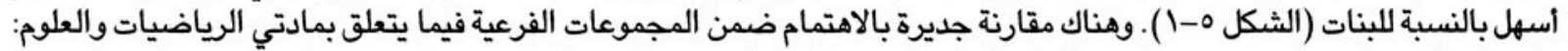

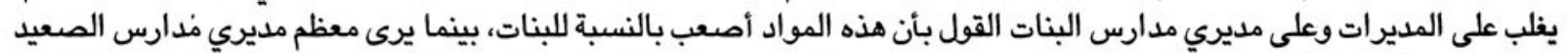

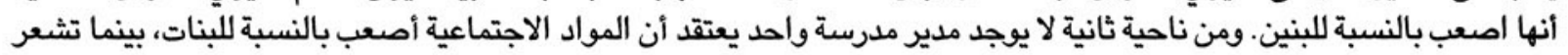

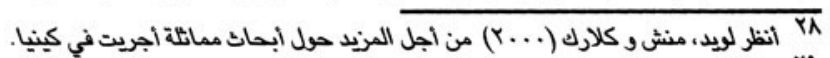

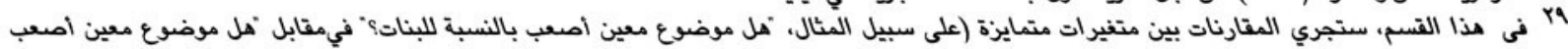

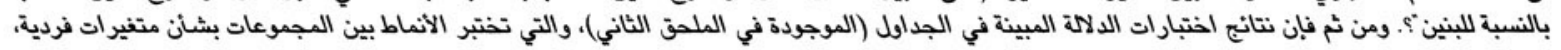

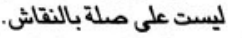

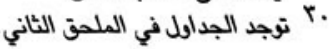


غالبية كبيرة من المديرين أن مادة اللغة العربية أصعب بالنسبة للبنات إلا في ثلاث حالات انقسمت فيها الآراء: مديرو مدارس البنين

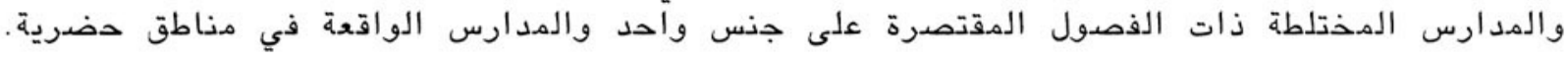

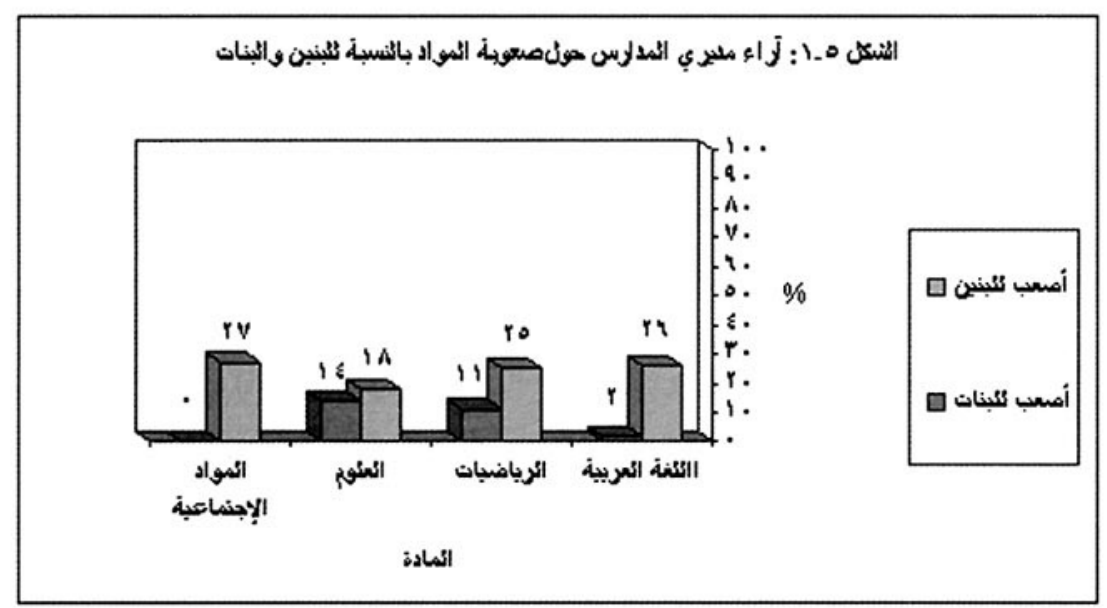

ب. ب المعلمون

سئل المعلمون بشأن صعوبة المواد التي يدرسونها للبنين والبنات. ويشعر المعلمون شأنهم في ذلك شأن المديرين بأن المواد الدواد الدراسية

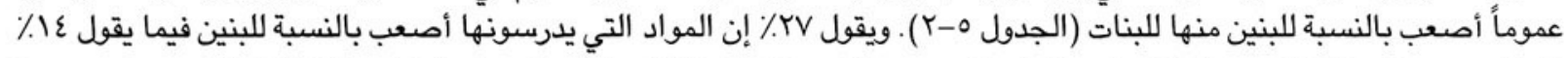

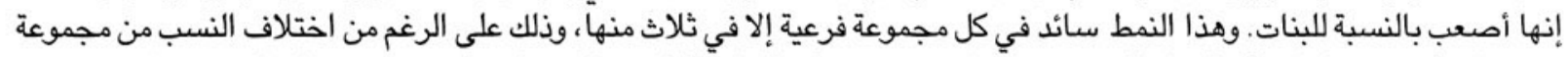

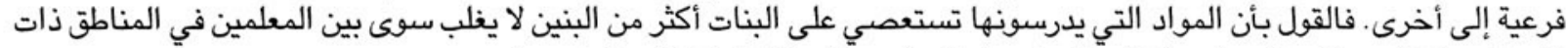

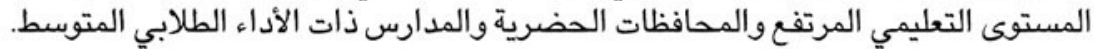

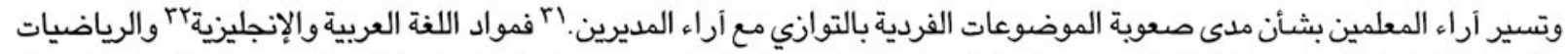

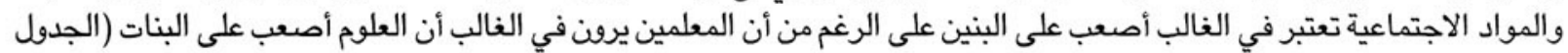

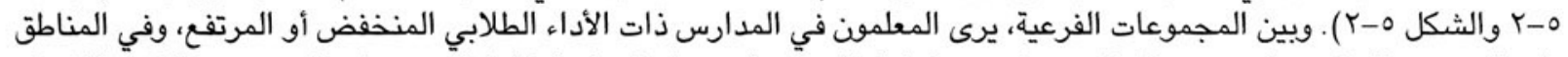

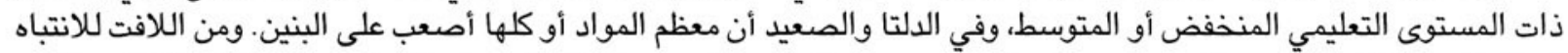

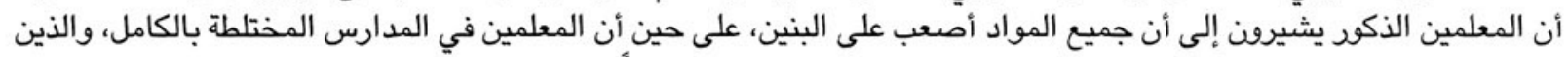

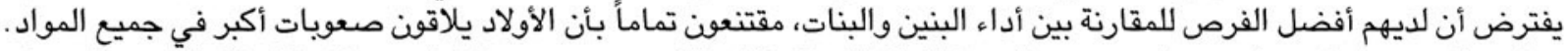

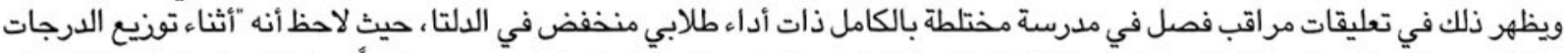
خلال حصة رياضيات، قال المعلم للفصل أن البنات أفضل من البنين. لقد ذكر أن أداءهن جيد دائماً ويشاركن في أنشطة الفصل الفيل.

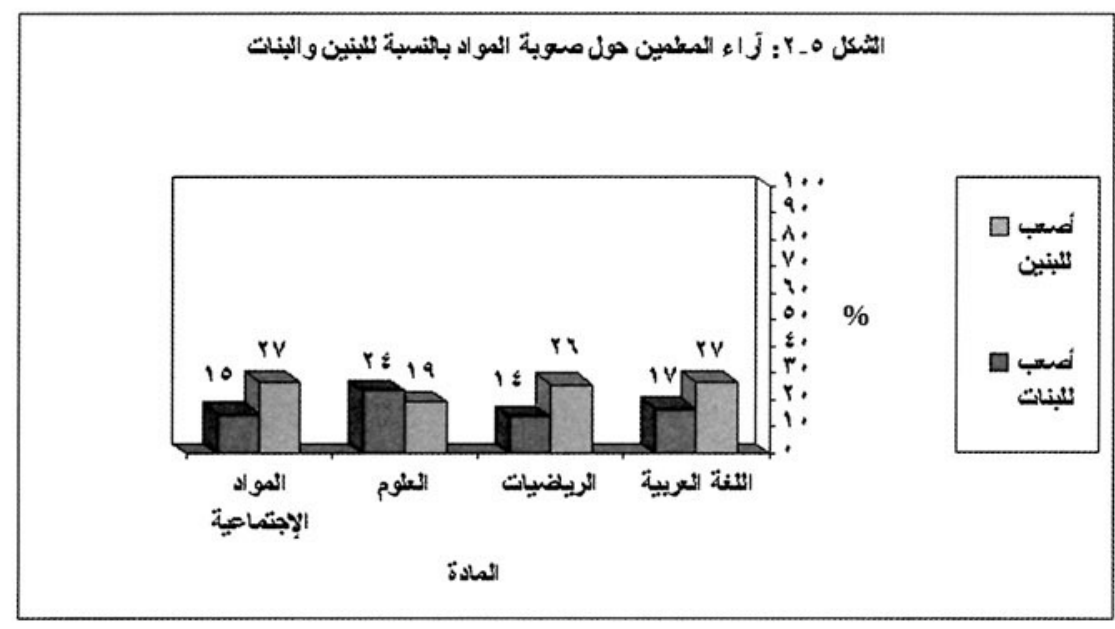

اب يتعين أن نلاحظ مع ذلك أن معلمي المادة المعينة فقط سئلوا عن مدى صعوبتها. أي أن الإجابات حول اللغة العربية جاهت من مدرسي اللفة العربية فقط، والإجابات

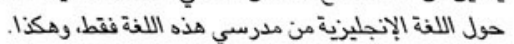

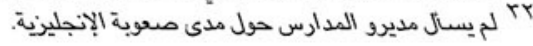




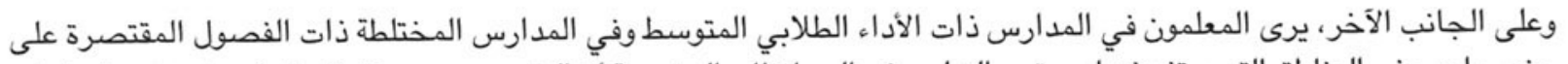

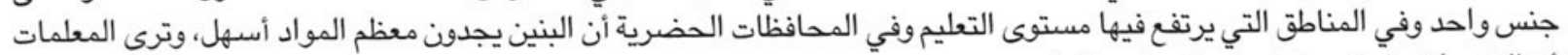
أن البنين أفضل في مادتي الزياضيات والعلوم.

\section{r. آراء العاملين حول قضايا مختارة تتصل بـالسياسات}

أ. السياسة الحالية المتعلقة بتدريس الاقتصاد المنزلي و الزر اعة والصناعة

تنص السياسة الحالية لوزارة التعليم على قصر تعليم الاقتصاد المنزلي على البنات فحسب بينما يتعلم البنين الزراعة والصناعة. وسئل مديرو المدارس والمعلمون عما إذا كانوا يؤيدون هذه السياسة التحاست

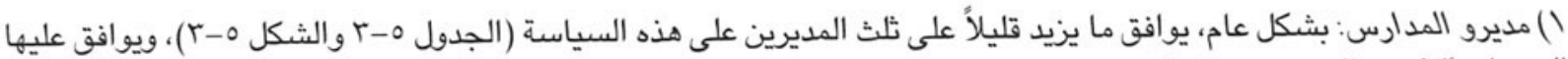

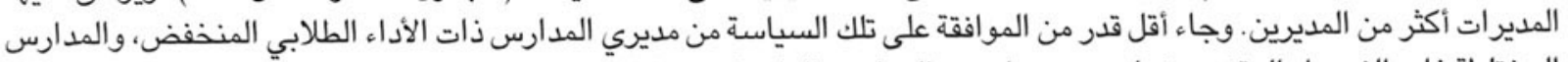

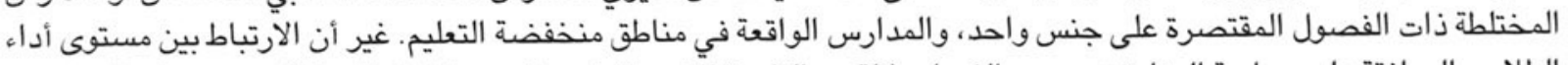

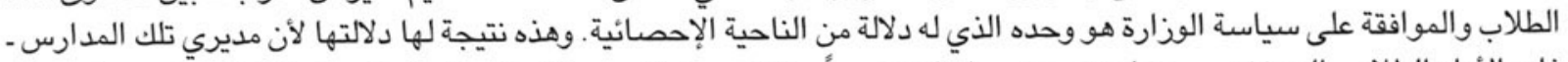

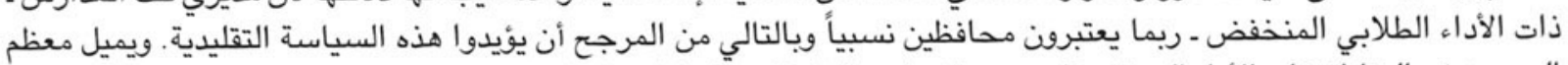

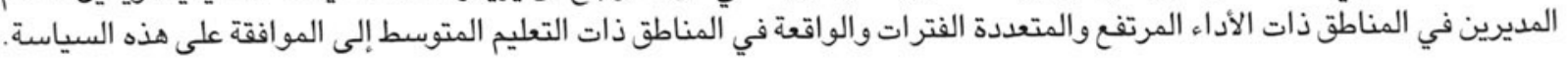

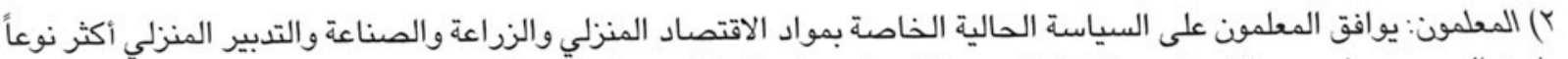

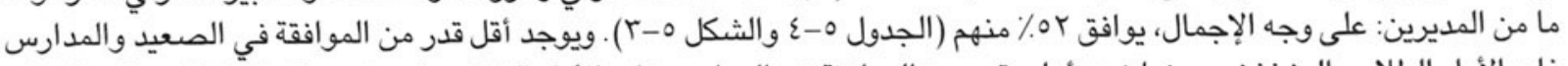

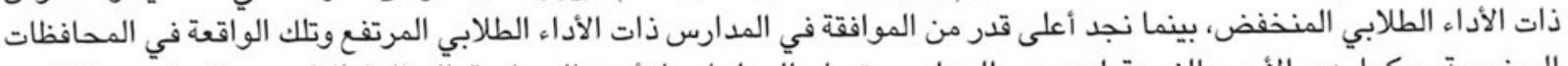

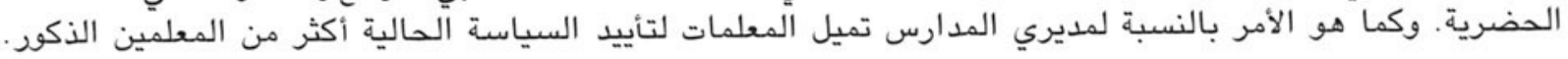

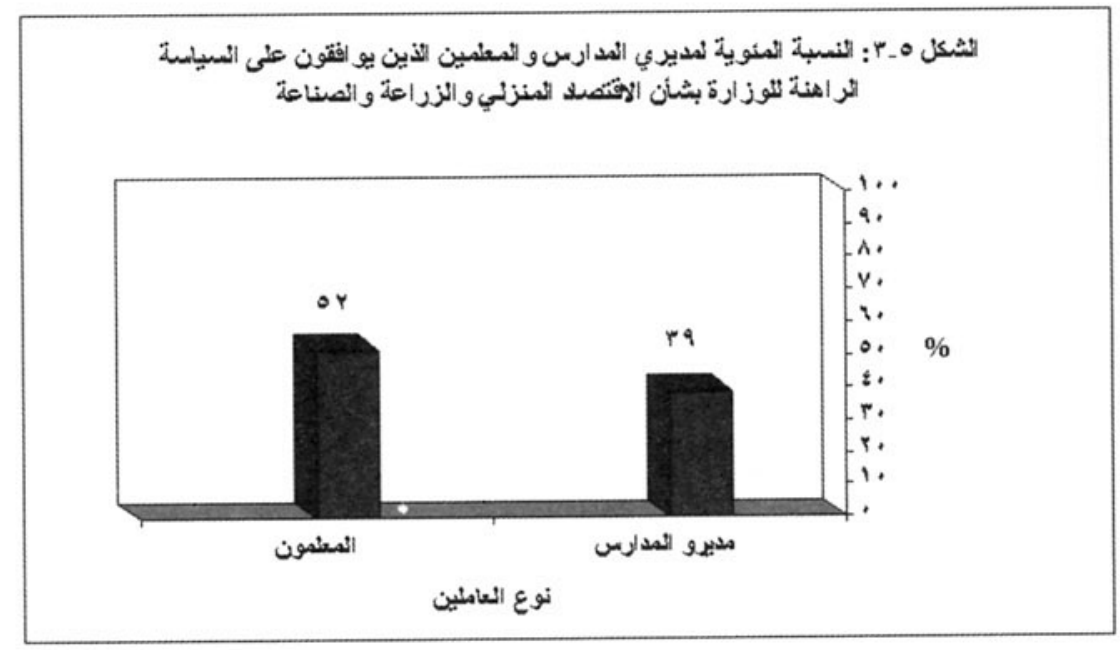

ب. الفصول المختلطة

(ا) مديرو المدارس: يعتقد نصف مديري المدارس تقريباً أن طلاب المرحلة الإعدادية يتعلمون بصورة أفضل في الفصول المختلطة

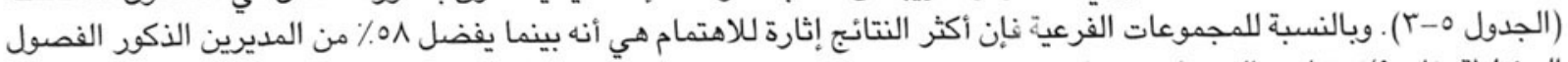

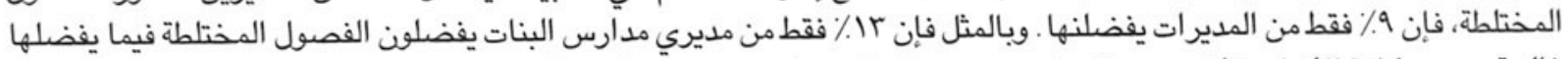

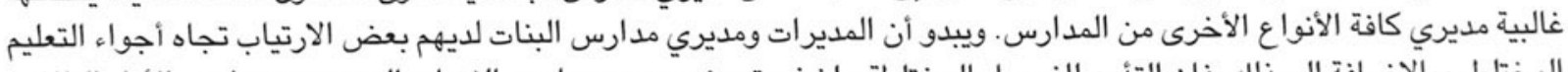

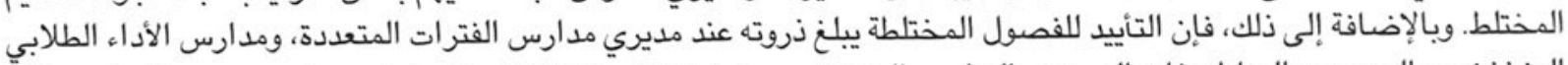

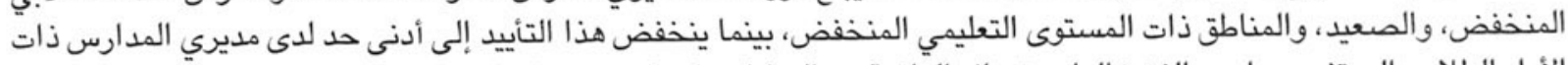

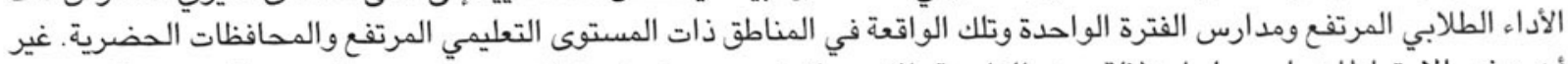

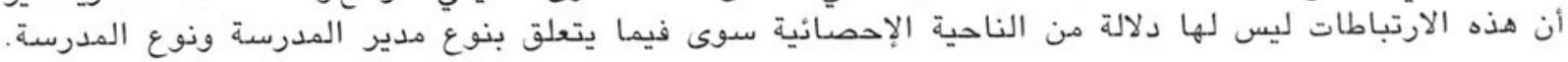




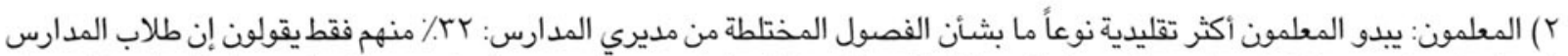

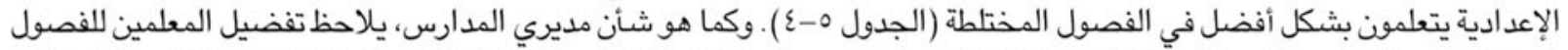

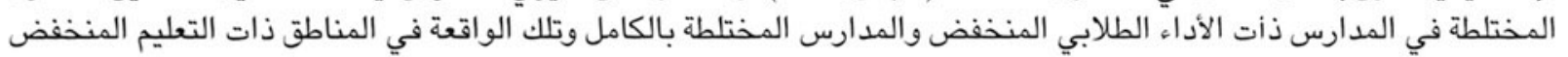

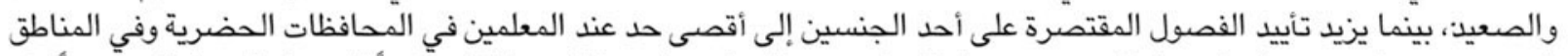

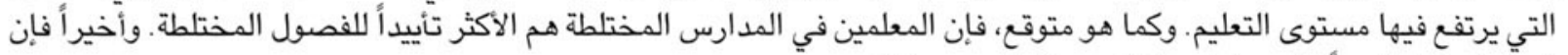

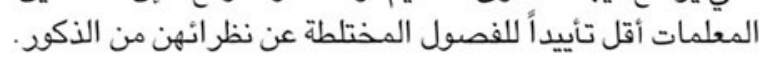

\section{ع. المفاضلة بين تدريس البنات و البنينrr}

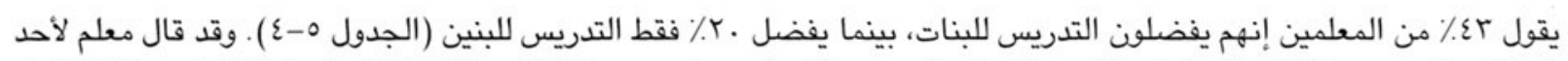

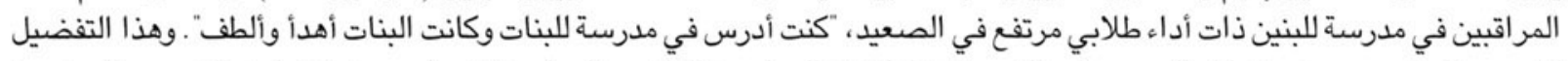

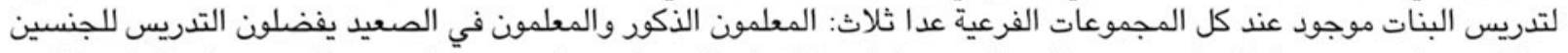

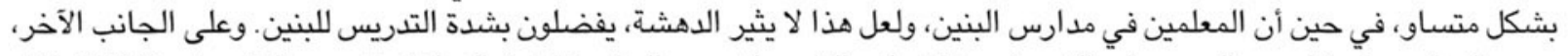

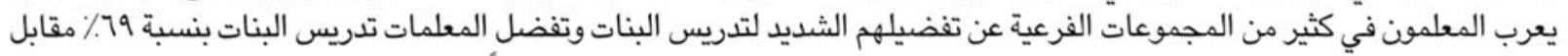

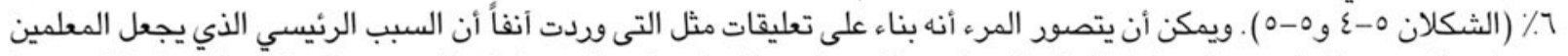

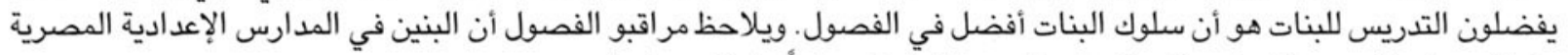
مشاغبين في كثير من الأحيان ولا يمكن ضبطهم، بينما البنات عادةً هادئات ومؤدبات.
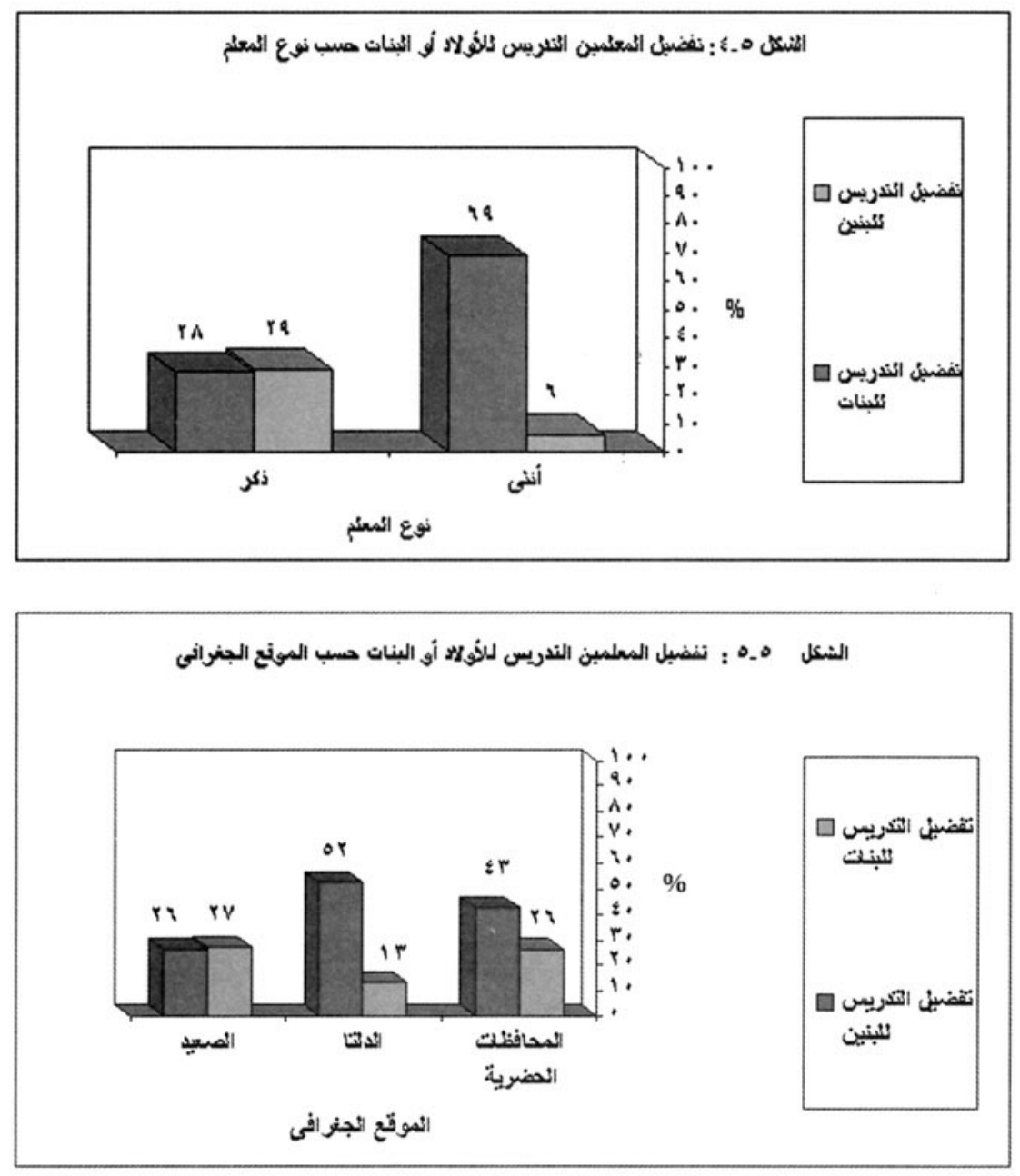

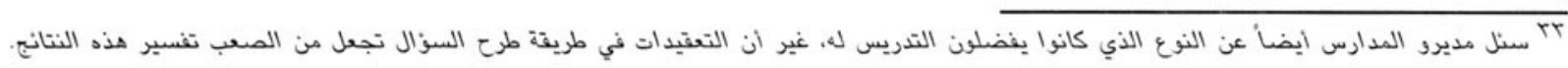




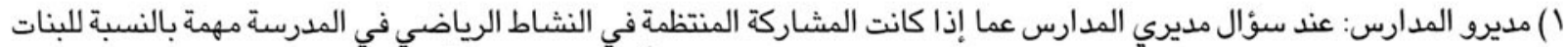

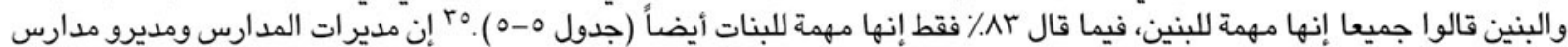

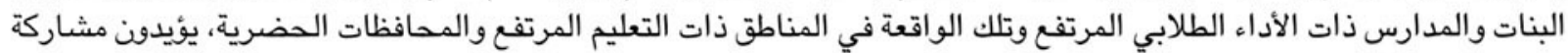

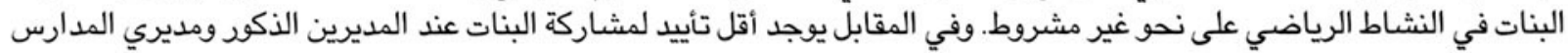

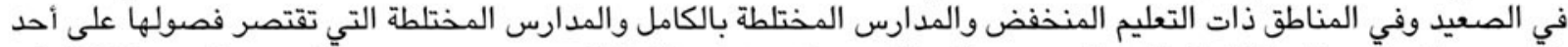

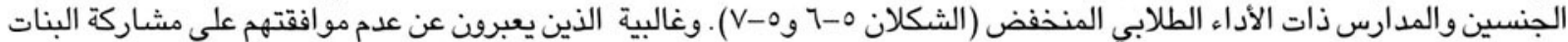
في النشاط الرياضي يشيرون إلى أن معارضتهم تعود إلى أسباب تتصل بالحشمة.
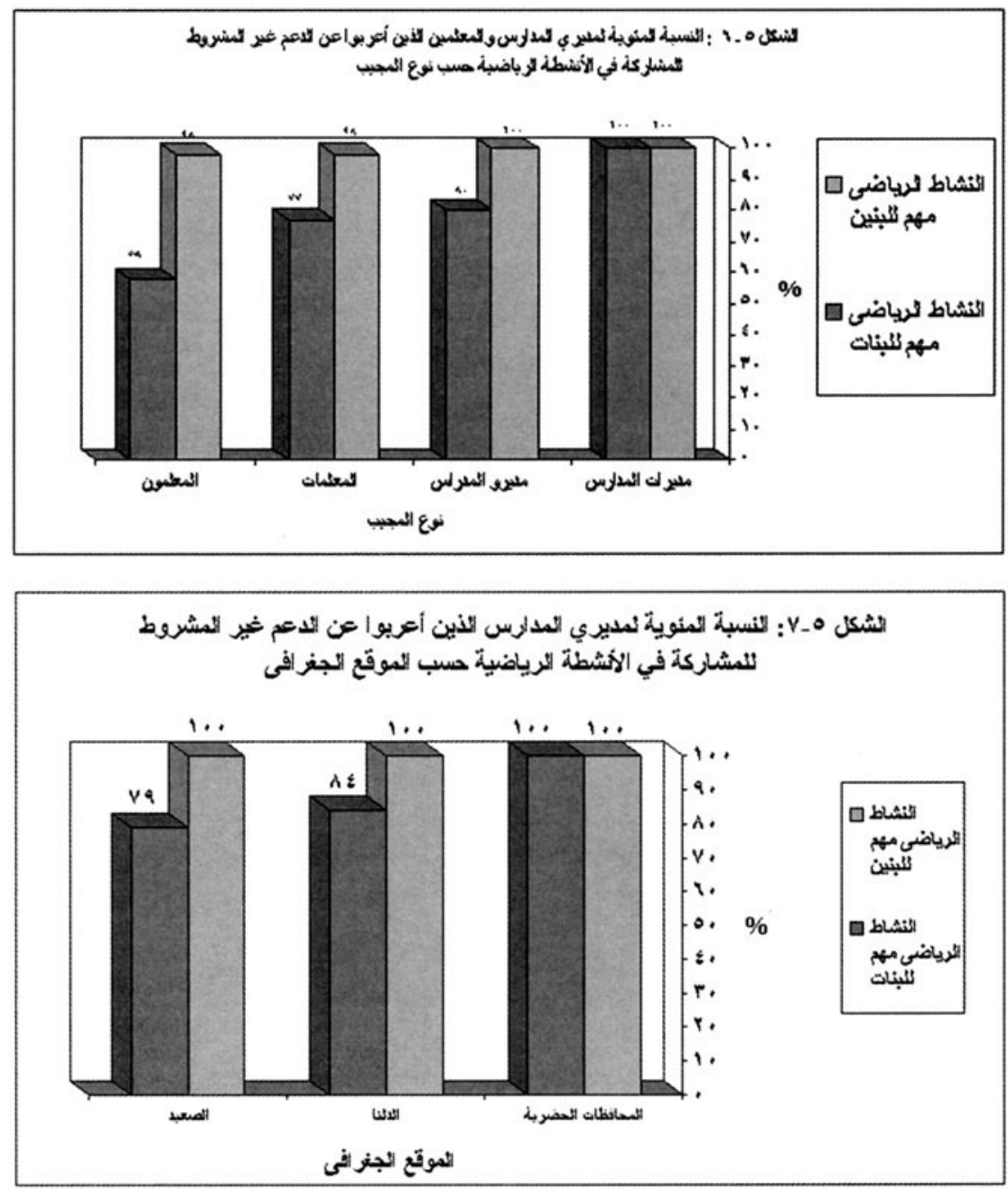

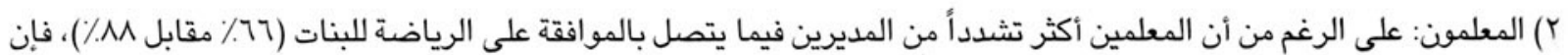

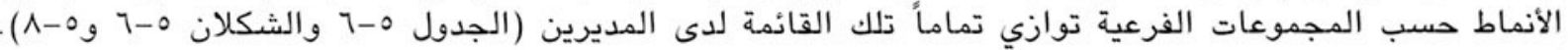

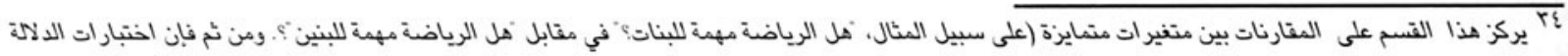

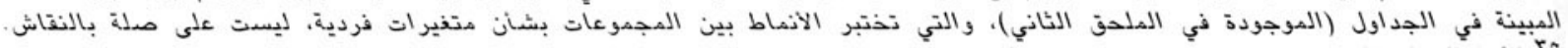

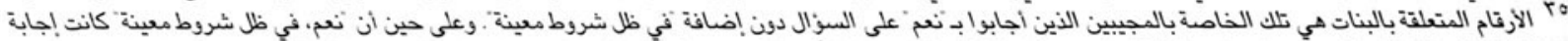

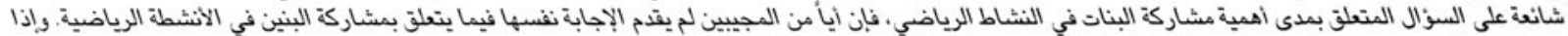

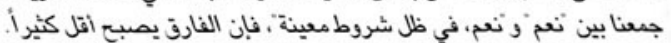




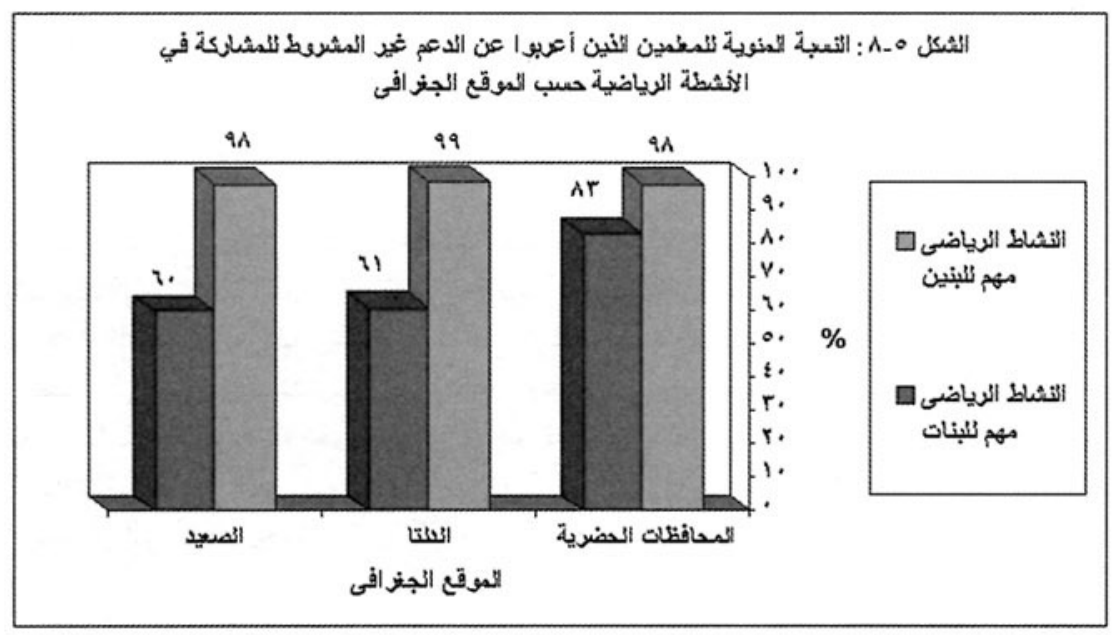

ب. قيمة الرياضة

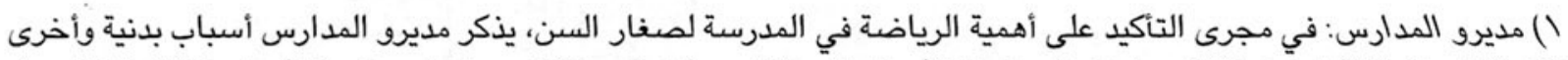

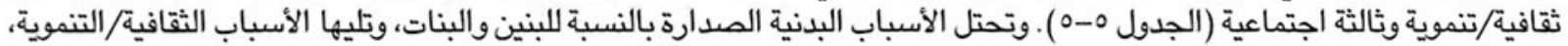

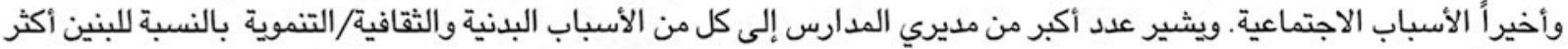
من البنات.

r) المعلمون: يرى المعلمون أن الفوائد البدنية للمشاركة الرياضية هي الأهم بالنسبة للجنسين، تليها الفوائد الثقافية/التنموية، وأخيراً

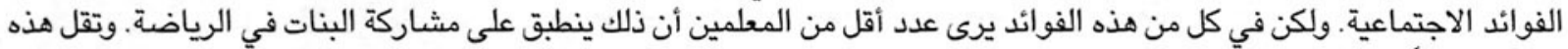

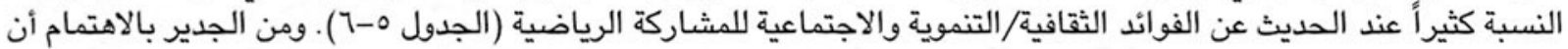

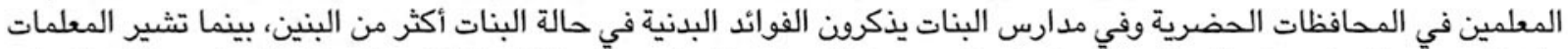

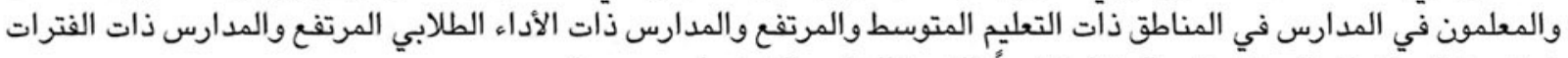
المتعددة إلى الفوائد البدنية بنفس المقدار تقريباً بالنسبة للبنات والبنين على حد سوات البراء.

\section{T. المستوى المثالي للتعليم وقيمته}

سئل مديرو المدارس والمعلمون والطلاب عن القسط الأمثل للتعليم الذي يتعين أن يحصل عليه البنون والبنات وقيمة التعليم لكل من الجنسين.

\section{أ. المستوى المثالي للتعليم}

() مديرو المدارس: إجمالاً، يعتقد 9٪ فقط من مديري المدارس أن على البنين أو البنات أن يتوقفوا عن التعليم عند المستوى الثانوي

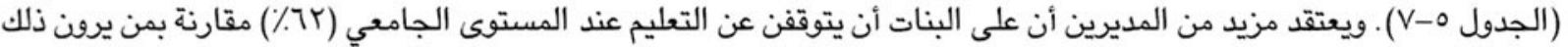

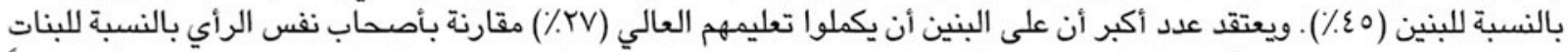

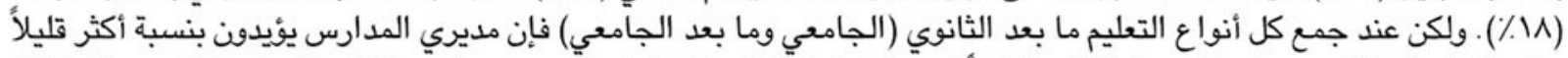

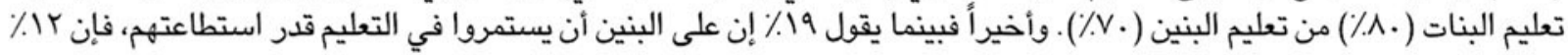
يقولون الشيء نفسه عن البنات.

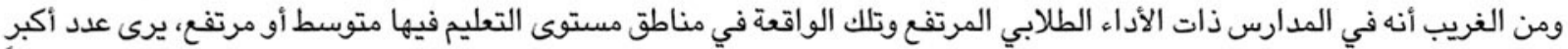

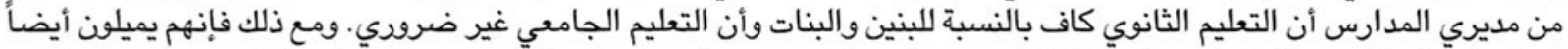

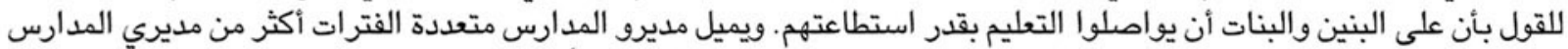

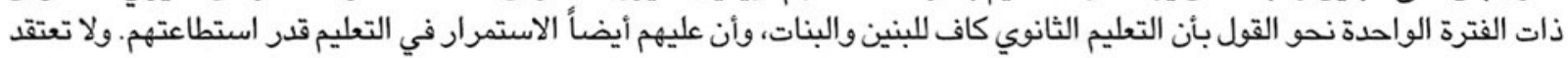
أي مديرة مدرسة أن التعليم الثانوي كاف للبنين أو البنات، وإن لم تكن لهذه النتيجة دلالة من الناحية الإحصائية. 


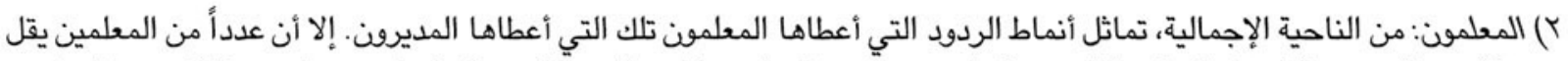

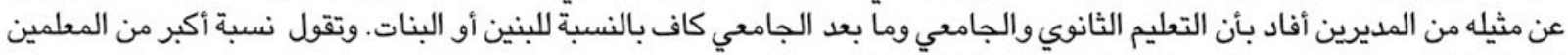

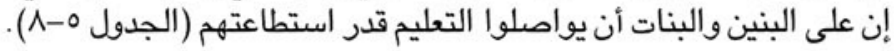

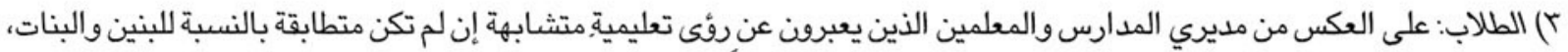

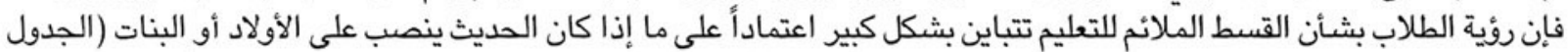

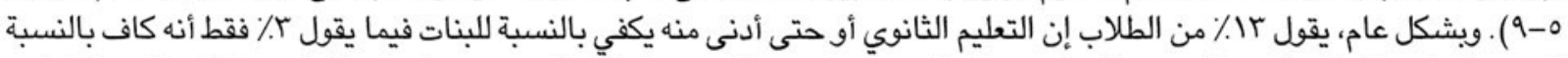

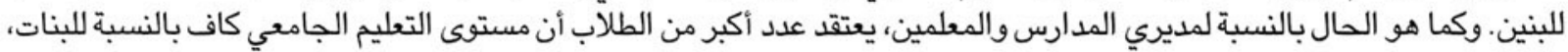

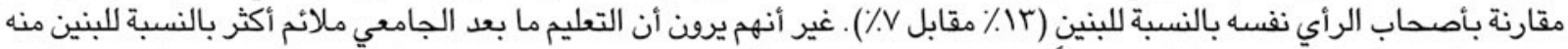

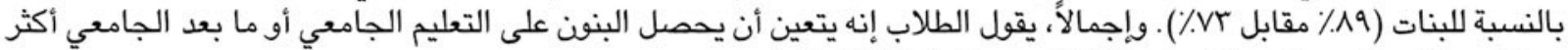

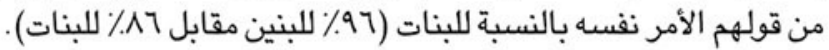

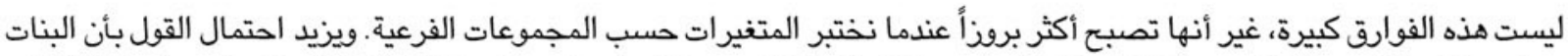

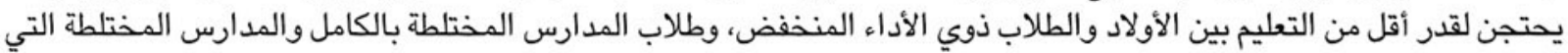

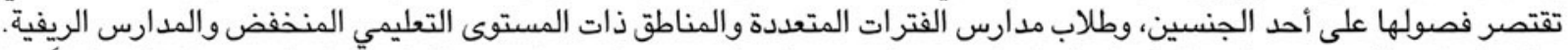

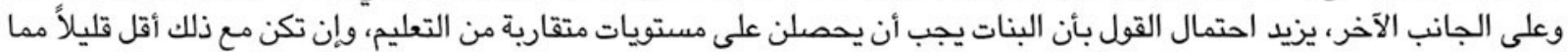

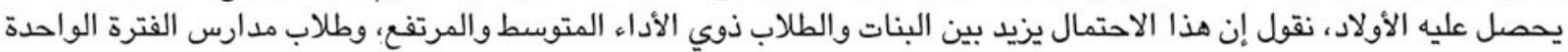

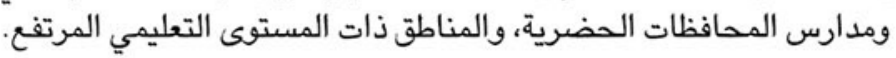

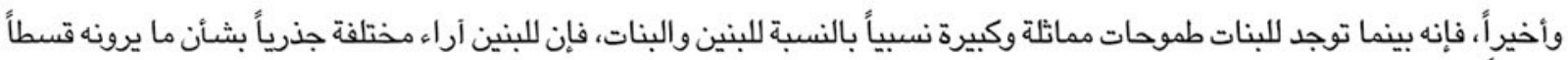

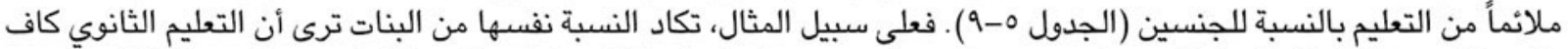

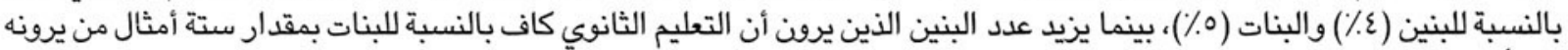

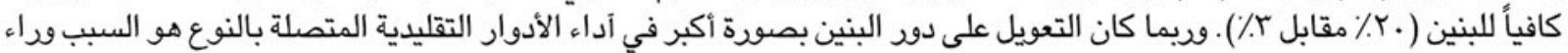

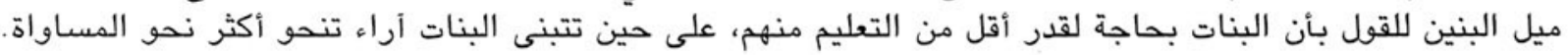

ب. قيمة التعليم

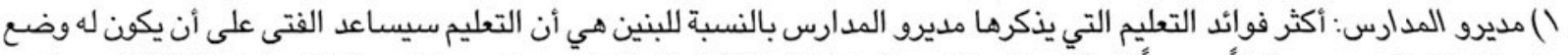

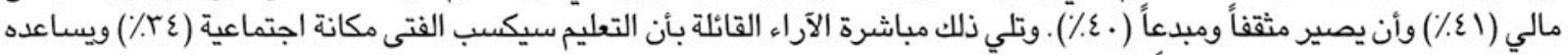

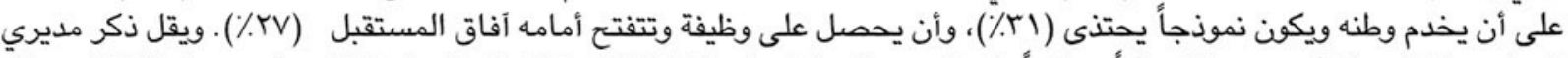

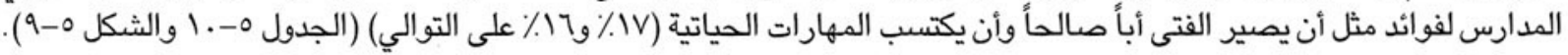

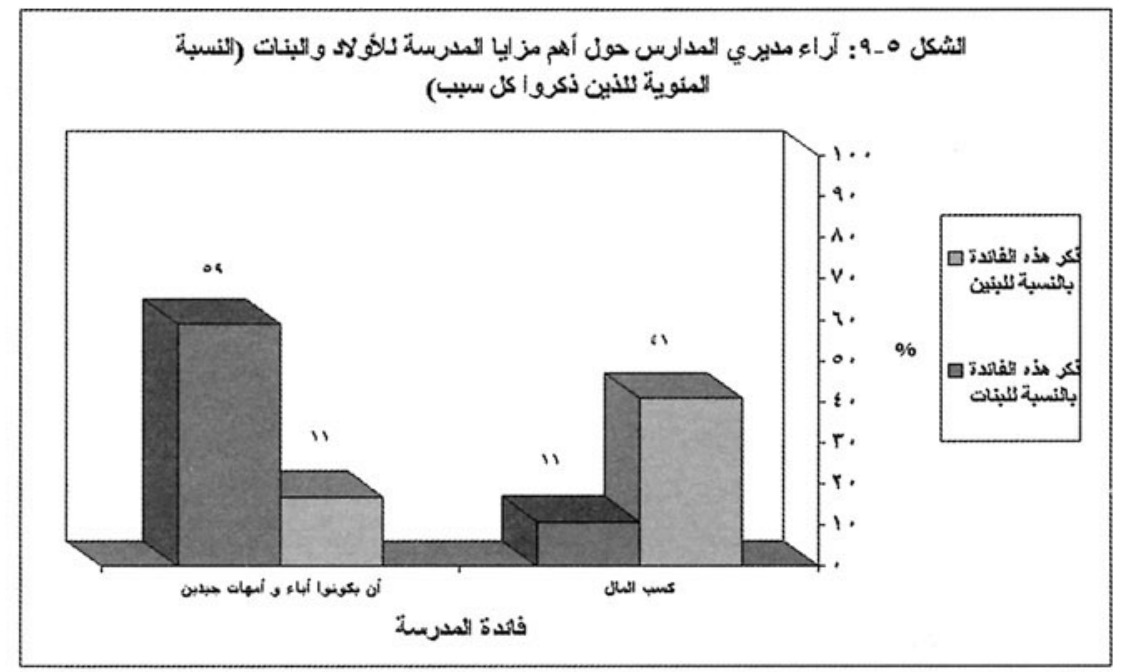

ويرد ذكر مديري المدارس لفوائد معينة للتعليم بنفس القدر تقريباً بالنسبة للبنات والبنين، وهو الأمر الذي يسري على اكتساب المهارات

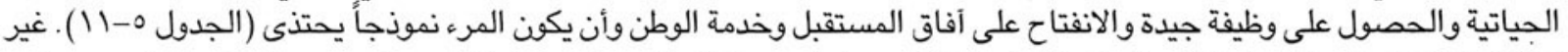

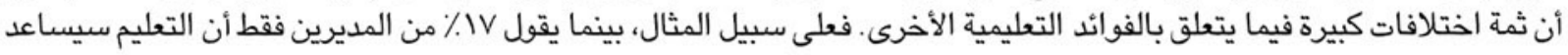




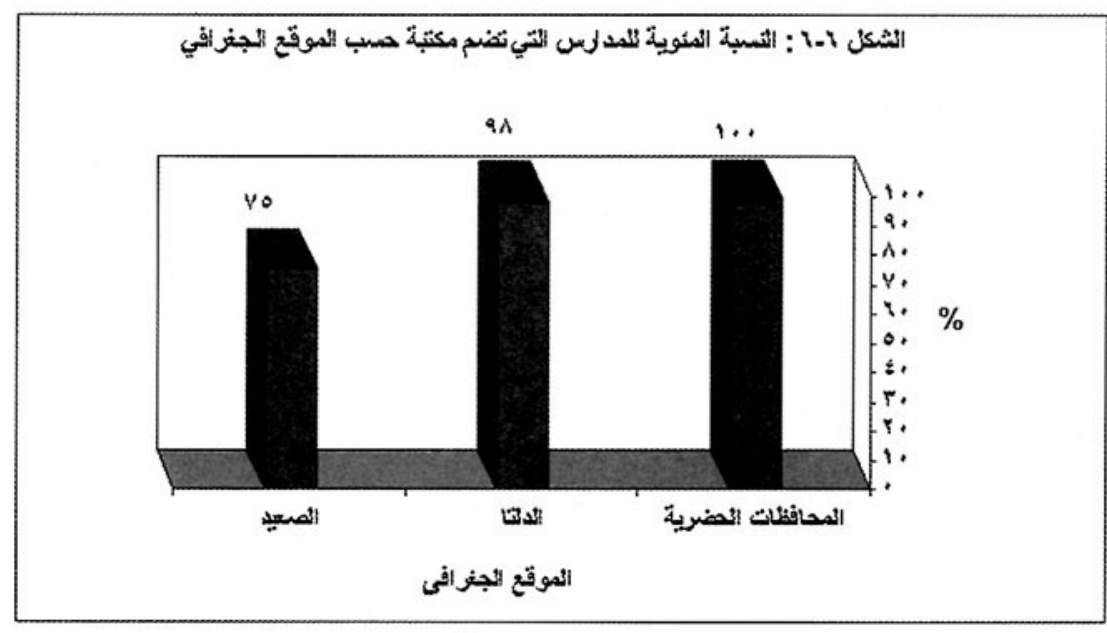

د. التقنيات الأخرى

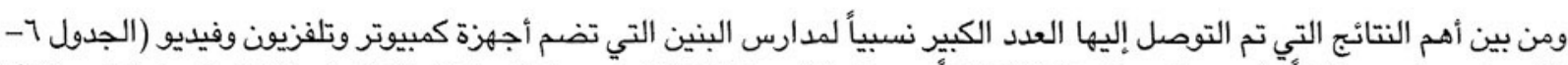

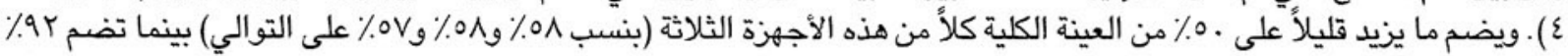

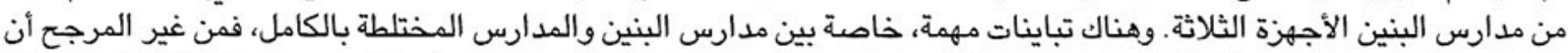

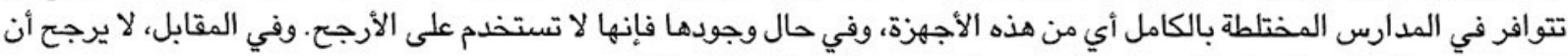

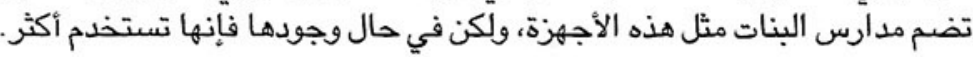

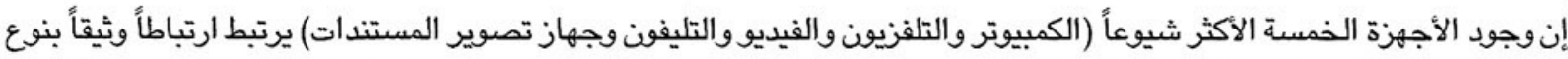

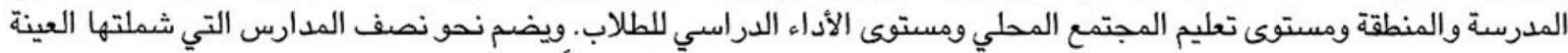

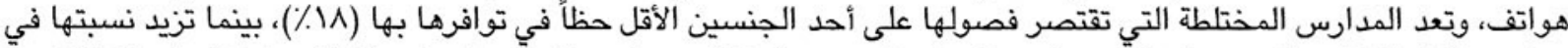

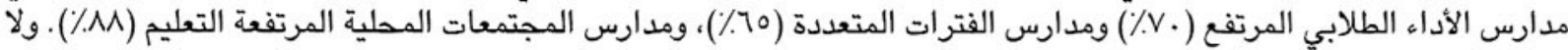

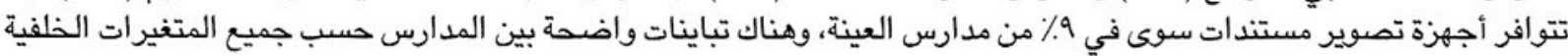

فيما عدا المنطقة.

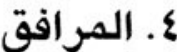

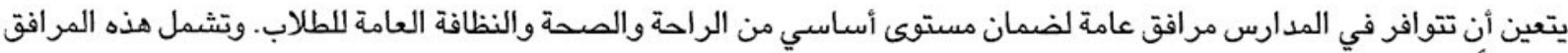

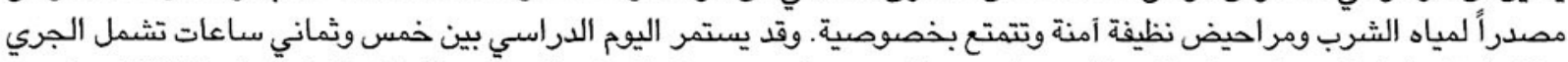

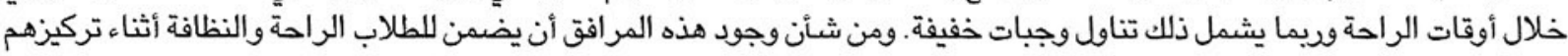

على الدروس.

\section{أ. مياه الشرب و الصنابير}

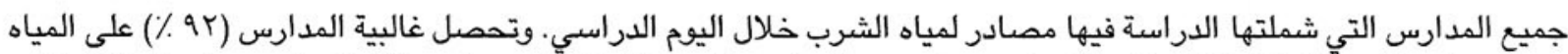

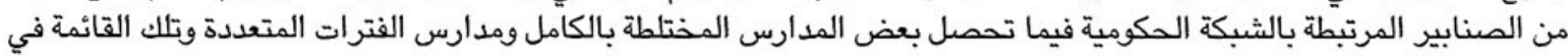

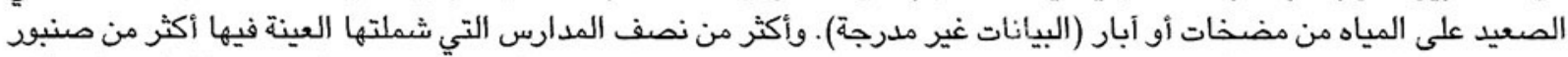

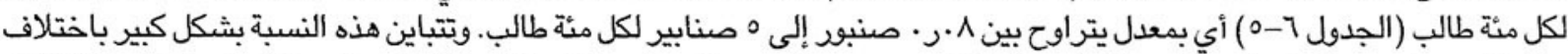

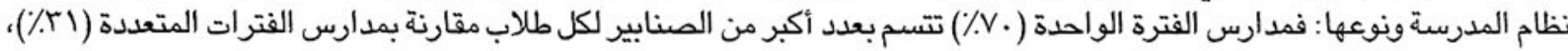

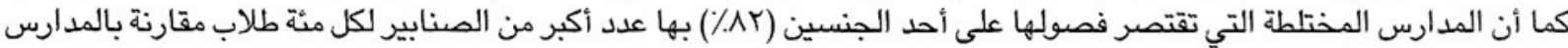

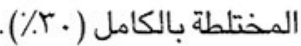

ب. المراحيض

جميع المدارس التي شملتها الدراسة فيها مراحيض متاحة للطلاب. والغالبية العظمى من هذه المدارس مرتبطة بشبكة الصرف الصحي، 
يذكر طلاب مدارس المحافظات الحضرية والمناطق المرتفعة التعليم كل فائدة من فوائد التعليم بالنسبة للبنين أكثر من غيرهم، بينما

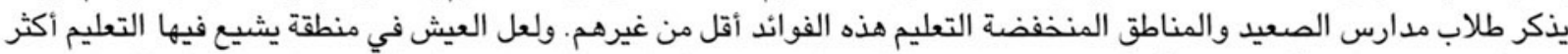

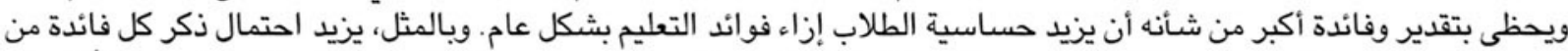

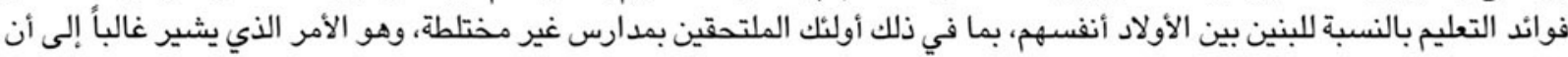

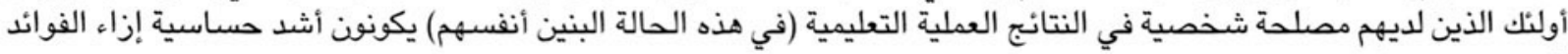

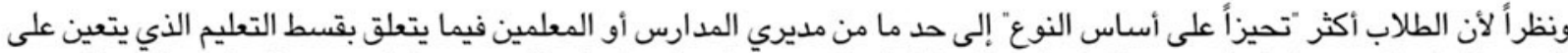

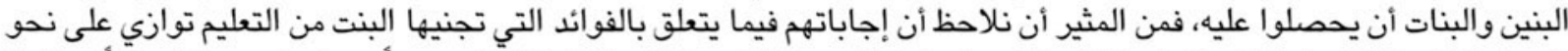

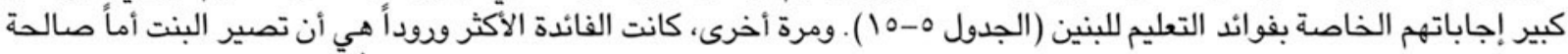

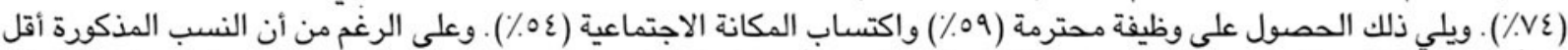

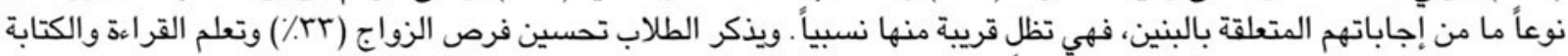

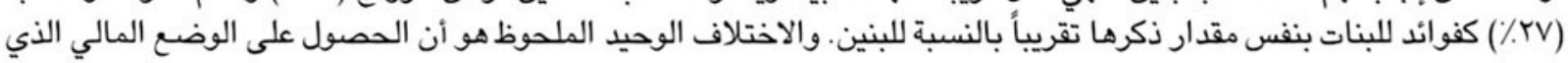

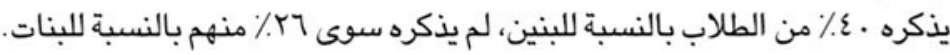

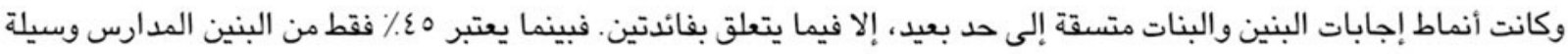

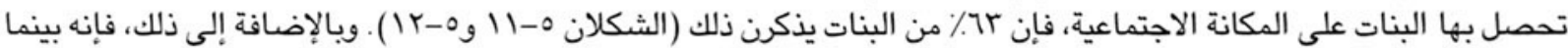

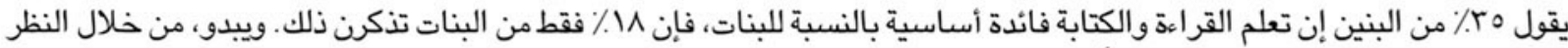

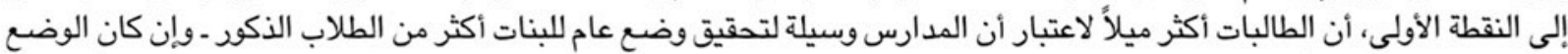

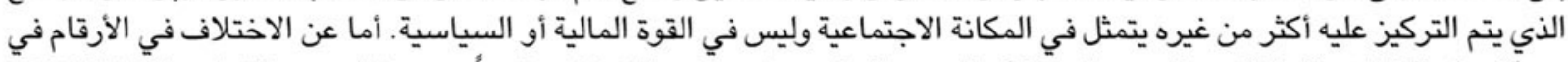

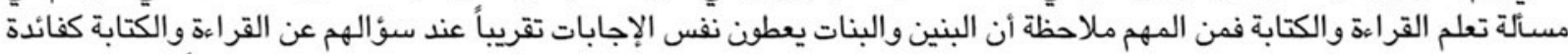

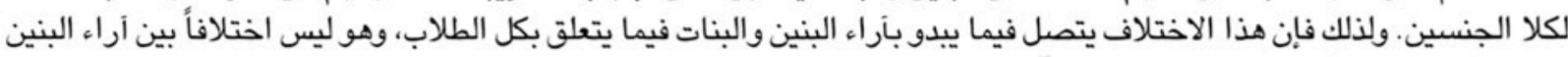
فيما يتعلق بالبنات وآراء البنات فيما يتعلق بالبنين.

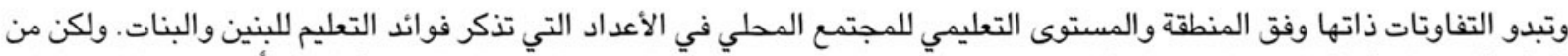

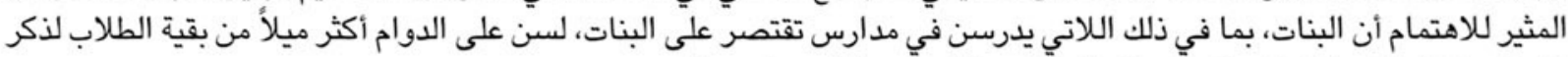

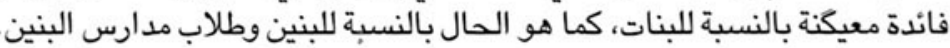

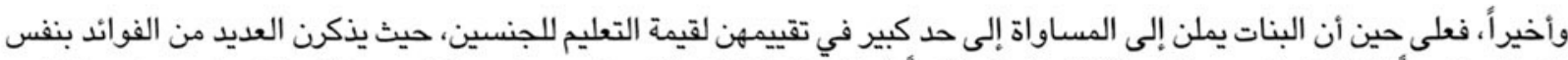

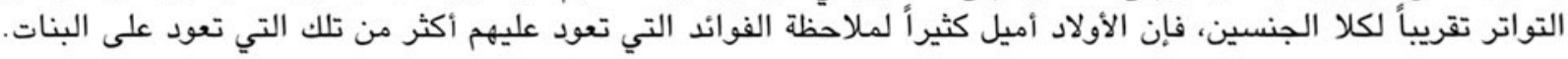

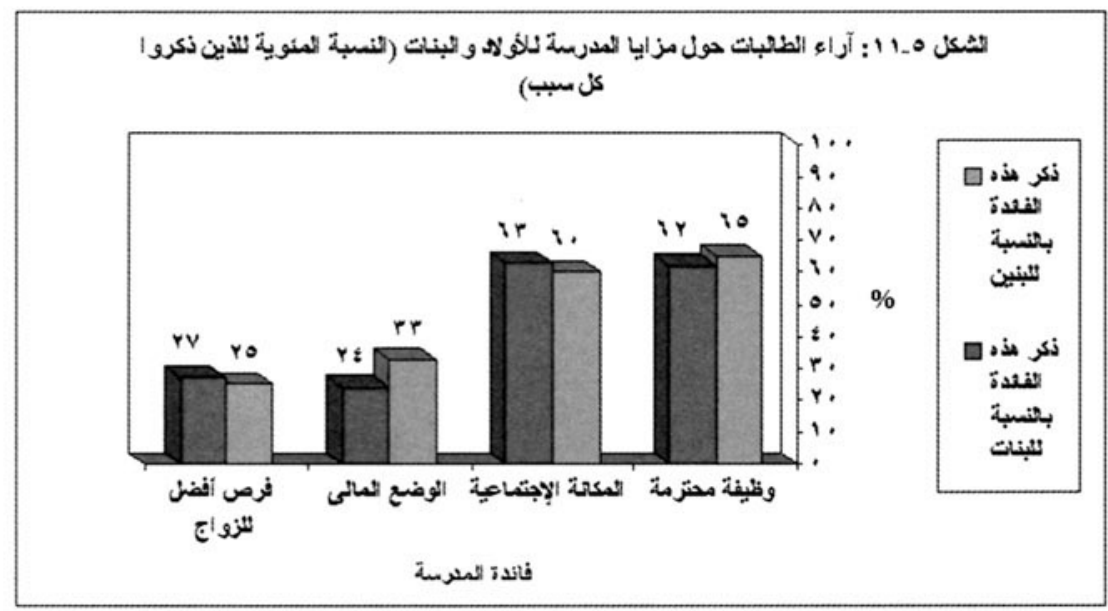




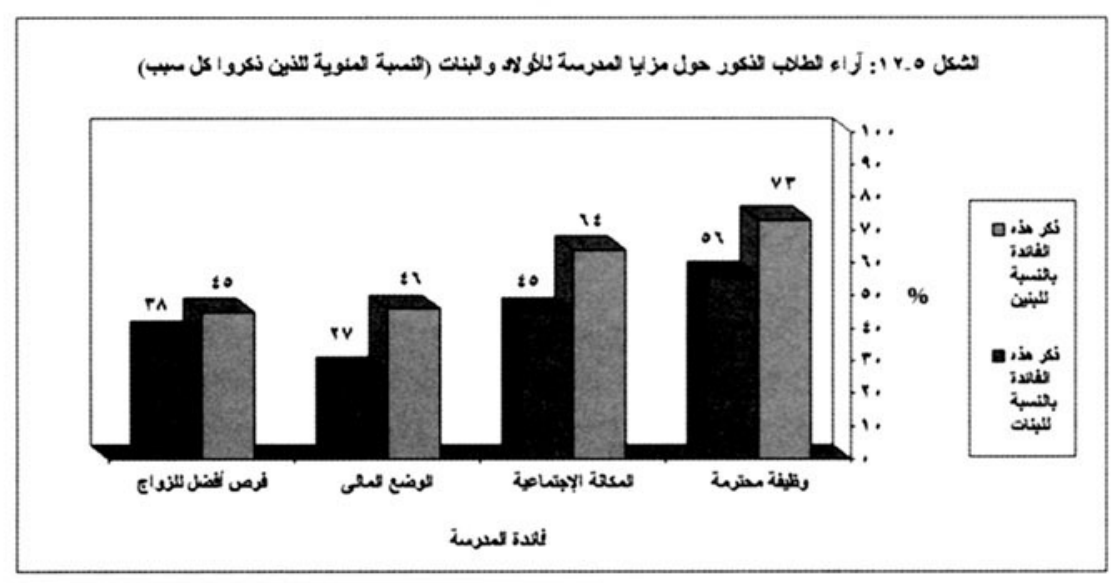

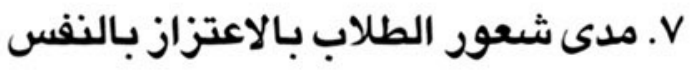

وجهت للطلاب ثلاثة أسنلة من أجل تقييم شعورهم نحو أنفسهم ومدى كفاءتهم. وسئل كل طالب وطالبة عما إذا كانوا يشعرون "أحياناً.

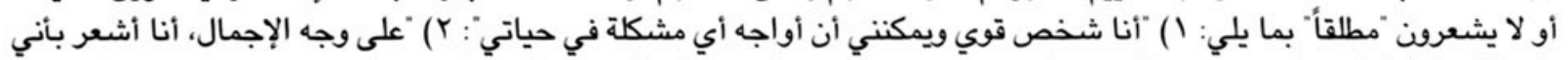

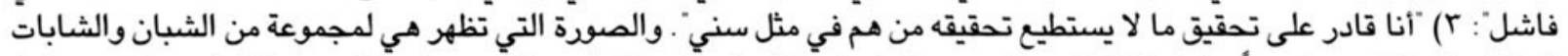

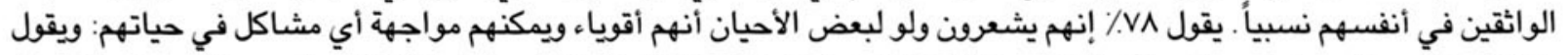

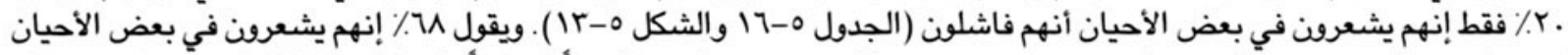

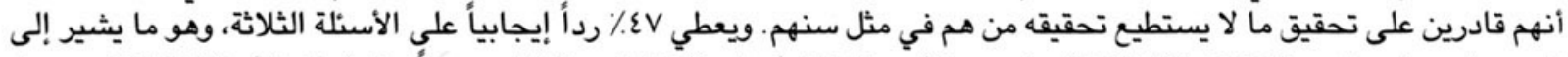

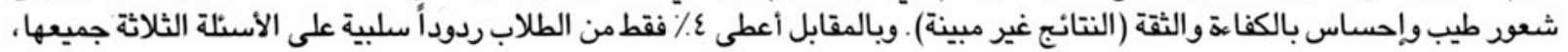

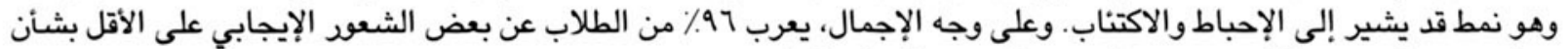

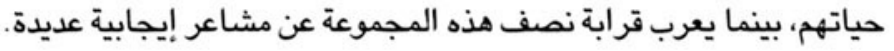

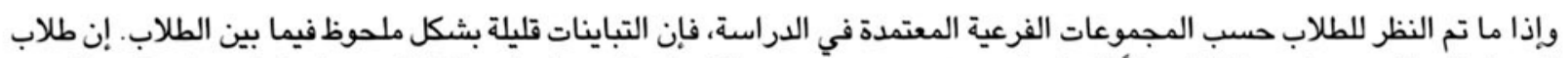

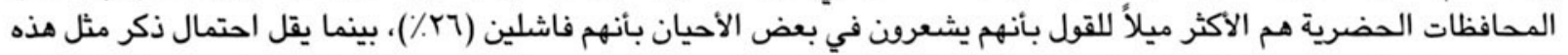

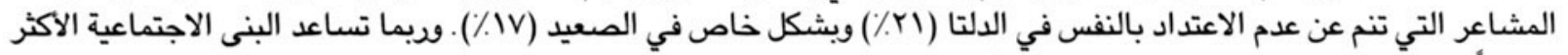

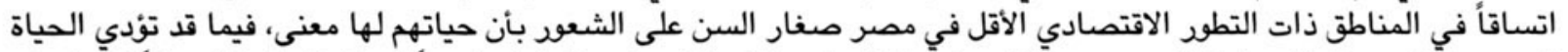

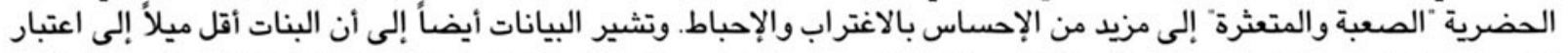

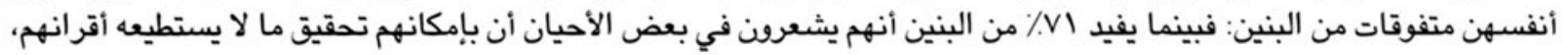

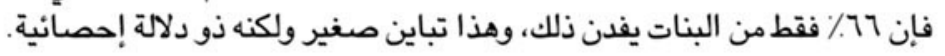

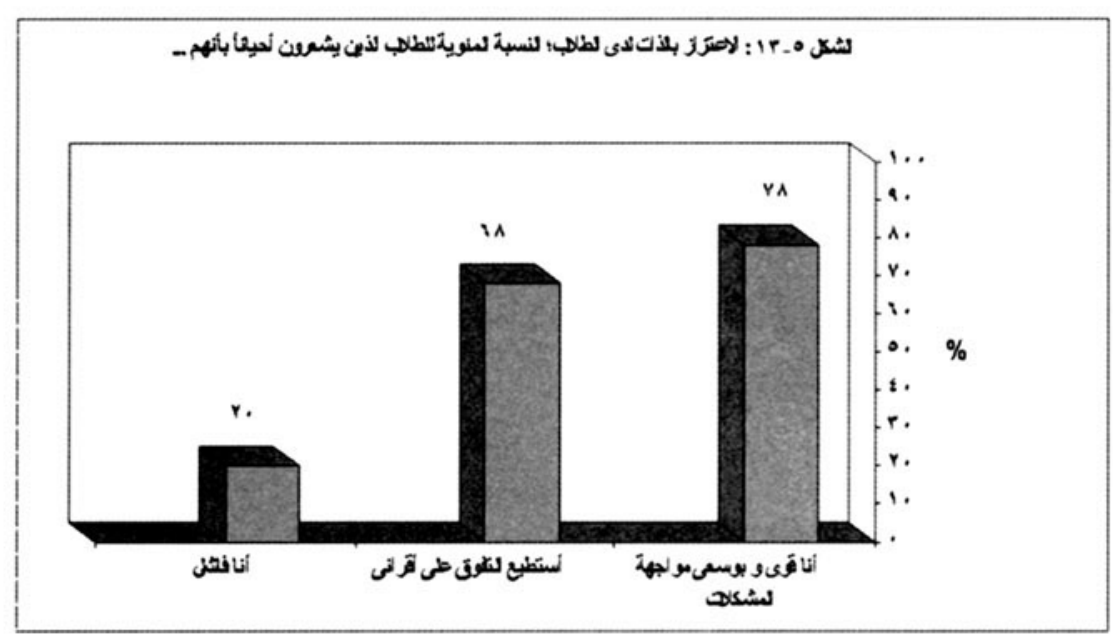




\section{1. آراء الطلاب بشأن المساواة في المعاملة على يد العاملين}

سئل الطلاب في كلا النوعين من المدارس المختلطة عما إذا كانوا يشعرون أن المعلمين والإداريين يعاملون البنين والبنات بشكل مختلف.

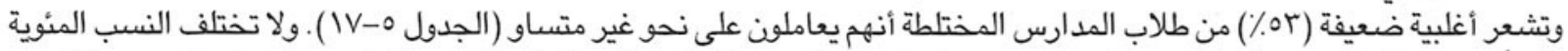

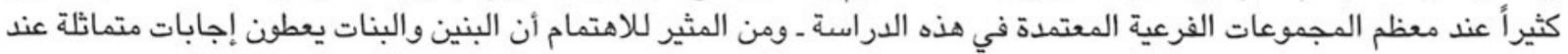

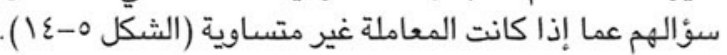

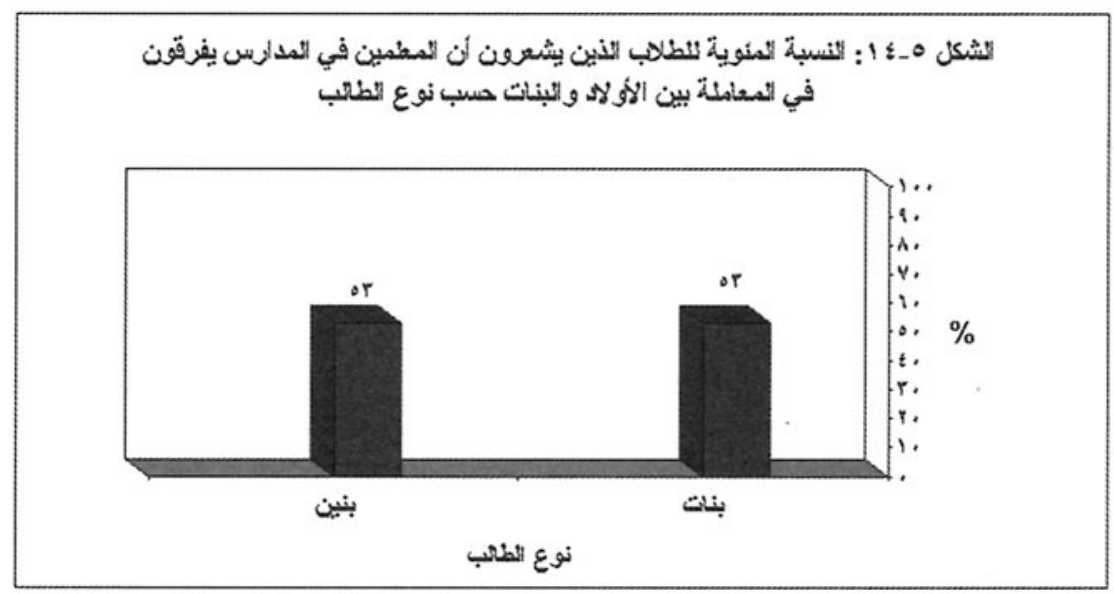

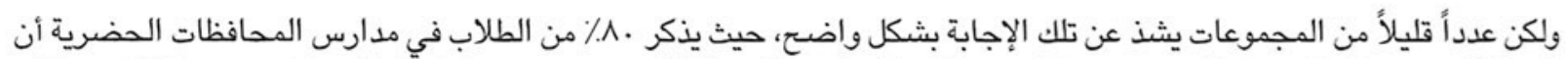

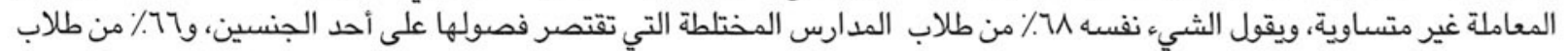

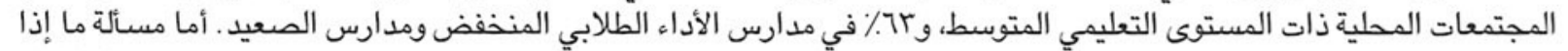

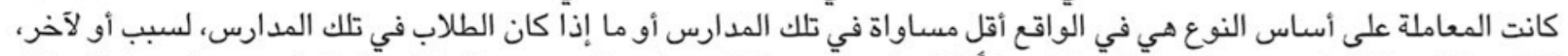

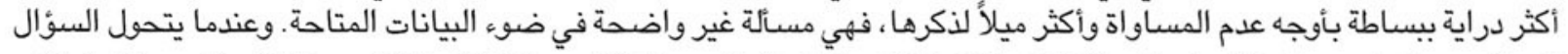

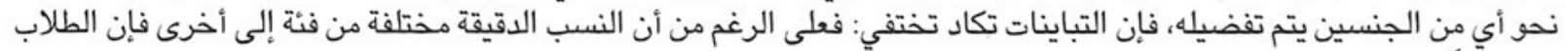

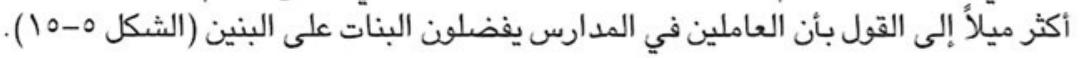

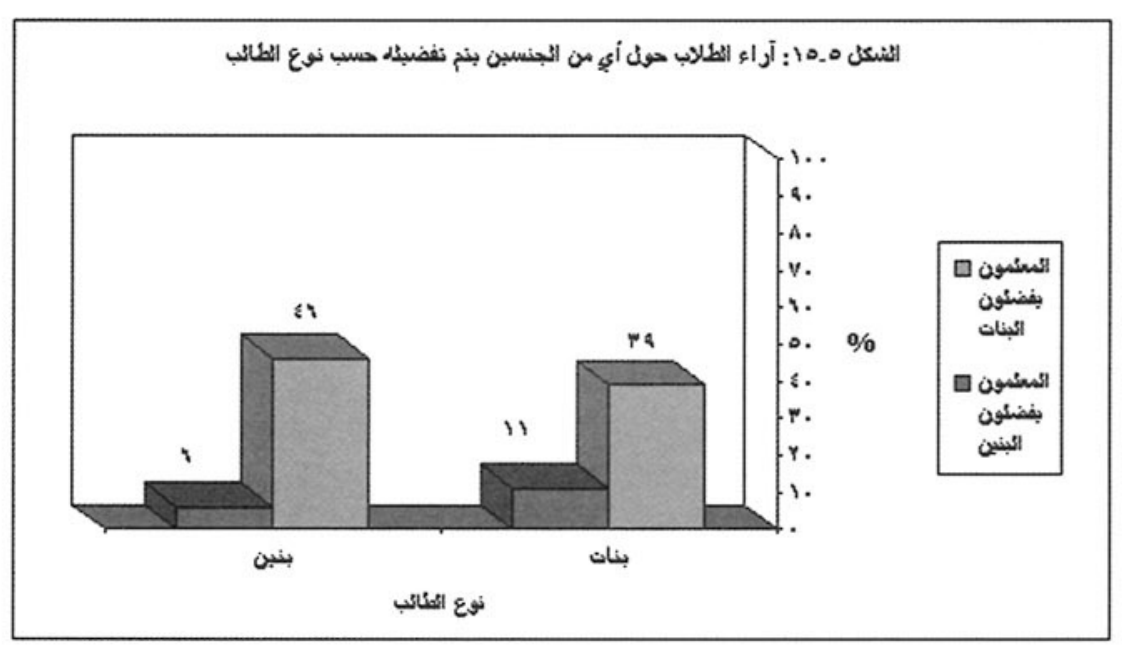

9. - 1استنتاجات

تفيد النتائج الواردة في هذا الفصل على نحو متكرر بأن البنات ينلن الأفضلية ويحظين بالتقدير كطلاب في المدارس الإعدادية المصرية

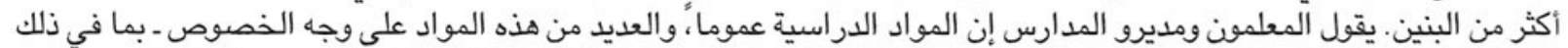

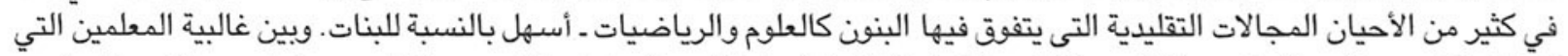

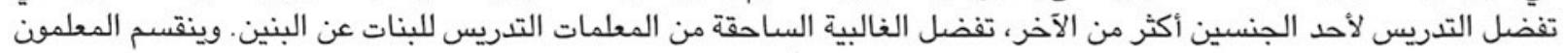

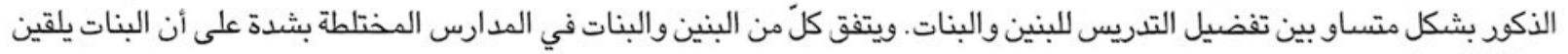


غير أن هناك أيضاً ما يفيد من واقع المواقف التي جرى رصدها هنا بأن البنات قد يكن أقل تميزاً على نحو لا لا يتم تبينه للوهلة الأولى.

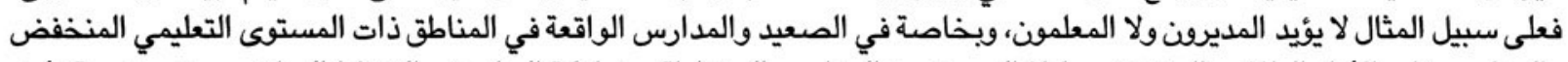

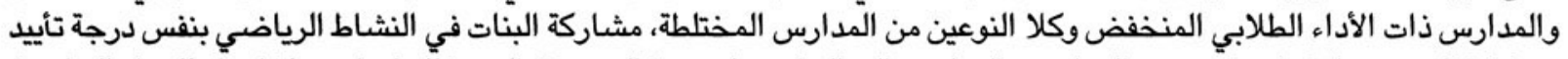

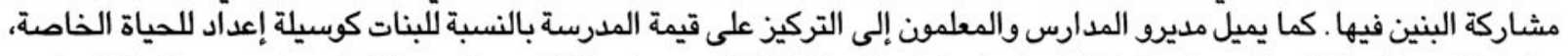

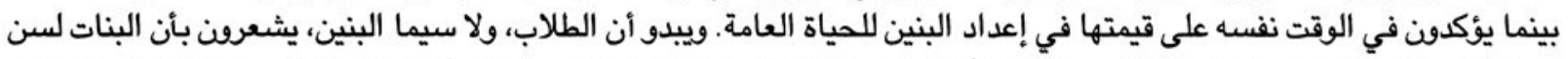

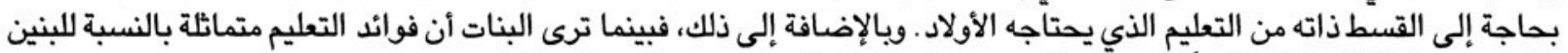

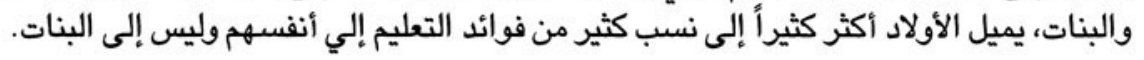

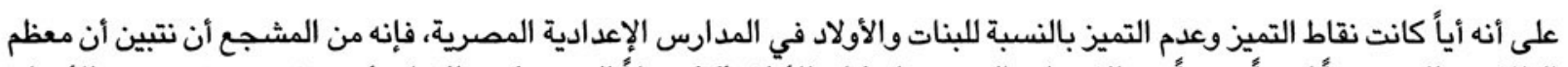

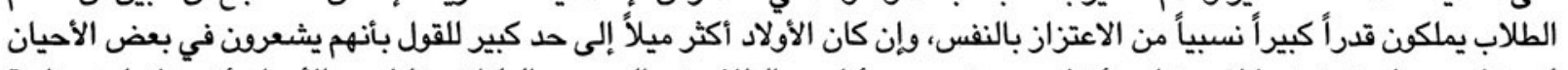

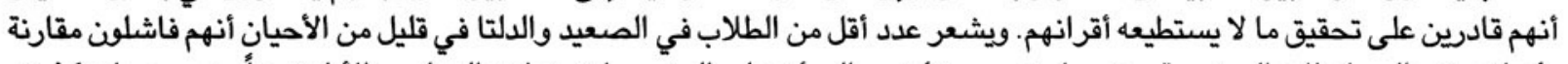

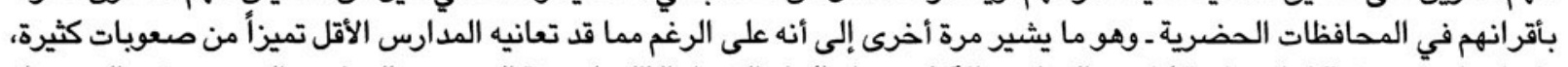

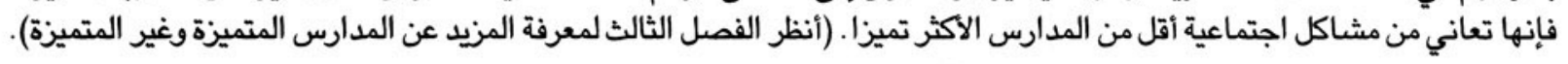

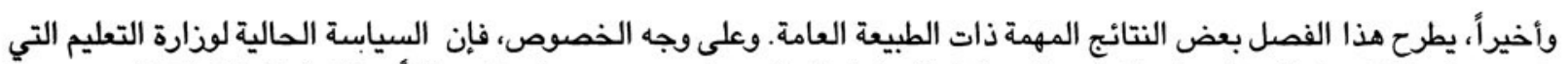

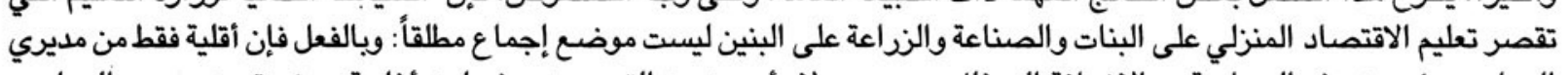

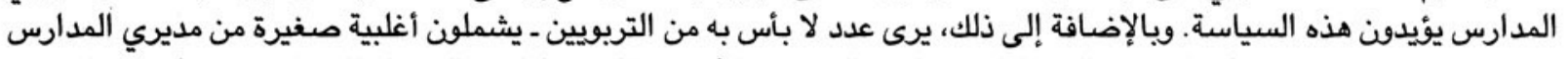

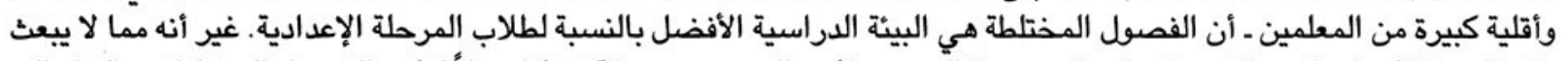

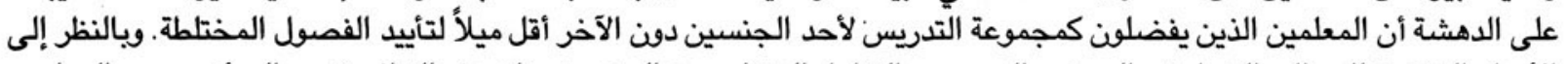

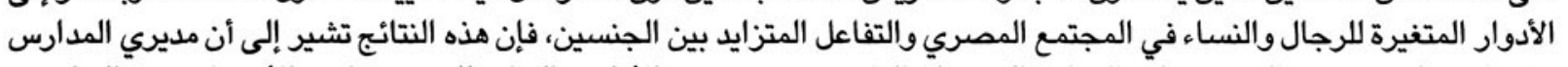

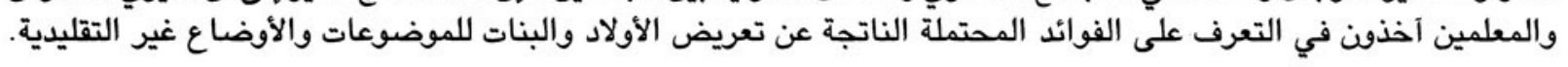




\section{الموارد المادية والبشرية}

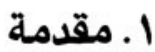

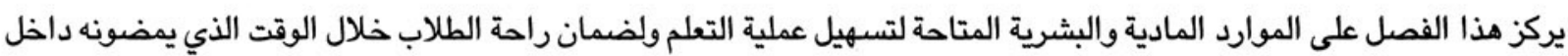

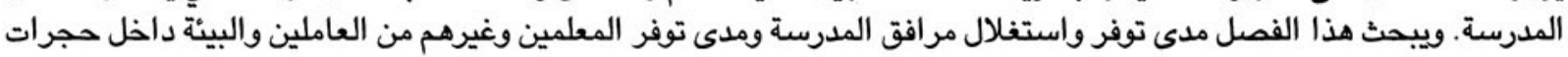

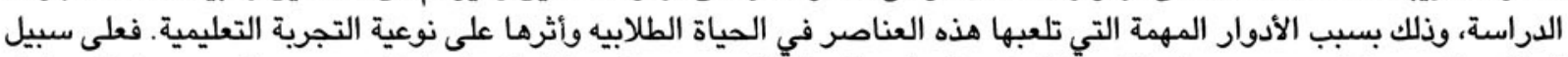

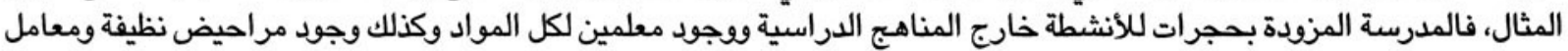

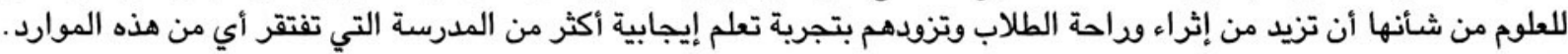

وقد استخدمت العديد من الأدوات بهدف الحصول على معلومات في هذا الفصل. وأجرى باحثو المسح جرداً بمرافق المدرسة وراقداقيوا

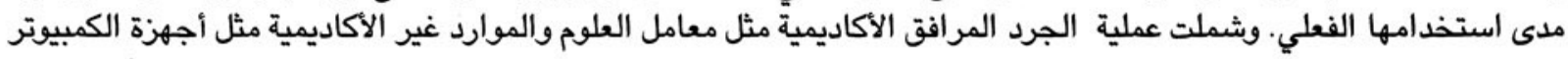

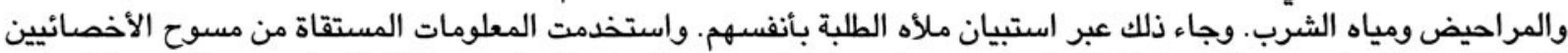

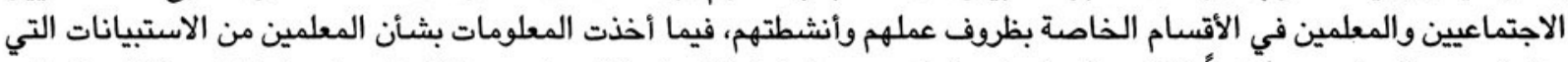

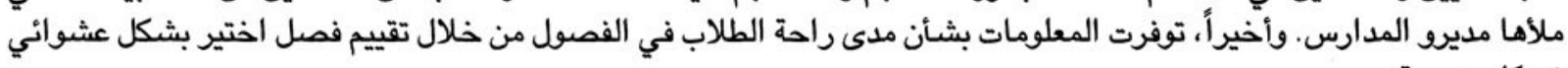
في كل مدرسة.

\section{r. (بحرات الدراسة}

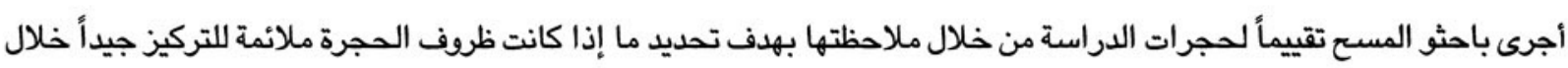

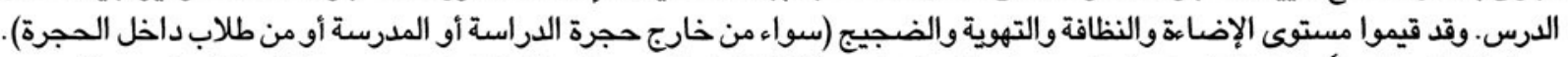

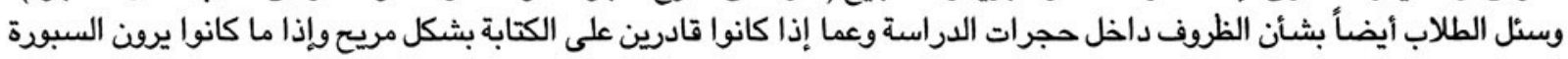
ويسمعن المعلم.

أ. - الد حجرات الدراسة

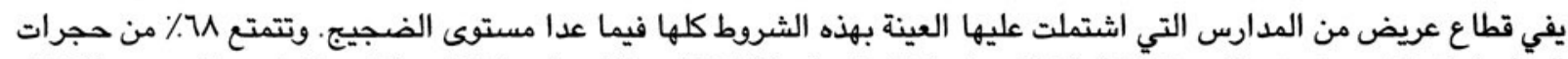

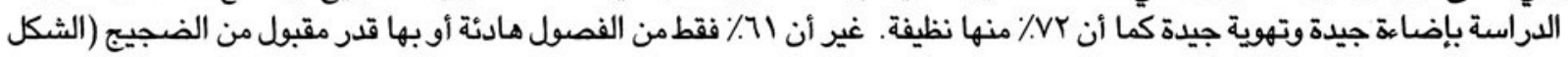

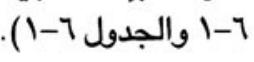

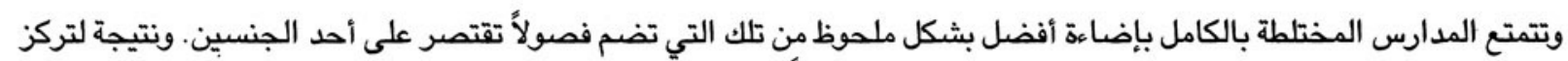

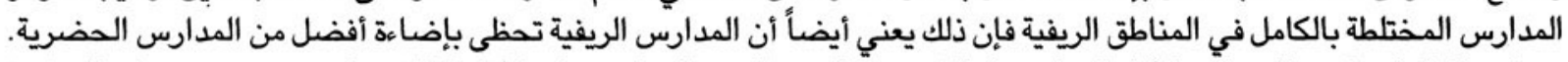

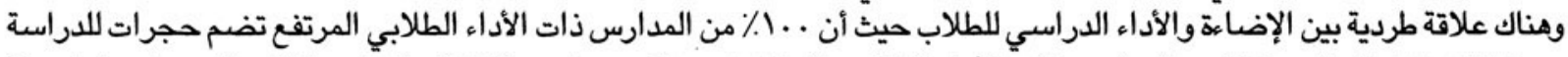

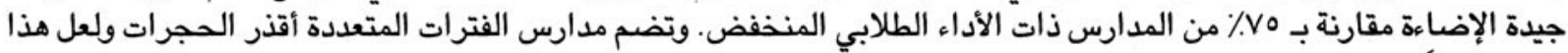

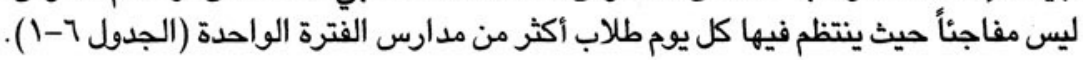




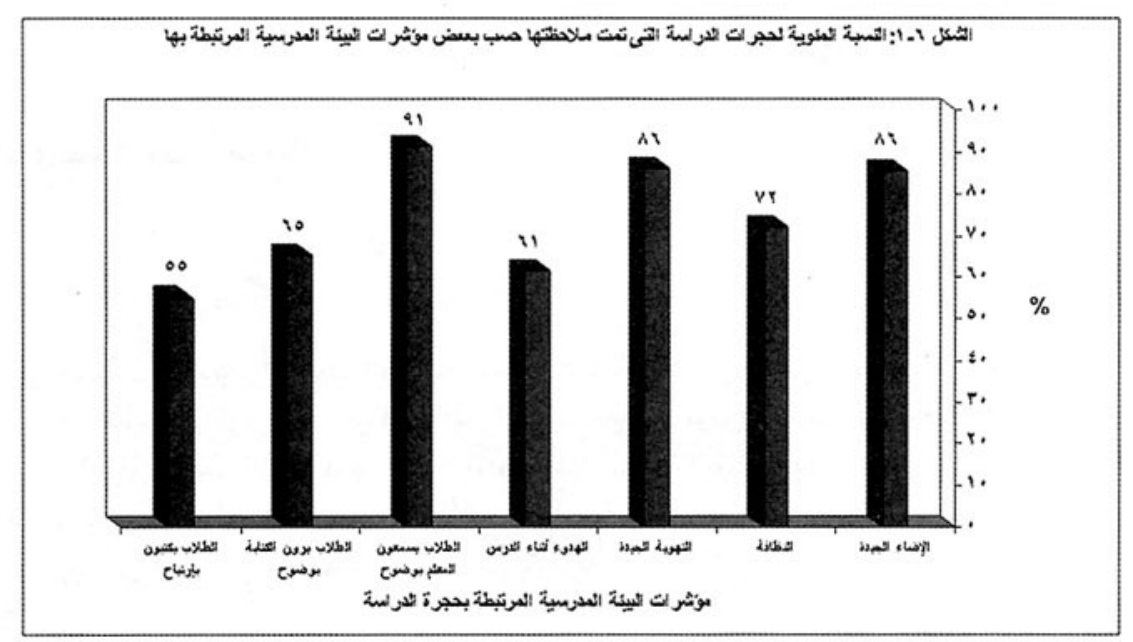

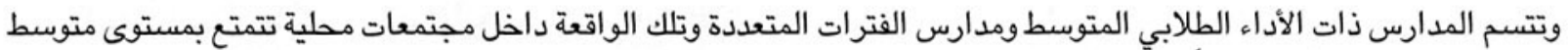

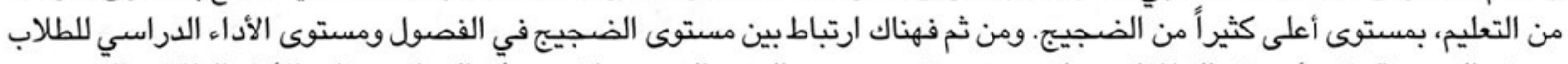

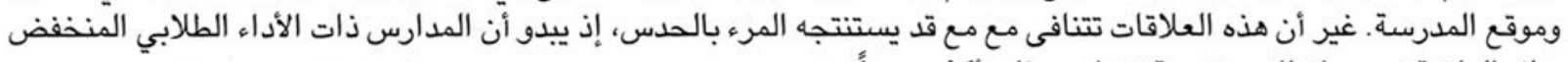
وتللك الواقعة في محافظات حضرية تحظى بييئات أكثر هدوءاً.

\section{ب. الدكك المكسورة}

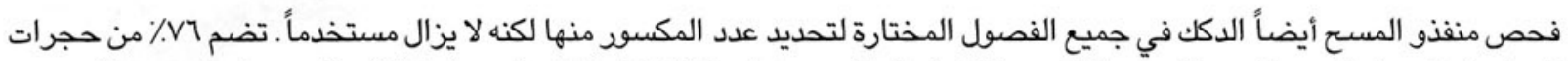

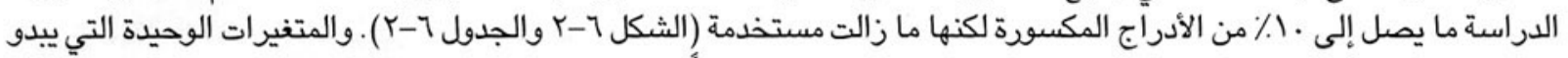

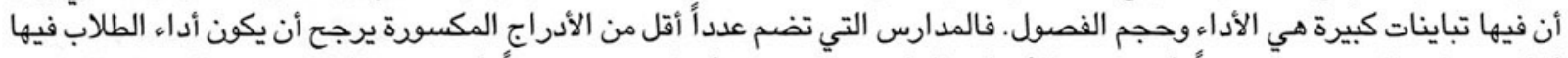

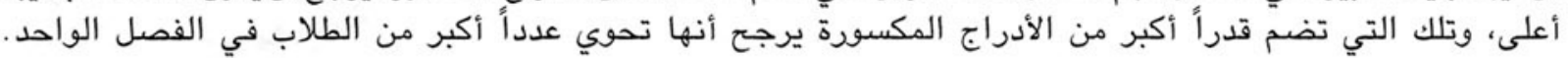

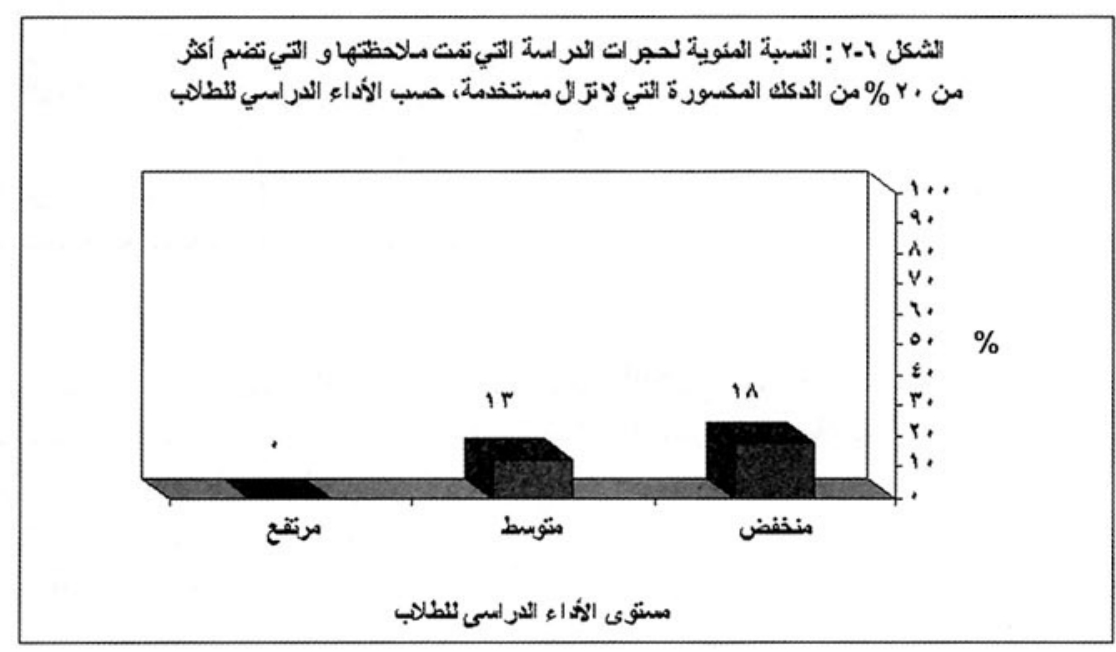

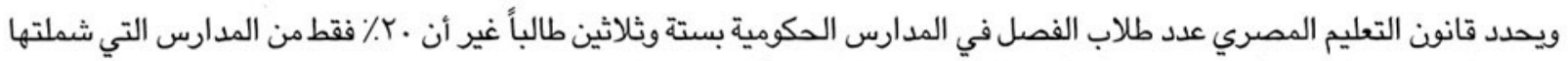

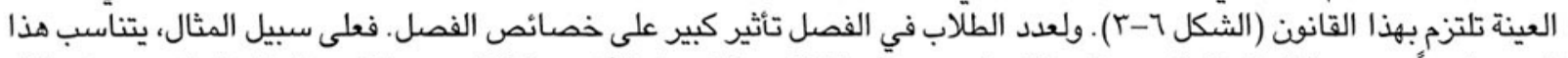

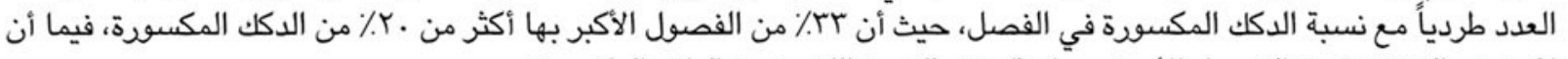
اثنين في المئة فقط من الفصول الأصغر بها مثل هذه النسبة الكبيرة من الدكل المكسورة. 


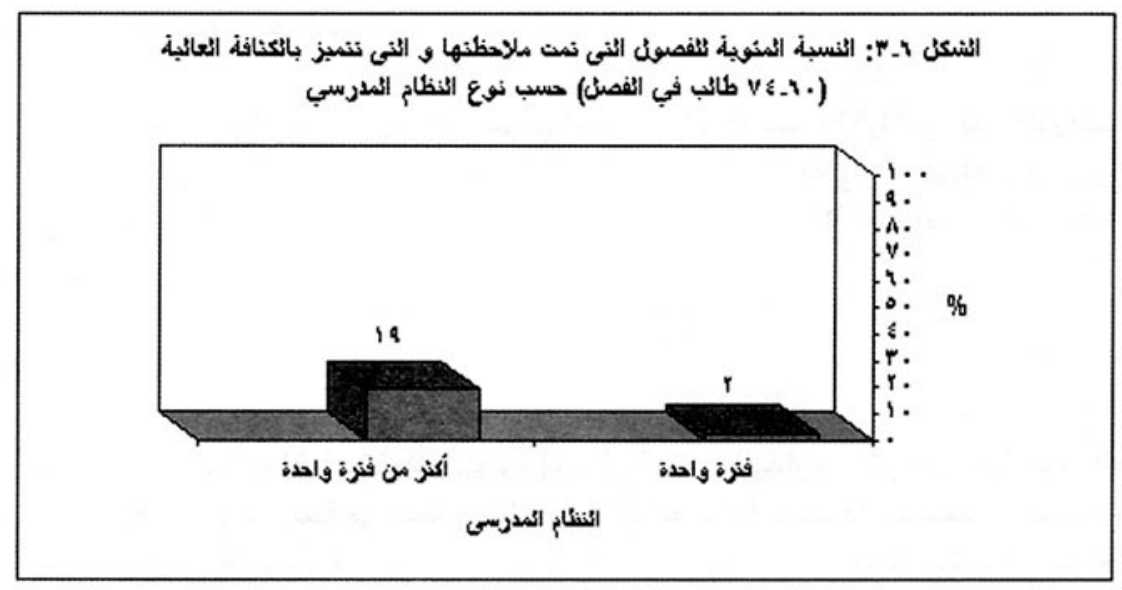

ج.راحة الطالب

يشير الطلاب إلى درجات متباينة من الراحة داخل حجرات الدراسة (الجدول 1-1). يقول أكثر من تسعين في المئة من الطلاب الذين

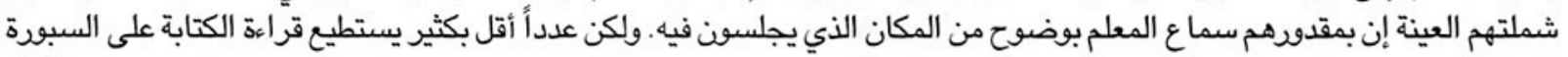

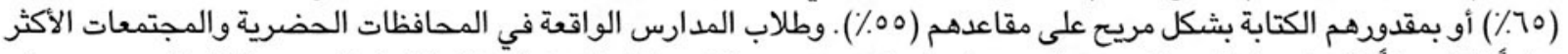

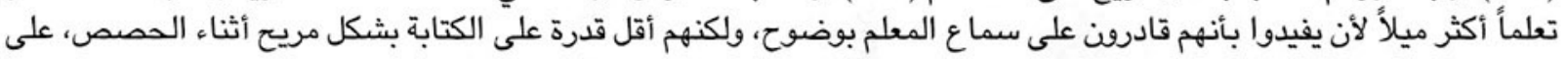

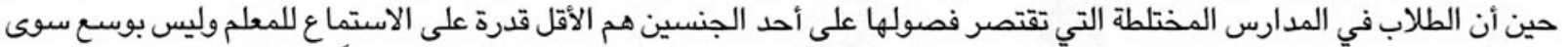

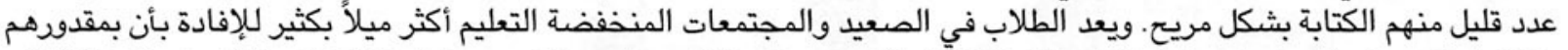

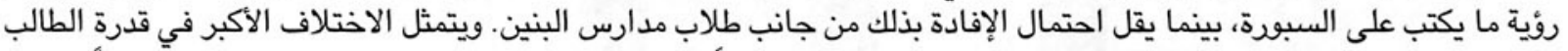

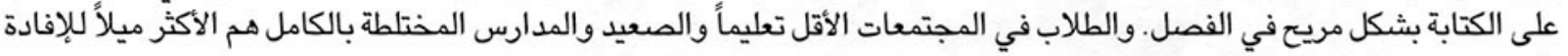
بأن بمقدوهم الكتابة بشكل مريح (الشكل 1- ع) .

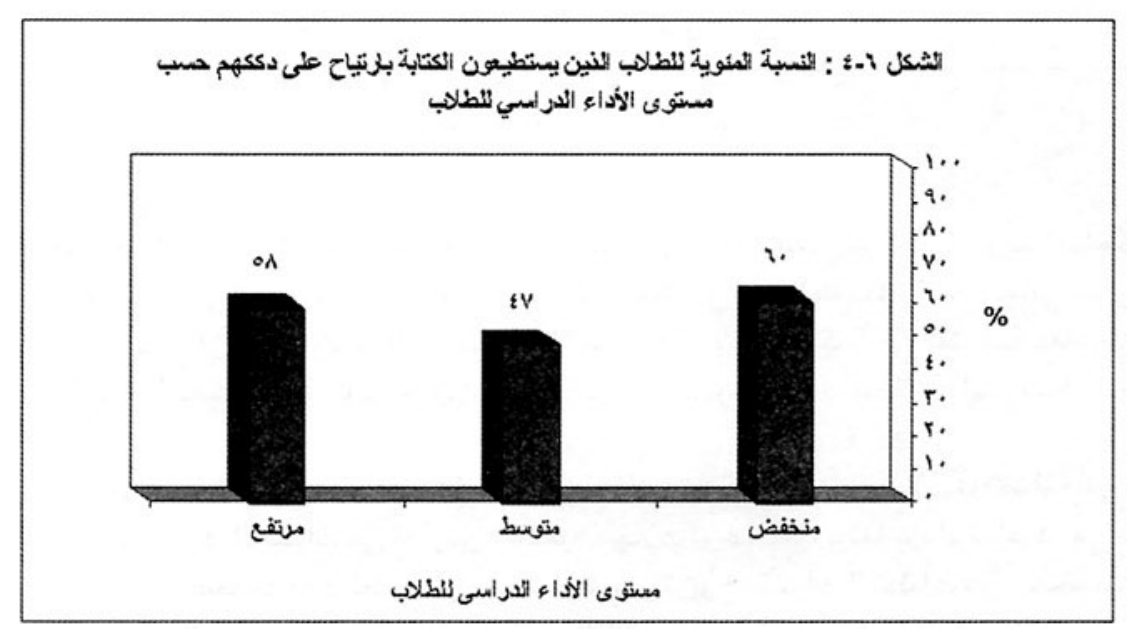

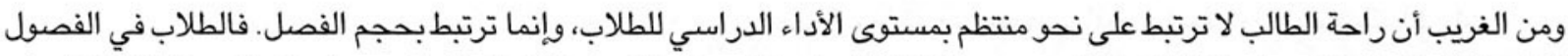

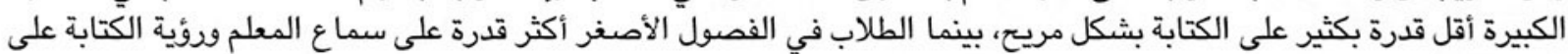
السبورة.

\section{r.توفر الموارد الأكاديمية}

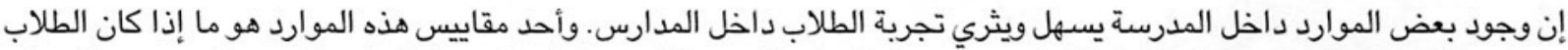

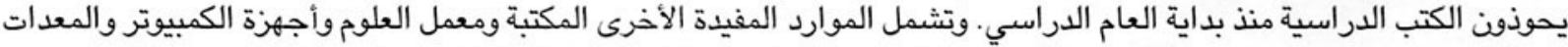
المرئية والمسموعة والمعدات غير الأكاديمية مثل الآلة الكاتبة وأجهزة الهاتف وأجهزة تصوية الهير المستية المستندات. 


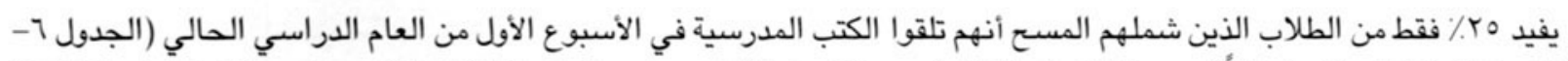

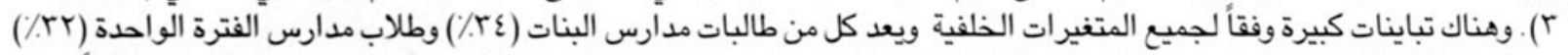

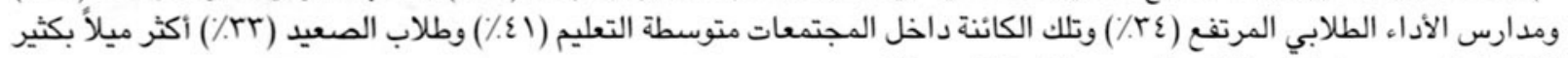
للإفادة بأنهم حصلوا على الكتب المدرسية في توقيت ملانم.

ب. معامل العلوم

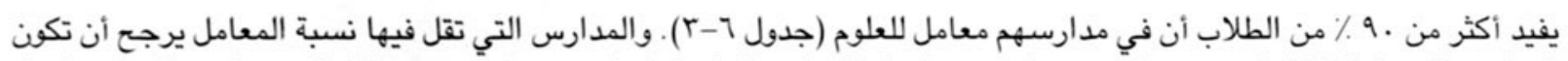

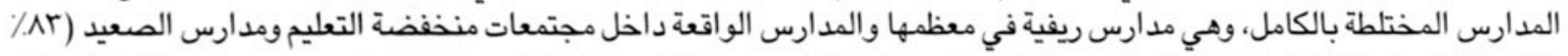

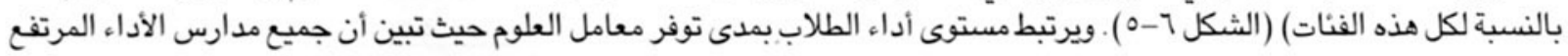

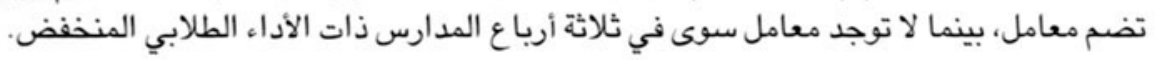

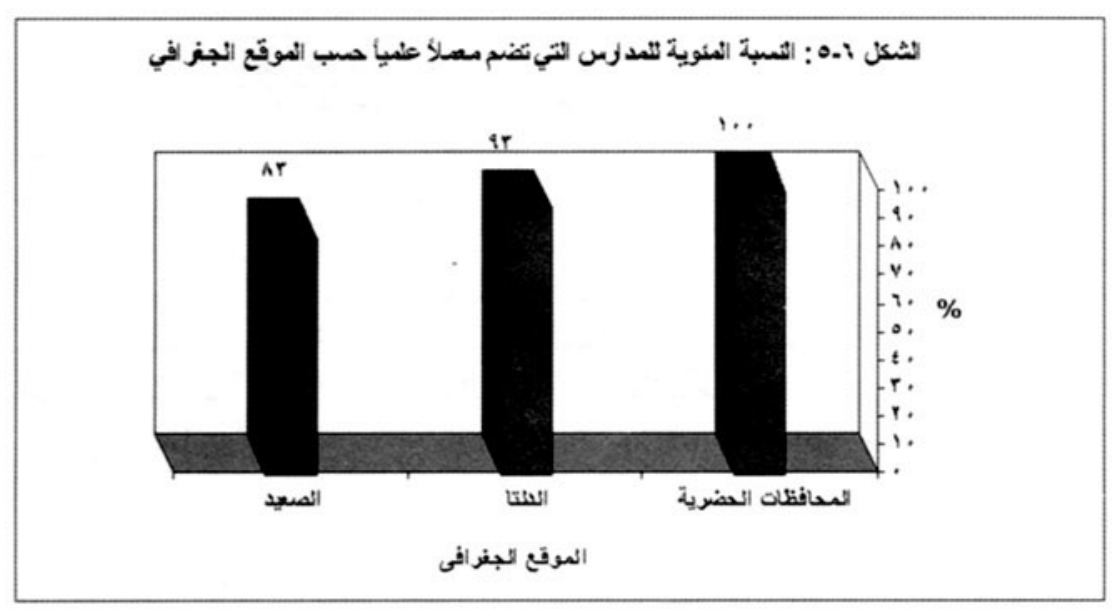

ج. المكتبة

يضم نحو تسعين في المئة من المدارس التي شملتها العينة مكتبة (الجدول 1-r) . والمدارس التي لا توجد فيها مكتبات مختلطة بالكامل

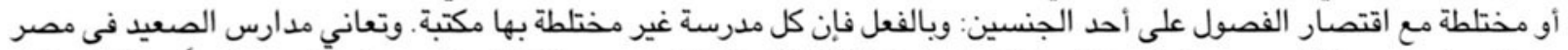

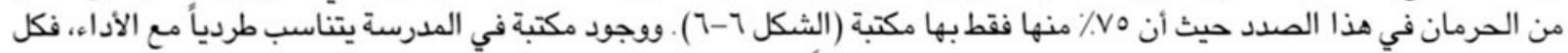

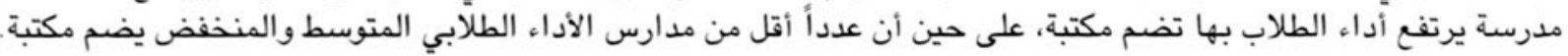

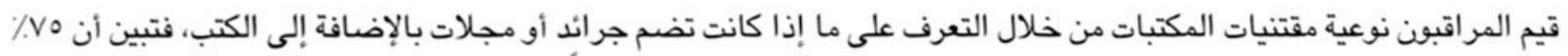

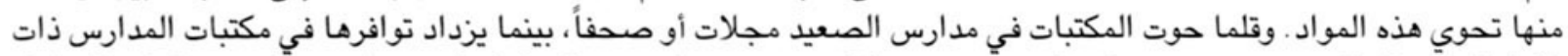

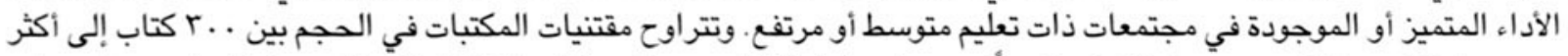

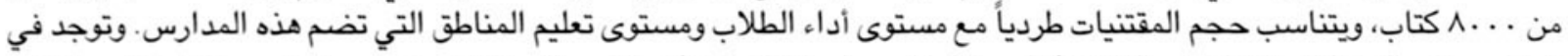

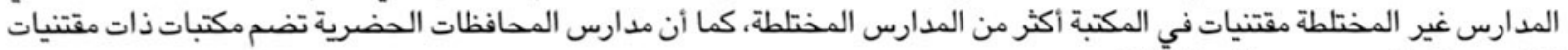
أكثر من تلل الموجودة في المناطق الأخرى. 


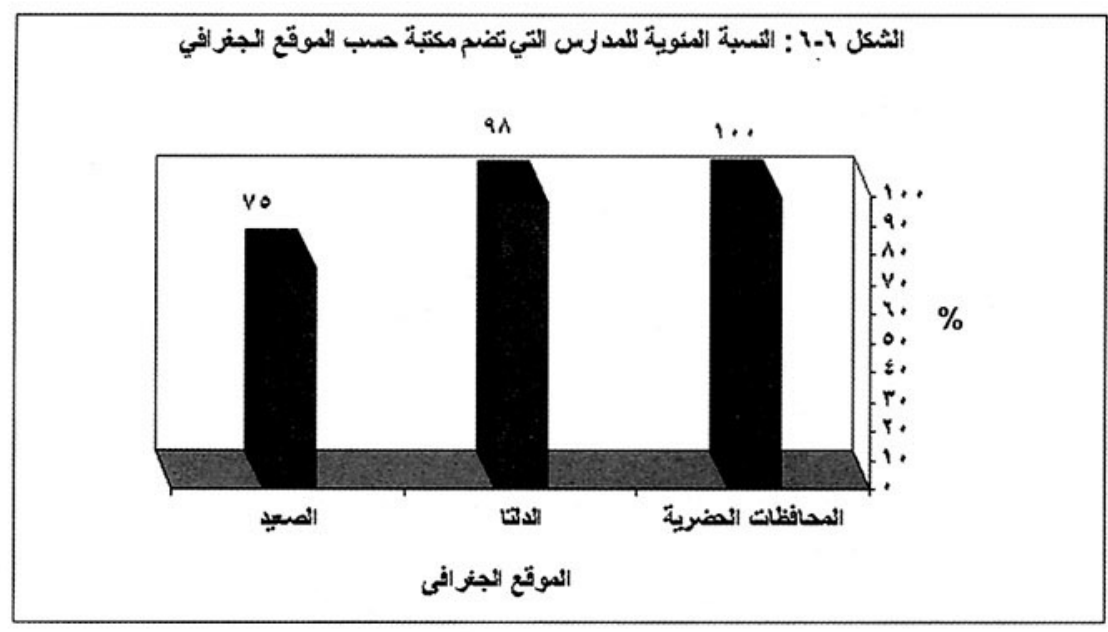

د. التقنيات الأخرى

ومن بين أهم النتائج التي تم التوصل إليها العدد الكبير نسبياً لمدارس البنين التي تضم أجهزة كمبيوتر وتلفزيون وفيديو (الجدول 1.

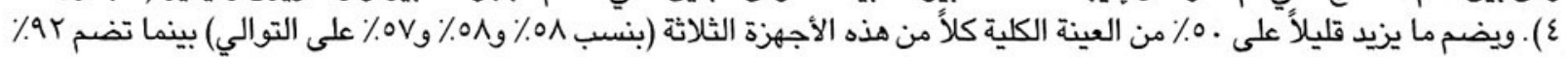

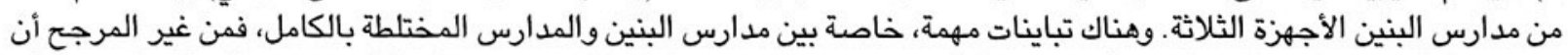

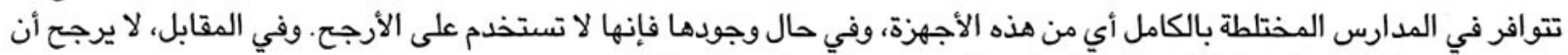
تضم مدارس البنات مثل هذه الأجهزة، ولكن في حال وجودها فال فإنها تستخدم أكثر.

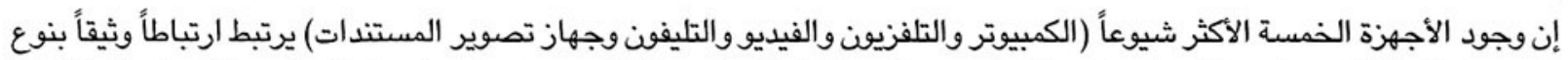

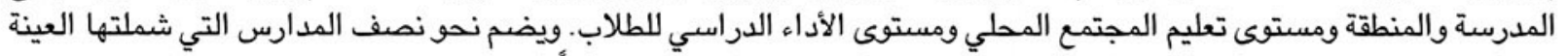

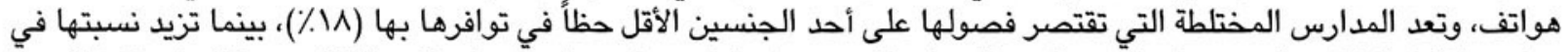

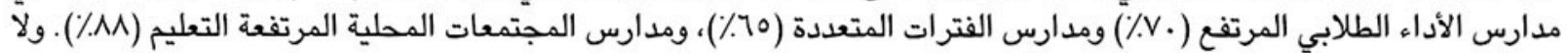

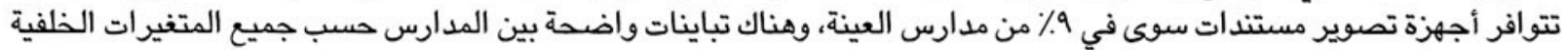

فيما عدا المنطقة.

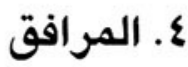

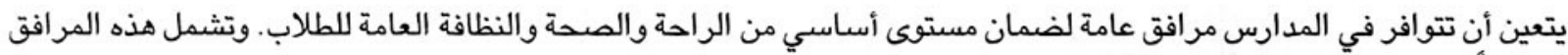

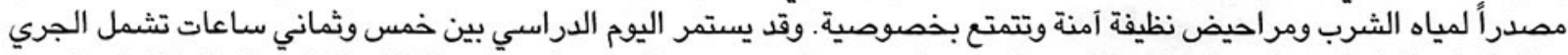

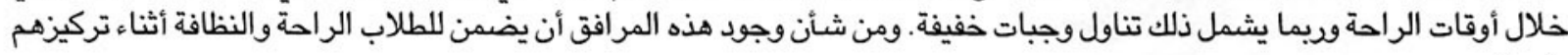

على الدروس.

أ. مياه الشربو الصنابير

جميع المدارس التي شملتها الدراسة فيها مصادر لمياه الشرب خلال اليوم الدراسي. وتحصل غالبية المدارس (Y و ٪ ٪) على المياه

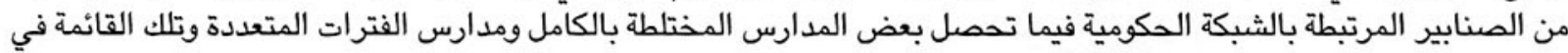

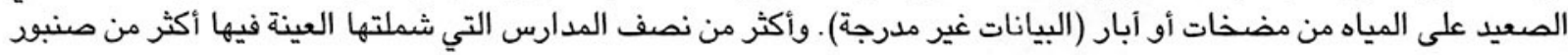

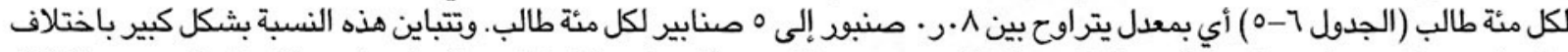

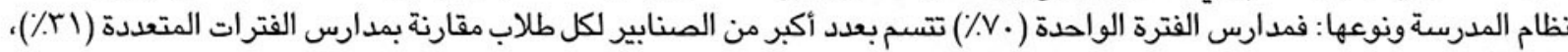

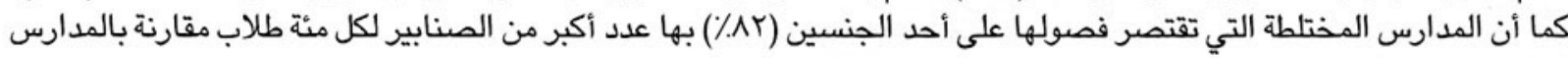

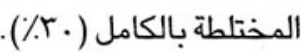

ب. المراحيض

جميع المدارس التي شملتها الدراسة فيها مراحيض متاحة للطلاب. والغالبية العظمى من هذه المدارس مرتبطة بشبكة الصرف الصحي، 


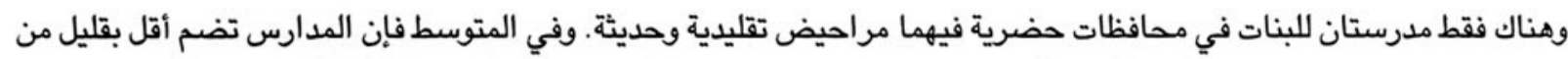

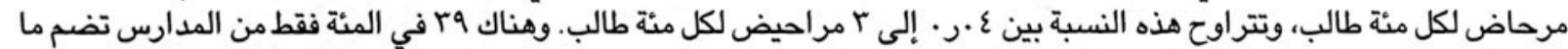

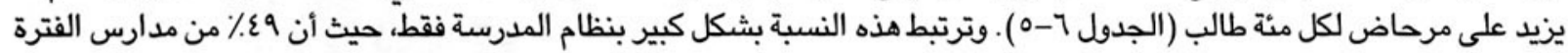

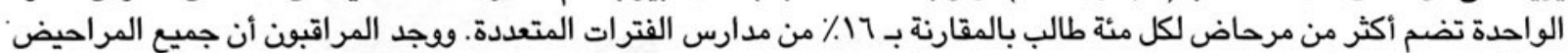
لها أبواب يمكن غلقها لضمان الخصوصية. غير أن هذه النتيجة لا علاقة لها برؤية الطلاب لمراحيضهم (أنظر أدناه).

1) نظافة المراحيض: قيم المراقبون نظافة المراحيض وفقاً لأربعة معايير مختلفة: (أ) القاذورات الملقاة على الأرض، (ب) المياه الموجودة

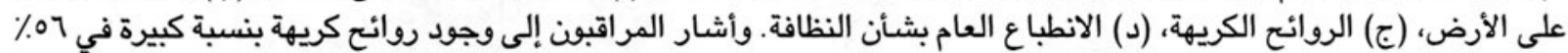

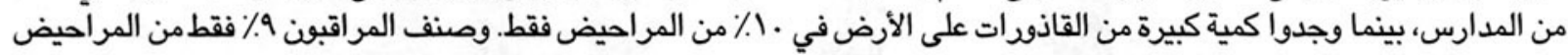

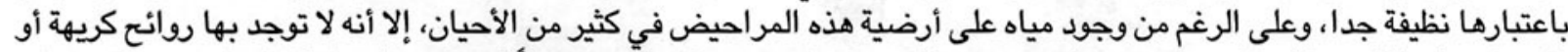

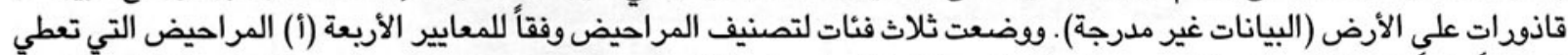

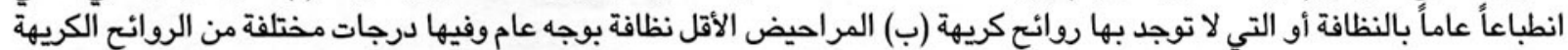

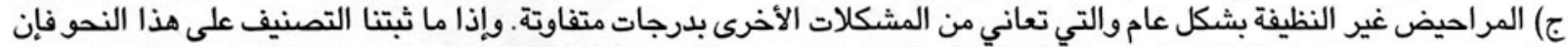

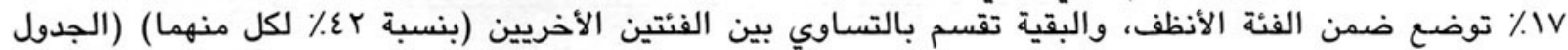

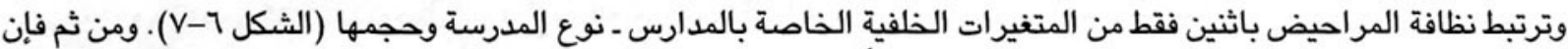

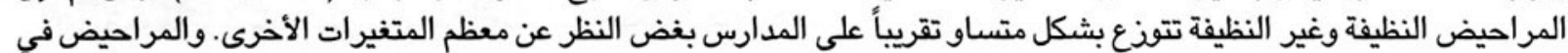

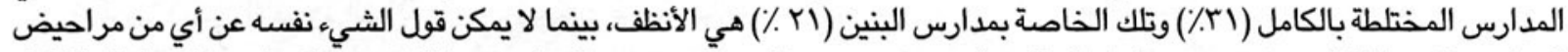

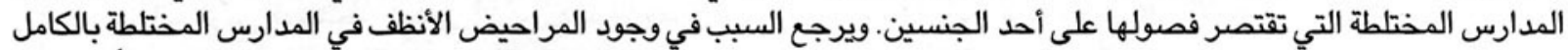

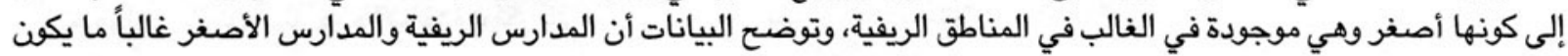

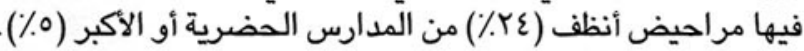

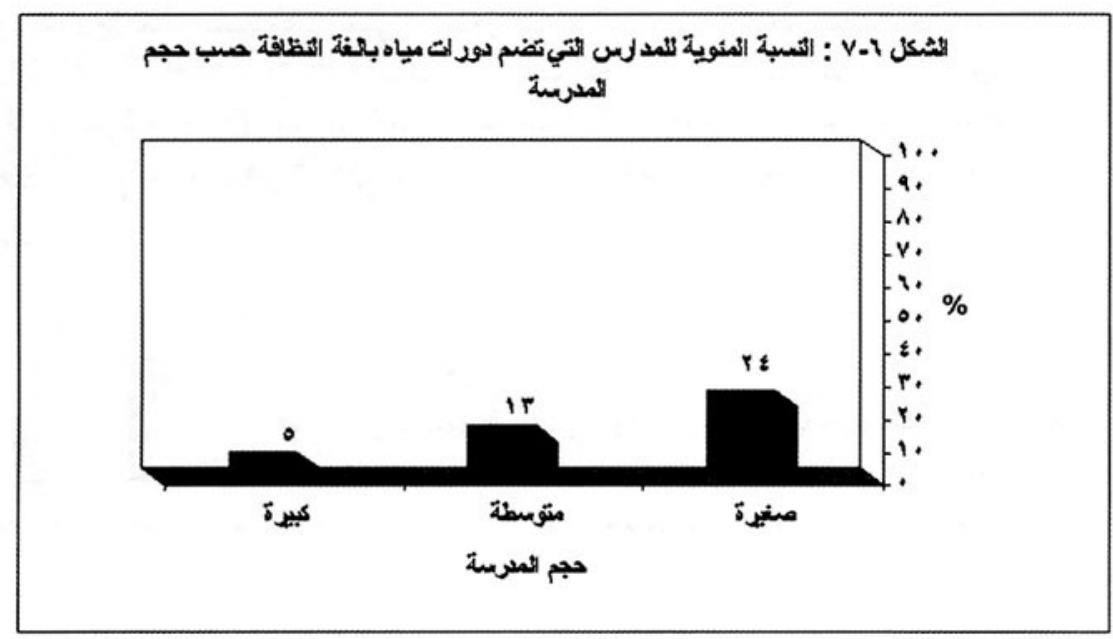

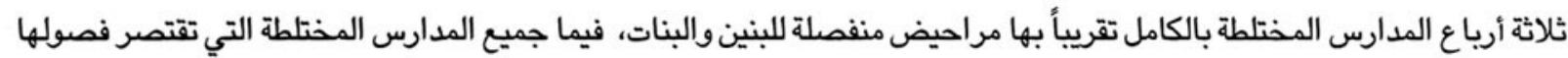

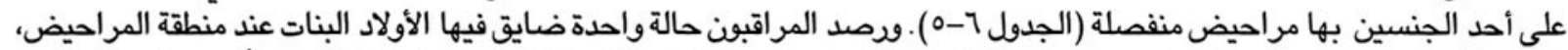

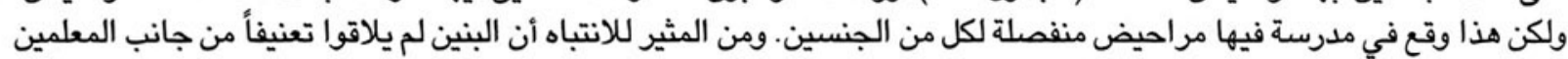

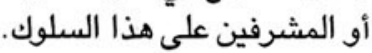

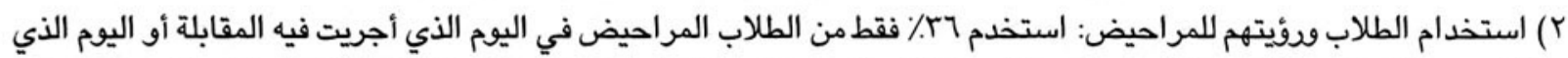

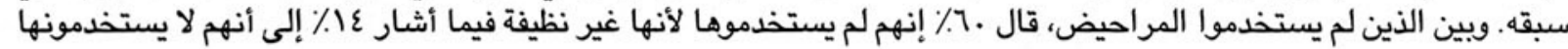
لعدم توافر الخصوصية بها.

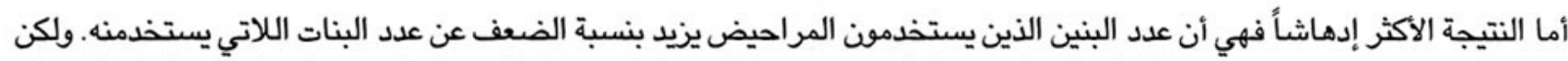

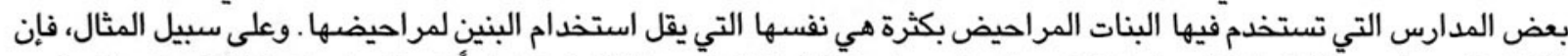

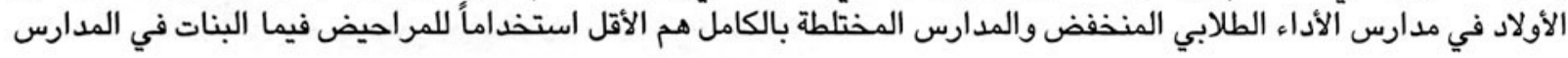




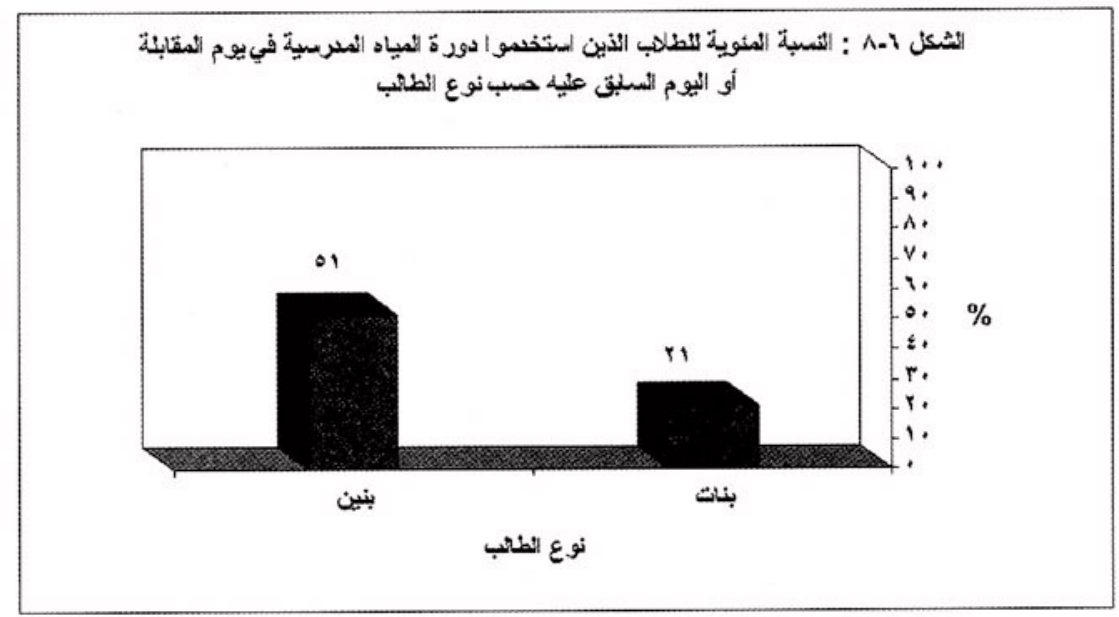

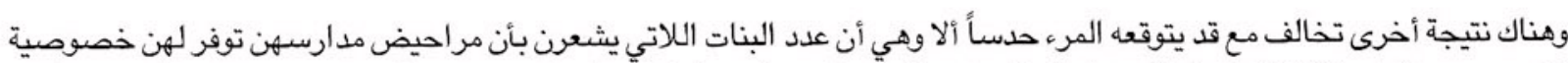

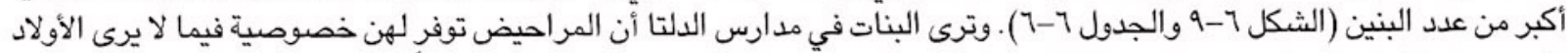

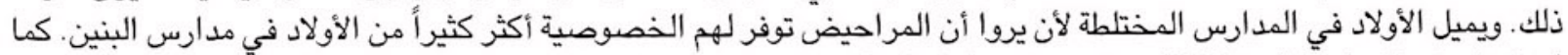

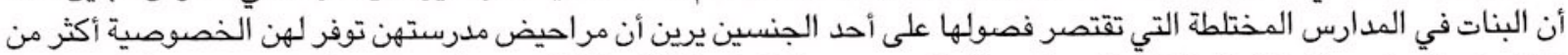

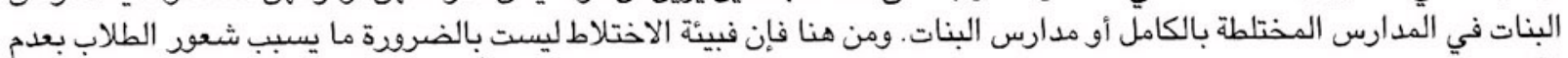

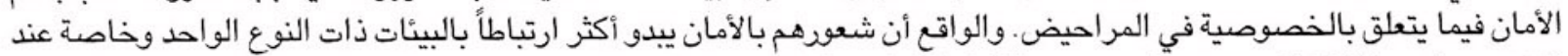

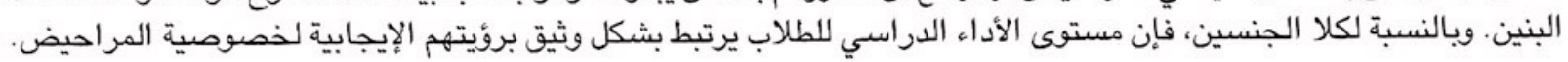

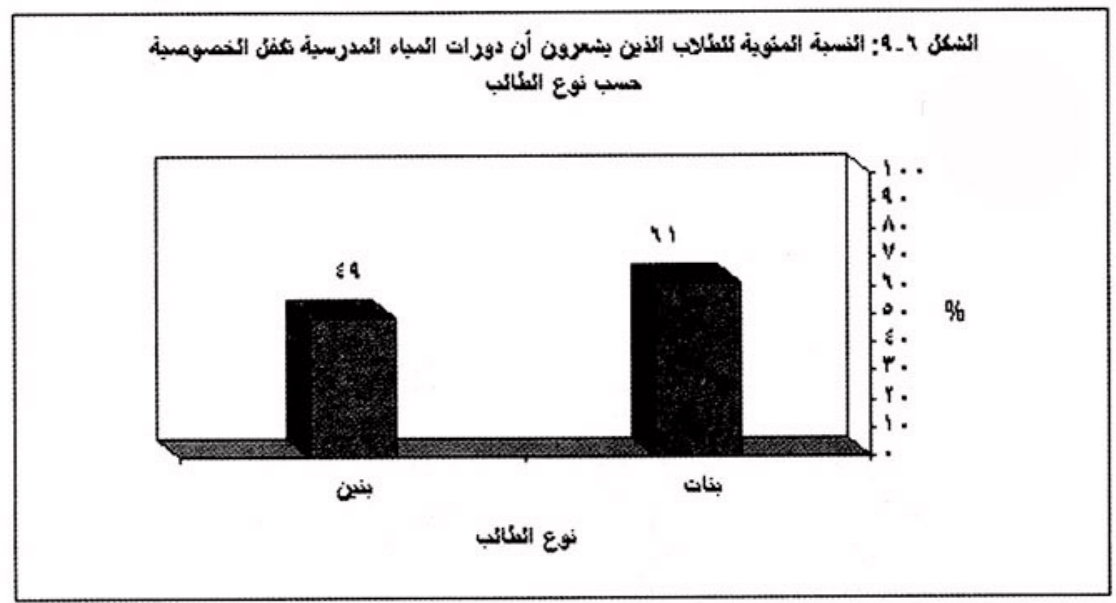

\section{๑ـ المساحة المتاحة للأنشطة والخدمات المدرسية غير الدراسية}

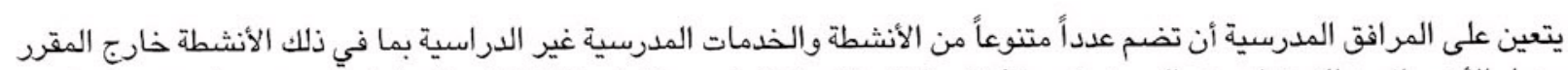

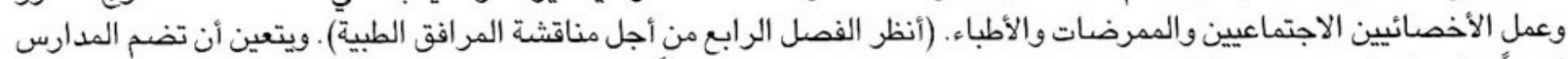

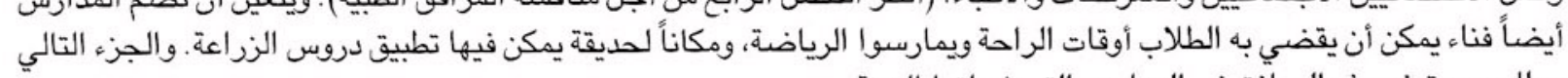
يحلل مدى توفر هذه المرافق في المدارس التي شملتها أنسا العينة. أ. الأنشطة خارج المقرد

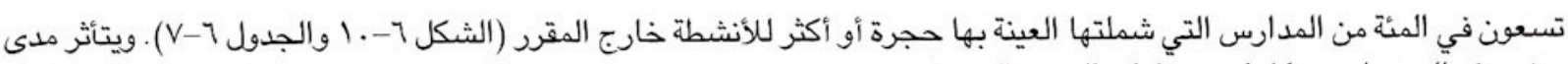

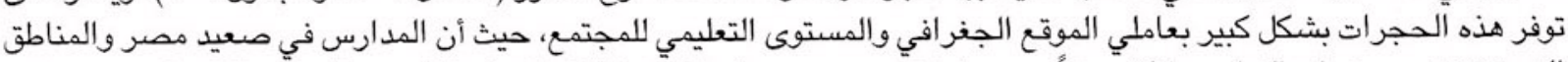

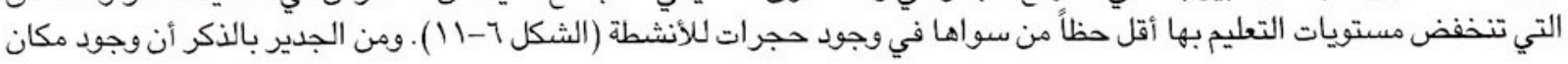




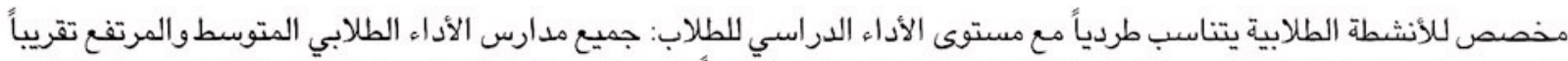

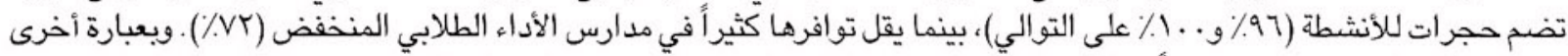

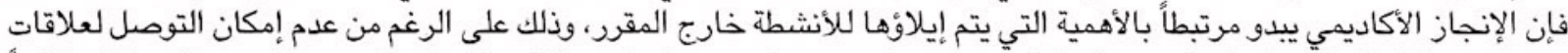

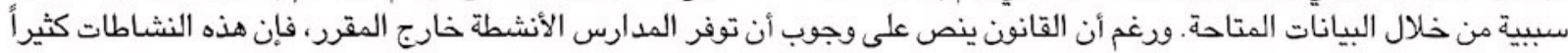

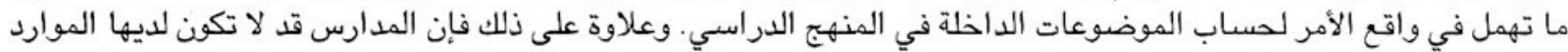

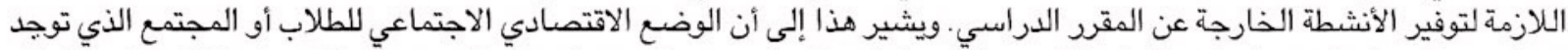

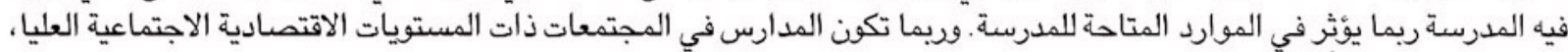

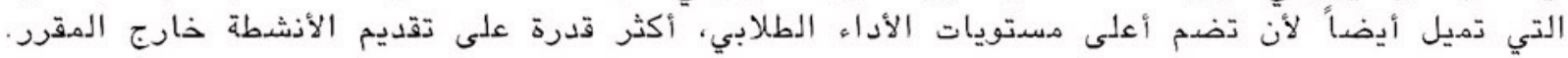

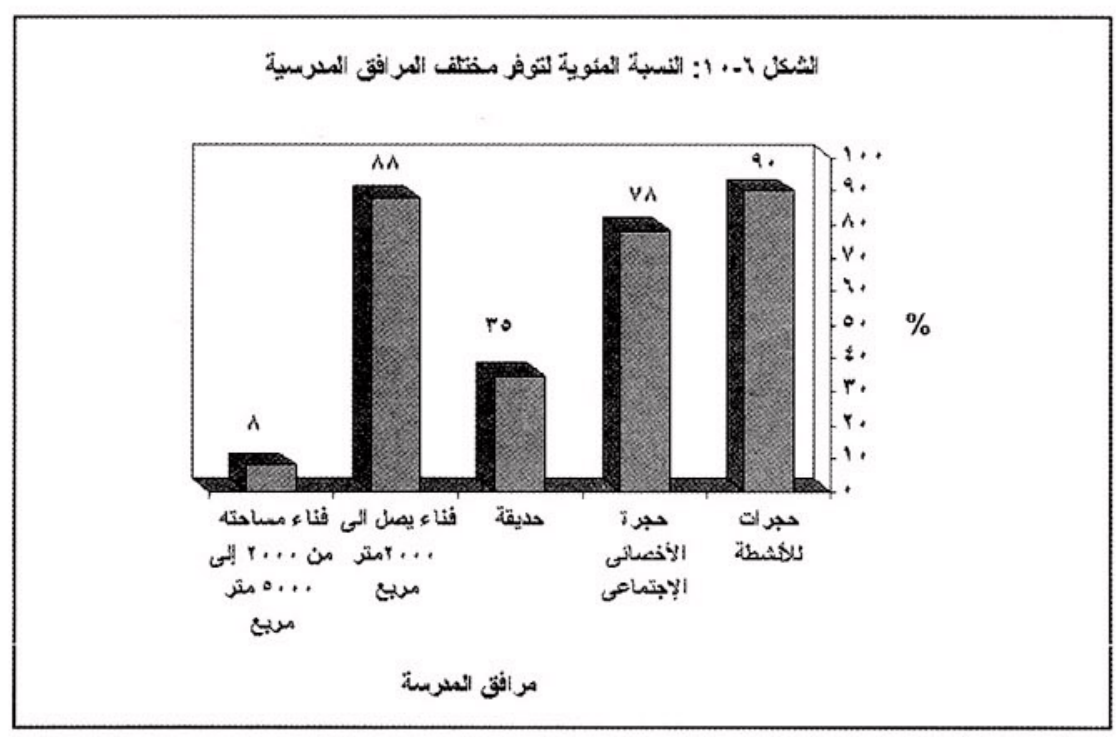

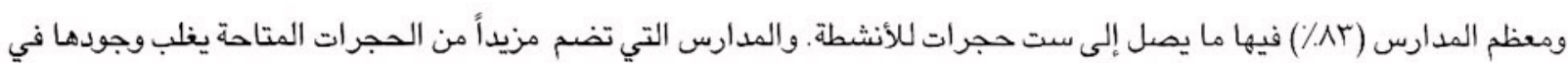

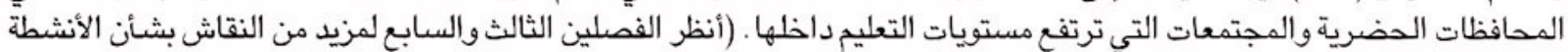

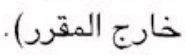

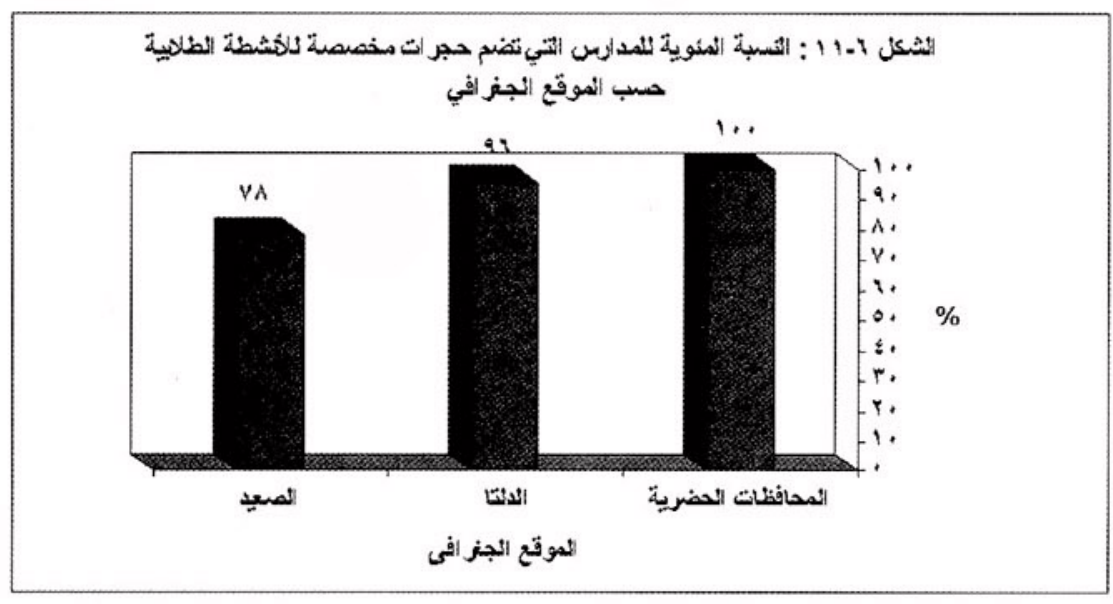

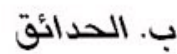

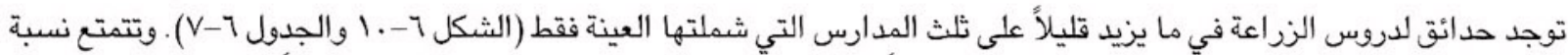

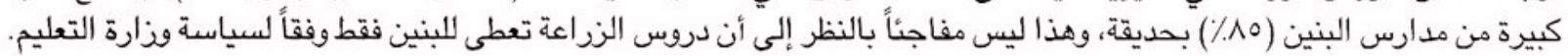

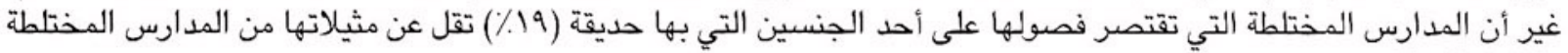

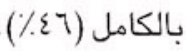




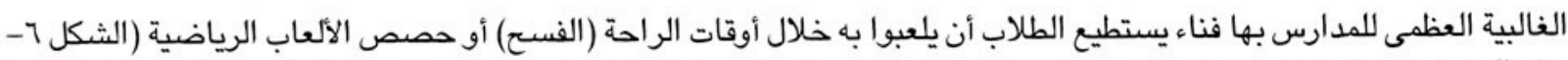

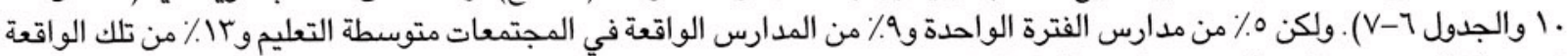

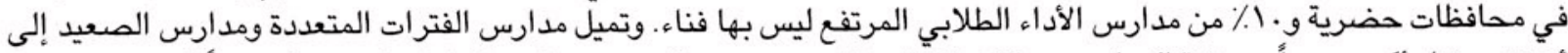

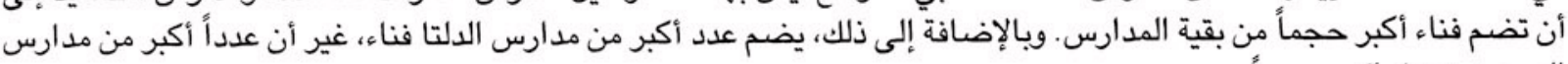

\section{د. حجرة اجتماعات للأخصائيين الاجتماعيين}

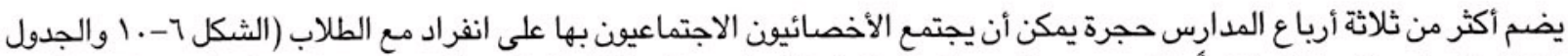

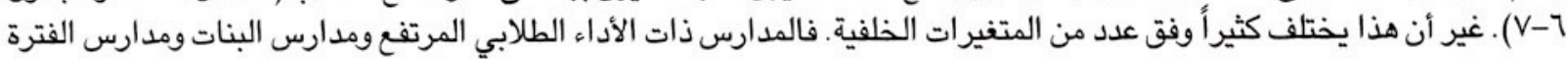

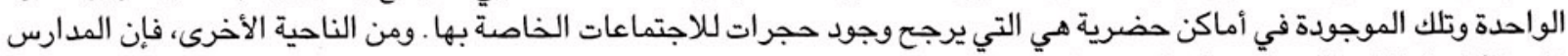

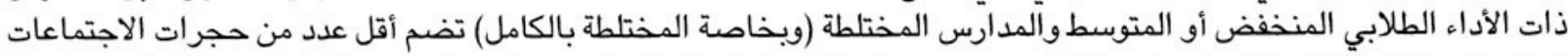

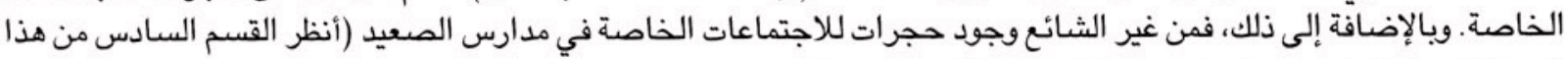

الفصل لمعرفة المزيد عن ظروف عمل الأخصائيين الاجتماعيين).

\section{7. ب الموارد البشرية}

من الواضح أن الموارد البشرية جزء مهم من قدرة المدرسة على توفير تعليم متعمق لطلابها ـ وقد يكون لمدى توفر المعلمين والأخصائيين

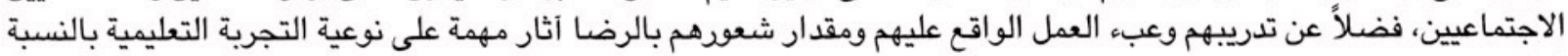

أ. المعلمون

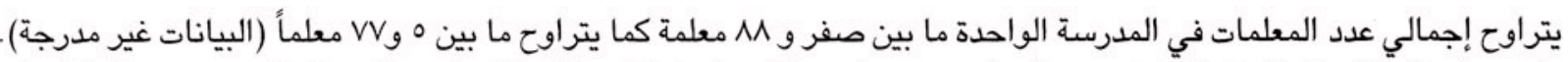

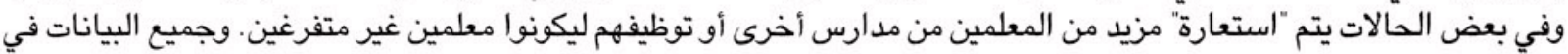

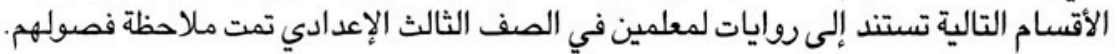

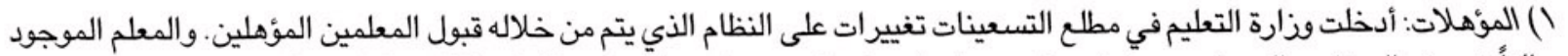

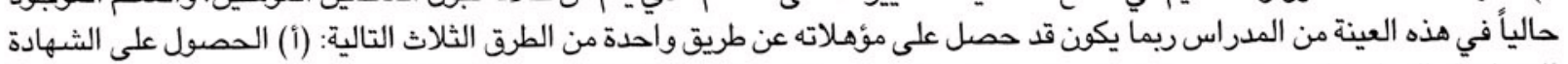

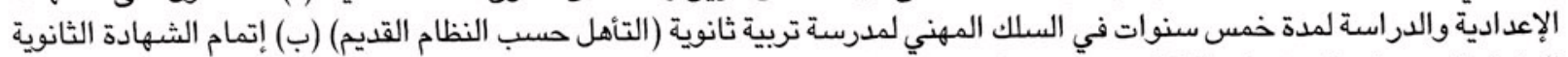

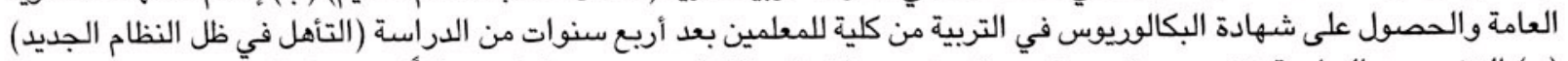

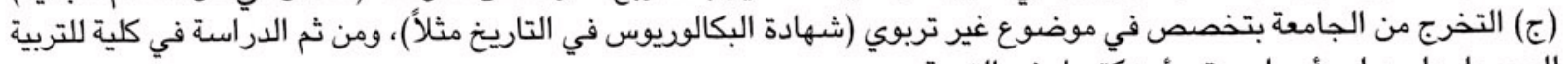
للحصول على دبلوم أو ماجستير أو دكتور اهي في التربية.

وهناك ب^/٪ من المعلمين الذين يحملون مؤهلات تعليمية ولكن هذا لا يرتبط إحصائياً بأي من المتغيرات الخلفية، ولا حتى بالأداء الدراسي

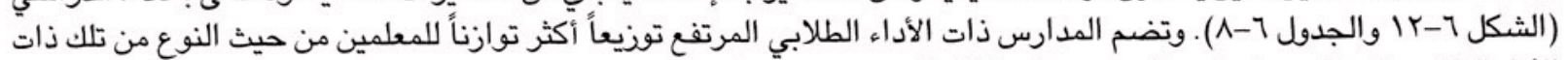

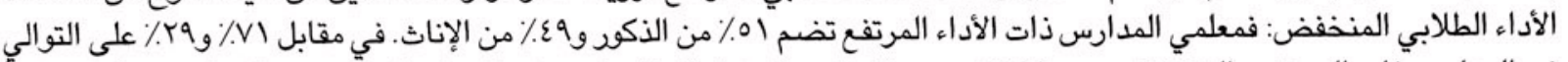

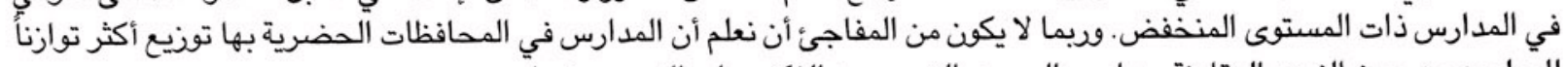
للمعلمين من حيث النوع بالمقارنة بمدارس الصعيد التي يهيمن الذكود على التدريس فيها. 


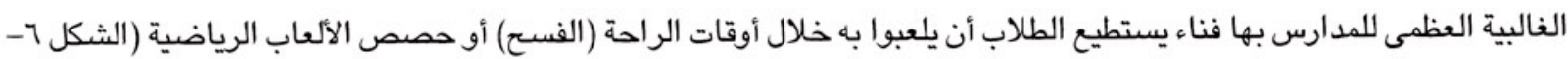

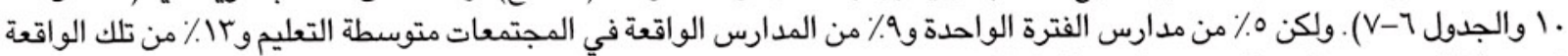

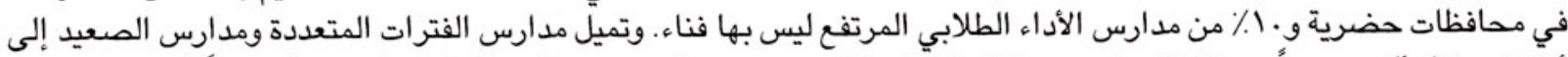

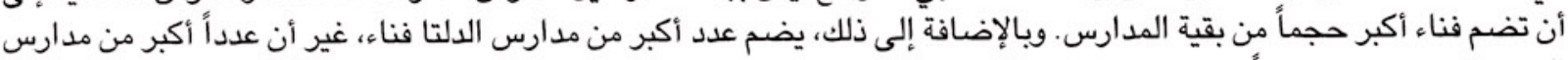

\section{د. حجرة اجتماعات للأخصائيين الاجتماعيين}

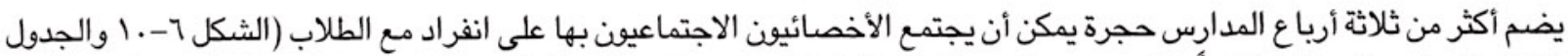

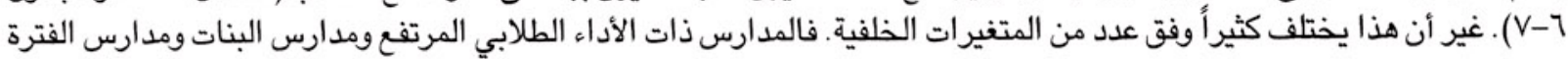

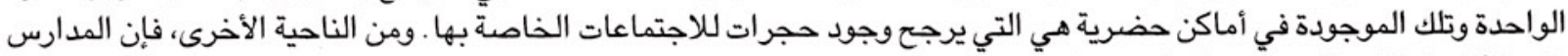

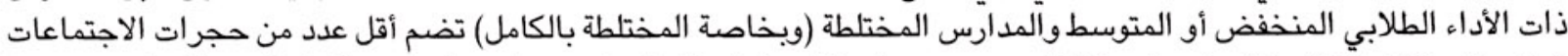

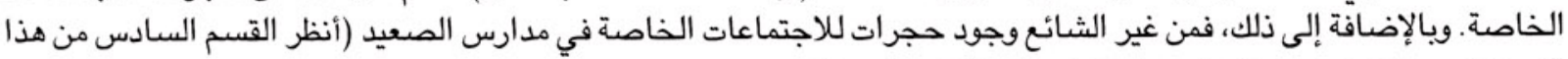

الفصل لمعرفة المزيد عن ظروف عمل الأخصائيين الاجتماعيين).

\section{7. ب الموارد البشرية}

من الواضح أن الموارد البشرية جزء مهم من قدرة المدرسة على توفير تعليم متعمق لطلابها ـ وقد يكون لمدى توفر المعلمين والأخصائيين

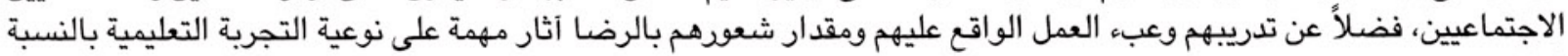

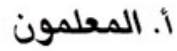

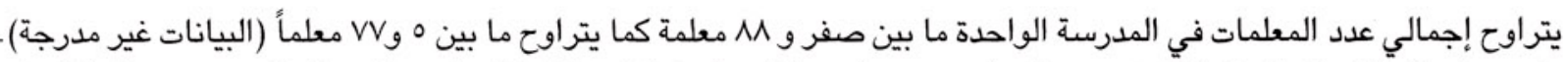

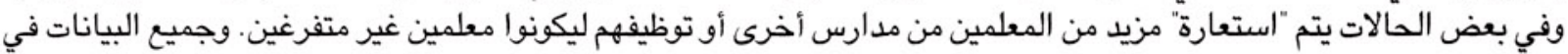

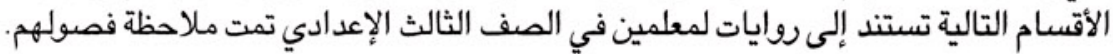

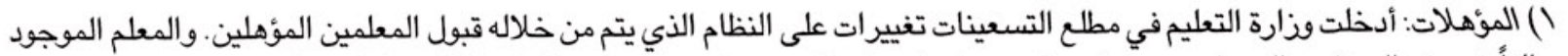

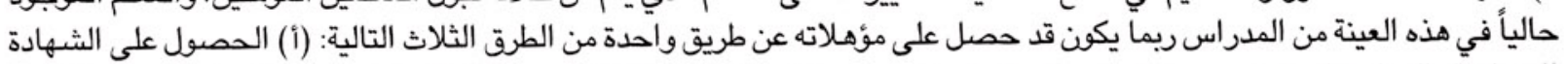

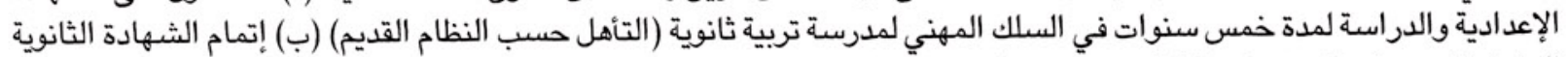

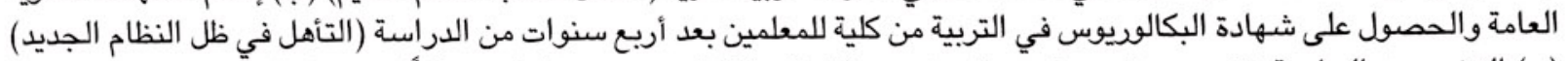

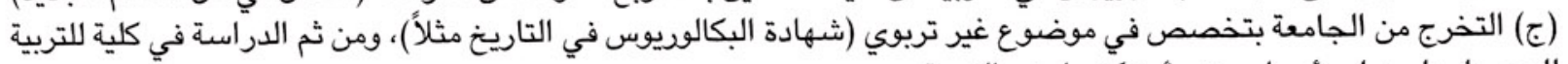
للحصول على دبلوم أو ماجستير أو دكتور اهي في التربية.

وهناك ب^/٪ من المعلمين الذين يحملون مؤهلات تعليمية ولكن هذا لا يرتبط إحصائياً بأي من المتغيرات الخلفية، ولا حتى بالأداء الدراسي

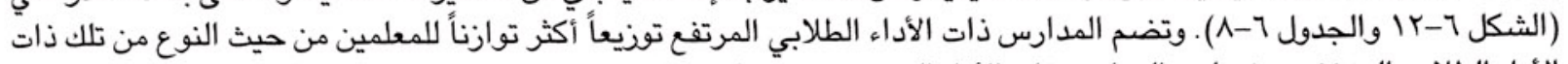

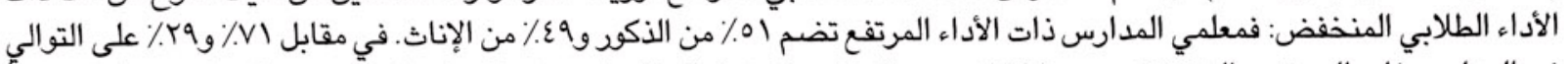

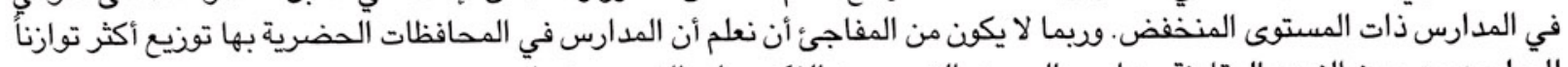
للمعلمين من حيث النوع بالمقارنة بمدارس الصعيد التي يهيمن الذكود على التدريس فيها. 


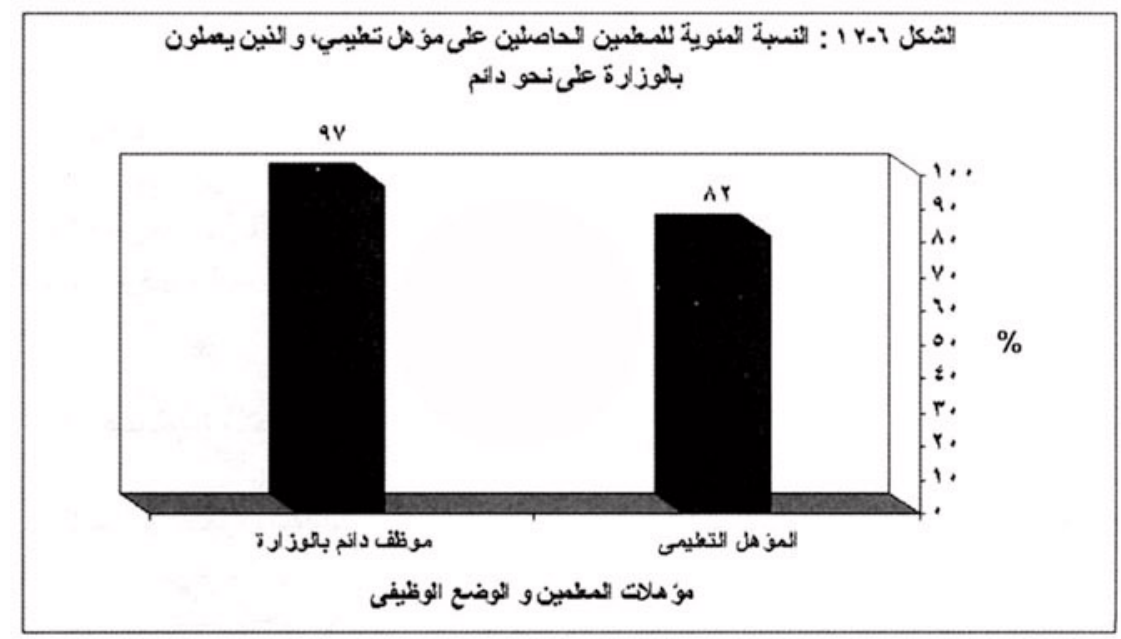

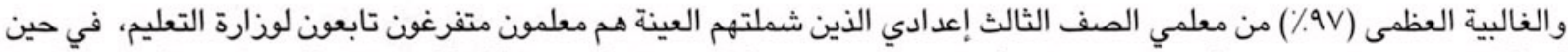

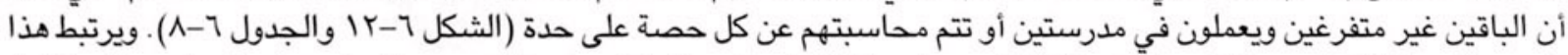

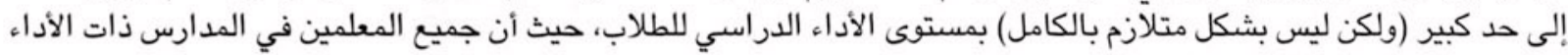
المرتفع موظفون متفرغون لدى الوزارة.

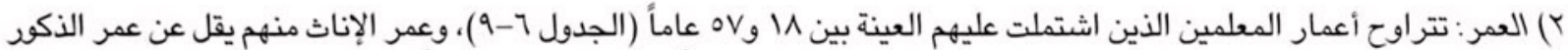

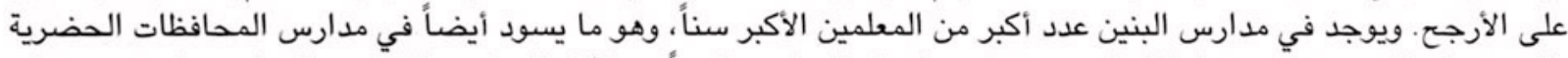
والمجتمعات التي يرتفع مستواها التعليمي. وتتناسب أعمار المعلمين طردياً مع الأداء الدراسي للطبلاب، ولكئ ولكن ليس على نحو منتظم.

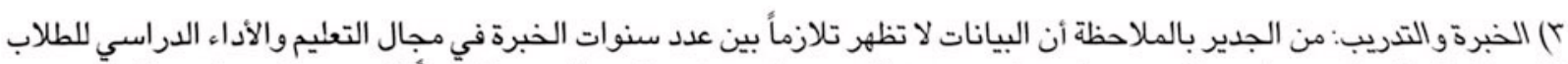

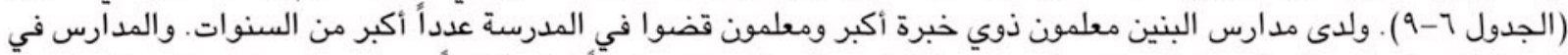
المحافظات الحضرية والمجتمعات ذات المستوى التعليمي المرتفع تضم نسبًا أعلى كثيراً من أصحاب الخبر الخبرة من المعلمين.

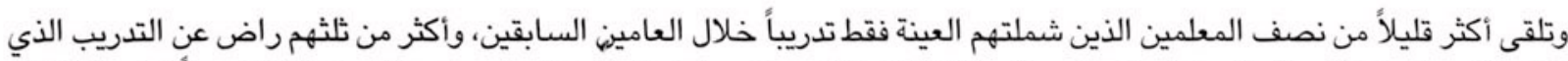

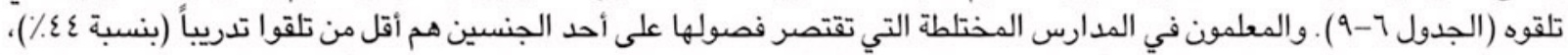

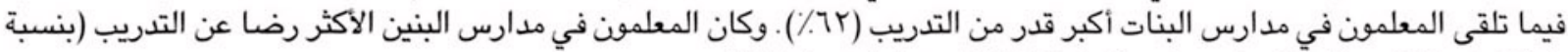

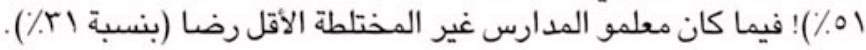

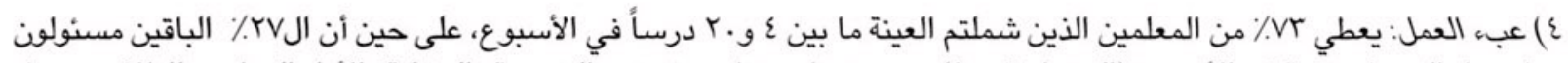

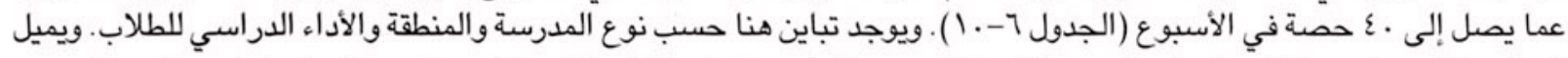

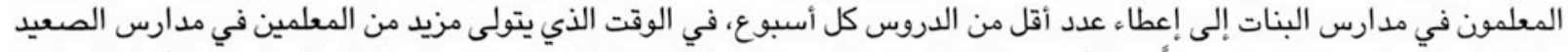

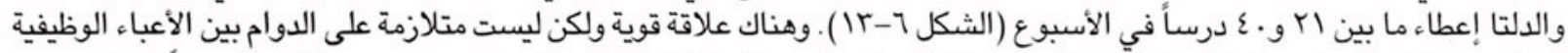

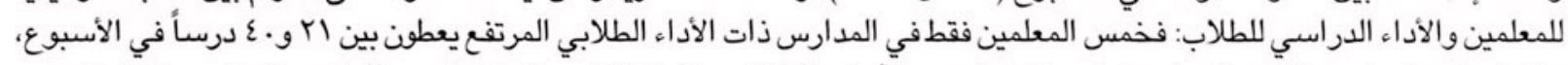

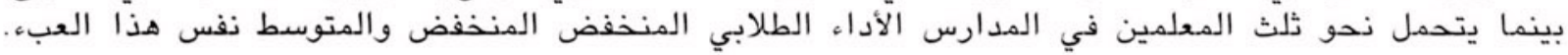




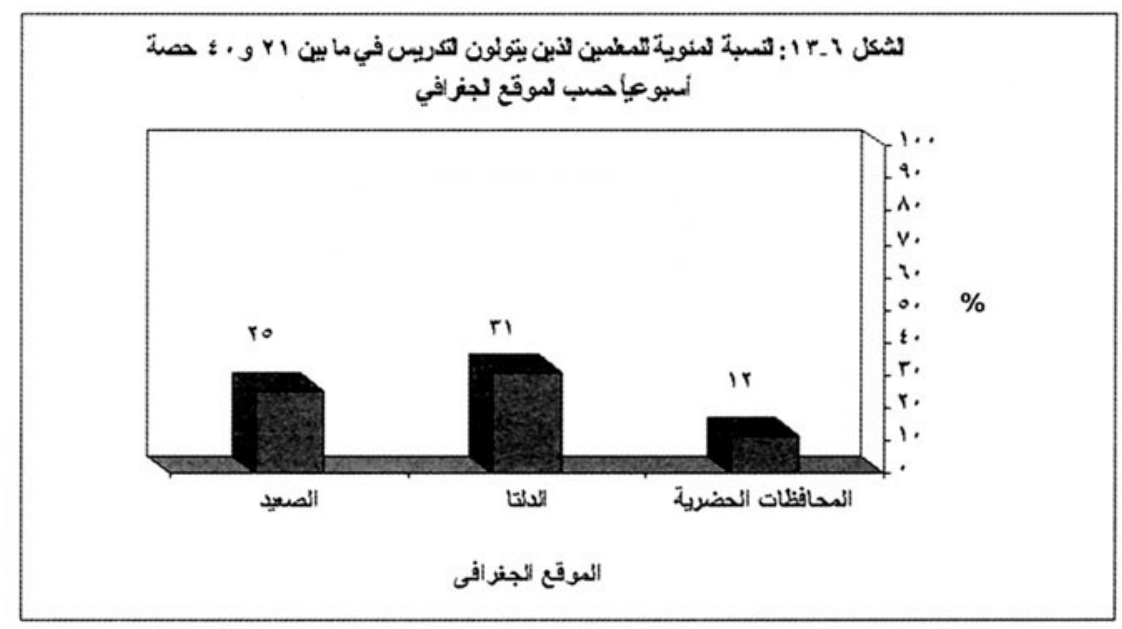

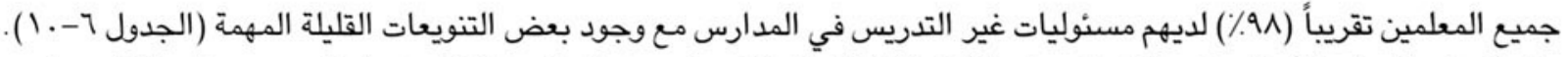

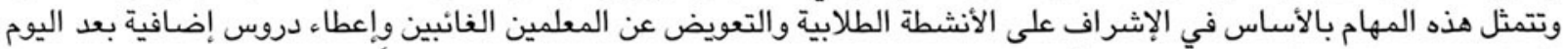

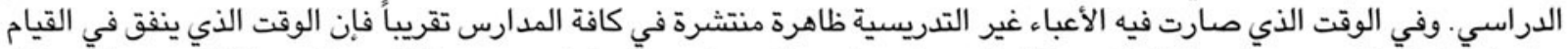

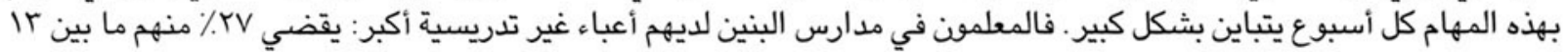

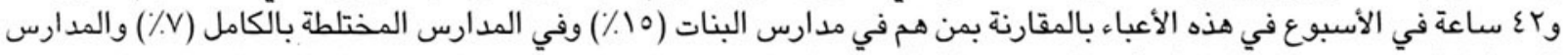

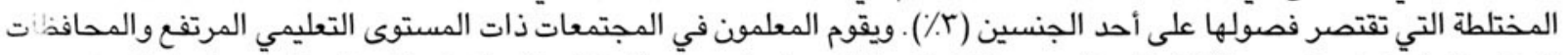

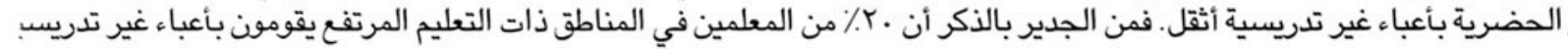

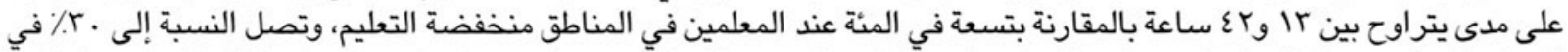

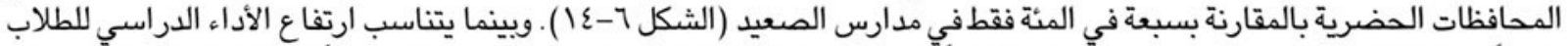

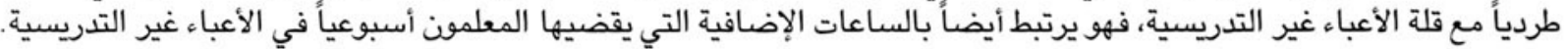

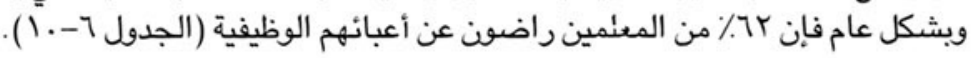

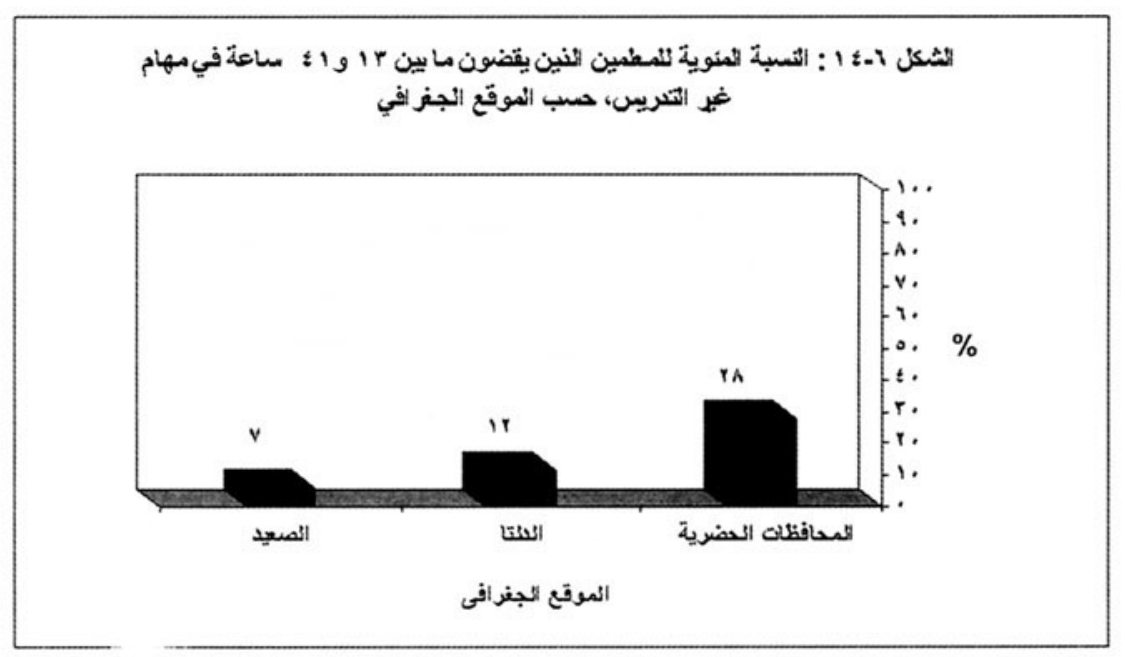

يميل عv٪ من المعلمين في المدارس المختلطة ذات الفصول المنفصلة لكلا الجنسين للرضا عن أعبانهم الوظيفية أكثر من غيرهم، وتجدر ألفاء

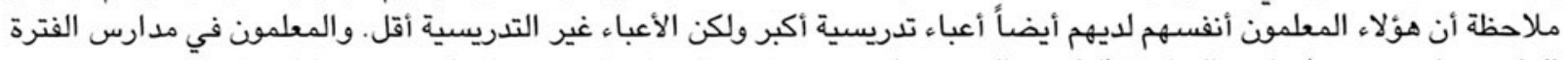

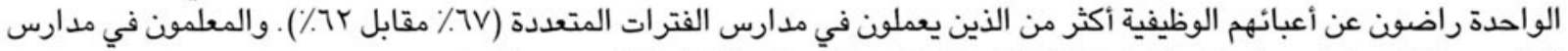

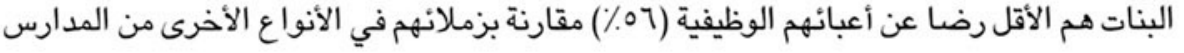

م) الإشر اف: هناك إشراف على المعلمين على مستويات مختلفة لضمان اتباعهم لجداول الفصول وترتيب الدروس في المنهج وللتأكد

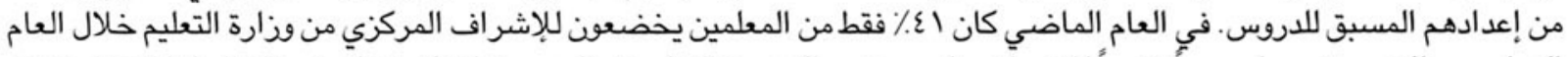

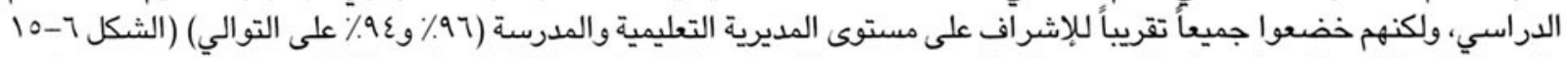

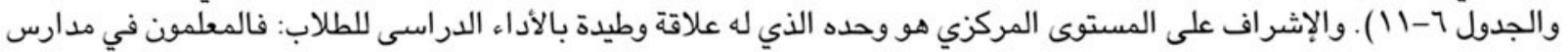




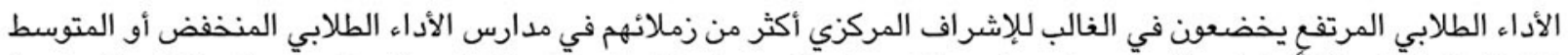

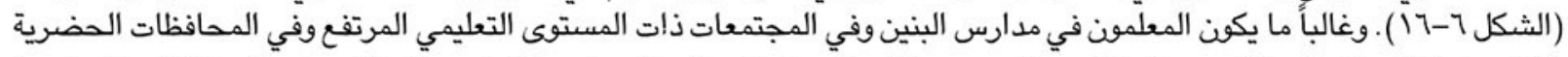

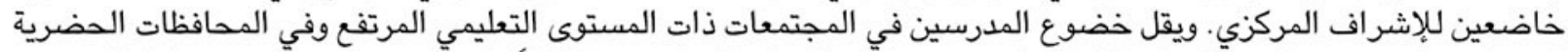

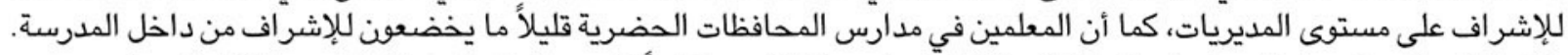

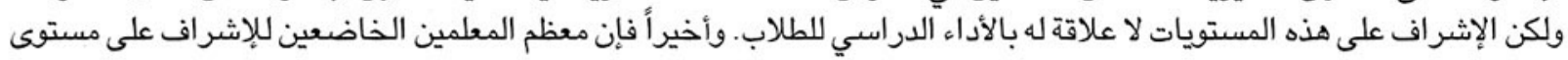

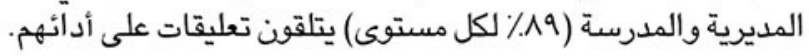

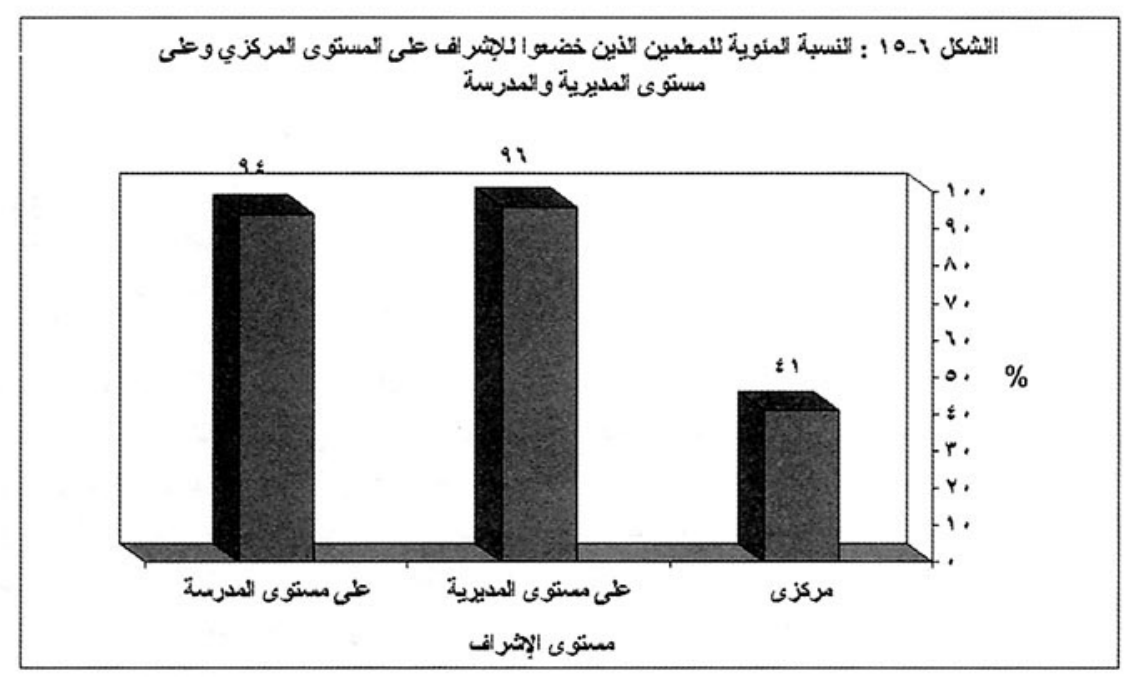

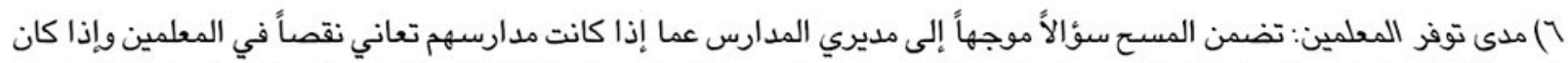

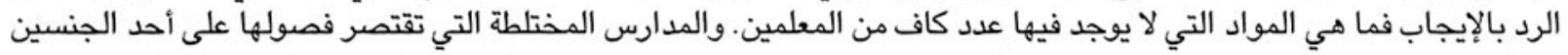

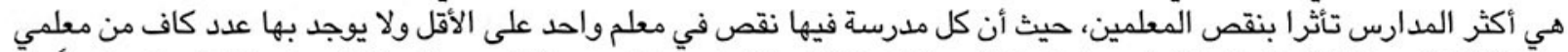

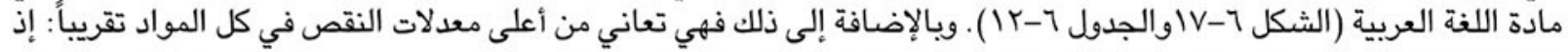

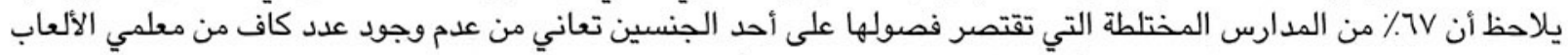

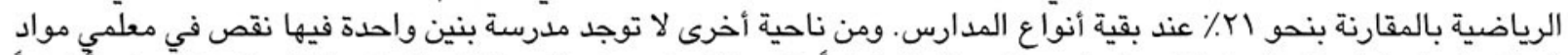

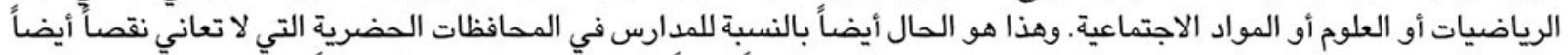

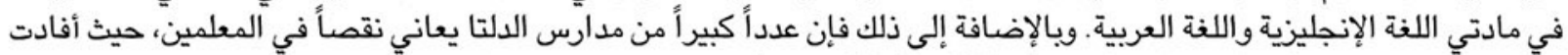

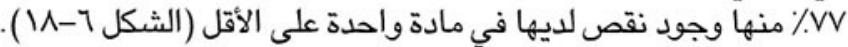

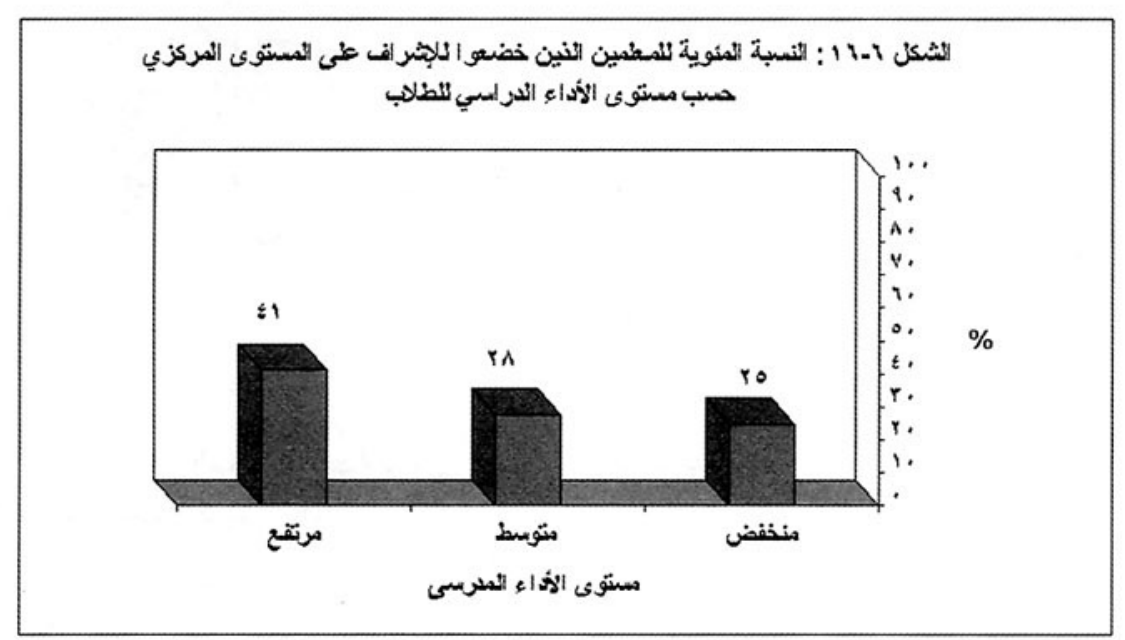




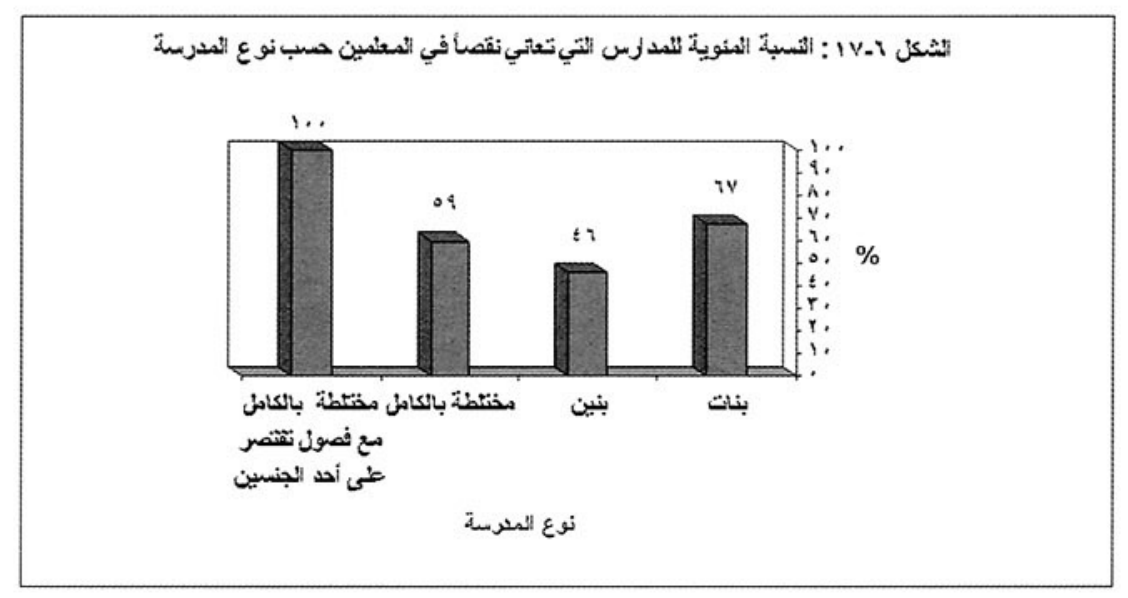

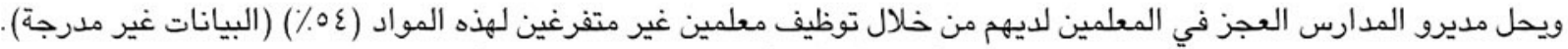

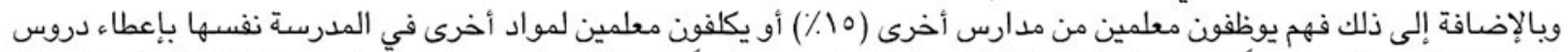

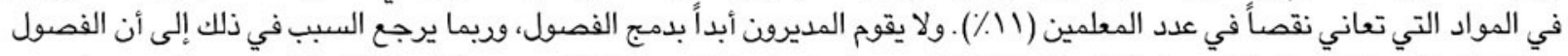

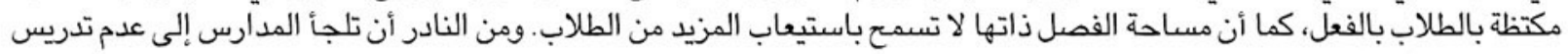
مادة معينة على الإطلاق.

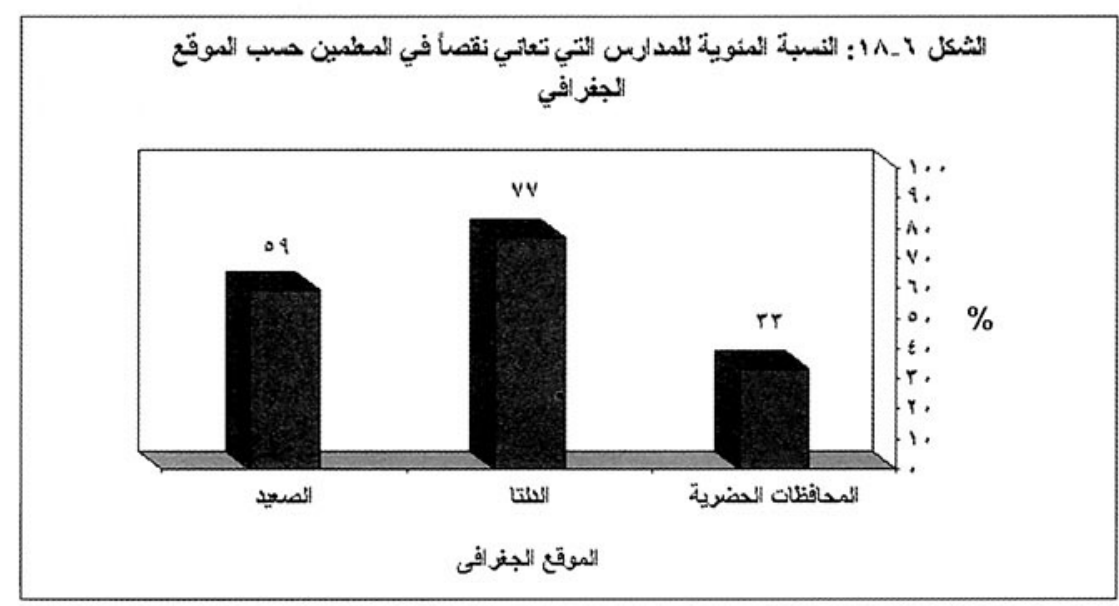

ب. الأخصائيون الاجتماعيون

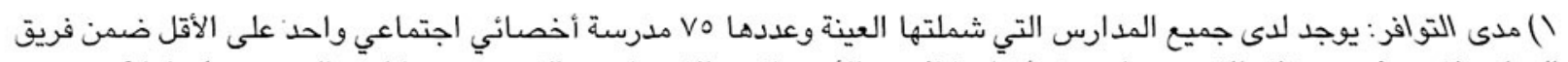

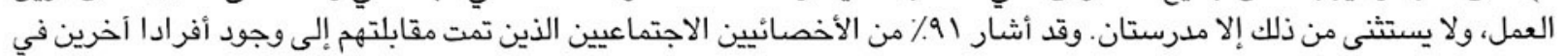

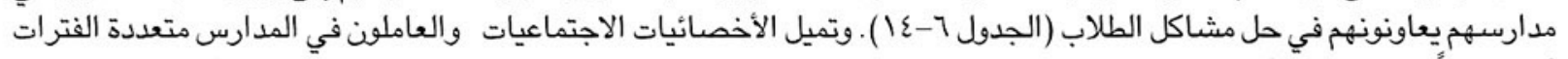

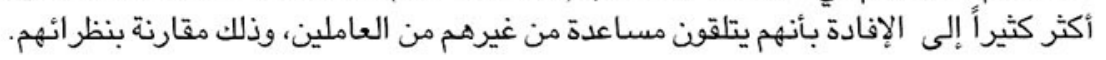

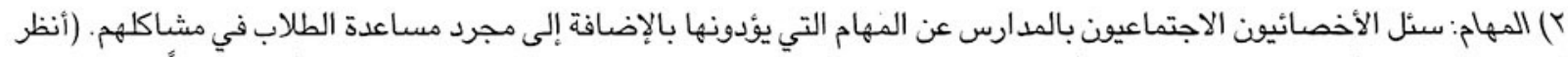

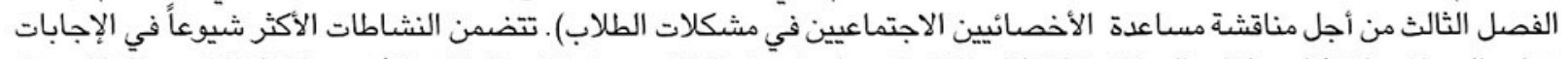

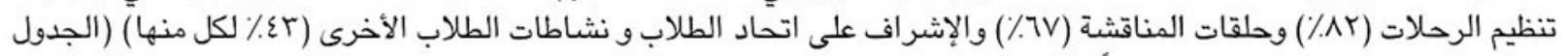

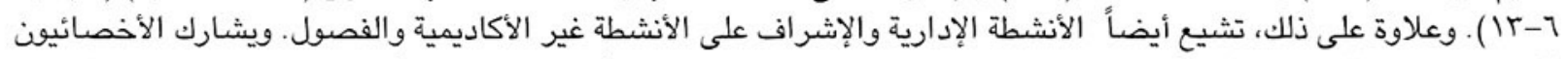

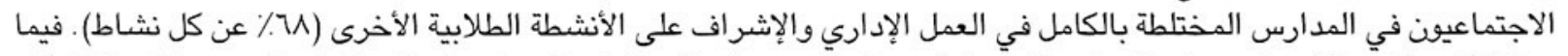

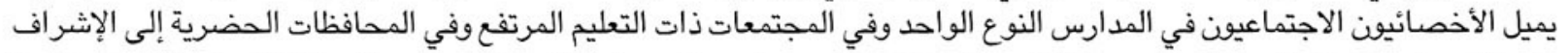

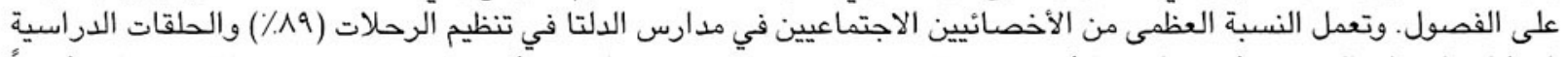

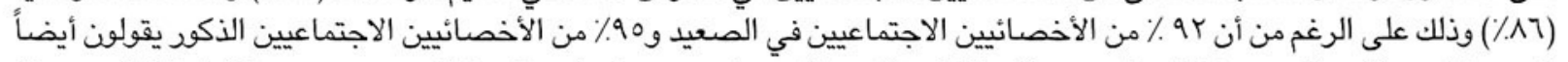

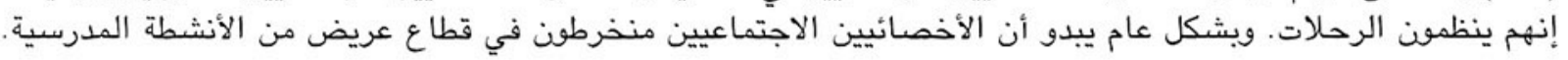


وهناك نشاط أخر مهم يقوم به الأخصائي الاجتماعي في المدرسة وهو الاجتما ع مع مجموعات من الطلاب لبحث عدد من المواضيع.

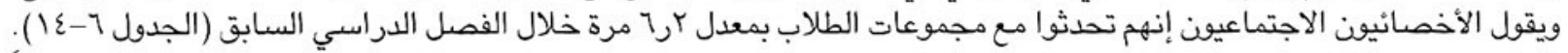

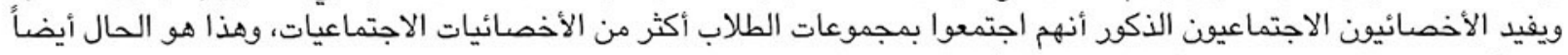

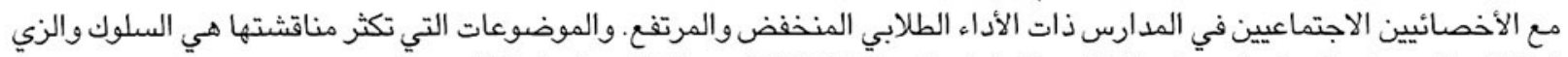

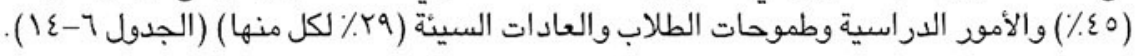

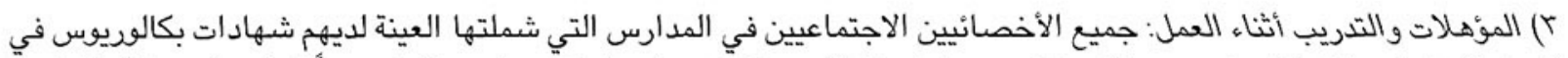

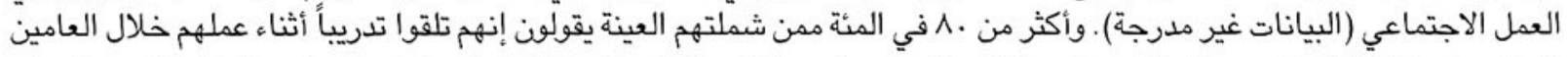

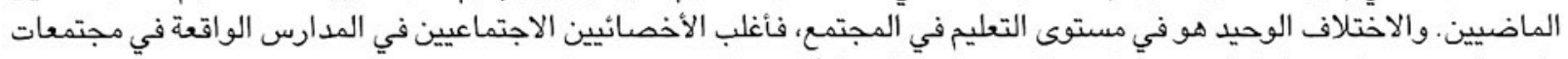

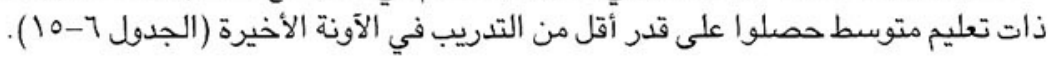

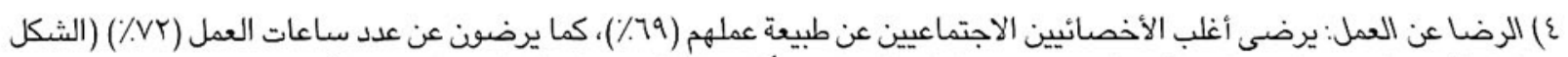

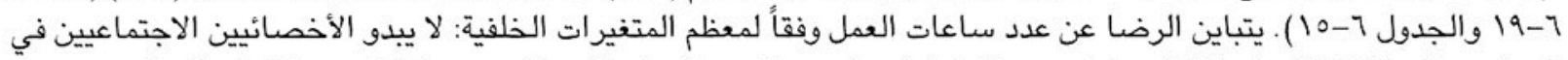

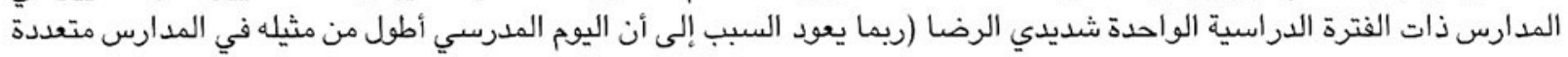

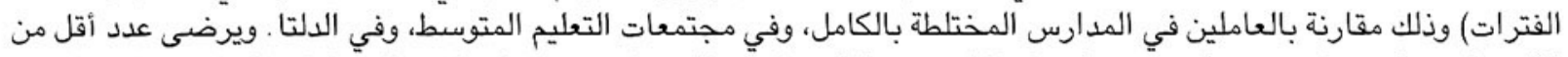

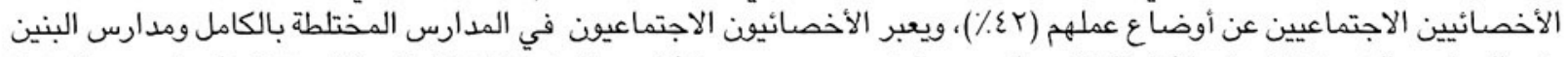

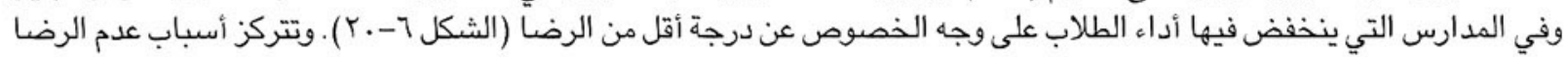

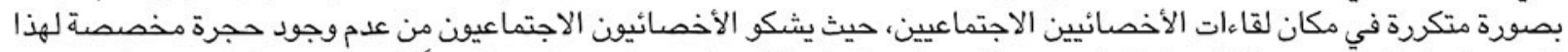

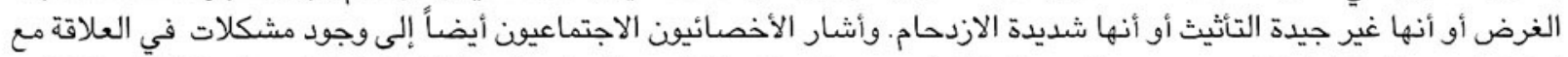

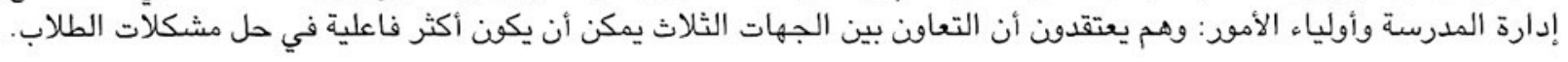
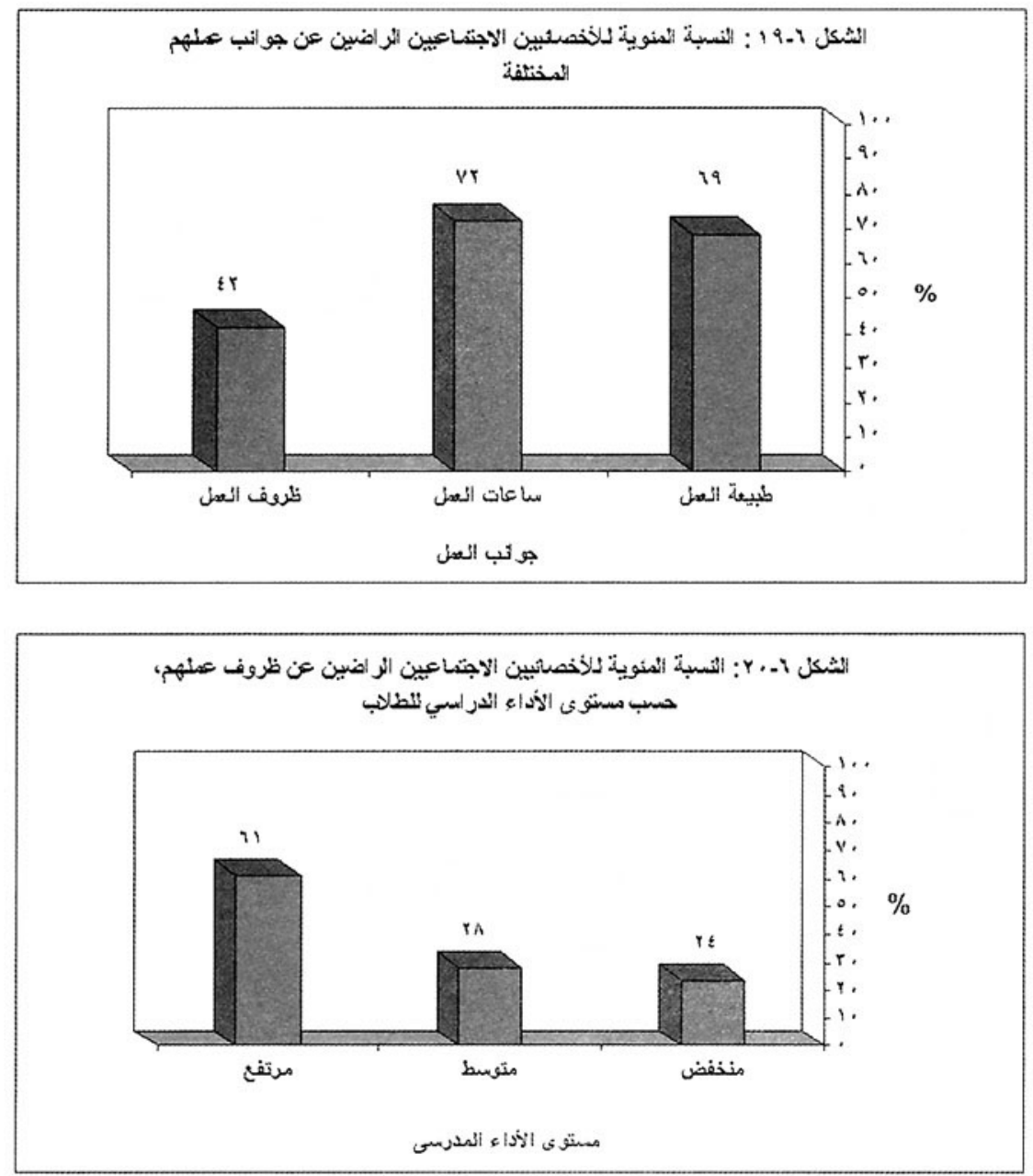
يبحث هذا الفصل في الموارد المادية والبشرية المتاحة من أجل تأمين بيئة تعليم مريحة وصحية للطلاب. معظم المدارس مجهزة بمدئ بمكتبة

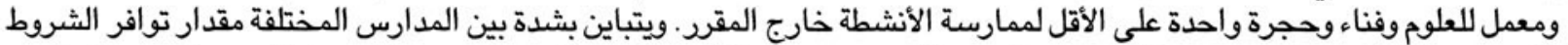
الأخرى، مثل أجهزة الكمبيوتر والتلفزيون وأجهزة الفيديو وحجرة الأخصائيين الاجتماعيين، والفصول الصحية جيدة التأثيث.

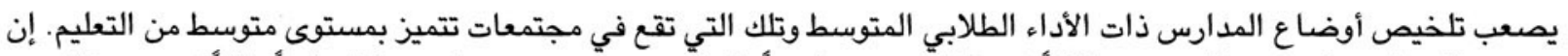

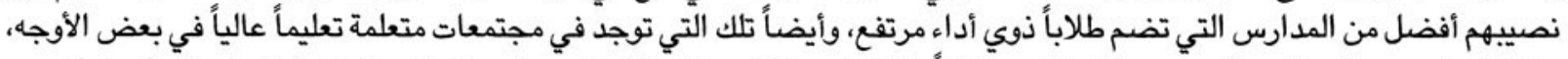

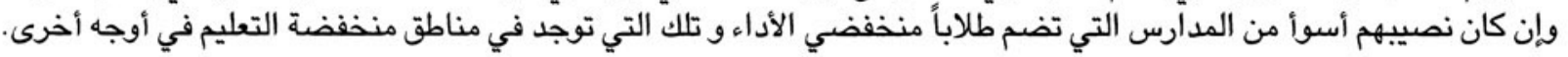

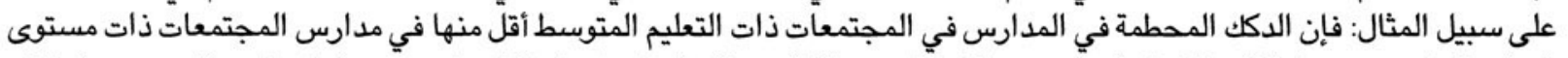

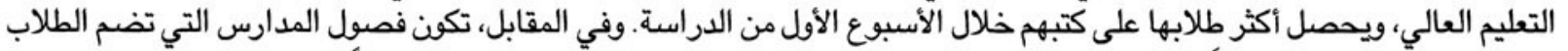

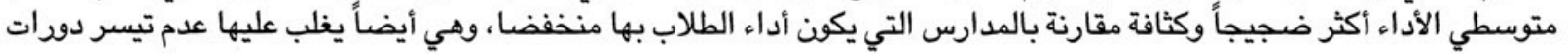
مياه منفصلة للبنين والبنات.

وتتمتع المدارس المختلطة بالكامل، ومعظمها في المناطق الريفية، بأكثر البيئات صحية: فتوجد فيها الفصول الأنظف والأكثر تهوية و

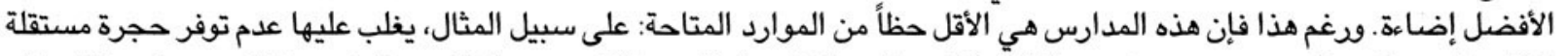

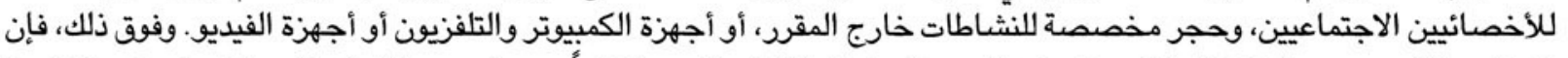

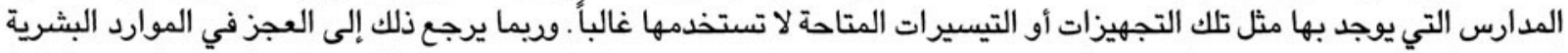

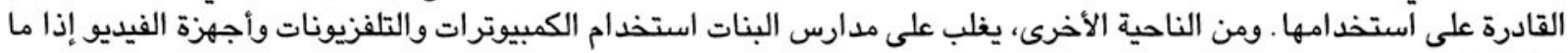

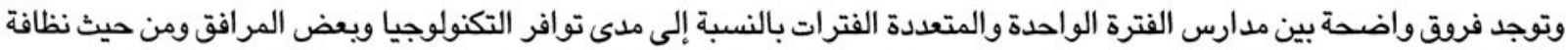

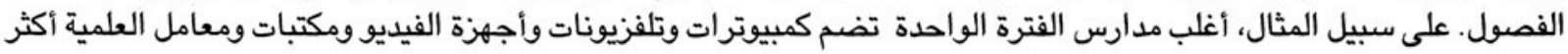

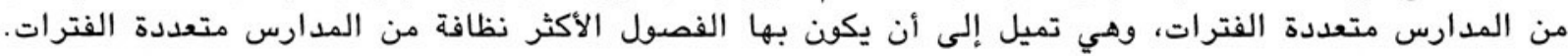

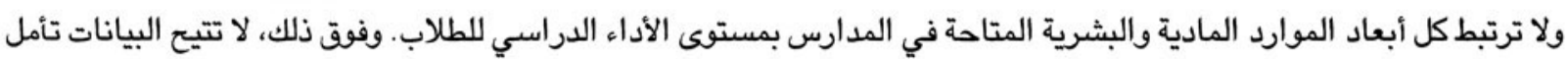

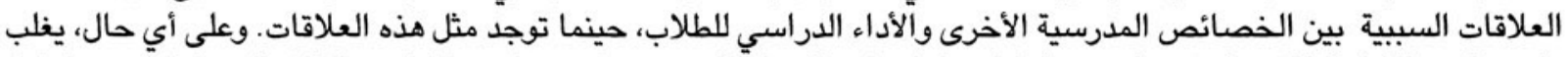

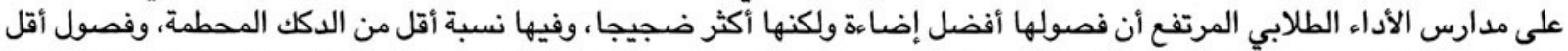

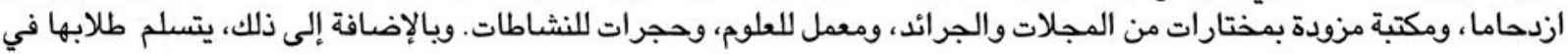
الغالب الكتب المدرسية خلال الأسبوع الأول من العام الدراسي.

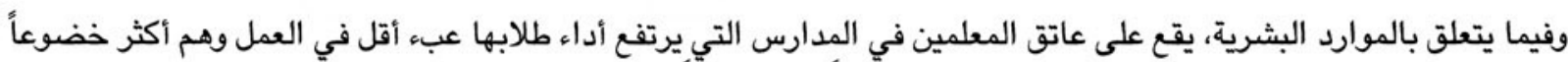

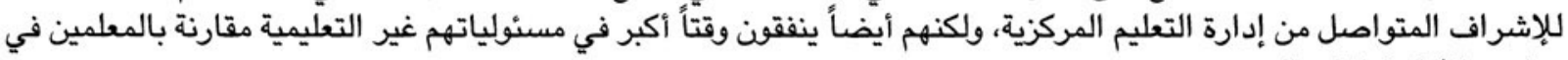
مدارس الأداء الطلابي المنخفض.

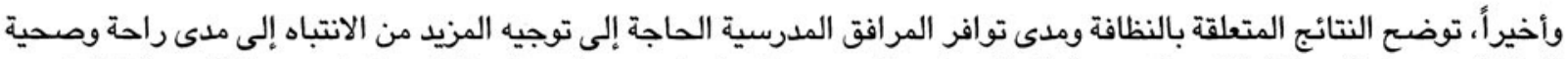

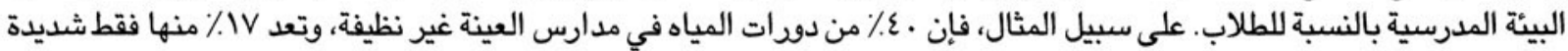

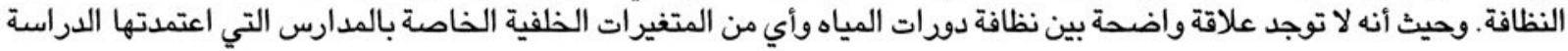

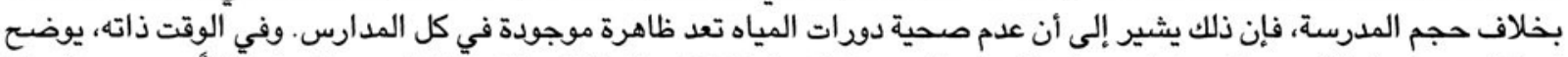

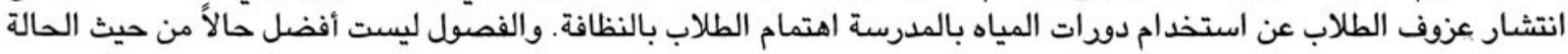

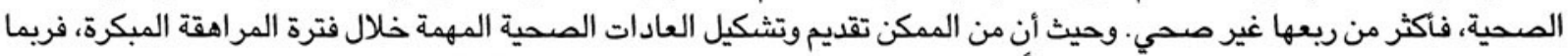
يضرب الانتباه المتزايد بصحية المدرسة مثالاً يحتذى للطلاب.

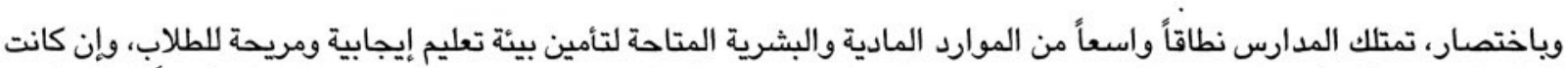

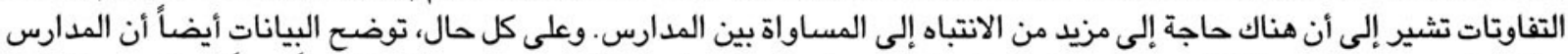

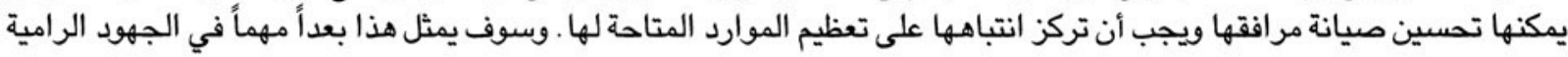
إلى تحسين نوعية التعليم في مصر. 


\section{فرص التعلم}

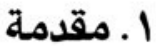

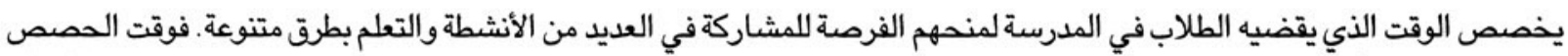

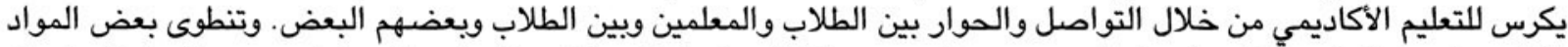

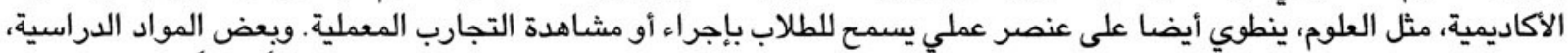

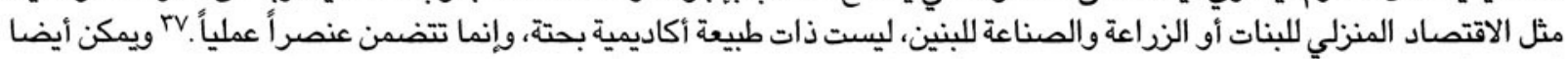

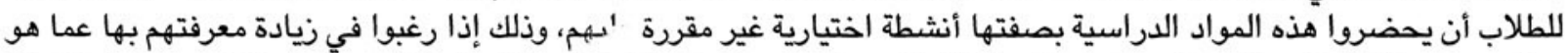

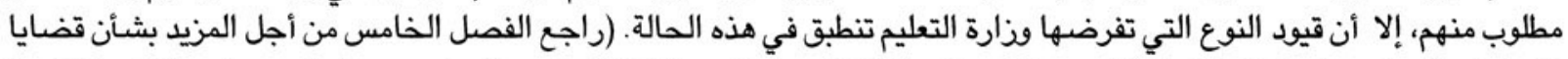

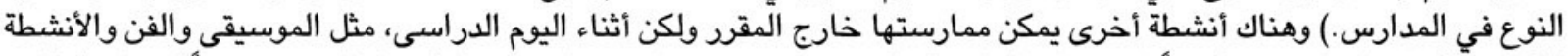

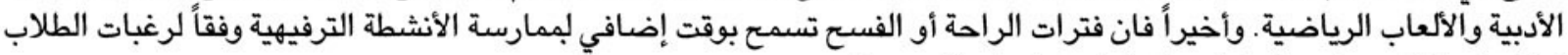

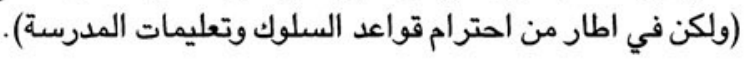

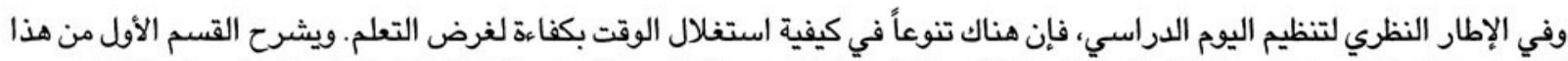

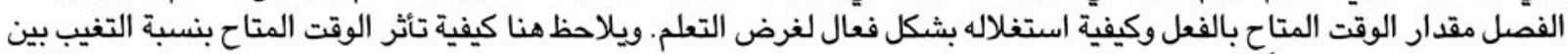

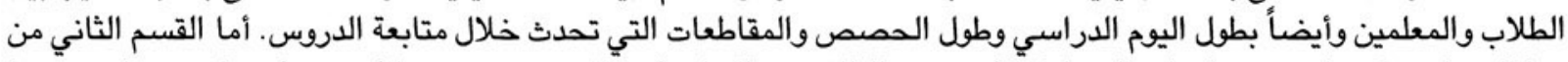

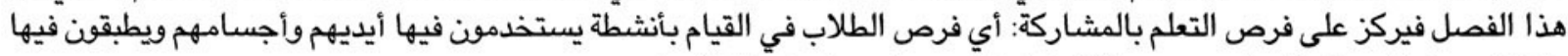

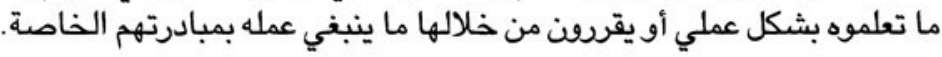

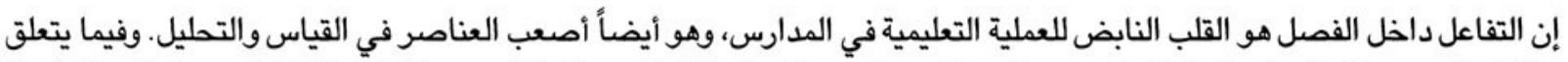

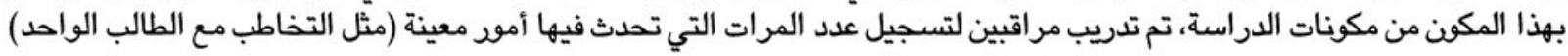

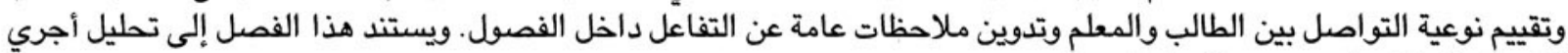
لكل هذه البيانات التي تمت ملاحظتها.

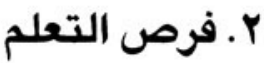 \\ أ. طول اليوم الدراسي و الحصص}

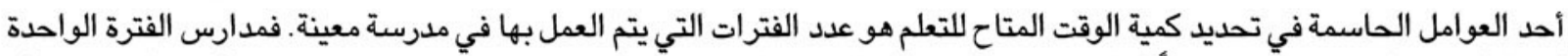

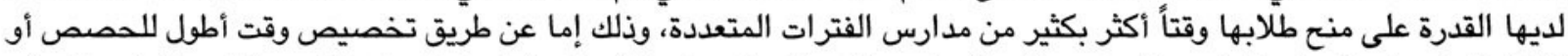

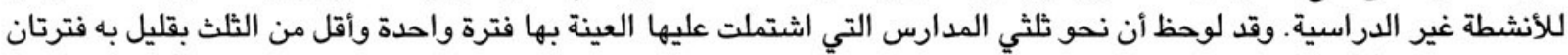

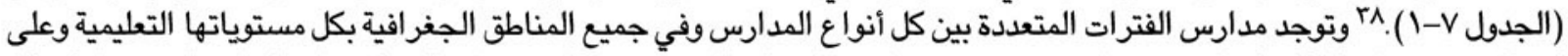

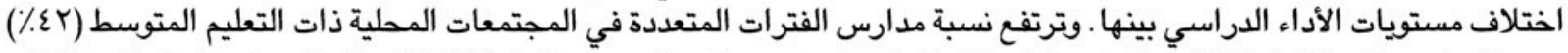

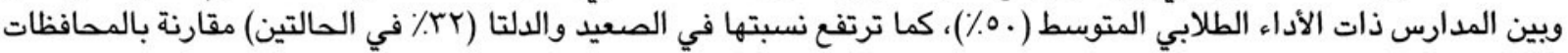

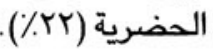

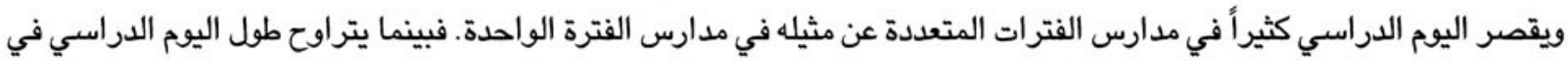

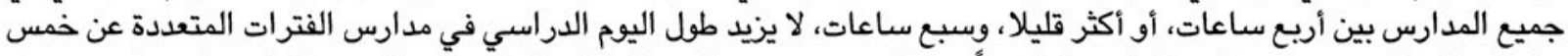

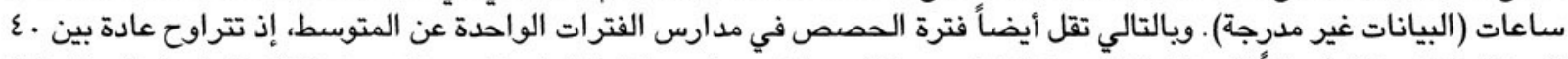

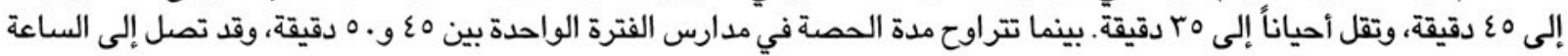

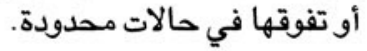

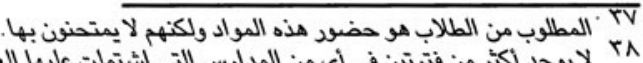

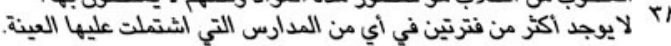


تنظر دراستنا هذه أيضاً في المدة المخصصة فعلياً بالحصة للتدريس وممارساته المختلفة، بما يشمل الشرح والقار والمناقشة والأسئلة

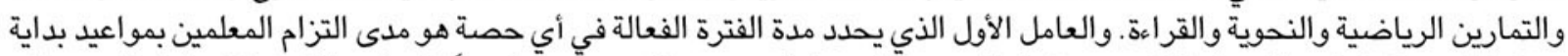

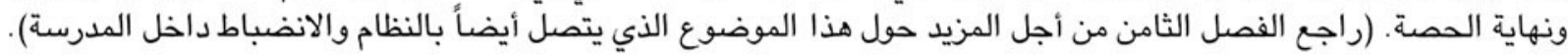

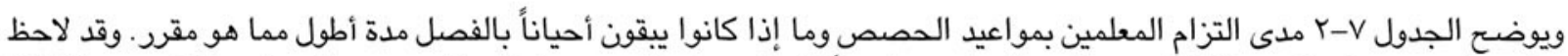

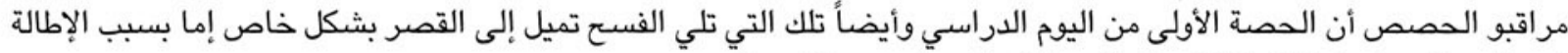
في طابور الصباح أو تأخر الطلاب في العودة إلى فصولّهم بعد الفسحة.

وقد لوحظ أن نصف عدد المعلمين الذين شملتهم العينة جاءوا إلى فصولهم متأخرين أو غادروها مبكرين عن مواعيدهم المقررة (الشكل

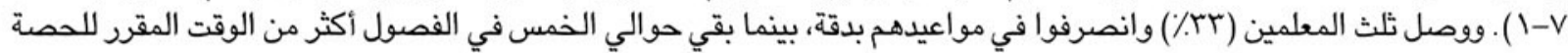

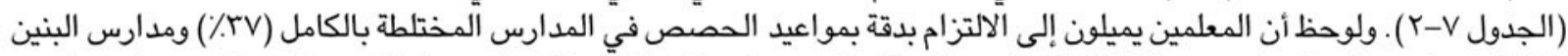

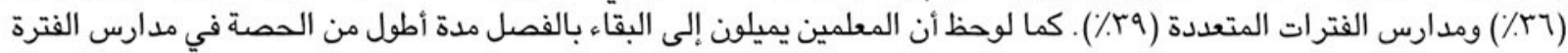

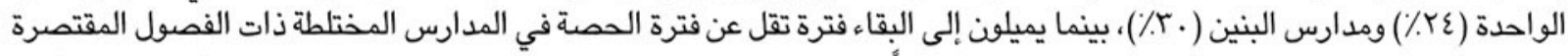

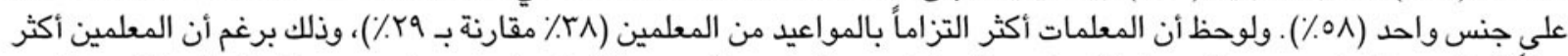

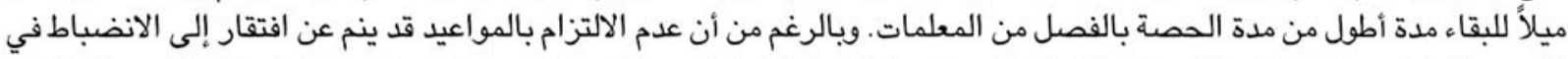

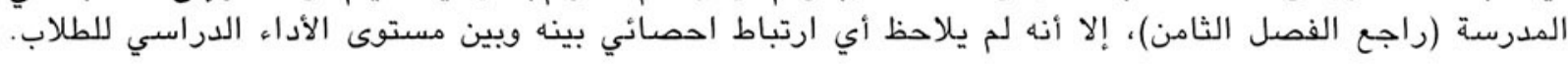

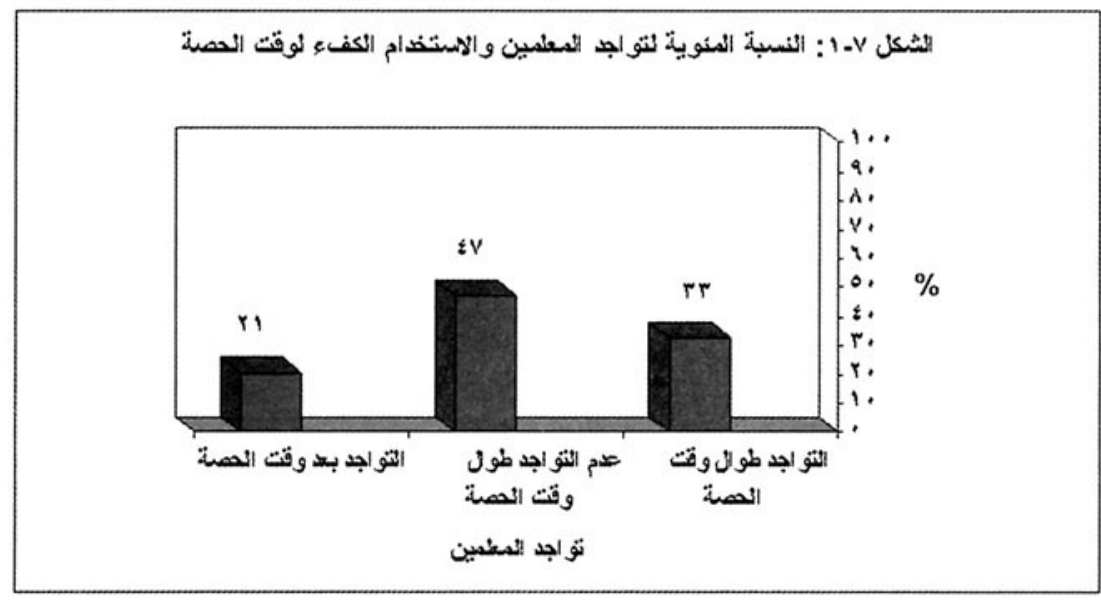

ج. الاستخدام الكفء لوقت الحصة

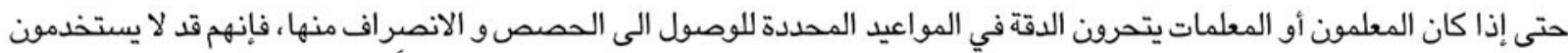

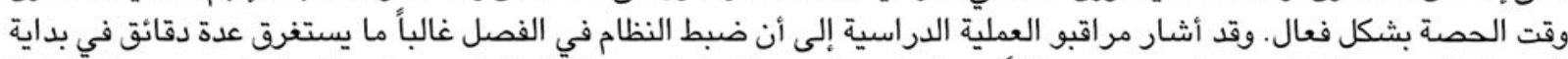

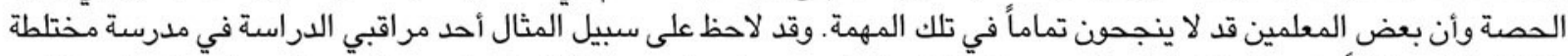

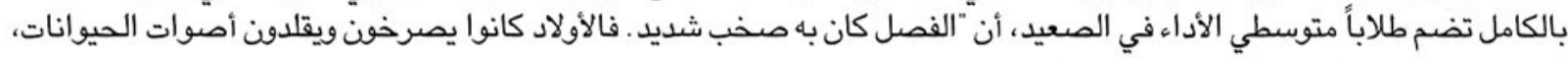
بينما وضعت ثلاثة أرباع البنات رؤوستهن على المكاتب فئ ورحن في النوم".

وتعطيل الدرس أمر شائع أثناء الحصص الدراسية. فقد لاحظ المراقبون أن بعض الطلاب موكل بالذهاب إلى كل الفصو الفصول، على الأقل

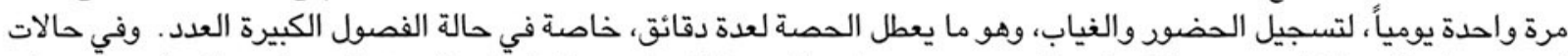

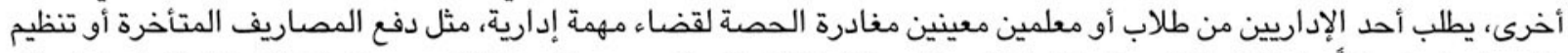

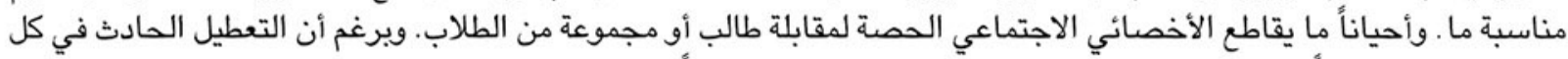

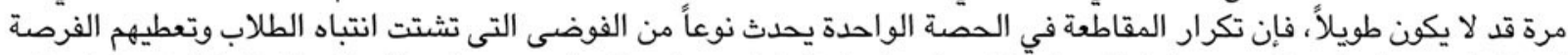

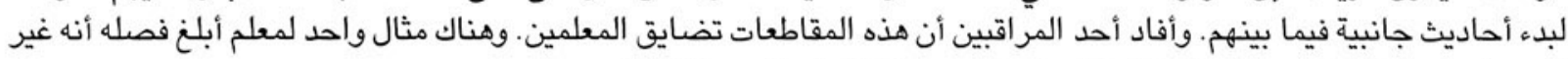
قادر على استكمال الدرس في ظلا تلل الظروف وانه أنه سيستكمله في الحصة التالية.

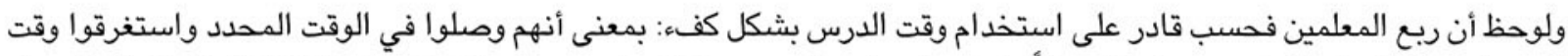

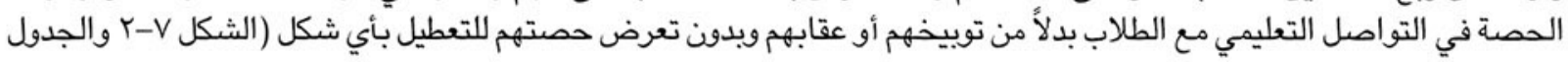




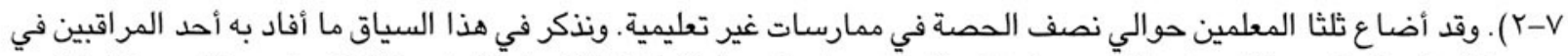

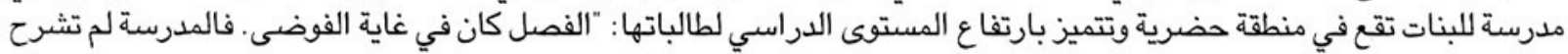
الدرس.... ولم تساعد طالباتها على الاطلاق. فقد أبلغتهن ببعض الأمود ثم جلست إلى جانب زميلة لها وأخذتا تتجاذبان أطراف الف الحديث."

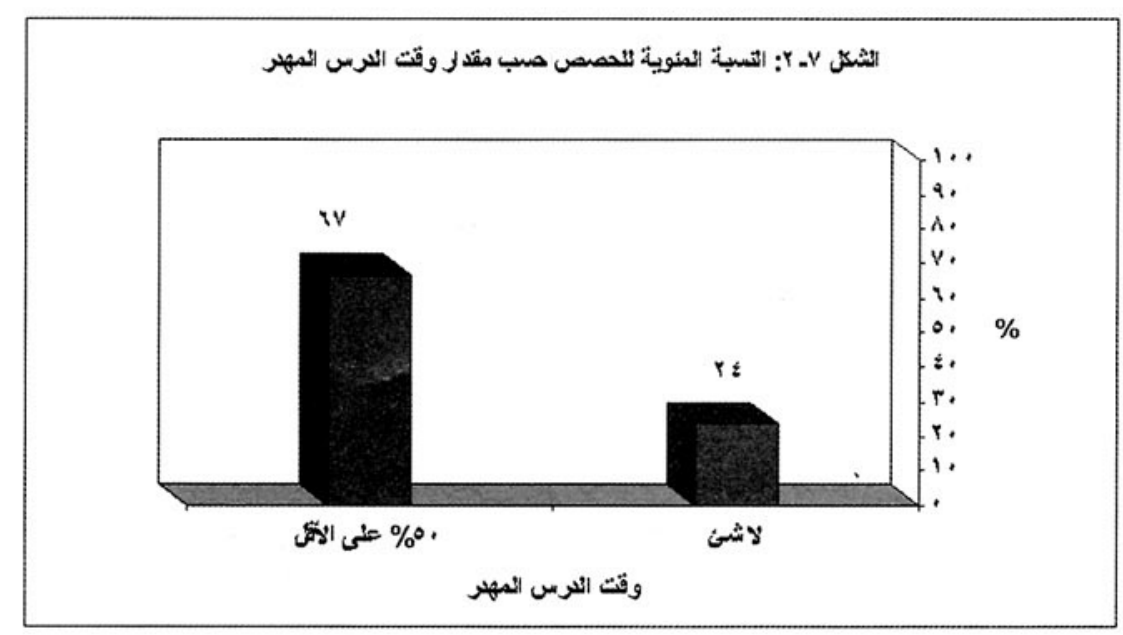

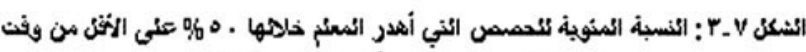

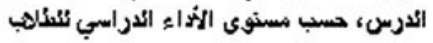

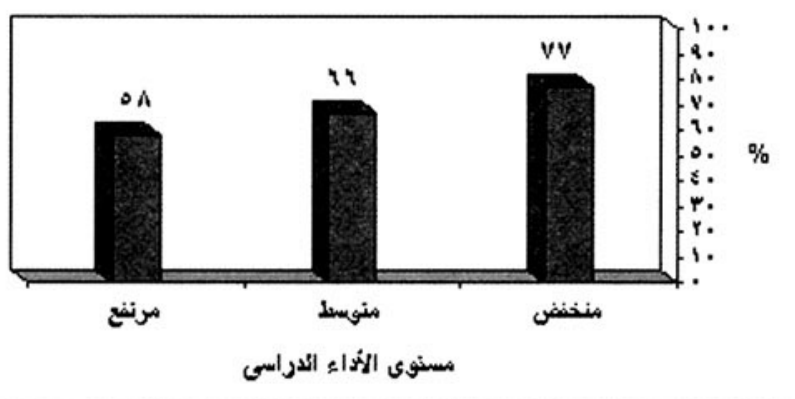

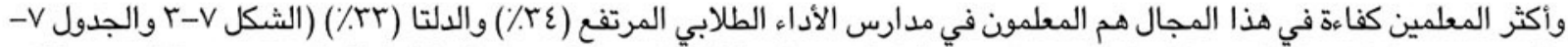

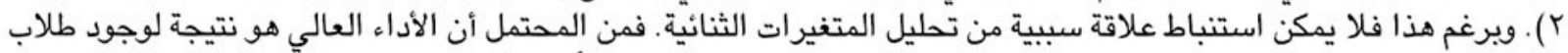

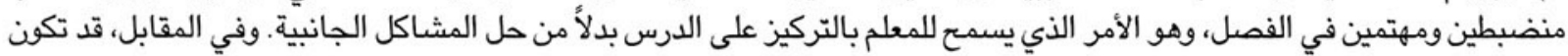

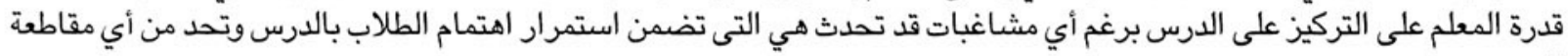
للدرس.

\section{د. التفيب بين الطلاب و المعلمين}

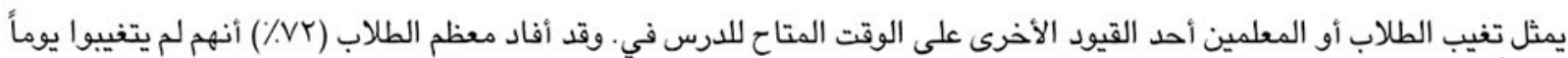

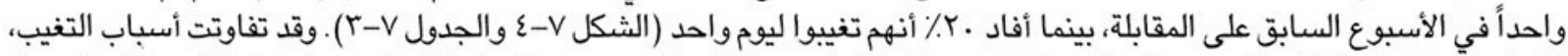

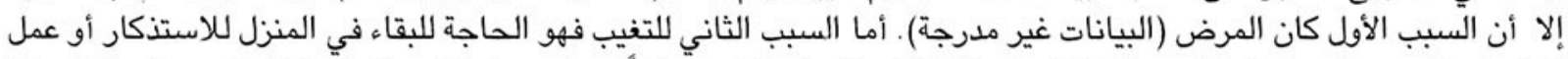

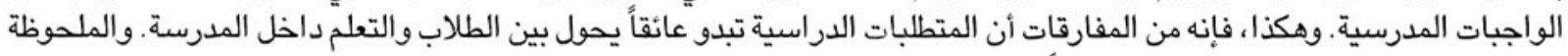

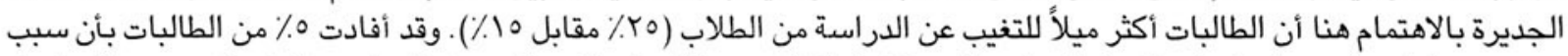

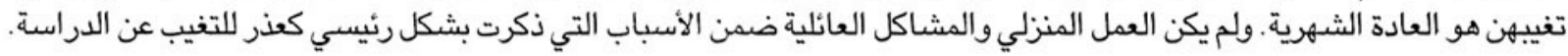




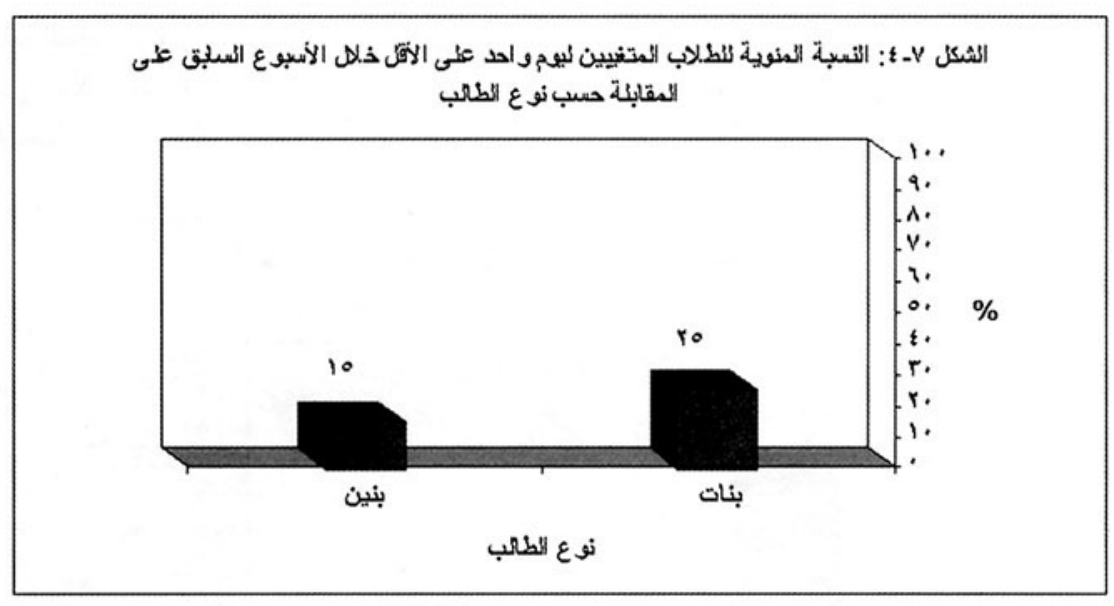

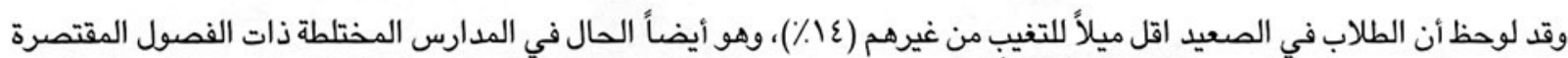

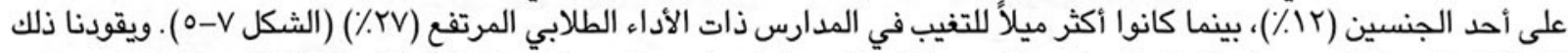

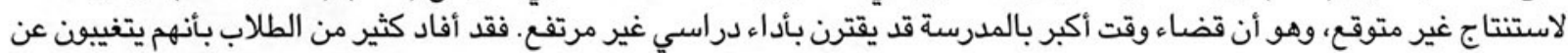

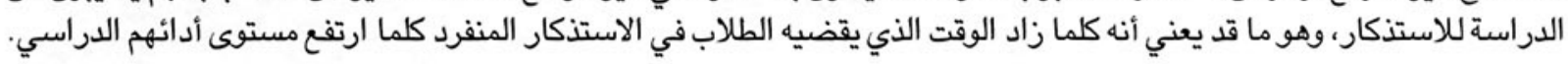

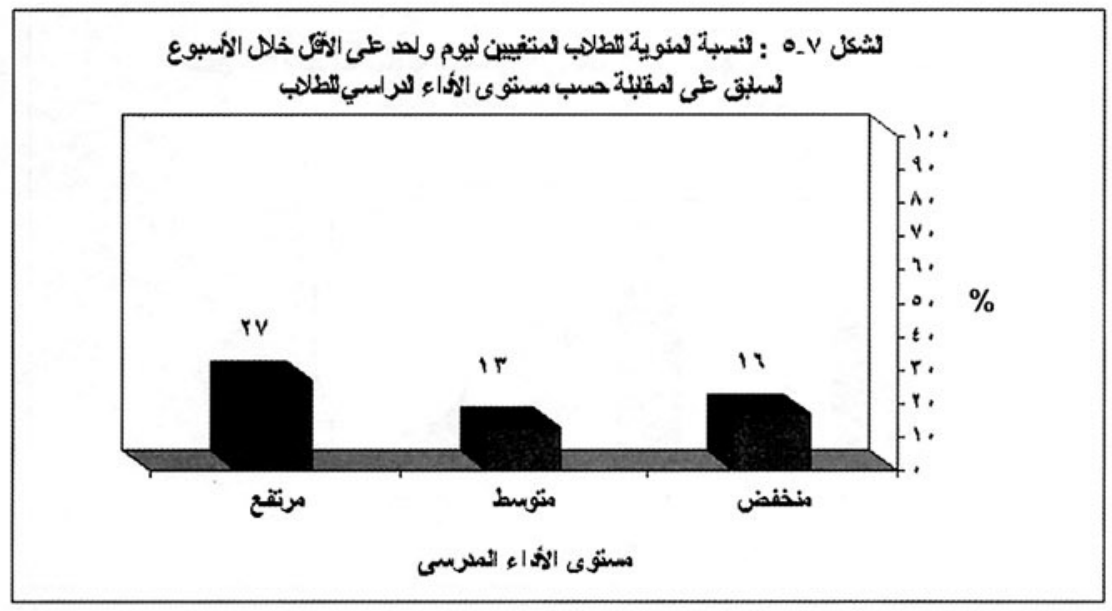

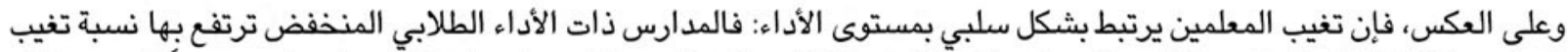

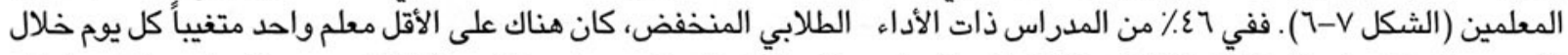

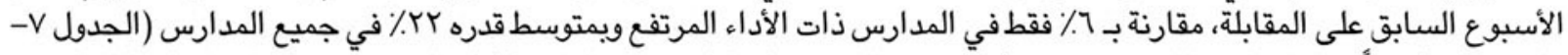

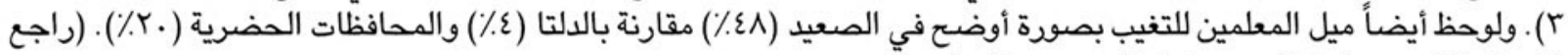
الفصل الثامن من أجل المزيد بشأن التغيب بين المعلمين).

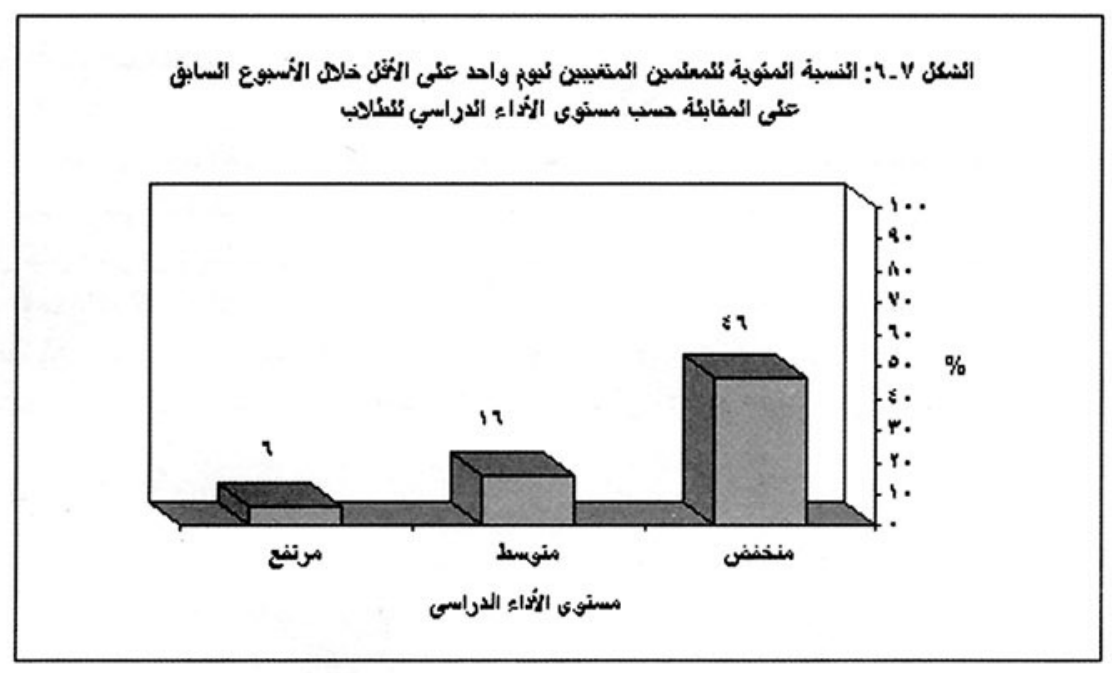




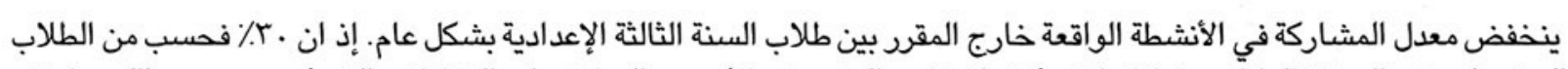

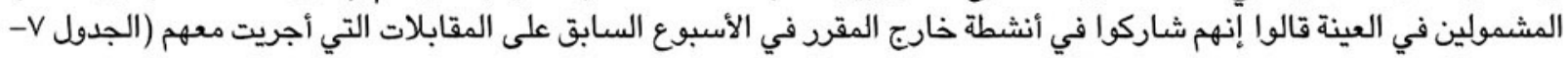

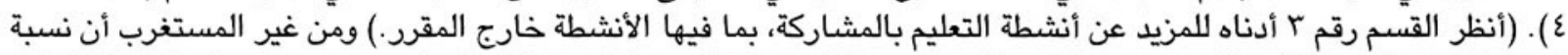

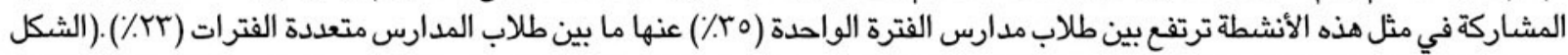

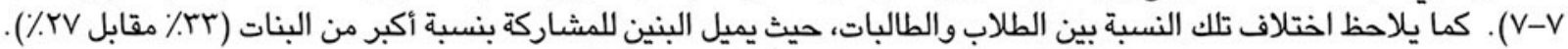

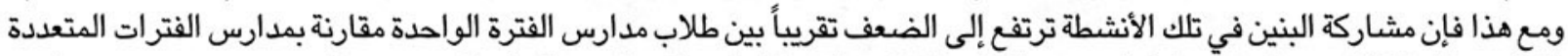

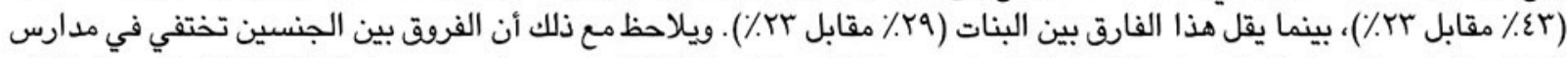

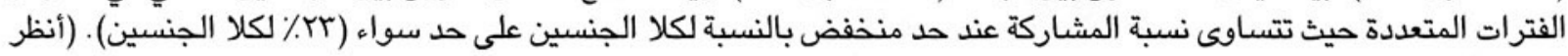
الفصل الثالث لتحليل إضافي حول الأنشطة خارج المقرد) .

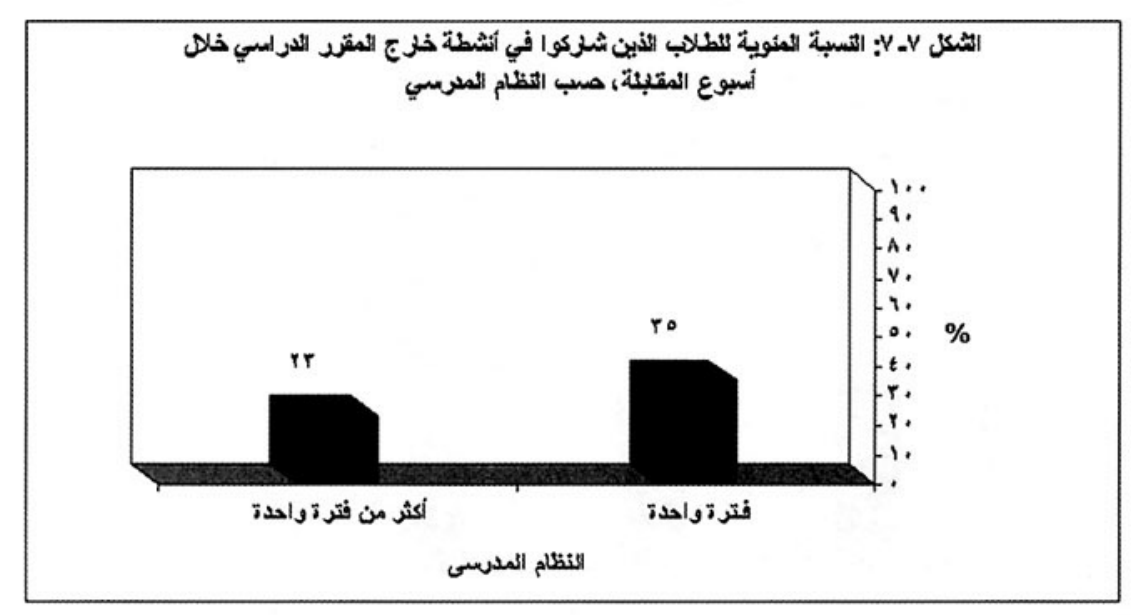

\section{r. التعلم بالمشاركة}

يوفر التعلم بالتجرية أو المشاركة الفرصة للطلاب لاكتساب مهارات تختلف عن تللك التي تزودهم بها الحصص الداب الدراسية التقليدية.

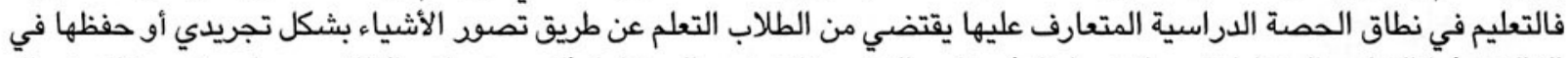

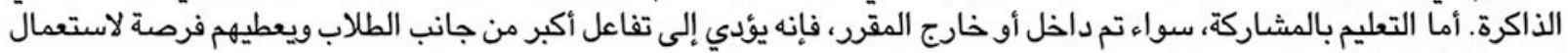

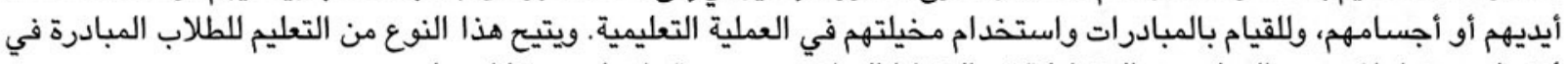
أنشطتهم وتعاملاتهم مع المعلمين، والمشاركة في النشاط الرياضي وامي ويتجرية ما تعلموه بشكل عملي.

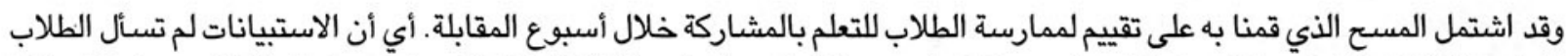

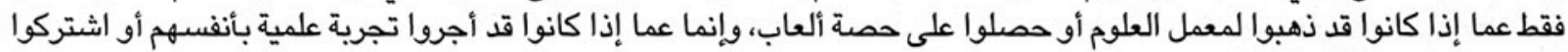

بالفعل في لعبة أو تمرين رياضي.

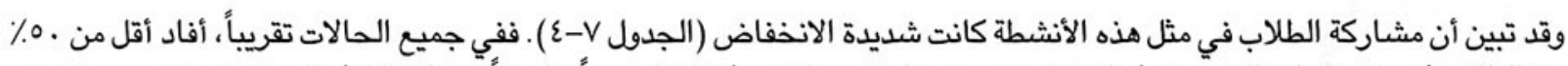

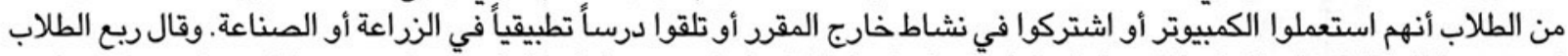

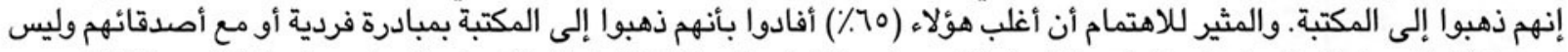

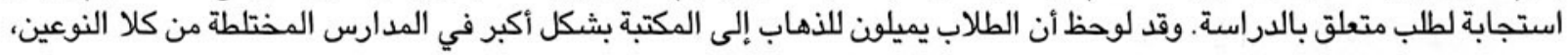
ولكنهم يذهبون بمبادرة شخصية بشكل أكبر في مدارس النوع الوراب الوند وفي المحافظات الحضرية.

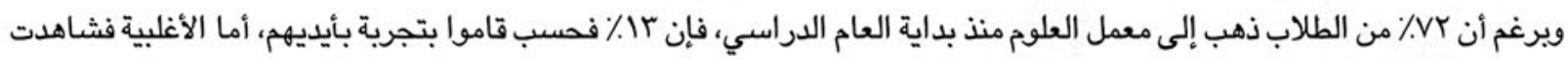

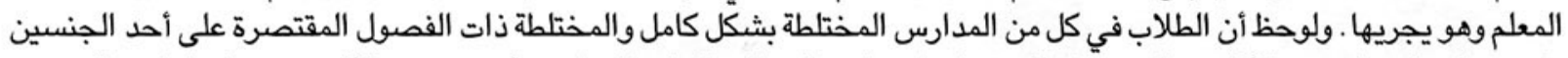

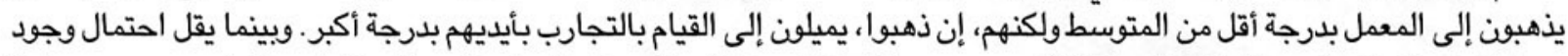

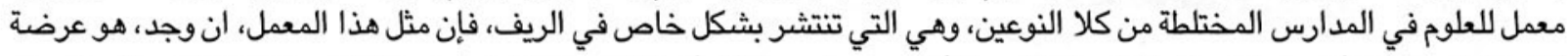

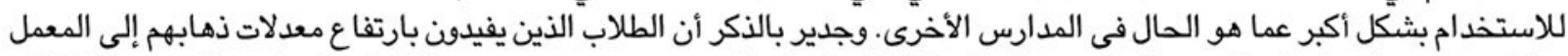
ـ طلاب مدارس المحافظات الحضرية والمجتمعات المحلية ذات التعليم المرتفع ـ تنخفض بينهم نسبة القيام بالتجارب بأنفسهم (الشكلان الشعان 

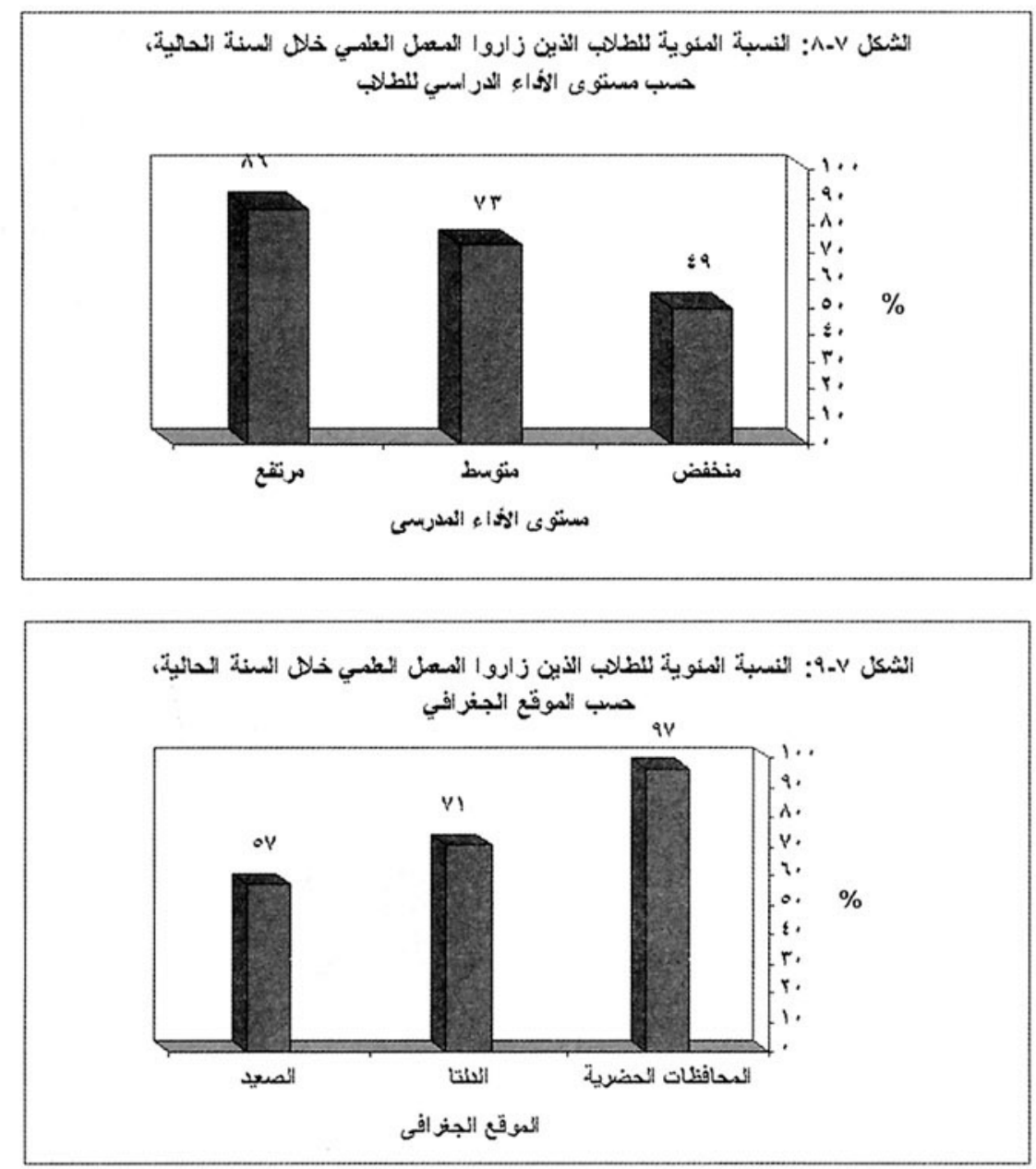

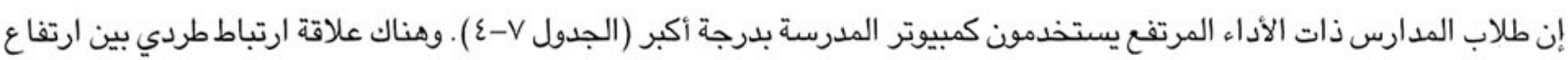

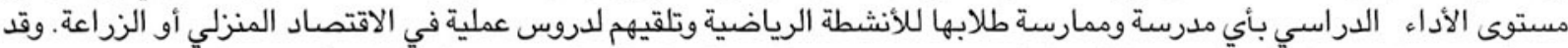

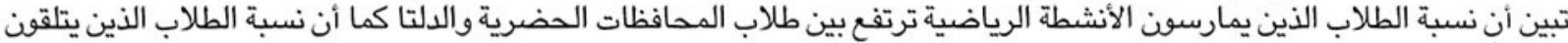
دروساً تطبيقية في الاقتصاد المنزلي أو الزراعة ترتفع في المحافظات الحضية الحضرية.

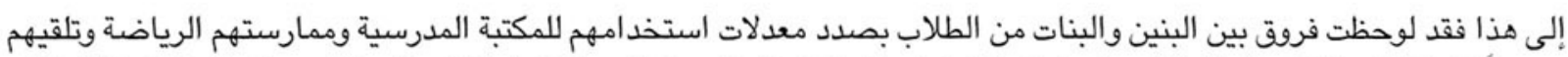

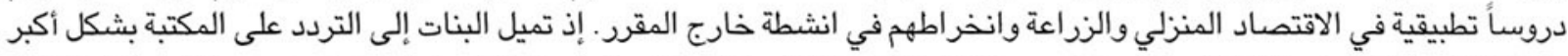

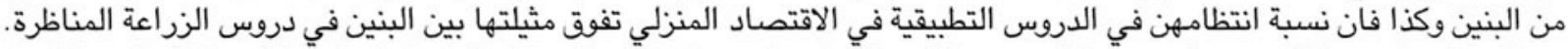

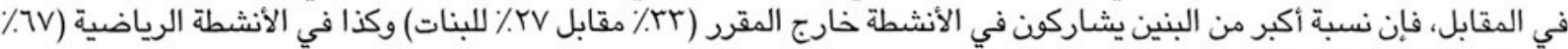

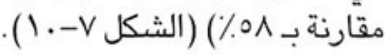

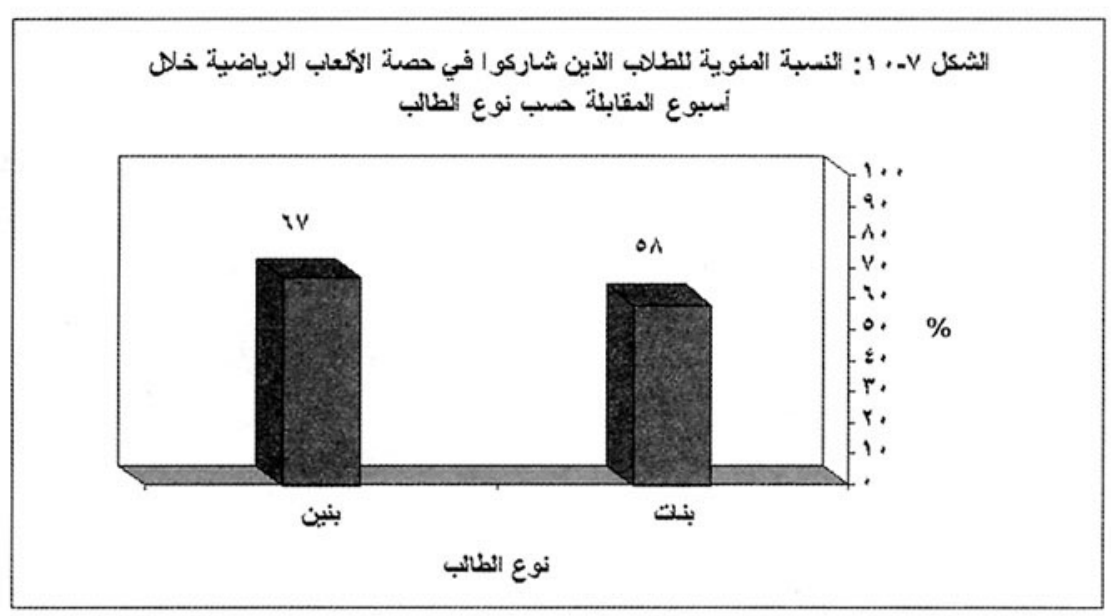




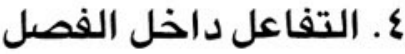

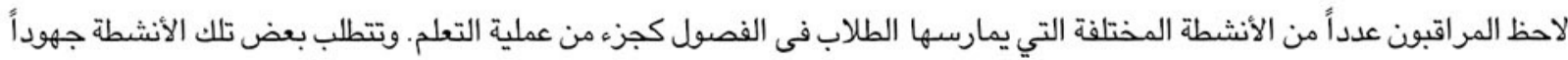

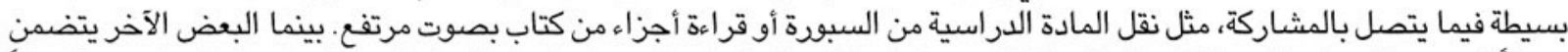

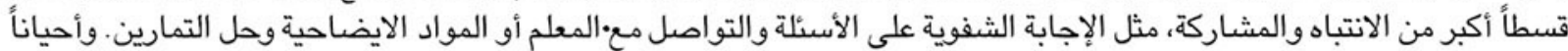

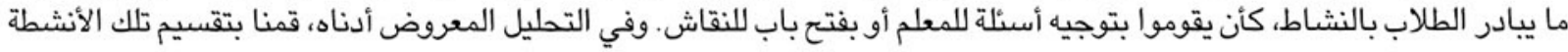
إلى فرص للطلاب للمشاركة في الحصة ومبادرات بات صادرة عن الطلاب.

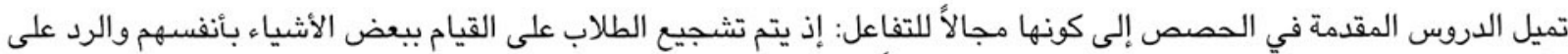

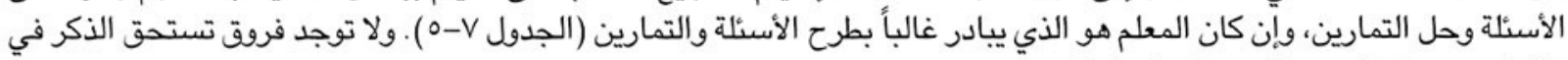
هذا الصدد وفق أي من المتغيرات الخلفية.

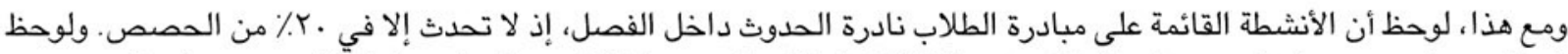

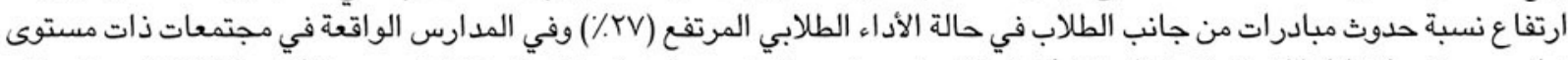

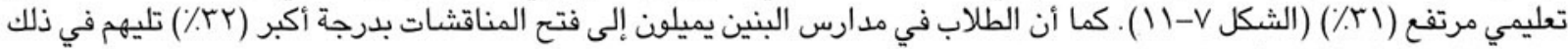

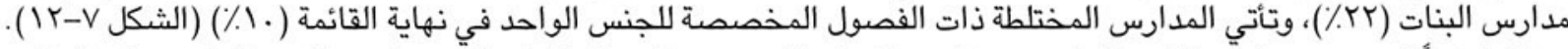

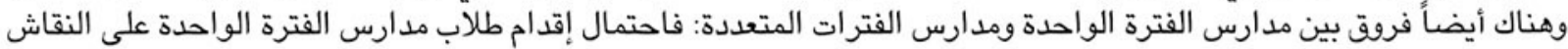

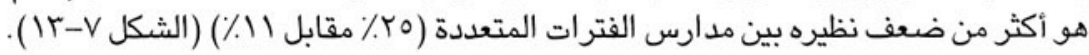
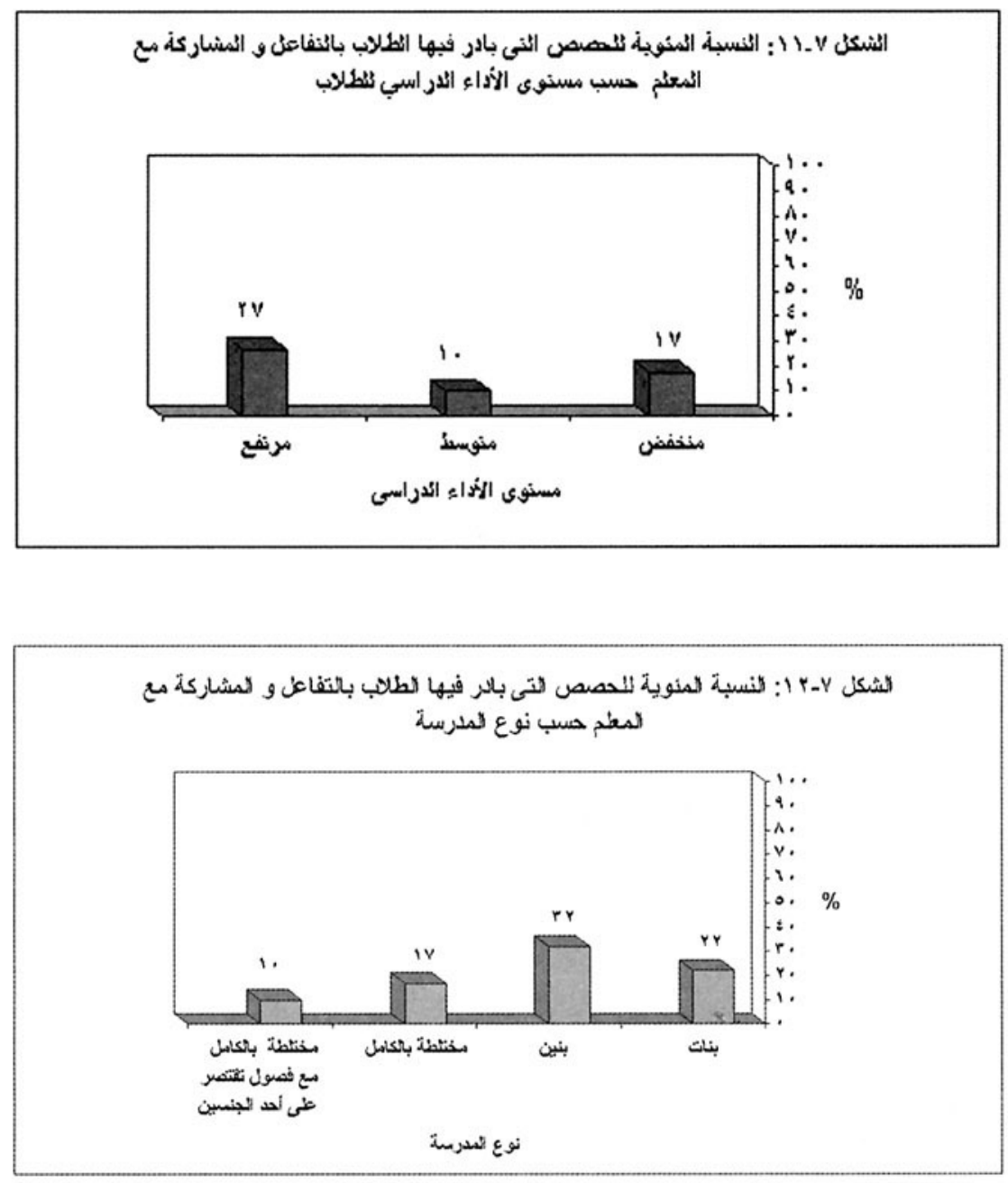


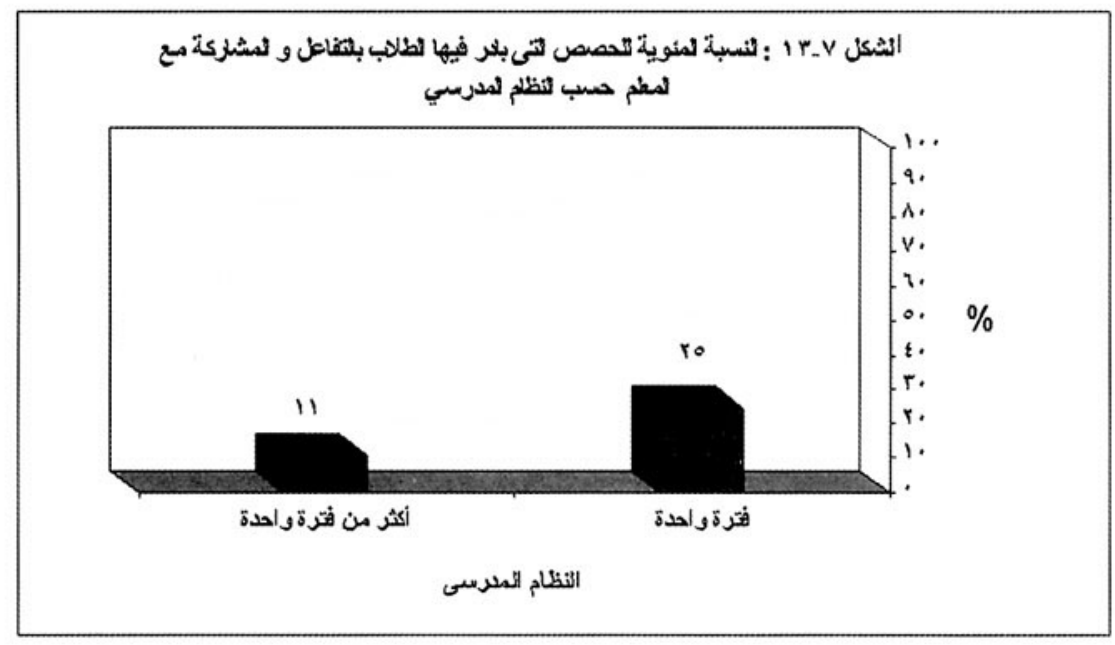

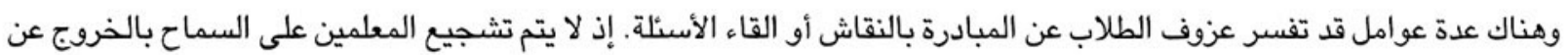

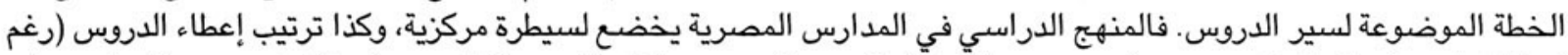

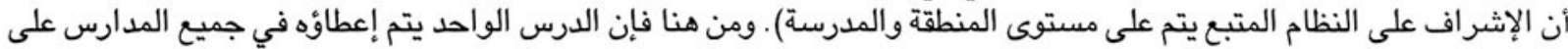

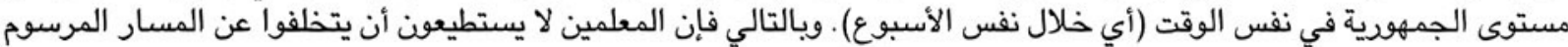

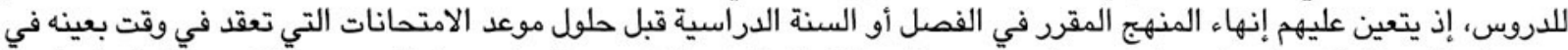

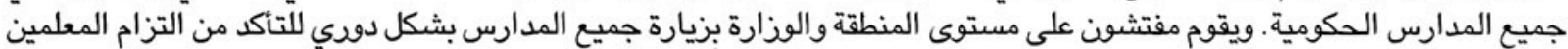

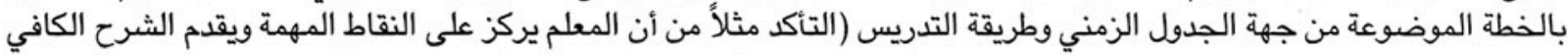

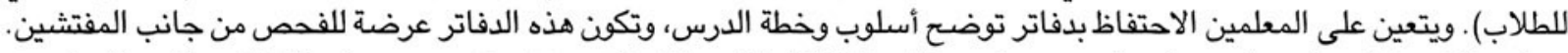

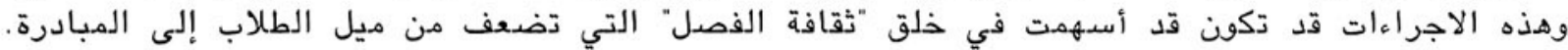

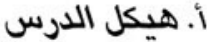

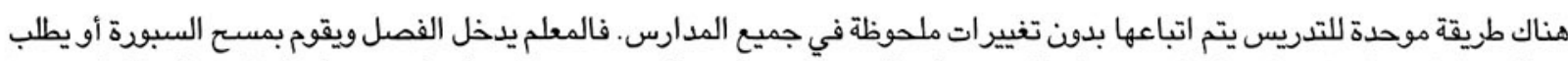

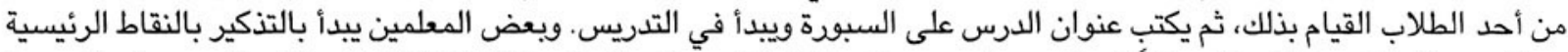

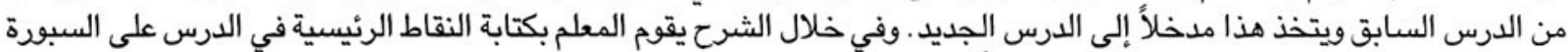

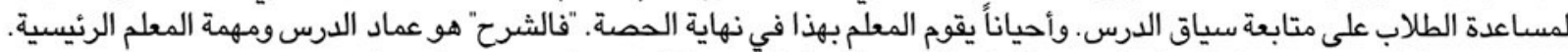

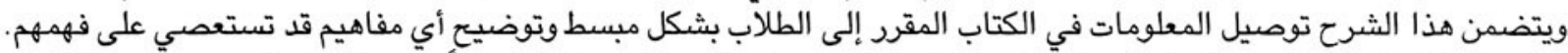

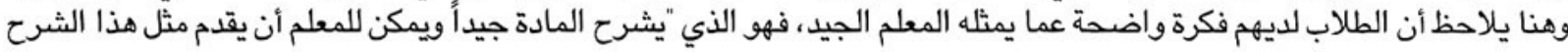

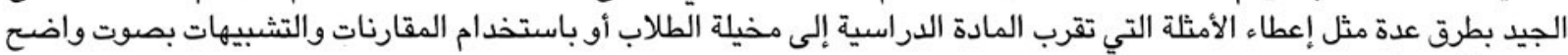

ومفعم بالحيوية.

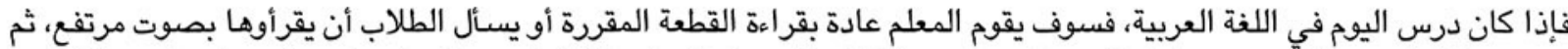

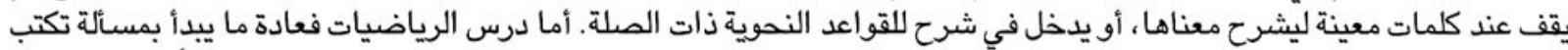

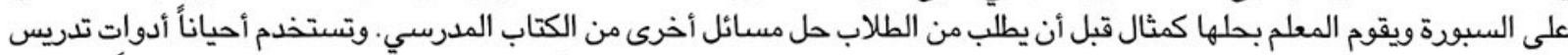

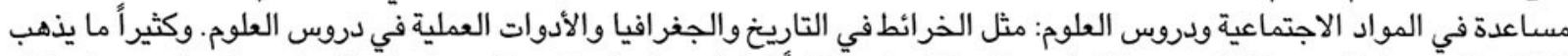

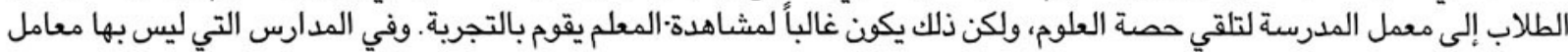

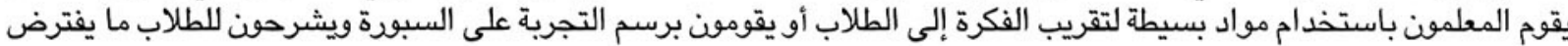

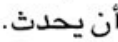

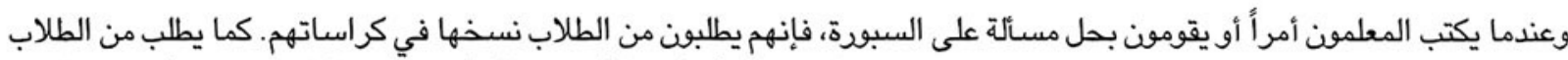

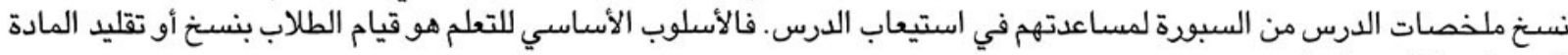
التي يقدمها إليهم المعلمون.

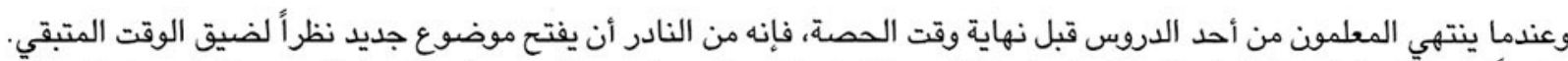

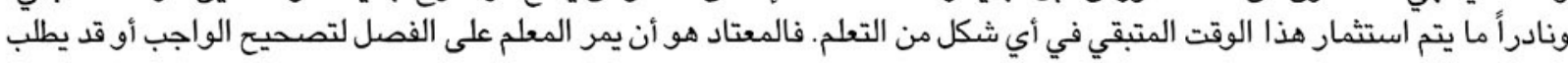




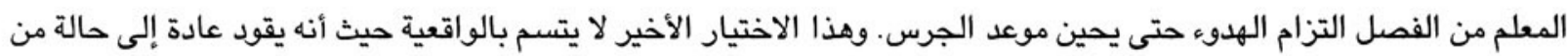
التململ والصخب أو الشجار بين الطلاب لا يلبث المعلم أن يواجهها بمحاولات لاستعادة النظام عن طريق معاقبة الطلاب.

ب. الأسئلة كأداة تعليمية

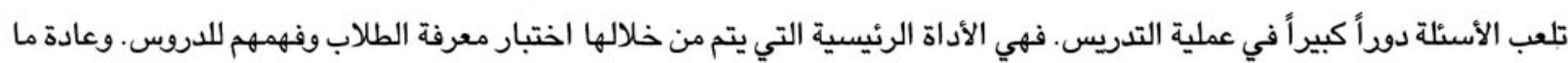

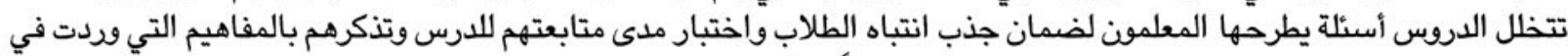

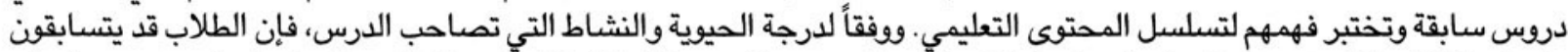

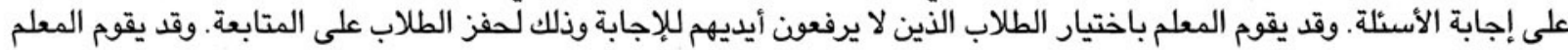

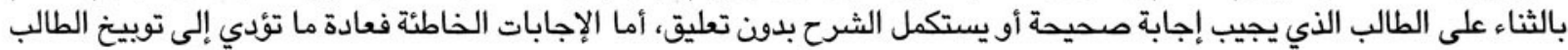
بدرجات متفاوتة قبل أن تعطى الفرصة لطالب أخر للرد.

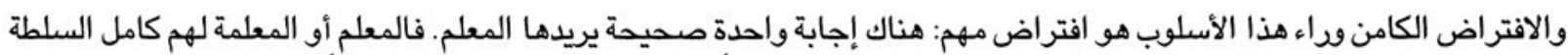

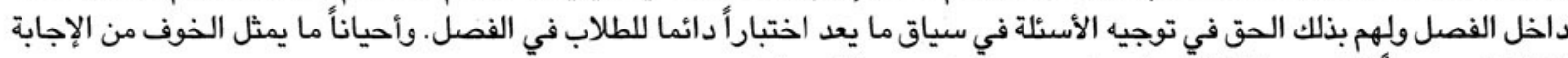

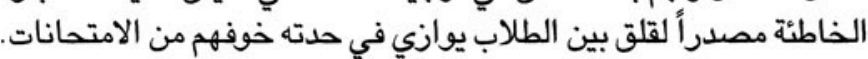

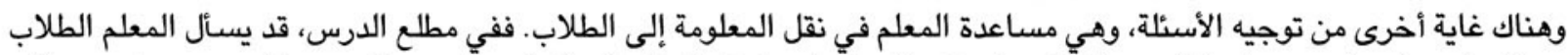

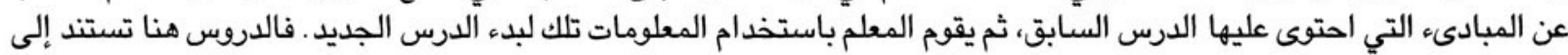

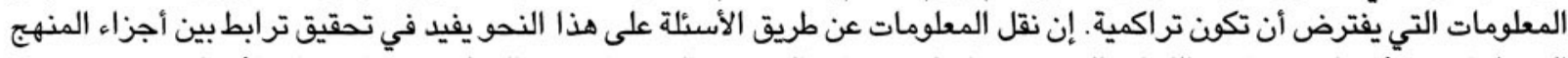

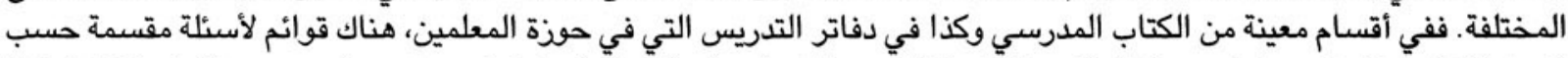

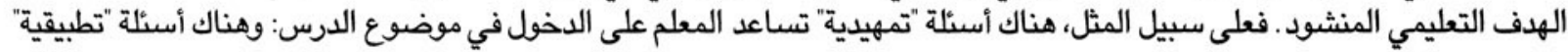
تطرح على الطلاب لتطبيق المبدأ النظري الرياضي وتجريته: كما أن هناك أسئلة "مراجعة" لاختبار استيعاب الطلاب وتذكرهم لما تعلموه.

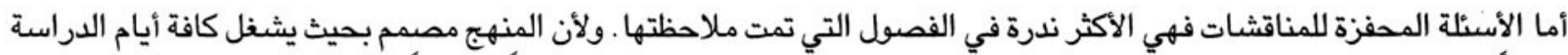

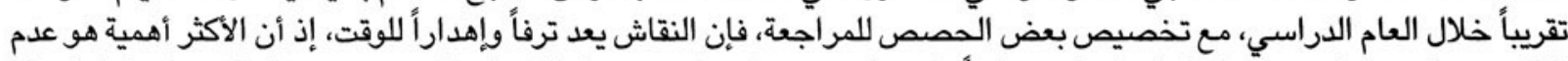

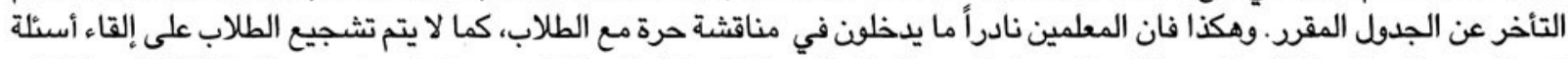

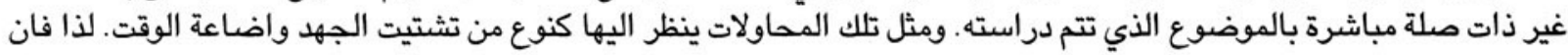

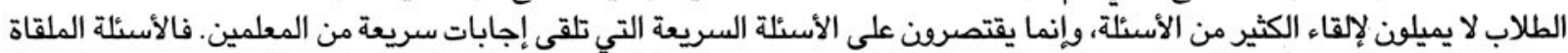

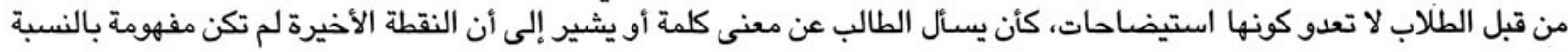

ورغم هذا فلدى الطلاب الرغبة في تجربة بعض الأفكار وبعضهم يسأل أسئلة تتعدى مجال الاستيضاح. و وتتفاوت استجابة المعلمين

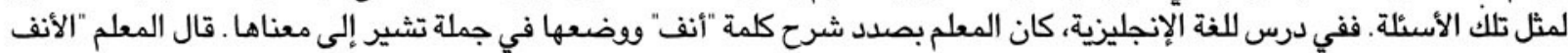

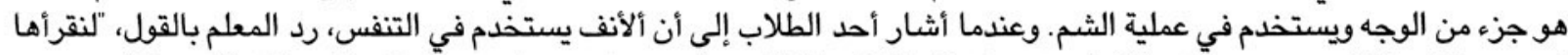

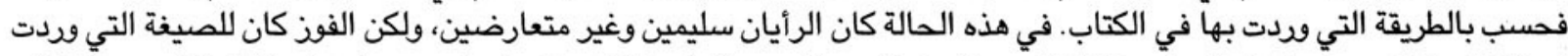

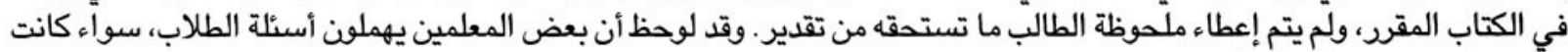
على صلة بموضوع الدرس أو لم تكن.

أظهر معلم آخر موقفاً أكثر إيجابية إزاء أسئلة الطلاب. ففي سياق درس في الجغرافيا عن أنهار أوريا، سأل طالب: "أي الأنهار هو الأطول

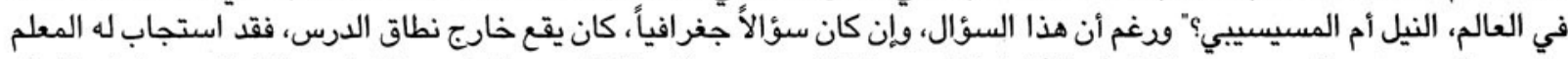

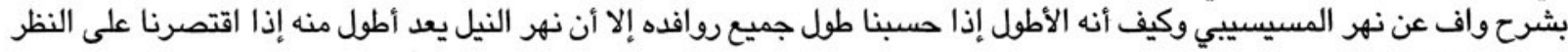
إلى طول النهر الرئيسي.

وماحدث في هذه الحالة هو أمران: فقد تم توصيل قطعة من المعرفة إلى الفصل، كما تم توصيل رسالة إيجابية إلى الطلاب الذين يسعون

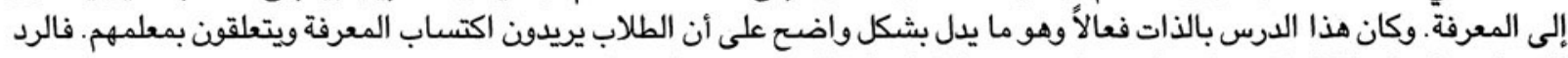
الإيجابي على أسئلة الطلاب عادة ما يرتبط بمدي فعالية العملية التعليمية في الفصل فالفيل 


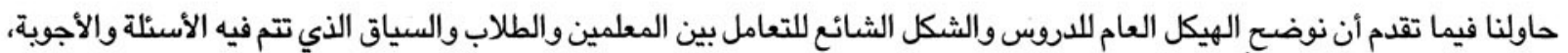

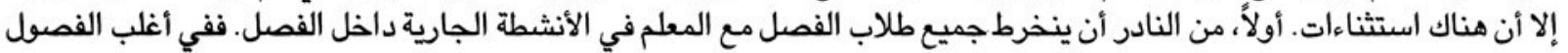

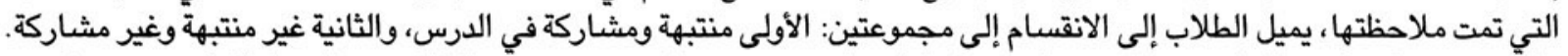

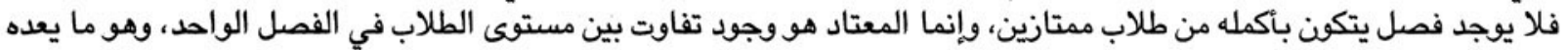

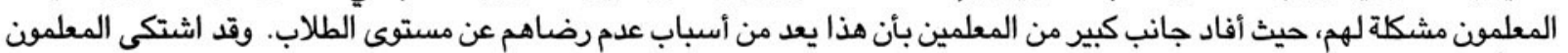

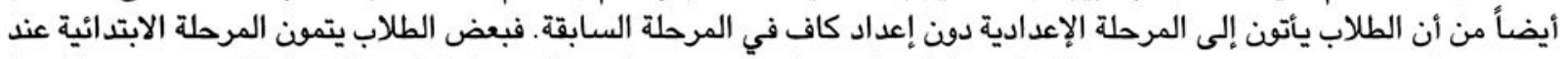

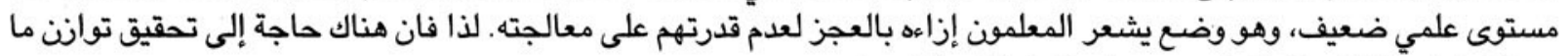
بين الاهتمام بالطلاب المتفوقين وعدم إهمال الطلاب الأضعف.

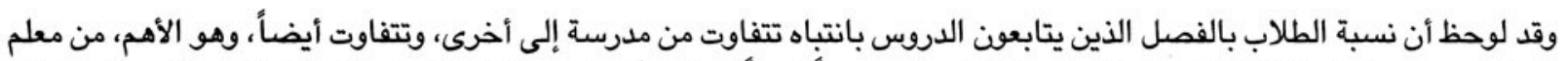

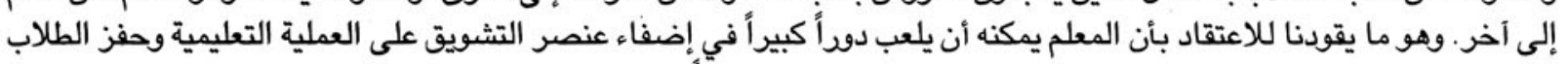

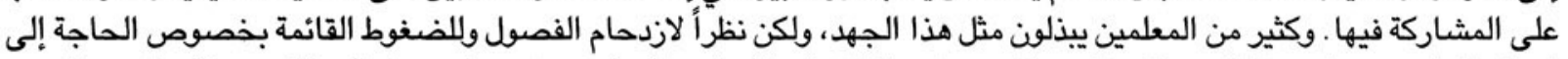

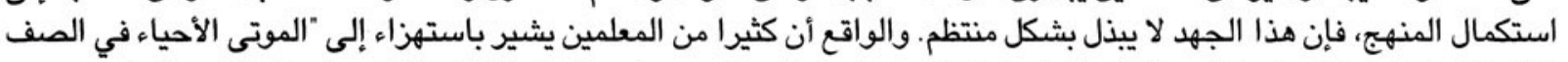

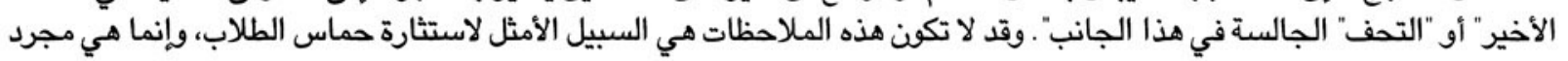

تنفيس عن الشعود بالإحباط.

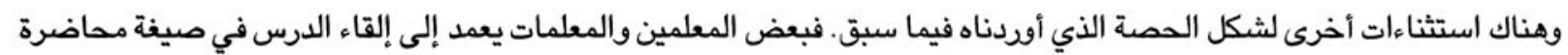

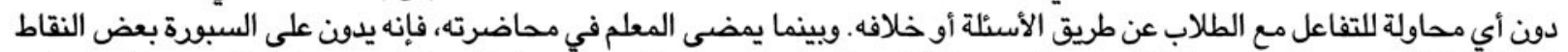

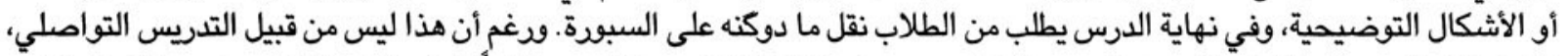

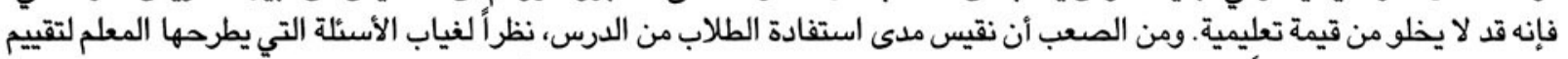

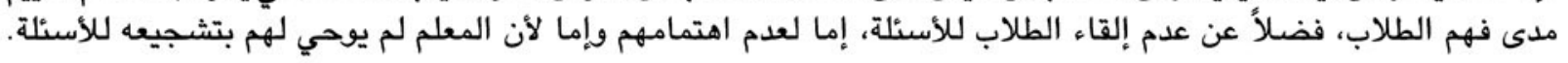

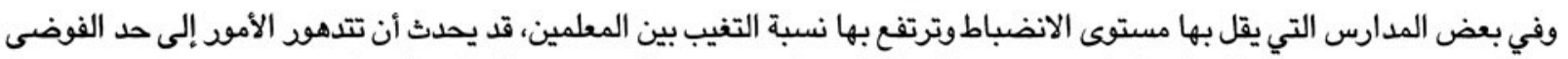

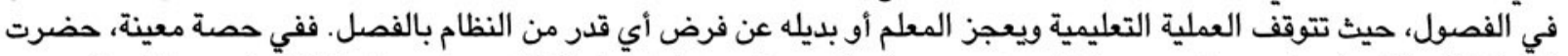

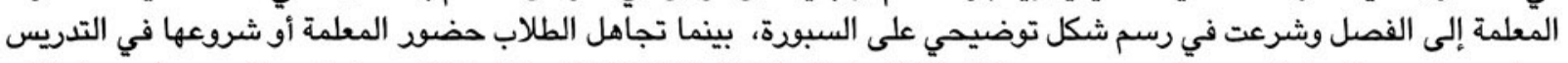

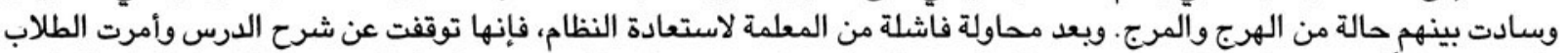

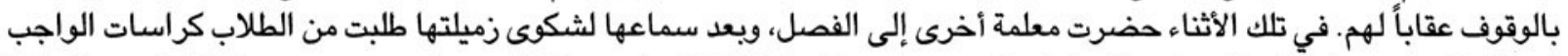

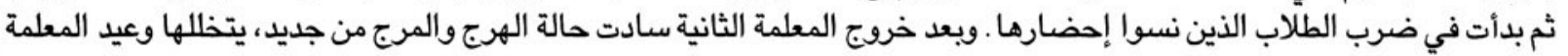

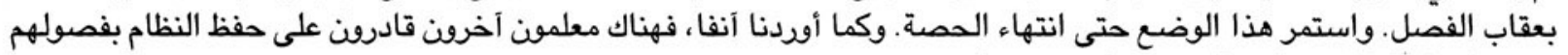
وجذب انتباه الطلاب وشرح الدروس على نحو فعال.

د. الشثجيع و العقاب

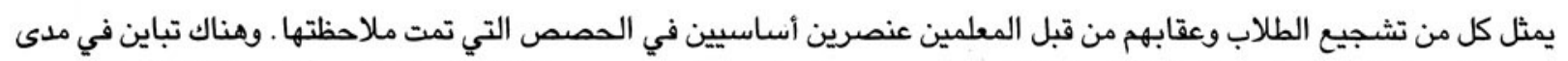

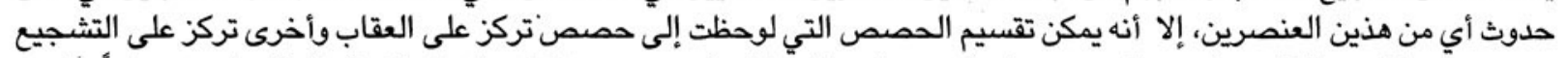

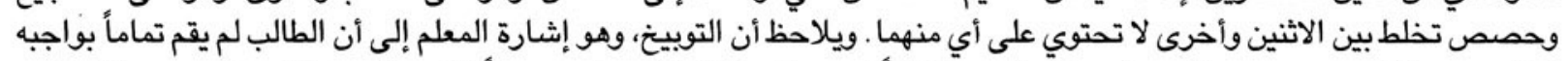

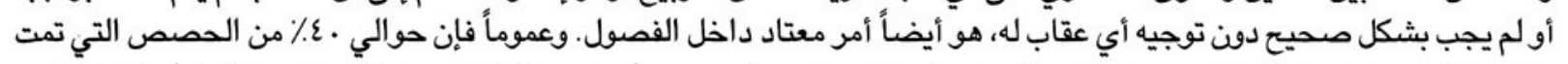
ملاحظتها لم يحدث بها أي تشجيع من جانب المعلم. ولم يتضمن ربع الحصص أي توحت أوبيخ للطلاب، بينما لم يتضمن ثلاثة أرباعها عقاب.

عادة ما يأخذ التشجيع شكل الثناء المباشر من المعلم الى الطالب الذى قدم اجابة صحيحة. و قد يصاحب هذا المديح تعليقا لزملائه

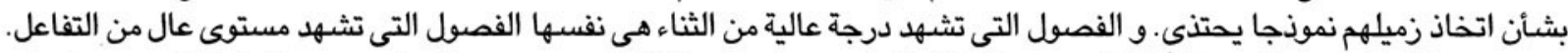

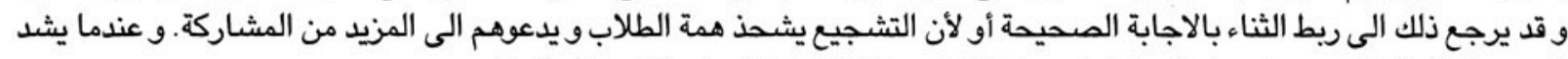

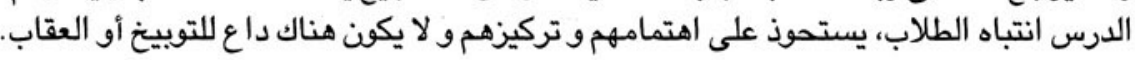

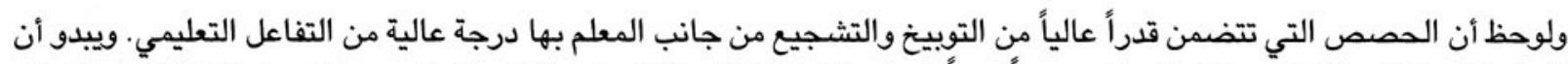

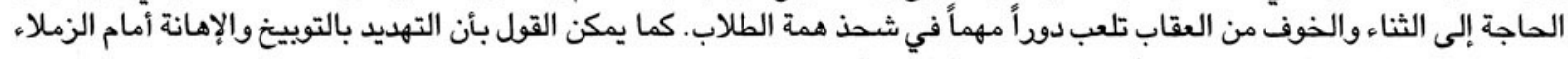
يرفع من درجة انتباه الطلاب ويرتفع أيضا بمستوى الطلاب الممتازين. 


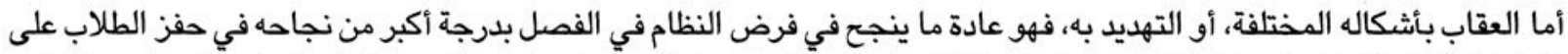

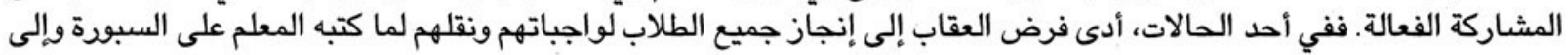

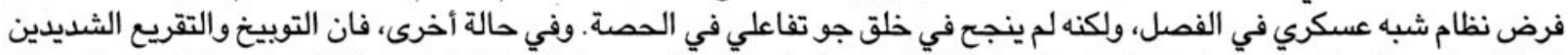
أديا الي استتباب الهدوء دأخل فصل، غير أن الطلاب لم يؤدوا واجباتهم المدرسية ولم يشاركوا بفعالية في أي نقاش في الحصة.

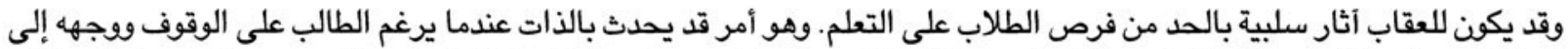

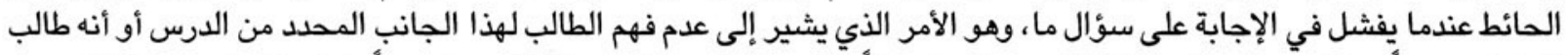

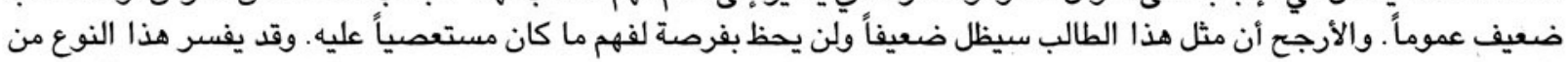

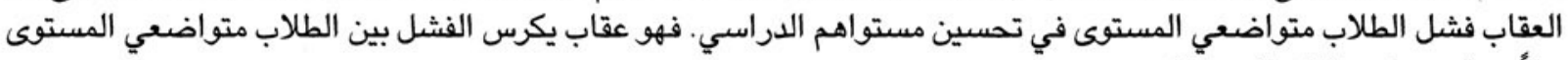
بدلاً من أن يحفزهم للارتفاع بأدائهم.

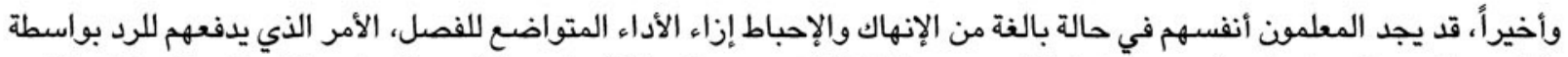

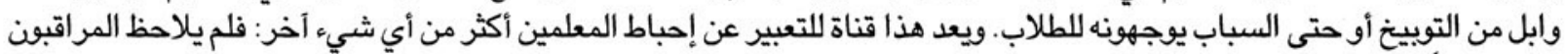
أن له تأثيراً على انتباه الطلاب أو تعلمهم.

\section{هـ. المحتوى والآراءو التوجهات المتعلقة بالنوع}

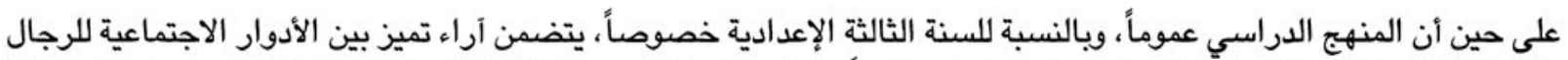

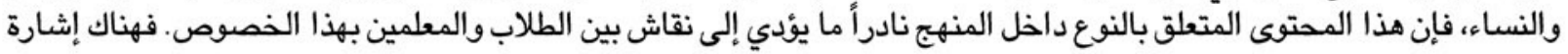

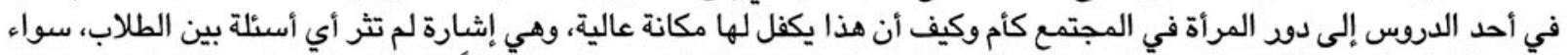

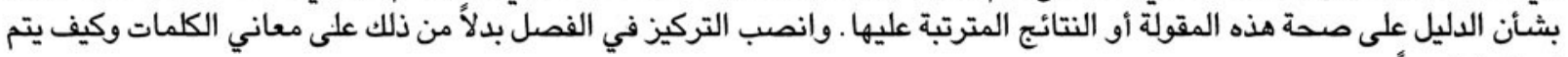

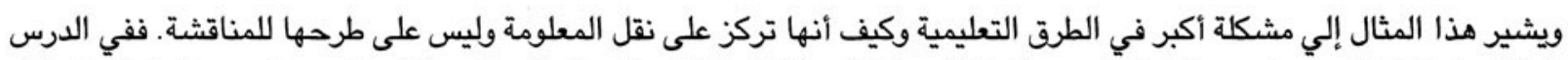

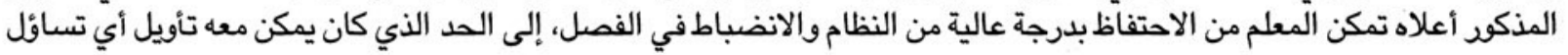

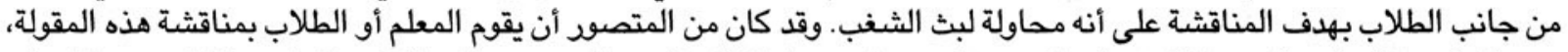

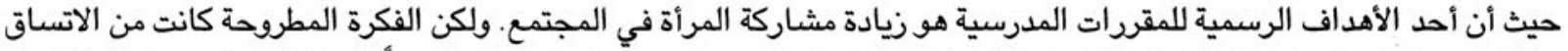

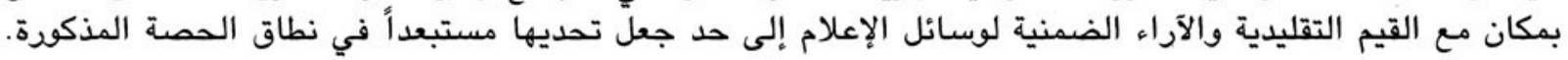

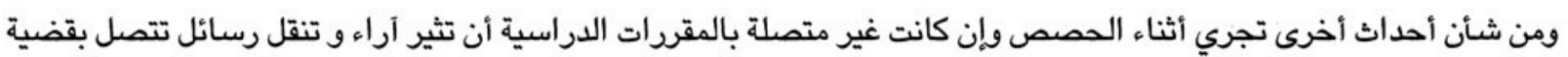

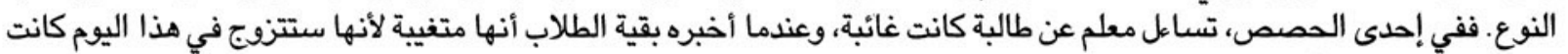

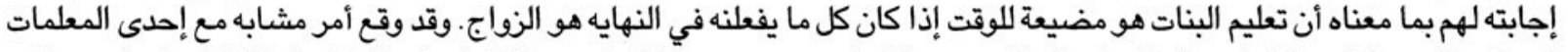

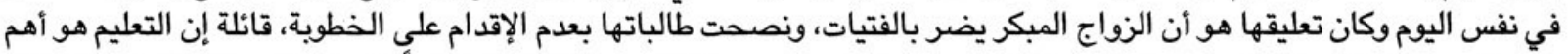

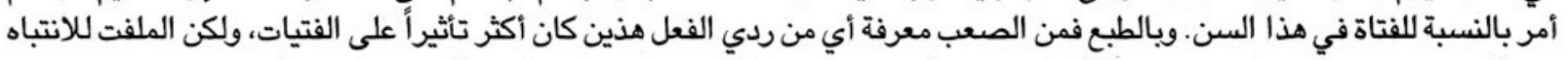

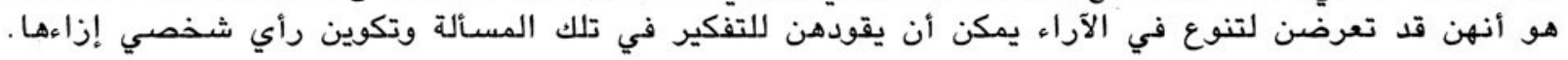

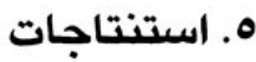

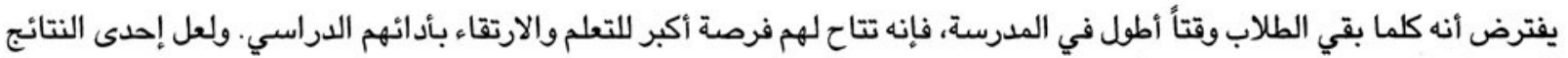

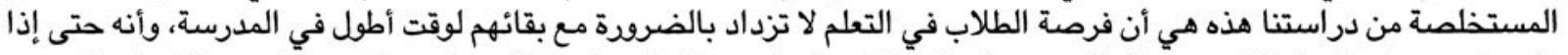

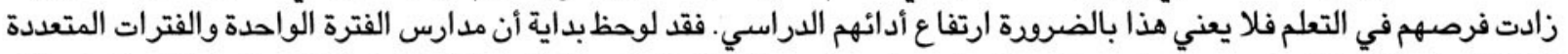

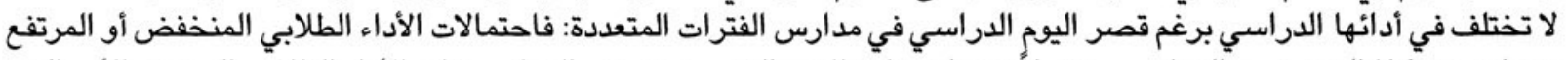

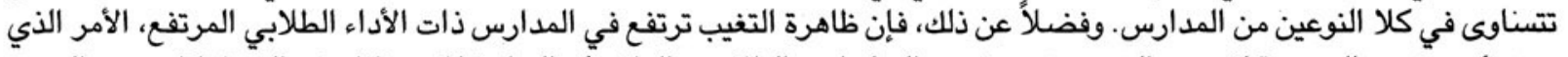

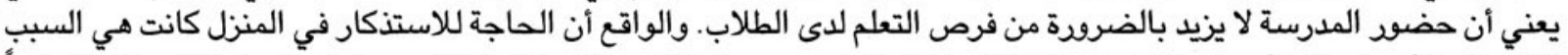

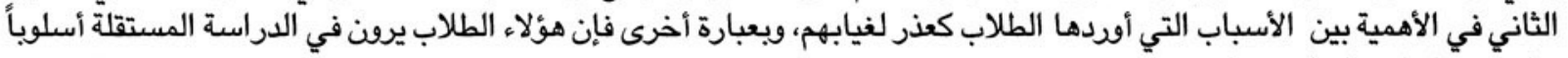
يوازي في كفاءته التعلم في المدرسة. وتوضح البيانات المستقاة من الدراسة بشكل عام أن الطلاب لا يترددون على المكتبات أو يمارسون الرياضة وغيرها من الأنشطة خارج 


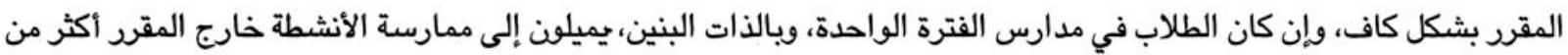

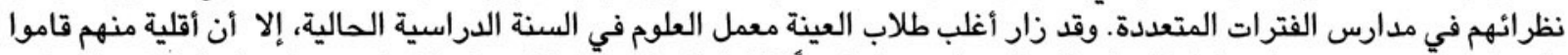

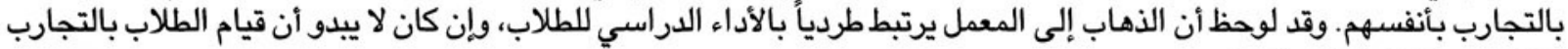
بأنفسهم يرتبط بأد ائهم الدراسي.

كما يبدو من البيانات المتاحة أن المدارس المختلطة من كلا النوعين، وهي المنتشرة في المناطق الريفية، تميل إلى استخدام مواردها

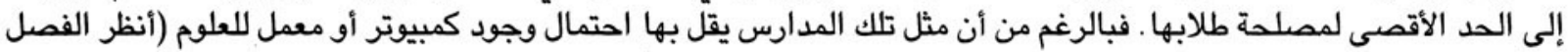
السادس)، فإنه في حالة وجود تلك الأدوات يميل الطلاب إلى أستخدامها بمعدلات أكبات أكبر من بقية المدارس.

إلى هذا لوحظ أن ظاهرة تغيب المعلمين تحدث بشكل خاص في المدارس ذات الأداء الطلابي المنخفض، ويبدو أنها ألها أكثر ارتباطاً بمستوى

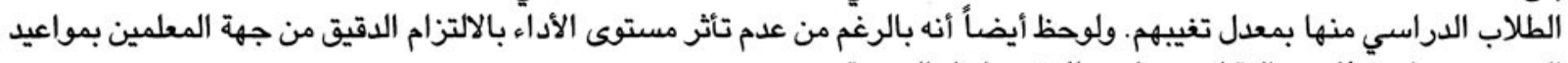

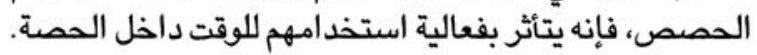

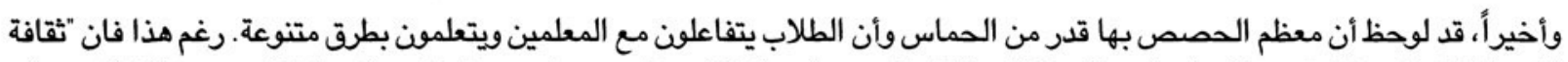

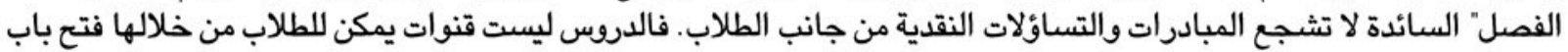

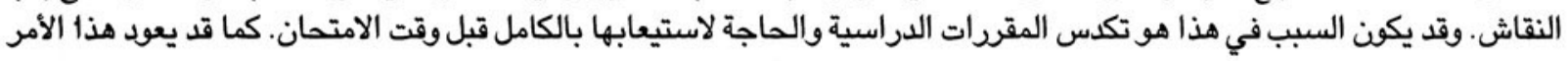
إلى نوع التدريب الذي يتلقاه المعلمون ومستوى النظام والانضباط المتوقع تحقيقه في المدارس.

وللإيجاز، يجد الطلاب فرصاً متنوعة للتعلم في المدرسة. بيد أنه من الواضح أن هذه الفرص ليست موزعة بشكل متساو بين المدارس:

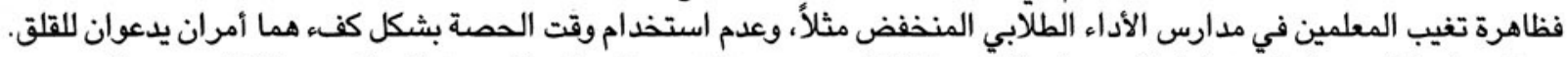

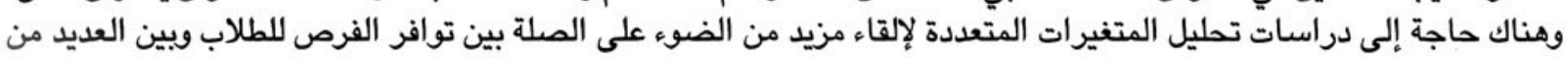
المتغيرات الخلفية، وعلى الأخص مستوى الأداء الدراسي للطعلاب. 


\section{القيادة المدرسية ودور أولياء الأمور}

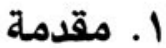

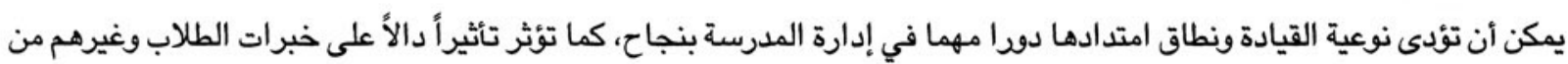

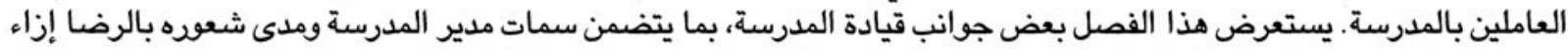
عدد من جوانب الحياة المدرسية مثل: قدر الدعم الإداري المتاح، والانضباط، ومدى انخر العاط الآباء والمجتمع المحلي في الحياة المدرسية.

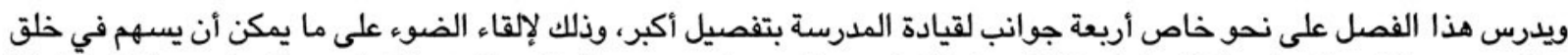

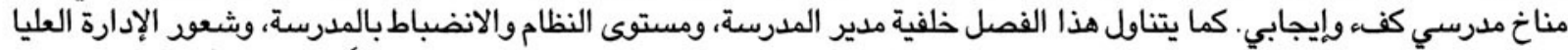

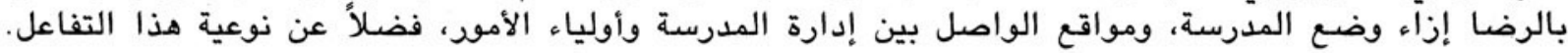

\section{Y r إدارة المدرسة: مدير المدرسة والدعم الإداري}

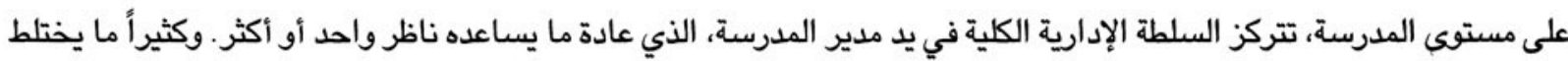

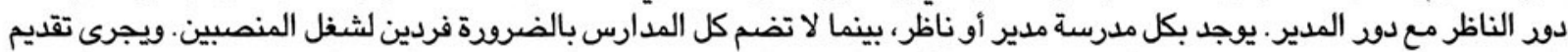

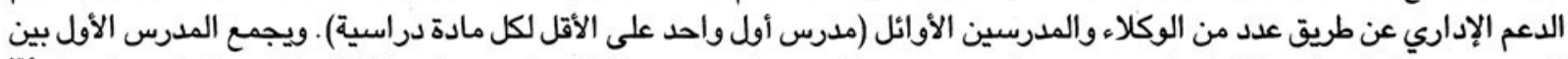

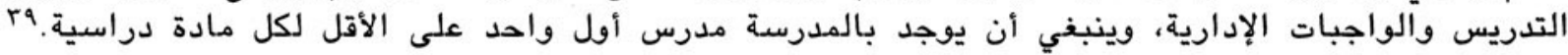

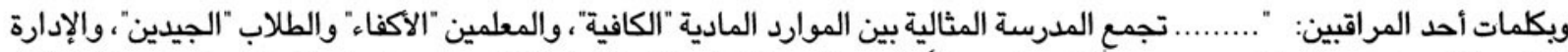

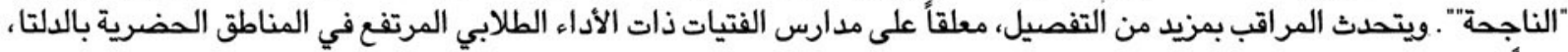

هناك عامل على درجة كبيرة من الأهمية أسهه في نجاح هذه المدرسة . .. إنه قوة شخصية مديرة المدرسة، التي

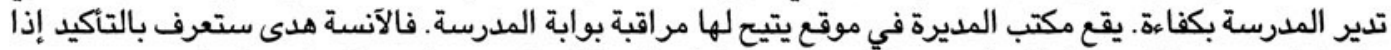

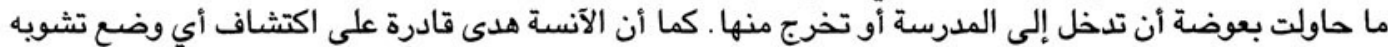

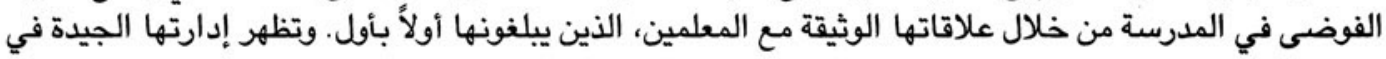

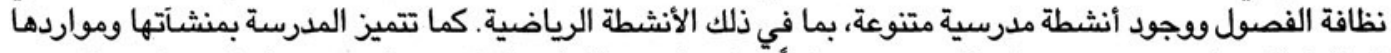

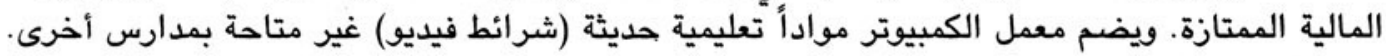

وقد أشار أحد الذين أجروا المقابلات إلى حزم الإدارة الشديد، والذي يحظى مع ذلك بتقدير كبير، بإحدى مدارس الأداء الطلابي المرتفع في المناطق الحضرية بالصعيد، كمثال أخر على القيادة المدرسية الإيجابية:

يعامل مدير المدرسة, المعلمين والطلاب بلطف، كما لو كانوا جميعاً أسرة واحدة. وعلاوة على ذلك، ينتقدهم بهدوء وليس أمام بعضهم البعض، ولهذا فهو محبوب من مجتمع المدرسة كله كلها

وقد أشار كثيرون ممن أجروا المقابلات إلى أن القيادة الرديئة عادة ما تنعكس على البيئة المدرسية، كما هو الحال في تلك المدرسة

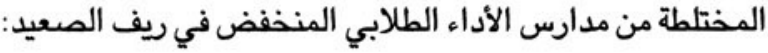

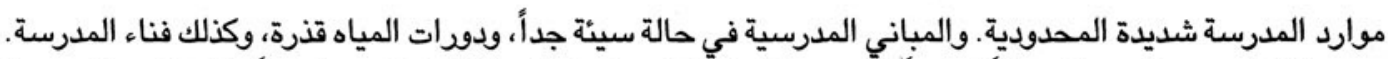

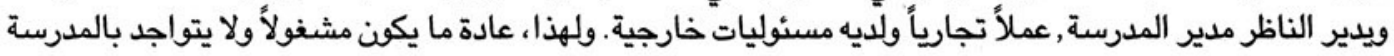

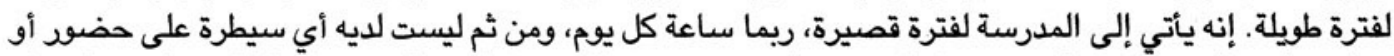

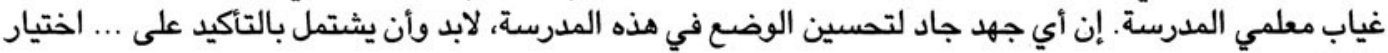
قيادة جديدة.

البّ يمبع المدرن مدرسا أولا على أساس عدد سنوات الخبرة، ونتانج التقيمات الدرية التي يقدمها مفتشو المديرية التعليمية بالمحافظة والمستوى المركزي الأعلى بوذارة 


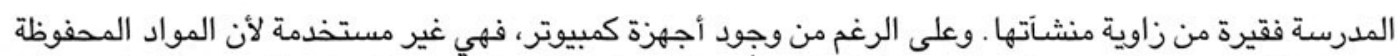

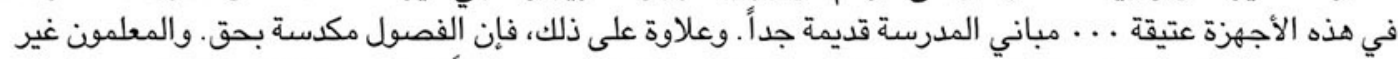

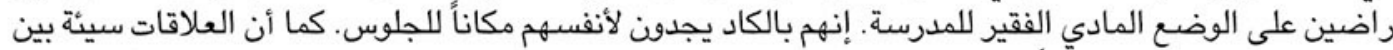

المعلمين والإدارة ضعيفة جداً.

أ. خلفية مدير المدرسة

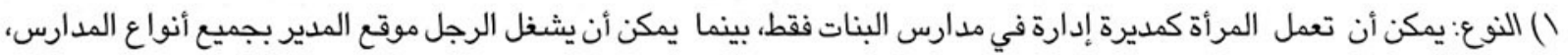

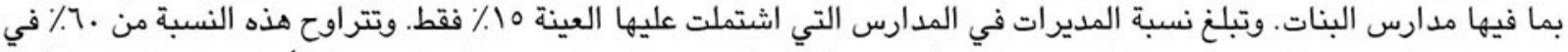

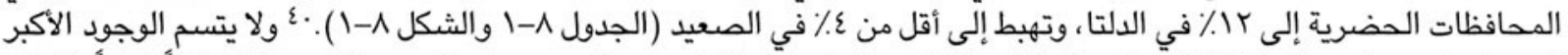

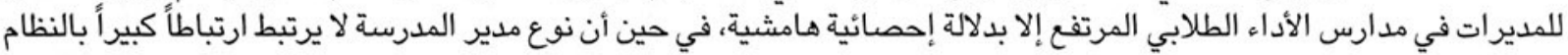
المدرسي.

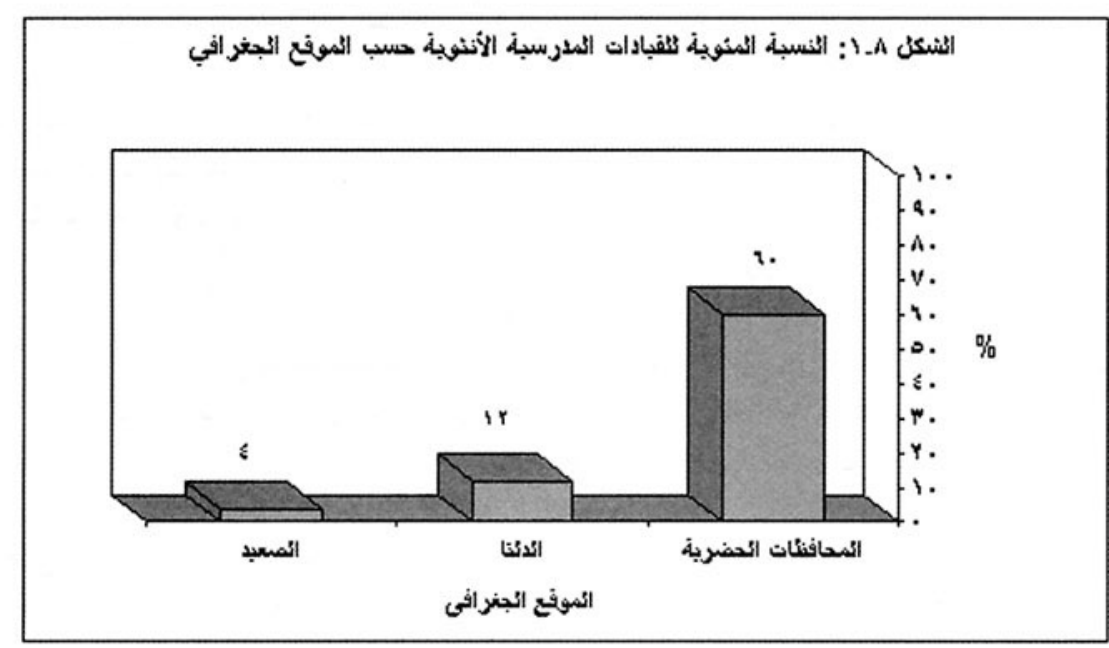

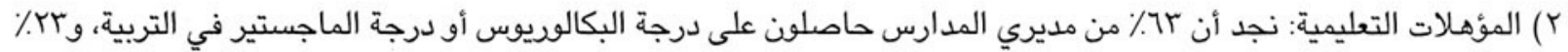

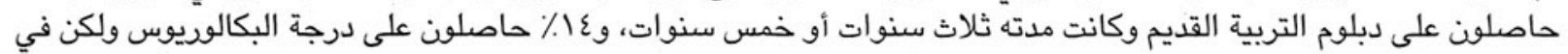

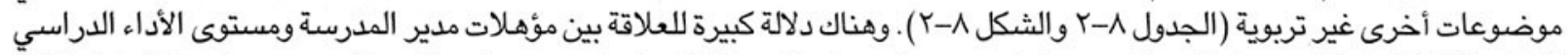

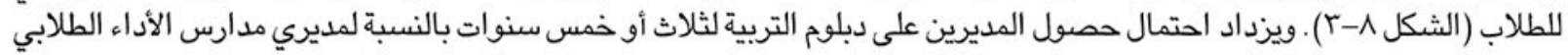

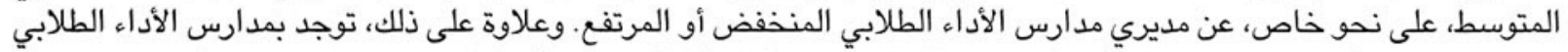

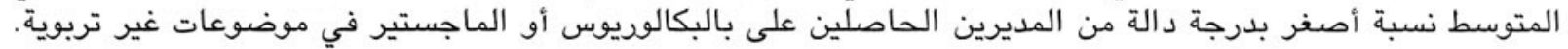

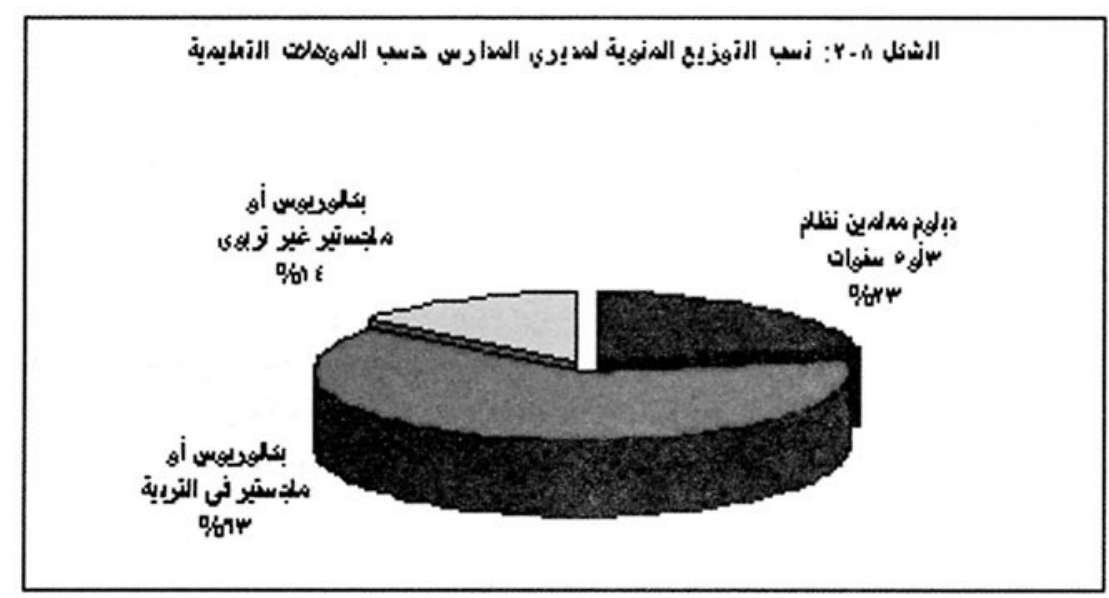

•ع تتسم الاختلافات بين المحافظات الحضرية والمنطقتين الأخرتين بدلالة إحصائية، ني حين لا بصدق نفس الشيء على الفارق بين الدلتا والصعيد. 


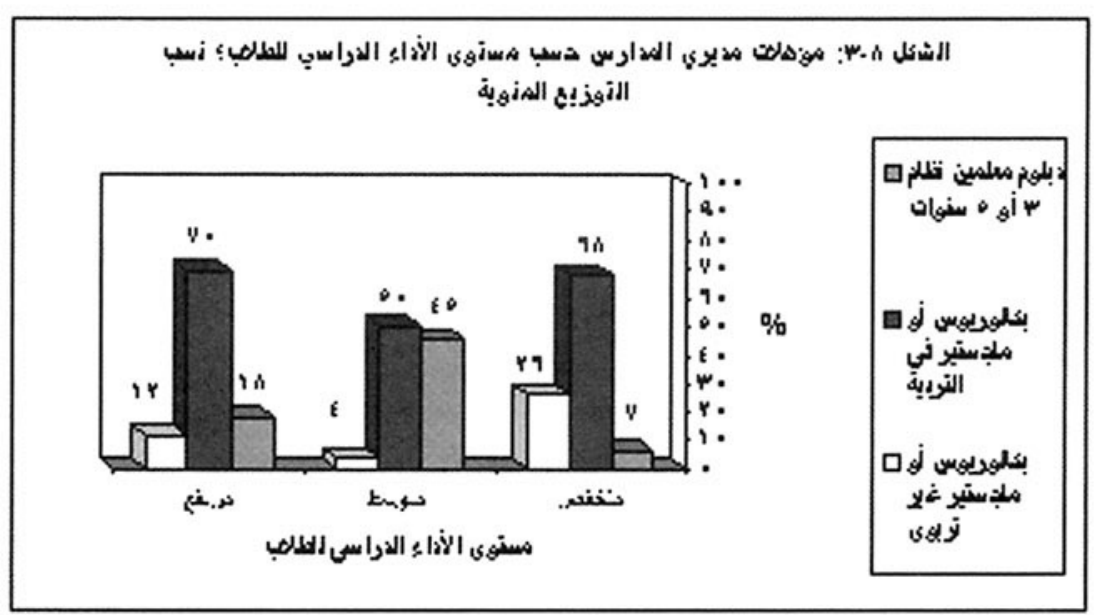

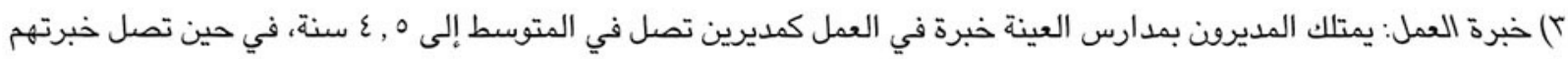

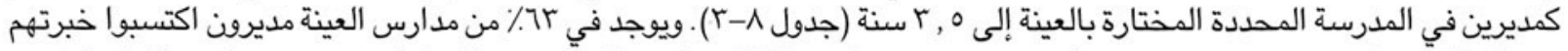

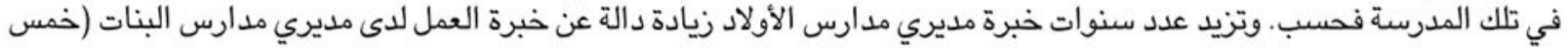

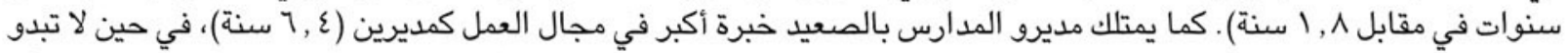

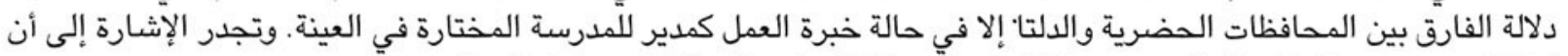
اختلاف مدة خبرة العمل مقارنة بمستوى الأداء الدراسي للطبلاب ليس ليس له دلالة إحصائية خاصة.

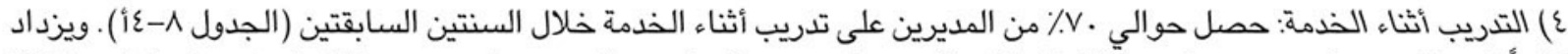

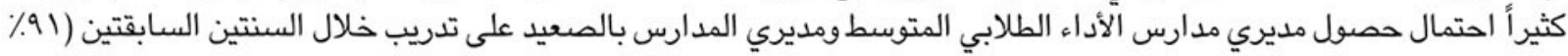
في كل منهما) مقارنة بالمديرين في المجموعات الأرئ الفرعية الأخرى.

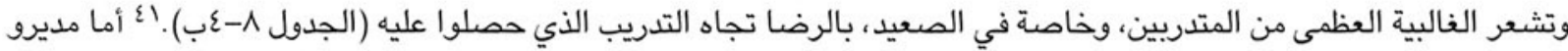

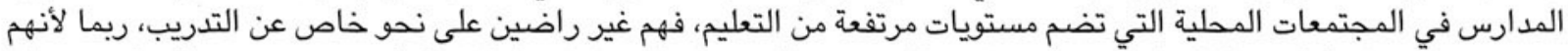

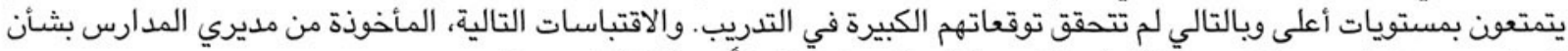

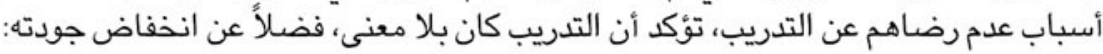

"المعلومات المقدمة ليست جديدة أو محدثة. ما حصلنا عليه هذا العام من تدريب هو ما سنحصل عليه العام القادمة. إن التدريب ليس

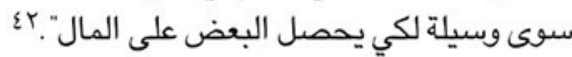
"المعلومات المقدمة في أغلبها لا معنى لها" البعال

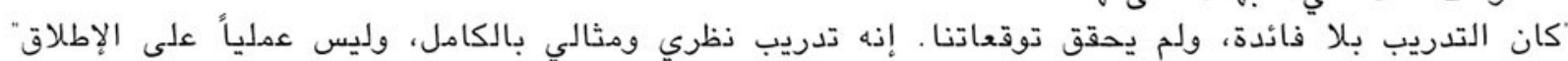

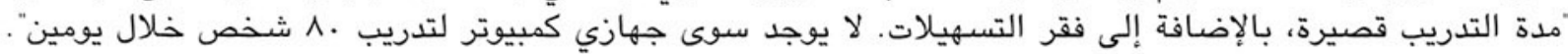

ب. ب الدعم الإداري

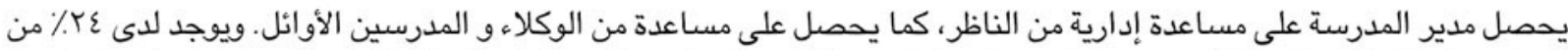

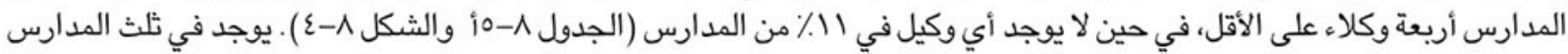

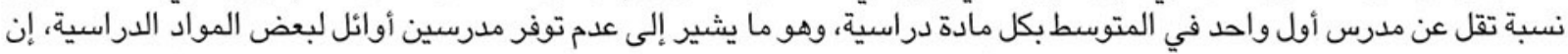

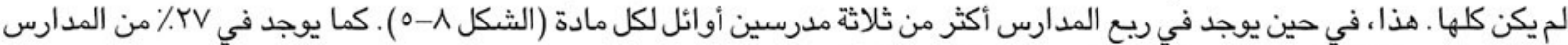

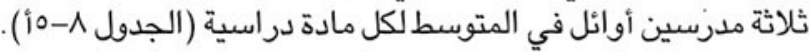

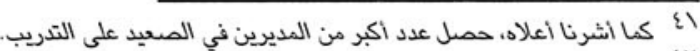

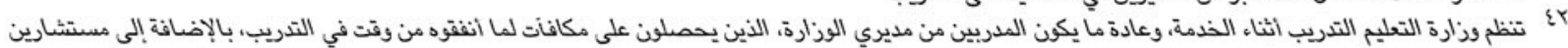

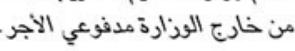



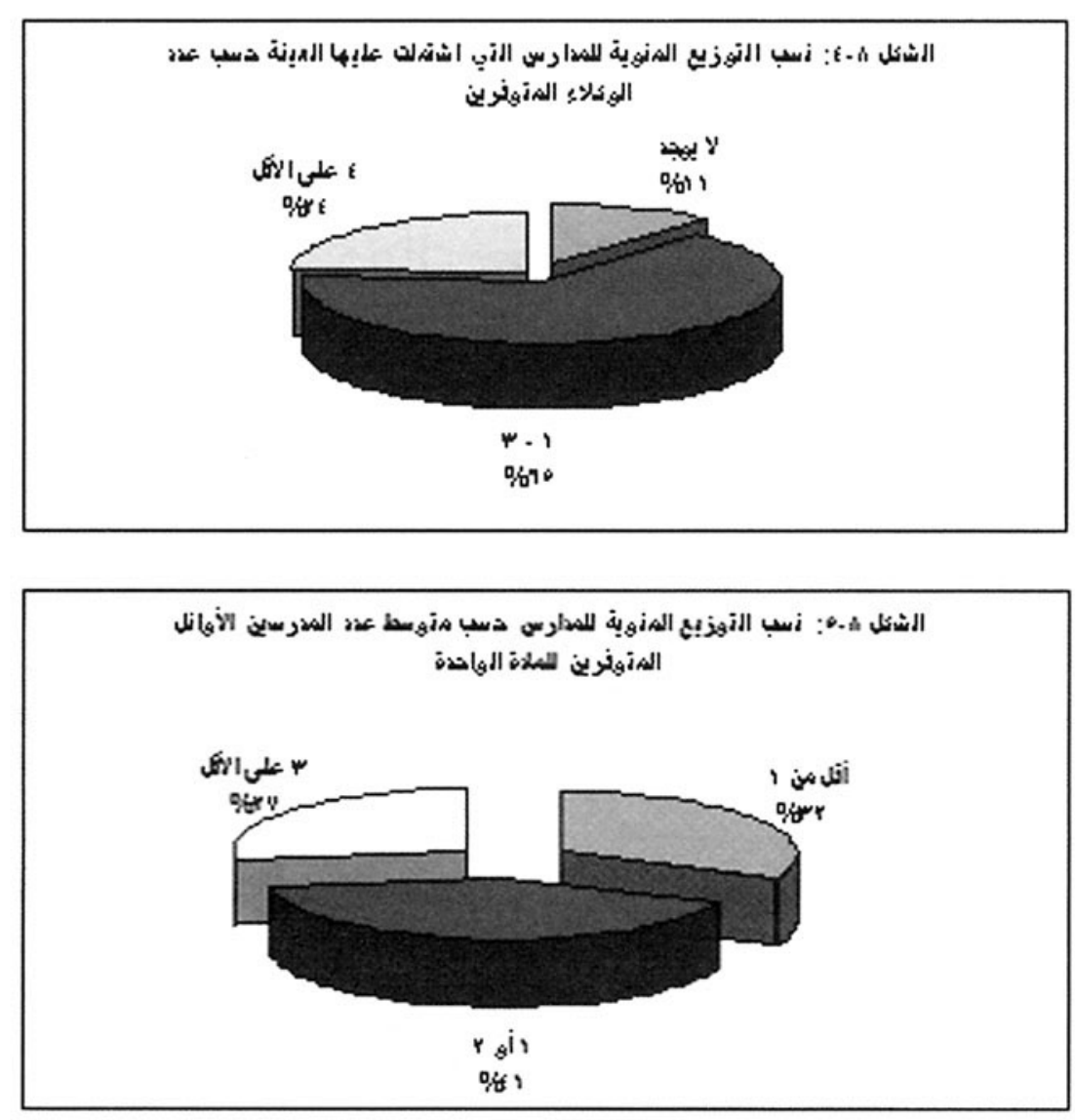

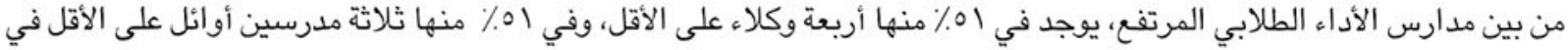

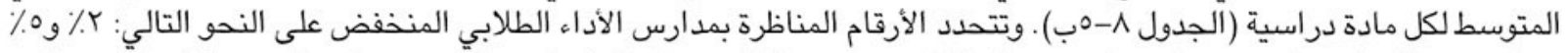

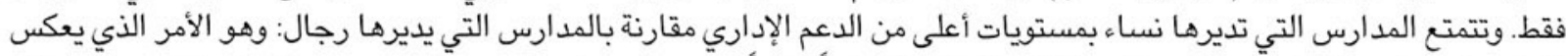

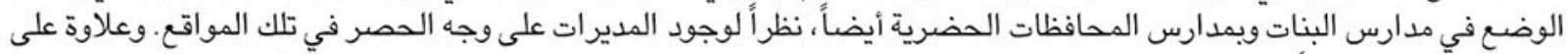

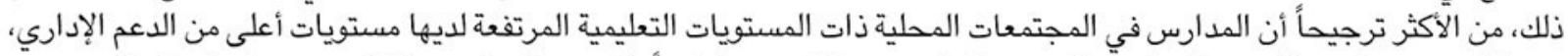

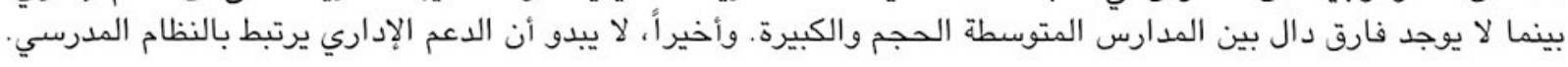

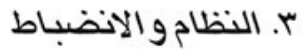

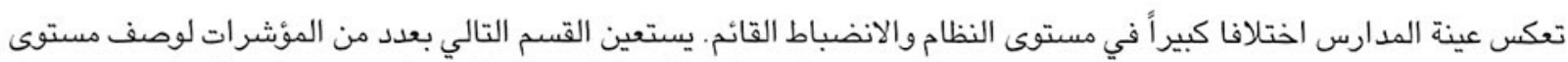

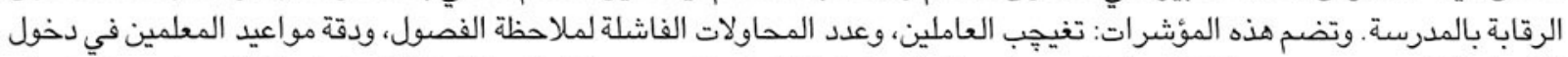

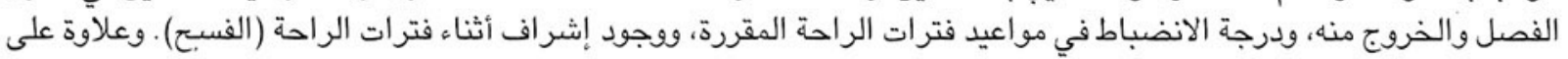

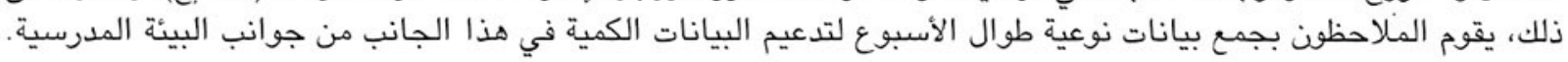

وجد الملاحظون مدارس جيدة التنظيم في جميع مستويات الأداء الدراسي للطلاب. تؤكد تقارير الملاحظين أن قوة شخصية مديري

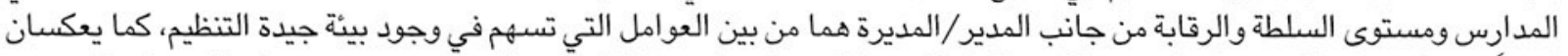

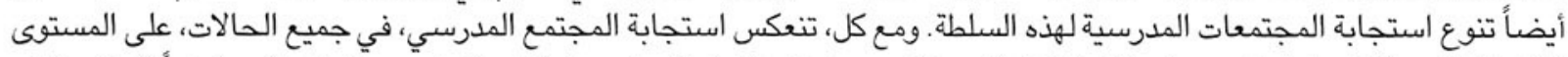

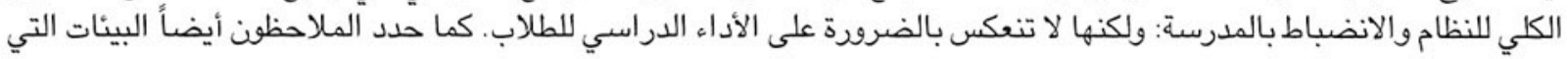

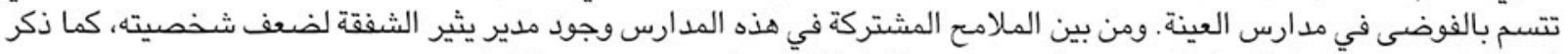

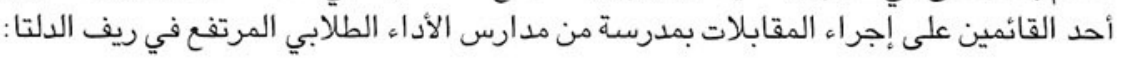

لا يوجد نظام بالمدرسة .... في أحد الأيام قام طالب بدق جرس المدرسة قبل موعده بحوالي 10 دقيقة، ويالتالي انتهي

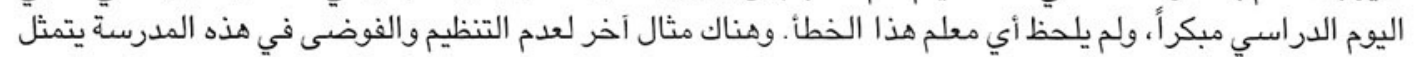
في بقاء بوابة المدرسة مفتوحة طوال اليوم، ويخرج الطلاب أثناء الحصص الحس دون قيود . 
ووصف شخص آخر ممن أجروا المقابلات الفوضى الموجودة في إحدى مدارس الأداء الطلابي المتوسط في الحضر بالصعيد قائلاً:

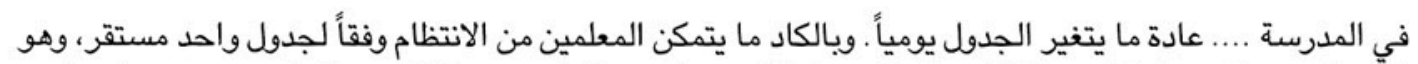

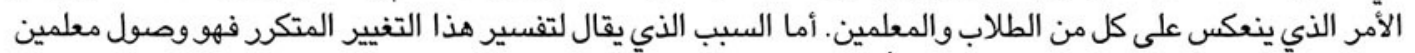

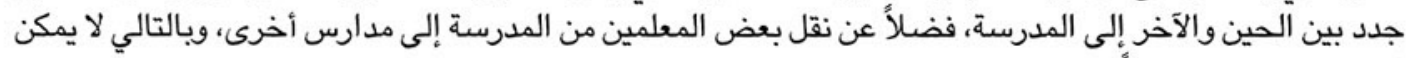
أن يظل الجدول مستقراً لفترة طويلة.

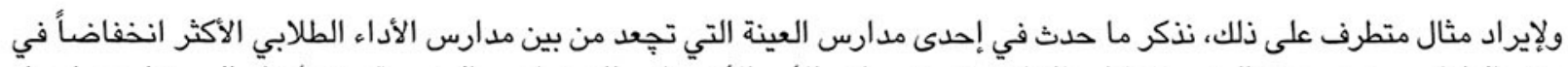

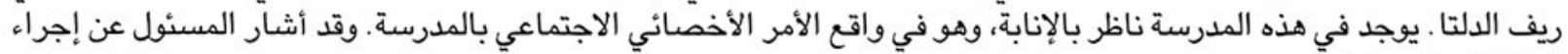

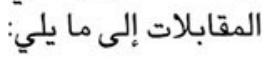

في هذه المدرسة بعينها، يبذل المعلمون بالفصل تحت الملاحظة فقط جهداً لإعطاء انطباع بالالتزام وانضباط المواع الاعيد.

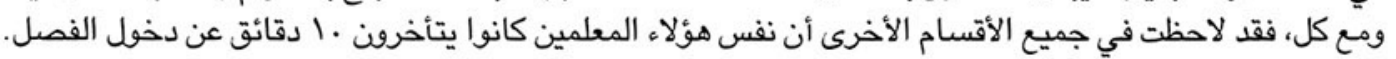

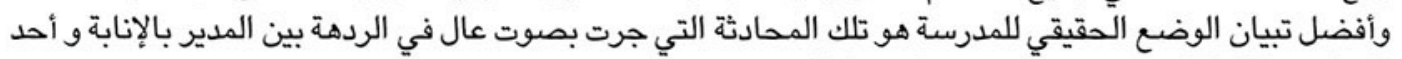

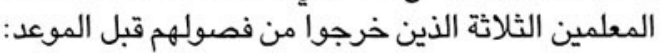

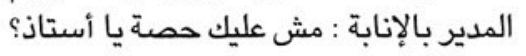

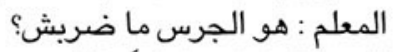

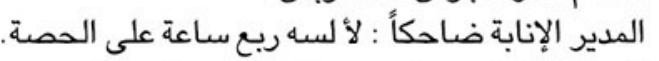

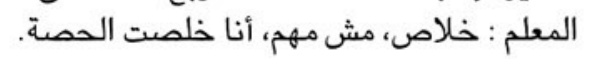
وضحك الجميع، بمن فيهم المدير بالإنابة الذي غادر المكان المكان، ويقى المعلمن جالسين في الخارج معاً.

أ. تخيب العاملين

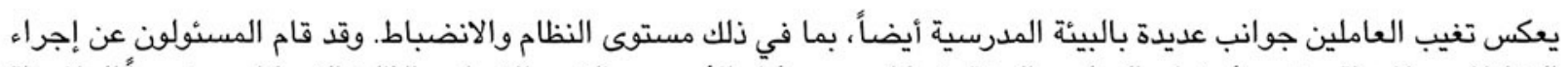

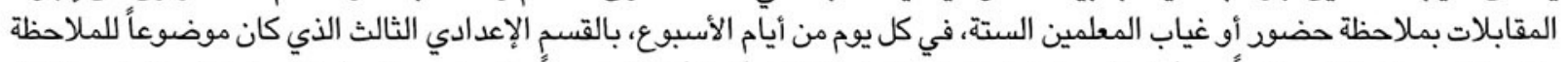

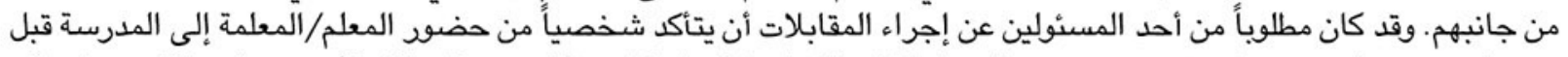

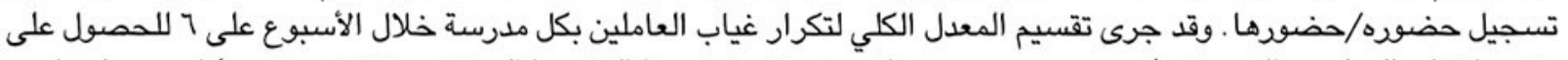

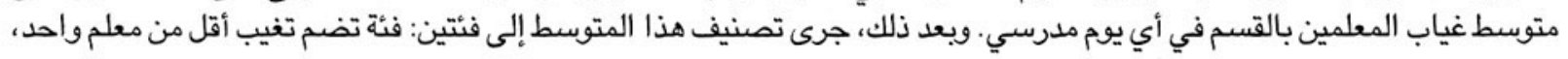

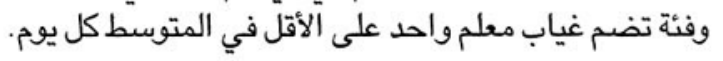

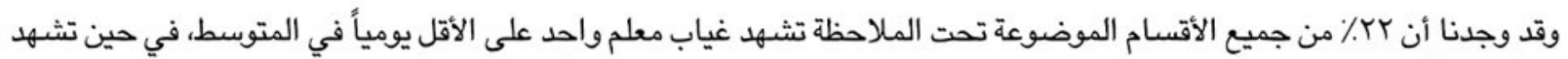

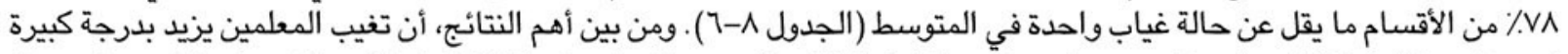

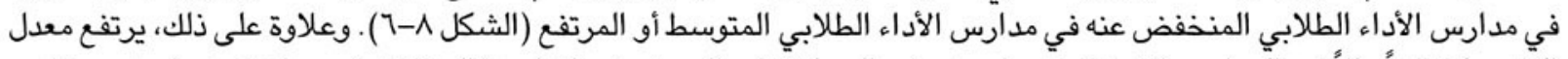

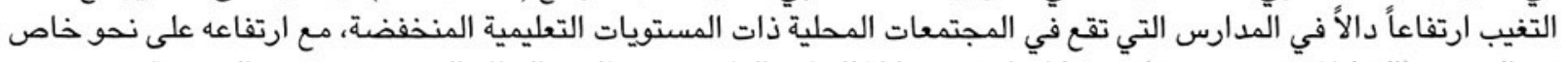

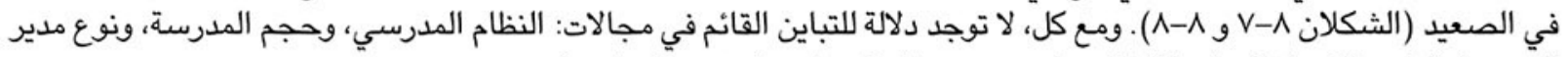
المدرسة. (راجع الفصل السابع للاطلاع على ملى مزيد من التفاصيل حول تلغيل لغيب المعلمين).

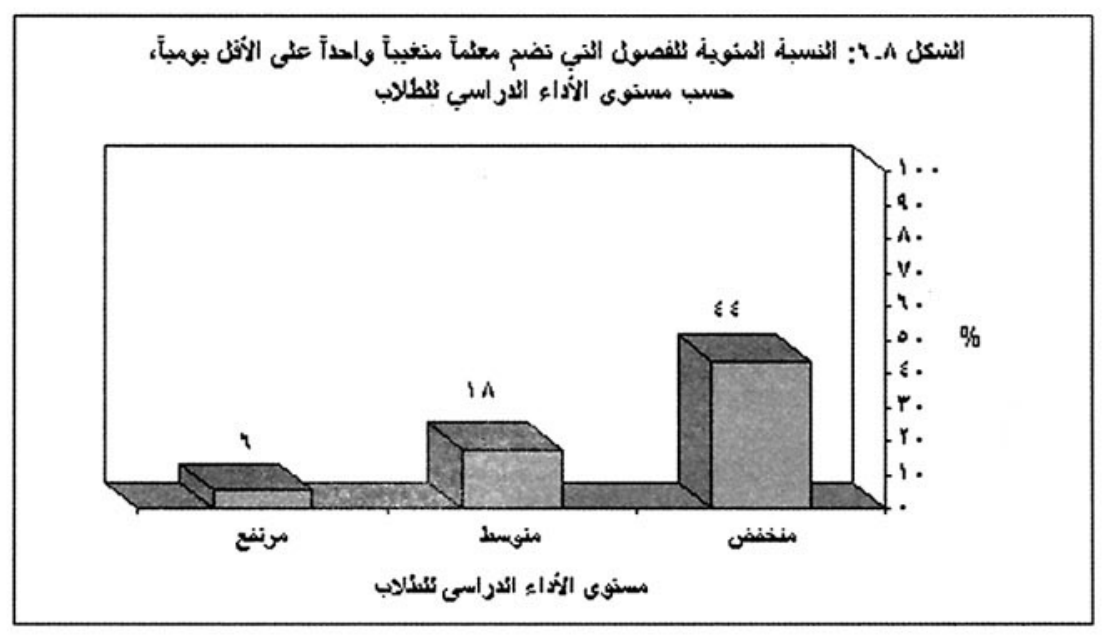



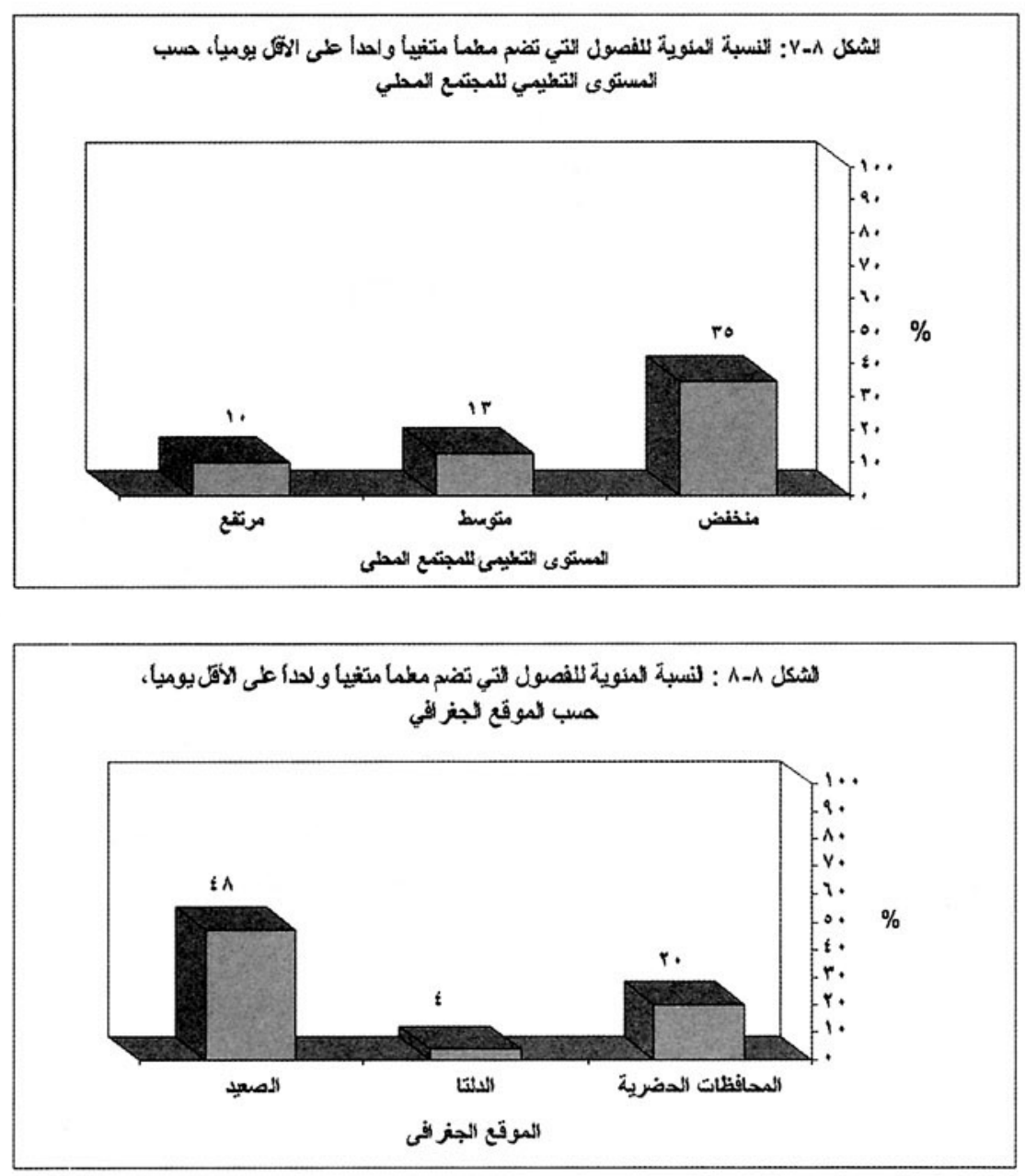

ب. عدد المحاو لات الفاشلة لملاحظة الحصص

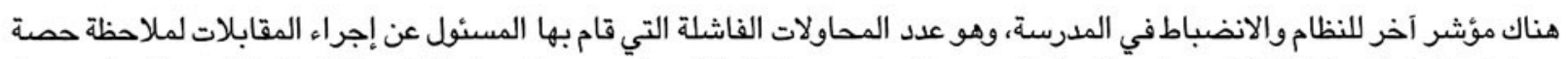

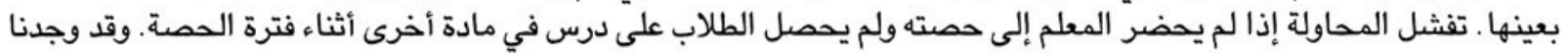

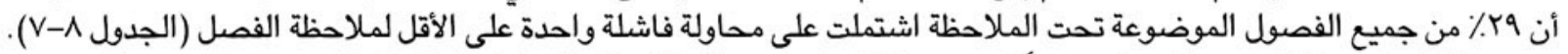
وجدير بالذكر أن هذا المؤشر لا يختلف وفقاً لمستوى الأداء الدراسي للطلاب، أو المنطقة، أو النظام المدرسي، أولاته أوحجم المدرسة.

\section{ج. دقة مواعيد الحصص}

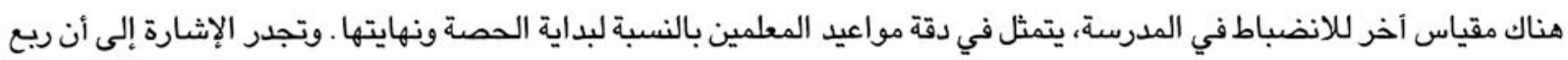

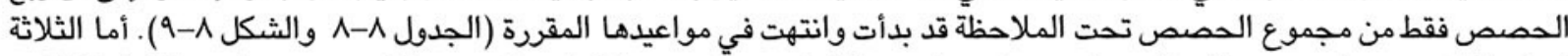

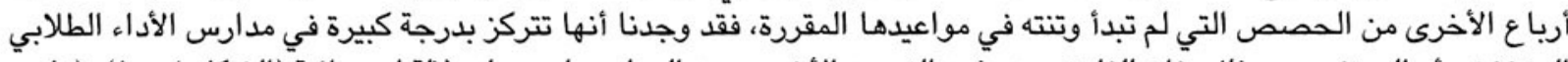

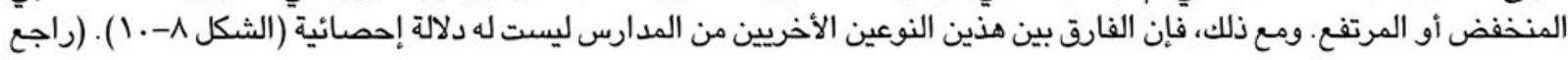

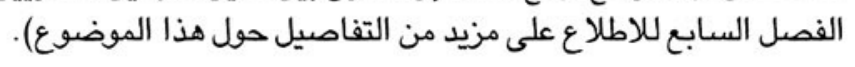



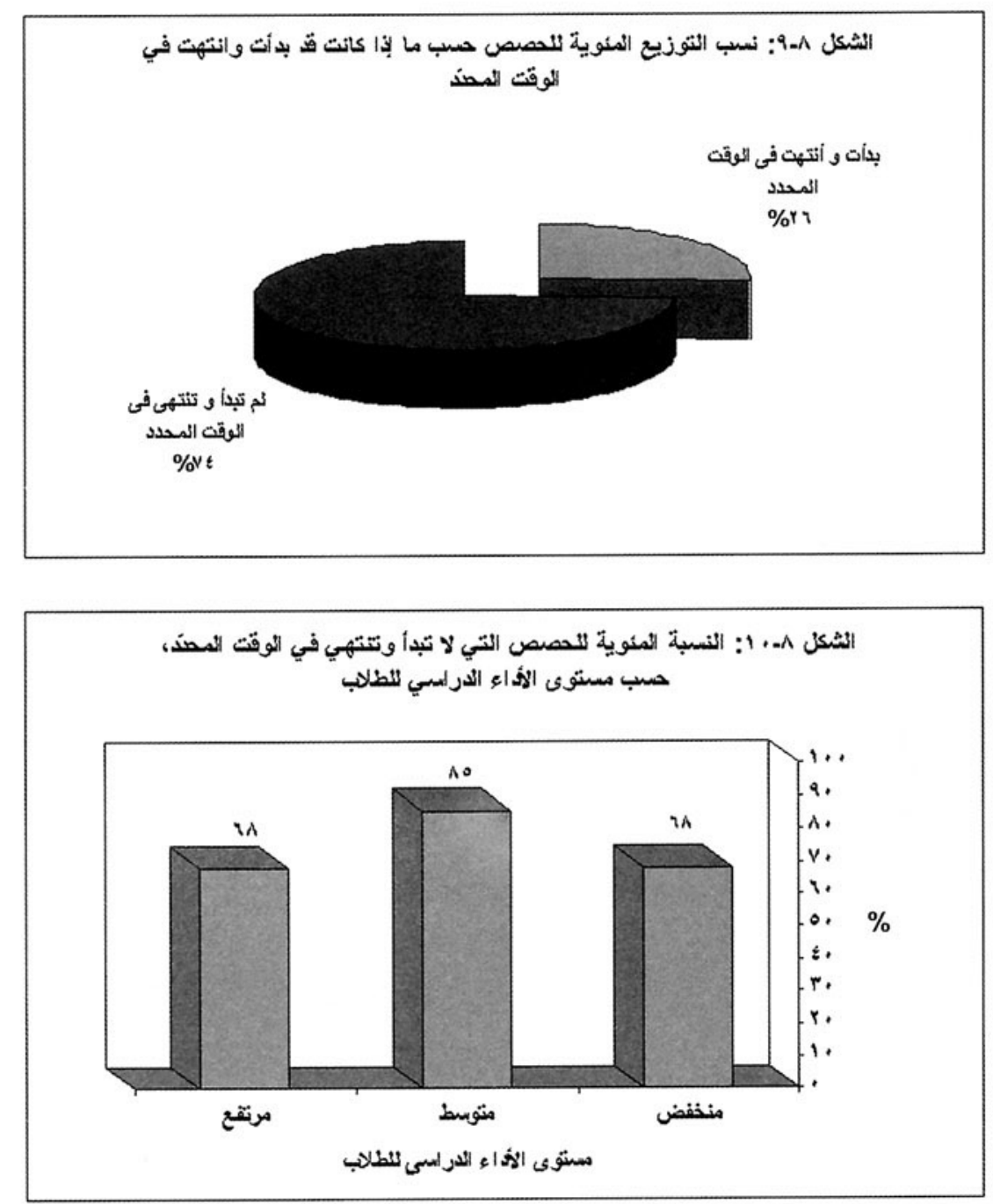

د. دقة مو اعيد فترات الر احة

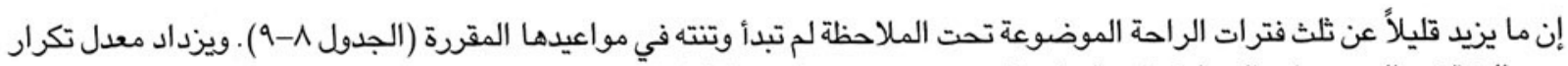

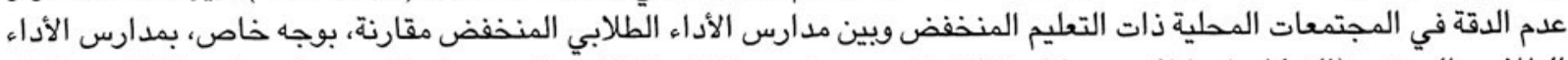
الطلابي المرتفع (الشكل ^-11) . ومع كل، فالفارق بين مدارس الأداء الطلابي المتوسط والمرتفع ليس لئ له دلالة إحصائية.

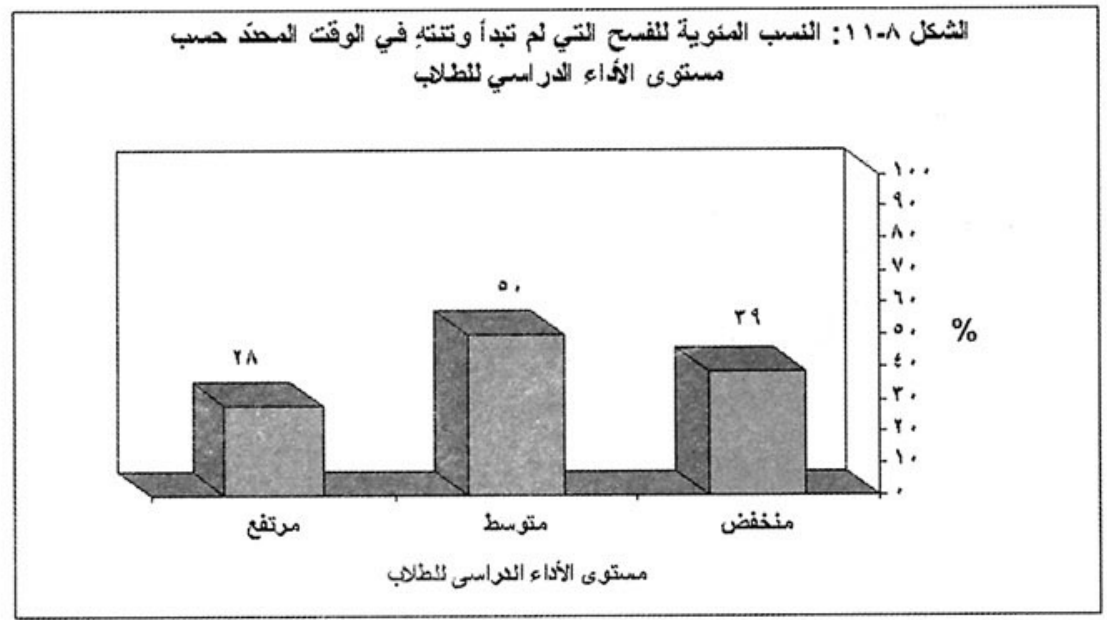




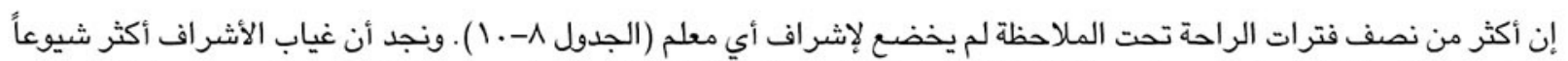

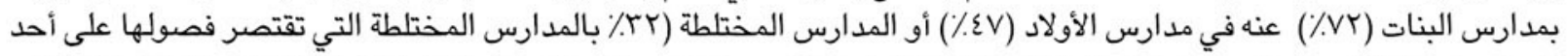

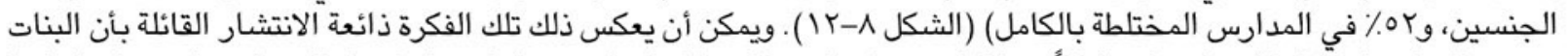

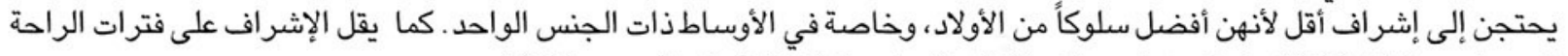

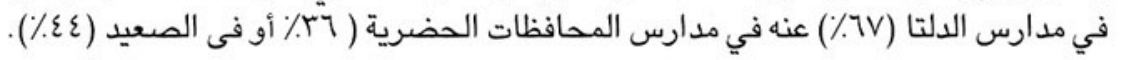

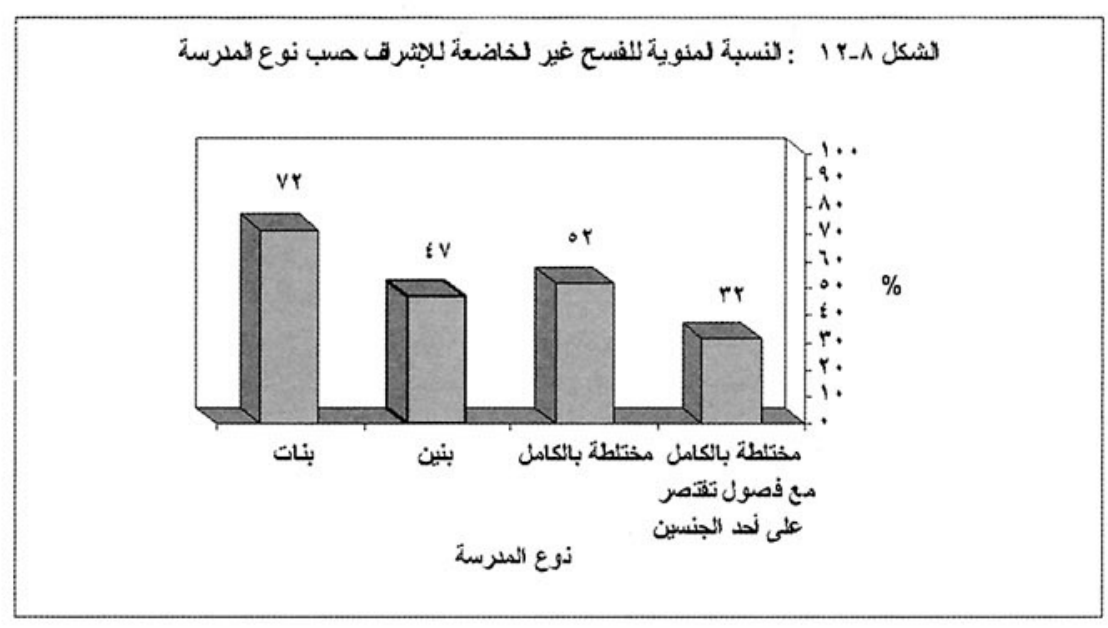

\section{ع. الشعور بالرضا تجاه حالة المدرسة}

أ. كثافة الفصول

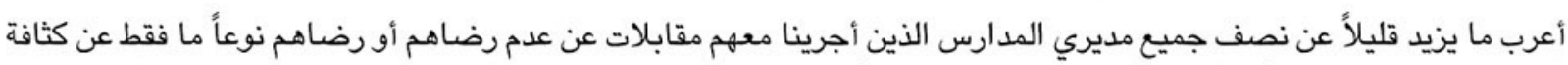

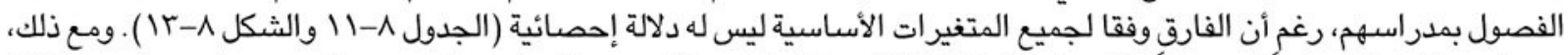

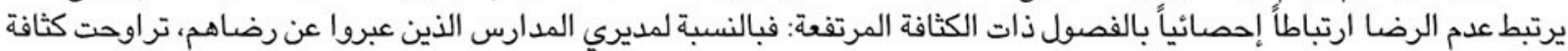

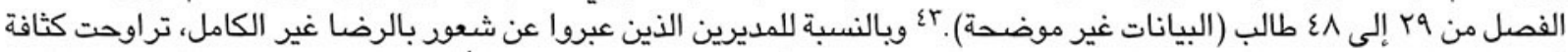

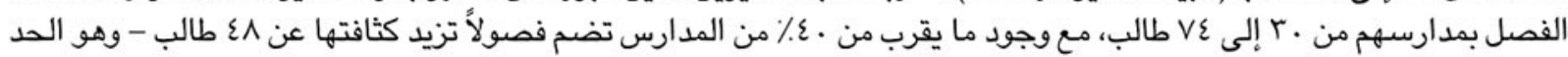

الأقصى في المجموعة التي تشعر بالرضا.

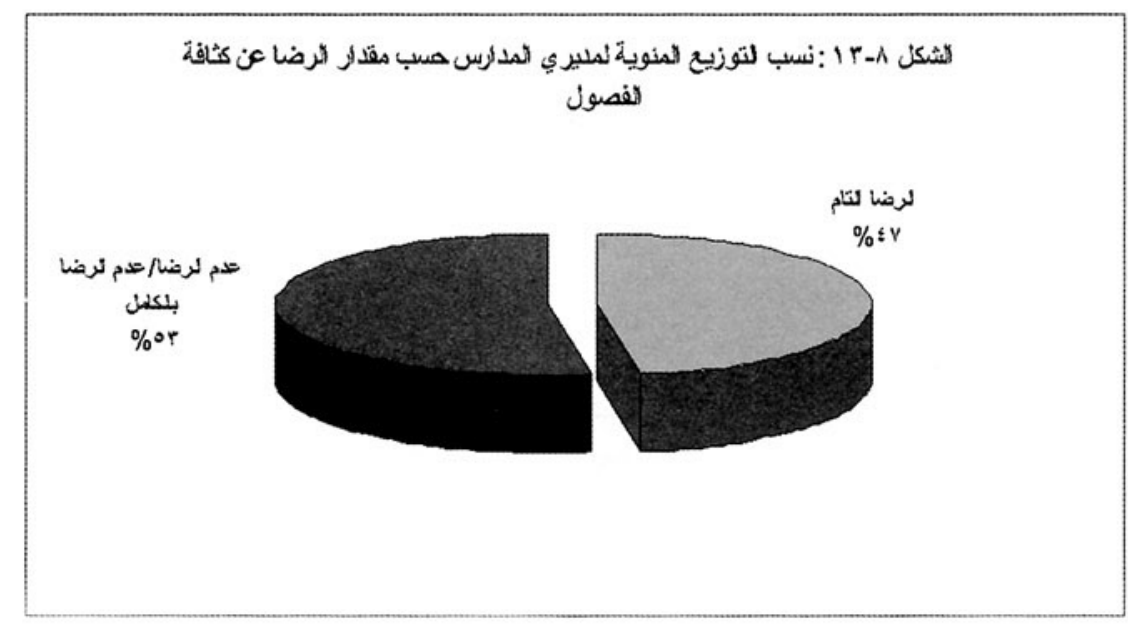

وتهتم مجموعة المديرين الذين يشعرون "برضا غير كامل" بالأثر السلبي للكثافة العالية للفصول على التحصيل الدراسي للطلاب. ومن

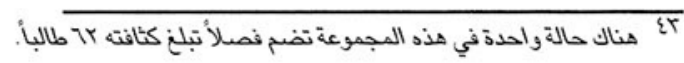




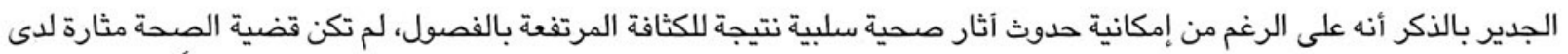

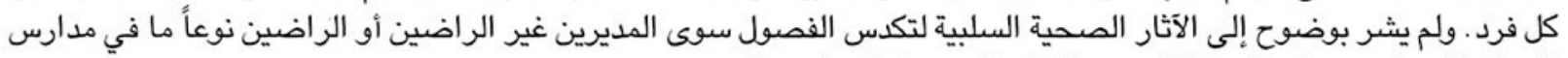
المحافظات والمجتمعات المحلية الحضرية ذات التار التحصيل الدراسي المرتفع.

ب. المرافق المدرسية

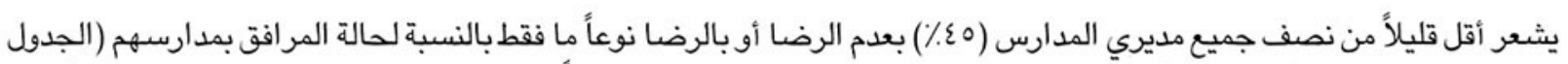

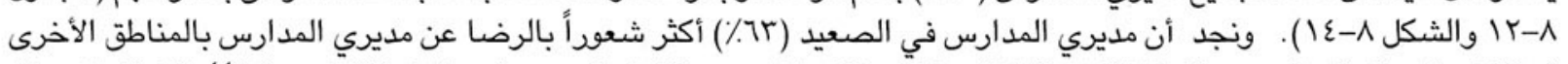

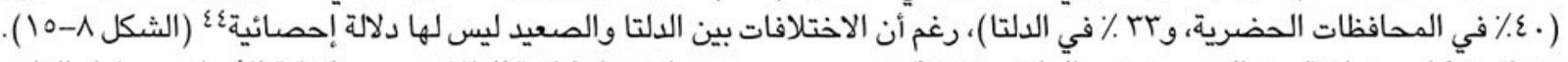

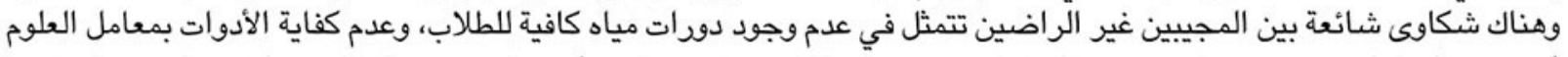

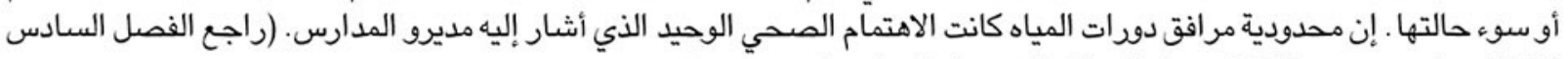

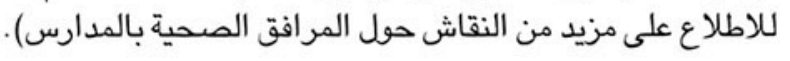
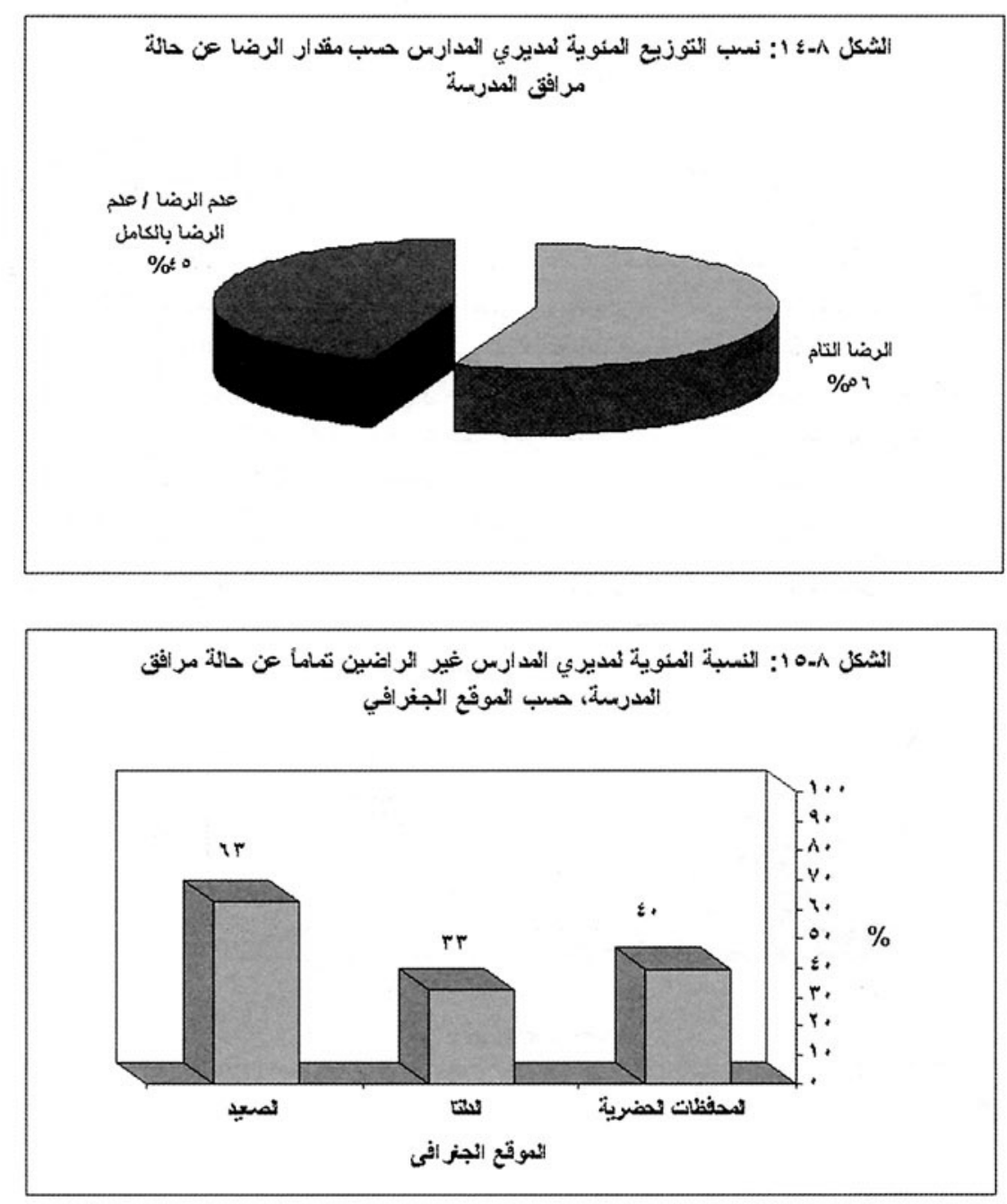

ج. ساعات العمل

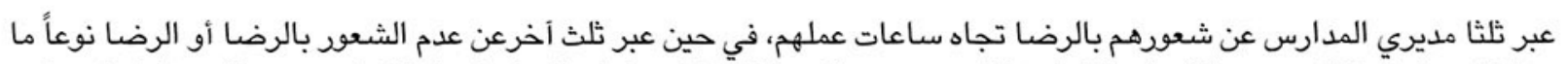

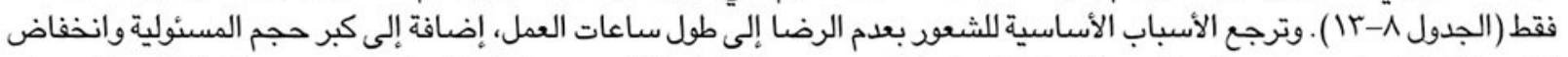

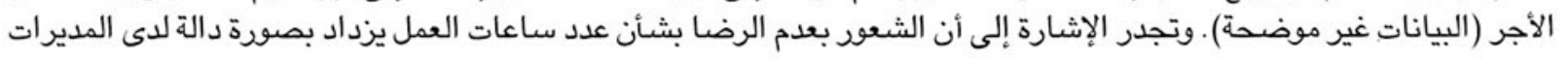

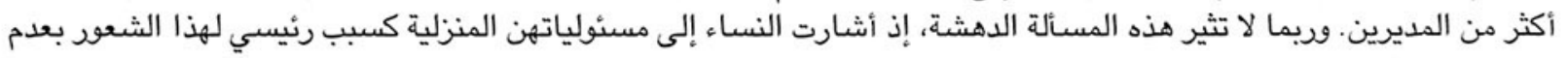

ع قد يعكس ذلل الأتشار الكير للمدارس الجديدة التي بنيت مؤخرأ في ريف الدلتا. 


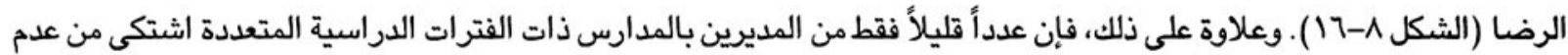

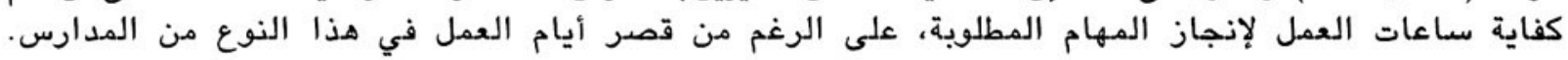

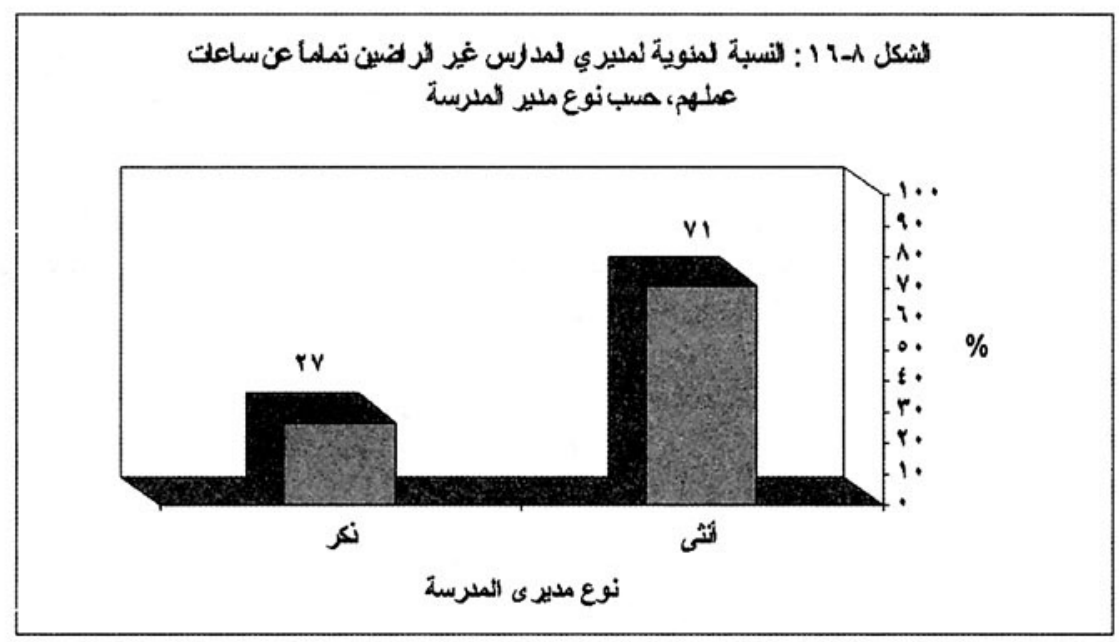

د. سلوك الطلاب والتواصل فيما بينهم

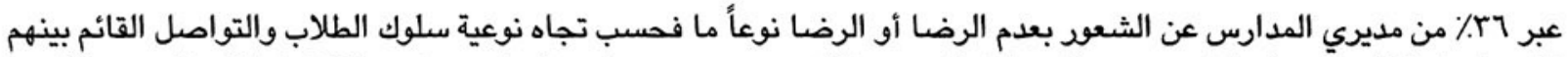

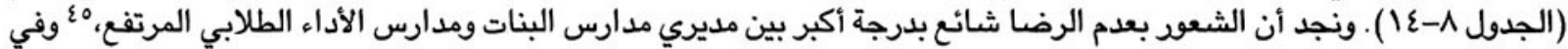

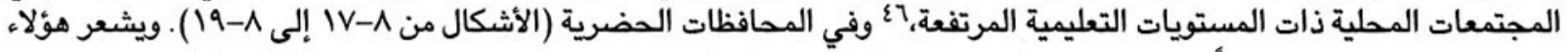

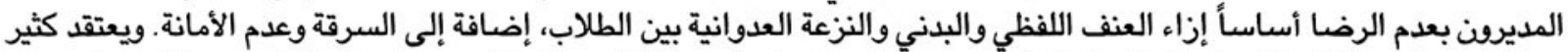

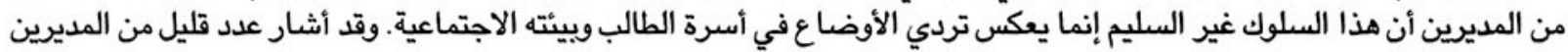

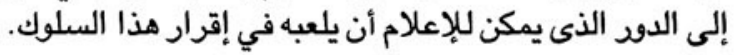

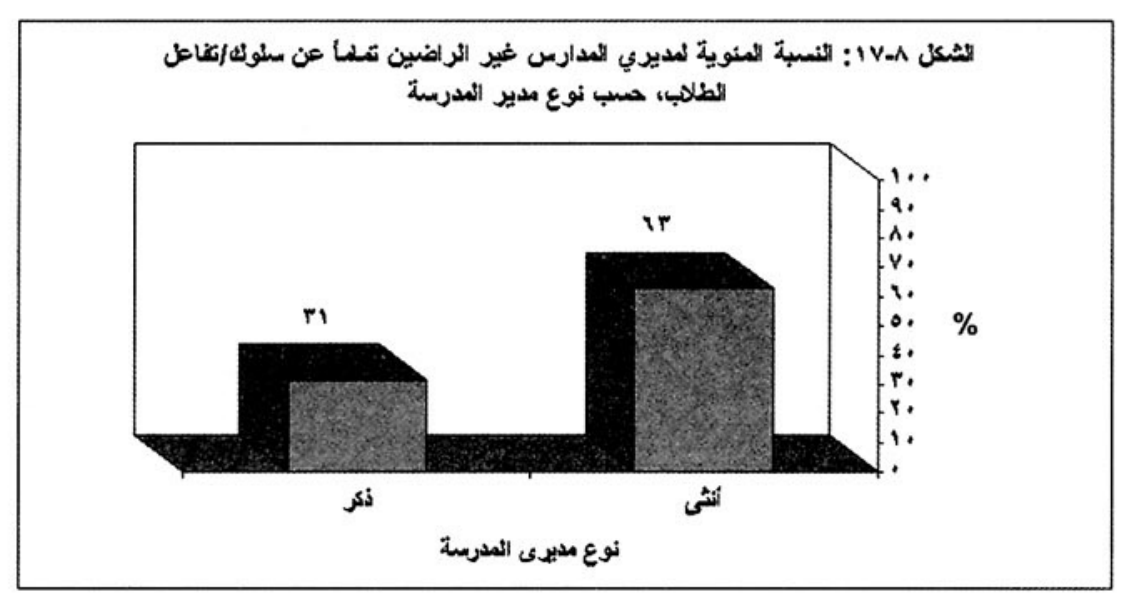

ع الاختلافات بين مدارس الأداء المنففض والمرتفع ليس لها دلالة إحصانية.

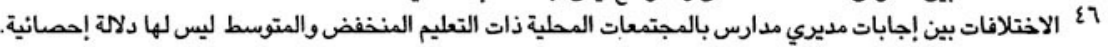



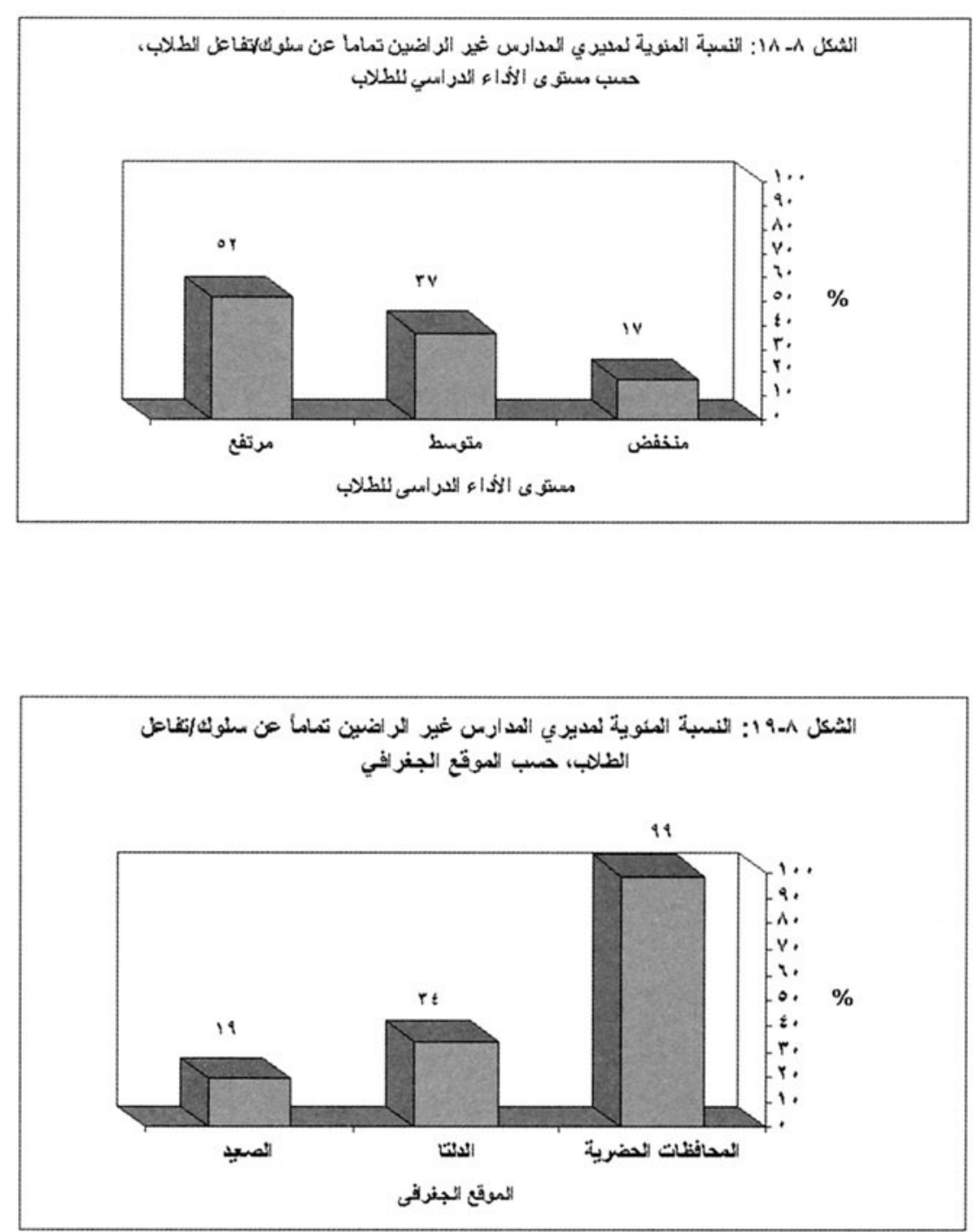

هـ. التو اصل بين المعلمين و الطلاب

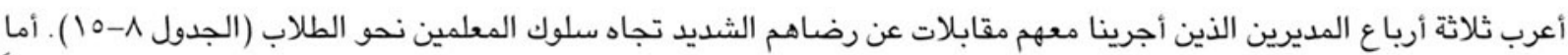

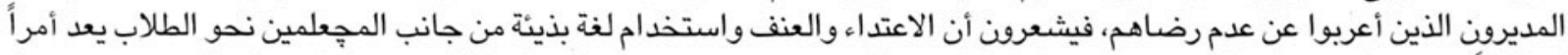

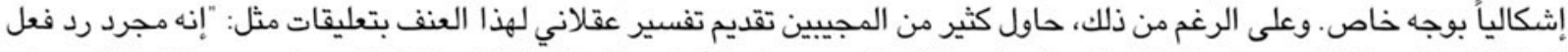

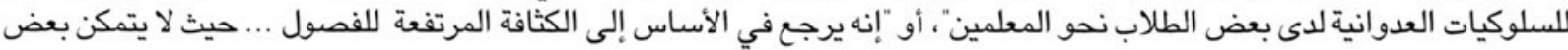

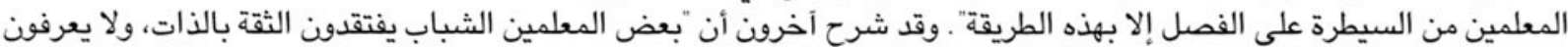

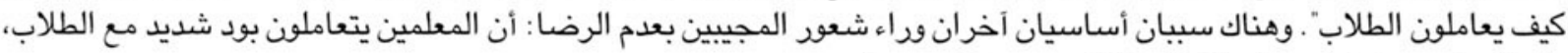

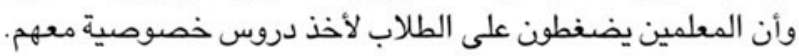

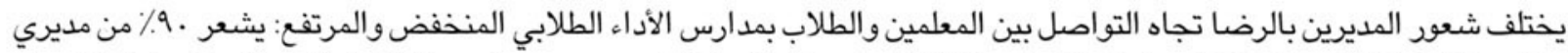

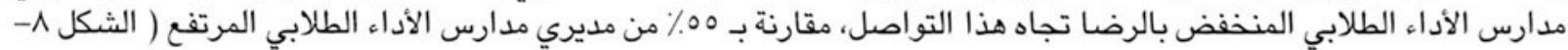

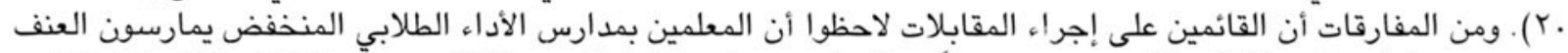

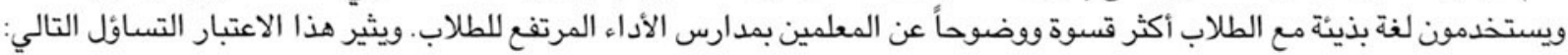

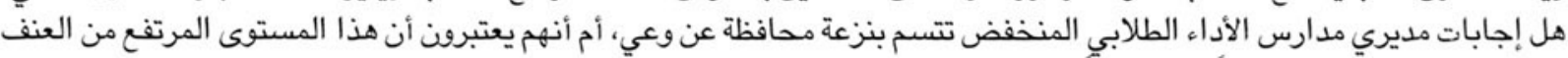

واستخدام اللغة البذيئة "عادياًً" و "مناسباً" ؟ الطابِ 


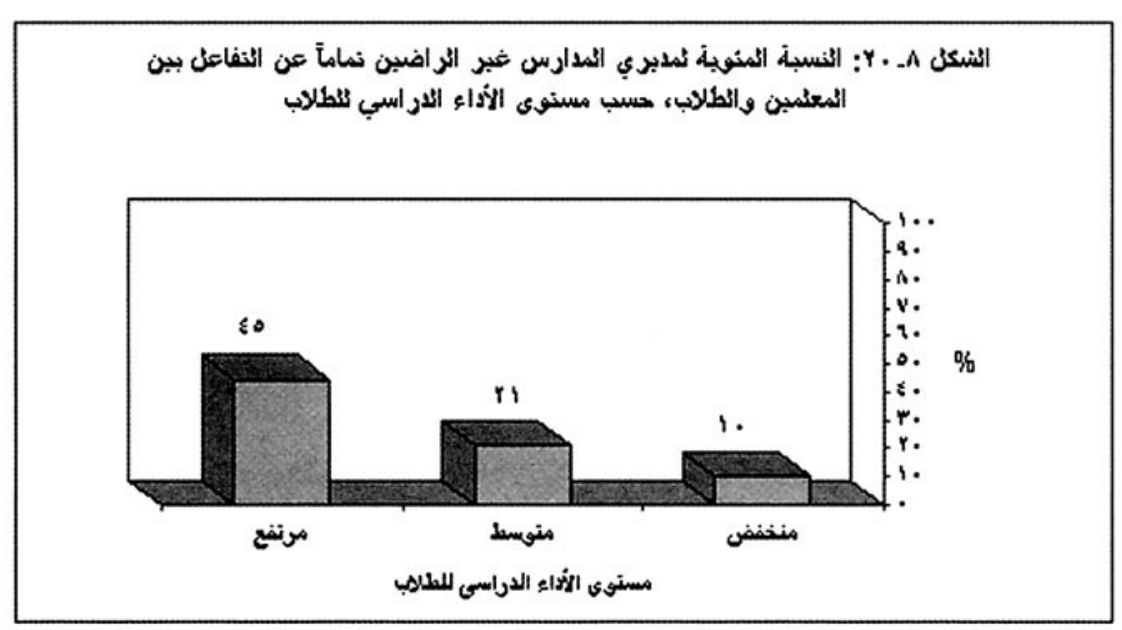

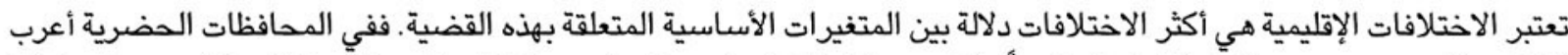

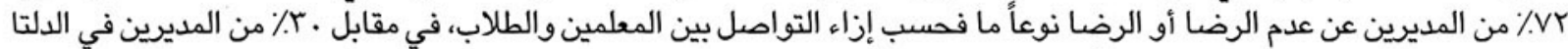

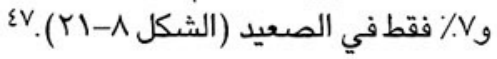

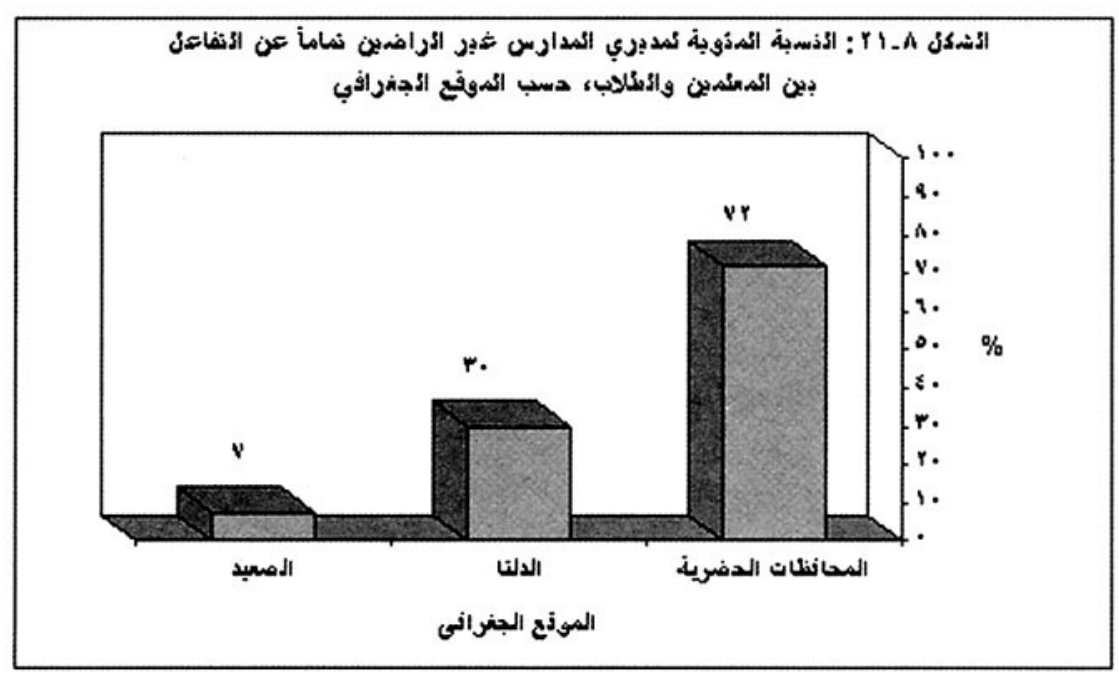

و. العلاقات بين المعلمين والإدارة

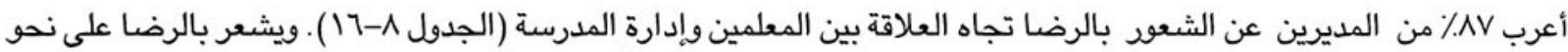

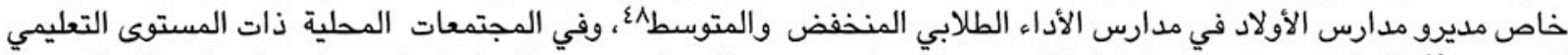

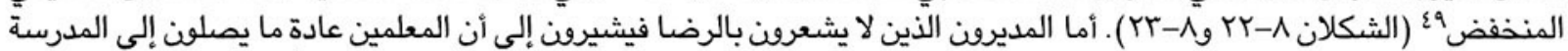

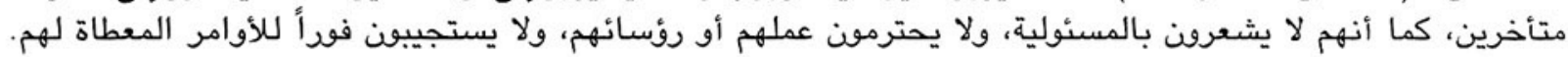

أ جميع الاختبار ات المزدوجة المماثلة لها دلالة احصانية.

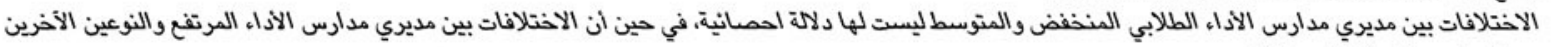
من المدارس لها دلالة الحصانية.

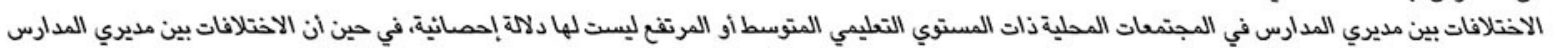

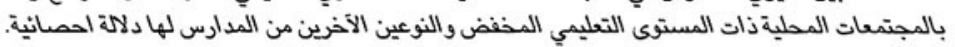



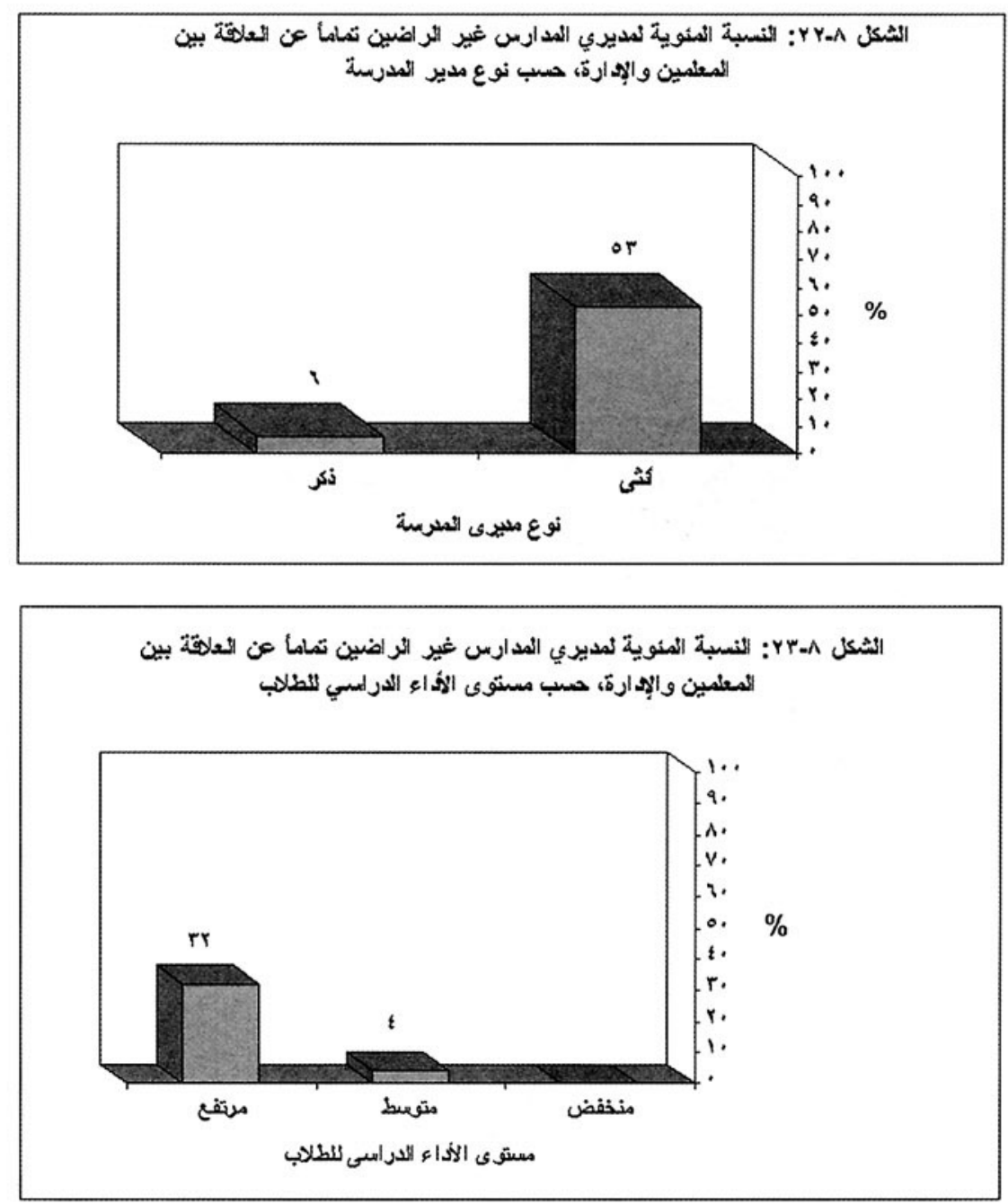

•. دور أولياء الأمور والمجتمع المحلي أ. تشجيع مشاركة الوالدين

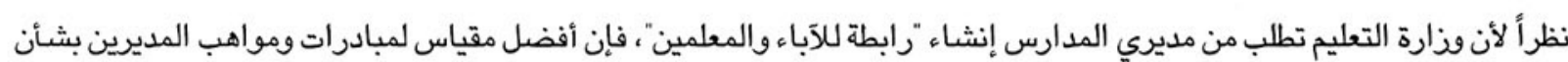

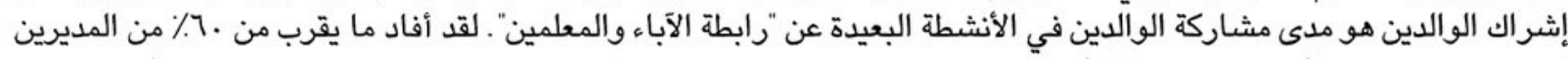

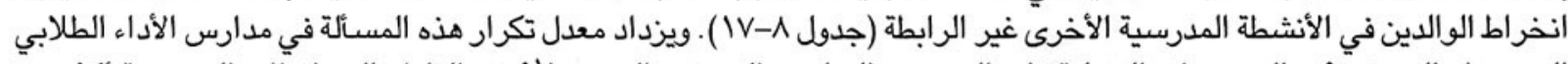

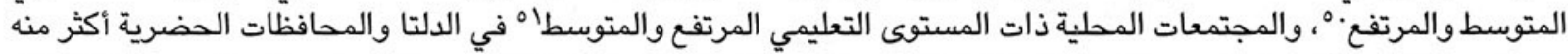

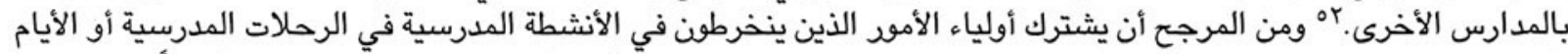

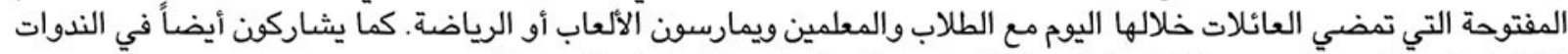
الثقافية والدينية، ويتعاونون مع الإدارة لحل مشكلات مدرسة، مثل تجديد المنشآت المدرسية.

ب. مساهمات المجتمع المحلي

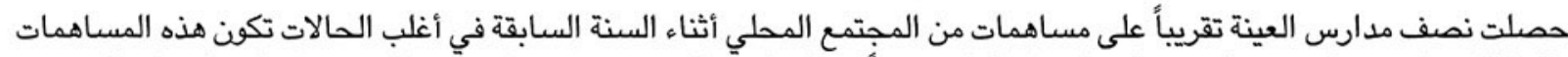

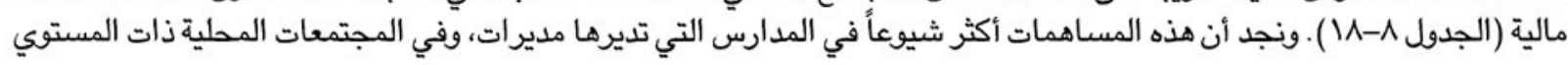
• الاختلافات بين مدارس الأدا، الطلابي المرتفع والمتوسطليست لها دلادة إحصائية، في حين الاختلافات بين مدارس الأدا، الطلابي المنفض والثوعين الآخرين من المدارس

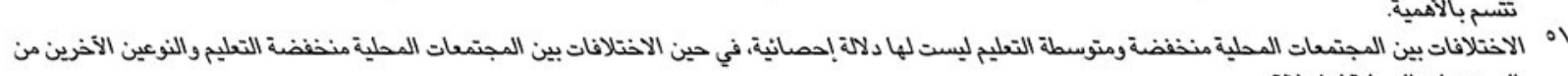
المجتمعات المحلية لها دالاتة. الاختلافات بين الدلتا والصعيد لها أهمية إحصائية خاصة. 


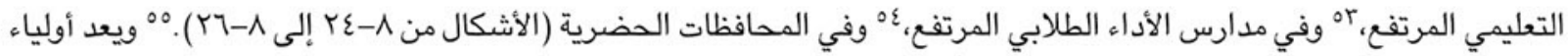

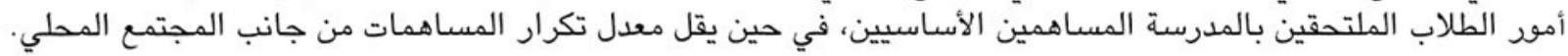
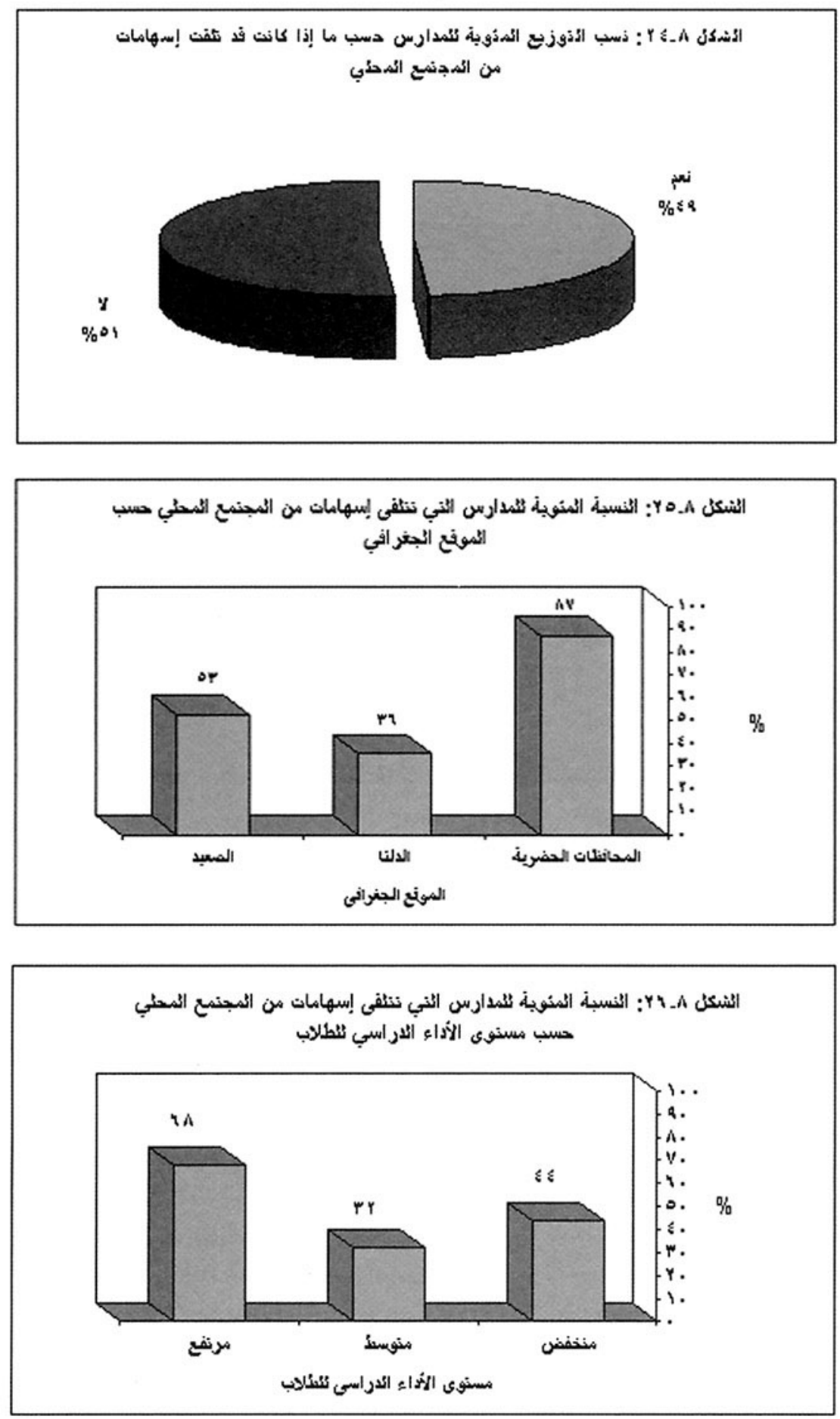

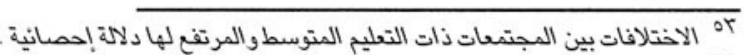

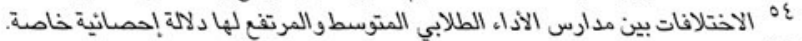
00 الاختلافات بين الدلتا والصعيد ليس لهانيا دلالة الحصائية. 


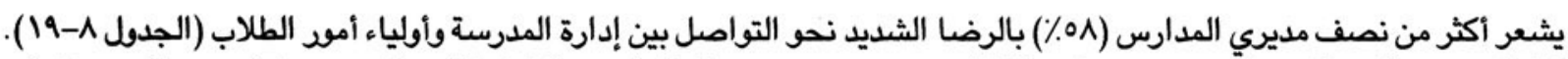

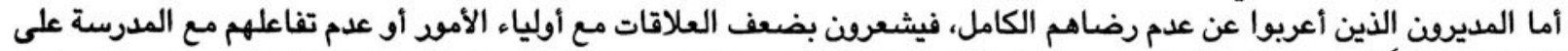

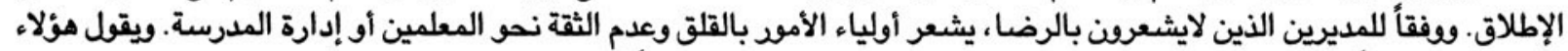

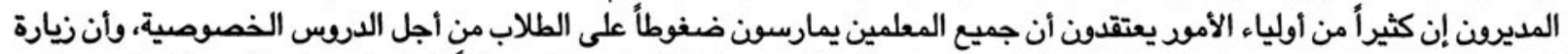

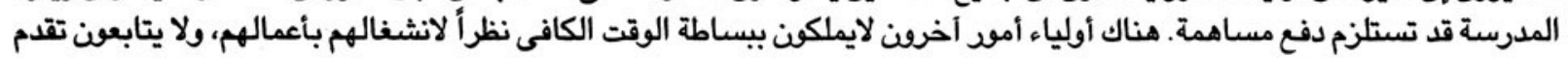

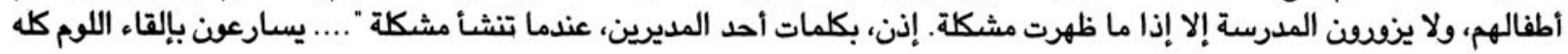

7. 1 الاستنتاجات

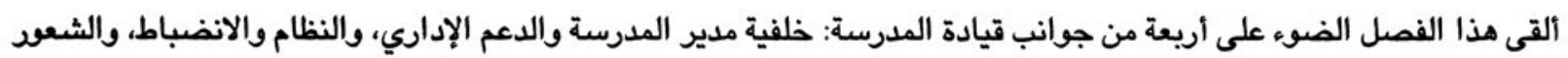

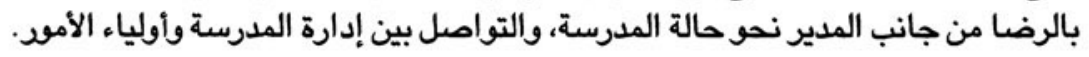

أ. النتائج المتعلقة بالقيادة المدرسية وفقاً للأداء الدراسي للطلاب

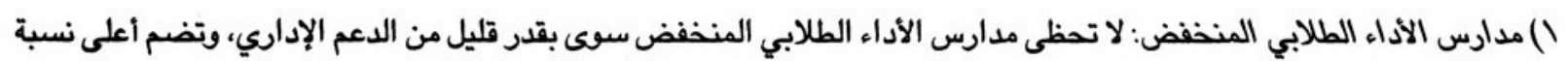

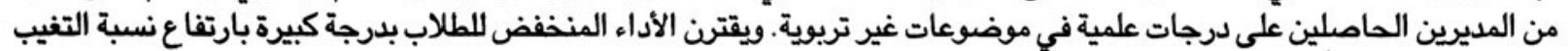

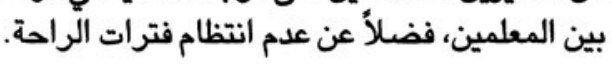

يتفق مديرو مدارس الأداء الطلابي المنخفض في عدم الرضا عن الظروف المادية بالمدرسة. ومع كل، فإنهم يتفقون أيضاً في التعبير

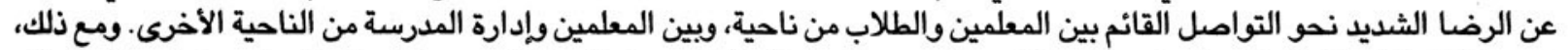

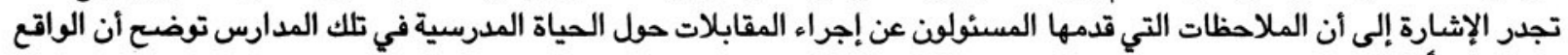

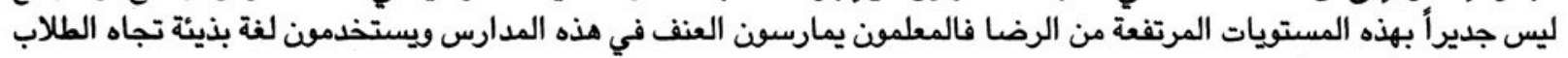

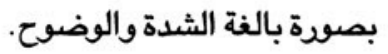

وعلاوة على ذلك، أشار المراقبون إلى أن مديري هذه المدارس، وخاصة في المدارس البعيدة عن مكاتب المنطقة التعليمية، عادة ما

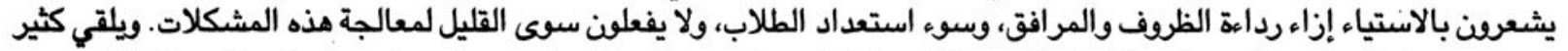

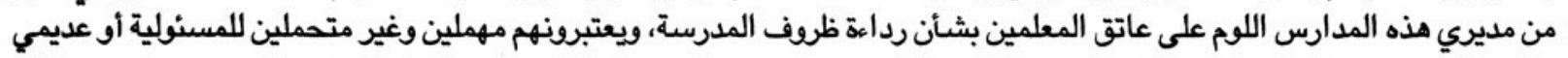

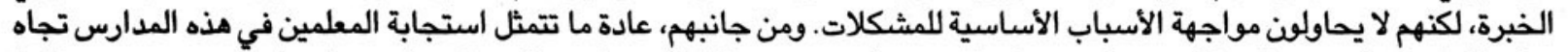

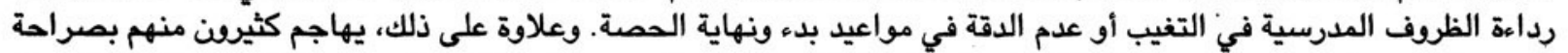

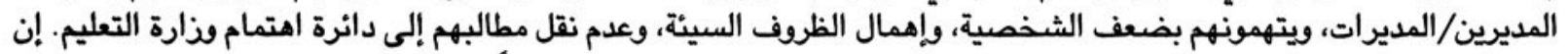

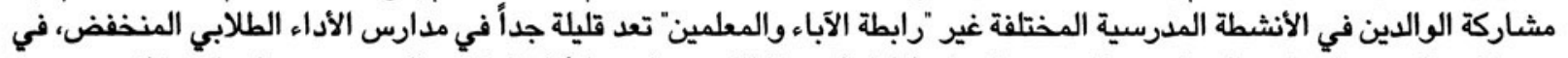

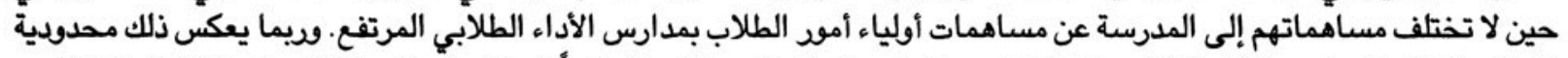

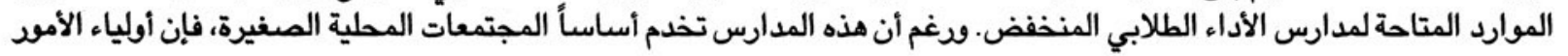

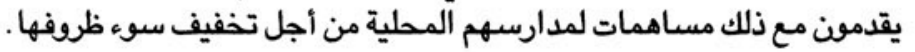

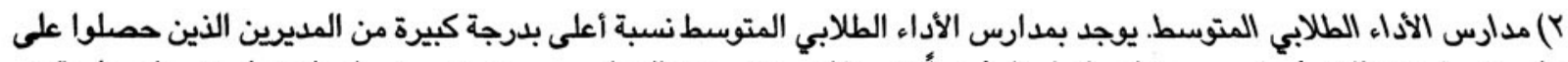

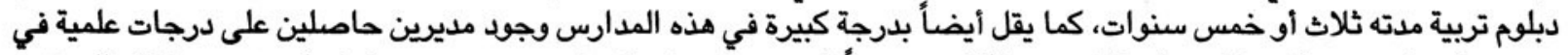

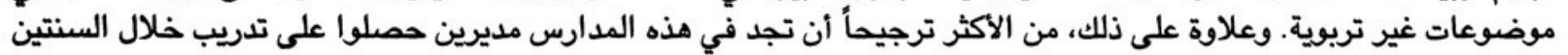

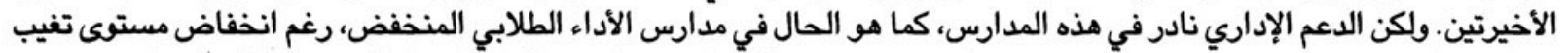

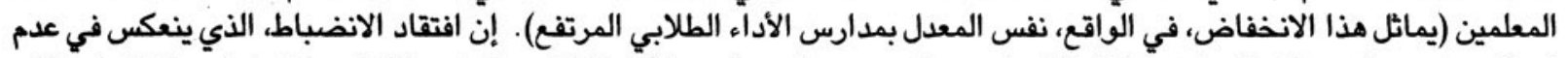

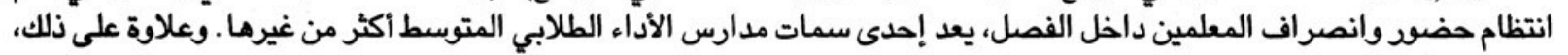

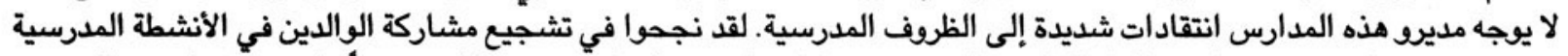

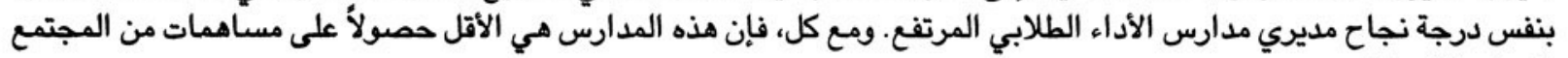
المحلي الذي تخدمه . 


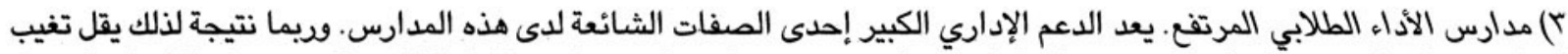

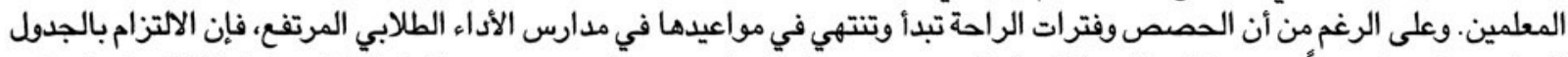

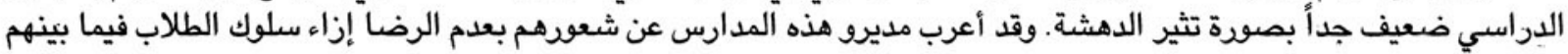

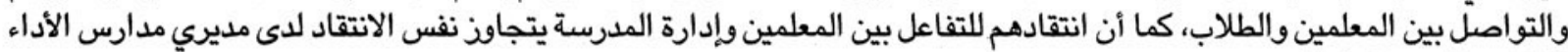
الطلابي المتوسط أو المنخفض.

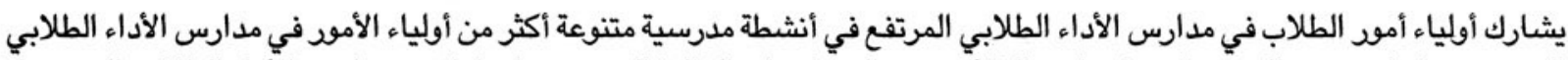

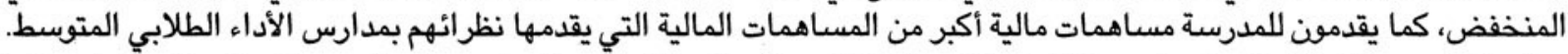

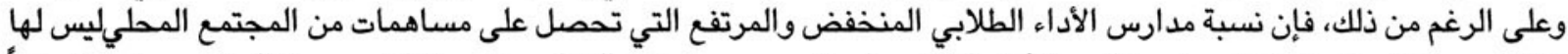

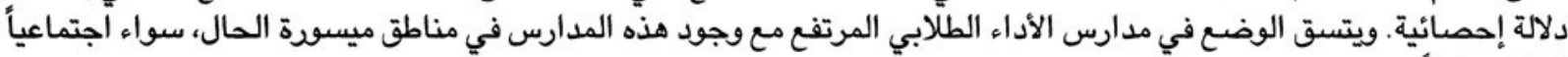

أو اقتصادياً.

\section{ب. النتائج حسب المنطقة الجغرافية}

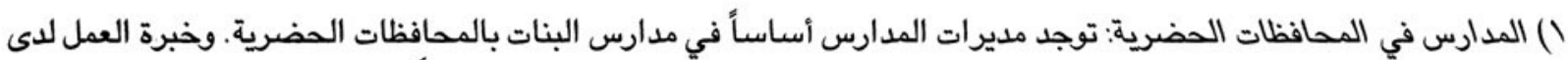

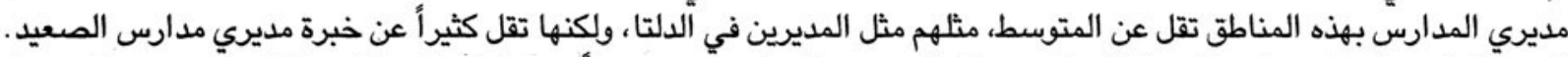

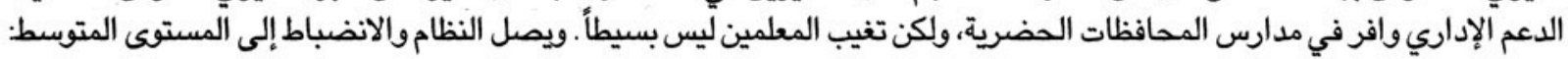

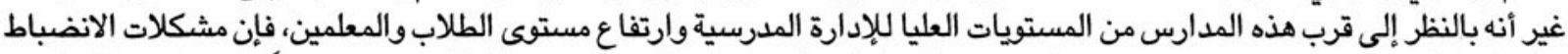

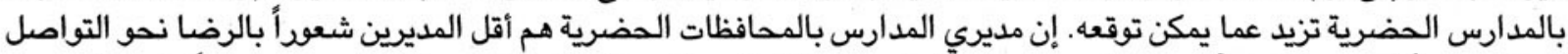

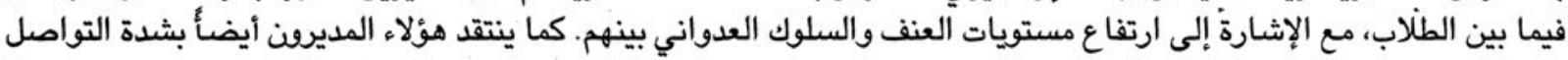

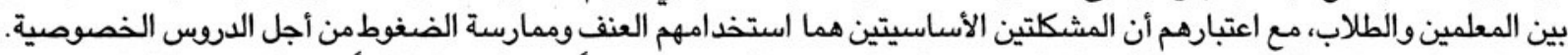

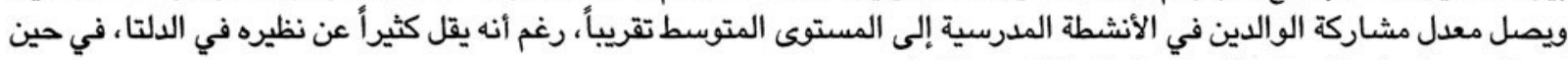

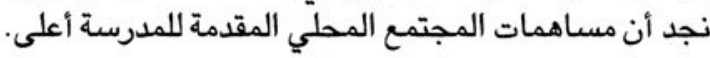

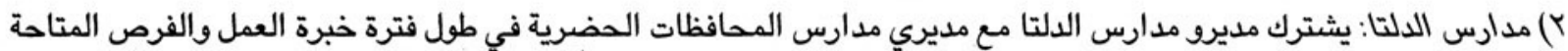

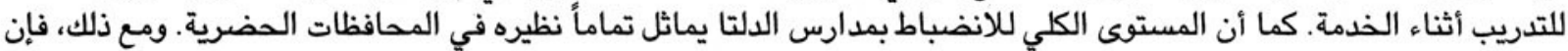

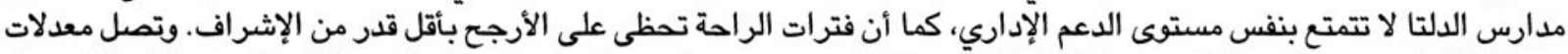

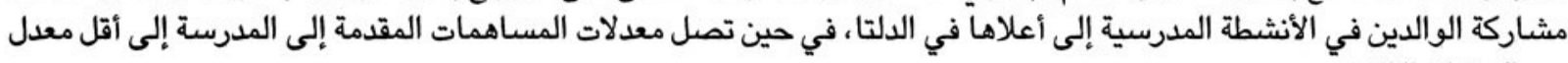

كا مدارس الصعيد. يمتلك مديرو مدارس الصعيد أطول فترة خبرة في هذا المنصب، مقارنة بمديري المدارس في المناطق الأخرى.

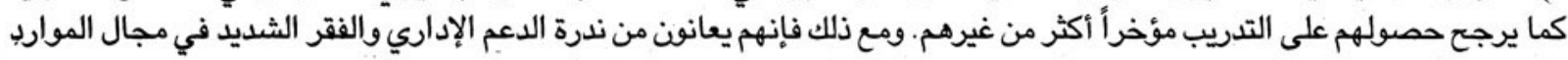

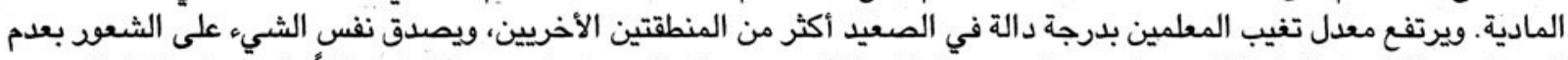

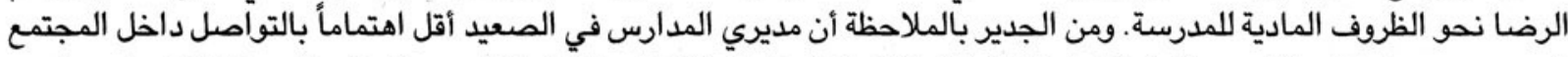

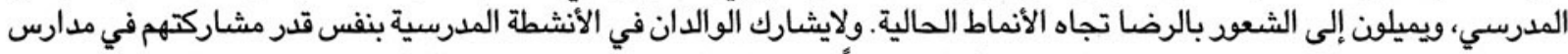

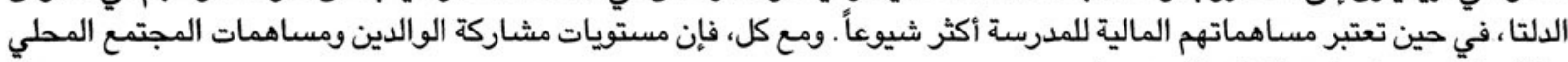

تماثل ما يجري في المحافظات الحضرية.

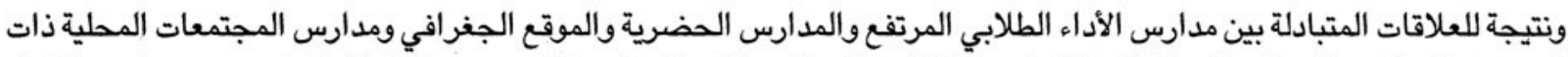

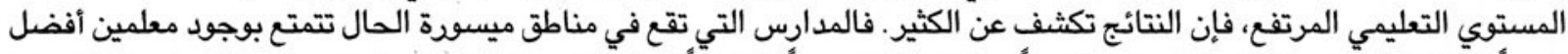

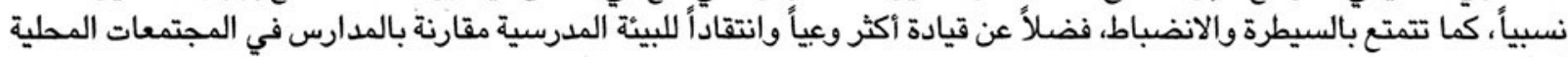
الفقيرة.

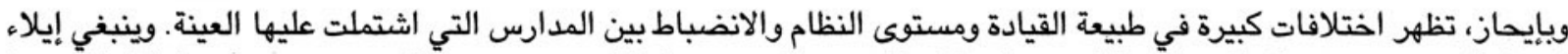

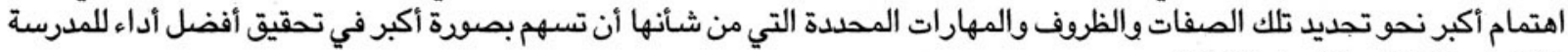
وأفضل بيئة تعليمية إيجابية للطلاب. 
الملحق الأول 


\section{حساب أوزان العينة}

للأوذان المستخدمة في التحليل مكوكنات ثلاثة أساسية: W, W, W

$$
\mathrm{W}=\mathrm{W}_{1} * \mathrm{~W}_{2} * \mathrm{~W}_{3}
$$

وتعكس W الونن المرتبط بتصميم عينة الددارس:

$$
\mathrm{W}_{1}=\frac{1}{\mathrm{f}} \frac{101}{37} \frac{\mathrm{Bi}}{\mathrm{bi}}
$$

المكن الأول (1/f) ) هو الونن الثابت الذى استخدم لاختيار عينة الأسر فى المسح القومى :

البال هو عد المد وحدات المعاينة الأولية التي اختيرت عينة المدارس من داخلها، وذلك ضمن المجموعة الكاملة لوحدات المعاينة الأولية

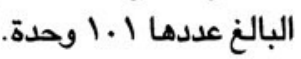

i هو عدد المدارس المختارة من وحدة المعاينة الأولية رقم bi

i هو العدد الإجمالي للمدارس الواردة في المسح القومي في وحدة المعاينة الأولية رقم Bi

وتعكس W2 العدد الفعلي للمدارس الإعدادية العامة الحكومية في المنطقة التعليمية التي تنتمي إليها وحدة المعاينة الأولية المختارة، وليس فقط العدد المذكود في المسح القوارس الإعي في هذه الوحدة بعينهاً.

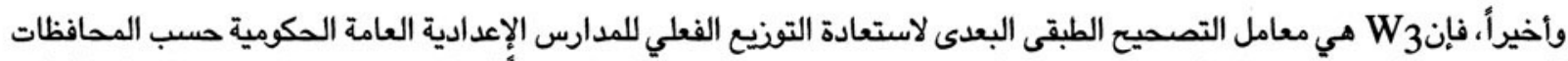

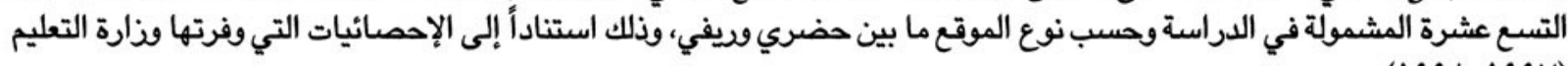

(1994-199V)

وإلى جانب الونن النهائي للمدرسة، هناك مكون رابع هو W4 اختلف بالنسبة لكل من الحصص والطلاب والمعلمين والأخصائيين

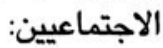

هالنسبة لملاحظة الحصص، يعكس W4 العدد الإجمالي لفصول الصف الثالث الإعدادي في المدرسة التي اشتملت عليها العينة. ه بالنسبة للمعلمين والأخصائيين الاجتماعيين، Wي هيبة العدد الإجمالي من المعلمين (أو الأخصائيين الاجتماعيين) في المدرسة إلى عدد الذين تمت مقابلتهم بالفعل.

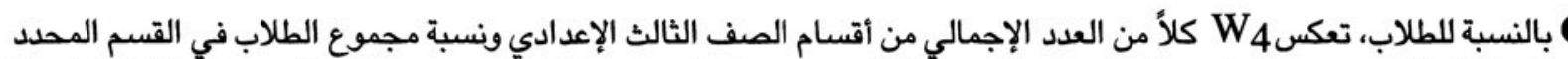

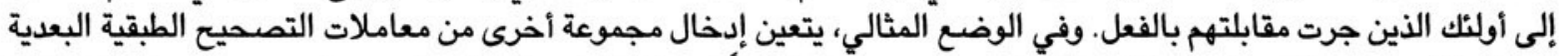

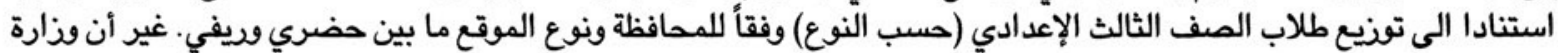

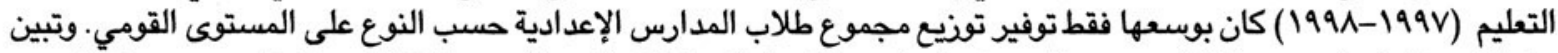

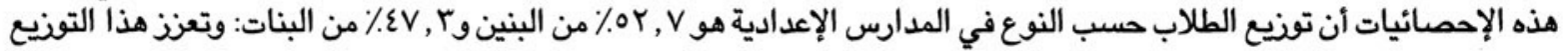

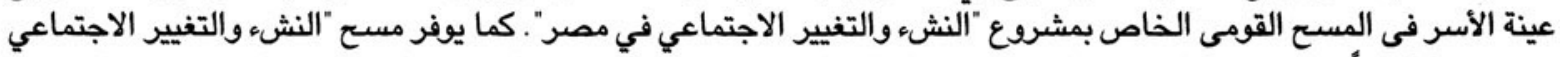

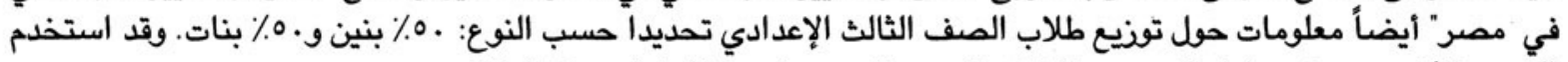

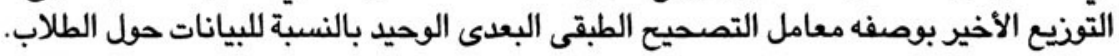


الملحق الثانى 


$$
\text { الجداول }
$$

الفصل الثالث

$$
\text { حياة الطلاب }
$$




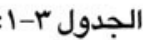

الخصائص الشخصية و الأسرية للمجيبين، وفق المتغيرات الخلفية الفردية و المدرسية

\begin{tabular}{|c|c|c|c|c|c|c|c|}
\hline الأم حاصلة علي & 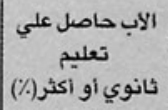 & يحيون مع الام (\%) & بحيون هع (1) & المدوس الاخوة & عدد الأخوات & العمر المتوسط & المتغيرات الخلفية \\
\hline $\begin{array}{l}r . \\
17\end{array}$ & $\begin{array}{l}r r \\
19\end{array}$ & $\begin{array}{l}9 \mathrm{~V} \\
90\end{array}$ & $\begin{array}{l}10 \\
\Lambda \varepsilon\end{array}$ & $\begin{array}{l}1,1 \\
r, .\end{array}$ & $\begin{array}{l}1,8 \\
1,9\end{array}$ & $\begin{array}{l}\text { ir, r } \\
\text { ir,v }\end{array}$ & نو نوع المجيب \\
\hline $\begin{array}{l}0 \\
i n \\
r v\end{array}$ & $\begin{array}{l}\text { ir } \\
19 \\
\text { ra }\end{array}$ & $\begin{array}{l}97 \\
97 \\
97\end{array}$ & $\begin{array}{l}\text { va } \\
\text { Ao } \\
\text { Av }\end{array}$ & $\begin{array}{l}r, r \\
1,9 \\
1,7\end{array}$ & $\begin{array}{l}r, r \\
1, v \\
1,0\end{array}$ & $\begin{array}{l}\text { ir, } \\
\text { ir, } \\
\text { ir,r }\end{array}$ & منخفض الاداء الدراسي للطلاب \\
\hline $\begin{array}{l}r r \\
r i \\
1 \\
9\end{array}$ & $\begin{array}{l}\text { ro } \\
\text { ro } \\
\text { ir } \\
\text { io }\end{array}$ & $\begin{array}{l}9 v \\
97 \\
90 \\
90\end{array}$ & $\begin{array}{l}\Lambda 0 \\
\Lambda 1 \\
\Lambda \varepsilon \\
\Lambda .\end{array}$ & $\begin{array}{l}1, v \\
1, v \\
r, 0 \\
r, r\end{array}$ & $\begin{array}{l}1,0 \\
1, v \\
r, r \\
r, r\end{array}$ & $\begin{array}{l}\text { ir, r } \\
\text { ir, } \\
\text { ir,v } \\
\text { ir, } 1\end{array}$ & 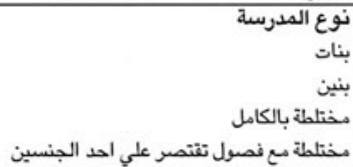 \\
\hline $\begin{array}{l}19 \\
18\end{array}$ & $\begin{array}{l}r r \\
r .\end{array}$ & $\begin{array}{l}97 \\
97\end{array}$ & $\begin{array}{l}\wedge \mathrm{r} \\
\Lambda \mathrm{T}\end{array}$ & $\begin{array}{l}1,9 \\
r, .\end{array}$ & $\begin{array}{l}1, v \\
1,1\end{array}$ & $\begin{array}{l}\text { ir, \& } \\
\text { ir, o }\end{array}$ & أكثر هن فتزرة النظد \\
\hline $\begin{array}{l}v \\
\text { iv } \\
\text { ra }\end{array}$ & $\begin{array}{l}\text { ir } \\
r 1 \\
r .\end{array}$ & $\begin{array}{l}97 \\
97 \\
91\end{array}$ & $\begin{array}{l}\Lambda Y \\
\Lambda \varepsilon \\
\Lambda T\end{array}$ & $\begin{array}{l}r, 0 \\
1,1 \\
1,0\end{array}$ & $\begin{array}{l}r, y \\
1, v \\
1, \varepsilon\end{array}$ & $\begin{array}{l}\text { ir, } v \\
\text { ir, } \\
\text { ir, }\end{array}$ & متخفض المستوى التعليمى اللمجتمع المحلى \\
\hline $\begin{array}{l}r . \\
\text { iv } \\
11\end{array}$ & $\begin{array}{l}r 7 \\
r r \\
r u\end{array}$ & $\begin{array}{l}\text { १1 } \\
97 \\
90\end{array}$ & $\begin{array}{l}17 \\
17 \\
11\end{array}$ & $\begin{array}{l}1, \varepsilon \\
1,1 \\
r, \varepsilon\end{array}$ & $\begin{array}{l}1, \varepsilon \\
1, v \\
r, 1\end{array}$ & $\begin{array}{l}\text { ir, o } \\
\text { ir, } \\
\text { ir, } 7\end{array}$ & 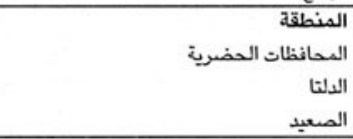 \\
\hline 11 & $r 1$ & 97 & $\wedge \varepsilon$ & 1,9 & 1,1 & ir,o & المجموع \\
\hline$r \sum q r$ & $r \varepsilon \wedge V$ & $r £ q r$ & $r \leqslant 9$. & $r\{\wedge \varepsilon$ & $r \& v$. & $r\{91$ & عدد الحالات \\
\hline
\end{tabular}

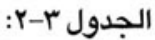
متوسط عدد السنوات المقضية في المدرسة الإعدادية الحالية و النسبة المئوية للطلاب الذين يستغرقون أقل من نصف ساعة للوصول إلى المدرسة, وفق المتغيرات الخلفية الفردية و المدرسية العدية

\begin{tabular}{|c|c|c|}
\hline وقت الوصول إلى المدرسة(النسبة المئوية & متوسط عدد السنوات في المدرسة & المتغيرات الخلفية \\
\hline $\begin{array}{l}M \\
\text { vi }\end{array}$ & $\begin{array}{l}r, 1 \\
r, r\end{array}$ & نوع انوي \\
\hline $\begin{array}{l}\text { vi } \\
\text { 1i } \\
\text { 10 }\end{array}$ & $\begin{array}{l}r, r \\
r, r \\
r, \cdot\end{array}$ & متخفض الأداء الدراسي للطلاب \\
\hline $\begin{array}{l}\text { Av } \\
\text { Vi } \\
\text { Al } \\
\text { sr }\end{array}$ & $\begin{array}{l}r, 1 \\
r, 1 \\
r, r \\
r, r\end{array}$ & بنات بنتين \\
\hline $\begin{array}{l}\text { Ar } \\
\wedge 1\end{array}$ & $\begin{array}{l}r, 1 \\
r, r\end{array}$ & أكثره واحدة فتزة المدرسي \\
\hline $\begin{array}{l}\mathrm{VI} \\
\mathrm{M} \\
\wedge .\end{array}$ & $\begin{array}{l}r, r \\
r, l \\
r, .\end{array}$ & متخفض المستوى التعليمى للمجتمع المحلى \\
\hline $\begin{array}{l}v q \\
\wedge 9 \\
v \varepsilon\end{array}$ & $\begin{array}{l}r, . \\
r, 1 \\
r, r\end{array}$ & 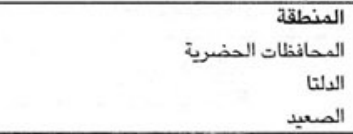 \\
\hline$\Lambda r$ & $r, 1$ & المجموع \\
\hline rITE & $r \leqslant \wedge 9$ & عدد الحالات \\
\hline
\end{tabular}




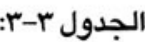

توزيع الطلاب حسب متغيرات عبء العمل و الجهد المبذول، تبعا للمتغيرات الخلفية الفردية و المدرسية

\begin{tabular}{|c|c|c|c|c|c|c|}
\hline 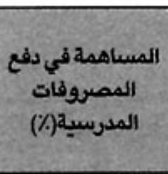 & 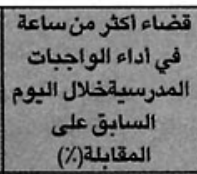 & 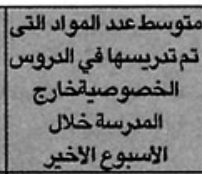 & 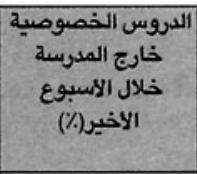 & 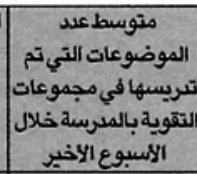 & التغيب في الاسبوعي اللعمل & المتغيرات الخلفية \\
\hline$\dot{u}$ & $\begin{array}{l}\text { v. } \\
\text { u }\end{array}$ & $\begin{array}{l}r, Y \\
1, \Lambda\end{array}$ & $\begin{array}{l}\text { vo } \\
\text { oq }\end{array}$ & $\begin{array}{l}, r \\
., 0\end{array}$ & $\begin{array}{l}r \\
r\end{array}$ & نو نو المجى \\
\hline $\begin{array}{l}10 \\
\text { ir } \\
9\end{array}$ & $\begin{array}{l}\text { to } \\
v i \\
v .\end{array}$ & $\begin{array}{l}1, . \\
r, . \\
r, i\end{array}$ & $\begin{array}{l}\varepsilon 1 \\
19 \\
\text { А }\end{array}$ & $\begin{array}{l}\cdot, \mathrm{v} \\
-, \varepsilon \\
., \mathrm{r}\end{array}$ & $\begin{array}{l}\varepsilon \\
r \\
r\end{array}$ & $\begin{array}{r}\text { منذفض الاداء الداسي للطلاب } \\
\text { متوسط }\end{array}$ \\
\hline $\begin{array}{l}\varepsilon \\
17 \\
r . \\
i r\end{array}$ & $\begin{array}{l}v 1 \\
v \varepsilon \\
i r \\
07\end{array}$ & $\begin{array}{l}r, \varepsilon \\
r, . \\
1, . \\
r, .\end{array}$ & $\begin{array}{l}\text { 11 } \\
\text { TV } \\
\varepsilon 9 \\
0 .\end{array}$ & $\begin{array}{l}0, r \\
, r \\
i, 1 \\
,, o\end{array}$ & $\begin{array}{l}r \\
r \\
r \\
0\end{array}$ & 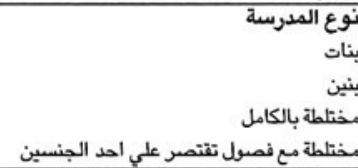 \\
\hline $\begin{array}{l}11 \\
\text { ir }\end{array}$ & $\begin{array}{l}\text { v. } \\
\text { u }\end{array}$ & $\begin{array}{l}r, 1 \\
1,1\end{array}$ & $\begin{array}{l}\text { vr } \\
\text { ir }\end{array}$ & $\begin{array}{l}-, \varepsilon \\
., \varepsilon\end{array}$ & $\begin{array}{l}r \\
r\end{array}$ & أكثر واحدة \\
\hline $\begin{array}{l}\text { in } \\
\text { ir } \\
1\end{array}$ & $\begin{array}{l}71 \\
7 \varepsilon \\
\mathrm{VA}\end{array}$ & $\begin{array}{l}1,1 \\
r, r \\
r, 0\end{array}$ & $\begin{array}{l}\varepsilon v \\
v r \\
\Lambda .\end{array}$ & $\begin{array}{l}-, 1 \\
-, \varepsilon \\
., r\end{array}$ & $\begin{array}{l}r \\
\varepsilon \\
1\end{array}$ & متففض متوى التعليمى للمجتمع المحلى \\
\hline $\begin{array}{l}\text { is } \\
\text { ir }\end{array}$ & $\begin{array}{l}\text { va } \\
17 \\
17\end{array}$ & $\begin{array}{l}r, r \\
r, r \\
i, r\end{array}$ & $\begin{array}{l}11 \\
v \varepsilon \\
\varepsilon q\end{array}$ & $\begin{array}{l}., 1 \\
., r \\
., v\end{array}$ & $\begin{array}{l}1 \\
r \\
r\end{array}$ & المالتافظات الحضرية \\
\hline ir & 79 & $r, \cdot$ & TV & $\cdot, \varepsilon$ & $r$ & المجموع \\
\hline rEAq & YEAT & rEA $\mathrm{r}$ & TEา० & 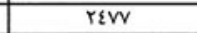 & $r E W$ & عدد الحالات \\
\hline
\end{tabular}

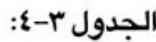
النسبة المئوية للطلاب الذين فهموا درسي اللغة العربية والرياضيات الأخيرين و الطباب الطباب الذين تلقوا العقاب بسبب أدائهم الدراسي خلال

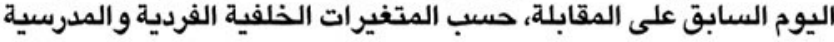

\begin{tabular}{|c|c|c|c|}
\hline المقابلة بسقبب خلال اليوف الاداء السابق على العى & فهمدرس الرياضيات الاخير & فهم درس اللغة العربية الاخير & المتغيرات الخلفية \\
\hline$\varepsilon$ & $\begin{array}{l}v q \\
v \varepsilon\end{array}$ & $\begin{array}{l}\text { 9. } \\
\text { A. }\end{array}$ & نو نوع المجيب \\
\hline$\hat{\imath}$ & $\begin{array}{l}\text { w } \\
\text { ve } \\
\text { vo }\end{array}$ & $\begin{array}{l}\text { ar } \\
\text { Ar } \\
\text { Ar }\end{array}$ & منفضض الاداء الدراسي للطلاب \\
\hline $\begin{array}{l}\varepsilon \\
\hat{\imath} \\
\hat{0}\end{array}$ & $\begin{array}{l}\text { va } \\
\text { vi } \\
\text { va } \\
\text { Al }\end{array}$ & $\begin{array}{l}91 \\
\text { Ar } \\
\text { A9 } \\
\text { VI }\end{array}$ & 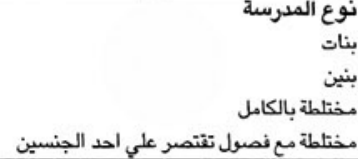 \\
\hline $\begin{array}{l}v \\
i\end{array}$ & $\begin{array}{l}\mathrm{v} \varepsilon \\
\wedge .\end{array}$ & $\begin{array}{l}\text { Av } \\
\text { Ar }\end{array}$ & أكثره من فتدرة \\
\hline $\begin{array}{l}\varepsilon \\
\vdots \\
0\end{array}$ & $\begin{array}{l}\text { va } \\
\text { ve } \\
\text { vr }\end{array}$ & $\begin{array}{l}A v \\
\wedge r \\
\Lambda T\end{array}$ & متخفضف \\
\hline $\begin{array}{l}\varepsilon \\
v \\
1\end{array}$ & $\begin{array}{l}v_{0} \\
v \varepsilon \\
\text { Al }\end{array}$ & $\begin{array}{l}\wedge \circ \\
\wedge \varepsilon \\
\wedge v\end{array}$ & الملتافظات الحضرية المبلة \\
\hline 7 & $w$ & 10 & المجموع \\
\hline$r \varepsilon r$. & $r \varepsilon q r$ & rEqr & عدد الحالات \\
\hline
\end{tabular}


الجدول r-0:

النسبة المئوية للمعلمين الراضين عن المستوى الدراسي للطلاب و أسباب عدم الرضا، وفق المتغيرات الخلفية الفردية و المدرسية

\begin{tabular}{|c|c|c|c|c|c|c|c|c|c|}
\hline \multicolumn{7}{|c|}{ الاسباب الاكثدر شيوعا لعدم الرضا عن المستوى الدراسي للطلاب في هذه المرحلة } & \multicolumn{2}{|c|}{ 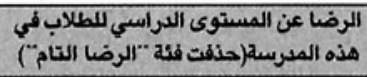 } & \multirow{2}{*}{ المتغيرات الخلفية } \\
\hline المتطلابات المتفماربة & الالجناح الاجتماعي & | ارتفاع كثافة الفصول| & العقر & عدم اكتراث الطلاب & فيتويات متباينة & انخفاض المستوى & $\begin{array}{l}\text { عدم الرضا } \\
\end{array}$ & 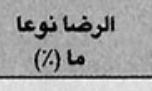 & \\
\hline$i$ & $\stackrel{\varepsilon}{11}$ & ; & ir & is & ir & $\varepsilon 1$ & $r r$ & ר. & انتوع المجيب \\
\hline $\begin{array}{l}\text { ir } \\
\text { r } \\
i\end{array}$ & i: & iv & $\begin{array}{l}\text { ir } \\
\text { ir } \\
\text { v }\end{array}$ & $\begin{array}{l}i 9 \\
i \\
i r\end{array}$ & $\hat{i r}$ & $\begin{array}{l}8 r \\
r a \\
r o\end{array}$ & $\begin{array}{l}\text { in } \\
\text { in }\end{array}$ & $\begin{array}{l}o v \\
v \\
11\end{array}$ & 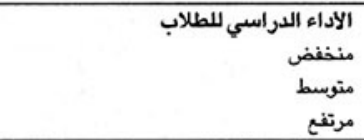 \\
\hline i & $\begin{array}{l}\vdots \\
\vdots \\
\end{array}$ & $\begin{array}{l}\varepsilon \\
11 \\
i \\
1\end{array}$ & $\begin{array}{l}\text { i } \\
i 1 \\
i 1\end{array}$ & in. & $\begin{array}{c}n \\
\vdots \\
\vdots \\
1\end{array}$ & $\begin{array}{l}r \varepsilon \\
r a \\
r a \\
i q\end{array}$ & $\begin{array}{l}19 \\
r r \\
r 7 \\
r \varepsilon\end{array}$ & $\begin{array}{l}09 \\
17 \\
v 1 \\
i r\end{array}$ & 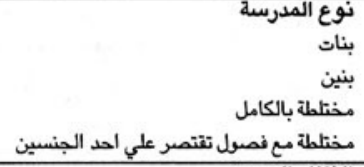 \\
\hline$\hat{r}$ & $\hat{\imath}$ & ir & $\hat{i r}$ & $\begin{array}{l}r . \\
\text { ir }\end{array}$ & $\begin{array}{l}1 . \\
19\end{array}$ & $\begin{array}{l}r u \\
r v\end{array}$ & $\begin{array}{l}\mathrm{rv} \\
\mathrm{iv}\end{array}$ & $\begin{array}{ll}01 \\
r\end{array}$ & 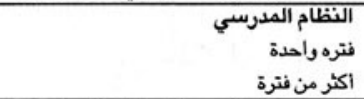 \\
\hline is & $\begin{array}{l}1 \\
\vdots \\
\end{array}$ & q & ir & iv & ì. & $\begin{array}{l}\varepsilon r \\
r v \\
r \varepsilon\end{array}$ & $\begin{array}{l}\text { rv } \\
\text { r. } \\
\text { it }\end{array}$ & $\begin{array}{l}\text { oq } \\
\text { iv } \\
\text { is }\end{array}$ & 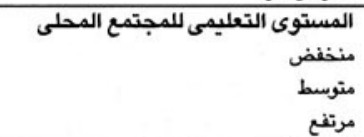 \\
\hline v & $\begin{array}{c}r \\
\vdots \\
i\end{array}$ & a & "1 & $\begin{array}{l}\text { iv } \\
10 \\
r 1\end{array}$ & $\begin{array}{l}19 \\
19 \\
v\end{array}$ & $\begin{array}{l}r \varepsilon \\
r \\
\varepsilon \varepsilon\end{array}$ & $\begin{array}{l}r \varepsilon \\
r r \\
r q\end{array}$ & $\begin{array}{l}1 . \\
10 \\
18\end{array}$ & الدالتافظقات الحضرية \\
\hline 7 & $\Lambda$ & $\mathrm{v}$ & 9 & IV & $1 \varepsilon$ & $r A$ & $r r$ & $1 \varepsilon$ & المجموع \\
\hline$\varepsilon \mathrm{VN}$ & $8 \mathrm{~V} / \mathrm{N}$ & $\varepsilon \mathrm{VN}$ & $\varepsilon \mathrm{VA}$ & $\varepsilon \mathrm{VA}$ & $\varepsilon \mathrm{VA}$ & $+\varepsilon \mathrm{VA}$ & $\varepsilon \Lambda$. & $* \varepsilon \Lambda$. & عدد الحالات \\
\hline
\end{tabular}


الجدول ب-ר:

مقدار مشاركة الطلاب في الأنشطة غير الدراسية و النسبة المئوية للمشاركة في الأنشطة الاكثر شيوعا، وفق المتغيرات الخلفية الفردية

\begin{tabular}{|c|c|c|c|c|c|c|c|}
\hline \multicolumn{6}{|c|}{ الانشطة غير الدراسية الاكثر شيوعا } & \multirow{2}{*}{ الاستشطاركة غير المبل } & \multirow[b]{2}{*}{ المتغيرات الخلفية } \\
\hline الابب/اللغة & الموسيقى & الاقتصاد المنزلي/الزراعة & الالعاب الرياضية & الإذاعة المدرسية & 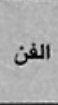 & & \\
\hline$r$ & $r$ & $r$ & 。 & 。 & $\wedge$ & rv & انوي المجيب \\
\hline 1 & $r$ & $\varepsilon$ & ir & $\varepsilon$ & $v$ & $r r$ & ذكر \\
\hline & & & & & & & الالداء الدراسي للطلاب \\
\hline$\vdots$ & $i$ & $\varepsilon$ & $v$ & $\vdots$ & a & $r \varepsilon$ & منتفط \\
\hline$\varepsilon$ & $r$ & 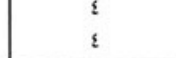 & $\hat{\imath}$ & $\varepsilon$ & 1 & ro & مرتفع \\
\hline & & & & & & & نوع المدرسة \\
\hline 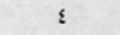 & $r$ & $r$ & 1 & $r$ & 1 & $r \varepsilon$ & بنات \\
\hline 1 & 1 & 。 & ir & $\varepsilon$ & 1 & $\mathrm{rr}$ & بنين \\
\hline 1 & r & 1 & ir & 9 & 11 & rq & مختلطة بالكامل \\
\hline 1 & 1 & $r$ & $v$ & $\varepsilon$ & $\wedge$ & $\mathrm{rt}$ & مختلطة ميع فصول تقتصر علي احد الجنسين \\
\hline & & & & & & & النظام المدرسي \\
\hline 1 & $r$ & 。 & 11 & $\varepsilon$ & $\mathrm{v}$ & ro & 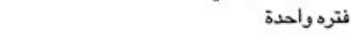 \\
\hline$r$ & 1 & $r$ & $\mathrm{v}$ & $\varepsilon$ & $\wedge$ & $\mathrm{rr}$ & أكثر من فترة \\
\hline & & & & & & & المستوى التعليمى للمجتمع المحلى \\
\hline . & 1 & $r$ & $\wedge$ & $v$ & 1. & ri & منففض \\
\hline 1 & $r$ & 。 & 11 & $r$ & $v$ & rA & متوسط \\
\hline 。 & 1 & $r$ & $\wedge$ & $\varepsilon$ & 。 & ro & مرتفع \\
\hline & & & & & & & المنطقة \\
\hline 7 & 1 & $\varepsilon$ & $v$ & $r$ & $\varepsilon$ & ra & المحافظات الحضرية \\
\hline 1 & $r$ & $\varepsilon$ & 11 & $\varepsilon$ & $\wedge$ & rA & الدلتا ا \\
\hline 1 & $r$ & $\varepsilon$ & $\wedge$ & 1 & 9 & $\mathrm{rT}$ & الصعيد \\
\hline$r$ & $r$ & $\varepsilon$ & 9 & $\varepsilon$ & $\mathrm{v}$ & $r$. & المجموع \\
\hline & & $r s$ & ؛ & & & $r £ 9 r$ & عدد الحالات \\
\hline
\end{tabular}

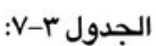
النسبة المئوية للطلاب الذي تلوانوافر لهم حصص الألعاب الرياضية و الذين شاركوا في حصص الألعاب الرياضية، و مقدار الشعور بالحرج

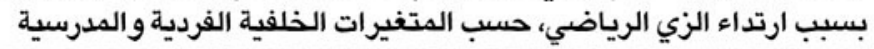

\begin{tabular}{|c|c|c|c|c|}
\hline 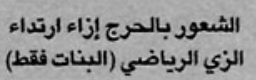 & المشاركة في حصة الإخيرة & خلال حصر تدريس الالرياضي الاخيرة فعلا & الفصل ياخذ حصصي & المتغيرات الخلفية \\
\hline $\begin{array}{c}7 \varepsilon \\
\text { لا بنطبق }\end{array}$ & $\begin{array}{ll}\text { oN } \\
\text { iv }\end{array}$ & $\begin{array}{l}\text { iv } \\
\mathrm{nI}\end{array}$ & $\begin{array}{l}\text { Ar } \\
\text { १ะ }\end{array}$ & نون الثجى \\
\hline $\begin{array}{l}\text { لا ينطبق } \\
\text { v. } \\
\text { T. }\end{array}$ & $\begin{array}{l}\text { ir } \\
o v \\
\text { iv }\end{array}$ & $\begin{array}{l}\varepsilon q \\
\text { Ar } \\
\mathrm{v} .\end{array}$ & qu & 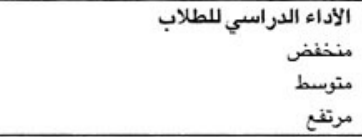 \\
\hline $\begin{array}{l}\text { Ir } \\
\text { لا ينطبق } \\
\text { vo }\end{array}$ & $\begin{array}{l}\circ v \\
\text { iv } \\
\text { v. } \\
\text { oq }\end{array}$ & $\begin{array}{l}17 \\
r \\
i r \\
\text { vo }\end{array}$ & $\begin{array}{l}\text { 10 } \\
\text { १i } \\
\text { Aq } \\
\text { vr }\end{array}$ & 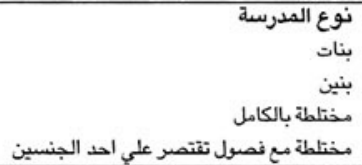 \\
\hline $\begin{array}{l}\text { ir } \\
10\end{array}$ & $\begin{array}{l}\text { vi } \\
0 \varepsilon\end{array}$ & $\begin{array}{l}\text { vr } \\
10\end{array}$ & AT & 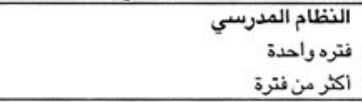 \\
\hline $\begin{array}{l}\text { va } \\
11 \\
\text { ov }\end{array}$ & $\begin{array}{l}u \\
1 \varepsilon \\
09\end{array}$ & $\begin{array}{l}\text { iv } \\
\text { ir } \\
\mathrm{w}\end{array}$ & $\begin{array}{l}\text { vq } \\
\text { १. } \\
\text { १६ }\end{array}$ & منففض منفتوى التعليمى للمجتمع المحلى \\
\hline $\begin{array}{l}\stackrel{-1}{11} \\
\mathrm{ir}\end{array}$ & $\begin{array}{l}07 \\
1 \varepsilon \\
79\end{array}$ & $\begin{array}{l}\text { Ar } \\
\text { is } \\
\text { iv }\end{array}$ & $\begin{array}{l}\text { १ह } \\
\text { १ิ } \\
\text { vi }\end{array}$ & 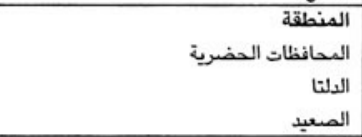 \\
\hline $7 \varepsilon$ & ir & 19 & $M$ & المجموع \\
\hline ETr & $|r r|$ & 1770 & rE१ะ & عدد الحالات \\
\hline
\end{tabular}


ملاحظات الذين أجروا المقابلات عن الأنشطة الجارية أثناء فترة الراحة (الفسحة)، و النسبة المئوية لملاحظي الفسحة الذين أفادوا حدوث كل نشاط، حسب المتغيرات الخلفية الفردية و المدربية

\begin{tabular}{|c|c|c|c|c|c|c|c|c|c|}
\hline بغادرون المدرسيحة & $\begin{array}{l}\text { الطلاب الفناءودودون } \\
\text { المشاركة }\end{array}$ & الرياضل & أنشطة الكمبيوتر & القراءة في & نشاط الاقتنصاد & النشاط الادبي & الفن & الموسيقى & المتغيرات الخلفية \\
\hline $\begin{array}{l}\varepsilon \varepsilon \\
r q \\
r \\
\end{array}$ & $\begin{array}{l}\text { A1 } \\
\text { A. } \\
\text { का }\end{array}$ & $\begin{array}{l}r . \\
r r \\
\varepsilon r\end{array}$ & $\begin{array}{l}\varepsilon \\
r \\
r .\end{array}$ & $\begin{array}{l}r . \\
r \\
\vdots 9\end{array}$ & $\begin{array}{l}1 \\
1 \\
r\end{array}$ & $\begin{array}{l}1 \\
1 \varepsilon \\
\varepsilon r\end{array}$ & ir & is & منزفيط \\
\hline $\begin{array}{l}1 \\
\text { ro } \\
\text { of } \\
\text { or }\end{array}$ & $\begin{array}{l}\text { Av } \\
a r \\
\text { vi } \\
a 1\end{array}$ & $\begin{array}{l}r r \\
o r \\
r . \\
r \varepsilon\end{array}$ & $\begin{array}{l}r \\
r \\
\varepsilon \\
.\end{array}$ & $\begin{array}{l}\text { ¿9 } \\
\text { is } \\
\text { ro }\end{array}$ & $\dot{r}$ & $\begin{array}{l}\ddot{0} \\
\text { ir } \\
\text { ir }\end{array}$ & $\begin{array}{l}r r \\
i r \\
i\end{array}$ & $\begin{array}{l}10 \\
1 . \\
r \\
1\end{array}$ & 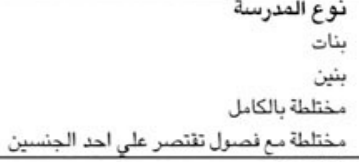 \\
\hline$\because$ & $\begin{array}{l}\wedge \varepsilon \\
\wedge \\
\wedge\end{array}$ & $\begin{array}{l}r \Lambda \\
r .\end{array}$ & in & $\begin{array}{l}\text { ra } \\
r a\end{array}$ & is & $\begin{array}{l}r \\
r\end{array}$ & in & 9 & 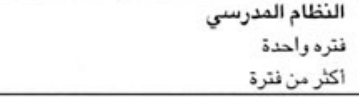 \\
\hline $\begin{array}{l}\text { or } \\
\text { ir } \\
\text { ir }\end{array}$ & $\begin{array}{l}\Delta r \\
\Lambda 1 \\
\Lambda r\end{array}$ & $\begin{array}{l}r_{0} \\
r_{0} \\
r r\end{array}$ & $\begin{array}{l}r \\
r r \\
i r\end{array}$ & $\begin{array}{l}r_{1} \\
r_{0} \\
00\end{array}$ & $\begin{array}{l}1 \\
\text { r. } \\
\text { is }\end{array}$ & $\begin{array}{l}1 . \\
r_{\varepsilon} \\
r_{0}\end{array}$ & $\begin{array}{l}1 \\
\text { in } \\
\mathrm{rv}\end{array}$ & $\begin{array}{l}r \\
\varepsilon \\
r_{0}\end{array}$ & هنخفض منتوى التعليمى للمجتمع المحلى \\
\hline $\begin{array}{l}10 \\
r A \\
\varepsilon r\end{array}$ & $\begin{array}{l}97 \\
\Lambda \varepsilon \\
\Lambda 1\end{array}$ & $\begin{array}{l}\varepsilon \\
r \varepsilon \\
11\end{array}$ & $\begin{array}{l}11 \\
19 \\
r\end{array}$ & $\begin{array}{l}10 \\
\text { r7 } \\
19\end{array}$ & $\begin{array}{c}19 \\
17 \\
1\end{array}$ & $\begin{array}{l}19 \\
r r \\
11\end{array}$ & $\begin{array}{l}\varepsilon \\
10 \\
r \\
\end{array}$ & $\begin{array}{l}r . \\
\vdots \\
0\end{array}$ & 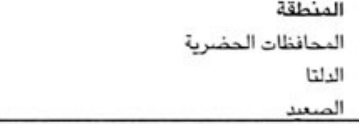 \\
\hline$r r$ & $\Lambda \varepsilon$ & ra & ir & $\mathrm{ri}$ & 11 & $r$ & ir & $\wedge$ & المجهوع \\
\hline $\mathrm{rrv}$ & rrv & ril & rm & rm & רוז & $\mathrm{rrm}$ & rev & rrv & عدد الحالات \\
\hline
\end{tabular}


الجدول r-_a_9 النسبة المئوية للطلاب المعرضين للمضايقات في المدرسة أو في الطريق إلى المدرسة آو منها خلال الأسبوع السابق على المقابلة، ومصدر المضايقة و طبيعتها حسب المتغيرات الخلفية الفردية و المدرسية

\begin{tabular}{|c|c|c|c|c|c|c|c|c|c|}
\hline \multicolumn{4}{|c|}{ طبيعة المعاكسات أو المضايقات } & \multicolumn{3}{|c|}{ مصدر المعاكسات أو المضايقات } & \multirow{2}{*}{ الو التعرضاياقات فيساتي } & \multirow{2}{*}{ 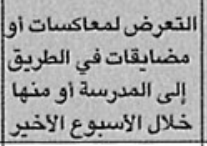 } & \multirow{2}{*}{ المتغيرات الخلفية } \\
\hline الضرب & المضايقة & السباب/التحقير & الزعيق & العاملون بالددرسة & البنين & 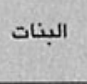 & & & \\
\hline$\hat{r}$. & $\begin{array}{l}\mathrm{v} \\
\wedge\end{array}$ & $\begin{array}{l}\mathrm{r} \\
\mathrm{r}\end{array}$ & $\begin{array}{l}\text { rI } \\
17\end{array}$ & $\begin{array}{l}r_{\varepsilon} \\
r_{1}\end{array}$ & $\begin{array}{c}r \\
r\end{array}$ & $\begin{array}{r}r_{\varepsilon} \\
0\end{array}$ & $\begin{array}{l}0 . \\
\text { or }\end{array}$ & $\begin{array}{l}\text { rA } \\
r q\end{array}$ & نو نوع المجيب \\
\hline $\begin{array}{l}r y \\
i 4 \\
19\end{array}$ & 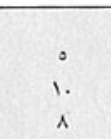 & $\begin{array}{l}r_{0} \\
r i \\
r r\end{array}$ & $\begin{array}{l}\text { ir } \\
r \\
r .\end{array}$ & $\begin{array}{l}r v \\
r \varepsilon \\
r i\end{array}$ & $\begin{array}{l}19 \\
r . \\
r i\end{array}$ & $\begin{array}{l}i r \\
r r \\
r i\end{array}$ & $\begin{array}{l}\text { Eo } \\
\text { or } \\
\text { or }\end{array}$ & $\begin{array}{l}r \varepsilon \\
r q \\
r .\end{array}$ & مترنفض مراء الدراسي للطلاب \\
\hline $\begin{array}{l}9 \\
\text { m } \\
\text { ir } \\
\text { is }\end{array}$ & $\begin{array}{c}v \\
11 \\
\varepsilon \\
\wedge\end{array}$ & $\begin{array}{l}\text { ri } \\
2 . \\
19 \\
r 9\end{array}$ & $\begin{array}{l}r \\
r \\
r \\
19\end{array}$ & $\begin{array}{l}\text { ro } \\
\text { so } \\
\text { in } \\
\text { ri }\end{array}$ & $\begin{array}{l}1 \\
\varepsilon 7 \\
i r \\
r r\end{array}$ & $\begin{array}{c}r i \\
\varepsilon \\
9 \\
1 \varepsilon\end{array}$ & $\begin{array}{l}\text { or } \\
10 \\
\text { rr } \\
\Sigma 9\end{array}$ & $\begin{array}{l}r . \\
r r \\
r r \\
r \varepsilon\end{array}$ & 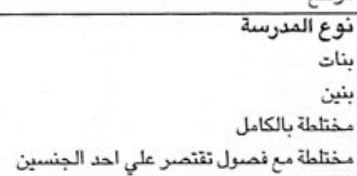 \\
\hline $\begin{array}{l}\text { r. } \\
\text { is }\end{array}$ & 1 & $\begin{array}{l}r 1 \\
r a\end{array}$ & $\begin{array}{l}\text { r. } \\
\text { iv }\end{array}$ & $\begin{array}{l}r \varepsilon \\
r \wedge\end{array}$ & $\begin{array}{l}19 \\
\mathrm{rr}\end{array}$ & $\begin{array}{l}\text { r. } \\
\text { in }\end{array}$ & $\begin{array}{l}\text { of } \\
\text { or }\end{array}$ & $\begin{array}{l}r_{\Lambda} \\
r \Lambda\end{array}$ & 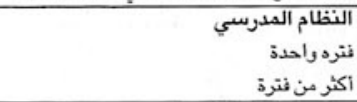 \\
\hline $\begin{array}{l}17 \\
19 \\
\text { rr }\end{array}$ & $\stackrel{\circ}{i}$ & $\begin{array}{l}r \\
r r \\
r o\end{array}$ & $\begin{array}{l}\text { ir } \\
\text { io } \\
\text { rv }\end{array}$ & $\begin{array}{l}r r \\
r . \\
\varepsilon .\end{array}$ & $\begin{array}{l}\text { iv } \\
\text { is } \\
r_{0}\end{array}$ & $\begin{array}{l}11 \\
r 1 \\
r \varepsilon\end{array}$ & $\begin{array}{l}\varepsilon \\
\text { os } \\
\text { ir }\end{array}$ & $\begin{array}{l}\text { ro } \\
\text { ro } \\
\text { rr }\end{array}$ & 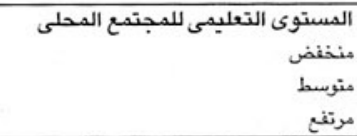 \\
\hline $\begin{array}{l}r r \\
r . \\
\text { iv }\end{array}$ & $\begin{array}{l}i r \\
\hat{0}\end{array}$ & $\begin{array}{l}r_{0} \\
\text { ro } \\
r .\end{array}$ & $\begin{array}{l}\text { ri } \\
17 \\
\text { ir }\end{array}$ & $\begin{array}{l}\varepsilon \\
r r \\
r r\end{array}$ & $\begin{array}{l}\text { ro } \\
\text { is } \\
19\end{array}$ & $\begin{array}{l}r v \\
r r \\
1 .\end{array}$ & $\begin{array}{l}11 \\
07 \\
81\end{array}$ & $\begin{array}{l}r \varepsilon \\
r v \\
r\end{array}$ & الصنافئات الصنات الحضرية \\
\hline 19 & $\Lambda$ & $r$. & M & ri & r. & 19 & or & TA & المجموع \\
\hline \multicolumn{4}{|c|}{ rEYT } & \multicolumn{3}{|c|}{ YEOT } & रะ१६ & rEq. & عدد الحالات \\
\hline
\end{tabular}


الجدول r-1.

النسبة المئوية للطلاب الذين أفادوا التعرض للتحقير، حسب المتغيرات الخلفية الفردية و المدرسية

\begin{tabular}{|c|c|c|}
\hline 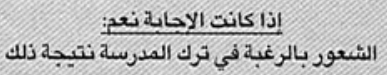 & الوحف بالفئل من جانب الصعلم & المتغيرات الخلفية \\
\hline $\begin{array}{l}r r \\
r v\end{array}$ & $\begin{array}{l}1 \varepsilon \\
r \varepsilon\end{array}$ & نوني انوع المجيب \\
\hline $\begin{array}{l}\varepsilon r \\
r r \\
r r\end{array}$ & $\begin{array}{l}r v \\
r q \\
r .\end{array}$ & 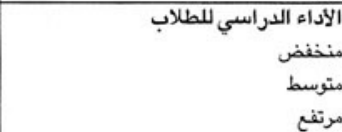 \\
\hline $\begin{array}{l}r r \\
r a \\
r o \\
r a\end{array}$ & $\begin{array}{l}10 \\
r \varepsilon \\
r 1 \\
r V\end{array}$ & بنين بنتئ المدرسة \\
\hline $\begin{array}{l}r_{A} \\
r r\end{array}$ & $\begin{array}{l}r \varepsilon \\
r \varepsilon\end{array}$ & 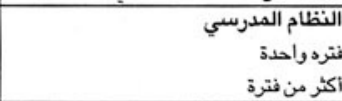 \\
\hline $\begin{array}{l}\varepsilon r \\
r \varepsilon \\
r r\end{array}$ & $\begin{array}{l}19 \\
r 8 \\
r 9\end{array}$ & متخفضط مترى التعليمى للمجتمع المحلى \\
\hline $\begin{array}{l}r r \\
r \varepsilon \\
\varepsilon r\end{array}$ & $\begin{array}{l}\text { ra } \\
\text { ro } \\
19\end{array}$ & 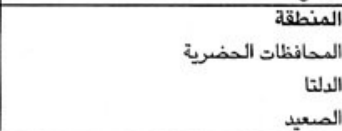 \\
\hline ro & $r \xi$ & المجموع \\
\hline $0 \leqslant r$ & $r \xi q \varepsilon$ & عدد الحالات \\
\hline
\end{tabular}

الجدول البو-11: (1)

النسبة المئوية للطلاب الذين تعرضوا للعقاب خلال اليوم السابق، و سبب العقاب و طريقته، حسب المتغيرات الخلفية الفردية و المدرسية

\begin{tabular}{|c|c|c|c|c|c|c|}
\hline \multicolumn{2}{|c|}{ طرق العقاب الاكثر شيوعا } & \multicolumn{3}{|c|}{ الاسباب الاكثر نسيوعا وراء العقاب } & \multirow{2}{*}{ |اليوم الدراسي البعاب خابل } & \multirow{2}{*}{ الصتغبرات الحلفية } \\
\hline الوقوف جنب الحانط التئ & الضرب/الأساءة & نسيان الكتب أو الأوراق & | & سوء السلوه & & \\
\hline 1 & ${ }_{\text {rV }}^{T}$ & $\begin{array}{l}\varepsilon \\
\wedge\end{array}$ & $\varepsilon$ & $\begin{array}{c}\varepsilon \\
11\end{array}$ & $\begin{array}{l}1 \varepsilon \\
r T\end{array}$ & 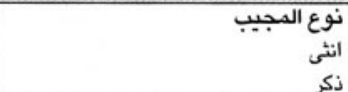 \\
\hline $\begin{array}{l}1 \\
1 \\
1\end{array}$ & $\begin{array}{l}\pi \\
19 \\
1 .\end{array}$ & $\hat{i}$ & $\hat{\imath}$ & $\begin{array}{l}i \\
1 . \\
v\end{array}$ & $\begin{array}{l}\text { r. } \\
\text { ri } \\
\text { iv }\end{array}$ & متخفضط الأداء الدراسي للطلاب \\
\hline $\begin{array}{l}v \\
v \\
r \\
r\end{array}$ & $\begin{array}{l}\text { v } \\
\text { ri } \\
\text { ir } \\
\text { ir }\end{array}$ & $\begin{array}{l}0 \\
\text { v } \\
i \\
\text { v }\end{array}$ & $\begin{array}{l}i \\
1 \\
\hat{1} \\
0\end{array}$ & $\begin{array}{l}\text { ir } \\
\varepsilon \\
\mathrm{v}\end{array}$ & $\begin{array}{l}10 \\
r v \\
r . \\
r i\end{array}$ & 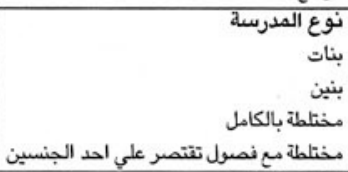 \\
\hline i & $\begin{array}{l}1 \varepsilon \\
r .\end{array}$ & $\varepsilon$ & $\begin{array}{l}v \\
i\end{array}$ & $\begin{array}{l}v \\
\wedge\end{array}$ & $\begin{array}{l}\text { r. } \\
\text { rv }\end{array}$ & 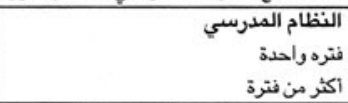 \\
\hline $\begin{array}{l}i \\
\mathrm{v} \\
\mathrm{v}\end{array}$ & $\begin{array}{l}\text { ir } \\
\text { ir } \\
\text { is }\end{array}$ & $\begin{array}{l}1 \\
\hat{1} \\
\varepsilon\end{array}$ & $\begin{array}{l}\varepsilon \\
\vdots \\
\end{array}$ & $\begin{array}{l}0 \\
i \\
1\end{array}$ & $\begin{array}{l}r . \\
r i \\
r i\end{array}$ & متفنفض المستوى التعليمى للمجتمع المحلى \\
\hline $\begin{array}{l}1 \\
1 \\
1\end{array}$ & $\begin{array}{l}\text { ir } \\
\text { in } \\
\text { in }\end{array}$ & $\begin{array}{l}\varepsilon \\
1 \\
1\end{array}$ & $\begin{array}{l}\varepsilon \\
v \\
1\end{array}$ & $\hat{\imath}$ & $\begin{array}{l}r . \\
r \varepsilon \\
r o\end{array}$ & الدالتافظات الحضرية \\
\hline 7 & IV & 7 & 7 & $\mathrm{v}$ & $r r$ & المجموع \\
\hline \multicolumn{2}{|c|}{ rirV } & \multicolumn{3}{|c|}{ rer. } & Yะด ई & عدد الحالات \\
\hline
\end{tabular}


الجدول r-r إ:

النسبة المئوية للطلاب الذين أفادو التمييز في معاملة الطلاب من جانب المعلمين

\begin{tabular}{|c|c|c|c|c|c|c|}
\hline \multicolumn{5}{|c|}{ أسباب التمييز في معاملة الطلاب من جانب المعلمين } & \multirow{2}{*}{ تمييز في المعاملة المبلد } & \multirow[b]{2}{*}{ المتغيرات الخلفية } \\
\hline عدم تحديد الاسباب & 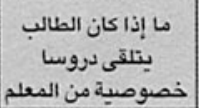 & السلوك الجيد/ السيء & الاداءالدراسي & الأسرة/الصلات & & \\
\hline$r \varepsilon$ & w & If & rr & ir & $\pi$ & انثى المجيب \\
\hline$r r$ & ri & 1. & ir & $1 \varepsilon$ & ०A & ذكري \\
\hline $\begin{array}{l}r . \\
r i \\
r\end{array}$ & $\begin{array}{l}r r \\
\text { is } \\
\text { ri }\end{array}$ & $\begin{array}{l}1 . \\
17 \\
1 .\end{array}$ & $\begin{array}{l}17 \\
19 \\
11\end{array}$ & $\begin{array}{l}v \\
\text { iv } \\
10\end{array}$ & $\begin{array}{l}\text { if } \\
\text { ir } \\
\text { i1 }\end{array}$ & منذفض الأداء الدراسي للطلاب \\
\hline $\begin{array}{l}\text { rv } \\
r r \\
17 \\
r .\end{array}$ & $\begin{array}{l}r . \\
r \varepsilon \\
i \varepsilon \\
a\end{array}$ & $\begin{array}{l}11 \\
1 . \\
11 \\
r 1\end{array}$ & $\begin{array}{l}r 1 \\
11 \\
18 \\
r .\end{array}$ & $\begin{array}{l}\text { IE } \\
\text { IV } \\
9 \\
1 .\end{array}$ & $\begin{array}{l}\text { ir } \\
i r \\
\varepsilon r \\
v .\end{array}$ & بنتين بنتلة \\
\hline $\begin{array}{l}r \\
r\end{array}$ & $\begin{array}{l}\text { rv } \\
17\end{array}$ & $\begin{array}{l}11 \\
11\end{array}$ & $\begin{array}{l}\text { r. } \\
10\end{array}$ & $\begin{array}{l}\text { ir } \\
10\end{array}$ & $\begin{array}{l}\text { ir } \\
\text { or }\end{array}$ & 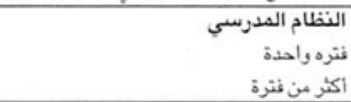 \\
\hline $\begin{array}{l}r r \\
r \\
r \varepsilon\end{array}$ & $\begin{array}{l}\text { is } \\
\text { in } \\
\text { ir }\end{array}$ & $\begin{array}{l}11 \\
\text { ir } \\
\text { ir }\end{array}$ & $\begin{array}{l}10 \\
r r \\
1 \varepsilon\end{array}$ & $\begin{array}{l}1 . \\
a \\
r\end{array}$ & $\begin{array}{l}\varepsilon \wedge \\
o v \\
v r\end{array}$ & 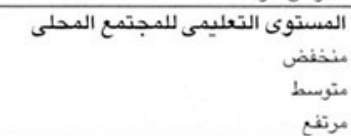 \\
\hline $\begin{array}{l}r \mu \\
r r \\
r r\end{array}$ & $\begin{array}{l}r \\
r 1 \\
1 \varepsilon\end{array}$ & $\begin{array}{l}10 \\
\text { ir } \\
1 .\end{array}$ & $\begin{array}{l}\text { ir } \\
\text { ro } \\
\text { ir }\end{array}$ & $\begin{array}{l}y_{0} \\
11 \\
9\end{array}$ & $\begin{array}{l}\mathrm{vA} \\
i r \\
\varepsilon\end{array}$ & 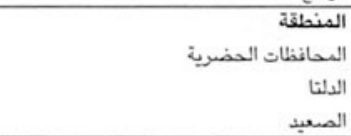 \\
\hline$r \xi$ & $r y$ & ir & in & IE & 09 & المجموع \\
\hline & & $r \leqslant T r$ & & & r... & عدد الحالات \\
\hline
\end{tabular}


الجدول r-r إ:

النسبة المئوية للمعلمين الراضين عن سلوك المعلمين نحو الطلاب و الأسباب الاكثر شيوعا لعدم الرضا، حسب المتغيرات الخلفية الفردية و المدرسية

\begin{tabular}{|c|c|c|c|c|c|c|c|c|c|}
\hline \multicolumn{7}{|c|}{ الاسباب الاكثر شيوعا لعدم الرضا عن سلول المعلمين نحو الطلاب } & \multicolumn{2}{|c|}{ 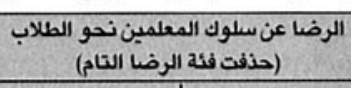 } & \multirow[b]{2}{*}{ 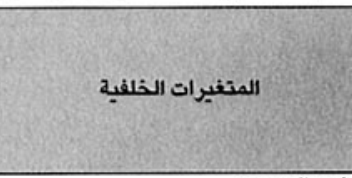 } \\
\hline في معاملة الطالاقب & الإخلاص/الأتقار الىضباط & الكثر منالالالوزية & إلجبار الطلاب على الخروسي & 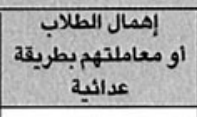 & التمييز في معاملة & سب/ضرب الطلاب & علمم الرضا & 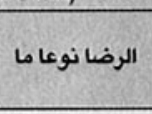 & \\
\hline$x^{\circ} \quad x_{2}$ & . & 18 & -2 & . & - & $\hat{\imath}$ & i & ir & انوئي المجيب \\
\hline$\vdots$ & i & r & i & i & $\vdots$ & $\begin{array}{l}10 \\
11 \\
r\end{array}$ & i & $\begin{array}{l}\mathrm{rv} \\
\mathrm{rr} \\
\mathrm{r}\end{array}$ & 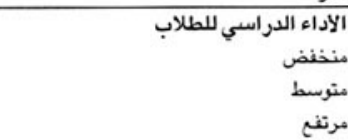 \\
\hline$\vdots$ & $\begin{array}{l}r \\
r \\
r \\
r\end{array}$ & i & $\vdots$ & $\vdots$ & $\begin{array}{l}i \\
i \\
r\end{array}$ & 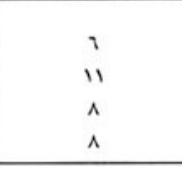 & i & $\begin{array}{l}r \\
r \leq \\
r \\
r \\
r \\
\end{array}$ & 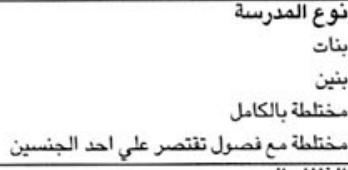 \\
\hline \& & $i$ & i & i & i & i & $\begin{array}{l}\checkmark \\
\wedge\end{array}$ & r & $\begin{array}{l}r r \\
1 .\end{array}$ & 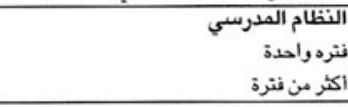 \\
\hline i & $\begin{array}{l}r \\
r \\
i\end{array}$ & r & i & i & $\begin{array}{l}\vdots \\
r \\
0\end{array}$ & it & $\begin{array}{l}r \\
i \\
i \\
\end{array}$ & $\begin{array}{l}\text { ro } \\
i \\
i\end{array}$ & رئنسفن \\
\hline ; & i & $\vdots$ & $i$ & i & $\varepsilon$ & i & i & r. & الالنائنات الحضرية \\
\hline$\frac{1}{r}$ & $\frac{r}{r}$ & $\frac{i}{r}$ & $\frac{r}{1}$ & $\frac{r}{1}$ & $\frac{r}{q}$ & $\frac{i r}{n}$ & $\frac{r}{r}$ & $\frac{\pi}{r}$ & المجمبوع \\
\hline Eva & Eva & \&va & $8 \mathrm{va}$ & \&va & \&va & Eva & $8 \mathrm{va}$ & \&va & 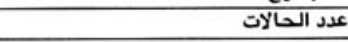 \\
\hline
\end{tabular}




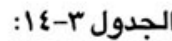

النسبة المئوية للطلاب الذين سعوا لنصح الاخصائي الاجتماعي و تلقوا المساعدة منه، و الذين حصلوا على دعم من البالغين في المدرسة، حسب المتغيرات الخلفية الفرديةو المدرسية

\begin{tabular}{|c|c|c|c|c|c|c|c|}
\hline \multicolumn{3}{|c|}{ من هو هذا الشخص البالغو } & \multirow{2}{*}{ 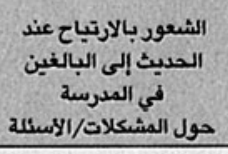 } & \multirow{2}{*}{ | تصث الإخماني الاجتهاعي } & \multirow{2}{*}{ 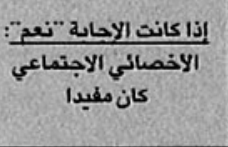 } & \multirow{2}{*}{ السعي لنمبح الاخمائي } & \multirow[b]{2}{*}{ المتغيرات الخلكية } \\
\hline أحد العاملين الاخرين & معلم ألعابر رياضية & معلم أكاسيمي & & & & & \\
\hline$\vdots$ & 1 & $\begin{array}{l}r_{1} \\
r_{0}\end{array}$ & $\begin{array}{l}m \\
\varepsilon\end{array}$ & $\begin{array}{l}\text { ir } \\
\text { IE }\end{array}$ & $\begin{array}{l}\text { v. } \\
\Sigma q\end{array}$ & $\begin{array}{l}\text { ir } \\
\text { rq }\end{array}$ & نونى النى المجيب \\
\hline ¿ & $\dot{r}$ & $\begin{array}{l}r \mu \\
r . \\
r r\end{array}$ & $\begin{array}{l}r_{0} \\
\varepsilon \\
\varepsilon 0\end{array}$ & $\hat{\hat{n}}$ & $\begin{array}{l}\text { \&r } \\
\text { of } \\
\text { ir }\end{array}$ & $\begin{array}{l}10 \\
18 \\
\pi\end{array}$ & مترتفط متراء الدراسي للطلاب \\
\hline $\begin{array}{l}1 \\
\vdots \\
\vdots \\
\end{array}$ & $\begin{array}{l}1 \\
\varepsilon \\
\varepsilon \\
1\end{array}$ & $\begin{array}{l}r v \\
r v \\
r v \\
r .\end{array}$ & $\begin{array}{l}r v \\
\qquad 1 \\
r 7 \\
29\end{array}$ & $\begin{array}{l}\text { is } \\
10 \\
\text { ir } \\
1 .\end{array}$ & $\begin{array}{l}\text { vi } \\
\text { or } \\
\text { t. } \\
\text { ra }\end{array}$ & $\begin{array}{l}\text { ir } \\
r \varepsilon \\
10 \\
r r\end{array}$ & 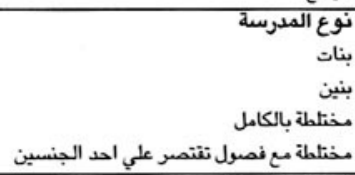 \\
\hline$\hat{0}$ & $\begin{array}{l}\varepsilon \\
r \\
\end{array}$ & $\begin{array}{l}r 1 \\
r a\end{array}$ & $\begin{array}{l}\varepsilon r \\
r A\end{array}$ & $\begin{array}{l}17 \\
1 .\end{array}$ & $\begin{array}{l}\circ v \\
\therefore o\end{array}$ & $\begin{array}{l}\text { iv } \\
\text { i9 }\end{array}$ & 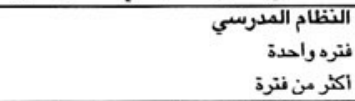 \\
\hline $\begin{array}{c}r \\
11 \\
0\end{array}$ & $\begin{array}{l}r \\
\dot{r} \\
r\end{array}$ & $\begin{array}{l}r \Lambda \\
r . \\
r r\end{array}$ & $\begin{array}{l}r_{0} \\
\approx 1 \\
\approx 1\end{array}$ & $\begin{array}{l}\text { a } \\
\text { iv } \\
\text { ir }\end{array}$ & $\begin{array}{l}\text { ?A } \\
\text { ov } \\
\text { oq }\end{array}$ & $\begin{array}{l}\text { is } \\
\text { iv } \\
\text { rr }\end{array}$ & 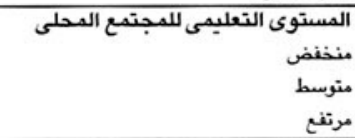 \\
\hline$\varepsilon$ & i & $\begin{array}{l}r v \\
r A \\
r q\end{array}$ & $\begin{array}{l}\varepsilon r \\
\varepsilon \varepsilon \\
r_{0}\end{array}$ & $\begin{array}{l}\text { ir } \\
\text { iv } \\
\text { a }\end{array}$ & $\begin{array}{l}\text { ov } \\
i . \\
\text { is }\end{array}$ & $\begin{array}{l}r . \\
r . \\
\text { iq }\end{array}$ & 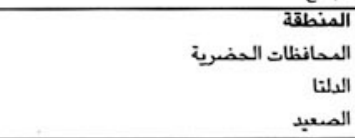 \\
\hline $\mathrm{v}$ & ร & $r$. & $\$$ & ir & 07 & 11 & المجموع \\
\hline & riी. & & Yधवः & TEAT & raA & TE9० & عدد الحالات \\
\hline
\end{tabular}




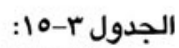

مقدار تفاعل الاخصائي الاجتماعي مع الطلاب و الطرف الذي بدأ التفاعل، حسب المتغيرات الخلفية الفردية و المدرسية

\begin{tabular}{|c|c|c|c|c|c|}
\hline 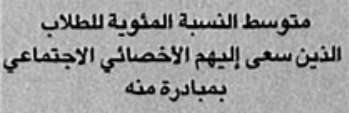 & 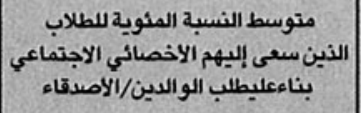 & الأين احالنهم الإدارة إلى للىلاب & الذين لجاوا إلى الاخبه المئوية اللطبلاب & التحتث إبهه الاسبوع السبابق & المتغيرات الخلفيه \\
\hline $\begin{array}{l}r \\
r r\end{array}$ & $\begin{array}{l}11 \\
10\end{array}$ & $\begin{array}{l}\varepsilon . \\
r_{0}\end{array}$ & $\begin{array}{l}r a \\
r A\end{array}$ & $\begin{array}{l}\text { IV,A } \\
\text { IV, }\end{array}$ & نوكئ المجيب \\
\hline $\begin{array}{l}r r \\
r \varepsilon \\
r .\end{array}$ & $\begin{array}{l}v \\
\text { iv } \\
11\end{array}$ & $\begin{array}{l}r_{1} \\
r_{0} \\
r_{1}\end{array}$ & $\begin{array}{l}r_{0} \\
r_{0} \\
r_{1}\end{array}$ & $\begin{array}{l}19,1 \\
1 r, . \\
r i, r\end{array}$ & مترنفض الاداء الدراسي للطلاب \\
\hline $\begin{array}{l}i n \\
r 1 \\
r \varepsilon \\
r i\end{array}$ & $\begin{array}{l}v \\
10 \\
10 \\
\text { iv }\end{array}$ & $\begin{array}{l}\varepsilon \\
r 1 \\
r o \\
r v\end{array}$ & $\begin{array}{l}r \varepsilon \\
r r \\
r r \\
r u\end{array}$ & $\begin{array}{l}M, \varepsilon \\
r, \varepsilon \\
M, v \\
11,0\end{array}$ & 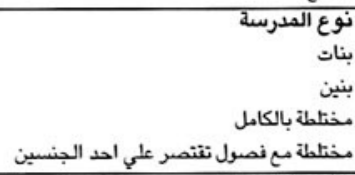 \\
\hline $\begin{array}{l}r \varepsilon \\
\text { in }\end{array}$ & $\begin{array}{l}9 \\
\text { iv }\end{array}$ & $\begin{array}{l}r \varepsilon \\
r .\end{array}$ & $\begin{array}{l}\mathrm{rr} \\
\mathrm{rq}\end{array}$ & $\begin{array}{l}17, r \\
r ., r\end{array}$ & 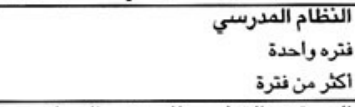 \\
\hline $\begin{array}{l}\mathrm{rr} \\
\mathrm{iv} \\
\mathrm{in}\end{array}$ & $\begin{array}{l}0 \\
\text { ri. } \\
i 11\end{array}$ & $\begin{array}{l}r . \\
r v \\
r a\end{array}$ & $\begin{array}{l}r r \\
r o \\
r r\end{array}$ & $\begin{array}{l}1 \mathrm{~A}, . \\
10, \varepsilon \\
r ., r\end{array}$ & مرتخفئ المستوى التعليمى للمجتمع المحلى \\
\hline $\begin{array}{l}\text { ir } \\
\text { rr } \\
\text { rv }\end{array}$ & $\begin{array}{l}11 \\
10 \\
1 .\end{array}$ & $\begin{array}{l}\varepsilon \varepsilon \\
r . \\
r q\end{array}$ & $\begin{array}{l}r r \\
r r \\
r q\end{array}$ & $\begin{array}{l}r r, . \\
i v, r \\
i 1, r\end{array}$ & المنافظظات الحضرية \\
\hline $\begin{array}{l}\text { لا ينطبق } \\
\text { لا بنطبق } \\
\end{array}$ & $\begin{array}{l}\text { لا بنطبنق } \\
\text { لا بنطبق } \\
\end{array}$ & $\begin{array}{l}\text { لا بنطبقب } \\
\text { لا بنطبق } \\
\end{array}$ & $\begin{array}{l}\text { لا لا ينطبق } \\
\text { لا بنطبق } \\
\end{array}$ & $\begin{array}{l}10, r \\
r \varepsilon, 1 \\
10,1\end{array}$ & صنجم المدرسة \\
\hline$r r$ & Ir & $r r$ & $r$ & $1 \mathrm{v}, 9$ & المجموع \\
\hline$\Lambda \varepsilon$ & $\Lambda \varepsilon$ & $\Lambda \varepsilon$ & $\Lambda \varepsilon$ & $\Lambda_{0}$ & عدد الحالات \\
\hline
\end{tabular}


الجدول r-7 17 طبيعة النقاشات بين الطلاب و الأخصائيين الاجتماعيين، النسبة المئوية للاخصائيين الاجتماعيين الذين يناقشون القضايا الاكثر شيوعا مع الطلاب، حسب المتغيرات الخلفية الفردية و المدرسية

\begin{tabular}{|c|c|c|c|c|c|c|c|c|}
\hline الملابس غير الملائمة & المشكلات المالبة & المشكلات المنزلية & الجنس & المخدرات/السجائر & الكتئاب/الانطواء & السلوك/الانضباط & الاداء الدراسي & المتغيرات الخلفية \\
\hline YA & $\begin{array}{l}10 \\
1 .\end{array}$ & $\begin{array}{l}\text { re } \\
19\end{array}$ & $\begin{array}{l}r v \\
r v\end{array}$ & 19. & $\begin{array}{l}r r \\
V\end{array}$ & $\begin{array}{l}9 . \\
\text { ar }\end{array}$ & $\begin{array}{l}\text { or } \\
71\end{array}$ & انوي المجيب \\
\hline $\begin{array}{l}i \\
i r \\
i x\end{array}$ & $\begin{array}{l}i r \\
r \\
r i\end{array}$ & $\begin{array}{l}r \varepsilon \\
r r \\
r r\end{array}$ & $\begin{array}{l}r \varepsilon \\
\varepsilon \\
r\end{array}$ & $\begin{array}{l}r \varepsilon \\
r \\
r\end{array}$ & ir & $\begin{array}{l}9 \varepsilon \\
M \\
9 \varepsilon\end{array}$ & $\begin{array}{l}\text { or } \\
\text { o. } \\
\text { io }\end{array}$ & 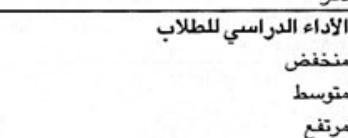 \\
\hline $\begin{array}{l}\varepsilon \\
\dot{5} \\
\dot{*}\end{array}$ & $\begin{array}{l}11 \\
0 \\
17 \\
17\end{array}$ & $\begin{array}{l}\xi 1 \\
r_{0} \\
r 1 \\
i r\end{array}$ & $\begin{array}{l}\text { m } \\
0 \\
\text { or } \\
\text { ri }\end{array}$ & $\begin{array}{c}. \\
10 \\
i \varepsilon\end{array}$ & $\begin{array}{l}r . \\
10 \\
r 7 \\
.\end{array}$ & $\begin{array}{l}\text { 10 } \\
\text { 90 } \\
9 \varepsilon \\
1 . .\end{array}$ & $\begin{array}{l}\varepsilon r \\
v . \\
\text { Ar } \\
\text { ri }\end{array}$ & 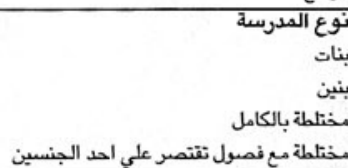 \\
\hline$\hat{r}$ & $\begin{array}{l}19 \\
r\end{array}$ & $\begin{array}{l}r \\
r\end{array}$ & $\begin{array}{l}10 . \\
0 .\end{array}$ & $\begin{array}{c}1 \\
10\end{array}$ & $\begin{array}{l}17 \\
r \varepsilon\end{array}$ & $\begin{array}{l}\mathrm{AT} \\
\mathrm{qV}\end{array}$ & $\begin{array}{l}0 \wedge \\
0 \&\end{array}$ & 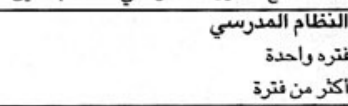 \\
\hline $\begin{array}{l}\varepsilon \\
11 \\
r 1\end{array}$ & $\begin{array}{l}\mathrm{rr} \\
\mathrm{v} \\
\mathrm{v}\end{array}$ & $\begin{array}{l}r r \\
r r \\
r r\end{array}$ & $\begin{array}{l}n \\
r \\
r 1\end{array}$ & $\begin{array}{l}\text { in } \\
i \\
r\end{array}$ & $\begin{array}{l}q \\
r r \\
r \varepsilon\end{array}$ & $\begin{array}{l}97 \\
9 . \\
9 .\end{array}$ & $\begin{array}{l}71 \\
10 \\
71\end{array}$ & متفنفض المستوى التعليمى للمجتمع المحلى \\
\hline $\begin{array}{l}\text { ro } \\
1 \varepsilon \\
\varepsilon\end{array}$ & $\begin{array}{l}\text { i } \\
\text { iv } \\
1\end{array}$ & $\begin{array}{l}\varepsilon \\
r \varepsilon \\
r A\end{array}$ & $\begin{array}{l}r \wedge \\
r v \\
1\end{array}$ & $\begin{array}{c}1 \\
0 \\
17\end{array}$ & $\begin{array}{l}19 \\
r \varepsilon \\
\text { ir }\end{array}$ & $\begin{array}{l}\text { a\& } \\
\text { ar } \\
M\end{array}$ & $\begin{array}{l}\varepsilon \varepsilon \\
17 \\
\text { or }\end{array}$ & 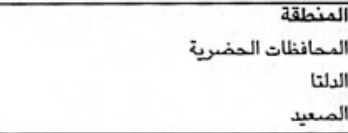 \\
\hline TE & ir & YA & ra & 9 & 19 & 91 & ov & المجموع \\
\hline$\Lambda \varepsilon$ & $\Lambda \varepsilon$ & $\Lambda \varepsilon$ & $\Lambda \varepsilon$ & $\Lambda \varepsilon$ & $r \varepsilon$ & $\Lambda \varepsilon$ & $\Lambda \varepsilon$ & عدد الحالات \\
\hline
\end{tabular}


الجدول r ا IV-r: حل الاخصائيين الاجتماعيين لمشكلات الطلاب، النسبة المئوية لمن أفادوا اتخاذ إجراءات لصالح الطلاب الذين التقوا بهم خلال الاسبوع السابق، حسب المتغيرات الخلفية الفرديةو المدرسية

\begin{tabular}{|c|c|c|c|c|c|c|c|c|c|}
\hline المراقبة & 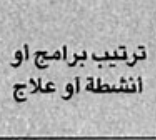 & 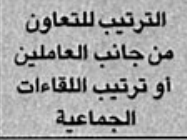 & تبسيط المشكلة & التوسط في الثزاع & العقاب/التهديد & |تقيم النصح/الإرشاد| & طلى الإدارة & استدعاء الوالدين & المتغيرات الخلفيه \\
\hline $\begin{array}{l}v \\
i s\end{array}$ & $\stackrel{i r}{v}$ & $\stackrel{i r}{0}$ & $\begin{array}{l}19 \\
10\end{array}$ & $\begin{array}{l}\varepsilon \varepsilon \\
r \varepsilon\end{array}$ & $\begin{array}{l}r \wedge \\
\vdots \wedge\end{array}$ & $\begin{array}{l}\text { v. } \\
\text { ar }\end{array}$ & $\begin{array}{l}r \eta \\
r \varepsilon\end{array}$ & i. & نوني انوع المجيب \\
\hline $\begin{array}{c}1 \\
r \\
19\end{array}$ & $\begin{array}{l}i r \\
a \\
i\end{array}$ & i & $\begin{array}{l}\text { ir } \\
\text { ro } \\
\text { is }\end{array}$ & $\begin{array}{l}r_{0} \\
r_{1} \\
r r\end{array}$ & $\begin{array}{l}\llbracket \\
r £ \\
r \wedge\end{array}$ & $\begin{array}{l}M \\
11 \\
\text { ar }\end{array}$ & $\begin{array}{l}r 1 \\
r r \\
r o\end{array}$ & $\begin{array}{l}v_{0} \\
r \varepsilon \\
v_{r}\end{array}$ & مترتفظ \\
\hline $\begin{array}{c}v \\
r \\
i \\
i\end{array}$ & $\begin{array}{l}1 . \\
11 \\
\text { ir }\end{array}$ & $\begin{array}{l}1 . \\
: \\
\text { ir }\end{array}$ & $\begin{array}{l}1 . \\
n \\
n \\
n\end{array}$ & $\begin{array}{l}\varepsilon v \\
r v \\
r v \\
i r\end{array}$ & $\begin{array}{l}r . \\
r r \\
v \varepsilon \\
r i\end{array}$ & $\begin{array}{l}\text { ir } \\
90 \\
9 . \\
\text { Mi }\end{array}$ & $\begin{array}{l}r . \\
r \\
r y \\
r a\end{array}$ & $\begin{array}{l}1 . \\
10 \\
i r \\
i 1\end{array}$ & 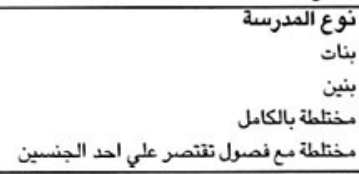 \\
\hline $1 !$ & 1. & i. & $\begin{array}{l}i r \\
r y\end{array}$ & $\begin{array}{l}r \varepsilon \\
\varepsilon v\end{array}$ & $\begin{array}{l}r . \\
\text { iv }\end{array}$ & $\begin{array}{l}A \varepsilon \\
\text { va }\end{array}$ & $\begin{array}{l}\text { in } \\
\text { ro }\end{array}$ & $\begin{array}{l}01 \\
1 .\end{array}$ & 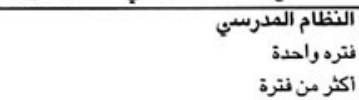 \\
\hline $\begin{array}{c}0 \\
r \\
r r\end{array}$ & $\begin{array}{c}9 \\
r \\
17\end{array}$ & $\begin{array}{c}\varepsilon \\
17 \\
v\end{array}$ & $\begin{array}{l}9 \\
17 \\
r r\end{array}$ & $\begin{array}{l}r r \\
r \varepsilon \\
\varepsilon r\end{array}$ & $\begin{array}{l}r \\
0 . \\
r\end{array}$ & $\begin{array}{l}91 \\
w \\
w v\end{array}$ & $\begin{array}{l}r r \\
r 7 \\
11\end{array}$ & $\begin{array}{l}1 \xi \\
\imath \wedge \\
i r\end{array}$ & مترتفض \\
\hline $\begin{array}{l}\text { ro } \\
\text { ir }\end{array}$ & $\begin{array}{l}\dot{v} \\
\mathrm{r} \\
\mathrm{r}\end{array}$ & in & $\begin{array}{l}i n \\
i \varepsilon \\
r \varepsilon\end{array}$ & $\begin{array}{l}79 \\
r r \\
r A\end{array}$ & $\begin{array}{l}\text { ro } \\
\text { of } \\
\text { it }\end{array}$ & $\begin{array}{l}10 \\
\Lambda 1 \\
M\end{array}$ & $\begin{array}{l}r \varepsilon \\
r r \\
i r\end{array}$ & $\begin{array}{l}10 \\
11 \\
\vdots 1\end{array}$ & المانطظة الصنات الحضرية \\
\hline 11 & 9 & 9 & IV & $r r$ & rv & AT & ro & $0 A$ & المجموع \\
\hline$\Lambda \varepsilon$ & $\wedge \varepsilon$ & $\Lambda \varepsilon$ & $\Lambda \varepsilon$ & $\Lambda \varepsilon$ & $\Lambda \varepsilon$ & $\Lambda \varepsilon$ & $\Lambda \varepsilon$ & $\Lambda \varepsilon$ & عدد الحالات \\
\hline
\end{tabular}




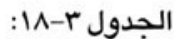

أراء الأخصائيين الاجتماعيين حول أكبر نجاح في حل مشكلات الطلاب، النسبة المئوية للأخصائين الاجتماعينين الذين أفادوا أنهم حققوا

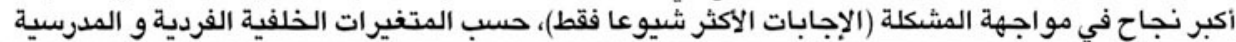

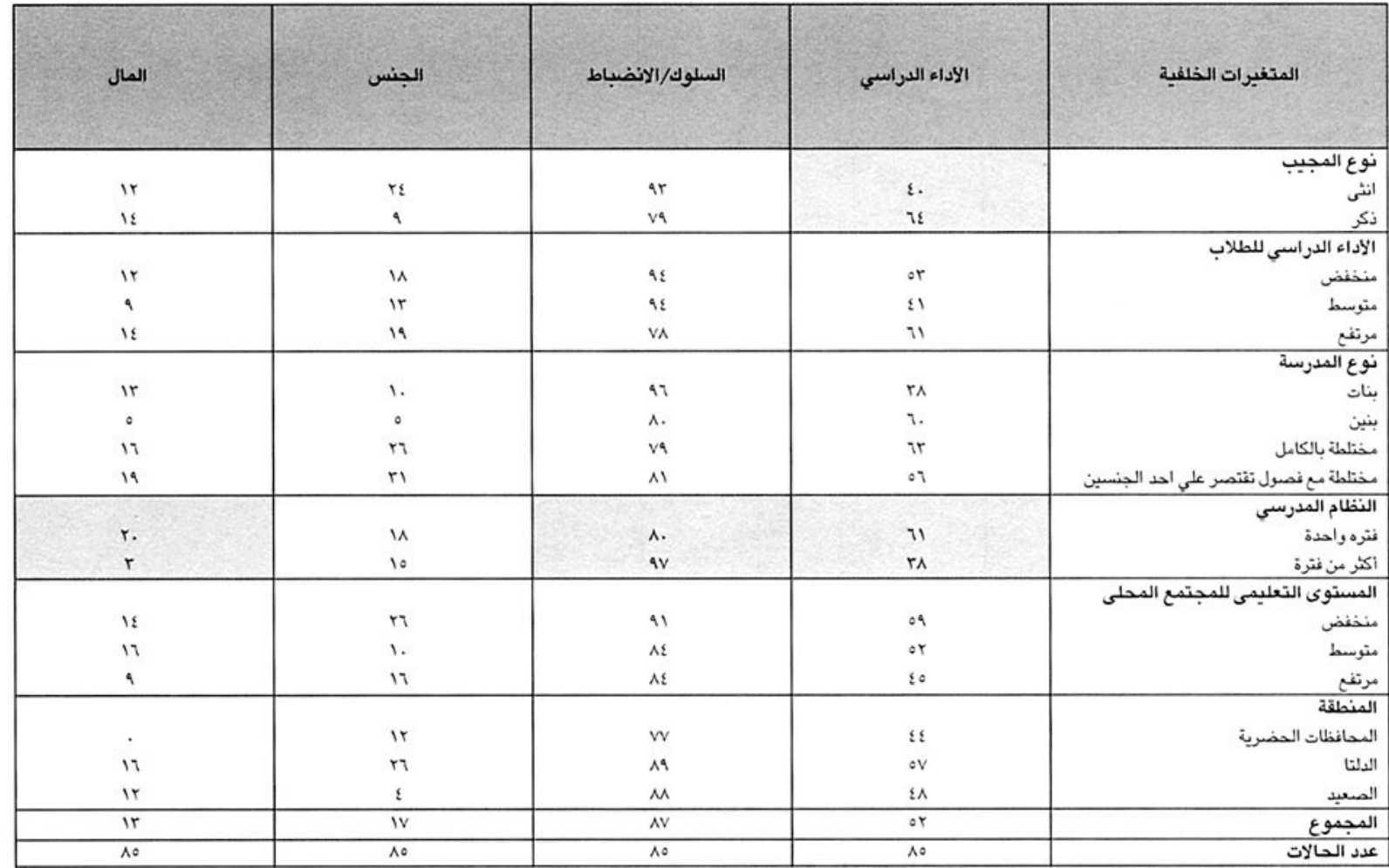

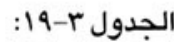
أراء الأخصائين الاجتماعيين حول أخطر المشكلات الخاصة بالطلاب في المدرسة، النسبة المئوية لمن ذكروا كل مشكلة (الإجابات الاكثر

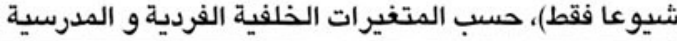

\begin{tabular}{|c|c|c|c|c|}
\hline المال & الجنس & السلواك/الاتضباط & الاداء الدراسي & المتغيرات الخلفية \\
\hline $\begin{array}{l}v \\
\text { l. }\end{array}$ & rq & $\begin{array}{l}r \wedge \\
\leqslant \Lambda\end{array}$ & If & نون انتى المجيب \\
\hline $\begin{array}{l}\text { i } \\
\text { iv }\end{array}$ & $\begin{array}{l}1 \\
\text { ro } \\
1\end{array}$ & $\begin{array}{l}0 . \\
\vdots \varepsilon \\
\varepsilon r\end{array}$ & $\begin{array}{l}0 . \\
17 \\
\text { ro }\end{array}$ & منغفض الأدراء الدراسي للطلاب \\
\hline $\begin{array}{c}v \\
i \\
19\end{array}$ & $\begin{array}{c}\text { iv } \\
\text { ri } \\
i\end{array}$ & $\begin{array}{l}\text { ir } \\
0 . \\
r r \\
0 .\end{array}$ & $\begin{array}{l}v \\
\varepsilon . \\
r v \\
r_{0}\end{array}$ & بنات بنتين \\
\hline $\begin{array}{l}\text { ir } \\
r\end{array}$ & $\begin{array}{c}r \\
\text { rv }\end{array}$ & $\begin{array}{l}\text { rr } \\
09\end{array}$ & $\begin{array}{l}r \\
\text { ir }\end{array}$ & 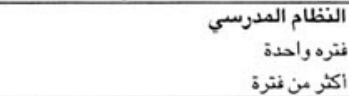 \\
\hline $\begin{array}{c}\circ \\
17 \\
r\end{array}$ & $\begin{array}{l}\circ \\
i 9\end{array}$ & $\begin{array}{l}\because \\
0 . \\
r\end{array}$ & $\begin{array}{l}84 \\
19 \\
19\end{array}$ & منغفض مترست التعليمى للمجتمع المحلى \\
\hline i & $\begin{array}{l}\text { ra } \\
\text { ir } \\
\varepsilon\end{array}$ & $\begin{array}{l}19 \\
\vdots 9 \\
0 .\end{array}$ & $\begin{array}{l}r 9 \\
r i \\
r \varepsilon\end{array}$ & المالتافظات الحضرية المنطيد \\
\hline$\Lambda$ & ir & \&r & ri & المجموع \\
\hline Ar & Ar & Nr & Ar & عدد الحالات \\
\hline
\end{tabular}




\begin{tabular}{|c|c|c|}
\hline \multicolumn{2}{|c|}{ مصدر مشكلات الطلاب (المنتل او المدرسة أو الائنين) } & \multirow{2}{*}{ المتغيرات الخلفية } \\
\hline المدربسة و المنزل معا & المنزل & \\
\hline $\begin{array}{l}\text { ry } \\
\text { or }\end{array}$ & $\begin{array}{l}\text { Vr } \\
\text { ¿A }\end{array}$ & نوع النى \\
\hline $\begin{array}{l}r q \\
\varepsilon \varepsilon \\
r q\end{array}$ & $\begin{array}{l}n \\
\text { or } \\
11\end{array}$ & متخفض الاد الدراسي للطلاب \\
\hline $\begin{array}{l}\text { IV } \\
\text { ir } \\
\text { \&V } \\
\text { rA }\end{array}$ & $\begin{array}{l}\text { Ar } \\
\text { rr } \\
\text { or } \\
\text { ir }\end{array}$ & بنتين \\
\hline $\begin{array}{l}r q \\
\$ 1\end{array}$ & $\begin{array}{l}89 \\
09\end{array}$ & اكترد مالنظام الددرسي فترة \\
\hline $\begin{array}{l}o . \\
\text { rq } \\
\text { rr }\end{array}$ & $\begin{array}{l}0 . \\
o x \\
u\end{array}$ & متففض المستوى التعليسى اللمجتمع المحلى \\
\hline $\begin{array}{l}r i \\
r \varepsilon \\
\text { or }\end{array}$ & $\begin{array}{l}79 \\
18 \\
\leq 1\end{array}$ & 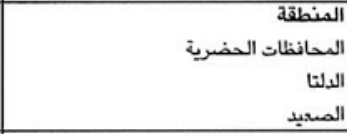 \\
\hline rq & 7. & المجموع \\
\hline 10 & 10 & عدد الحالات \\
\hline
\end{tabular}

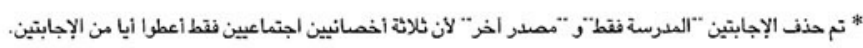
النسبة المئوية للمعلمين الراضين عن سلوك الطلاب نحو بعضهم البعض و الأسباب الرئيسية لعدم الرضا، حسب المتغيرات الخلفية الفردية

\begin{tabular}{|c|c|c|c|c|c|c|}
\hline \multicolumn{4}{|c|}{ الاسباب الرئيسية لعدم الرضا عن سلوك الطلاب في هذه المدرسة } & \multicolumn{2}{|c|}{ 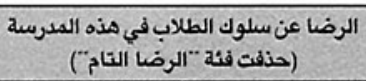 } & \multirow{2}{*}{ المتغيرات الخلفية } \\
\hline فعل الانضباطا & عدم التعاون بين & الكنب/السرة2ة & السلوك العدائي & النسبة المئوية & الرضنا الوعا مانية & \\
\hline$\vdots$ & $\begin{array}{l}v \\
1\end{array}$ & ir & $\begin{array}{l}\text { Ir } \\
o v\end{array}$ & $\begin{array}{l}\text { ro } \\
19\end{array}$ & $\begin{array}{l}\$ 9 \\
0 \leqslant\end{array}$ & نوكرع المجيب \\
\hline $\begin{array}{l}1 \\
\vdots \\
0\end{array}$ & $\begin{array}{l}10 \\
\dot{r}\end{array}$ & $\begin{array}{l}1 \\
\text { ir } \\
9\end{array}$ & $\begin{array}{l}0 . \\
\text { iv } \\
\text { OA }\end{array}$ & $\begin{array}{l}r . \\
r s \\
r i\end{array}$ & $\begin{array}{l}\text { \&v } \\
\text { ol } \\
\text { or }\end{array}$ & متخفض الاداء الدراسي للطلاب \\
\hline $\begin{array}{l}\dot{0} \\
i \\
i\end{array}$ & $\begin{array}{l}r \\
q \\
a \\
a\end{array}$ & $\begin{array}{l}1 \xi \\
\varepsilon \\
1 \\
1\end{array}$ & $\begin{array}{l}71 \\
\text { vr } \\
81 \\
\text { or }\end{array}$ & $\begin{array}{l}r \xi \\
r r \\
v \\
r I\end{array}$ & $\begin{array}{l}\text { or } \\
\varepsilon \wedge \\
\varepsilon \wedge \\
00\end{array}$ & 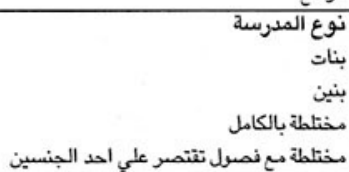 \\
\hline i & $\begin{array}{l}v \\
\vdots\end{array}$ & $\stackrel{0}{10}$ & $\begin{array}{l}21 \\
29\end{array}$ & $\begin{array}{l}r \\
r r\end{array}$ & or & 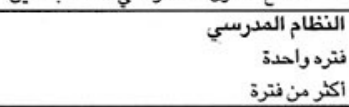 \\
\hline $\begin{array}{l}\dot{v} \\
\dot{r} \\
\mathrm{v}\end{array}$ & $\begin{array}{l}\text { ir } \\
\varepsilon \\
\varepsilon\end{array}$ & $\begin{array}{l}0 \\
11 \\
1 .\end{array}$ & $\begin{array}{l}\text { \&v } \\
\text { iv } \\
\text { ov }\end{array}$ & $\begin{array}{l}19 \\
r 1 \\
r \leq\end{array}$ & $\begin{array}{l}\vdots 9 \\
07 \\
\vdots 7\end{array}$ & مترسفض مرتفي \\
\hline $\begin{array}{l}v \\
r \\
\text { s }\end{array}$ & $\begin{array}{c}\vdots \\
\vdots \\
i .\end{array}$ & $\begin{array}{l}q \\
\text { ir } \\
\text { r }\end{array}$ & $\begin{array}{l}1 \varepsilon \\
i r \\
\varepsilon v\end{array}$ & $\begin{array}{l}r 1 \\
19 \\
17\end{array}$ & $\begin{array}{l}\xi v \\
o v \\
\varepsilon v\end{array}$ & الدالتافظات الحضرية \\
\hline 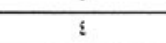 & 1 & 9 & $2 \Lambda$ & ri & 91 & المجموع \\
\hline \multicolumn{4}{|c|}{$\frac{1}{+\mathrm{VA}}$} & \&A. & *!人. & عدد الحالات \\
\hline
\end{tabular}


الجدول rrrr النسبة المئوية للطلاب الذين يتلقون معلومات حول التغيرات المصاحبة للنضوج أو الحيض و الشئون الصحية المتصلة بالحيض (البنات فقط) في المدرسة و مصادر المعلومات، حسب المتغيرات الخلفية الفرديةو المدرسية النية

\begin{tabular}{|c|c|c|c|c|c|c|c|c|}
\hline \multicolumn{3}{|c|}{ هصدر المعلومات } & \multirow{2}{*}{ تلقي معلومات حول المتون الصدية } & \multicolumn{3}{|c|}{ مصدر المعلومات } & \multirow{2}{*}{ الحيض المعلومات التغول التيرات } & \multirow{2}{*}{ الهتغيرات الخلفيه } \\
\hline اصدقاء & معلم الدين & معلم أكاديمي & & اصدقاء & معلم الدين & معلم اكاديمي & & \\
\hline لا لائطبق & لا بنطبق 17 & لا بنطبق & لا بانطبق & $\begin{array}{l}n \\
1\end{array}$ & $\begin{array}{l}r \\
1\end{array}$ & $\begin{array}{l}\text { ir } \\
\text { iv }\end{array}$ & $\begin{array}{l}11 \\
r .\end{array}$ & نوني المجيب \\
\hline $\begin{array}{l}1 \\
i r \\
i 1\end{array}$ & $\begin{array}{l}1 \\
r \\
1 .\end{array}$ & $\begin{array}{l}\text { ir } \\
r_{0} \\
\text { rv }\end{array}$ & $\begin{array}{l}r r \\
7 . \\
\varepsilon \varepsilon\end{array}$ & $\begin{array}{l}1 . \\
19 \\
10\end{array}$ & $\begin{array}{l}1 \\
r \varepsilon \\
1 \varepsilon\end{array}$ & $\begin{array}{l}r \\
\varepsilon r \\
r r\end{array}$ & $\begin{array}{l}\text { ro } \\
\because q \\
\varepsilon A\end{array}$ & متخفضط الاداء الدراسي للطلاب \\
\hline $\begin{array}{c}10 \\
10 \\
11 \\
11\end{array}$ & 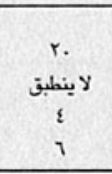 & $\begin{array}{l}\text { rA } \\
\text { rr } \\
\text { ro }\end{array}$ & $\begin{array}{l}\sum 9 \\
\text { لy } \\
r i \\
r_{0}\end{array}$ & $\begin{array}{l}\hat{H} \\
1 \varepsilon \\
1 \varepsilon\end{array}$ & $\begin{array}{c}n \\
1 \\
11 \\
1 .\end{array}$ & $\begin{array}{l}2 r \\
i r \\
r r \\
r i\end{array}$ & $\begin{array}{l}u \\
r \\
\varepsilon T \\
\varepsilon r\end{array}$ & 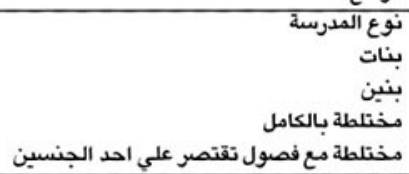 \\
\hline $\begin{array}{l}10 \\
11\end{array}$ & ii & $\begin{array}{l}r \\
r\end{array}$ & $\begin{array}{l}\text { ra } \\
00\end{array}$ & $\begin{array}{l}\text { ir } \\
\text { iv }\end{array}$ & $\begin{array}{l}1 \\
n\end{array}$ & $\begin{array}{l}r A \\
r r\end{array}$ & $\because 1$ & 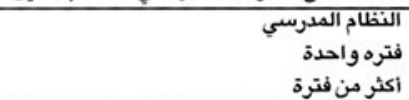 \\
\hline $\begin{array}{l}11 \\
15 \\
\text { ir }\end{array}$ & $\begin{array}{l}r \\
r_{0}\end{array}$ & $\begin{array}{l}\text { iv } \\
r i \\
r i\end{array}$ & $\begin{array}{l}r v \\
\varepsilon r \\
11\end{array}$ & $\begin{array}{l}1 . \\
\text { is } \\
\text { it }\end{array}$ & $\begin{array}{l}v \\
i \varepsilon \\
r_{0}\end{array}$ & $\begin{array}{l}r . \\
r v \\
r .\end{array}$ & $\begin{array}{l}r \varepsilon \\
o v \\
o .\end{array}$ & هنخفض المستوى التعليمى للمجتمع المحلى \\
\hline $\begin{array}{l}10 \\
10 \\
1\end{array}$ & ¿ & $\begin{array}{l}r \varepsilon \\
r q \\
1 \varepsilon\end{array}$ & $\begin{array}{l}v . \\
\varepsilon r \\
r\end{array}$ & $\begin{array}{l}17 \\
\text { is } \\
1 .\end{array}$ & $\begin{array}{l}r \Lambda \\
1 \varepsilon \\
1\end{array}$ & $\begin{array}{l}r r \\
r i \\
i s\end{array}$ & $\begin{array}{l}\because 1 \\
\because \\
r y\end{array}$ & 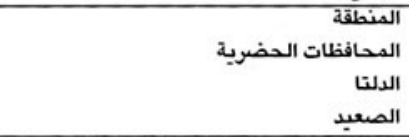 \\
\hline If & 17 & rv & !1 & 10 & 10 & $r$. & \&凡 & المجموع \\
\hline \multicolumn{3}{|c|}{ Triv } & $1 \times 19$ & \multicolumn{3}{|c|}{ TEA9 } & TE9० & عدد الحالات \\
\hline
\end{tabular}


الجدول r-rrr: تطلعات الطلاب و توقعاتهم بشأن مواصلة التعليم و العمل، و النسبة المئوية لمن يتوقعون مو اصلة التعليم الثانوي، و اسباب توقع التوقف عن التعليم، و(بين البنات) التوقعات المتعلقة بالعمل، حسبب

\begin{tabular}{|c|c|c|c|c|c|c|c|c|c|}
\hline \multicolumn{5}{|c|}{ البنات فقط. } & \multirow{2}{*}{\multicolumn{3}{|c|}{ 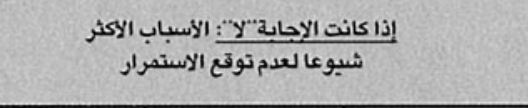 }} & \multirow{3}{*}{ تلتعقيم مواصليلة } & \multirow[b]{3}{*}{ المتغيرات الخلفية } \\
\hline \multirow{2}{*}{ الاسرة سوف تسمبح } & \multicolumn{3}{|c|}{ إذا كانت الإجايح لا: اكثر الاسباب شيوعا لعدم العمل } & \multirow{2}{*}{ ترغب في العمل بعد } & & & & & \\
\hline & لانها لاترغب في & لكي تكون ربة & لا يجب أن تعمل & & عدم تحبيذ & ضعف الاداء & ضعف الإمكانيات & & \\
\hline 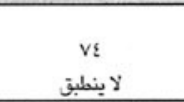 & $\begin{array}{c}\hat{y} \\
\text { لابنطبق }\end{array}$ & لابنطبئ & لاينطبي & لاينطبيق & $\begin{array}{l}\text { ir } \\
\mathrm{v}\end{array}$ & $\begin{array}{l}r \xi \\
r q\end{array}$ & $\begin{array}{l}\text { ir } \\
\text { ir }\end{array}$ & $\begin{array}{l}\text { v. } \\
09\end{array}$ & نوني المجيب \\
\hline $\begin{array}{l}11 \\
\text { v. } \\
\text { va }\end{array}$ & $\begin{array}{c}\varepsilon \\
17 \\
r\end{array}$ & $\begin{array}{l}\varepsilon \\
r \\
\circ\end{array}$ & $\begin{array}{l}\text { Aq } \\
\text { va } \\
\text { q. }\end{array}$ & $\begin{array}{l}\text { Aq } \\
\text { ar } \\
\text { M }\end{array}$ & $\begin{array}{l}r r \\
r \\
q\end{array}$ & $\begin{array}{l}\mathrm{rr} \\
\mathrm{rv} \\
\mathrm{iv}\end{array}$ & $\begin{array}{l}\ddot{0} \\
11 \\
v r\end{array}$ & $\begin{array}{l}\text { ir } \\
\text { ir } \\
\text { iv }\end{array}$ & منتوسط الأداء الدراسي اللطلاب 1 منفع \\
\hline $\begin{array}{l}v_{0} \\
711 \\
\text { vह }\end{array}$ & $\begin{array}{c}9 \\
\text { لابنطبق } \\
\vdots \\
\vdots\end{array}$ & $\begin{array}{l}r \\
\text { لاينطبق } \\
1 . \\
.\end{array}$ & 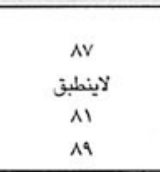 & Y & $\begin{array}{c}1: \\
\hat{1} \\
11 \\
0\end{array}$ & $\begin{array}{l}r 1 \\
r n \\
r r \\
r o\end{array}$ & $\begin{array}{l}i r \\
11 \\
o v \\
i .\end{array}$ & $\begin{array}{l}v . \\
07 \\
u \\
18\end{array}$ & 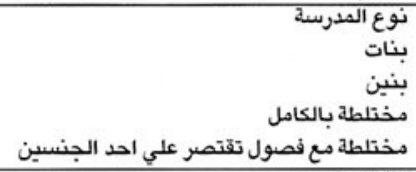 \\
\hline $\begin{array}{l}w \\
79\end{array}$ & $\begin{array}{l}r \\
i r\end{array}$ & $\begin{array}{l}1 \\
r\end{array}$ & $\begin{array}{l}\text { Av } \\
\text { Ao }\end{array}$ & १9. & $\begin{array}{l}1 . \\
i r\end{array}$ & $\begin{array}{l}n \\
m\end{array}$ & $\begin{array}{l}\text { ir } \\
\text { ir }\end{array}$ & $\begin{array}{l}7 \varepsilon \\
10\end{array}$ & 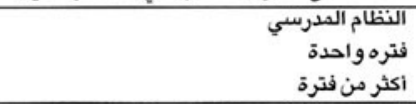 \\
\hline $\begin{array}{l}10 \\
n \\
n\end{array}$ & is & i & $\begin{array}{l}\text { Ao } \\
\text { is } \\
\text { ir }\end{array}$ & $\begin{array}{l}91 \\
\text { १i } \\
90\end{array}$ & $\begin{array}{l}\text { iv } \\
1 . \\
\text {. }\end{array}$ & $\begin{array}{l}r 1 \\
r . \\
r v\end{array}$ & $\begin{array}{l}\text { or } \\
\text { v. } \\
\text { oq }\end{array}$ & $\begin{array}{l}7 r \\
10 \\
70\end{array}$ & منتخفض \\
\hline $\begin{array}{l}v_{0} \\
v_{r} \\
v_{r}\end{array}$ & $\begin{array}{r}r . \\
r \\
r\end{array}$ & i & $\begin{array}{l}v . \\
19 \\
97\end{array}$ & $\begin{array}{l}90 \\
\text { A1 } \\
\text { 11 }\end{array}$ & $\begin{array}{c}\varepsilon \\
1 \\
r 1\end{array}$ & $\begin{array}{l}\varepsilon 7 \\
r \varepsilon \\
r_{0}\end{array}$ & $\begin{array}{l}0 . \\
79 \\
0 \varepsilon\end{array}$ & $\begin{array}{l}11 \\
11 \\
11\end{array}$ & 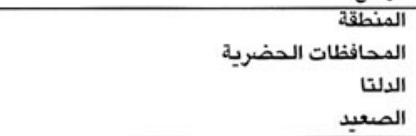 \\
\hline $\mathrm{v}$ ! & $\mathrm{v}$ & $\varepsilon$ & 17 & 9. & 11 & $r 7$ & Ir & $7 \varepsilon$ & المجموع \\
\hline IrIV & & 1.1 & & 1891 & & $r .$. & & rEq. & عدد الحالات \\
\hline
\end{tabular}


الجداول

الفصل الرابع

الصحة والنظافة العامة 
الجدول ؟-1:

نسب التوزيع المئوية للمددارس حسب توفر الخدمات الصحية ونوعية مقدم الخدمات الطبية (طبيب/ مدرضة)، حسب الدتغيرات الخلفية المدرسية.

\begin{tabular}{|c|c|c|c|}
\hline لاهذا ولاذاك & مصرضة & طبيب & الهتغيرات الخلفية \\
\hline $\begin{array}{l}\$ 9, Y \\
\$ 1,1 \\
10, r\end{array}$ & $\begin{array}{l}\varepsilon r, 1 \\
\varepsilon, 7 \\
r 0,7\end{array}$ & $\begin{array}{l}v, v \\
11,8 \\
09,1\end{array}$ & منخفض الاداء المدرسي للطلاب \\
\hline $\begin{array}{l}1 r, 8 \\
1 r, r \\
\text { or, } \\
01,9\end{array}$ & $\begin{array}{l}r i, \wedge \\
\llbracket 1, \wedge \\
\llbracket \varepsilon, v \\
r q, \varepsilon\end{array}$ & $\begin{array}{l}10,1 \\
\varepsilon ., 9 \\
r . v \\
11, v\end{array}$ & بنات بنتين \\
\hline $\begin{array}{l}r v, 1 \\
r v, r\end{array}$ & $\begin{array}{l}r \leqslant, q \\
r v, A\end{array}$ & $\begin{array}{l}r_{\Lambda}, 1 \\
r_{0} . .\end{array}$ & 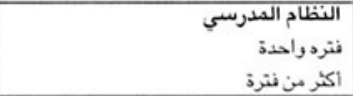 \\
\hline $\begin{array}{l}- \\
r v, t \\
0 \leqslant, 1\end{array}$ & $\begin{array}{l}r, . \\
\qquad r, \wedge \\
r, \varepsilon\end{array}$ & $\begin{array}{l}9 v, . \\
r 9,9 \\
9,0\end{array}$ & الدالتطافظة الحضرية \\
\hline $\begin{array}{l}r, 7 \\
\text { or, },\end{array}$ & $\begin{array}{l}r \&, 7 \\
\varepsilon r, v\end{array}$ & $\begin{array}{l}\text { Vr,A } \\
\qquad, 1\end{array}$ & الموقع (حضري/ريغي) \\
\hline $\begin{array}{l}7.9 \\
\cdots \\
17,1\end{array}$ & 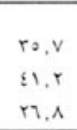 & $\begin{array}{l}r, \varepsilon \\
2 \wedge, 1 \\
27, r\end{array}$ & صنبم المدرسة \\
\hline$r \leqslant,$. & $r_{0,1}$ & $r \cdot, r$ & الدجدوع \\
\hline \multicolumn{3}{|c|}{ vo } & عدد الحالات \\
\hline
\end{tabular}

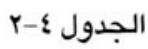
توافر مقدمي الخدمت في مدارس العينة: التوزيع المئوية بين المدارس التي تقدم الخدمات الصحية، حسب المتغيرات الخلفية الفردية والمدرسية

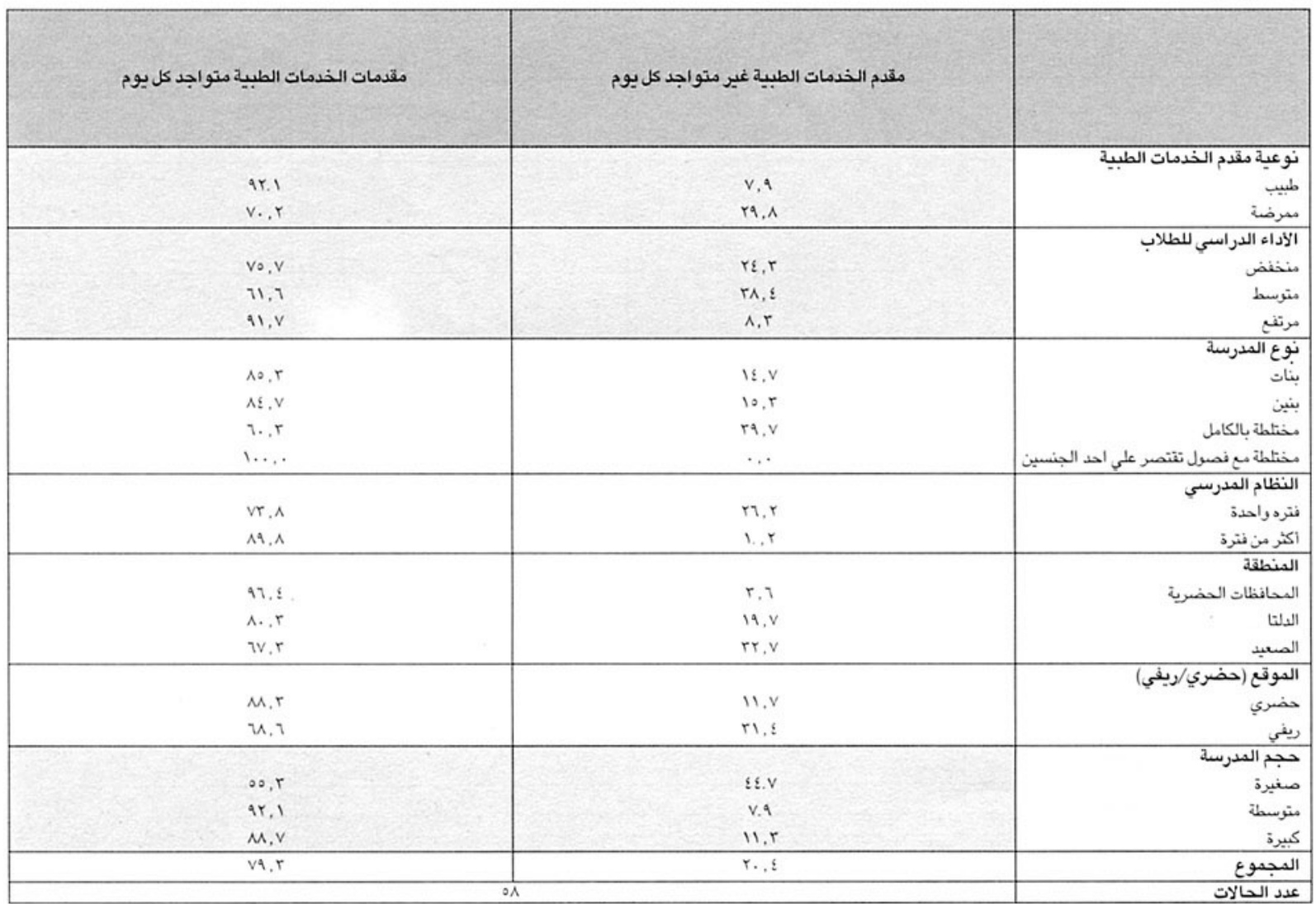




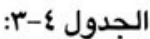
نسب التوزيع المئوية لمقدمي الخدمات الطبية حسب النوع و المؤهلات والمتغيرات الخلفية المدرسية بالمدارس التى تقدم الخدمات الصحية

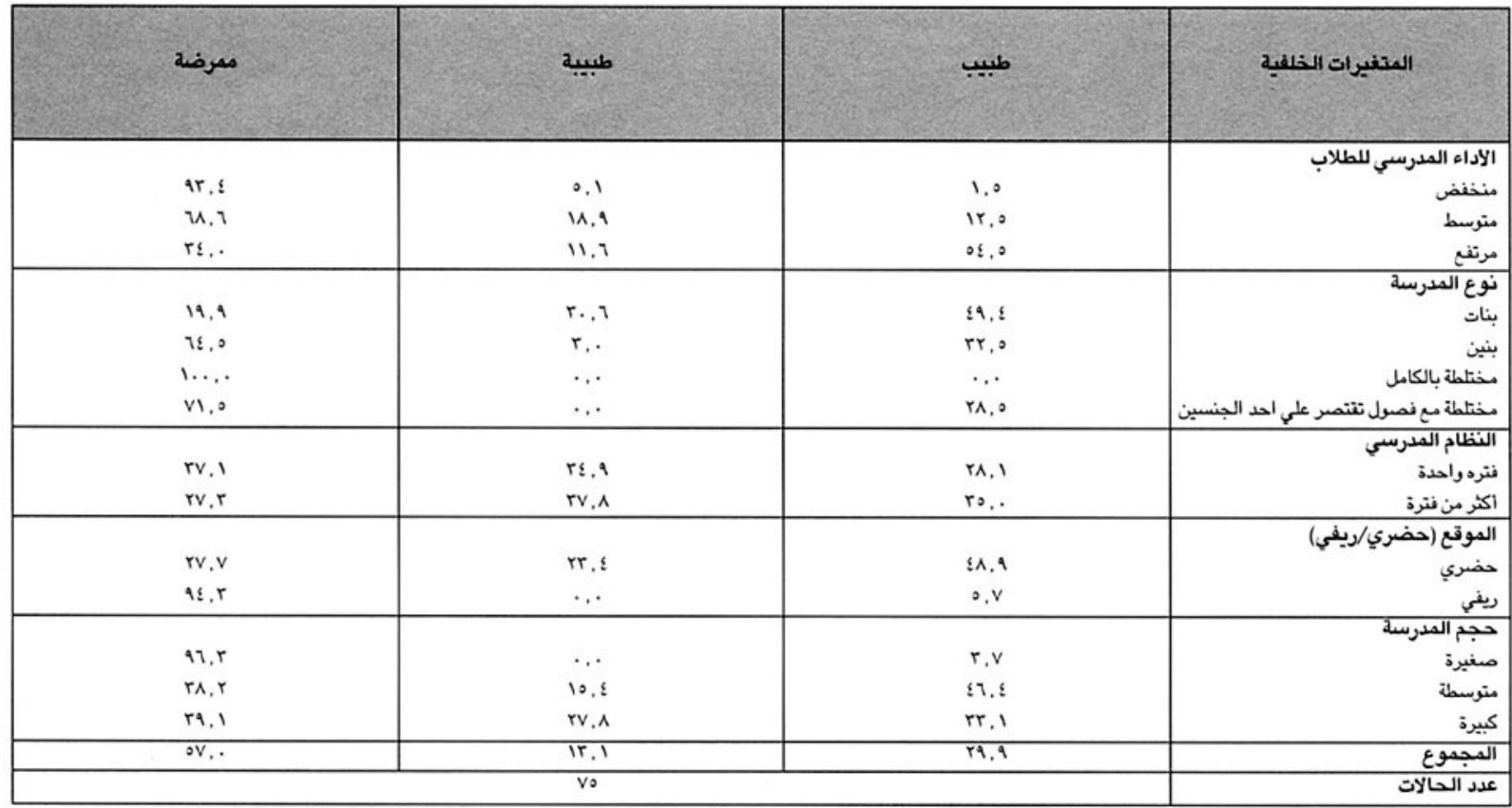

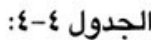
الوقت الذي يستغرقه مقدم الخدمات الطبية للوصول الي المدربة الفردة: نسب التوزيع المئوية بين العاملين بالمدارس التي تقدم الخدمات الصحية، حسب المتغيرات الخلفية الفردية والمدرسية.

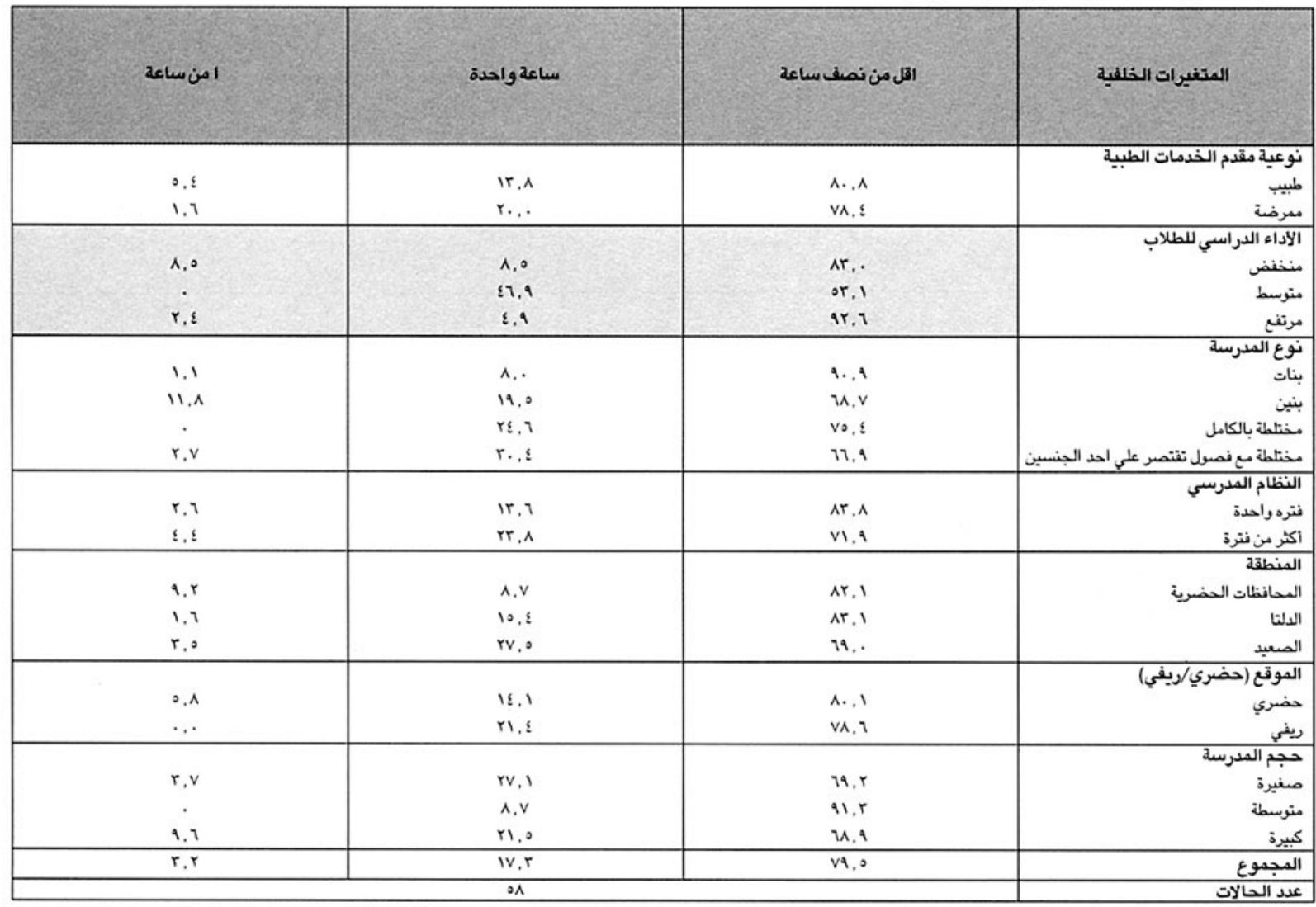




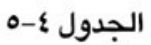

توفر عيادة بالمدارس التي تقدم الخدمات الصحية: نسب التوزيع المئوية حسب المتغيرات الخلفية الفردية والمدرسية.

\begin{tabular}{|c|c|c|}
\hline y & نعم & المتغيرات الخلفية \\
\hline $\begin{array}{c}\cdots \wedge \\
0 \wedge, v\end{array}$ & $\begin{array}{l}1 \ldots, 8 \\
\Sigma 1, r\end{array}$ & نوعيبة مقدم الخدمات الطبية \\
\hline 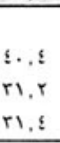 & $\begin{array}{l}09,7 \\
u, 1 \\
u, v\end{array}$ & مترسف \\
\hline 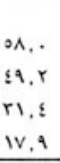 & $\begin{array}{l}\lambda r, 1 \\
u, 1 \\
0, \lambda \\
\vdots r, 1\end{array}$ & 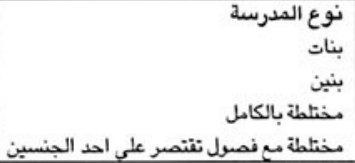 \\
\hline $\begin{array}{l}r q, r \\
r r, r\end{array}$ & $\begin{array}{l}1 ., v \\
\text { v1.v }\end{array}$ & 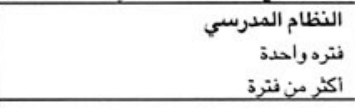 \\
\hline $\begin{array}{l}\cdots \\
r \cdots, v \\
\varepsilon v, .\end{array}$ & $\begin{array}{l}1 \cdots, . \\
i r . r \\
o r .\end{array}$ & 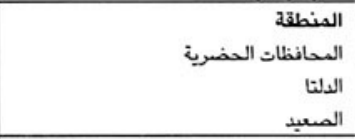 \\
\hline $\begin{array}{l}r, r \\
0 ., \varepsilon \\
0, r\end{array}$ & $\begin{array}{l}\text { va,1 } \\
\$ 9,1\end{array}$ & الموقع (ضري/ريفي) \\
\hline $\begin{array}{l}0 r, r \\
r, q \\
r ., v\end{array}$ & $\begin{array}{l}\varepsilon \mathrm{v}, \mathrm{s} \\
\mathrm{vA}, \mathrm{l} \\
\mathrm{iq,r}\end{array}$ & صنيرة المدرسة \\
\hline$r r, 0$ & 11.0 & المجموع \\
\hline
\end{tabular}

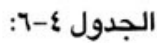
نسب التوزيع المئوية للمدارس التي تضم مختلفة من المعدات الاساسية في العيادات، بين المدارس(ه○) التي تقدم الخدمات الصحية

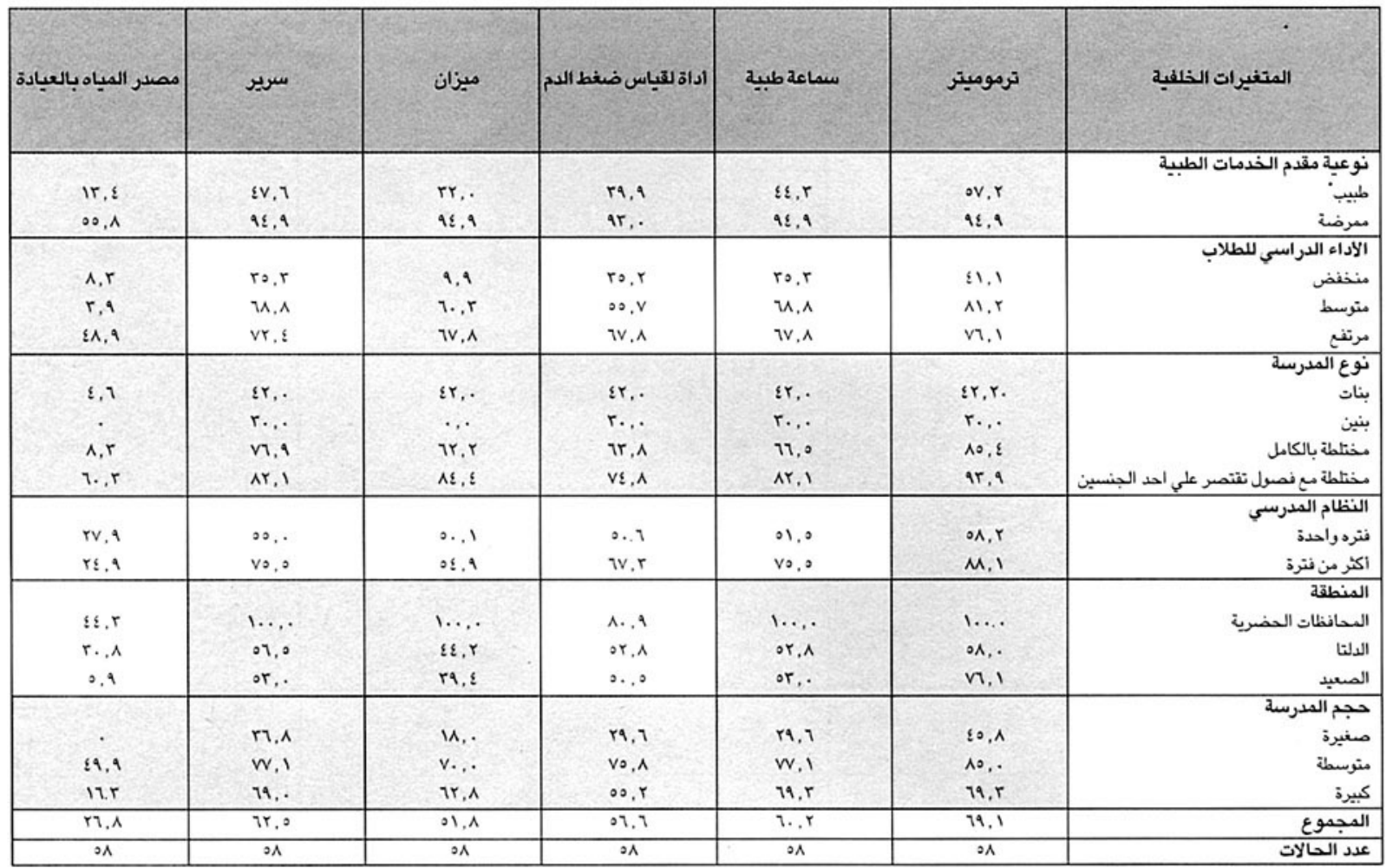




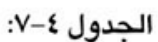

نسب التوزيع المئوية لعبء العمل الواقع علي مقدمي الخدمات الطبية بين المدارس التي تقدم الخدمات الطبية، حسب المتغيرت الخلفية

الفردية والمدرسية

\begin{tabular}{|c|c|c|c|}
\hline ثلاث مدارس او اكثر & مدرستان & مدرسة واحدة & المتغيرات الخلفية \\
\hline $\begin{array}{l}v \varepsilon, 1 \\
r v, q\end{array}$ & $\begin{array}{l}10,1 \\
10,1\end{array}$ & $\begin{array}{l}1 \varepsilon, 0 \\
07, r\end{array}$ & طوعية مقدم الخدمات الطبية \\
\hline $\begin{array}{l}r \cdot, \cdot \\
r v, \varepsilon \\
r 1,9\end{array}$ & $\begin{array}{l}r r, v \\
17, v \\
r, 0\end{array}$ & $\begin{array}{l}r v, r \\
\varepsilon r, \Lambda \\
r o, v\end{array}$ & منفيض الاداء الدراسي للطلاب \\
\hline $\begin{array}{l}u, \cdot \\
\varepsilon \wedge, 1 \\
r 0, v \\
., .\end{array}$ & $\begin{array}{l}11, \varepsilon \\
r, \cdot \\
r, r \\
., .\end{array}$ & $\begin{array}{l}r ., 7 \\
01,9 \\
r r, 1 \\
1 \ldots, .\end{array}$ & 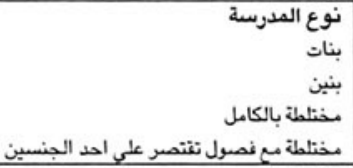 \\
\hline $\begin{array}{l}\leq\{, q \\
\text { or, o }\end{array}$ & $\begin{array}{l}17,1 \\
9,8\end{array}$ & $\begin{array}{l}r q, . \\
r v, i\end{array}$ & فتره واحدة النظام المدرسي \\
\hline $\begin{array}{l}\text { or, } \\
\$ 1,9 \\
\text { oq,r }\end{array}$ & $\begin{array}{l}19,1 \\
1 r, 0 \\
1 r, 1\end{array}$ & $\begin{array}{l}r v, r \\
£ 0, v \\
r v, v\end{array}$ & $\begin{array}{r}\text { المحانظقات الحضرية } \\
\text { الدلتا } \\
\text { المعبد }\end{array}$ \\
\hline $\begin{array}{l}r, 1 \\
r A, 9\end{array}$ & $\begin{array}{l}\wedge, r \\
r ., 0\end{array}$ & $\begin{array}{l}r \Lambda, v \\
0 ., 1\end{array}$ & رضوي \\
\hline $\begin{array}{l}r \cdot r \\
v \cdot r \\
r, r\end{array}$ & $\begin{array}{l}r \Lambda, r \\
r, \cdot \\
r i, r \\
\end{array}$ & $\begin{array}{l}\$ 1,7 \\
r 9,7 \\
\text { or, } 1\end{array}$ & كتيرة المدرسة \\
\hline$\{\wedge$, & ir,v & $r \Lambda, r$ & المجموع \\
\hline
\end{tabular}

الجدول §-1:

نسب التوزيع المئوية لمقدمي الخدمات الطبية الذين يشعرون ان الطلاب يحتاجون لتعلم الوعي الصحي بين المدارس التي تقدم الخدمات الطبية، حسب المتغيرات الخلفية الفردية والفئ المدرسية.

\begin{tabular}{|c|c|c|}
\hline y & نعم & المتغيرات الخلفية \\
\hline $\begin{array}{l}17, . \\
1 ., r\end{array}$ & $\begin{array}{l}\wedge \varepsilon, \cdot \\
\wedge \uparrow, \wedge\end{array}$ & مُبيبية مقدم الخدمات الطبية \\
\hline $\begin{array}{l}r r, r \\
11, \wedge \\
11, v\end{array}$ & $\begin{array}{l}v i, 1 \\
\wedge a, r \\
M, r\end{array}$ & متفوسف \\
\hline $\begin{array}{l}. \\
r v, 1 \\
i r, q \\
1,0\end{array}$ & $\begin{array}{l}41,0 \\
\wedge 1,1 \\
i r, r \\
1 \ldots, .\end{array}$ & 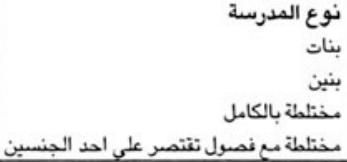 \\
\hline $\begin{array}{l}1 \%, 8 \\
10,7\end{array}$ & $\begin{array}{l}\wedge \uparrow, \mathcal{1} \\
\wedge \varepsilon, \delta\end{array}$ & 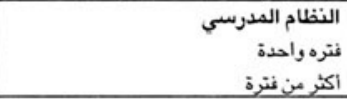 \\
\hline $\begin{array}{l}v, 0 \\
10,1 \\
11, r\end{array}$ & $\begin{array}{l}\text { ar, o } \\
\text { Ar, a } \\
\text { Ar, } 9\end{array}$ & المافنظة الصنات الحضرية \\
\hline $\begin{array}{c}1, \varepsilon \\
r \leqslant, 1\end{array}$ & $\begin{array}{l}9 r, 7 \\
v_{0}, 9\end{array}$ & رضيري (حضري/ريفي) \\
\hline $\begin{array}{l}r £, v \\
i r, T \\
r, .\end{array}$ & $\begin{array}{l}\text { vo,r } \\
\wedge v, \varepsilon \\
\text { qu, . }\end{array}$ & متخم المدرسة \\
\hline $1 \varepsilon, r$ & $\wedge 0, \wedge$ & المجموع \\
\hline
\end{tabular}




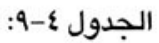

مشاركة مقدمي الخدمات الطبية في التدريب أثناء الخدمة خلال السنتين السابقتين، بين المدارس التي تقدم الخدمات الصحية.

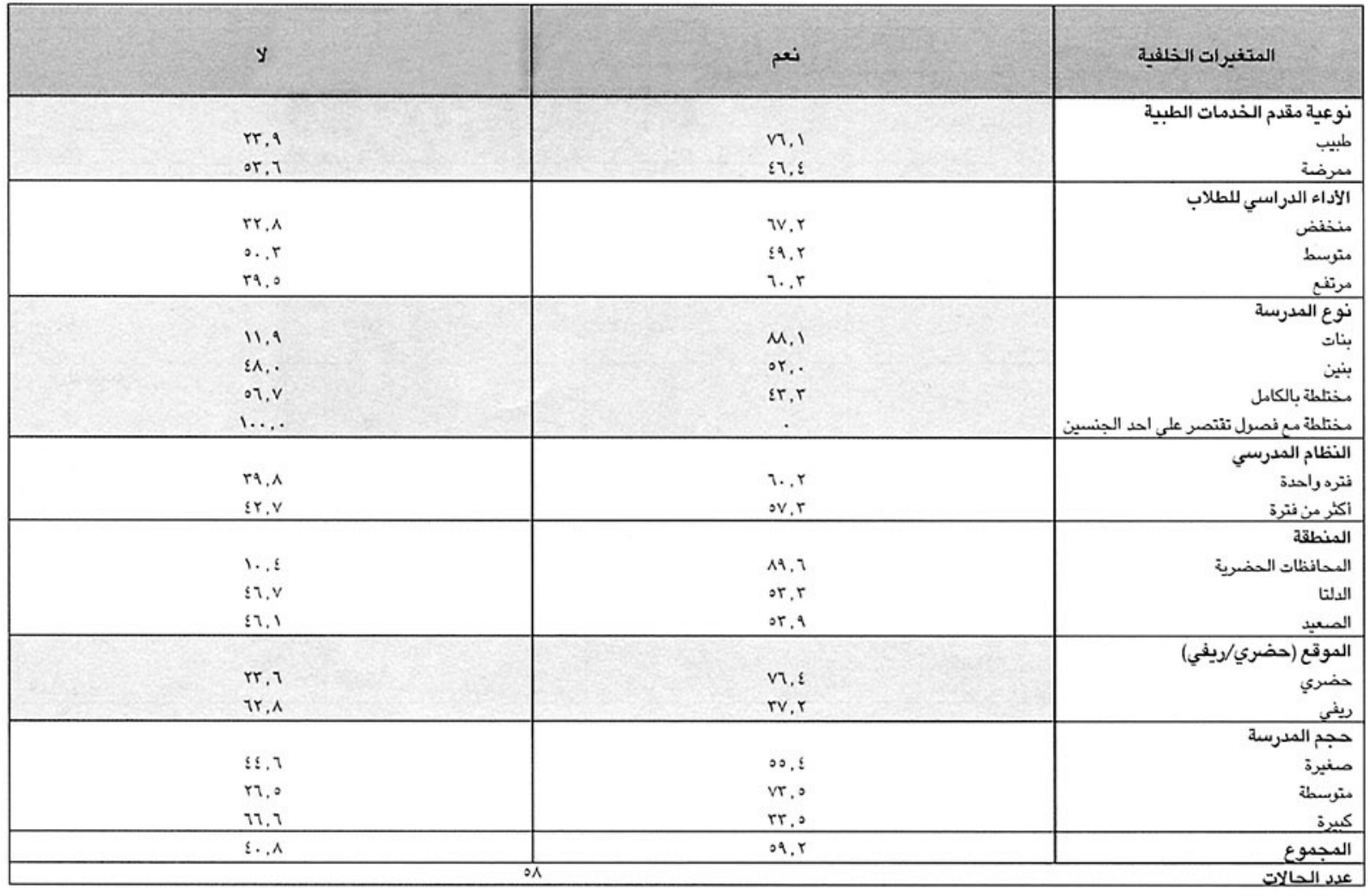

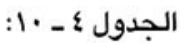
رضنا مقدمي الخدمات الطبية عن واجباتهم ومسئولياتهم، وساعات عملهم، و الدكان المخصص لعملهم، نسب التوزيع المئوية بين المدارس

\begin{tabular}{|c|c|c|c|c|c|c|}
\hline \multicolumn{2}{|c|}{ المكان المخصص للعصل } & \multicolumn{2}{|c|}{ ساعات العمل } & \multicolumn{2}{|c|}{ الواجبات والههام } & \multirow[b]{2}{*}{ المتغيرات الخلفية } \\
\hline |ن عدم الرضا بالكامل & الرضا التام & أو عدم الرضا بالكامل & الرضا التام & |او عدم الرما الرضال باملز & الرضا الدام & \\
\hline $\begin{array}{l}i r, 1 \\
8 r, v\end{array}$ & $\begin{array}{l}A v, q \\
01, r\end{array}$ & $\begin{array}{l}r r .8 \\
\mathrm{u}, \mathrm{r}\end{array}$ & $\begin{array}{r}11.7 \\
\text { A1.v } \\
\end{array}$ & $\begin{array}{l}r 9,8 \\
19,8\end{array}$ & $\begin{array}{l}\text { v.,r } \\
\Lambda ., 1\end{array}$ & طوعيبة مقدم الخدمات الطبية \\
\hline $\begin{array}{l}\lfloor 1.1 \\
5 r . v \\
10 . .\end{array}$ & $\begin{array}{l}\text { or. } 9 \\
\text { ov,r } \\
\text { Ao.. }\end{array}$ & $\begin{array}{l}r \leqslant . q \\
r \wedge, q \\
1 \wedge . .\end{array}$ & $\begin{array}{l}10,1 \\
n, 1 \\
\text { si. . }\end{array}$ & $\begin{array}{l}\qquad 1, . \\
r 0,0 \\
11,9\end{array}$ & $\begin{array}{l}o \leqslant, . \\
v \leqslant, 0 \\
M, 1\end{array}$ & منتوسف \\
\hline $\begin{array}{l}19 . \varepsilon \\
r ., v \\
\varepsilon r .0 \\
r \leqslant . v\end{array}$ & $\begin{array}{l}1, .1 \\
19, r \\
01,0 \\
10, r\end{array}$ & $\begin{array}{l}r 9,1 \\
r .8 \\
19.8 \\
r o, 1\end{array}$ & 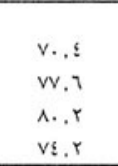 & 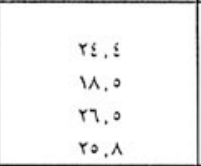 & $\begin{array}{l}\text { vo, } \\
\wedge 1,0 \\
\text { vr.0 } \\
\text { vi,r }\end{array}$ & 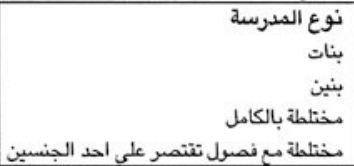 \\
\hline $\begin{array}{l}r v .9 \\
r r .9\end{array}$ & $\begin{array}{l}v r, 1 \\
n \pi, 1 \\
\end{array}$ & $\begin{array}{l}r . .1 \\
r r . .\end{array}$ & $\begin{array}{l}\text { va.q } \\
\text { רv. }\end{array}$ & $\begin{array}{l}r, \wedge \\
r r, A\end{array}$ & $\begin{array}{l}\text { vn.r } \\
n n, r\end{array}$ & 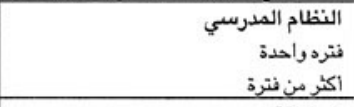 \\
\hline $\begin{array}{l}A, v \\
r A, 0 \\
\varepsilon v, r\end{array}$ & $\begin{array}{l}91, r \\
v 1,0 \\
o r, 8\end{array}$ & $\begin{array}{l}? 1,7 \\
1 \mathrm{i}, 1 \\
r q, \mathrm{r}\end{array}$ & $\begin{array}{l}\text { or. } \\
\text { Ar.q } \\
\text { v., v }\end{array}$ & $\begin{array}{l}\lfloor 9 . . \\
r i, r \\
1 \leqslant .\end{array}$ & 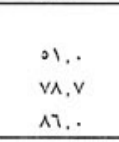 & 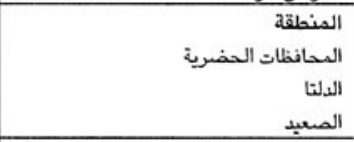 \\
\hline $\begin{array}{l}r .1 \\
\$ 1.7 \\
\end{array}$ & $\begin{array}{l}\mathrm{ve.9} \\
0 \mathrm{x.8}\end{array}$ & $\begin{array}{l}r .1 \\
1 \mathrm{x}, 1\end{array}$ & $\begin{array}{r}19,9 \\
11.9 \\
\end{array}$ & $\begin{array}{l}r \leqslant, \lambda \\
r r, i\end{array}$ & $\begin{array}{l}v_{0, r} \\
w_{1}\end{array}$ & رضئريع (حضري/ريفي) \\
\hline $\begin{array}{l}n \cdot r \\
r v, v \\
r ., r\end{array}$ & $\begin{array}{l}09, v \\
v r, r \\
v a, 1\end{array}$ & $\begin{array}{l}17,9 \\
r ., 5 \\
60,5\end{array}$ & $\begin{array}{l}\text { Ar, } \\
\text { va,r } \\
0 !, 1\end{array}$ & $\begin{array}{l}\mathrm{rV}, 0 \\
11,0 \\
{[0, \mathrm{r}}\end{array}$ & $\begin{array}{l}\text { vr,o } \\
M, 0 \\
o \leqslant .0\end{array}$ & صنوبر الددرسة \\
\hline$r ., r$ & 19.9 & $r \leqslant 9$ & $v_{0}, 1$ & $r r, A$ & $n, r$ & الدجموع \\
\hline
\end{tabular}




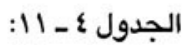
رضا مقدمي الخدمات الطبية عن تفاعلهم مع المعلمين وإدارة المدرسة وأولياء الأمور، نسب التوزيع المئوية بين المدارس التي تقدم الخدمات

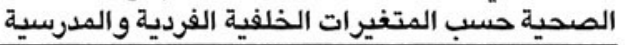

\begin{tabular}{|c|c|c|c|c|}
\hline \multicolumn{2}{|c|}{ التغاعل مع أولياء الأكور } & \multicolumn{2}{|c|}{ التذاعل مع العاملين وإدارة المدرسة } & \multirow[b]{2}{*}{ المتغيرات الخلفية } \\
\hline او عدم الرضا بالكامل & الرضا التام & او عدم الرضل بالكامل & الرضا التام & \\
\hline $\begin{array}{l}\varepsilon 1, r \\
i r, 0\end{array}$ & 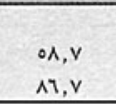 & 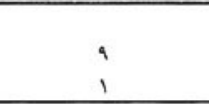 & $\begin{array}{l}91 \\
99\end{array}$ & مبيبية مقية مقدم الخدمات الطبية \\
\hline $\begin{array}{l}r q, 1 \\
19, v \\
r i, r\end{array}$ & $\begin{array}{l}\text { v.,r } \\
\text { A.,r } \\
v_{r, \varepsilon}\end{array}$ & $\begin{array}{l}\dot{r} \\
\dot{r}\end{array}$ & $\begin{array}{l}\text { १i } \\
1 . . \\
\text { ar }\end{array}$ & متوسفض \\
\hline $\begin{array}{l}\varepsilon r, 1 \\
9,1 \\
r \cdot, \lambda \\
.\end{array}$ & $\begin{array}{l}07,9 \\
9 ., 2 \\
v a, r \\
1 . ., .\end{array}$ & $\begin{array}{l}1 . \\
1 \\
. \\
.\end{array}$ & $\begin{array}{l}9 . \\
99 \\
1 . . \\
1 . .\end{array}$ & 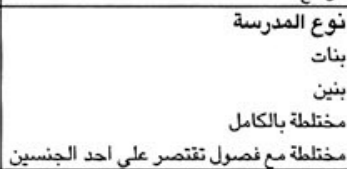 \\
\hline $\begin{array}{l}r ., \wedge \\
11,1\end{array}$ & $\begin{array}{r}79, r \\
\mathrm{Ar}, 9 \\
\end{array}$ & $\begin{array}{l}\mathrm{v} \\
.\end{array}$ & $\begin{array}{l}\text { ar } \\
1 . .\end{array}$ & 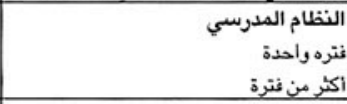 \\
\hline $\begin{array}{l}\varepsilon, r \\
r \varepsilon, \gamma \\
u, 1\end{array}$ & $\begin{array}{l}09, v \\
v_{0}, 8 \\
11,9\end{array}$ & $\begin{array}{l}i . \\
\circ\end{array}$ & $\begin{array}{l}9 . \\
97 \\
1 . .\end{array}$ & المالثافظقات الحضرية \\
\hline $\begin{array}{l}r_{0}, . \\
i r, r\end{array}$ & $\begin{array}{l}10, . \\
\text { Ai, }\end{array}$ & $\hat{\imath}$ & $\begin{array}{l}\text { ar } \\
1 . .\end{array}$ & رضغري (حضري/ريفي) \\
\hline $\begin{array}{l}w, r \\
r, r \\
r, r\end{array}$ & $\begin{array}{l}\wedge 1, \wedge \\
79, \wedge \\
\mathrm{v} \varepsilon, .\end{array}$ & $\begin{array}{l}j \\
\text { is } \\
i \varepsilon\end{array}$ & $\begin{array}{l}1 \ldots \\
91 \\
11\end{array}$ & متغيرة المدرسة \\
\hline$r_{0, \varepsilon}$ & $v \varepsilon, 1$ & $\varepsilon$ & 97 & المجموع \\
\hline & & & & عرد الحالات \\
\hline
\end{tabular}

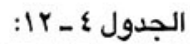
استخدام الخدمات الصحية المدرسية من جانب الطلاب الذين شعروا بالمرض خلال الفصل الدراسي الأول، نسب التوزيع المئوية بين

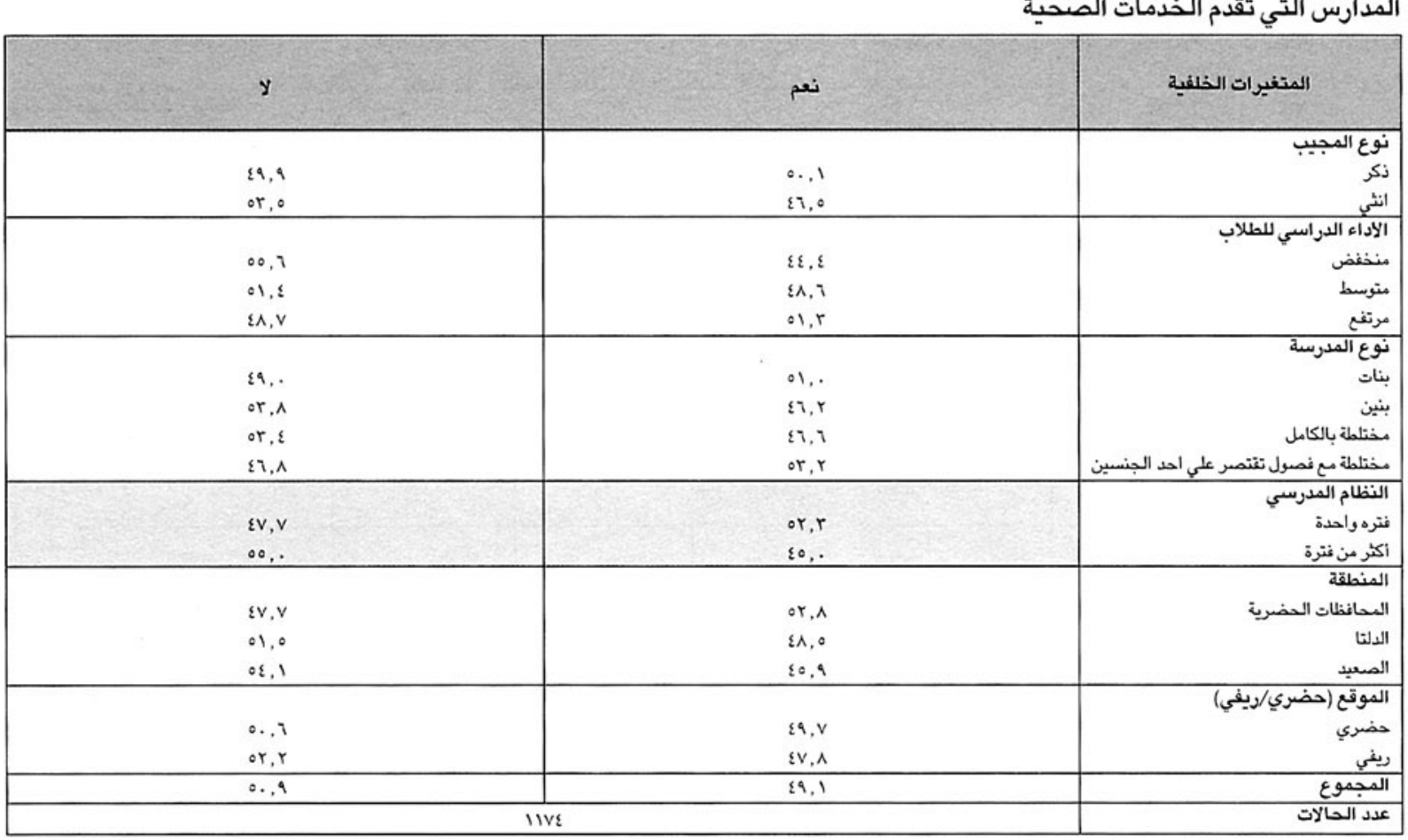




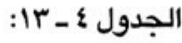

نتيجة استشارة الطلاب لمقدمي الخدمات الطبية في المدرسة، النسبة المئوية بين المدارس التي تقدم الخدمات الصحية حسب المتغيرات الخلفية الفردية والمدرسية.

\begin{tabular}{|c|c|c|c|c|}
\hline لمبيخذ ائيراء & الحمويل المي مركز ميحي & ومف علاج & توفير دواء & المتغيرات الخغلهية \\
\hline $\begin{array}{l}\mid r, r \\
1 \varepsilon, 0\end{array}$ & $\begin{array}{l}r i, q \\
r v, q\end{array}$ & $\begin{array}{l}r \xi, 1 \\
r q, r\end{array}$ & $\begin{array}{l}r r, 1 \\
r, r\end{array}$ & مبيبي ميزة مقدم الخدمات الطبية \\
\hline $\begin{array}{l}r ., . \\
i r, . \\
1 ., v\end{array}$ & $\begin{array}{l}r A, r \\
r i, \Lambda \\
r r, \varepsilon\end{array}$ & $\begin{array}{l}r ., 1 \\
r q, 0 \\
r i, \Lambda\end{array}$ & $\begin{array}{l}r i, 1 \\
r n, 1 \\
r o, r\end{array}$ & منغفض متفر الدراسي للطلاب \\
\hline $\begin{array}{l}9,7 \\
1 r, 1 \\
11,9 \\
r 1, .\end{array}$ & $\begin{array}{l}17,7 \\
r 1,9 \\
r 9 . \\
r r, r\end{array}$ & $\begin{array}{l}r v, v \\
r A, . \\
r r, r \\
r \varepsilon, q\end{array}$ & $\begin{array}{l}m, v \\
m, r \\
r \Lambda, q \\
r, i\end{array}$ & 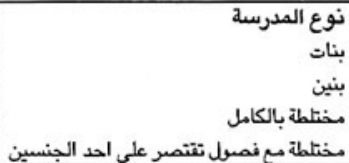 \\
\hline $\begin{array}{l}11, r \\
1 \varepsilon, 9\end{array}$ & $\begin{array}{l}r r, v \\
r r, q\end{array}$ & $\begin{array}{l}r_{Q}, \varepsilon \\
r_{0}, \Lambda\end{array}$ & $\begin{array}{l}r_{0}, 0 \\
r r, 1\end{array}$ & 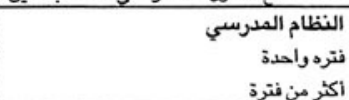 \\
\hline $\begin{array}{l}1 \varepsilon, r \\
1, r \\
1 \varepsilon, r\end{array}$ & $\begin{array}{l}r, 1 \\
11,9 \\
r r, 9\end{array}$ & $\begin{array}{l}r_{0}, 1 \\
r_{v}, 1 \\
r_{0,0}\end{array}$ & $\begin{array}{l}r+., \\
\varepsilon r, 0 \\
r q, q\end{array}$ & المالمافظات الحضرية \\
\hline $\begin{array}{l}11,7 \\
1 v, v\end{array}$ & $\begin{array}{l}r r, \varepsilon \\
r r, 0\end{array}$ & $\begin{array}{l}r r, r \\
r v, r\end{array}$ & $\begin{array}{l}r, \wedge \\
r r, 0\end{array}$ & رفضريع (حضري/ريفي) \\
\hline Ir,A & $r r, r$ & $r r_{1}$ & $r 1,9$ & المجموع \\
\hline \multicolumn{4}{|c|}{$.7 v$} & عدد الحالات \\
\hline
\end{tabular}

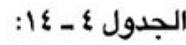
رضا مقدمي الخدمات الطبية عن الحالة الصحية للطلاب، نسب التوزيعا لمئوية بين المدارس التي تقدم الخدمات الصحية حسب المتغيرات الخلفية الفردية والمدرسية الخية عردية

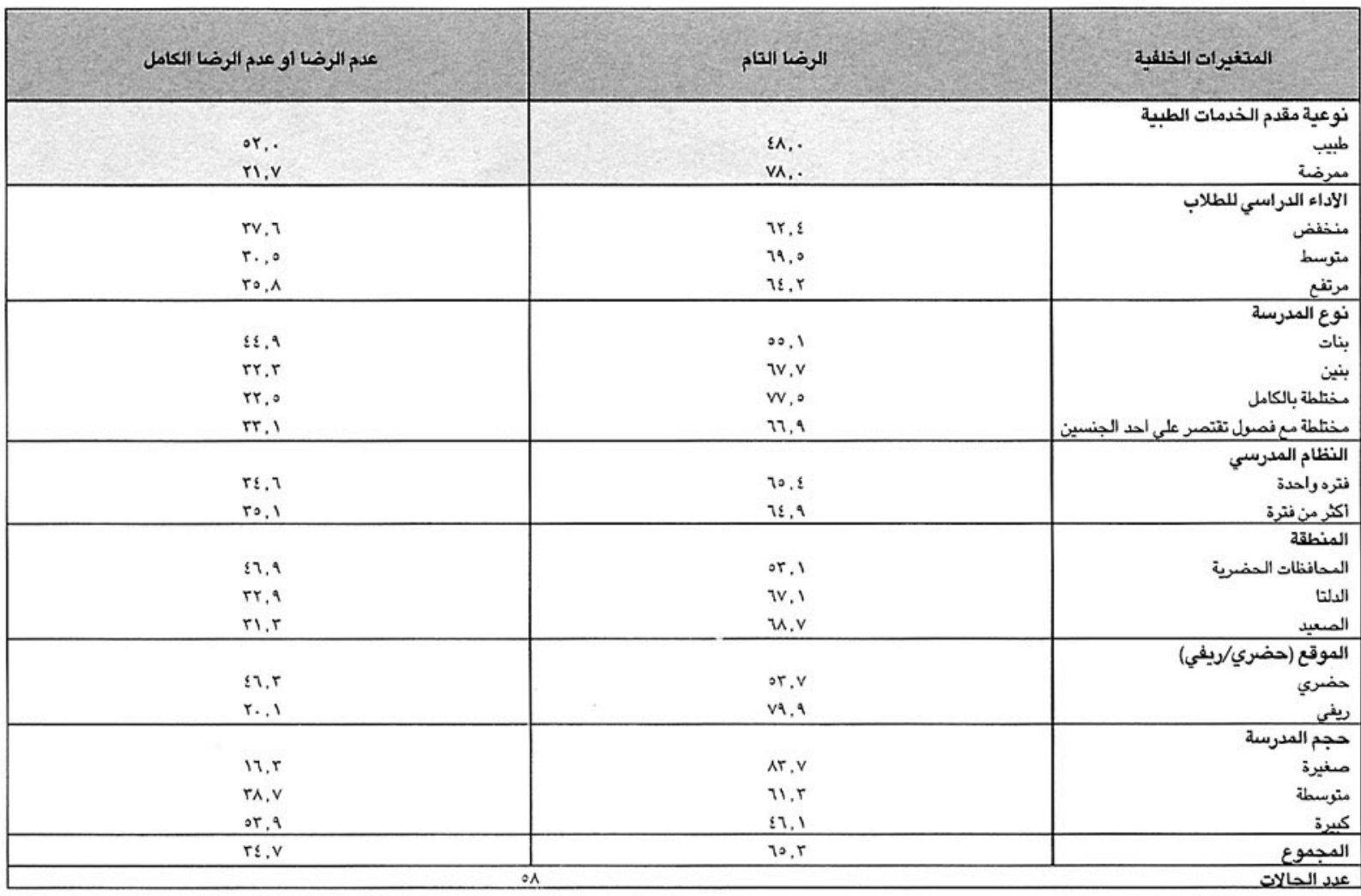




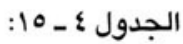

رضا مقدمي الخدمات الطبية عن مستوي النظافة في المدرسة، نسب التوزيع المئوية بين المدارس التي تقدم الخدمات الصحية حسب المتغيرات الخلفية الفردية و المدرسية الطنية

\begin{tabular}{|c|c|c|}
\hline عدم الرضًا أو عدم الرضا بالكامل & الرضا التام & المتغيرات الخلفية \\
\hline $\begin{array}{l}r q, v \\
\varepsilon \wedge, r\end{array}$ & $\begin{array}{l}v,, \varepsilon \\
0,1\end{array}$ & نوكية مقدم الخدهات الطبية \\
\hline $\begin{array}{l}\{0,1 \\
Y A, Y\end{array}$ & $\begin{array}{l}0\{, 4 \\
v 1,1\end{array}$ & منبيبية مقدم الخدمات الطبية \\
\hline $\begin{array}{l}r, \wedge \\
r \wedge, r \\
r \wedge, q\end{array}$ & $\begin{array}{l}i r, r \\
n, v \\
i n, 1\end{array}$ & متخفض الاداء الدراسي للطلاب \\
\hline $\begin{array}{l}\varepsilon \cdot, 9 \\
17,9 \\
r r, 0 \\
91,1\end{array}$ & $\begin{array}{l}09,1 \\
\wedge r, 1 \\
r, 0 \\
\wedge, 9\end{array}$ & 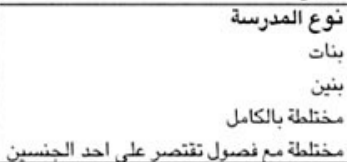 \\
\hline $\begin{array}{l}r r, \wedge \\
\varepsilon, 1\end{array}$ & $\begin{array}{l}7 V, r \\
09,9\end{array}$ & 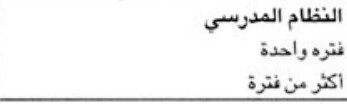 \\
\hline $\begin{array}{l}r r, \cdot \\
r a, \varepsilon \\
r \varepsilon, 0\end{array}$ & $\begin{array}{l}\mathrm{va}, \mathrm{.} \\
1, \mathrm{i} \\
10,0\end{array}$ & الدمائلات الحضرية \\
\hline $\begin{array}{l}r v, 0 \\
r r, q\end{array}$ & $\begin{array}{l}\text { Tr,o } \\
\text { Tw, }\end{array}$ & رضغري (المضري/ريفي) \\
\hline $\begin{array}{l}0, . \\
r \wedge, \wedge \\
\wedge ., \varepsilon\end{array}$ & $\begin{array}{l}90, . \\
18, r \\
19,7\end{array}$ & كنبرة \\
\hline$r 0,0$ & $7 \varepsilon, 0$ & المجموع \\
\hline & & عدد الحالات \\
\hline
\end{tabular}




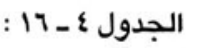
النسبة المئوية لمقدمي الخدمات الطبية في المدارس الذين تلقوا اسئلة من الطلاب حول الصحة العامة و البلوغ والأسئلة الاكثر شيوعا في كل موضوع حسب المتغيرات الخلفية الفردية والمدرسية

\begin{tabular}{|c|c|c|c|c|c|c|c|c|c|}
\hline \multicolumn{2}{|c|}{ الاسثلة الوثر شيوعا حول البلوغ } & \multirow[b]{2}{*}{ |تلقي اسيلة حول البلوغ } & \multicolumn{5}{|c|}{ الاسيلة الكثر شيوعا } & \multirow{2}{*}{ حول الصقي اسئل العامة } & \multirow[b]{2}{*}{ المتغيرات الخلفية } \\
\hline التغيرات البدنية & الدورة الشهرية & & العاطفيه/ التركيز & الغذاء/ التغذية & مشكلات التبول & الامراض الجباب/ & اعراض الامراض & & \\
\hline $\begin{array}{l}8 \\
19 \\
\end{array}$ & $\begin{array}{l}18 \\
19 \\
\end{array}$ & $\begin{array}{l}7 \varepsilon \\
\text { vo } \\
\end{array}$ & r & r. & $\hat{1}$ & r. & $\begin{array}{l}r \Lambda \\
r i\end{array}$ & $\begin{array}{l}n \\
n\end{array}$ & طبيبي \\
\hline $\begin{array}{l}r \varepsilon \\
r r\end{array}$ & $\begin{array}{l}n \\
\varepsilon \varepsilon\end{array}$ & $\begin{array}{l}\text { A. } \\
\text { o. }\end{array}$ & . & ra & $\begin{array}{l}\text { ir } \\
11\end{array}$ & $\begin{array}{l}r_{0} \\
1\end{array}$ & $\begin{array}{l}r A \\
r q\end{array}$ & as & نوكرع المجيب \\
\hline $\begin{array}{l}r \\
r . \\
r a\end{array}$ & $\begin{array}{l}\mathrm{AT} \\
\varepsilon \mathrm{v} \\
\mathrm{u}\end{array}$ & $\begin{array}{l}17 \\
07 \\
11\end{array}$ & $\begin{array}{l}\text { ir } \\
\text { ro }\end{array}$ & is & $\begin{array}{c}r 1 \\
19 \\
\varepsilon \\
\end{array}$ & $\begin{array}{l}r 9 \\
19 \\
11\end{array}$ & $\begin{array}{l}\text { ov } \\
\text { ro } \\
\text { ri }\end{array}$ & $\begin{array}{l}\text { Ni } \\
\text { vr } \\
\text { vo }\end{array}$ & منفراء \\
\hline $\begin{array}{l}\varepsilon \varepsilon \\
\text { iv } \\
\text { ro } \\
\text {. }\end{array}$ & $\begin{array}{l}v \varepsilon \\
9 \varepsilon \\
1 \ldots\end{array}$ & $\begin{array}{l}v \varepsilon \\
i 1 \\
9 \varepsilon \\
1 . . \\
\end{array}$ & $\begin{array}{l}r q \\
\wedge \\
r\end{array}$ & $\begin{array}{l}r \\
\cdot \\
\cdot \\
\cdot\end{array}$ & $\begin{array}{l}8 \\
\text { iv } \\
19 \\
r .\end{array}$ & $\begin{array}{l}\varepsilon \\
r r \\
r \\
.\end{array}$ & $\begin{array}{l}\text { ro } \\
r r \\
07 \\
.\end{array}$ & $\begin{array}{l}v 1 \\
v_{0} \\
1 . . \\
r r\end{array}$ & 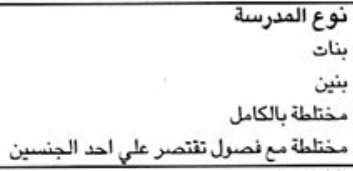 \\
\hline $\begin{array}{l}r 1 \\
1 \varepsilon \\
\end{array}$ & $\begin{array}{l}\mathrm{vr} \\
\mathrm{ov}\end{array}$ & $\begin{array}{l}\text { vo } \\
\text { ir }\end{array}$ & $\begin{array}{l}19 \\
1 .\end{array}$ & ! & $\begin{array}{l}17 \\
1 .\end{array}$ & tr & $\begin{array}{l}r \wedge \\
r \Lambda\end{array}$ & $\begin{array}{l}\mathrm{vN} \\
\mathrm{vi}\end{array}$ & 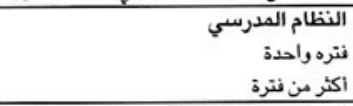 \\
\hline $\begin{array}{l}\text { ro } \\
r r \\
r v\end{array}$ & $\begin{array}{ll}\wedge . \\
\varepsilon 1 \\
\Lambda .\end{array}$ & $\begin{array}{l}\wedge \varepsilon \\
\therefore . \\
\wedge\end{array}$ & $\begin{array}{l}\text { ir } \\
\text { ir }\end{array}$ & ir & $\begin{array}{l}\text { ro } \\
a \\
\end{array}$ & $\begin{array}{l}r 1 \\
18 \\
19\end{array}$ & $\begin{array}{l}\varepsilon \\
r \\
r \\
r\end{array}$ & $\begin{array}{l}\mathrm{v} \varepsilon \\
\wedge 1 \\
10\end{array}$ & منفنضف \\
\hline $\begin{array}{l}\llbracket \varepsilon \\
r 9 \\
10\end{array}$ & $\begin{array}{l}\mathrm{Tv} \\
v \varepsilon \\
\varepsilon \mathrm{T}\end{array}$ & $\begin{array}{l}\mathrm{uv} \\
\mathrm{v} \varepsilon \\
\mathrm{ir}\end{array}$ & $\begin{array}{l}11 \\
r r \\
v\end{array}$ & i. & $\begin{array}{l}11 \\
1 \varepsilon \\
\text { ir }\end{array}$ & $\begin{array}{l}\cdot \\
r \varepsilon \\
i \varepsilon\end{array}$ & $\begin{array}{l}\varepsilon . \\
\varepsilon 1 \\
1 \varepsilon\end{array}$ & $\begin{array}{l}\varepsilon \varepsilon \\
M \\
i \varepsilon\end{array}$ & الصنافظات الحضرية \\
\hline rA & $\mathrm{Tv}$ & $\mathrm{v}$. & 17 & 9 & ir & in & $r A$ & n & المجموع \\
\hline 07 & 07 & 87 & $0 \Lambda$ & os & $2 \Lambda$ & $0 \wedge$ & $0 \Lambda$ & ${ }^{0 \Lambda}$ & عدد الحالات \\
\hline
\end{tabular}


الجدول ع _ V إ: النهبة المئوية للمعلمين والاخصائيين الاجتماعيين الذين يؤيدون توفير المعلومات المتصلة بالنضوج للطلاب في المدرسة حسب المتغيرات الخلفية الفردية والمدرسية

\begin{tabular}{|c|c|c|c|}
\hline 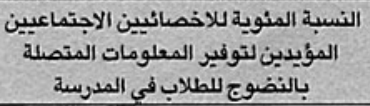 & 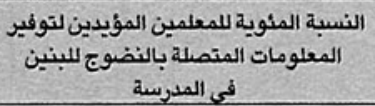 & 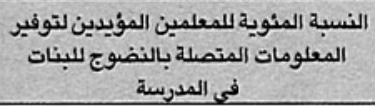 & الصتغيرات الخلفية \\
\hline $\begin{array}{l}\text { \$1 } \\
\text { Qr }\end{array}$ & $\begin{array}{l}\text { Ar } \\
\text { \$1 }\end{array}$ & 9. & نوكرع المجيب \\
\hline $\begin{array}{l}\text { qv } \\
\text { ar } \\
\text { Av }\end{array}$ & $\begin{array}{l}\text { ar } \\
\text { Av } \\
\text { Ar }\end{array}$ & $\begin{array}{l}4 r \\
\wedge 9 \\
4 .\end{array}$ & منفظف الاد الدراسي للطلاب \\
\hline $\begin{array}{l}49 \\
A \varepsilon \\
1 .\end{array}$ & $\begin{array}{l}\Delta 9 \\
\Delta r \\
9 \varepsilon\end{array}$ & $\begin{array}{l}91 \\
19 \\
9 r\end{array}$ & المانطقة المانظات الحضرية الصعبد \\
\hline QY & $M$ & 91 & المجموع \\
\hline No & โA. & $\varepsilon \wedge$. & عدد الحالات \\
\hline
\end{tabular}




\section{الجداول}

\section{الفصل الخامس}

الأبعاد المتصلة بالنوع فى البيئة المدرسية 
الجدول 0 ـ 1: النسبة المئوية لمديري المدارس الذين يعتقدون ان بعض المواد أصعب بالنسبة لأحد الجنسين أكثر من الآخر، حسب المتغيرات الخلفية الفردية والمدرسية

\begin{tabular}{|c|c|c|c|c|c|c|c|c|c|c|}
\hline \multicolumn{2}{|c|}{ المواد الاجتمبة اليعة أصعب } & \multicolumn{2}{|c|}{ بالنسبة الصيب... } & \multicolumn{2}{|c|}{ باليشبية الي.... } & \multicolumn{2}{|c|}{ بالنسبة اليية أصعب... } & \multicolumn{2}{|c|}{ بعض المواد أصعب } & \multirow[t]{2}{*}{ المتغيرات الخلفية } \\
\hline البنات & البنين & البنات & البنين & البنات & الينين & البنات & البنين & البنات & البينين & \\
\hline . & $\begin{array}{l}r_{1} \\
r_{0}\end{array}$ & $\begin{array}{l}r 7 \\
11\end{array}$ & ir & $\begin{array}{c}r i \\
\mathrm{r}\end{array}$ & $\dot{r}$ & r & $\begin{array}{l}r_{1} \\
\text { ro }\end{array}$ & $\begin{array}{l}m \\
11\end{array}$ & $\begin{array}{l}r_{1} \\
r_{0}\end{array}$ & نو انوع الدجيب \\
\hline . & $\begin{array}{l}i r \\
\vdots \\
r \Lambda\end{array}$ & $\begin{array}{l}\text { iv } \\
\text { iv }\end{array}$ & $\begin{array}{l}A \\
r r \\
i \varepsilon\end{array}$ & $\begin{array}{l}\text { i } \\
\text { iv }\end{array}$ & $\begin{array}{l}r r \\
r r \\
i \varepsilon\end{array}$ & : & $\begin{array}{l}i r \\
r \\
r i\end{array}$ & $\begin{array}{l}\text { iv } \\
\text { iv }\end{array}$ & $\begin{array}{l}r \mu \\
21 \\
r 1\end{array}$ & 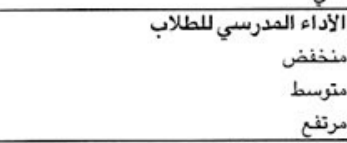 \\
\hline $\begin{array}{l}\dot{r} \\
\dot{.} \\
\dot{.}\end{array}$ & $\begin{array}{l}r . \\
\dot{1} \\
i\end{array}$ & $\begin{array}{l}r r \\
i r \\
a\end{array}$ & $\begin{array}{l}\text { ir } \\
\text { rv } \\
\text { r }\end{array}$ & $\begin{array}{l}r r \\
\hat{\imath} \\
\varepsilon \\
q\end{array}$ & $\begin{array}{l}\text { ir } \\
\text { \&i } \\
\text { rv }\end{array}$ & $\dot{.}$ & $\begin{array}{l}\text { ro } \\
\text { \& } \\
a\end{array}$ & $\begin{array}{l}r r \\
\wedge \\
i r \\
a\end{array}$ & $\begin{array}{l}\text { ro } \\
0 \\
0 .\end{array}$ & 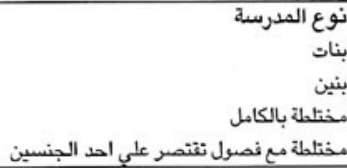 \\
\hline . & $\begin{array}{l}11 \\
\varepsilon \wedge\end{array}$ & $\begin{array}{l}1 . \\
r i\end{array}$ & $\begin{array}{l}17 \\
\text { ro }\end{array}$ & $\frac{1}{r r}$ & $\begin{array}{l}\text { ry } \\
\text { ro }\end{array}$ & $\dot{\varepsilon}$ & $\begin{array}{l}r . \\
\varepsilon r\end{array}$ & $\begin{array}{l}1 . \\
r r\end{array}$ & $\begin{array}{l}\text { rq } \\
\text { \&A }\end{array}$ & 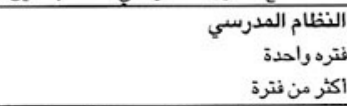 \\
\hline$\dot{.}$ & $\begin{array}{l}\text { in } \\
\text { ro } \\
\text { ri }\end{array}$ & $\begin{array}{l}11 \\
11 \\
1\end{array}$ & $\begin{array}{l}1 \varepsilon \\
1 \varepsilon \\
r A\end{array}$ & $\begin{array}{c}r \\
r \\
1 \\
1\end{array}$ & $\begin{array}{l}r o \\
i \varepsilon \\
r \Lambda\end{array}$ & ; & $\begin{array}{l}\text { in } \\
r_{1} \\
r_{0}\end{array}$ & $\begin{array}{c}11 \\
r 1 \\
1\end{array}$ & $\begin{array}{l}r_{1} \\
r_{0} \\
r_{0}\end{array}$ & 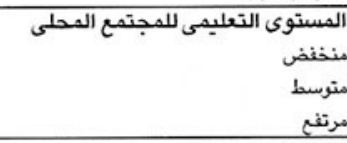 \\
\hline$\dot{.}$ & $\begin{array}{l}\text { ir } \\
\text { ri }\end{array}$ & iv & in & ri & ri & $\dot{r}$ & $\begin{array}{l}\text { r } \\
\text { rr } \\
\text { ra }\end{array}$ & rv & $\begin{array}{l}\dot{\varepsilon} \\
\dot{r a}\end{array}$ & 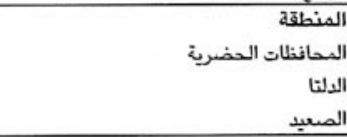 \\
\hline. & $\mathrm{rv}$ & $1 \varepsilon$ & 11 & 11 & ro & $r$ & $r 7$ & $1 \varepsilon$ & $r_{0}$ & المجموع \\
\hline $\mathrm{V} \varepsilon$ & $\mathrm{v} \varepsilon$ & $v \varepsilon$ & $\mathrm{V} \varepsilon$ & $\mathrm{v} \varepsilon$ & $v \varepsilon$ & $v \varepsilon$ & $\mathrm{V} \varepsilon$ & $\mathrm{v} \varepsilon$ & $\mathrm{V} \varepsilon$ & عدد الحالات \\
\hline
\end{tabular}




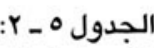

النسبة المئوية للمعلمين الذين يعتقدون ان بعض المواد اصعب بالنسبة لاحد الجنسين اكثر من الاخر، حسب المتغيرات الخلفية الفردية والمدرسية

\begin{tabular}{|c|c|c|c|c|c|c|c|c|c|c|c|c|}
\hline \multicolumn{2}{|c|}{ المواد الاجنسبة اليعية أصعب } & \multicolumn{2}{|c|}{ بالنسبة اليعب... } & \multicolumn{2}{|c|}{ بالنسبةالي...* } & \multicolumn{2}{|c|}{ اللغة الانجليزية أصعب الئ... } & \multicolumn{2}{|c|}{ اللغالنسبة العيبة أصعب } & \multicolumn{2}{|c|}{ بالنسبة اليعب.. } & \multirow[t]{2}{*}{ المتغيرات الخلفية } \\
\hline البنات & البنين & البنات & البنين & البنات & البنين & البنات & البنين & البنات & البنين & البنات & البنين & \\
\hline $\begin{array}{l}17 \\
17\end{array}$ & $\begin{array}{l}\text { ra } \\
\text { rr }\end{array}$ & $\begin{array}{l}\text { rA } \\
\text { in }\end{array}$ & $\begin{array}{l}10 \\
r \varepsilon\end{array}$ & $\begin{array}{l}r r \\
10\end{array}$ & riq & i & $\begin{array}{l}\varepsilon \wedge \\
r r\end{array}$ & $\begin{array}{l}r \varepsilon \\
\text { ir }\end{array}$ & $\begin{array}{l}r_{0} \\
r r\end{array}$ & $\begin{array}{l}\text { r. } \\
\text { ir }\end{array}$ & $\begin{array}{l}r A \\
r v\end{array}$ & نون انوع المجيب \\
\hline $\begin{array}{l}i r \\
r \wedge \\
0\end{array}$ & $\begin{array}{l}r_{0} \\
r r \\
r \varepsilon\end{array}$ & $\begin{array}{l}r \varepsilon \\
r_{0} \\
i k\end{array}$ & $\begin{array}{l}\text { ro } \\
9 \\
10\end{array}$ & $\begin{array}{l}i r \\
\pi \\
1 .\end{array}$ & $\begin{array}{l}\varepsilon . \\
i \varepsilon \\
r \wedge\end{array}$ & i. & $\begin{array}{l}\varepsilon v \\
r_{0} \\
r r\end{array}$ & $\begin{array}{l}r \wedge \\
r .\end{array}$ & $\begin{array}{l}0 . \\
r 7 \\
17\end{array}$ & $\begin{array}{l}\text { iv } \\
\text { rv } \\
\text { v }\end{array}$ & $\begin{array}{l}\varepsilon \\
r r \\
r \varepsilon\end{array}$ & 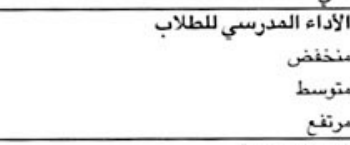 \\
\hline $\begin{array}{l}\text { iv } \\
\text { ir } \\
1 \\
\text { r }\end{array}$ & $\begin{array}{l}19 \\
\text { ro } \\
\varepsilon v \\
9\end{array}$ & $\begin{array}{l}r i \\
r q \\
i r \\
r .\end{array}$ & $\begin{array}{l}1 \varepsilon \\
r 1 \\
\vdots 1 \\
.\end{array}$ & $\begin{array}{l}4 \\
\text { ro } \\
\text { ris }\end{array}$ & $\begin{array}{l}r 9 \\
1 \\
\vdots 1 \\
\text { ir }\end{array}$ & i & $\begin{array}{l}r v \\
r r \\
\varepsilon r \\
i \varepsilon\end{array}$ & $\begin{array}{l}\mathrm{m} \\
1 \\
14 \\
10\end{array}$ & $\begin{array}{l}1 . \\
r \varepsilon \\
r_{0} \\
0 \varepsilon\end{array}$ & $\begin{array}{l}10 \\
\text { ir } \\
9 \\
r \varepsilon\end{array}$ & $\begin{array}{l}r 1 \\
r \varepsilon \\
\varepsilon r \\
r .\end{array}$ & نينات بنوع الهدرسة \\
\hline $\begin{array}{l}\text { Is } \\
\text { r. }\end{array}$ & $\begin{array}{l}\text { iv } \\
\text { sr }\end{array}$ & $\begin{array}{l}19 \\
r 1\end{array}$ & $\begin{array}{l}r 1 \\
17 \\
\end{array}$ & $\begin{array}{l}r . \\
\text { v }\end{array}$ & $\begin{array}{l}r r \\
r r\end{array}$ & i & $\begin{array}{l}\text { rv } \\
\text { or }\end{array}$ & $\begin{array}{c}9 \\
r 7\end{array}$ & $\begin{array}{l}r 7 \\
\text { ir }\end{array}$ & $\begin{array}{l}\text { ir } \\
\text { iv }\end{array}$ & $\begin{array}{l}\text { ro } \\
\text { ri }\end{array}$ & 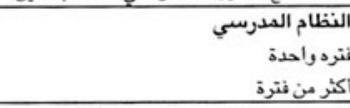 \\
\hline $\begin{array}{l}i n \\
i . \\
r i\end{array}$ & $\begin{array}{l}r y \\
\varepsilon . \\
1 .\end{array}$ & $\begin{array}{l}r \\
4 \\
i s\end{array}$ & $\begin{array}{c}r r \\
i \\
r .\end{array}$ & $\begin{array}{l}r 1 \\
i r \\
11\end{array}$ & $\begin{array}{l}r r \\
r 9 \\
19\end{array}$ & $\varepsilon$ & $\begin{array}{l}\varepsilon 1 \\
0 . \\
1 \varepsilon\end{array}$ & $\begin{array}{c}r \\
\varepsilon \\
r\end{array}$ & $\begin{array}{l}\varepsilon 1 \\
r q \\
1 .\end{array}$ & $\begin{array}{c}\text { iv } \\
\hat{1} \\
19\end{array}$ & $\begin{array}{l}r q \\
r . \\
\text { is }\end{array}$ & يرتخفض المستوى التعليمى للمجتمع المحلى \\
\hline $\begin{array}{l}r . \\
i . \\
i \varepsilon\end{array}$ & $\begin{array}{l}\circ \\
r r \\
r\end{array}$ & $\begin{array}{l}09 \\
10 \\
18\end{array}$ & $\begin{array}{l}\text { i } \\
\text { iv } \\
\text { rr }\end{array}$ & $\begin{array}{l}7 \\
17 \\
10\end{array}$ & $\begin{array}{l}r r \\
r . \\
r o\end{array}$ & $\dot{r}$ & $\begin{array}{l}0 \\
\text { i1 } \\
\text { ir }\end{array}$ & $\begin{array}{l}\text { rv } \\
1 \\
\text { rr }\end{array}$ & ra & $\begin{array}{l}\text { re } \\
1 . \\
\text { ir }\end{array}$ & $\begin{array}{l}v \\
r \\
r_{0}\end{array}$ & 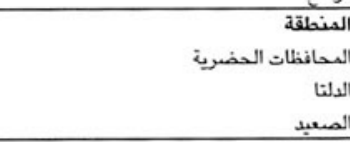 \\
\hline 10 & rv & $r \varepsilon$ & 19 & $1 \varepsilon$ & $r 7$ & $r$ & $r 7$ & iv & rV & Iह & rv & الدجموع \\
\hline \multicolumn{2}{|c|}{$w$} & \multicolumn{2}{|c|}{11} & \multicolumn{2}{|c|}{$* * v_{0}$} & \multicolumn{2}{|c|}{ va } & \multicolumn{2}{|c|}{ A. } & \multicolumn{2}{|c|}{$+r a r$} & عدد الحالات \\
\hline
\end{tabular}

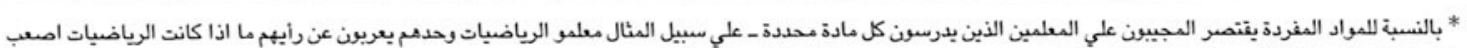

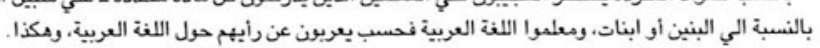

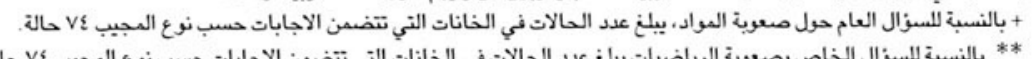




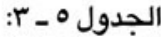

النسبة المئوية لمديري المدارس الذين يتفقون مع سياسة وزارة التعليم الخاصة بدروس الاتتصاد المنزلي و النزاعة، ويرون ان طلاب المرحلة الاعدادية يتعلمون افضل في المدارس المختلطة حسب المتغيرات الخلفية الفردية والفية المدرسية

\begin{tabular}{|c|c|c|}
\hline 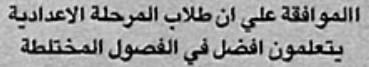 & 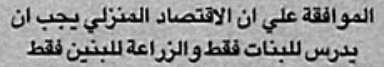 & المتغيرات الخلقية \\
\hline$a_{01}^{9}$ & ?ר & نونى انوي \\
\hline $\begin{array}{l}\text { i. } \\
\text { o. } \\
\text { ir }\end{array}$ & $\begin{array}{l}\text { ir } \\
00 \\
0 .\end{array}$ & متخفض الاداء الدراسي للطلاب \\
\hline $\begin{array}{l}\text { ir } \\
\text { oq } \\
\mathrm{v} \\
\mathrm{T}\end{array}$ & $\begin{array}{l}r q \\
5 \\
r 7 \\
r v\end{array}$ & 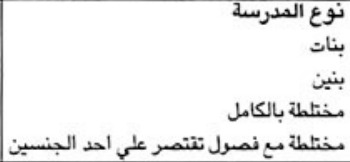 \\
\hline $\begin{array}{l}\text { ?v } \\
\text { os }\end{array}$ & $\begin{array}{l}r 1 \\
0 \leq\end{array}$ & 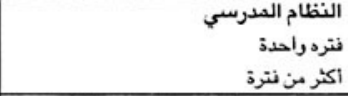 \\
\hline $\begin{array}{l}\text { ir } \\
\text { o. } \\
\text { ra }\end{array}$ & $\begin{array}{l}\text { rv } \\
\text { or } \\
\text { ro }\end{array}$ & منفنض المستوى التعليمى للمجتمع المحلى \\
\hline $\begin{array}{l}r r \\
07 \\
\vdots 7\end{array}$ & $\begin{array}{l}r r \\
\vdots 0 \\
r r\end{array}$ & المالمافظظات الحضرية \\
\hline 21 & ra & المجدوع \\
\hline vo & vo & عدد الحالات \\
\hline
\end{tabular}

النسبة المئوية لمديري المدارس الذين يتفقون مع سياسة وزارة التعليم الخاصة بدروس الاقتصاد المنزلي والزراعة ويرون ان طلاب المرحلة

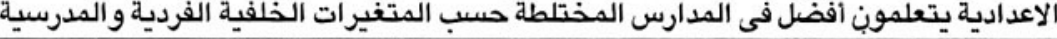

\begin{tabular}{|c|c|c|c|c|}
\hline \multicolumn{2}{|c|}{ تفضيل التدريس للـ... } & \multirow{2}{*}{ 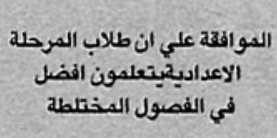 } & \multirow{2}{*}{ 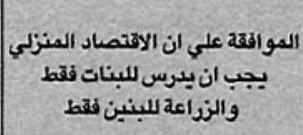 } & \multirow[b]{2}{*}{ المتغيراتالخلفيه } \\
\hline بنات & بنين & & & \\
\hline $\begin{array}{l}79 \\
\text { rA }\end{array}$ & $\begin{array}{l}1 \\
r 9\end{array}$ & $\begin{array}{l}r r \\
r A\end{array}$ & $\begin{array}{l}\text { ON } \\
\text { sv }\end{array}$ & نوني النئ \\
\hline $\begin{array}{l}r . \\
\$ 1 \\
\vdots 9\end{array}$ & $\begin{array}{l}\text { rv } \\
\text { in } \\
19\end{array}$ & $\begin{array}{l}\text { ¿o } \\
\text { rq } \\
\text { rA }\end{array}$ & $\begin{array}{l}\varepsilon . \\
\$ \wedge \\
\circ 9\end{array}$ & منففض الاداء الدراسي للطلاب \\
\hline $\begin{array}{l}\text { oq } \\
\text { ir } \\
\text { ra } \\
\text { or }\end{array}$ & $\begin{array}{l}\text { ir } \\
\text { of } \\
v \\
\text { ir }\end{array}$ & $\begin{array}{l}\text { ro } \\
\text { rr } \\
\text { or } \\
\text { ra }\end{array}$ & $\begin{array}{l}0 \leqslant \\
0 \leqslant \\
0 \wedge \\
01\end{array}$ & بنتين \\
\hline $\begin{array}{l}\varepsilon \gamma \\
\mathrm{rV}\end{array}$ & $\begin{array}{l}\text { ro } \\
\text { ir }\end{array}$ & $\begin{array}{l}r q \\
r 7\end{array}$ & $\begin{array}{l}01 \\
05\end{array}$ & 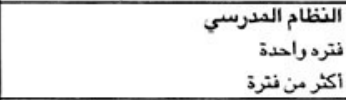 \\
\hline $\begin{array}{l}\text { rA } \\
0 \xi \\
\varepsilon r\end{array}$ & $\begin{array}{l}r 1 \\
i 1 \\
r r\end{array}$ & $\begin{array}{l}\varepsilon r \\
r \\
r \varepsilon\end{array}$ & $\begin{array}{l}\leqq \mathrm{V} \\
\text { or } \\
\text { ov }\end{array}$ & هنتفضف \\
\hline $\begin{array}{l}\varepsilon r \\
\text { or } \\
17\end{array}$ & $\begin{array}{l}\text { ri } \\
\text { ir } \\
\text { iv }\end{array}$ & $\begin{array}{l}\text { ir } \\
\text { ro } \\
\text { ir }\end{array}$ & $\begin{array}{l}\text { ir } \\
01 \\
\varepsilon r\end{array}$ & الملتافظظات الحضرية \\
\hline थr & $r$. & $r r$ & or & المجدوع \\
\hline \multicolumn{2}{|c|}{ **rav } & $+\{\Lambda$. & *!vq & عدد الحالات \\
\hline
\end{tabular}

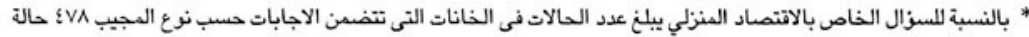

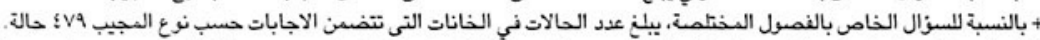

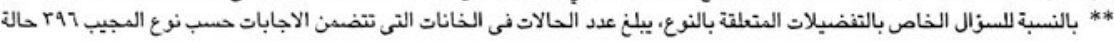




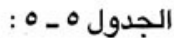

مواقف مديرى المدارس من المشاركة في الألعاب الرياضية: النسبة المئوية لمن يعتقدون ان المشاركة في النشاط الرياضي مهمة لكلا الجنسين

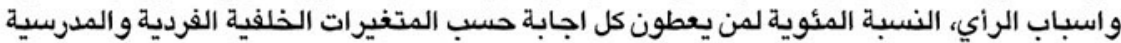

\begin{tabular}{|c|c|c|c|c|c|c|c|c|c|}
\hline \multirow{2}{*}{ 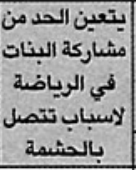 } & \multicolumn{2}{|c|}{ الرتماعية بالنسبة لاسباب } & \multicolumn{2}{|c|}{ الرياضوية مهمة لاسباب ثلقائيم/ } & \multicolumn{2}{|c|}{ الرياضة مهمة لاسباب بدنية } & \multicolumn{2}{|c|}{ المشاركة المنتظمة في الالكعاب } & \multirow[t]{2}{*}{ المتغيرات الخلفية } \\
\hline & 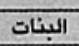 & البنين & | البنات & البنين & 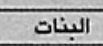 & البنين & 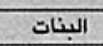 & البنين & \\
\hline ia & $\begin{array}{l}\text { I } \\
\varepsilon \mathrm{V}\end{array}$ & $\begin{array}{l}00 \\
\varepsilon v\end{array}$ & $\begin{array}{l}00 \\
0 \wedge\end{array}$ & $\begin{array}{l}00 \\
\text { v. }\end{array}$ & $\begin{array}{l}1 . . \\
w\end{array}$ & $\begin{array}{l}1 . . \\
\mu\end{array}$ & $\begin{array}{l}1 \ldots \\
\wedge .\end{array}$ & $\begin{array}{l}1 \ldots \\
1 \ldots\end{array}$ & نو نوع المجيب \\
\hline $\begin{array}{l}r \varepsilon \\
1 \varepsilon \\
1 .\end{array}$ & $\begin{array}{l}\varepsilon \\
\varepsilon \\
1 \varepsilon\end{array}$ & $\begin{array}{l}\text { or } \\
\text { \&r } \\
\text { \&A }\end{array}$ & $\begin{array}{l}\text { vr } \\
\text { iq } \\
\text { ra }\end{array}$ & $\begin{array}{l}\text { vi } \\
91 \\
\text { \&1 }\end{array}$ & $\begin{array}{l}\text { A. } \\
\text { Ar } \\
\text { va }\end{array}$ & $\begin{array}{l}79 \\
97 \\
1 . .\end{array}$ & $\begin{array}{l}\text { vi } \\
\text { At } \\
\text { q. }\end{array}$ & $\begin{array}{l}1 . . \\
1 \cdots \\
1 . .\end{array}$ & متففض الاداء الدراسي للطلاب \\
\hline$\varepsilon$ & ra & $\llbracket \varepsilon$ & ov & 10 & va & 1... & 97 & 1.. & بنات المدرسة \\
\hline 10 & $\varepsilon$ & 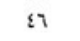 & $\circ v$ & 19 & 10 & 1.. & ^o & 1.. & بنين \\
\hline ri & of & o. & $1 \varepsilon$ & n & Ar & Ar & va & I.. & مختلطة بالكامل \\
\hline rv & $\circ$ & $\infty$ & $\llbracket 7$ & $7 \varepsilon$ & iv & n & $1 \varepsilon$ & 1.. & مختلطلة بع نصول تقنصر علي احد الجنسين \\
\hline $\begin{array}{l}r . \\
\wedge\end{array}$ & $\begin{array}{l}\text { rv } \\
v \varepsilon\end{array}$ & $\begin{array}{l}\& r \\
\text { ox }\end{array}$ & $\begin{array}{l}09 \\
0 \&\end{array}$ & $\begin{array}{l}19 \\
7 \mathrm{~V}\end{array}$ & $\begin{array}{l}\mathrm{WV} \\
\mathrm{AV}\end{array}$ & $\begin{array}{l}\wedge r \\
1 \ldots\end{array}$ & $\begin{array}{l}\Lambda . \\
\mu\end{array}$ & $\begin{array}{l}1 . . \\
1 . .\end{array}$ & 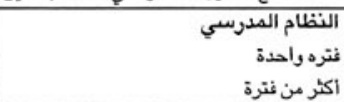 \\
\hline $\begin{array}{l}r \\
\varepsilon \\
1\end{array}$ & $\begin{array}{l}\varepsilon . \\
\text { ov } \\
\text { o. }\end{array}$ & $\begin{array}{l}\infty \\
\varepsilon 1 \\
r o\end{array}$ & $\begin{array}{l}\text { i. } \\
\text { ov } \\
\text { or }\end{array}$ & $\begin{array}{l}\text { ir } \\
\text { va } \\
\text { o9 }\end{array}$ & $\begin{array}{l}\text { vv } \\
\text { vr } \\
\text { q }\end{array}$ & $\begin{array}{l}n r \\
97 \\
1 . .\end{array}$ & $\begin{array}{l}\text { Tr } \\
\text { ११ } \\
\text { १ะ }\end{array}$ & $\begin{array}{l}1 . . \\
1 \cdots \\
1 . .\end{array}$ & 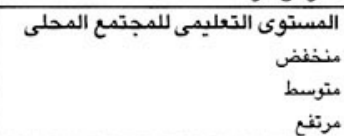 \\
\hline . & 07 & 07 & 91 & ir & 1.. & 1.. & 1.. & 1.. & المحافظقات الحضرية \\
\hline 17 & 17 & 01 & ¿9 & .0 & ^. & 1... & $\wedge \varepsilon$ & $1 .$. & الدلتا \\
\hline ri & rr & $\varepsilon r$ & $u$ & $\wedge 9$ & n & v. & va & $1 .$. & الصعيد \\
\hline 17 & §9 & 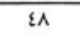 & ov & $\mathrm{u}$ & va & 19 & Ar & I... & المجموع \\
\hline vo & $v_{0}$ & vo & vo & vo & $v_{0}$ & vo & vo & $v_{0}$ & عدد الحالات \\
\hline
\end{tabular}

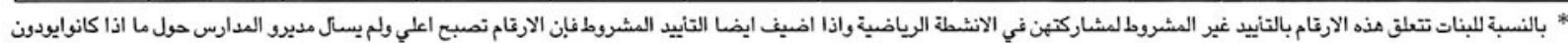
غرض شروط على ممارسة البنين للرياضة.

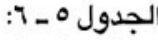

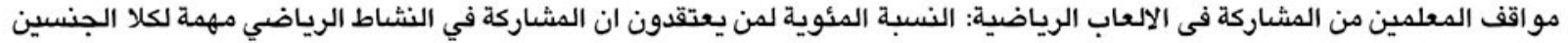

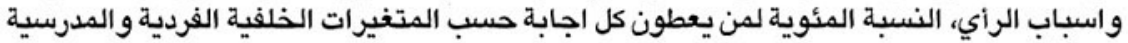

\begin{tabular}{|c|c|c|c|c|c|c|c|c|c|}
\hline \multirow{2}{*}{ 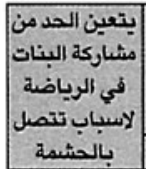 } & \multicolumn{2}{|c|}{ الجتماعية بالنسبة مهية لانباب... } & \multicolumn{2}{|c|}{ 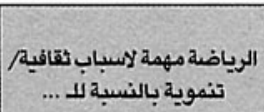 } & \multicolumn{2}{|c|}{ الرياضة مهمة لاسباب بنانية } & \multicolumn{2}{|c|}{ المشاركة المنتظمة في الالعاب مهمة للـ... الرياض } & \multirow[t]{2}{*}{ المتغيرات الخلفية } \\
\hline & البنات & البينين & البنات & البنين & البنات & البنين & البنات & البنين & \\
\hline $\begin{array}{l}\mathrm{rq} \\
\mathrm{rq}\end{array}$ & $\begin{array}{l}9 \\
18\end{array}$ & $\begin{array}{l}\text { ؛0 } \\
\text { \& }\end{array}$ & $\begin{array}{l}r r \\
r v\end{array}$ & $\begin{array}{l}0 . \\
\text { ro }\end{array}$ & $\begin{array}{l}\text { vi } \\
\text { or }\end{array}$ & $\begin{array}{l}19 \\
10\end{array}$ & $\begin{array}{l}\text { VV } \\
\text { ON }\end{array}$ & $\begin{array}{l}91 \\
91\end{array}$ & نون انثى المجيب \\
\hline $\begin{array}{l}r \\
r a \\
r .\end{array}$ & $\begin{array}{l}9 \\
9 \\
\text { iv }\end{array}$ & $\begin{array}{l}\text { rA } \\
\text { rr } \\
0 .\end{array}$ & $\begin{array}{l}\text { rr } \\
\text { rr } \\
\text { ro }\end{array}$ & $\begin{array}{l}\text { TE } \\
7 . \\
07\end{array}$ & $\begin{array}{l}\text { or } \\
11 \\
\text { ir }\end{array}$ & $\begin{array}{l}v . \\
r r \\
r r\end{array}$ & $\begin{array}{l}\text { i. } \\
\text { ir } \\
\text { v. }\end{array}$ & $\begin{array}{l}99 \\
91 \\
91\end{array}$ & هنغ منفض الاد الدراسي للطلاب \\
\hline $\begin{array}{l}r A \\
r r \\
r A \\
\varepsilon 0\end{array}$ & $\begin{array}{l}1 . \\
\text { rr } \\
10\end{array}$ & $\begin{array}{l}0 . \\
\varepsilon v \\
r Y \\
\varepsilon q\end{array}$ & $\begin{array}{l}r r \\
\varepsilon r \\
\varepsilon \\
r \wedge\end{array}$ & $\begin{array}{l}\varepsilon v \\
V r \\
11 \\
10\end{array}$ & $\begin{array}{l}\text { u } \\
\text { ov } \\
\text { op } \\
\varepsilon \varepsilon\end{array}$ & $\begin{array}{l}7 . \\
17 \\
v 7 \\
w\end{array}$ & $\begin{array}{l}\text { vr } \\
\text { iv } \\
\text { ir } \\
\text { or }\end{array}$ & $\begin{array}{l}9 \mathrm{~A} \\
9 \mathrm{v} \\
1 . \\
1 \ldots\end{array}$ & 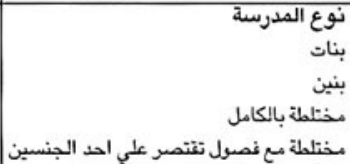 \\
\hline $\begin{array}{l}r r \\
r\end{array}$ & $\begin{array}{l}17 \\
\wedge\end{array}$ & $\begin{array}{l}\varepsilon \wedge \\
r_{0}\end{array}$ & $\begin{array}{l}\mathrm{rA} \\
\mathrm{rr}\end{array}$ & $\begin{array}{l}09 \\
0 A\end{array}$ & $\begin{array}{l}0 \wedge \\
7 \varepsilon\end{array}$ & i & 70 & $\begin{array}{l}91 \\
99\end{array}$ & أكثر من فنترة المدرة \\
\hline $\begin{array}{l}\varepsilon 1 \\
\varepsilon r \\
i 1\end{array}$ & $\begin{array}{l}1 . \\
10 \\
\text { ir }\end{array}$ & $\begin{array}{l}r A \\
\varepsilon r \\
\varepsilon A\end{array}$ & $\begin{array}{l}m \\
r \\
r o\end{array}$ & $\begin{array}{l}\text { ir } \\
7 . \\
00\end{array}$ & $\begin{array}{l}\varepsilon 9 \\
71 \\
v .\end{array}$ & $\begin{array}{l}\text { v. } \\
\text { io } \\
\text { iv }\end{array}$ & $\begin{array}{l}\text { ov } \\
\text { ir } \\
\text { va }\end{array}$ & $\begin{array}{l}99 \\
99 \\
97\end{array}$ & هنغ هنفض \\
\hline $\begin{array}{l}11 \\
\varepsilon r \\
r q\end{array}$ & $\begin{array}{l}\text { ir } \\
\text { ir } \\
\text { ir }\end{array}$ & $\begin{array}{l}\text { or } \\
\text { \& } \\
\text { ra }\end{array}$ & $\begin{array}{l}\text { ro } \\
\text { rA } \\
r r\end{array}$ & $\begin{array}{l}0 . \\
\text { ir } \\
\text { oq }\end{array}$ & $\begin{array}{l}v \wedge \\
\circ q \\
\varepsilon V\end{array}$ & $\begin{array}{l}19 \\
61 \\
09\end{array}$ & $\begin{array}{l}\text { Ar } \\
\text { il } \\
\text { r. }\end{array}$ & $\begin{array}{l}91 \\
99 \\
91\end{array}$ & المالدافظلات الحضرية \\
\hline$r r$ & ir & $\varepsilon r$ & $r 7$ & 09 & 7. & IV & $7 \pi$ & 91 & المجموع \\
\hline \&A. & $\varepsilon \wedge$. & $\varepsilon \wedge$. & $\varepsilon \wedge$. & $\varepsilon \wedge$. & $\sum \wedge$. & $\{\wedge$. & \{^. & $\varepsilon \wedge$. & عدد الحالات \\
\hline
\end{tabular}

* بالنسبة للبنات تتعلق هذه الارتام بالتأييد غير المشروط لمشاركتين في الانشطة الرياضية واذا اضيف ايضا التأييد المشروط فابن الارقام تصبح اعلي.

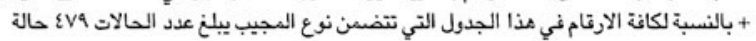


الجدول ه V V

آراء مديري المدارس حوله النول المستوي الملائم من التعليم لكل من البنين والبنات: النسبة المئوية لمن يعطون كل اجابة حسب المتغيرات الخلفية

الفردية والمدريسية العدارسي

\begin{tabular}{|c|c|c|c|c|c|c|c|c|}
\hline \multicolumn{4}{|c|}{ الي أي حد يتعين ان تواصل الفتاة تعليمهاء } & \multicolumn{4}{|c|}{ الي اي حد بتعين ان يواصل الفتي تعليمه؟ } & \multirow[b]{2}{*}{ المتغيرات الخلفية } \\
\hline حد يستطيعي اتصي & دراسات عليا & جامعي & ثانوي & حد يستطيعي اتصي & دراسات عليا & جامعي & ثانوي & \\
\hline 14 & . & $\Delta r$ & . & rV & רז & TV & . & نوع المجيب \\
\hline " & r. & .9 & १ & iv & ro & « & "1 & ذكر \\
\hline 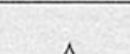 & $r$. & $v_{r}$ & . & \{ & $r s$ & $\mathrm{vr}$ & . & الالداء الدراسي للطلاب \\
\hline . & rq & ir & 1. & ir & ro & $\llbracket$ & a & متوسط \\
\hline ro & $\mathrm{v}$ & o\& & If & m & ro & ri & in & مرنفغ \\
\hline & & & & & & & & نوع المدرسة \\
\hline rv & $1 \varepsilon$ & 09 & . & rr & rA & ra & . & بنات \\
\hline if & r & $7 \varepsilon$ & . & . & ri & ir & $\wedge$ & بنين \\
\hline . & If & vi & If & "1 & $1 \varepsilon$ & 11 & If & مختلطة بالكامل م \\
\hline 9 & tr & $\mathrm{r}$ & tr & rv & rר & in & is & مختلطة مع فصول تتنتصر علي احد الجنسين \\
\hline & & & & & & & & النظام الددرسي \\
\hline If & iv & 18 & 1 & $\mathrm{~m}$ & rr & $\llbracket 9$ & $\varepsilon$ & نترد واحدة \\
\hline$\wedge$ & iv & ox & iv & $\varepsilon$ & ra & ra & iv & أكثر من فنترة \\
\hline & & & & & & & & المستوى التعليدى للمجتمع المحلى \\
\hline$v$ & $1 \varepsilon$ & va & $\cdot$ & i. & 18 & vr & r & منفضض \\
\hline in & ro & \& $r$ & I! & ro & \&r & in & 18 & متوسط \\
\hline ir & ir & 70 & ir & rr & rr & $\llbracket$ & 11 & 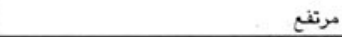 \\
\hline & & & & & & & & المنطقة \\
\hline rr & . & $\mathrm{ve}$ & . & rr & 11 & 07 & . & الححافظات الحضرية \\
\hline ir & ri & ะ & 10 & in & ra & rs & 10 & الدلتا \\
\hline 11 & $1:$ & vo & . & 10 & 19 & ir & ؛ & الصعيد \\
\hline ir & in & $\pi$ & 9 & 19 & tr & @ & 9 & المجموع \\
\hline \multicolumn{4}{|c|}{ vo } & \multicolumn{4}{|c|}{ vo } & عدد الحالات \\
\hline
\end{tabular}

الجدول • ـ ^ : اراء المعلمين حول المستوى الملائم من التعليم لكل من البنين و البنات: النسبة المئوية لمن يعطون كل اجابة حسب المتغيرات الخلفية الفردية والمدرسية المعنية

\begin{tabular}{|c|c|c|c|c|c|c|c|c|}
\hline \multicolumn{4}{|c|}{ الي أي حد يتعين ان تواصل الفتاة تعليمها ** } & \multicolumn{4}{|c|}{ الي اي حد بتعين ان يواصل الفتي تعليمهه } & \multirow[b]{2}{*}{ المتغيرات الخلفية } \\
\hline حديستطبعي & دراسات علبيا & جامعي & ثانوي أو اقل & حد يِيتطبعي الصي & لر اسات عليا & جامعي & ثانوي أو أقل & \\
\hline $\begin{array}{l}r r \\
r r\end{array}$ & $\begin{array}{l}\text { If } \\
\text { r. }\end{array}$ & $\begin{array}{l}09 \\
81\end{array}$ & il & $\begin{array}{l}r r \\
r .\end{array}$ & $\begin{array}{l}18 \\
r 9\end{array}$ & $\begin{array}{l}\text { or } \\
\text { rA }\end{array}$ & $\begin{array}{l}r \\
\varepsilon\end{array}$ & نوني \\
\hline $\begin{array}{l}\text { ri } \\
\text { ro } \\
r r\end{array}$ & $\begin{array}{l}r 1 \\
1 . \\
r r\end{array}$ & $\begin{array}{l}\text { ध1 } \\
01 \\
\text { \&9 }\end{array}$ & $\begin{array}{l}11 \\
9 \\
v\end{array}$ & $\begin{array}{l}r q \\
r q \\
r r\end{array}$ & $\begin{array}{l}r . \\
\text { ir } \\
r i\end{array}$ & $\begin{array}{l}\text { rv } \\
\text { or } \\
\text { \&1 }\end{array}$ & $\vdots$ & 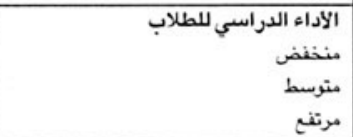 \\
\hline $\begin{array}{l}\text { ra } \\
1 \\
\text { ri } \\
\text { ir }\end{array}$ & $\begin{array}{l}11 \\
r 7 \\
10 \\
r .\end{array}$ & $\begin{array}{l}\text { or } \\
\text { or } \\
\text { o. } \\
\text { \&o }\end{array}$ & $\begin{array}{l}v \\
\dot{r} \\
r \\
r r\end{array}$ & $\begin{array}{l}8 . \\
1 . \\
r i \\
r r\end{array}$ & $\begin{array}{l}\text { ir } \\
\varepsilon 1 \\
r i \\
r A\end{array}$ & $\begin{array}{l}\varepsilon r \\
\varepsilon v \\
r \wedge \\
\varepsilon 1\end{array}$ & $\begin{array}{l}r \\
r \\
r \\
r\end{array}$ & بنات بنتين \\
\hline $\begin{array}{l}r T \\
r r\end{array}$ & $\begin{array}{l}\text { r1 } \\
10\end{array}$ & $\begin{array}{l}81 \\
07\end{array}$ & a & $\begin{array}{l}\text { ri } \\
\text { ra }\end{array}$ & $\begin{array}{l}\text { rv } \\
\text { iv }\end{array}$ & $\begin{array}{l}\text { ra } \\
\text { o. }\end{array}$ & $\begin{array}{l}r \\
\vdots\end{array}$ & 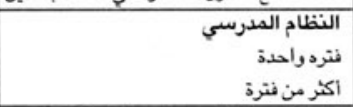 \\
\hline $\begin{array}{l}r r \\
r v \\
i n\end{array}$ & $\begin{array}{l}r r \\
\text { ir } \\
r r\end{array}$ & $\begin{array}{l}\text { @o } \\
\text { op } \\
\text { or }\end{array}$ & $\begin{array}{l}11 \\
1 \\
v\end{array}$ & $\begin{array}{l}r 1 \\
r r \\
r i\end{array}$ & $\begin{array}{l}\text { ri } \\
17 \\
\text { ro }\end{array}$ & $\begin{array}{l}\text { ri } \\
0 . \\
\text { \&r }\end{array}$ & $\begin{array}{l}r \\
r \\
\vdots\end{array}$ & متخفض متوى التعليمى للمجتمع المحلى \\
\hline $\begin{array}{l}\text { in } \\
r . \\
r r\end{array}$ & $\begin{array}{l}\text { r1 } \\
\text { iv } \\
19\end{array}$ & $\begin{array}{l}\because \varepsilon \\
\because 0 \\
\& .\end{array}$ & $\hat{\imath}$ & $\begin{array}{l}r_{0} \\
\text { ra } \\
r_{9}\end{array}$ & $\begin{array}{l}r r \\
r r \\
r r\end{array}$ & $\begin{array}{l}\varepsilon v \\
\text { ri }\end{array}$ & $\begin{array}{l}1 \\
r \\
r\end{array}$ & 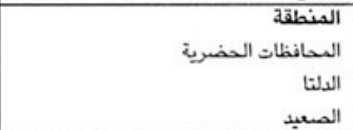 \\
\hline$r r$ & 11 & 01 & $\wedge$ & $r$ & $r T$ & \&r & $r$ & المجدوع \\
\hline «A. & ؛ی. & ๕A. & $\lfloor\Lambda$. & ؛ิ. & ؛A. & ؛ิ. & $+\lfloor\hat{\Lambda}$. & عدد الحالات \\
\hline
\end{tabular}

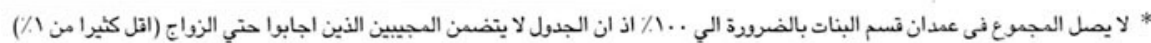

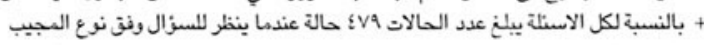


الجدول 0ـ

مو اتف الطلاب حول المستوي الملائم من التعليم لكل من البنين والبنات: النسبة المئوية لمن يعطون كل اجابة حسب المتغيرات الخلفية

الفردية والمدرسية

\begin{tabular}{|c|c|c|c|c|c|c|}
\hline \multicolumn{3}{|c|}{ الي أي حد يتعين ان تواصل الفتاة تعلبمها؟* } & \multicolumn{3}{|c|}{ الي اي حد يتعين ان يواصل الفتي تعليمه؟ } & \multirow[b]{2}{*}{ المتغيرات الخلفية } \\
\hline دراسات عليا & 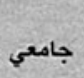 & ثانوي او اقل & دراسات عليا & 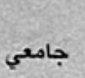 & ثانوي او القل & \\
\hline $\begin{array}{l}\mathrm{Ar} \\
\mathrm{ir}\end{array}$ & $\begin{array}{l}11 \\
17\end{array}$ & r. & $\begin{array}{l}\text { Av } \\
91\end{array}$ & $\hat{\imath}$ & $\varepsilon$ & نوني \\
\hline $\begin{array}{l}11 \\
\text { vi } \\
\text { Ar }\end{array}$ & $\begin{array}{l}18 \\
10 \\
11\end{array}$ & $\begin{array}{l}\text { rr } \\
\text { ir } \\
1\end{array}$ & $\begin{array}{l}\text { AV } \\
M \\
91\end{array}$ & $\hat{i}$ & $\begin{array}{l}1 \\
\varepsilon \\
r\end{array}$ & 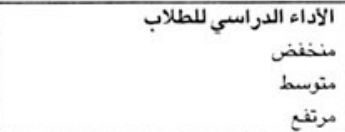 \\
\hline $\begin{array}{l}A \varepsilon \\
i v \\
i r \\
i \varepsilon\end{array}$ & $\begin{array}{l}\text { ir } \\
\text { iv } \\
\text { is } \\
1 .\end{array}$ & $\begin{array}{l}\varepsilon \\
1 \varepsilon \\
r r \\
r r\end{array}$ & $\begin{array}{l}M \\
M r \\
M \\
M T\end{array}$ & $\begin{array}{l}\hat{i} \\
i \\
i\end{array}$ & $\vdots$ & 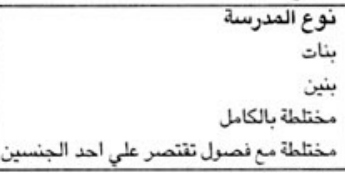 \\
\hline $\begin{array}{l}\mathrm{va} \\
11\end{array}$ & $\begin{array}{l}\text { ir } \\
10\end{array}$ & $\hat{i A}$ & $\begin{array}{l}91 \\
\text { AV }\end{array}$ & $\begin{array}{l}1 \\
1 \\
\end{array}$ & $\begin{array}{l}r \\
\varepsilon \\
\end{array}$ & 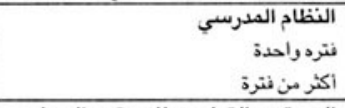 \\
\hline $\begin{array}{l}\text { oq } \\
\text { vo } \\
\text { va }\end{array}$ & $\begin{array}{l}17 \\
11 \\
18\end{array}$ & $\begin{array}{l}\text { rs } \\
1 . \\
i\end{array}$ & $\begin{array}{l}\text { 17. } \\
9 . \\
9 .\end{array}$ & $\begin{array}{l}v \\
1 \\
\wedge\end{array}$ & $\begin{array}{l}r \\
r \\
r\end{array}$ & 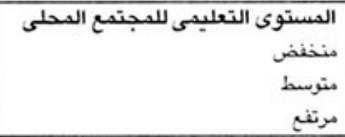 \\
\hline $\begin{array}{l}\text { ir } \\
\text { va } \\
\text { ov }\end{array}$ & $\begin{array}{l}\text { ir } \\
\text { il } \\
\text { iv }\end{array}$ & $\begin{array}{l}r \\
1 . \\
r \varepsilon\end{array}$ & $\begin{array}{l}19 \\
91 \\
11\end{array}$ & $\begin{array}{l}i \\
\vdots \\
1\end{array}$ & $\begin{array}{l}r \\
r \\
0\end{array}$ & الصالمافظات الحضرية \\
\hline r & ir & ir & 19 & $\mathrm{v}$ & $r$ & المجموع \\
\hline \multicolumn{3}{|c|}{$r \leqq 9 r$} & & Y!AY & & عدد الحالات \\
\hline
\end{tabular}

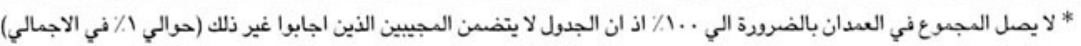

جدول 0 - ·1:

مواقف مديري المدارس حول مزايا التعليم للبنين : النسبة المئوية لمن يعطون كل اجابة حسب المتغيرات الخلفية الفردية المدرسية

\begin{tabular}{|c|c|c|c|c|c|c|c|}
\hline مكاند مالية & ندونجا يحتنئي & اكتساب مكانة & 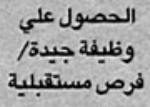 & ان يصبح ابا & مثقلا مبدعا & اكتساب مهارات & المتغيرات الخلفية \\
\hline $\begin{array}{l}r 7 \\
\vdots r\end{array}$ & $\begin{array}{l}r v \\
r i\end{array}$ & $\begin{array}{l}\vdots 1 \\
11\end{array}$ & i & $\begin{array}{c}1 \\
19\end{array}$ & $\begin{array}{l}7 \varepsilon \\
77\end{array}$ & iq & نوكر انثي \\
\hline 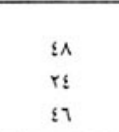 & $\begin{array}{l}r q \\
\vdots \\
r 1\end{array}$ & $\begin{array}{l}r . \\
r q \\
\text { ra }\end{array}$ & $\begin{array}{l}\text { is } \\
\text { is } \\
\text { in }\end{array}$ & $\begin{array}{l}\text { is } \\
\text { iv }\end{array}$ & $\begin{array}{l}1 \varepsilon \\
\text { rr } \\
\text { ro }\end{array}$ & $\begin{array}{l}i r \\
15 \\
r 1\end{array}$ & متخفض الأد الدراسي للطلاب \\
\hline $\begin{array}{l}\mathrm{rr} \\
10 \\
\text { or } \\
7 \varepsilon\end{array}$ & $\begin{array}{l}r A \\
r i \\
r q \\
r\end{array}$ & $\begin{array}{l}\text { or } \\
r 1 \\
11 \\
1 \varepsilon\end{array}$ & $\begin{array}{l}r . \\
\hat{r} \\
r .\end{array}$ & $\begin{array}{l}9 \\
r 9 \\
11 \\
11\end{array}$ & $\begin{array}{l}\lfloor \\
\vdots 1 \\
r 7 \\
r y\end{array}$ & $\begin{array}{l}i r \\
r 1 \\
11 \\
r\end{array}$ & 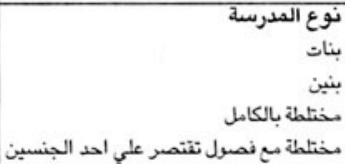 \\
\hline ؛ & $\begin{array}{l}\text { ra } \\
\text { ra }\end{array}$ & $\begin{array}{l}\text { ro } \\
\text { r. }\end{array}$ & $\begin{array}{l}\text { ro } \\
\text { ir }\end{array}$ & rs & $\begin{array}{l}r v \\
\vdots 1\end{array}$ & r. & 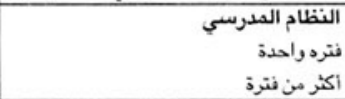 \\
\hline $\begin{array}{l}00 \\
r 1 \\
r o\end{array}$ & $\begin{array}{l}\text { iv } \\
r A \\
\vdots \mathrm{v}\end{array}$ & $\begin{array}{l}r r \\
\vdots \wedge \\
r q\end{array}$ & $\begin{array}{l}\text { or } \\
\text { iv } \\
\text { i }\end{array}$ & $\begin{array}{l}\text { r. } \\
\text { iv } \\
\text { ir }\end{array}$ & $\begin{array}{l}0 . \\
r r \\
r o\end{array}$ & $\begin{array}{l}r . \\
i s \\
i k\end{array}$ & منتخفض المستوى التعليمى للمجتمع الدحلى \\
\hline or & $\begin{array}{l}5 \\
r 1 \\
r a\end{array}$ & $\begin{array}{l}11 \\
r v \\
r 7\end{array}$ & $\begin{array}{l}11 \\
\text { ir } \\
0 \varepsilon\end{array}$ & $\begin{array}{l}r r \\
11 \\
r 1\end{array}$ & $\begin{array}{l}r \Lambda \\
r r \\
0 .\end{array}$ & $\begin{array}{l}11 \\
r 1 \\
v\end{array}$ & الصحافظلات الحضرية الصنائ \\
\hline$\$$ & ri & $r !$ & rv & iv & \&. & 17 & المجموع \\
\hline$v_{0}$ & vo & $v_{0}$ & $v_{0}$ & vo & vo & vo & عدد الحالات \\
\hline
\end{tabular}


الجدول • ـ 11:

مواقف مديري المدارس حول مزايا التعليم للبنات: النسبة المئوية لمن يعطون كل اجابة حسب المتغيرات الخلفية الفردية والمدرسية

\begin{tabular}{|c|c|c|c|c|c|c|c|c|}
\hline الفضل للمرصول & مكانه مالية علي & 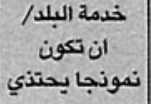 & اكتساب اجكانة & ورفيفة جيدةل علية & ان انسبيح & مثقفة/ مبدعه & |كتساب مهارات & المتغيرات الخلفية \\
\hline $\begin{array}{c}9 \\
17\end{array}$ & $i$. & 9 & $i$ & $\begin{array}{l}00 \\
r .\end{array}$ & $\begin{array}{l}v r \\
07\end{array}$ & $\begin{array}{l}r v \\
r r\end{array}$ & iv & نونى المجيب \\
\hline $\begin{array}{l}17 \\
11 \\
11\end{array}$ & $\begin{array}{c}\varepsilon \\
r r \\
r\end{array}$ & $\begin{array}{l}r_{1} \\
\vdots 1 \\
r_{0}\end{array}$ & $\begin{array}{l}\hat{1} \\
\stackrel{1}{11}\end{array}$ & $\begin{array}{l}\text { ro } \\
\text { rs } \\
\text { s }\end{array}$ & $\begin{array}{l}07 \\
\text { 15 } \\
\text { ov }\end{array}$ & $\begin{array}{l}\varepsilon \varepsilon \\
\text { If } \\
\text { IV }\end{array}$ & $\begin{array}{l}\text { ir } \\
\text { ir } \\
\text { is }\end{array}$ & منغفض \\
\hline $\begin{array}{l}\text { ir } \\
v \\
\text { ro } \\
\text { a }\end{array}$ & $\begin{array}{c}\text { ir } \\
1 \\
10 \\
.\end{array}$ & $\begin{array}{l}r q \\
r i \\
r \\
r\end{array}$ & $\begin{array}{l}r y \\
\wedge \\
\vdots \\
.\end{array}$ & $\begin{array}{l}51 \\
10 \\
r q \\
51\end{array}$ & $\begin{array}{l}\varepsilon 1 \\
\text { w } \\
\text { ov } \\
\text { vr }\end{array}$ & $\begin{array}{l}r 7 \\
r r \\
r o \\
r v\end{array}$ & $\begin{array}{c}9 \\
57 \\
11 \\
9\end{array}$ & بنتئ بنتئ \\
\hline $\begin{array}{l}\text { If } \\
\text { iv }\end{array}$ & $\begin{array}{l}i r \\
\Lambda\end{array}$ & $\begin{array}{l}r 1 \\
r q\end{array}$ & $\begin{array}{l}\text { IT } \\
\vdots\end{array}$ & $\begin{array}{l}\text { ro } \\
r r\end{array}$ & $\begin{array}{l}\text { ov } \\
70\end{array}$ & $\begin{array}{l}\text { rA } \\
\text { iv }\end{array}$ & $\begin{array}{l}\text { is } \\
\text { iv }\end{array}$ & 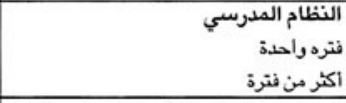 \\
\hline $\begin{array}{l}\text { IV } \\
\vdots \\
r \leq\end{array}$ & $\begin{array}{l}v \\
11 \\
11\end{array}$ & $\begin{array}{l}\text { IV } \\
\text { or } \\
\text { in }\end{array}$ & $\begin{array}{l}r \\
i n \\
i\end{array}$ & $\begin{array}{l}5 \\
r r \\
r q\end{array}$ & $\begin{array}{l}\text { or } \\
\text { vi } \\
\text { or }\end{array}$ & $\begin{array}{l}\S . \\
1 . \\
r \varepsilon\end{array}$ & $\begin{array}{l}i . \\
i n \\
i n\end{array}$ & متخفض المستوى التعليمى للمجتمع المحلى \\
\hline ir & $\begin{array}{c}\text { ir } \\
\text { ir }\end{array}$ & $\begin{array}{l}11 \\
r \vdots \\
r .\end{array}$ & $\begin{array}{l}11 \\
17 \\
\varepsilon\end{array}$ & $\begin{array}{l}Y_{Y} \\
\text { so }_{0}\end{array}$ & $\begin{array}{l}7 v \\
7 \Sigma \\
\vdots 7\end{array}$ & $\begin{array}{l}r \lambda \\
17 \\
r r\end{array}$ & $\begin{array}{l}11 \\
\text { in } \\
15\end{array}$ & الدالتطات المقات الحضرية \\
\hline 10 & 11 & ri & 1. & $r !$ & 29 & ro & 10 & المجهوع \\
\hline vo & vo & vo & vo & vo & Yo & vo & vo & عدد الحالات \\
\hline
\end{tabular}

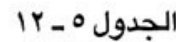
مواقف المعلمين حول مزايا التعليم للبنين: النسبة المئوية لمن يعطون كل اجابة حسب المتغيرات الخلفية الفردية والمدرسية

\begin{tabular}{|c|c|c|c|c|c|c|c|}
\hline مكاند مالبي & ندونجا يحتندي & اكتساب مكانه & فرضيهة جيدة علية & انيدبيج ابا & مثقفا مبدعاح & اكتساب مهارات & المتغيرات الخلفية \\
\hline $\begin{array}{l}\mathrm{M} \\
17\end{array}$ & $\begin{array}{l}i n \\
r \varepsilon\end{array}$ & $\begin{array}{l}r r \\
r \xi\end{array}$ & $\begin{array}{l}r q \\
r q\end{array}$ & $\begin{array}{l}r 1 \\
1 .\end{array}$ & $\begin{array}{l}01 \\
01\end{array}$ & $\begin{array}{l}r y \\
r r\end{array}$ & 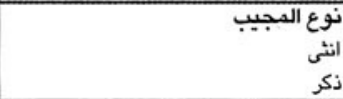 \\
\hline $\begin{array}{l}\text { in } \\
\text { ir } \\
r y\end{array}$ & $\begin{array}{l}r \varepsilon \\
r \\
r \\
r\end{array}$ & $\begin{array}{l}r_{0} \\
r_{0} \\
r_{9}\end{array}$ & $\begin{array}{l}\text { rq } \\
\text { is } \\
\text { rq }\end{array}$ & $\begin{array}{l}0 \\
11 \\
\text { rq }\end{array}$ & $\begin{array}{l}71 \\
1 \varepsilon \\
\varepsilon 1\end{array}$ & $\begin{array}{l}r T \\
r v \\
i n\end{array}$ & متخفض \\
\hline $\begin{array}{l}\text { ir } \\
\text { ir } \\
\text { in } \\
\text { iv }\end{array}$ & $\begin{array}{l}r \varepsilon \\
r r \\
r \varepsilon \\
i v\end{array}$ & $\begin{array}{l}r q \\
r i \\
r q \\
r .\end{array}$ & $\begin{array}{l}r r \\
r r \\
\text { ir } \\
\text { or }\end{array}$ & $\begin{array}{l}r v \\
i r \\
i r \\
11\end{array}$ & $\begin{array}{l}01 \\
00 \\
07 \\
\varepsilon 1\end{array}$ & $\begin{array}{l}19 \\
r 7 \\
r 1 \\
r \varepsilon\end{array}$ & 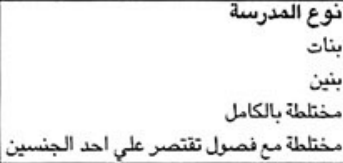 \\
\hline $\begin{array}{l}r 7 \\
1 .\end{array}$ & $\begin{array}{l}r 7 \\
r .\end{array}$ & $\begin{array}{l}r . \\
r r\end{array}$ & $\begin{array}{l}r_{0} \\
r_{0}\end{array}$ & $\begin{array}{l}\text { iv } \\
\text { r. }\end{array}$ & $\begin{array}{l}\text { or } \\
\text { oq }\end{array}$ & $\begin{array}{l}r r \\
r\end{array}$ & 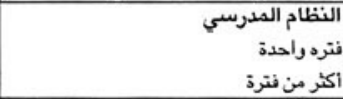 \\
\hline $\begin{array}{l}r 7 \\
r r \\
i r\end{array}$ & $\begin{array}{l}r 1 \\
r \\
r r\end{array}$ & $\begin{array}{l}r . \\
r r \\
19\end{array}$ & $\begin{array}{l}r i \\
r \varepsilon \\
r \varepsilon\end{array}$ & $\begin{array}{l}\text { ir } \\
\text { ra } \\
\text { ir }\end{array}$ & $\begin{array}{l}\text { or } \\
\text { or } \\
\text { i. }\end{array}$ & $\begin{array}{l}r \varepsilon \\
r \varepsilon \\
r r\end{array}$ & 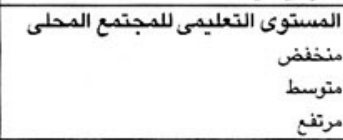 \\
\hline $\begin{array}{l}1 \\
\text { rv } \\
\text { ri }\end{array}$ & $\begin{array}{l}r 1 \\
r q \\
r 1\end{array}$ & $\begin{array}{l}r r \\
r . \\
r A\end{array}$ & $\begin{array}{l}r . \\
r r \\
r q\end{array}$ & $\begin{array}{l}1 \varepsilon \\
r \varepsilon \\
1 \varepsilon\end{array}$ & $\begin{array}{l}11 \\
\text { or } \\
\text { ov }\end{array}$ & $\begin{array}{l}r r \\
r \\
r\end{array}$ & المحافظلات الحضرية المطية \\
\hline$r$. & $\mathrm{rv}$ & rv & $r$ & 19 & 00 & $r \xi$ & المجموع \\
\hline \&A. & $\varepsilon \Lambda$. & $\varepsilon \wedge$. & $\S \Lambda$. & $\varepsilon \wedge$. & 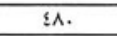 & $\varepsilon \wedge$. & عدد الحالات \\
\hline
\end{tabular}




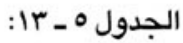

مواقف المعلمين حول مزايا التعليم للبنات: النسبة المئوية لمن يعطون كل اجابة حسب المتغيرات الخلفية الفردية والمدرسية

\begin{tabular}{|c|c|c|c|c|c|c|c|}
\hline مكاندة مانبه & نمونجا يحتندي & 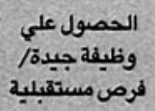 & اكتساب مكانه & ان انمبيح & مثقفلم/مبدعة & اكتساب مهارات & المتغيرات الخلفيه \\
\hline$\stackrel{10}{1}$ & $\begin{array}{l}\text { ir } \\
\text { ri }\end{array}$ & $\begin{array}{l}r \varepsilon \\
\text { is }\end{array}$ & $\begin{array}{l}\mathrm{rq} \\
\mathrm{rv}\end{array}$ & $\begin{array}{l}.9 \\
07\end{array}$ & $\begin{array}{l}r A \\
r A\end{array}$ & $\begin{array}{l}\text { rr } \\
\text { iv }\end{array}$ & نونئ المجيب \\
\hline $\begin{array}{l}\varepsilon \\
\text { iv }\end{array}$ & $\begin{array}{l}r \xi \\
\text { iv } \\
\text { r. }\end{array}$ & $\begin{array}{l}10 \\
1 . \\
r r\end{array}$ & $\begin{array}{l}r 1 \\
10 \\
r T\end{array}$ & $\begin{array}{l}01 \\
1 \leqslant \\
0 \leqslant\end{array}$ & $\begin{array}{l}r u \\
r r \\
r q\end{array}$ & $\begin{array}{l}19 \\
\text { ri } \\
11\end{array}$ & متزفيط \\
\hline $\begin{array}{c}16 \\
\hat{1} \\
10\end{array}$ & $\begin{array}{l}\text { M } \\
\text { rr } \\
\text { rr } \\
\text { 10 }\end{array}$ & $\begin{array}{l}\text { rq } \\
1 \xi \\
9 \\
\text { in }\end{array}$ & $\begin{array}{l}r v \\
r A \\
r \xi \\
r r\end{array}$ & $\begin{array}{l}11 \\
01 \\
11 \\
87\end{array}$ & $\begin{array}{l}r . \\
r r \\
r r \\
r r\end{array}$ & $\begin{array}{l}r . \\
19 \\
19 \\
10\end{array}$ & 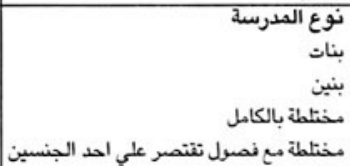 \\
\hline $\begin{array}{l}10 \\
1\end{array}$ & $\begin{array}{l}19 \\
r 1\end{array}$ & $\begin{array}{l}r \varepsilon \\
\Lambda\end{array}$ & $\begin{array}{l}r \Lambda \\
r 1\end{array}$ & $\begin{array}{l}\text { ov } \\
\text { ov }\end{array}$ & $\begin{array}{l}r \xi \\
r A\end{array}$ & $\begin{array}{l}19 \\
19\end{array}$ & 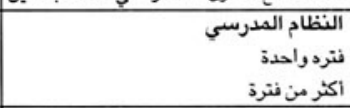 \\
\hline $\begin{array}{l}\text { i. } \\
\text { iv } \\
\text { v }\end{array}$ & $\begin{array}{l}19 \\
\text { rr } \\
19\end{array}$ & $\begin{array}{l}\text { iv } \\
\text { rr } \\
\text { ir }\end{array}$ & $\begin{array}{l}r_{1} \\
r_{q} \\
r_{0}\end{array}$ & $\begin{array}{l}.9 \\
\text { ir } \\
\text { o. }\end{array}$ & $\begin{array}{l}r 7 \\
r q \\
r r\end{array}$ & $\begin{array}{l}17 \\
\text { iv } \\
\text { ri }\end{array}$ & متخفضف \\
\hline $\begin{array}{l}r \\
\text { iv } \\
9\end{array}$ & $\begin{array}{l}18 \\
r r \\
r r\end{array}$ & $\begin{array}{l}\text { ir } \\
r \\
17\end{array}$ & $\begin{array}{l}r_{1} \\
r^{2} \\
r_{0}\end{array}$ & $\begin{array}{l}01 \\
01 \\
11\end{array}$ & $\begin{array}{l}r \xi \\
r r \\
r i\end{array}$ & $\begin{array}{l}\text { in } \\
\text { in } \\
r i\end{array}$ & 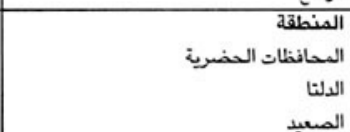 \\
\hline 11 & $r$. & in & $\mathrm{rv}$ & ov & $r r$ & 19 & المجموع \\
\hline धA. & $\xi \Lambda$. & «A. & 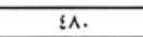 & ¿A. & in. & ¿A. & عدد الحالات \\
\hline
\end{tabular}

بالنسبة لكافة الارقام في هذا الجدول الني تتضمن نوع المجيب يبلغ عدد الحالات V9؛ حالة

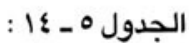

مواتف الطلاب حول مزايا التعليم للبنين: النسبة المئوية لمن يعطون كل اجابة حسب المتغيرات الخلفية الفردية والمدرسية

\begin{tabular}{|c|c|c|c|c|c|c|}
\hline لروص المضول للزيواج & تعلم القراعة & اكتساب مكانة & اكتساب مكاند & وظيفة محترمة & ان يصبح ابا جيدا & المتغيرات الخلفية \\
\hline $\begin{array}{l}\text { ro } \\
\varepsilon_{0}\end{array}$ & $\begin{array}{l}\text { iv } \\
\text { ri }\end{array}$ & $\begin{array}{l}r \\
\llbracket 7\end{array}$ & $\begin{array}{l}1 . \\
18\end{array}$ & $\begin{array}{l}10 \\
\text { vr }\end{array}$ & $\begin{array}{l}u \\
v_{0}\end{array}$ & نوني المجيب \\
\hline $\begin{array}{l}r . \\
r A \\
r i\end{array}$ & $\begin{array}{l}r r \\
r i \\
r v\end{array}$ & $\begin{array}{l}r_{0} \\
\varepsilon r \\
\$ 1\end{array}$ & $\begin{array}{l}0 \% \\
10 \\
10\end{array}$ & $\begin{array}{l}\text { ir } \\
\text { w } \\
\text { iv }\end{array}$ & $\begin{array}{l}11 \\
\text { A. } \\
\text { un }\end{array}$ & متزفيض \\
\hline $\begin{array}{l}r \varepsilon \\
01 \\
r \varepsilon \\
\varepsilon 1\end{array}$ & $\begin{array}{l}17 \\
\text { ir } \\
\text { in } \\
r .\end{array}$ & $\begin{array}{l}r r \\
\text { or } \\
r 1 \\
\varepsilon\end{array}$ & $\begin{array}{l}\text { ir } \\
\text { un } \\
\text { or } \\
\text { ir }\end{array}$ & $\begin{array}{l}10 \\
n \\
i r \\
r r\end{array}$ & $\begin{array}{l}\text { it } \\
\text { A. } \\
\text { ir } \\
\text { vo }\end{array}$ & 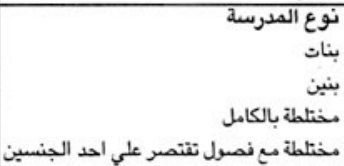 \\
\hline $\begin{array}{l}r v \\
r r\end{array}$ & $\begin{array}{l}r q \\
r \varepsilon\end{array}$ & $\begin{array}{l}\varepsilon r \\
r V\end{array}$ & $\begin{array}{l}u \\
\text { os }\end{array}$ & $\begin{array}{l}v 1 \\
u\end{array}$ & $\begin{array}{l}\text { vi } \\
\text { vr }\end{array}$ & 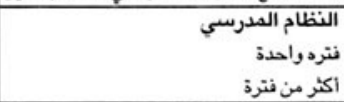 \\
\hline $\begin{array}{l}r V \\
r r \\
\varepsilon T\end{array}$ & $\begin{array}{l}\text { iv } \\
r \\
r 7\end{array}$ & $\begin{array}{l}r r \\
r \Lambda \\
\vdots 9\end{array}$ & $\begin{array}{l}\text { ol } \\
\text { ir } \\
\text { vr }\end{array}$ & $\begin{array}{l}1 \varepsilon \\
11 \\
\mathrm{VA}\end{array}$ & $\begin{array}{l}\text { To } \\
\text { IV } \\
\text { Ar }\end{array}$ & مترنفض متفني التعليمى للمجتمع المحلى \\
\hline $\begin{array}{l}\varepsilon q \\
r \varepsilon \\
r A\end{array}$ & $\begin{array}{l}\varepsilon . \\
\text { ri } \\
19\end{array}$ & $\begin{array}{l}\text { or } \\
\varepsilon \text {. } \\
\text { rr }\end{array}$ & $\begin{array}{l}w \\
\text { ir } \\
01\end{array}$ & $\begin{array}{l}\mathrm{Al} \\
10 \\
\mathrm{iv}\end{array}$ & $\begin{array}{l}\text { Ao } \\
\text { v. } \\
1 \varepsilon\end{array}$ & 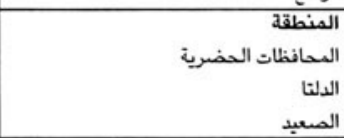 \\
\hline ro & rV & $\varepsilon$. & $\pi$ & 79 & vi & المجموع \\
\hline
\end{tabular}


الجدول 0ـ10:

مواقف الطلاب حول مزايا التعليم للبنات: النسبة المئوية لمن يعطون كل اجابة حسب المتغيرات الخلفية الفردية والمدرسية

\begin{tabular}{|c|c|c|c|c|c|c|}
\hline فرص الفضل للزيولي اج & تعلم القراهة & اكتساب مكاند & أجتاب مكانة & وظيفة محترملة الحصلي & ان تصبيح اما جيدة & المتغيرات الخلفية \\
\hline $\begin{array}{l}\text { rV } \\
\text { rA }\end{array}$ & $\begin{array}{l}\text { in } \\
\text { ro }\end{array}$ & $\begin{array}{l}\mathrm{r} \\
\mathrm{rV}\end{array}$ & $\begin{array}{l}\text { Ir } \\
\text { so }\end{array}$ & $\begin{array}{l}\text { Ir } \\
\text { or }\end{array}$ & $\begin{array}{l}\text { v. } \\
\text { va }\end{array}$ & نوني النو المجيب \\
\hline $\begin{array}{l}r \\
r q \\
r i\end{array}$ & $\begin{array}{l}r_{0} \\
r r \\
r r\end{array}$ & $\begin{array}{l}\text { IV } \\
\text { ra } \\
\text { ra }\end{array}$ & $\begin{array}{l}\text { ra } \\
\text { ov } \\
\text { ir }\end{array}$ & $\begin{array}{l}\text { or } \\
\text { ou } \\
\text { or }\end{array}$ & $\begin{array}{l}\text { vi } \\
\text { Ar } \\
\text { v. }\end{array}$ & هنوسف \\
\hline $\begin{array}{l}r v \\
\varepsilon \varepsilon \\
r . \\
r_{0}\end{array}$ & $\begin{array}{l}\text { iv } \\
r q \\
r r \\
r q\end{array}$ & $\begin{array}{l}r \varepsilon \\
r r \\
17 \\
r r\end{array}$ & $\begin{array}{l}\text { iv } \\
0 . \\
\text { ri } \\
\text { in }\end{array}$ & $\begin{array}{l}7 . \\
\text { ir } \\
01 \\
01\end{array}$ & $\begin{array}{l}19 \\
1 . \\
19 \\
\text { Ar }\end{array}$ & 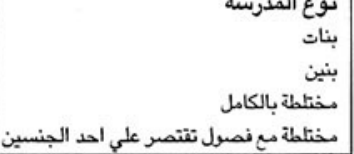 \\
\hline $\begin{array}{l}\mathrm{rr} \\
\mathrm{rr}\end{array}$ & $\begin{array}{l}r \\
r \Lambda\end{array}$ & $\begin{array}{l}\text { YA } \\
r r\end{array}$ & $\begin{array}{l}11 \\
81\end{array}$ & $\begin{array}{l}\text { T. } \\
\text { ov }\end{array}$ & $\begin{array}{l}n \\
n\end{array}$ & 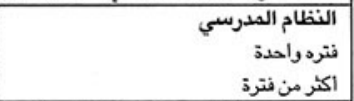 \\
\hline $\begin{array}{l}r . \\
r . \\
\varepsilon v\end{array}$ & $\begin{array}{l}\text { r. } \\
r_{0} \\
r_{0}\end{array}$ & $\begin{array}{l}10 \\
\text { rq } \\
\text { rV }\end{array}$ & $\begin{array}{l}\text { TV } \\
\text { ०A } \\
\text { To }\end{array}$ & $\begin{array}{l}0 . \\
0 \leqslant \\
v r\end{array}$ & $\begin{array}{l}v r \\
19 \\
\text { Nr }\end{array}$ & 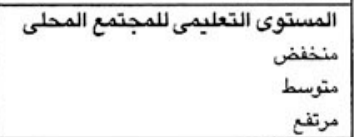 \\
\hline $\begin{array}{l}0 . \\
r i \\
r r\end{array}$ & $\begin{array}{l}r_{0} \\
r \varepsilon \\
r \varepsilon\end{array}$ & $\begin{array}{l}\S 1 \\
r_{0} \\
\text { iv }\end{array}$ & $\begin{array}{l}n \\
\because 9 \\
n\end{array}$ & $\begin{array}{l}\text { vi } \\
\text { on } \\
\text { or }\end{array}$ & $\begin{array}{l}\text { Ao } \\
\text { vr } \\
\text { v. }\end{array}$ & 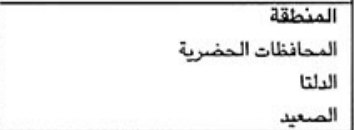 \\
\hline$r r$ & $\mathrm{rV}$ & $r 7$ & गई & 09 & $\mathrm{v}$. & المجموع \\
\hline
\end{tabular}

الجدول ه ـ 17 قياسات لشعور الطلاب بالاعتزاز : النسبة المئوية للطلاب الذين يتفقون مع الجمل المتصلة باعتزازهم بالذات وثقتهم في فعاليتهم حسب المتغيرات الخلفية الفردية و المدربسية

\begin{tabular}{|c|c|c|c|}
\hline 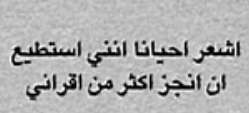 & اشعر احيانا انتي لناشل في حياتي & واستطبع مواجهة المشكلائات & المتغيرات الخلفيه \\
\hline $\begin{array}{l}17 \\
\text { 11 }\end{array}$ & $\begin{array}{l}r . \\
r\end{array}$ & $\begin{array}{l}\mathrm{vA} \\
\mathrm{vA}\end{array}$ & نو نو المجيب \\
\hline $\begin{array}{l}79 \\
\text { ir } \\
v r\end{array}$ & $\begin{array}{l}19 \\
r r \\
r .\end{array}$ & $\begin{array}{l}\text { va } \\
\wedge . \\
\text { vi }\end{array}$ & منغفض \\
\hline $\begin{array}{l}\text { iv } \\
v i \\
7 \varepsilon \\
v i\end{array}$ & $\begin{array}{l}r 1 \\
r r \\
17 \\
r 1\end{array}$ & $\begin{array}{l}v a \\
v a \\
v a \\
v a\end{array}$ & بنتين بنتات المدرسة \\
\hline $\begin{array}{l}\text { v. } \\
71\end{array}$ & $\begin{array}{l}r Y \\
\text { II }\end{array}$ & $\begin{array}{l}\text { nn } \\
\text { A. }\end{array}$ & 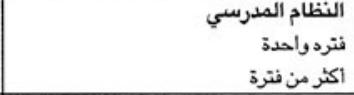 \\
\hline $\begin{array}{l}u \\
v 1 \\
11\end{array}$ & $\begin{array}{l}r . \\
19 \\
r r\end{array}$ & $\begin{array}{l}w \\
w \\
11\end{array}$ & متخفضط مترى التعليمى للمجتمع المحلى \\
\hline $\begin{array}{l}\text { io } \\
\mathrm{vi} \\
\mathrm{TV}\end{array}$ & $\begin{array}{l}r 7 \\
r i \\
\text { iv }\end{array}$ & $\begin{array}{l}\text { Ar } \\
w \\
w\end{array}$ & 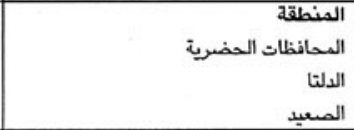 \\
\hline 71 & $r$. & $\mathrm{vA}$ & المجموع \\
\hline$r \leqslant \wedge 9$ & YISM & $r \leq 91$ & عدد الحالات \\
\hline
\end{tabular}


الجدول ه ـ IV

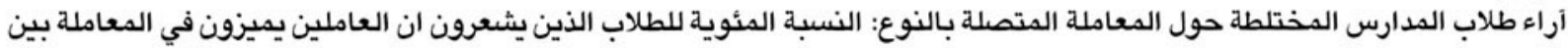

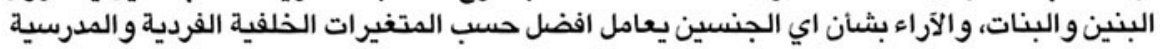

\begin{tabular}{|c|c|c|c|}
\hline \multicolumn{2}{|c|}{ من الذي يعامل بتسامح اكثر } & \multirow{2}{*}{ العاملون يمينزون في المعاملة } & \multirow{2}{*}{ المتغيرات الخلفية } \\
\hline البنات & البنين & & \\
\hline $\begin{array}{l}\mathrm{rq} \\
\vdots \mathrm{r}\end{array}$ & 11 & $\begin{array}{l}\text { or } \\
\text { or }\end{array}$ & نونى النجيب \\
\hline $\begin{array}{l}\text { ro } \\
\because r\end{array}$ & $\hat{i}$ & $\begin{array}{l}\text { IT } \\
\text { ir } \\
0 \&\end{array}$ & متخفض الاد الدراسي للطلاب \\
\hline $\begin{array}{l}r \varepsilon \\
o v\end{array}$ & $\begin{array}{l}v \\
\wedge\end{array}$ & $\begin{array}{l}\text { sr } \\
u\end{array}$ & 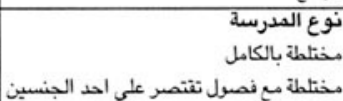 \\
\hline $\begin{array}{l}r 7 \\
\$ 9\end{array}$ & 1 & $\begin{array}{l}\text { @ } \\
\text { ov }\end{array}$ & 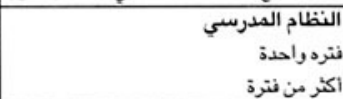 \\
\hline $\begin{array}{l}\text { ro } \\
\text { ov } \\
\varepsilon \varepsilon\end{array}$ & $\hat{\hat{1}}$ & $\begin{array}{l}87 \\
11 \\
\text { or }\end{array}$ & 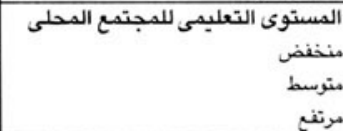 \\
\hline $\begin{array}{l}71 \\
\text { or } \\
\text { ri }\end{array}$ & $\begin{array}{l}\text { iv } \\
9 \\
1\end{array}$ & $\begin{array}{l}\text { A. } \\
\text { ir } \\
\text { ¿. }\end{array}$ & 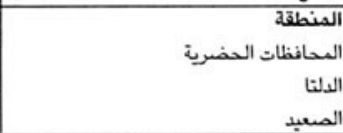 \\
\hline \&r & $\wedge$ & or & المجموع \\
\hline & & $v \leqslant 0$ & عدد الحالات \\
\hline
\end{tabular}

* الارقام في هذا العمود ليست متوازنة، اذ ان موازنة البيانات هنا اسفر عن مقام اصغر من ان يفرز نسبا مئوية هستقرة. 


$$
\text { الجداول }
$$

$$
\text { الموارد المادية والبشرية السادسية }
$$


الجدول 7-1:

النسبة المئوية للفصول وفق نوعية البيئة و مقدار الراحة المتوافره للطلاب، حسب المتغيرات الخلفية الفردية و المدرسية

\begin{tabular}{|c|c|c|c|c|c|c|c|}
\hline & \multicolumn{2}{|c|}{ راحه الطلاب } & \multicolumn{4}{|c|}{ نوعيه البينه في الفصلط } & \multirow[b]{2}{*}{ المتغيرات الخلفية } \\
\hline 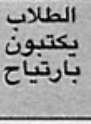 & 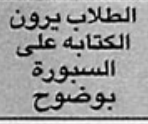 & يستمعنون & الحصصناء الحصد & تهوية & نظافة & جيدة إضة & \\
\hline $\begin{array}{l}\text { ov, } r \\
\text { or, } 1\end{array}$ & $\begin{array}{l}\text { Tr,v } \\
\mathrm{Tr}, \mathrm{I}\end{array}$ & $\begin{array}{l}q r, v \\
q ., r\end{array}$ & لا ينطبق & ل الا ينطبق & ل الا ينطبق & لا ينطبق & نوع المجى نبي \\
\hline $\begin{array}{l}7 ., . \\
\varepsilon V, Y \\
\circ V, \Lambda\end{array}$ & $\begin{array}{l}77.9 \\
70, . \\
7 \varepsilon, 1\end{array}$ & $\begin{array}{l}9.7 \\
9.7 \\
9 r .0\end{array}$ & $\begin{array}{l}\text { 10, } \\
r 1,1 \\
7 ., \mathrm{V}\end{array}$ & $\begin{array}{l}\text { M. } q \\
\text { AT, } \\
\text { AO, r }\end{array}$ & $\begin{array}{l}\text { vo,. } \\
\text { Ar, } 7 \\
7 ., \mathrm{V}\end{array}$ & $\begin{array}{l}\text { vo,. } \\
\text { Ar, } \\
1 \ldots, \text {. }\end{array}$ & 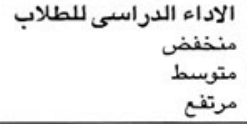 \\
\hline $\begin{array}{l}o v, q \\
\varepsilon v, r \\
V, \varepsilon \\
\varepsilon q, \varepsilon\end{array}$ & $\begin{array}{l}\text { v. } 2 \\
7 ., . \\
v ., 1 \\
7 \varepsilon, 1\end{array}$ & $\begin{array}{l}q r, v \\
q r, . \\
q ., v \\
\text { Av, }\end{array}$ & $\begin{array}{l}70, r \\
7 ., 5 \\
7 . . \\
\text { Tr, }\end{array}$ & $\begin{array}{l}10, v \\
\Lambda \varepsilon, 7 \\
97, r \\
\downarrow \Lambda, \wedge\end{array}$ & $\begin{array}{l}0 r, r \\
79, Y \\
\text { A. } \\
\text { Ni,r }\end{array}$ & $\begin{array}{l}\text { AT, } \\
9 r, r \\
97, r \\
7 r, 0\end{array}$ & 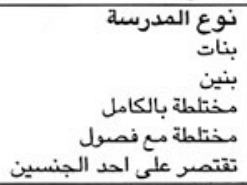 \\
\hline $\begin{array}{l}01, . \\
01,7\end{array}$ & $\begin{array}{l}\text { Ir. } \\
\text { W.V }\end{array}$ & $\begin{array}{l}9 \varepsilon, r \\
M, r\end{array}$ & $\begin{array}{l}67,9 \\
r 7,1\end{array}$ & $\begin{array}{l}9 ., 1 \\
\text { vi.. }\end{array}$ & $\begin{array}{l}\wedge r, . \\
\varepsilon \wedge . .\end{array}$ & $\begin{array}{l}\wedge \uparrow, \wedge \\
\wedge \varepsilon, .\end{array}$ & النظرهام الدراسى ماحدة فترة \\
\hline $\begin{array}{l}\text { Tr, } 9 \\
\text { ov, } 9 \\
\text { Er, } 1\end{array}$ & $\begin{array}{l}r, \varepsilon \\
\pi, q \\
7 ., .\end{array}$ & $\begin{array}{l}91, r \\
19,1 \\
9 \varepsilon, \varepsilon\end{array}$ & $\begin{array}{l}\text { vi.q } \\
\varepsilon ., . \\
\text { v. } 7\end{array}$ & $\begin{array}{l}\text { Av, ० } \\
\text { A. . } \\
\text { ar. }\end{array}$ & $\begin{array}{l}70,7 \\
\text { Ar, } \\
u, \wedge\end{array}$ & $\begin{array}{l}\text { Ml. } \\
\text { Ar.r } \\
9 \varepsilon, 1\end{array}$ & 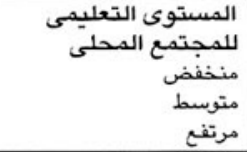 \\
\hline $\begin{array}{l}\varepsilon r, q \\
00, q \\
71, \varepsilon\end{array}$ & $\begin{array}{l}1 r, 7 \\
11, r \\
v r, 0\end{array}$ & $\begin{array}{l}91, . \\
19, \mathrm{r} \\
9 ., \mathrm{r}\end{array}$ & $\begin{array}{l}1 \ldots, . .0 \\
o r, \hat{r} \\
71, r\end{array}$ & $\begin{array}{l}M 1, q \\
19, v \\
V v, \varepsilon\end{array}$ & $\begin{array}{l}0 ., 0 \\
\text { va, } \\
\text { Tv, }\end{array}$ & $\begin{array}{l}1 \cdots, . \\
\text { Av.r } \\
\text { A... }\end{array}$ & المالدافظلات الحضرية \\
\hline $\begin{array}{l}0 \wedge, . \\
7 ., \hat{A} \\
r v, 0\end{array}$ & $\begin{array}{l}v ., 7 \\
7 r, r \\
i r, r\end{array}$ & $\begin{array}{l}90,1 \\
14,7 \\
9 ., 7\end{array}$ & $\begin{array}{l}u, \lambda \\
o r, \varepsilon \\
r r, r\end{array}$ & $\begin{array}{l}\text { AV, A } \\
\text { AV. . } \\
\text { TI, }\end{array}$ & $\begin{array}{l}\text { v1, } \\
7 ., 9 \\
77, v\end{array}$ & $\begin{array}{l}\text { M1, } \\
91, r \\
\varepsilon ., .\end{array}$ & 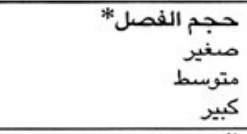 \\
\hline 00,1 & $70, \varepsilon$ & $91, \varepsilon$ & $71, \varepsilon$ & 17. 1 & 81.9 & 10,7 & المجموع \\
\hline \multicolumn{3}{|c|}{$r \leqslant 90$} & \multicolumn{4}{|c|}{$\wedge \varepsilon$} & عدد الحـالات \\
\hline
\end{tabular}




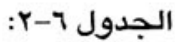

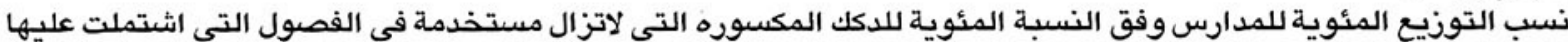

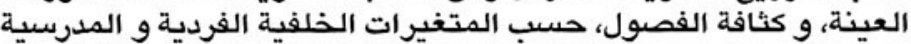

\begin{tabular}{|c|c|c|c|c|c|c|}
\hline \multicolumn{3}{|c|}{ كثافه الفصول } & \multicolumn{3}{|c|}{ الدكل المكسورة } & \multirow[b]{2}{*}{ المتغيرات الخلفية } \\
\hline 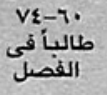 & طالباً فئى & 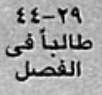 & اكثي من •الدكبث & الدكل المكسورة من & الدكل المكسورة & \\
\hline $\begin{array}{l}r, \varepsilon \\
r i, r \\
r, .\end{array}$ & $\begin{array}{l}r \varepsilon, 1 \\
r \cdot, \varepsilon \\
r v, 0\end{array}$ & $\begin{array}{l}v r, \varepsilon \\
\varepsilon v, \wedge \\
7 r, 0\end{array}$ & $\begin{array}{l}\text { IV,9 } \\
17, . \\
\cdots\end{array}$ & $\begin{array}{l}1 \mathrm{~V}, 9 \\
0 \\
\mathrm{r}, \mathrm{I}\end{array}$ & $\begin{array}{l}\mathrm{i} \varepsilon, r \\
\wedge \mathrm{V}, \cdot \\
\mathrm{v}, \mathrm{q}\end{array}$ & منتخفض الاداء الدراسى للطلاب \\
\hline $\begin{array}{l}9,1 \\
v, 1 \\
i, r \\
i \varepsilon, r\end{array}$ & $\begin{array}{l}r v, r \\
r i, \varepsilon \\
r v, r \\
r r, r\end{array}$ & 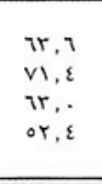 & $\begin{array}{l}\varepsilon, 0 \\
i \wedge, r \\
\vee, \varepsilon \\
i \wedge, \wedge\end{array}$ & $\begin{array}{l}1 \wedge, r \\
r, r \\
r i, r\end{array}$ & $\begin{array}{l}\text { Vv,r } \\
\wedge 1, \wedge \\
1 \wedge, q \\
0 ., .\end{array}$ & 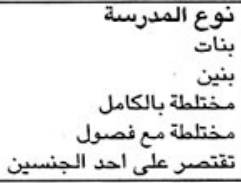 \\
\hline $\begin{array}{l}1, V \\
19, r\end{array}$ & $\begin{array}{l}r, . \\
0 ., .\end{array}$ & $\begin{array}{l}v \pi, r \\
r ., \Lambda\end{array}$ & $\begin{array}{r}0, \wedge \\
r ., .\end{array}$ & $\begin{array}{l}\text { Iv,r } \\
\wedge, .\end{array}$ & $\begin{array}{l}\text { vา, } 9 \\
\text { Vr,. }\end{array}$ & اكتره واحدة النّرة استى \\
\hline $\begin{array}{l}r, 1 \\
9, v \\
11,1\end{array}$ & $\begin{array}{l}r y, 1 \\
r y, r \\
i v, 7\end{array}$ & $\begin{array}{l}11,1 \\
0 \wedge, 1 \\
v ., 7 \\
\end{array}$ & $\begin{array}{l}r 1,9 \\
7,8 \\
7, . \\
\end{array}$ & $\begin{array}{l}1 \%, 0 \\
1 ., . \\
r o, .\end{array}$ & $\begin{array}{l}70,7 \\
\text { Ar, r } \\
\text { vo,. }\end{array}$ & 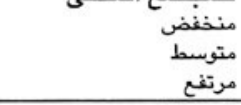 \\
\hline $\begin{array}{l}1 r, 0 \\
7, \hat{r} \\
r, r\end{array}$ & $\begin{array}{l}* \cdot \\
\varepsilon \cdot, q \\
r r, 7\end{array}$ & $\begin{array}{l}\text { Av, o } \\
\text { or, r } \\
v \varepsilon, r\end{array}$ & $\begin{array}{l}\ddot{0} \\
0,1 \\
r \cdot, .\end{array}$ & $\begin{array}{l}r A, t \\
1 ., r \\
i r, r\end{array}$ & $\begin{array}{l}\vee 1, \varepsilon \\
\wedge \varepsilon, 7 \\
77, v\end{array}$ & المالتافظات الحضرية \\
\hline 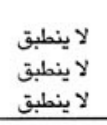 & 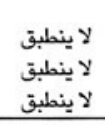 & 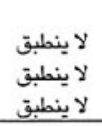 & $\begin{array}{l}r, 1 \\
r i, r \\
r r, r\end{array}$ & $\begin{array}{l}r \cdot \wedge \\
\cdots \\
\cdots \\
\end{array}$ & $\begin{array}{l}v v, 1 \\
v \wedge, r \\
77, v\end{array}$ & 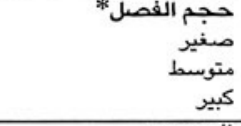 \\
\hline 7,9 & $r ., \varepsilon$ & $T r, v$ & $1 ., 7$ & $1 T, 7$ & $v_{0}, v$ & المجموع \\
\hline 7 & $r 7$ & or & $\wedge$ & 1. & oA & عدد الحالات \\
\hline
\end{tabular}

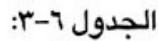

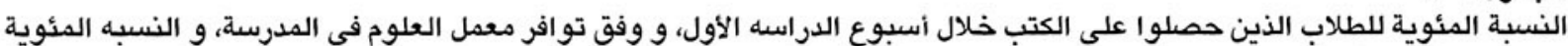

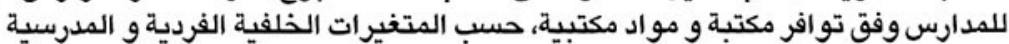

\begin{tabular}{|c|c|c|c|c|c|c|c|}
\hline & & & & & وحود معمل & الطلاب حصلوا & \\
\hline 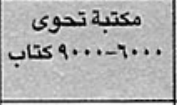 & مكتبة تصوى ......... & من منبة تحوى أقلاب & صحف مكتبة تضبم & مكتبة & للعلوم فى المدرسة & اسبى الكتب خلال الدراسة & المتغيرات الخلفية \\
\hline$\cdot, \cdot$ & $M, 0$ & $\wedge 1,0$ & $\varepsilon r, 0$ & va, r & $v_{0},$. & ir, 1 & منذفضاء المدرسي للطلاب \\
\hline $10,$. & ro,. & o.,. & $\wedge \varepsilon, r$ & $A v$, . & $9 \varepsilon, 1$ & $r i, \Lambda$ & متوسط \\
\hline 4,1 & $r q, \varepsilon$ & 01,0 & Av, 9 & $1 \ldots$, & $1 \ldots$, & $r \varepsilon,$. & هرتفع \\
\hline & & & & & & & نوع المدرسة \\
\hline$r r, v$ & $r 7, \varepsilon$ & $\varepsilon ., q$ & Ar, $T$ & $1 \ldots$, & $9 \varepsilon, \varepsilon$ & $r \varepsilon,$. & \\
\hline $17, v$ & $\bullet \wedge, r$ & $r_{0},$. & $91, v$ & $1 \ldots$, & 91,2 & ir, r & \\
\hline$\cdot$, & $17, v$ & Ar, r & $70,$. & v.,$\varepsilon$ & Ar, $\wedge$ & $\mathrm{ra}, \mathrm{A}$ & مختلطة بالكامل \\
\hline$\therefore$ & r., & A.,. & 71,9 & 90,0 & ar, \& & $r \cdot, \Lambda$ & مختلمة مع فصول نفتصر علي احد الجنسين \\
\hline & & & & & & & النظلام المدرسي ا \\
\hline$v, 1$ & $r, \lambda$ & 7,1 & $v_{0}, \cdot$ & $\wedge \uparrow, \varepsilon$ & q., v & $r r, r$ & كتره واحدة \\
\hline ir, o & rv, 0 & $0 .,$. & v., 1 & $97, \cdot$ & $9 \mathrm{r}, \mathrm{.}$ & 10,1 & أكثر من غترة \\
\hline & & & & & & & المستوى التعليمى للمجتمع المحلى \\
\hline$\because \cdot$ & $r r, 9$ & $w, 1$ & $0 \wedge .1$ & 10, $\mathrm{V}$ & $\wedge r, \varepsilon$ & $1 \varepsilon, Y$ & 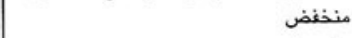 \\
\hline$r, r$ & $r r, 1$ & $7 \varepsilon, r$ & $9 r, 9$ & $A V, 0$ & $9 ., 1$ & $\varepsilon ., 9$ & متوسط \\
\hline$r i, r$ & $0 . .$. & $\mathrm{M}, \mathrm{A}$ & $v_{0},$. & $1 \ldots$. & $99,$. & $1 \varepsilon, v$ & مرتفع \\
\hline 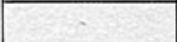 & & & & & & & المنطقة \\
\hline$\varepsilon \varepsilon, \varepsilon$ & $\varepsilon \varepsilon, \varepsilon$ & 11,1 & $1 \ldots$, & $1 \ldots$, & 99,0 & IV, Y & المحافظات الحضرية \\
\hline$\cdots$ & $r v, q$ & $v r, 1$ & Al, $\varepsilon$ & qv, $v$ & ar, $\varepsilon$ & $r r, v$ & الدلتا \\
\hline$v, \varepsilon$ & $r 9,7$ & ir, . & or, r & $v_{0},$. & Ar, 9 & 11,7 & الصعيد \\
\hline 1,7 & $r \cdot, 7$ & $7 ., 9$ & $v \varepsilon, \varepsilon$ & $19, r$ & $91, r$ & $r \varepsilon, v$ & المجموع \\
\hline vo & vo & vo & vo & vo & $r \leqslant 90$ & $r \leqslant 90$ & عدد الحالات \\
\hline
\end{tabular}




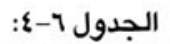

النسبةالمئوية للمدارس وفق توافر و استخدام الموارد و المرافق الدراسية، حسب المتغيرات الخلفية الفردية و المدرسية

\begin{tabular}{|c|c|c|c|c|c|c|c|c|c|}
\hline \multicolumn{3}{|c|}{ اله حاسبة/تليفون/الد تصوير/هستندات } & \multicolumn{2}{|c|}{ فيبيو } & \multicolumn{2}{|c|}{ تليفزيون } & \multicolumn{2}{|c|}{ كمبيوتر } & \multirow[b]{2}{*}{ المتغيرات الخلفيج } \\
\hline متوافر & متوافر & متوافر & لا بستخدم & متوافر & لا يستخدم & متوافر & لايستخدم & متوافر & \\
\hline $\begin{array}{l}\cdots \\
\varepsilon, r \\
r i, r\end{array}$ & $\begin{array}{l}r o, v \\
r 7,1 \\
r 9, v\end{array}$ & $\begin{array}{l}\cdots \\
\cdots \\
\cdots\end{array}$ & $\begin{array}{l}i r, 1 \\
9,1 \\
\cdots\end{array}$ & $\begin{array}{l}r \varepsilon, 1 \\
0 \ldots, \\
A v, q\end{array}$ & $\begin{array}{l}\text { Ir,A } \\
\text { ir,e }\end{array}$ & $\begin{array}{l}r \varepsilon, 1 \\
0 \varepsilon, r \\
\Delta v, q\end{array}$ & $\begin{array}{l}1 \varepsilon, r \\
r q, r \\
r, .\end{array}$ & $\begin{array}{l}r A, T \\
\$ 1, V \\
9 ., 9\end{array}$ & مترنفض \\
\hline $\begin{array}{l}r, v \\
r r, l \\
\cdots \\
\cdots, \\
\end{array}$ & $\begin{array}{l}v \Lambda, r \\
79, r \\
r v, . \\
i \Lambda, r\end{array}$ & $\begin{array}{l}\because, \\
\mathrm{v}, \mathrm{v} \\
\cdots, \\
\cdots \\
.,\end{array}$ & $\begin{array}{l}i, \\
v, v \\
11,1 \\
9,0\end{array}$ & $\begin{array}{l}v r, q \\
q r, r \\
r r, r \\
\varepsilon v, \tau\end{array}$ & $\begin{array}{l}\because, . \\
v, v \\
11,1 \\
9,0\end{array}$ & $\begin{array}{l}r r, q \\
q r, r \\
r v, . \\
\varepsilon r, .\end{array}$ & $\begin{array}{l}\varepsilon, r \\
\Lambda, r \\
r r, 1 \\
9,0\end{array}$ & $\begin{array}{l}A r, 1 \\
91, v \\
r ., v \\
\varepsilon v, 1\end{array}$ & بنات بنتطة المدرسة \\
\hline $\begin{array}{l}0,1 \\
r ., .\end{array}$ & $\begin{array}{l}r q, . \\
70, \varepsilon\end{array}$ & $\begin{array}{l}\cdots \\
\ldots . \\
\end{array}$ & $\begin{array}{l}0,1 \\
11,0\end{array}$ & $\begin{array}{l}00,9 \\
0 v, v\end{array}$ & $\begin{array}{r}1,1 \\
11,0 \\
\end{array}$ & $\begin{array}{l}\text { ov, } 1 \\
\text { ov, },\end{array}$ & $\begin{array}{l}\mathrm{A}, \mathrm{l} \\
\mathrm{rr}, \mathrm{l}\end{array}$ & $\begin{array}{l}1 ., r \\
0 .,\end{array}$ & 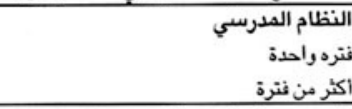 \\
\hline $\begin{array}{l}\cdots \\
10,7 \\
12,7\end{array}$ & $\begin{array}{l}r \varepsilon, r \\
\varepsilon, r \\
A v, \varepsilon\end{array}$ & $\begin{array}{l}\cdots \\
\cdots \\
\cdots\end{array}$ & $\begin{array}{l}A, r \\
9, \varepsilon \\
\cdots,\end{array}$ & $\begin{array}{l}m, 1 \\
n, 9 \\
v_{0}, .\end{array}$ & $\begin{array}{l}A, 1 \\
9, \mathrm{~V} \\
\cdots,\end{array}$ & $\begin{array}{l}\varepsilon ., . \\
\text { vi.. } \\
\text { vo,. }\end{array}$ & $\begin{array}{l}A, r \\
r r, 1 \\
\ldots .,\end{array}$ & $\begin{array}{l}\varepsilon \varepsilon, \varepsilon \\
\circ \wedge, 1 \\
\mathrm{Av}, \mathrm{e}\end{array}$ & مترنفض \\
\hline $\begin{array}{l}r r, r \\
9,1 \\
1, r\end{array}$ & 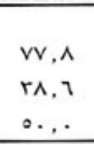 & $\begin{array}{l}-, \\
\cdots, \\
\cdots \\
\end{array}$ & $\begin{array}{l}\cdots \\
i r, 1 \\
\cdots\end{array}$ & $\begin{array}{l}w, A \\
v_{0}, . \\
r r, i\end{array}$ & $\begin{array}{l}11,1 \\
1 r, 1 \\
\ldots\end{array}$ & $\begin{array}{l}11, \mathrm{v} \\
\mathrm{ro}_{0} . \\
\mathrm{ra}, \mathrm{r}\end{array}$ & $\begin{array}{l}\text { ir.o } \\
\text { r.,o } \\
\ldots\end{array}$ & $\begin{array}{l}A v, 0 \\
u, r \\
r o, 0\end{array}$ & 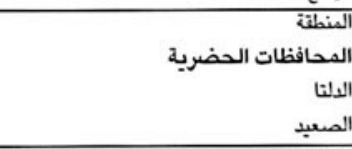 \\
\hline $9, r$ & $\varepsilon v, r$ & $\cdot, \wedge$ & $V, r$ & $07, \mathrm{~V}$ & $\mathrm{v}, \Lambda$ & ov, 9 & $\mathbb{1 r}, \Lambda$ & ov, 0 & المجموع \\
\hline vo & $v_{0}$ & $v_{0}$ & vo & $\mathrm{v}_{0}$ & $\mathrm{v}_{0}$ & $\mathrm{v}_{0}$ & vo & vo & عدد الحالات \\
\hline
\end{tabular}


الجدول T-0:

النسبة المئوية للمدارس وفق تو افر الصنابير و المراحيض، حسب المتغيرات الخلفية الفردية و المدرسية

\begin{tabular}{|c|c|c|c|c|c|c|}
\hline \multicolumn{3}{|c|}{ نظافة مراحيض الطلاب } & \multirow{2}{*}{ مراحيضن منفصلة } & \multirow{2}{*}{ أكثل من مرحاض . الكالب } & \multirow{2}{*}{ اكلى من صناطبور } & \multirow[b]{2}{*}{ المتغيرات الخلفية } \\
\hline نظيفة جدأ & نظيفة & 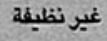 & & & & \\
\hline & & & & & & الأداء الدراسي للطلاب \\
\hline $1 \varepsilon$ & \&r & \&r & A. & ra & Ło & منخفض م م م \\
\hline rr & $\llbracket$ & ro & is & ra & ov & متوسط \\
\hline ir & 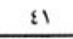 & $\varepsilon \mathrm{v}$ & $1 .$. & ra & ver & 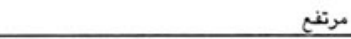 \\
\hline & & & & & & نوع المدرسة \\
\hline ir & r. & ov & لا ينطبق & 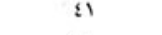 & 09 & بنات \\
\hline ri & ra & o. & لا ينطبق & of & 79 & بنين \\
\hline ri & ro & ro & vr & r & r. & مختلطة بالكامل \\
\hline . & n & ra & $1 .$. & ¿^ & Ar & مختلطة مى فمسل تقتتمر علي احد الجنسبن \\
\hline & & & & & & 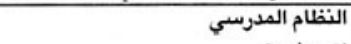 \\
\hline 19 & 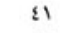 & ๕. & $\mathrm{v \varepsilon}$ & $\varepsilon 9$ & $\mathrm{v}$. & غتره واحدة \\
\hline ir & ¿r & 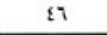 & ar & 17 & ri & اكتر من فترة: \\
\hline & & & & & & المستوى التعليمى للمجتمع المحلى \\
\hline "1 & ור & or & $\wedge \varepsilon$ & r & $0 ؟$ & منخفض م \\
\hline rr & ra & $\because$ & u & $\{r$ & $" 1$ & متوسط \\
\hline in & .9 & $r \varepsilon$ & $1 .$. & or & .9 & 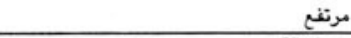 \\
\hline & & & & & & المنطقة \\
\hline rr & 07 & rr & 1.. & $\llbracket$ & $\llbracket$ & المحافظلات الحضرية \\
\hline ir & $\varepsilon r$ & $\llbracket$ & n & 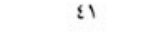 & u & الدلتا \\
\hline rr & ra & $\S$ & Ar & ¿^ & ¿^ & 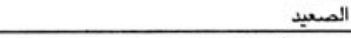 \\
\hline YI & & & & & & حجم الفصل \\
\hline ir & iv & v. & $1 .$. & $r i, v^{\prime \prime N}$ & ir, & 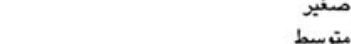 \\
\hline . & \&r & or & $1 .$. & 0,1 & $0 .,$. & كبير \\
\hline iv & \& & \&r & A. & $r^{4}$ & OA & 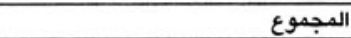 \\
\hline$v_{0}$ & $v_{0}$ & vo & $r r$ & vo & vo & عدد الحالات \\
\hline
\end{tabular}

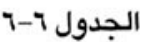

استخدام الطلاب لمراحيض المدرسة و تصورهم للخصوصية داخل دورات المياة: النسبة المئوية حسب المتغيرات الخلفية الفرديةو المدرسية

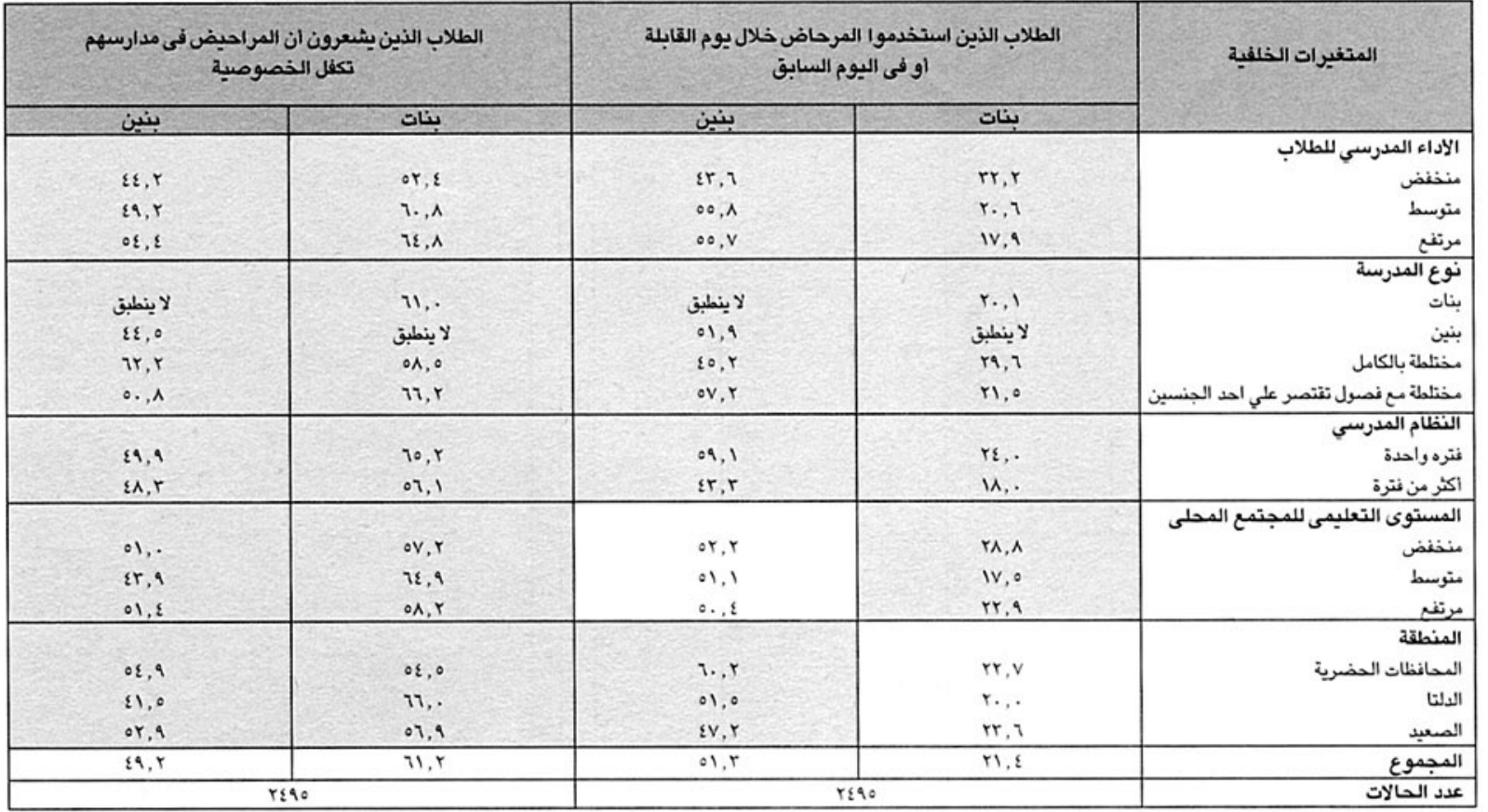




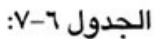
النسبة المئوية للمدارس وفق توافرالأنشطة و الحجرات المخصصة للأخصائيين الاجتماعيين و الحديقه، و حجم فناء المدرسه، حسب المتغيرات الخلفيه الفردية و المدرسية

\begin{tabular}{|c|c|c|c|c|c|c|c|}
\hline \multicolumn{2}{|c|}{ فناء المدرسة } & \multirow{2}{*}{ النزرسية } & \multirow{2}{*}{ الاخصنماءئى } & \multicolumn{3}{|c|}{ حجرات الانشطة } & \multirow[b]{2}{*}{ المتغيرات الخلفية } \\
\hline 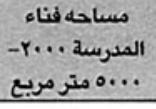 & 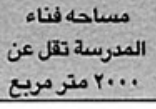 & & & للانشطة حجرة & عند لحجريدات & حترات الانشطة & \\
\hline $\begin{array}{l}1 \leqslant, r \\
4, r \\
1, r\end{array}$ & 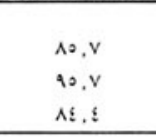 & $\begin{array}{l}\varepsilon r, q \\
\varepsilon v, \Lambda \\
i \Lambda, \Lambda\end{array}$ & $\begin{array}{l}v ., 7 \\
v 1,9 \\
M, 9\end{array}$ & $\begin{array}{l}\ddots r \\
\cdots \\
\mathrm{k}, \mathrm{r}\end{array}$ & $\begin{array}{l}\text { vi, } 2 \\
90, v \\
\wedge 1, \wedge\end{array}$ & $\begin{array}{l}v r, \varepsilon \\
90, v \\
1 \ldots . .\end{array}$ & منخفض الاداء الدراسي للطلاب \\
\hline $\begin{array}{l}i r . \\
v, v \\
m, 1 \\
\cdots\end{array}$ & $\begin{array}{l}\text { Ar. } \\
\text { Ar.r } \\
M, 9 \\
9 ., 0\end{array}$ & $\begin{array}{l}\wedge, v \\
\wedge \leqslant, 1 \\
\varepsilon 1, r \\
19, .\end{array}$ & $\begin{array}{l}97,1 \\
\wedge ., . \\
\varepsilon v, \varepsilon \\
\text { vi, }\end{array}$ & $\begin{array}{l}11, r \\
17, v \\
\cdots \\
\cdots \\
\end{array}$ & $\begin{array}{l}w, r \\
\wedge r, r \\
w, \Lambda \\
90,0\end{array}$ & $\begin{array}{l}90,0 \\
1 \ldots, 0 \\
w, 1 \\
90,0\end{array}$ & بنات بنتين \\
\hline $\begin{array}{l}1, v \\
r ., . \\
\end{array}$ & $\begin{array}{l}9 r, 1 \\
1 ., . \\
\end{array}$ & $\begin{array}{l}r ., 0 \\
\leqslant 1, r\end{array}$ & $\begin{array}{l}\text { A }\{, r \\
\text { ๆ }, 1\end{array}$ & $\begin{array}{l}1 . r \\
\ldots \\
\end{array}$ & $\begin{array}{l}w v .1 \\
91 . .\end{array}$ & $\begin{array}{l}1 \mathrm{v}, 9 \\
91, .\end{array}$ & 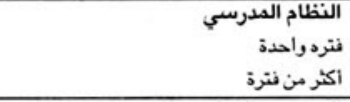 \\
\hline $\begin{array}{l}11,1 \\
r, 1 \\
11,1\end{array}$ & $\begin{array}{l}M, 9 \\
\text { Av, } \\
\Lambda, r\end{array}$ & $\begin{array}{l}\text { rv, } \\
\text { ri,r } \\
\text { ro,r }\end{array}$ & $\begin{array}{l}u, r \\
u, \wedge \\
u r, \wedge\end{array}$ & $\begin{array}{r}\because, 1 \\
r q, \varepsilon\end{array}$ & $\begin{array}{l}A ., . \\
q r, \wedge \\
v ., 1\end{array}$ & $\begin{array}{l}1 ., . \\
47,9 \\
1 \ldots .\end{array}$ & 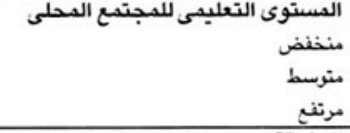 \\
\hline $\begin{array}{l}\cdots \\
r, r \\
i n, \Lambda\end{array}$ & $\begin{array}{l}\text { Av, o. } \\
\text { Ar,. } \\
\text { Al, r }\end{array}$ & $\begin{array}{l}00,7 \\
r \leqslant, 1 \\
r 9 .\end{array}$ & $\begin{array}{l}1 \ldots . \\
10,9 \\
M, .\end{array}$ & $\begin{array}{l}\varepsilon \varepsilon, \varepsilon \\
r, r \\
r, 1\end{array}$ & $\begin{array}{l}00,1 \\
9 r, r \\
\text { vo., }\end{array}$ & $\begin{array}{l}1 \ldots, 0 \\
90,0 \\
\mathrm{vA}, 1\end{array}$ & 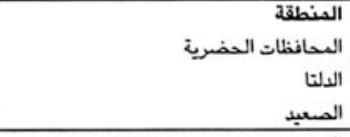 \\
\hline$\wedge, 1$ & M.r & $r \leqslant, v$ & $\mathrm{vA}, \cdot$ & $V, r$ & $\Lambda \mathrm{r}, \Lambda$ & $9 . .$. & المجموع \\
\hline vo & vo & vo & vo & vo & $v_{0}$ & vo & عدد الحالات \\
\hline
\end{tabular}

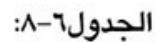
نسب التوزيع المئوية للمعلمين من الذكور و الإناث و المعلمين ذوى المؤهلات التعليمية، و الذين يعدون موظفين دائمين في الوزارة، حسب المتغيرات الخلفية الفردية و المدرسية النية

\begin{tabular}{|c|c|c|c|c|}
\hline \multirow{2}{*}{ الموظلفين الدائمين } & \multirow{2}{*}{ الموهلات التعليمبة } & \multicolumn{2}{|c|}{ المعلمون } & \multirow{2}{*}{ المتغيرات الخلفيه } \\
\hline & & إناث & نكور & \\
\hline & & & & الاداء الددرسي للطلاب \\
\hline 97.8 & 11.9 & ra,r $r$ & $v, \cdot v$ & منخفض \\
\hline ar, $r$ & $\mathrm{n}, \mathrm{l}$ & $r a, r$ & $1 ., \mathrm{v}$ & متوسط \\
\hline $1 \ldots$, & 10,9 & $\varepsilon 9, \mathrm{r}$ & $0,1,1$ & مرتنغ \\
\hline $1 \ldots$. & $\Delta r, v$ & $0, v$ & $\Leftrightarrow \varepsilon, \mathrm{r}$ & نونات الدرسة \\
\hline $9 \mathrm{v}, \mathrm{r}$ & $v \leqslant, r$ & $1 \mathrm{~A}, 9$ & $\wedge 1,1$ & بنين \\
\hline $9 r .9$ & $\Delta r, \mathrm{~T}$. & rA, V & $v i, r$ & مختلطة بالكامل \\
\hline १४, r & $\wedge$ ^... & $0 ., 8$ & $\$ 9,7$ & مختلطة مب فصصل تثتتصر علي احد الجنسين \\
\hline & & & & النظام الدررسي \\
\hline $9 \mathrm{v}, \mathrm{r}$ & Ar, r & rq.1 & 1.9 & فترد واحدة \\
\hline $97 . \mathrm{V}$ & $v a, r$ & $\$ 1,1$ & $0 \mathrm{A.9}$ & أكثر من فترة \\
\hline & & & & الدستوى التعليدى للمجتمع الححلى \\
\hline $9 \mathrm{v}, 1$ & $\wedge \cdot, \Lambda$ & $r a, v$ & v., $r$ & 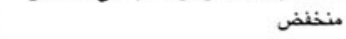 \\
\hline 90,1 & $\Delta r, q$ & 01,8 & $\{\Lambda, \uparrow$ & مترسط \\
\hline $1 \ldots$ & A., v & $r a, r$ & $1,1,1$ & 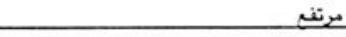 \\
\hline & & & & المنطقة \\
\hline $1 \ldots, \cdot$ & $v_{0}, 9$ & $\varepsilon r, A$ & $\cdot 1, r$ & الححافظلات الحضرية \\
\hline qv, r & $\Lambda_{0}, 1$ & $\llbracket \llbracket, v$ & $00, r$ & الدلتا \\
\hline$\$ 1, r$ & $\mathrm{~V}, \mathrm{\varepsilon}$ & ri,v & $u, r$ & الصعبد \\
\hline $9 \mathrm{v}, 1$ & $\Delta r, \cdot$ & $\mathrm{ra}, \mathrm{V}$ & $7 ., \mathrm{r}$ & 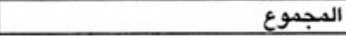 \\
\hline s $\mathrm{v}_{0}$ & sn & & & 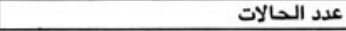 \\
\hline
\end{tabular}


الجدول ז-9:

نسب التوزيع المئوية للمعلمين وفق العمر و الخبرة المهنية، و النسبة المئوية لمن تلقوا التدريب مؤخرأ، حسب المتغيرات الخلفية الفردية و المدرسية

\begin{tabular}{|c|c|c|c|c|c|c|c|c|c|}
\hline \multirow{2}{*}{ التدريب عن } & \multirow{2}{*}{ خلال السينتين } & \multicolumn{2}{|c|}{ سنوات التدريس فى المدرسه الحالية } & \multicolumn{2}{|c|}{ السنوات التى امضوهـا فى } & \multicolumn{3}{|c|}{ اعمار المعلمين } & \multirow{2}{*}{ المتغيرات الخلفية } \\
\hline & & ro-11 & $1 \cdot-1$ & $m-11$ & $1 \cdot-1$ & $O V-E 1$ & $\varepsilon \cdot-r \mid$ & $r \cdot-11$ & \\
\hline$r a, 7$ & or, 9 & A,r & $\$ 1,1$ & $r \varepsilon,$. & $\pi,$. & $0, r$ & $\{7,1$ & $\{\Lambda, V$ & انوع المجيب \\
\hline$r a, 8$ & or, $r$ & $i r, r$ & $\Delta 1, \mathrm{v}$ & rA, $\varepsilon$ & 711 & $v, 0$ & $\circ 9, r$ & $r r, r \varepsilon$ & نكر \\
\hline & & & & & & & & & الاداء الدراسي للطلاب \\
\hline$\{., 1$ & 00,1 & 14,1 & Av, 9 & $r 1,0$ & $u, 0$ & $r, \varepsilon$ & ov, : & $\varepsilon .\rceil$, & منخفض \\
\hline$\varepsilon_{0}$, & or, 1 & 9,7 & 9. . & $r a, r$ & 1., $\mathrm{v}$ & 1,9 & $\varepsilon v, \varepsilon$ & $\varepsilon r, v$ & هتوسمط \\
\hline$r \varepsilon, r$ & $0, r$ & 11,7 & $M, \varepsilon$ & $\varepsilon \cdot, \cdot$ & 1.,. & 1,0 & 07,1 & $r \varepsilon, q$ & مرتغع \\
\hline$\varepsilon \varepsilon, \varepsilon$ & ir, r & 7,1 & $4 r, 9$ & $\varepsilon r, 0$ & 07,0 & 7,9 & $00,$. & rA, r & بنات نوع المدرسة \\
\hline $0, v$ & $\circ v, 0$ & r.,. & A., . & or,. & $\varepsilon \wedge$, & $r 1,9$ & 01, r & $r 1,9$ & \\
\hline$r, r$ & $0 ., 9$ & 11,7 & $M, \varepsilon$ & $r 1,0$ & $u, 0$ & -1 & or, $v$ & $\varepsilon 0, v$ & مختلطة بالكامل \\
\hline ri,. & $\{r\}$, & 11,1 & M,r & $\mathrm{rn}, \mathrm{q}$ & vr, 1 & $\varepsilon, r$ & or, 1 & $\varepsilon r,$. & مختلطة مع فصول نفتصر علي احد الجنسين \\
\hline & & & & & & & & & النظام المدرسي الم \\
\hline$r 9,1$ & or,. & ir, & $A v, 1$ & $r_{0, r}$ & $1 \varepsilon, \wedge$ & $1, r$ & or, $v$ & $\$ 1,1$ & فتره واحدة \\
\hline$r \wedge, 0$ & or, \{ & $9, r$ & 4., $\mathrm{v}$ & $\{., \varepsilon$ & 09,1 & $v, r$ & $\circ \mathrm{V}, \mathrm{T}$ & $r_{0}, 1$ & أكثر من غترة \\
\hline & & & & & & & & & المستوى التعليمى للمجتمع المحلى \\
\hline ri, r & $\circ\},\{$ & Ir, \{ & ᄉт, 1 & $\mathrm{rr}, \cdot$ & iv,. & $r, r$ & ov, 9 & $r \wedge, \wedge$ & منخفض \\
\hline$\varepsilon r, \cdot$ & $\leq 9,1$ & 7,7 & $4 r, \varepsilon$ & $r r, q$ & 17,1 & $\varepsilon, \varepsilon$ & $\varepsilon 9, r$ & $\varepsilon 1, \varepsilon$ & منوسط \\
\hline$£ 1, r$ & $07, \mathrm{v}$ & 10,0 & $\Lambda \varepsilon, 0$ & $0 ., 0$ & $£ 9,0$ & IV,0 & $00, v$ & $\mathrm{rr}, \mathrm{A}$ & مرنفع \\
\hline & & & & & & & & & المنقلة \\
\hline$\llbracket \wedge$, & $\bullet \wedge, \cdot$ & $17,$. & $\wedge \varepsilon, \cdot$ & $\bullet 9, r$ & $\varepsilon \cdot, \wedge$ & $r, 0$ & ov, I & $17, r$ & الححافظلات الحضرية \\
\hline$r_{\Lambda, T}$ & $0 ., 8$ & $1 ., 0$ & 19,0 & $r \varepsilon, r$ & 70,1 & $r, q$ & 00,0 & $\{., 1$ & الدلتا الئا \\
\hline$r v, s$ & $0 \leqslant, 9$ & $11 .$. & $\wedge 9 .$. & $r \varepsilon, \varepsilon$ & 10,0 & $\varepsilon, \varepsilon$ & or, o & $\varepsilon r, r$ & المعبد \\
\hline$r a, r$ & or, 9 & $11, r$ & $M, V$ & $r, \wedge$ & ir, r & 1,0 & $0 \varepsilon, r$ & $r q, r$ & المجموع \\
\hline$r_{10}$ & ¿A. & & & & & & (1) & & عدد الحالات \\
\hline
\end{tabular}

الجدولז-.1:

نسب التوزيع المئوية للمعلمين وفق مقدار التدريس و المسئوليات الأخرى، و الرضا عن عبء العمل،حسب المتغيرات الخلفية الفردية

و المدرسية

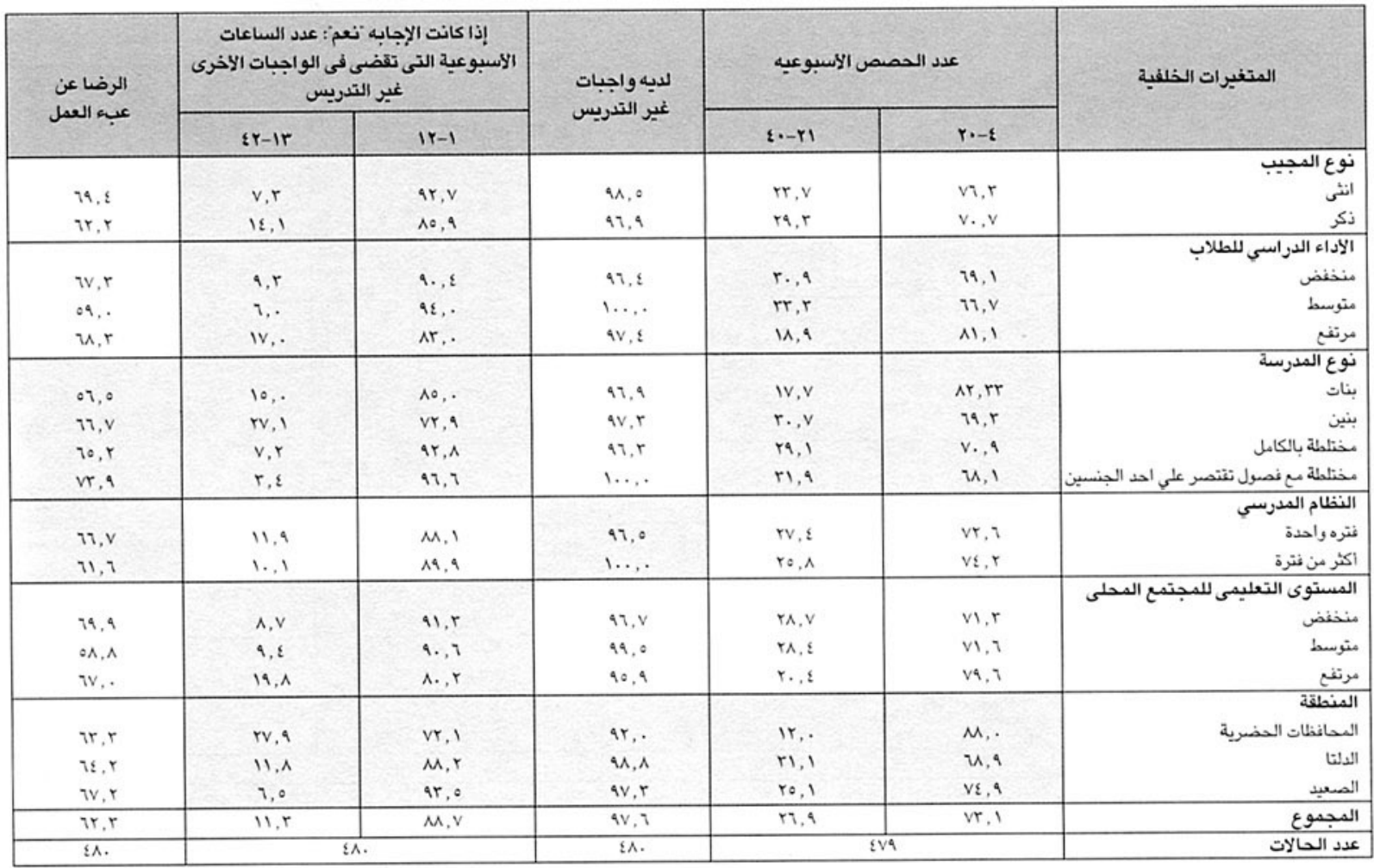


الجدولج-11: (1) مقدار الإثراف على المعلم: النسبة المئوية للمعلمين الذين يخضعون للإثراف المركزى و الإثراف على مستوى المديرية و المدرسة ،حسب المتغيرات الخلفية الفردية والمعلية الندربية

\begin{tabular}{|c|c|c|c|c|c|}
\hline من بين الموالاه: النياتين & داخل المدربسة من & من بين المواحلاء النقين & مستوى المنيرية & إثراف مركزي & المتغيرات الخلفية \\
\hline $\begin{array}{l}91, v \\
10,0\end{array}$ & $\begin{array}{l}91, . \\
11, v\end{array}$ & $\begin{array}{r}91,0 \\
\quad 17,9\end{array}$ & $\begin{array}{l}9 v, 7 \\
9 r, 9\end{array}$ & $\begin{array}{l}r ., q \\
r r . .\end{array}$ & نوكر النى \\
\hline $\begin{array}{l}9 ., Y \Lambda \\
A v, v \\
\Lambda 9,1\end{array}$ & $\begin{array}{l}90, r \\
9 r, 1 \\
9 \varepsilon, r\end{array}$ & $\begin{array}{l}\text { q., r. } \\
\text { A , } 9 \\
9 r, \wedge\end{array}$ & $\begin{array}{l}97,1 \\
97, r \\
90,8\end{array}$ & $\begin{array}{l}r \varepsilon, v \\
r v, r \\
\varepsilon 1, r\end{array}$ & $\begin{array}{r}\text { متخفض الاداء الدراسي للطلاب } \\
\text { مترسط }\end{array}$ \\
\hline $\begin{array}{l}\wedge 1,1 \Lambda \\
q r, r \\
\$ 1, \Lambda \\
\text { Av,. }\end{array}$ & $\begin{array}{l}9 \xi, r \\
M, 1 \\
9 \mathrm{v}, 1 \\
9 \mathrm{r}, \mathrm{s}\end{array}$ & $\begin{array}{l}\text { A } \varepsilon, r \\
\text { Av,r } \\
90, \mathrm{~T} \\
\text { A9,r }\end{array}$ & $\begin{array}{l}9 \mathrm{qr}, \mathrm{s} \\
9 \varepsilon, \mathrm{s} \\
9 \mathrm{v}, \mathrm{A} \\
9 \mathrm{v}, \mathrm{r}\end{array}$ & $\begin{array}{l}r 9, r \\
0 \wedge, r \\
11, \varepsilon \\
r \Lambda, r\end{array}$ & بنين بنتاتة بالكامل \\
\hline $\begin{array}{l}\text { ar,. } \\
\text { Ar, }\end{array}$ & $\begin{array}{l}\text { १r, } \\
9, r, r\end{array}$ & $\begin{array}{l}9 ., \mathrm{V} \\
\mathrm{Av}, \mathrm{0}\end{array}$ & $\begin{array}{l}90,0 \\
9 ., r\end{array}$ & $\begin{array}{l}r, ., \\
r, r\end{array}$ & أكترد واحدة النظام المدرسي \\
\hline $\begin{array}{l}\Lambda q, r \\
a r, r \\
\Delta r, 1\end{array}$ & $\begin{array}{l}9 v, 1 \\
9 r, r \\
9 ., r\end{array}$ & $\begin{array}{l}91, \mathrm{v} \\
9 \varepsilon, 8 \\
\text { v1,0 }\end{array}$ & $\begin{array}{l}9 v, 1 \\
91,1 \\
0 ., 5\end{array}$ & $\begin{array}{l}r \Lambda, \varepsilon \\
r q, . \\
\lfloor\varepsilon, \Lambda\end{array}$ & 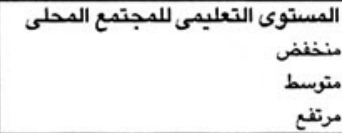 \\
\hline $\begin{array}{l}\text { vo,. } \\
9 \text { a., } \\
91,0\end{array}$ & $\begin{array}{l}11,1 \\
90, r \\
90,9\end{array}$ & $\begin{array}{l}10,1 \\
9 \varepsilon, r \\
19, v\end{array}$ & $\begin{array}{l}\mathrm{Av}, \hat{\Lambda} \\
90,1 \\
9 \mathrm{M}, \mathrm{.}\end{array}$ & $\begin{array}{l}o \varepsilon, . \\
r r_{1} . \\
r_{0,1}\end{array}$ & المحافظات الحضرية المطنا \\
\hline $19, r$ & $9 \$, 1$ & 19.7 & 90,9 & $r 1,9$ & المجموع \\
\hline rao & โrV & โ. & โrv & โrV & عدد الحالات \\
\hline
\end{tabular}




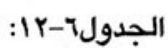
النسبة المئوية للمدارس التى تعانى نقصاً عاماً فى المعلمين و نقص المعلمين وفق المادة، حسب المتغيرات الخلفية الفردية والمدرسية

\begin{tabular}{|c|c|c|c|c|c|c|c|c|c|c|}
\hline 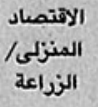 & الاتشططة & الفن & الرياضبية & الاجتماعية & العلوم & الرياضيات & الإنجليزية & اللغه العربية & المعلدبن & المتغيرات الخلقية \\
\hline $\begin{array}{l}r_{0} . . \\
\ldots .\end{array}$ & $\begin{array}{l}r \varepsilon, \varepsilon \\
9,1\end{array}$ & $\begin{array}{l}10,9 \\
9,1\end{array}$ & $\begin{array}{l}r 1, r \\
9,1\end{array}$ & $\begin{array}{l}1 ., 9 \\
9,1\end{array}$ & $\begin{array}{l}\varepsilon, v \\
\ldots .\end{array}$ & $\begin{array}{l}10.1 \\
\ldots .\end{array}$ & $\begin{array}{l}r ., r \\
\ldots .\end{array}$ & $\begin{array}{l}r \varepsilon, \varepsilon \\
r \eta, \varepsilon\end{array}$ & $\begin{array}{l}u, \wedge \\
0\{, 0\end{array}$ & نوني النئ المجيب \\
\hline $\begin{array}{l}r r .8 \\
9,1 \\
r i, \varepsilon\end{array}$ & $\begin{array}{l}\varepsilon, . \\
r r, v \\
r o, .\end{array}$ & $\begin{array}{l}17, . \\
9,0 \\
1 \varepsilon, r\end{array}$ & $\begin{array}{l}r r, \\
r i, i \\
r, \varepsilon\end{array}$ & $\begin{array}{l}\because, r \\
i n, r \\
i \varepsilon, r\end{array}$ & $\begin{array}{l}A, \cdot \\
q, 1 \\
\cdots\end{array}$ & $\begin{array}{l}17, . \\
r A, 1 \\
\cdots,\end{array}$ & $\begin{array}{l}r, . . \\
r i, \lambda \\
v, 1\end{array}$ & $\begin{array}{l}r r, \cdot \\
r \Lambda, \tau \\
\varepsilon \leqslant, \Lambda\end{array}$ & $\begin{array}{l}1 \varepsilon, \cdot \\
09,1 \\
v 1, \varepsilon\end{array}$ & 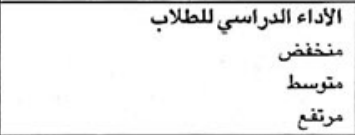 \\
\hline $\begin{array}{l}1 \mathrm{iv}, \varepsilon \\
\cdots \\
1 \varepsilon, r \\
v r, v\end{array}$ & $\begin{array}{l}r, v \\
r, 1 \\
r 0,9 \\
r .1\end{array}$ & $\begin{array}{l}\varepsilon, r \\
r i, \varepsilon \\
1,, v \\
\varepsilon 0,0\end{array}$ & $\begin{array}{l}r i, v \\
r n, \varepsilon \\
r, \varepsilon \\
r, v\end{array}$ & $\begin{array}{l}\mathrm{iv}, \varepsilon \\
\cdots, \\
v, 1 \\
\mathrm{u}, \mathrm{r}\end{array}$ & $\begin{array}{l}\cdots \\
\cdots, \\
r, v \\
u, r\end{array}$ & $\begin{array}{l}\varepsilon, r \\
\cdots \\
r 0, q \\
u, r\end{array}$ & $\begin{array}{l}A, v \\
10,8 \\
r r, r \\
r v, r\end{array}$ & $\begin{array}{l}r q, r \\
r r, 1 \\
r r, r \\
1 \ldots, r\end{array}$ & $\begin{array}{l}\pi 1, v \\
\varepsilon 7, r \\
09, r \\
1 \ldots, r\end{array}$ & 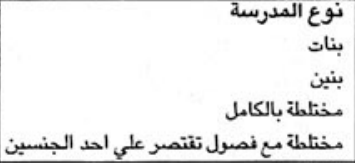 \\
\hline $\begin{array}{l}r r, 0 \\
r i, v\end{array}$ & $\begin{array}{l}r 1, \varepsilon \\
r o, .\end{array}$ & $\begin{array}{l}\text { Ir.v } \\
0, r\end{array}$ & $\begin{array}{l}r_{0}, r \\
r_{r}, 0\end{array}$ & $\begin{array}{l}v, \lambda \\
11, v\end{array}$ & $\begin{array}{l}r, \lambda \\
\Lambda, r\end{array}$ & $\begin{array}{l}10,8 \\
1 \%, 0\end{array}$ & $\begin{array}{l}19,1 \\
11 . .\end{array}$ & $\begin{array}{l}r \cdot, \Lambda \\
\varepsilon v, \Lambda\end{array}$ & $\begin{array}{l}11, v \\
10, r\end{array}$ & 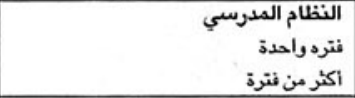 \\
\hline $\begin{array}{l}\mathrm{ru}, \mathrm{v} \\
\mathrm{rA,T} \\
\cdots\end{array}$ & $\begin{array}{l}\text { ri.e } \\
\text { ro,. } \\
\text { ro,r }\end{array}$ & $\begin{array}{l}r, v \\
\cdots, r \\
\cdots, \Lambda\end{array}$ & $\begin{array}{l}r ., . \\
r \wedge, t \\
r r, 0\end{array}$ & $\begin{array}{l}\cdots \\
r o, . \\
\cdots\end{array}$ & $\begin{array}{l}r .8 \\
1,4 \\
\cdots\end{array}$ & $\begin{array}{l}r, v \\
1 \leqslant, r \\
\cdots\end{array}$ & $\begin{array}{l}11, v \\
r, 8 \\
11,1\end{array}$ & $\begin{array}{l}\imath 1, \varepsilon \\
r o, v \\
r, 0\end{array}$ & $\begin{array}{l}10,0 \\
v 0,9 \\
0 ., .\end{array}$ & مترنفيط \\
\hline $\begin{array}{l}\cdots \\
r i, r \\
r i, \varepsilon\end{array}$ & $\begin{array}{l}r r, r \\
r r, r \\
r 0,9\end{array}$ & $\begin{array}{l}r r, r \\
i v, q \\
1 ., v\end{array}$ & $\begin{array}{l}r r, r \\
r r, v \\
r o, v\end{array}$ & $\begin{array}{l}\because \ddot{ } \\
1 \mathrm{k}, \varepsilon \\
\cdots,\end{array}$ & $\begin{array}{l}\because, \\
\mathrm{v}, \mathrm{v} \\
\cdots\end{array}$ & $\begin{array}{l}\cdots \\
v, v \\
r \Lambda, i\end{array}$ & $\begin{array}{l}\cdots \\
r ., 0 \\
\text { ru, }\end{array}$ & $\begin{array}{l}\because, r \\
21, r \\
r r, 1\end{array}$ & $\begin{array}{l}r r, r \\
v i, q \\
09, r\end{array}$ & 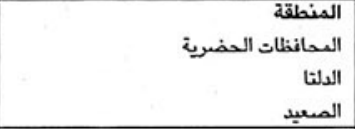 \\
\hline$r 1, \varepsilon$ & 89,9 & $1 \varepsilon, v$ & $r \Lambda, 1$ & $1 . r$ & $\varepsilon, r$ & $i r, q$ & iv, 9 & ro.v & 10,9 & المجموع \\
\hline $\mathrm{v}_{0}$ & $\mathrm{v}_{0}$ & $\mathrm{v}_{0}$ & $\mathrm{v}_{0}$ & $v_{0}$ & $v_{0}$ & $v_{0}$ & $v_{0}$ & $v_{0}$ & $v_{0}$ & عدد الحالات \\
\hline
\end{tabular}




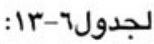

النسبة المئوية للأخصائين الاجتماعيين الذين أفادوا وجود أخرين يساعدونهم بشأن مشكلات الطلاب، و مسئولياتهم الاكثر شيوعاً، حسب المتغيرات الخلفية الفردية والمدرسية

\begin{tabular}{|c|c|c|c|c|c|c|c|c|}
\hline \multicolumn{7}{|c|}{ المسئوليات الاكثر شيوعاً (بخلاف المساعده في حل مشكلات الطلاب) } & \multirow[b]{2}{*}{ في المساعداه بشارسين } & \multirow[b]{2}{*}{ 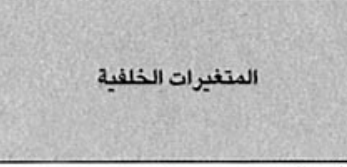 } \\
\hline الالإدارىى الإنى & الثشطة الطلاب الإخى & اتحاد الطلاب & على الفصول & الالإنشبط غير على & تنظيمندوات & تنظيمِرحلات & & \\
\hline $\begin{array}{l}r q \\
r r\end{array}$ & $\begin{array}{l}\because . \\
r i\end{array}$ & $\begin{array}{l}r r \\
00\end{array}$ & $\begin{array}{l}r \\
r r\end{array}$ & $\begin{array}{l}r r \\
r r\end{array}$ & $\begin{array}{l}10 \\
v .\end{array}$ & $\begin{array}{l}10 \\
90\end{array}$ & $\begin{array}{l}\text { Q1 } \\
\text { Ar }\end{array}$ & 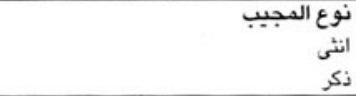 \\
\hline $\begin{array}{l}\$ 1 \\
\vdots 1 \\
19\end{array}$ & $\begin{array}{l}\& v \\
01 \\
r A\end{array}$ & $\begin{array}{l}\text { ro } \\
\vdots 1 \\
\text { or }\end{array}$ & $\begin{array}{l}\text { ir } \\
17 \\
\text { rr }\end{array}$ & $\begin{array}{l}\text { ir } \\
\text { ri } \\
\text { iv }\end{array}$ & $\begin{array}{l}10 \\
01 \\
1 .\end{array}$ & $\begin{array}{l}\text { Ar } \\
\wedge \varepsilon \\
\text { AI }\end{array}$ & $\begin{array}{l}\text { vv } \\
\text { qv } \\
\text { ar }\end{array}$ & منتخف الأداء الدراسي للطلاب \\
\hline $\begin{array}{l}r v \\
r_{0} \\
u \\
r\end{array}$ & $\begin{array}{l}\varepsilon v \\
r_{0} \\
u \\
r_{0}\end{array}$ & $\begin{array}{l}r \wedge \\
\varepsilon \\
\varepsilon r \\
i r\end{array}$ & $\begin{array}{l}\text { ra } \\
20 \\
0 \\
1\end{array}$ & $\begin{array}{l}\text { iv } \\
r . \\
\varepsilon r \\
\text { in }\end{array}$ & $\begin{array}{l}\text { or } \\
\text { lo } \\
\text { As } \\
\text { W }\end{array}$ & $\begin{array}{l}\text { vo } \\
\text { so } \\
1 \ldots \\
\text { Ar }\end{array}$ & $\begin{array}{l}9 \mathrm{~V} \\
90 \\
\text { A } \\
\text { A1 }\end{array}$ & 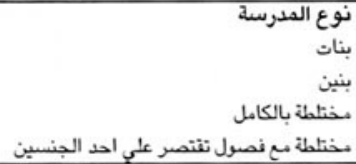 \\
\hline $\begin{array}{l}r_{0} \\
r \varepsilon\end{array}$ & $\begin{array}{l}\text { \& } \\
\text { s }\end{array}$ & $\begin{array}{l}\leqslant 0 \\
11\end{array}$ & $\begin{array}{l}r r \\
r \varepsilon\end{array}$ & $\begin{array}{l}r \varepsilon \\
r 1\end{array}$ & $\begin{array}{l}19 \\
10\end{array}$ & $\begin{array}{l}\text { A. } \\
\text { A. }\end{array}$ & $\begin{array}{l}A \varepsilon \\
1 \ldots\end{array}$ & 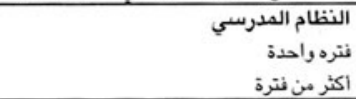 \\
\hline $\begin{array}{l}r r \\
r \Lambda \\
r r\end{array}$ & $\begin{array}{l}r 7 \\
\text { or } \\
\text { ra }\end{array}$ & $\begin{array}{l}r 7 \\
\text { or } \\
\vdots 1\end{array}$ & $\begin{array}{l}9 \\
17 \\
r i\end{array}$ & $\begin{array}{l}17 \\
\text { ri } \\
19\end{array}$ & $\begin{array}{l}18 \\
\wedge 1 \\
0 \wedge\end{array}$ & $\begin{array}{l}\text { Ai } \\
9 . \\
\text { vr }\end{array}$ & $\begin{array}{l}\text { Ar } \\
\text { Av } \\
1 . .\end{array}$ & متخفض مترنف التعليمى للمجتمع المحلى \\
\hline $\begin{array}{l}\text { ir } \\
\vdots 1 \\
r \alpha\end{array}$ & 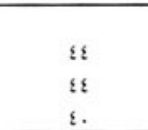 & $\begin{array}{l}r_{0} \\
\vdots 1 \\
\vdots\end{array}$ & $\begin{array}{l}0 . \\
\text { if } \\
r .\end{array}$ & $\begin{array}{l}\text { ir } \\
r_{0} \\
r \varepsilon\end{array}$ & $\begin{array}{l}\text { ir } \\
\text { A. } \\
\text { ¿A }\end{array}$ & $\begin{array}{l}\varepsilon v \\
\wedge q \\
q r\end{array}$ & $\begin{array}{l}1 . . \\
\wedge \varepsilon \\
१ 1\end{array}$ & 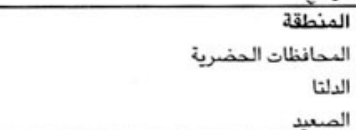 \\
\hline$r$ & 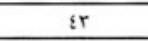 & $\varepsilon r$ & $\mathrm{rr}$ & $\pi r$ & $\mathrm{Tv}$ & Ar & 91 & المجهوع \\
\hline A. & Ao & 10 & $\Lambda_{0}^{\circ}$ & Ao & Ao & $\Lambda^{\circ}$ & $\Lambda_{0}^{\circ}$ & عدد الحالات \\
\hline
\end{tabular}



مقدار تفاعل الاخصائى الاجتماعى مع مجموعات من الطلاب و النسبه المئوية لمن افادوا مناقشه قضايا محذدة خلال اللقاءات (القضايا الاكثر شيوعاً فقط)، حسب المتغيرات الخلفية الفردية و المدرسية

\begin{tabular}{|c|c|c|c|c|c|c|c|c|c|}
\hline \multicolumn{8}{|c|}{ القضايا الاكثر شيوعاً التى تم تناولها في اللقاءات مع الطلاب } & \multirow{2}{*}{ 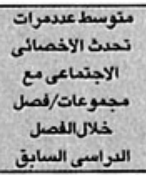 } & \multirow[b]{2}{*}{ المتغيرات الخلفية } \\
\hline أو الدخدرات & المدرسية & حسن معاملة & السيئة العادات & الزى المحترم & المدرسة & التطلعات & لور الاخصائي & & \\
\hline r. & $\begin{array}{l}r \\
\varepsilon r\end{array}$ & $\begin{array}{l}17 \\
19\end{array}$ & $\begin{array}{l}r \\
r r\end{array}$ & $\begin{array}{l}1 \varepsilon \\
\mathrm{r}\end{array}$ & $\begin{array}{l}1 . \\
\text { ri }\end{array}$ & $\begin{array}{l}r 7 \\
r r\end{array}$ & $\begin{array}{l}\text { ir } \\
\text { is }\end{array}$ & $\begin{array}{l}\ell, v \\
v, \wedge\end{array}$ & نوئ المجيب \\
\hline $\begin{array}{l}\text { ra } \\
9 \\
1 \leqslant\end{array}$ & $\begin{array}{l}\text { a } \\
\text { ir } \\
\text { ro }\end{array}$ & $\begin{array}{l}\text { in } \\
\text { r } \\
r_{0}\end{array}$ & $\begin{array}{l}r \varepsilon \\
r \wedge \\
r i\end{array}$ & $\begin{array}{l}\varepsilon v \\
r \wedge \\
0 .\end{array}$ & $\begin{array}{l}14 \\
4 \\
19\end{array}$ & $\begin{array}{l}r_{9} \\
r \varepsilon \\
r_{0}\end{array}$ & $\begin{array}{l}r \varepsilon \\
r \\
i v\end{array}$ & $\begin{array}{l}1, v \\
0, r \\
0,9\end{array}$ & متروسط الاداء الدراسي للطلاب \\
\hline $\begin{array}{l}\text { r. } \\
17 \\
19\end{array}$ & $\begin{array}{l}r \\
\varepsilon . \\
17 \\
\varepsilon 1\end{array}$ & $\begin{array}{l}r \\
r . \\
\text { r. } \\
\text { it } \\
.\end{array}$ & $\begin{array}{l}r r \\
r . \\
i v \\
i n\end{array}$ & $\begin{array}{l}19 \\
1 . \\
\text { ri } \\
10\end{array}$ & $\begin{array}{c}18 \\
0 \\
17 \\
19\end{array}$ & $\begin{array}{l}\xi 1 \\
r_{0} \\
r 7 \\
\text { ir }\end{array}$ & $\begin{array}{l}\text { iv } \\
\text { in } \\
r \varepsilon\end{array}$ & $\begin{array}{l}0,0 \\
0,1 \\
0,8 \\
0,4\end{array}$ & 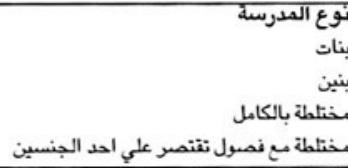 \\
\hline $\begin{array}{l}r . \\
9\end{array}$ & $\begin{array}{l}r 1 \\
9\end{array}$ & $\begin{array}{l}r A \\
.\end{array}$ & $\begin{array}{l}r A \\
r a \\
r a\end{array}$ & $\begin{array}{l}\varepsilon r \\
0 .\end{array}$ & $\begin{array}{l}r r \\
4\end{array}$ & $\begin{array}{l}r q \\
r q\end{array}$ & $\begin{array}{l}\text { ir } \\
\text { ir }\end{array}$ & $\begin{array}{l}1, v \\
0,1\end{array}$ & 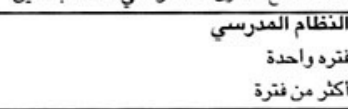 \\
\hline $\begin{array}{l}r r \\
1 . \\
i 1\end{array}$ & $\begin{array}{l}r 7 \\
\text { ir } \\
19\end{array}$ & $\begin{array}{l}i r \\
1 . \\
\text { ri }\end{array}$ & $\begin{array}{l}r r \\
r q \\
r y\end{array}$ & $\begin{array}{l}0 . \\
\text { rr } \\
\text { or }\end{array}$ & $\begin{array}{l}\text { ir } \\
\text { ro } \\
1 .\end{array}$ & $\begin{array}{l}r 0 \\
19 \\
r 7\end{array}$ & $\begin{array}{l}m \\
\text { ir } \\
r\end{array}$ & $\begin{array}{l}1, \cdot \\
\varepsilon, r \\
v, i\end{array}$ & 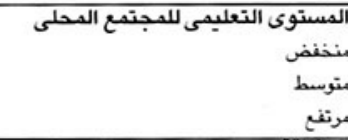 \\
\hline $\begin{array}{l}\text { ra } \\
\text { ir } \\
\text { ir }\end{array}$ & $\begin{array}{l}r o \\
r i \\
r .\end{array}$ & $\begin{array}{l}01 \\
v \\
1\end{array}$ & $\begin{array}{l}r_{0} \\
\text { ro } \\
\text { r. }\end{array}$ & $\begin{array}{l}0 q \\
\vdots 1 \\
\vdots\end{array}$ & $\begin{array}{l}\text { ir } \\
\text { ir }\end{array}$ & $\begin{array}{l}r \mu \\
r v \\
r \Lambda\end{array}$ & is & $\begin{array}{l}1.7 \\
0,1 \\
1, .\end{array}$ & المافطظة الصفات الحضرية \\
\hline 10 & rI & IV & $r a$ & \$0 & 17 & rq & IT & $T, r$ & الهجموع \\
\hline 10 & 10 & 10 & 10 & 10 & 10 & 10 & 10 & $\Delta r$ & عدد الحالات \\
\hline
\end{tabular}


الجدول $7-10:$

النسبة المئوية للأخصائيين الاجتماعيين الذين تلقوا التدريب خلال السنتين الأخيرتين و مقدار رضاهم عن مختلف ظروف عملهم، حسب المتغيرات الخلفية الفردية و المدرسية الأنصاعين

\begin{tabular}{|c|c|c|c|c|}
\hline الرضا عن ظروف العصل & الرضا عن ساعات العمل & الرضا عن طبيعة العمل & تلقى تدريب مؤرا & المتغيرات الخلفية \\
\hline $\begin{array}{l}r 0, v \\
\leqslant v, 1\end{array}$ & $\begin{array}{l}\text { va, } 1 \\
11, v\end{array}$ & $\begin{array}{l}19,1 \\
11, v\end{array}$ & $\begin{array}{l}\text { M, } 1 \\
\text { vi, }\end{array}$ & 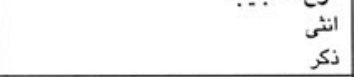 \\
\hline $\begin{array}{l}r r, 0 \\
r A, 1 \\
r 1,1\end{array}$ & $\begin{array}{l}\mathrm{Av}, \mathrm{O} \\
09,8 \\
\mathrm{vA}, 8\end{array}$ & $\begin{array}{l}7 r, 0 \\
10,7 \\
v r .\end{array}$ & $\begin{array}{l}\text { M,r } \\
\text { vo,. } \\
\text { Ar, }\end{array}$ & 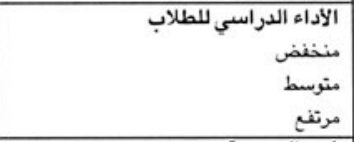 \\
\hline $\begin{array}{l}m r, r \\
r o, r \\
r u, r \\
\$ 1, r\end{array}$ & $\begin{array}{l}\text { vr. } \\
\text { A., } \\
\text { or, } \\
\text { Av, } \\
\end{array}$ & $\begin{array}{l}\text { vo. } 9 \\
u, 4 \\
\text { ov. } \\
\text { vo.. }\end{array}$ & $\begin{array}{l}\text { vi,v } \\
9 \cdots, . . \\
\text { As,r } \\
\text { vo.. }\end{array}$ & 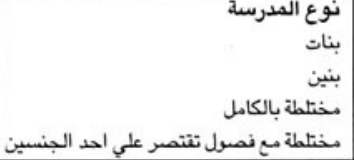 \\
\hline $\begin{array}{l}\varepsilon 9, . \\
r 1, \varepsilon\end{array}$ & $\begin{array}{l}\Delta r, v \\
00,9\end{array}$ & $\begin{array}{l}\text { vr,o } \\
11,1\end{array}$ & $\begin{array}{l}\text { A1,r } \\
\mathrm{vr}, \mathrm{o}\end{array}$ & 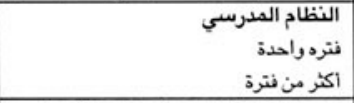 \\
\hline $\begin{array}{l}r r, v \\
\cdots, . \\
\lfloor\Lambda, \varepsilon\end{array}$ & $\begin{array}{l}9 ., 9 \\
01.9 \\
1.91\end{array}$ & $\begin{array}{l}w, r \\
7 \varepsilon, 0 \\
u, 1\end{array}$ & $\begin{array}{l}9 ., 9 \\
9 \varepsilon, 0 \\
9 ., r\end{array}$ & 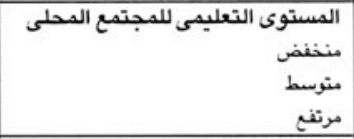 \\
\hline $\begin{array}{l}r 1, r \\
0,0 \\
\vdots \cdots\end{array}$ & $\begin{array}{l}1 \ldots . . \\
0 \wedge, 1 \\
1 . . .\end{array}$ & $\begin{array}{l}0 r .9 \\
7 v, 8 \\
\text { A. . . }\end{array}$ & $\begin{array}{l}4 \mathrm{r}, \Lambda \\
\mathrm{v}_{0}, . \\
\Lambda \varepsilon_{.} .\end{array}$ & المالتافظات الحضرية \\
\hline$\because 1,1$ & vr., $r$ & $\mathrm{n}, 0$ & A1.. & المجموع \\
\hline 10 & 10 & 10 & Ao & عدد الحالات \\
\hline
\end{tabular}


الجداول

الفصلالسابع

فرص التعلم 
الجدول v-1:

نسب التوزيع المئوية للمدارس وفق نظام الفترات، حسب المتغيرات الخلفية المدرسية

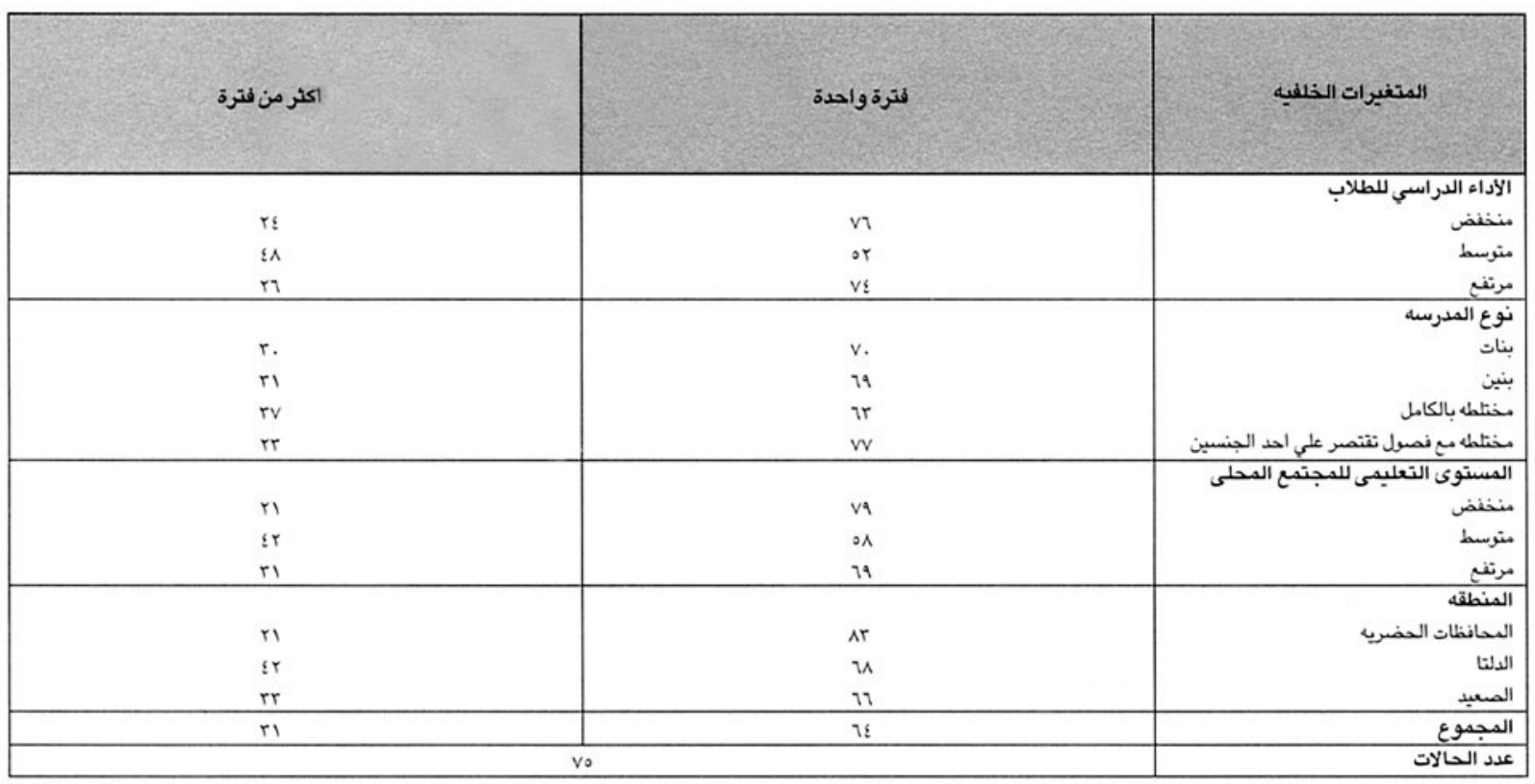

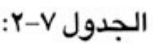

النسبة المئوية للحصص التي تمت ملاحظتها وفق تواجد المعلم و الاستخدام الكفء لوقت الحصة، حسب المتغيرات الفردية و المدرسية

\begin{tabular}{|c|c|c|c|c|c|}
\hline إضاعة ، \% على الاقل من & لم تتم إضاعة الي قدر من & المعلم متواجد بعد انتهاء & 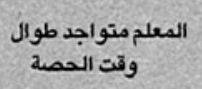 & 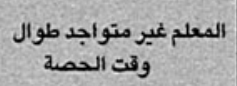 & المتغيرات الخلفيه \\
\hline $\begin{array}{l}\text { TV } \\
10\end{array}$ & $\begin{array}{l}r . \\
r v\end{array}$ & $\begin{array}{l}17 \\
\pi\end{array}$ & $\begin{array}{l}\text { rA } \\
r a\end{array}$ & $\begin{array}{l}\text { ?ר } \\
\text { ? }\end{array}$ & نونى المعلم \\
\hline $\begin{array}{l}w \\
11 \\
\text { os }\end{array}$ & $\begin{array}{l}i 0 \\
r . \\
r i s\end{array}$ & $\begin{array}{l}19 \\
19 \\
r r\end{array}$ & $\begin{array}{l}r r \\
r v \\
r y\end{array}$ & $\begin{array}{l}0 . \\
0 \vdots \\
\vdots 1\end{array}$ & منفضض متراء الدراسي للطلاب \\
\hline $\begin{array}{l}19 \\
1 . \\
17 \\
19\end{array}$ & $\begin{array}{l}r r \\
r i \\
r y \\
r .\end{array}$ & $\begin{array}{l}r 1 \\
r . \\
r \varepsilon \\
i r\end{array}$ & $\begin{array}{l}r 1 \\
r 7 \\
r v \\
r q\end{array}$ & $\begin{array}{l}\varepsilon \wedge \\
r \varepsilon \\
r q \\
01\end{array}$ & 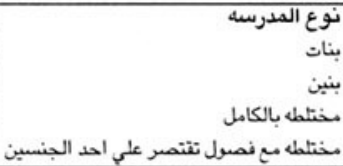 \\
\hline $\begin{array}{l}10 \\
19\end{array}$ & $\begin{array}{l}\text { rq } \\
\text { r. }\end{array}$ & $\begin{array}{l}r \varepsilon \\
10\end{array}$ & $\begin{array}{l}r q \\
r q\end{array}$ & $\begin{array}{l}\varepsilon v \\
\varepsilon v\end{array}$ & 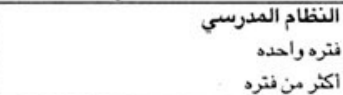 \\
\hline $\begin{array}{l}v £ \\
0 € \\
v r\end{array}$ & $\begin{array}{l}\text { iv } \\
r i \\
r \varepsilon\end{array}$ & $\begin{array}{l}i n \\
r r \\
r i\end{array}$ & $\begin{array}{l}r 1 \\
r i \\
r r\end{array}$ & $\begin{array}{l}01 \\
\vdots \\
\vdots 0\end{array}$ & مرتفنف مترستوى التعليمى للمجتمع المحلى \\
\hline $\begin{array}{l}\text { vr } \\
0 \text { ? } \\
\text { AI }\end{array}$ & $\begin{array}{l}r r \\
r r \\
i r\end{array}$ & $\begin{array}{l}r ! \\
r r \\
17\end{array}$ & $\begin{array}{l}r \varepsilon \\
r \varepsilon \\
r i\end{array}$ & $\begin{array}{l}\text { or } \\
\vdots: \\
\vdots 1\end{array}$ & المالتطافظات الحضريك \\
\hline $7 \mathrm{~V}$ & $r i$ & ri & $r r$ & ?v & المجموع \\
\hline \multicolumn{2}{|c|}{ เ幺 } & & 54 & & عدد الحالات \\
\hline
\end{tabular}




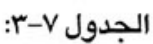

النسبة المئوية لتغيب الطلاب ومتدسط عدد الأيام التي تغيب فيها الطالب خلال الأسبوع الأخير، حسب المتغيرات الخلفية الفرديةو المدرسية

\begin{tabular}{|c|c|c|}
\hline متوسط عدد ابام تغيب الطالب & النسبة المنوية للطلاب المتغيبين ليوم الأسبوع الاخير & المتغيرات الخلفيه \\
\hline $\begin{array}{l}\cdots, o \\
., r\end{array}$ & $\begin{array}{l}Y \varepsilon, 0 \\
1 \varepsilon, 0\end{array}$ & نون انثى المجيب \\
\hline $\begin{array}{l}., r \\
-, \varepsilon \\
., 0\end{array}$ & $\begin{array}{l}17, \varepsilon \\
1 r, v \\
r 7,1\end{array}$ & 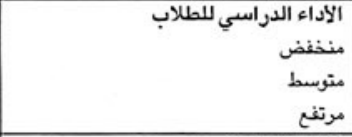 \\
\hline $\begin{array}{l}-, t \\
. r \\
., r \\
., r\end{array}$ & $\begin{array}{l}r 7,0 \\
17, r \\
1 \varepsilon, \varepsilon \\
i r, \varepsilon\end{array}$ & 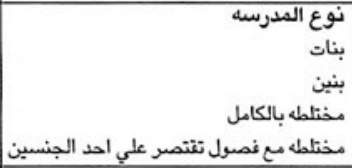 \\
\hline $\begin{array}{l}\cdots, 0 \\
\therefore, \varepsilon\end{array}$ & $\begin{array}{l}r r, \\
i v, r\end{array}$ & 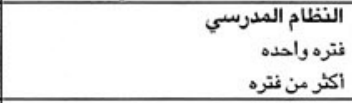 \\
\hline $\begin{array}{l}., r \\
., r \\
., r\end{array}$ & $\begin{array}{l}10, r \\
r r, i \\
1 \alpha, \varepsilon\end{array}$ & متفزفض المستوى التعليمى للمجتمع المحلى \\
\hline $\begin{array}{l}, r \\
\cdots, \\
,, \varepsilon \\
\end{array}$ & $\begin{array}{l}r ., T \\
r r, v \\
1 \varepsilon, r\end{array}$ & 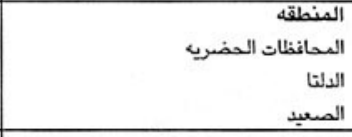 \\
\hline$\cdot, \varepsilon$ & 19,0 & المجموع \\
\hline$r \sum 10$ & $r \sum \bar{T}_{0}$ & عدد الحالات \\
\hline
\end{tabular}


مقدار تو افر فرص التعلم التطبيقية: النسبة المئوية للطلاب الذين أفادوا المشاركة في أنشطة متنوعة و تلقي دروس تطبيقية، نسب التوزيع المئوية حسب المتغيرات الخلفية الفردية و الددرسية

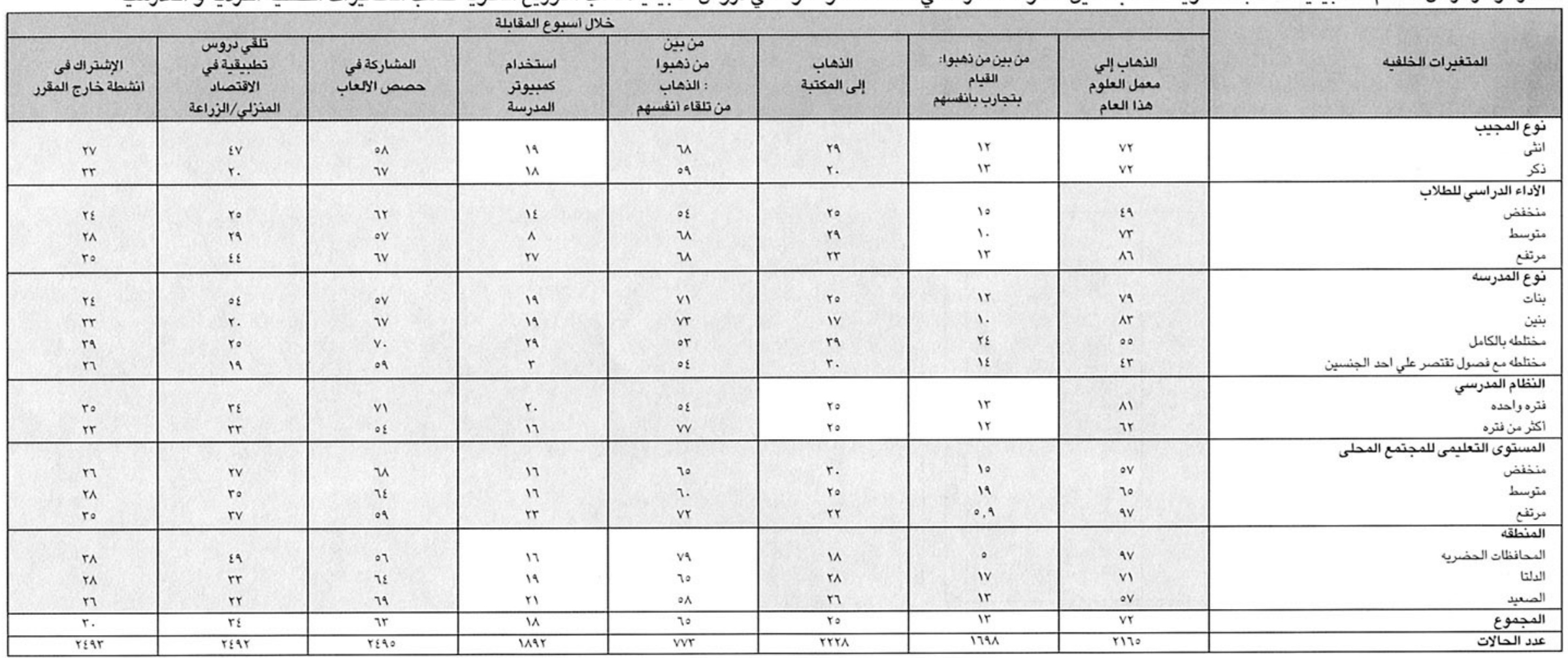




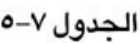

تو افر فرص التعلم الإيجابي و الانشطة التي يبادر بها الطلاب: النسبة المئوية للحصص، حسب المتغيرات الخلفية الفردية و المدرسية

\begin{tabular}{|c|c|c|}
\hline الانشطة التي يبادر بها الطلاب & توافر فرص الطلاب للتعلم & المتغيرات الخلفيه \\
\hline $\begin{array}{l}i v, \varepsilon \\
1, r \\
r i, 1\end{array}$ & $\begin{array}{l}9 r, \wedge \\
9 \varepsilon, q \\
91, v\end{array}$ & 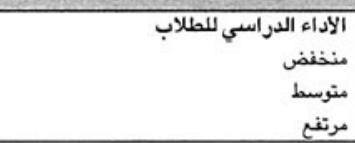 \\
\hline $\begin{array}{l}r r, r \\
r r, 1 \\
I V, . \\
1 ., 1\end{array}$ & $\begin{array}{l}9 r, r \\
9 r, r \\
90, r \\
9,, 8 \\
9 r, 9\end{array}$ & 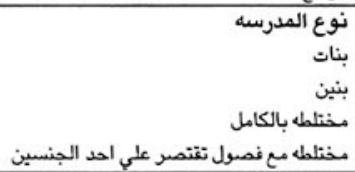 \\
\hline $\begin{array}{l}r \varepsilon, 0 \\
1 ., 0\end{array}$ & $\begin{array}{l}9 r, 7 \\
9 r, \varepsilon\end{array}$ & 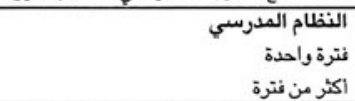 \\
\hline $\begin{array}{l}1 \varepsilon, 1 \\
10, . \\
r 1, r\end{array}$ & $\begin{array}{l}\text { ar, } \\
\text { ar, } \\
\text { aะ, }\end{array}$ & متفغضت المستوى التعليمى للمجتمع المحلى \\
\hline $\begin{array}{l}r r, 1 \\
19,1 \\
17,9\end{array}$ & $\begin{array}{l}91,1 \\
9 r, 7 \\
9 r, 9\end{array}$ & 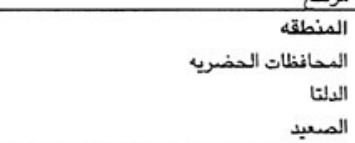 \\
\hline $19, Y$ & $9 r, 9$ & المجموع \\
\hline \&v9 & \&va & عدد الحالات \\
\hline
\end{tabular}




\section{الجداول}

$$
\begin{aligned}
& \text { الفصل الثامن } \\
& \text { القيادة المدرسية ودو أولياء الأمور }
\end{aligned}
$$




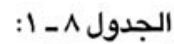

نوع مدير المدرسة (ذكر أو انثي) نسب التوزيع المئوية حسب المتغيرات الخلفية الفردية الخاصة بمدير المدرسة والخلفية المدرسية

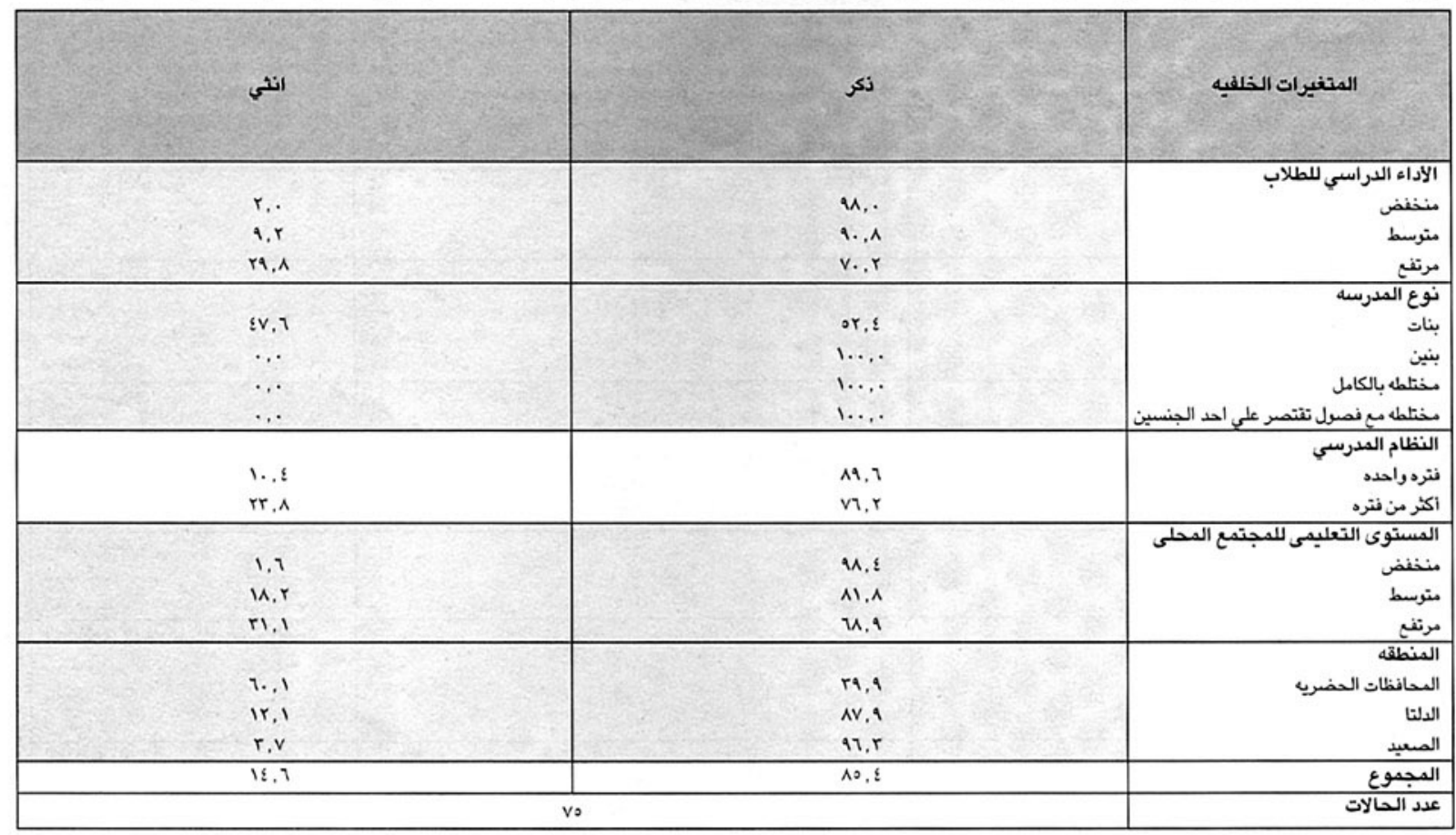

نسب التوزيع المئوية للمؤهلات التعليمية لمديري المدارس حسب المتغيرات الخلفية الفردية و المدرسية

\begin{tabular}{|c|c|c|c|}
\hline بلوم/بكالوريوس/ ماهلي ماجستير & بكالوريوس/ ماجستير تربية & حاصل علي بلوم تربية & المتغيرات الخلفيه \\
\hline $\begin{array}{l}r, \wedge \\
11, \xi\end{array}$ & $\begin{array}{l}a r, r \\
o v, v\end{array}$ & $\begin{array}{l}0, . \\
\text { ro, }\end{array}$ & نون نوع هدير المدرسة \\
\hline $\begin{array}{l}m, 1 \\
\varepsilon, r \\
11,9\end{array}$ & $\begin{array}{l}7 v, 0 \\
0 ., r \\
79,1\end{array}$ & $\begin{array}{l}1,0 \\
\varepsilon 0,8 \\
11, r\end{array}$ & 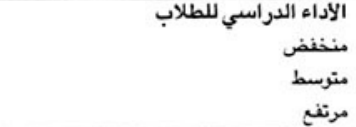 \\
\hline $\begin{array}{l}r, r \\
11, r \\
9, . \\
01,9\end{array}$ & $\begin{array}{l}A \varepsilon, v \\
00, v \\
u, 1 \\
r ., 1\end{array}$ & $\begin{array}{l}\text { Ir.v } \\
r r ., \\
r r, 9 \\
r v, 0\end{array}$ & 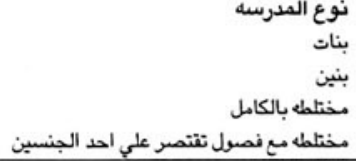 \\
\hline $\begin{array}{l}\text { Iv, } \\
\wedge, 1\end{array}$ & $\begin{array}{l}0 \leqslant, q \\
\text { va, }\end{array}$ & $\begin{array}{l}\mathrm{rv}, \mathrm{v} \\
\mathrm{ir}, \mathrm{O}\end{array}$ & 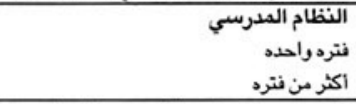 \\
\hline $\begin{array}{l}r \leqslant, 1 \\
1.9 \\
\cdots\end{array}$ & $\begin{array}{l}\text { or, } 1 \\
1 \leqslant, r \\
\text { va,v }\end{array}$ & $\begin{array}{l}r, r \\
r \leqslant, \Lambda \\
r ., r\end{array}$ & 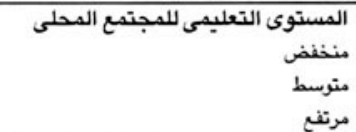 \\
\hline $\begin{array}{l}1 . . \\
10, v \\
11,1\end{array}$ & $\begin{array}{l}\text { Ar.1 } \\
11 . \text {. } \\
\text { or.o }\end{array}$ & $\begin{array}{l}17,9 \\
14, r \\
r 9,8\end{array}$ & الدالمافظقات الحضريك \\
\hline $1 \varepsilon, r$ & $\pi r, r$ & $r r, 1$ & المجموع \\
\hline & v. & & عدد الحالات \\
\hline
\end{tabular}


الجدول ^ - r" متوسط عدد سنوات خبرة العمل كمدير مدرسة ومدير لهذه المدرسة بالذات، حسب المتغيرات الخلفية الفردية و المدرسية

\begin{tabular}{|c|c|c|}
\hline متوسط عدد سنوات خبرة العمل كمدير لهذه المدرسة & متوسط عدد سنوات خبرة العمل كمدير مدرسة & المتغيرات الخلفيه \\
\hline $\begin{array}{l}1 . \varepsilon \\
r, 1\end{array}$ & $\begin{array}{l}1,1 \\
0, .\end{array}$ & نونئ ندير المدرسة \\
\hline $\begin{array}{l}\imath, r \\
r, \wedge \\
r, 1\end{array}$ & $\begin{array}{l}0,1 \\
\vdots, 0 \\
r, 1\end{array}$ & منتفضض الأ الدراسي للطلاب \\
\hline $\begin{array}{l}r, . \\
r, r \\
s, . \\
0, r\end{array}$ & $\begin{array}{l}r, 1 \\
5,9 \\
0,1 \\
1,1\end{array}$ & 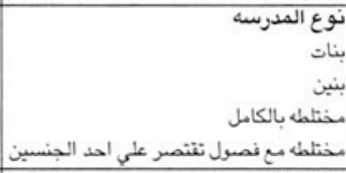 \\
\hline $\begin{array}{l}r, 1 \\
r, .\end{array}$ & $\begin{array}{l}\S, 1 \\
\S, \varepsilon \\
\end{array}$ & أنتر من واحتره \\
\hline $\begin{array}{l}\varepsilon, 1 \\
1, q \\
r .1\end{array}$ & $\begin{array}{l}1,1 \\
r, 9 \\
\therefore, 0\end{array}$ & متخفضط مترى التعليمى للمجتمع المحلى \\
\hline $\begin{array}{l}r, r \\
r, \varepsilon \\
\varepsilon, \Lambda\end{array}$ & $\begin{array}{l}r, v \\
r, r \\
i, \varepsilon\end{array}$ & المنافظقات الحضريك \\
\hline$r .9$ & $\varepsilon . r$ & المجموع \\
\hline$v \varepsilon$ & $v \xi$ & عدد الحالات \\
\hline
\end{tabular}




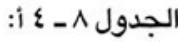
نسب التوزيع المئوية لمديري المدارس الذين تلقوا تدريبا اثناء الخدمة خلال السنتين الاخيرتين حسب المتغيرات الخلفية الفردية والمدرسية

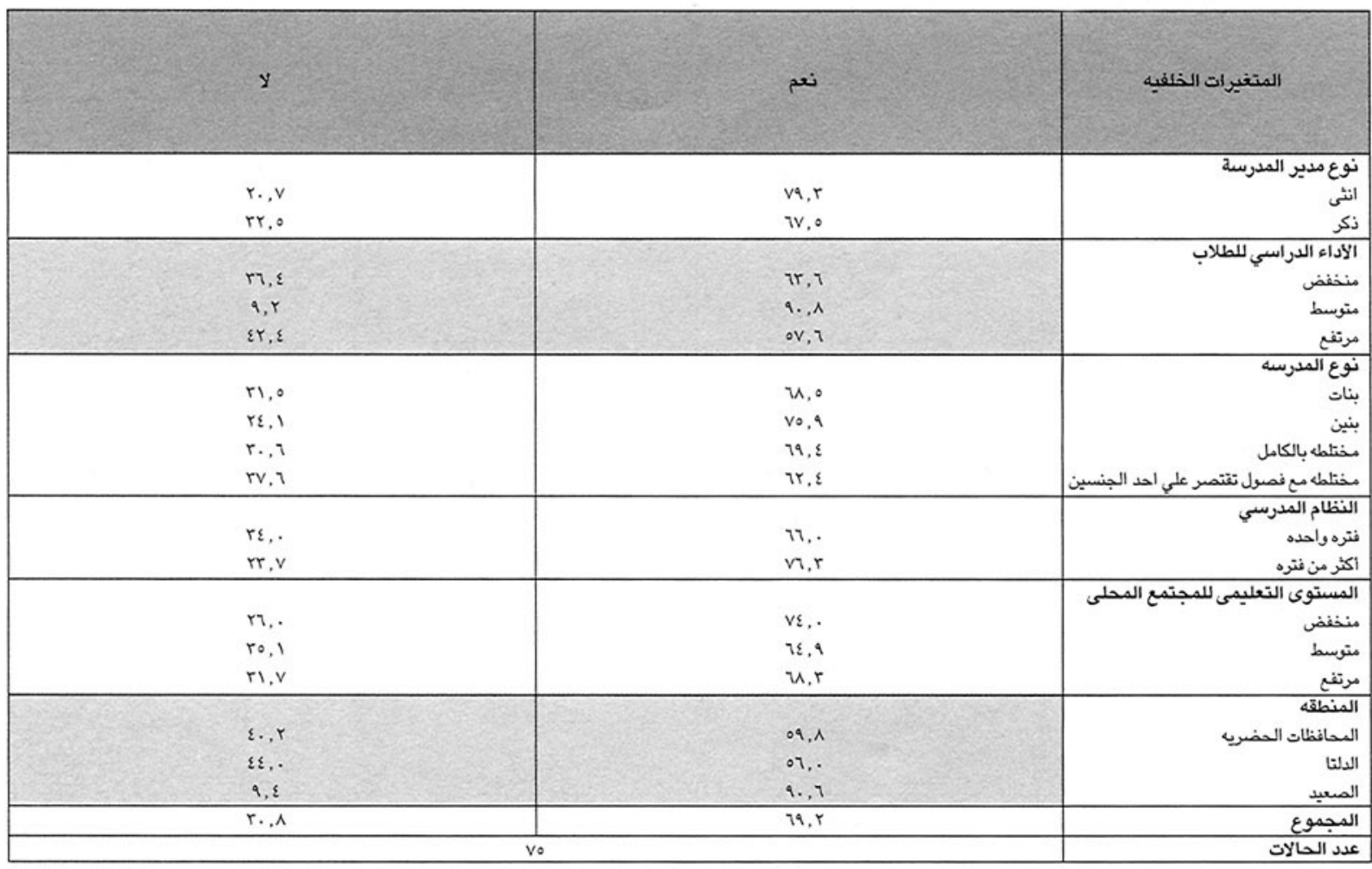

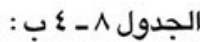
نسب التوزيع المئوية لمديري المدارس فيما يتعلق برضاهم عن التدريب اثناء الخدمة الذي تلقوه خلال السنتين الاخيرتين

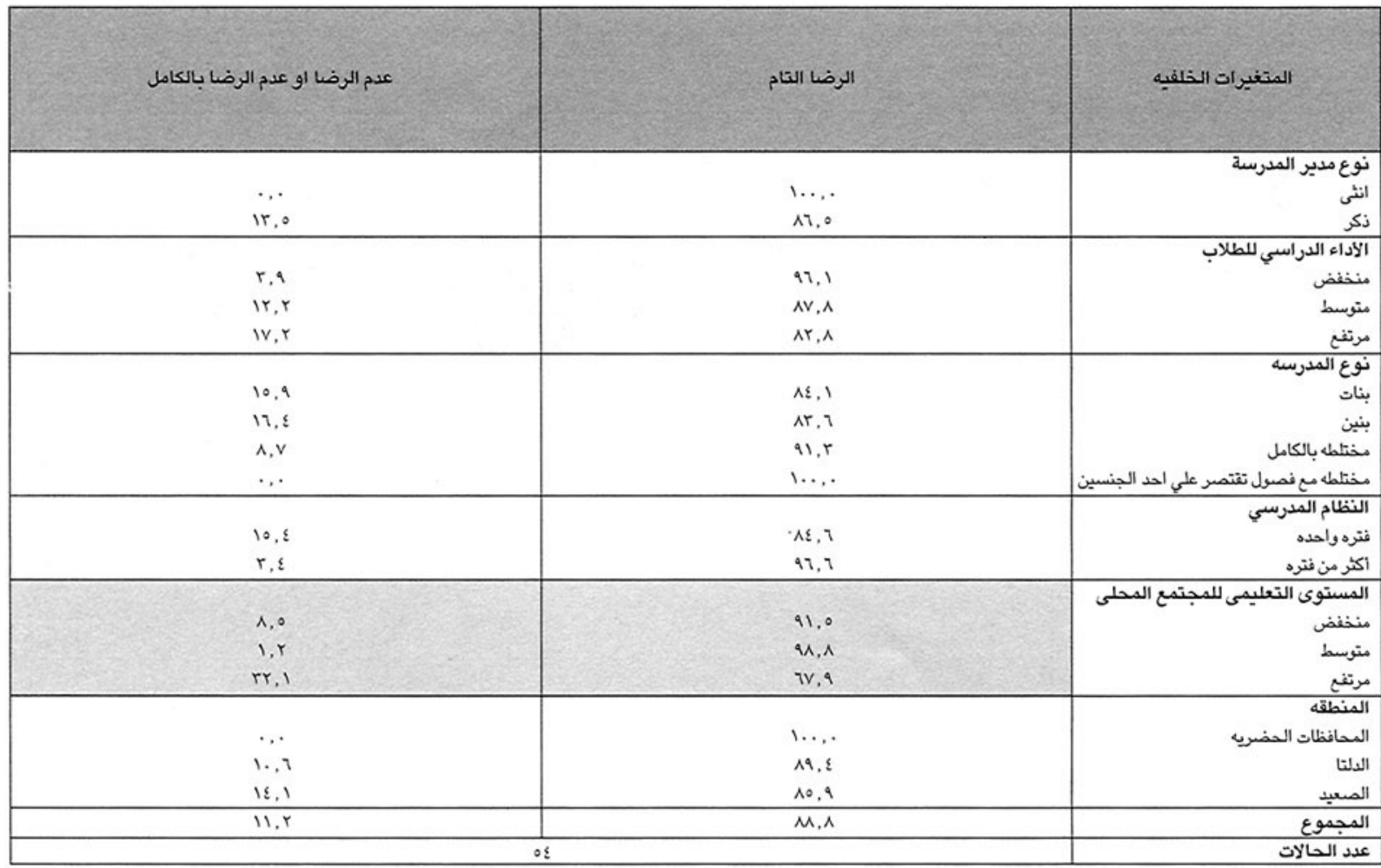



نسب التوزيع المئوية لمتوسط عدد المدرسين الاوائل لكل مادة حسب المتغيرات الخلفية الفردية الخاصة بمدير المدرسة والخلفية المدرسية

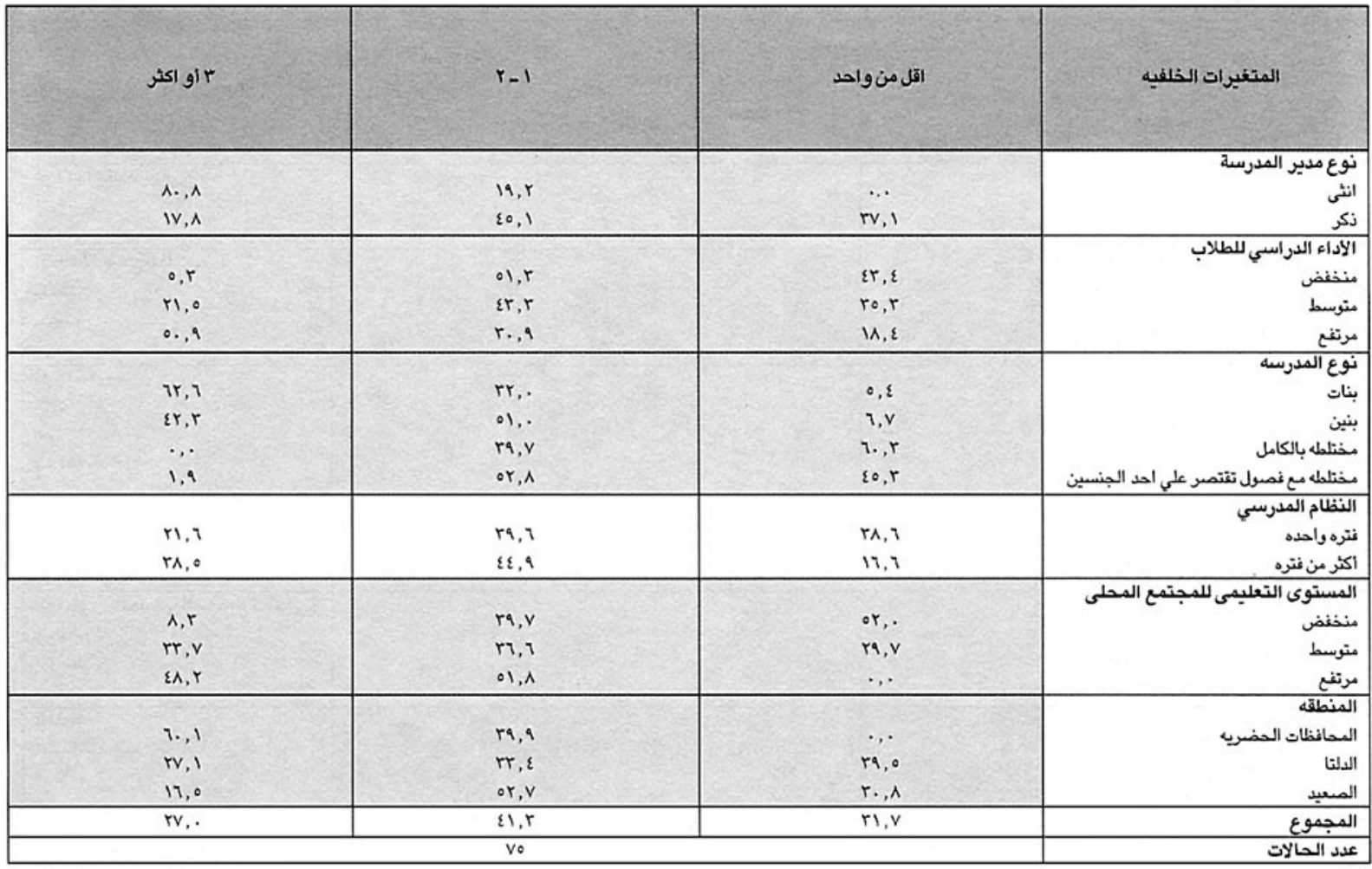

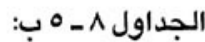

نسب التوزيع المئوية لمدارس العينة وفق عدد الوكلاء المتوافرين، حسب المتغيرات الخلفية الفردية والمدرسية

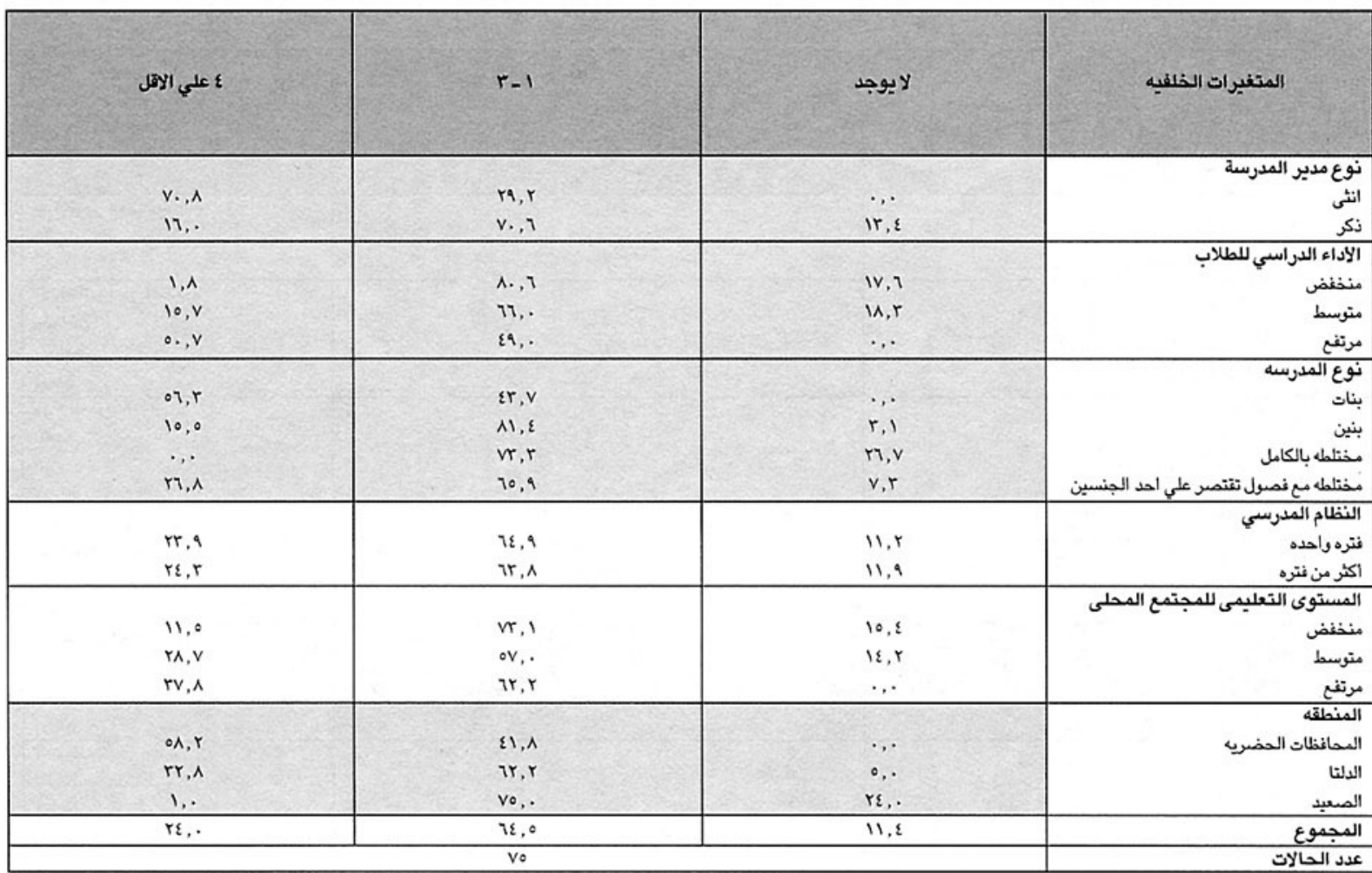




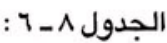

نسب التوزيع المئوية للاقسام التي تغيب بها معلم واحد علي الاقل في كل يوم، حسب المتغيرات الخلفية الفردية الخاصة بمدير المدرسة

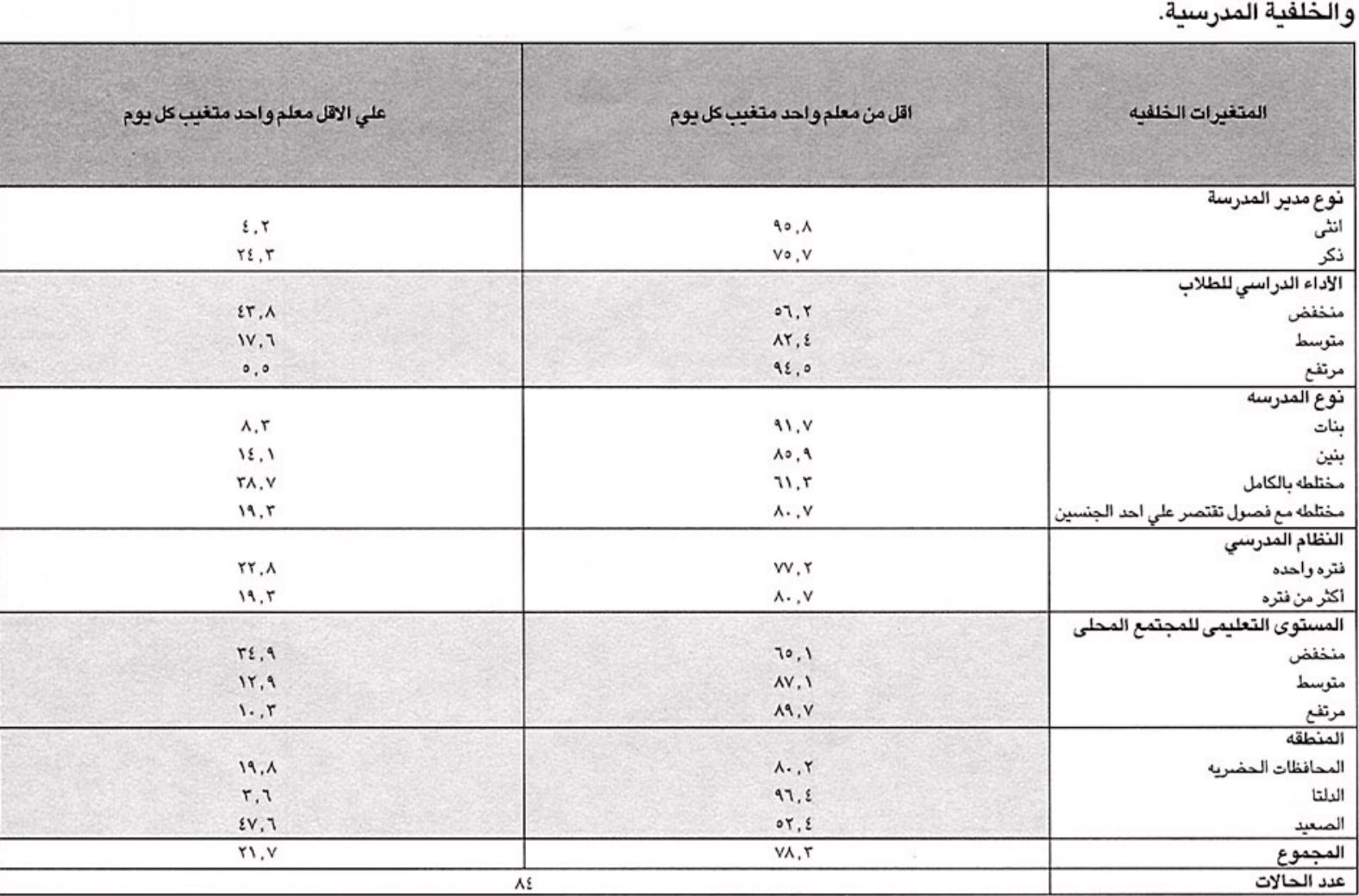

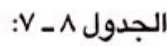

نسب التوزيع المئوية للاقسام وفق عدد محاولات ملاحظة الفصول الفاشلة، حسب المتغيرات الخلفية الفردية الخاصة بمدير المدرسة و الخلفية المدرسية التوزية

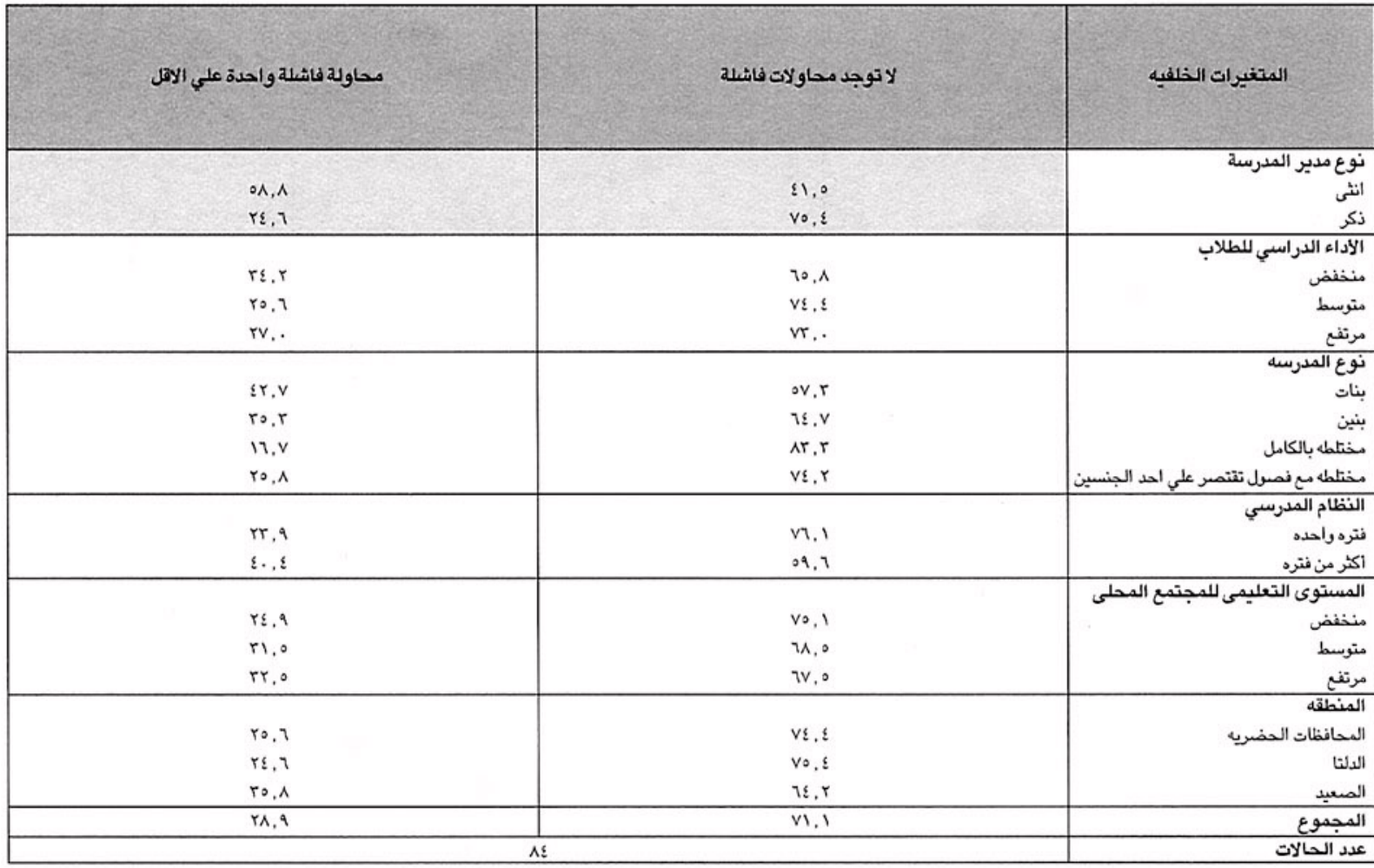




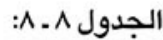
نسب التوزيع المئوية للحصص التي تمت ملاحظتها وفق ما اذا كانت قد بدأت وانتهت في موعدها المحدد، حسب المتغيرات الخلفية الخاصة بمدير المدرسة والخلفية المدرسية المئلية

\begin{tabular}{|c|c|c|}
\hline الحصلح لم تبدا وتنتته في موعدها & الحصلة بدات وانتهت في موعدها & المتغيرات الخلفيه \\
\hline $\begin{array}{l}\mathrm{vr}, \cdot \\
\mathrm{v} \varepsilon, \wedge\end{array}$ & $\begin{array}{l}r_{\Lambda}, \\
r_{0, Y}\end{array}$ & نانئى مدير المدرسة \\
\hline $\begin{array}{l}u, 0 \\
u, 0 \\
\Lambda \uparrow, .\end{array}$ & $\begin{array}{l}r i, 0 \\
1 \varepsilon, . \\
r i, v\end{array}$ & متفغضط الادراء الدراسي اللطلاب \\
\hline $\begin{array}{l}w, 0 \\
i v, r \\
v_{0}, r \\
v \varepsilon, 1\end{array}$ & $\begin{array}{l}r r, 0 \\
r r, \Lambda \\
r \varepsilon, \varepsilon \\
r 0,9\end{array}$ & 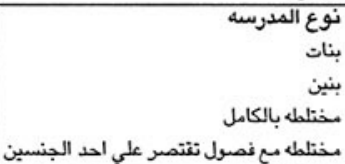 \\
\hline $\begin{array}{l}v_{0}, . \\
v_{r} .\end{array}$ & $\begin{array}{l}\text { ro,. } \\
\text { rv,. }\end{array}$ & 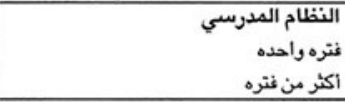 \\
\hline $\begin{array}{l}v r, 0 \\
v \varepsilon, r \\
v r, v\end{array}$ & $\begin{array}{l}r v, 0 \\
r o, v \\
r r, r\end{array}$ & 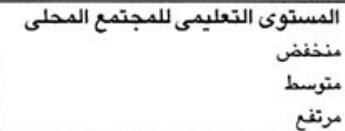 \\
\hline $\begin{array}{l}\Lambda 1, r \\
v_{0}, \varepsilon \\
u, r\end{array}$ & $\begin{array}{l}u, v \\
r \varepsilon, r \\
r i, v\end{array}$ & المنافظلات الحضريك \\
\hline \multirow{2}{*}{\multicolumn{2}{|c|}{$r_{0, v}$}} & المجموع \\
\hline & & عدد الحالات \\
\hline
\end{tabular}
نسب التوزيع المئوية الراحة (الفسح) التي تمت ملاحظتها وفق ما اذا كانت قد بدأت وانتهت في موعدها المحدد، حسب المتغيرات الخلفية الخاصة بمدير المدرسة والخلفية المدرسية الفية الفية

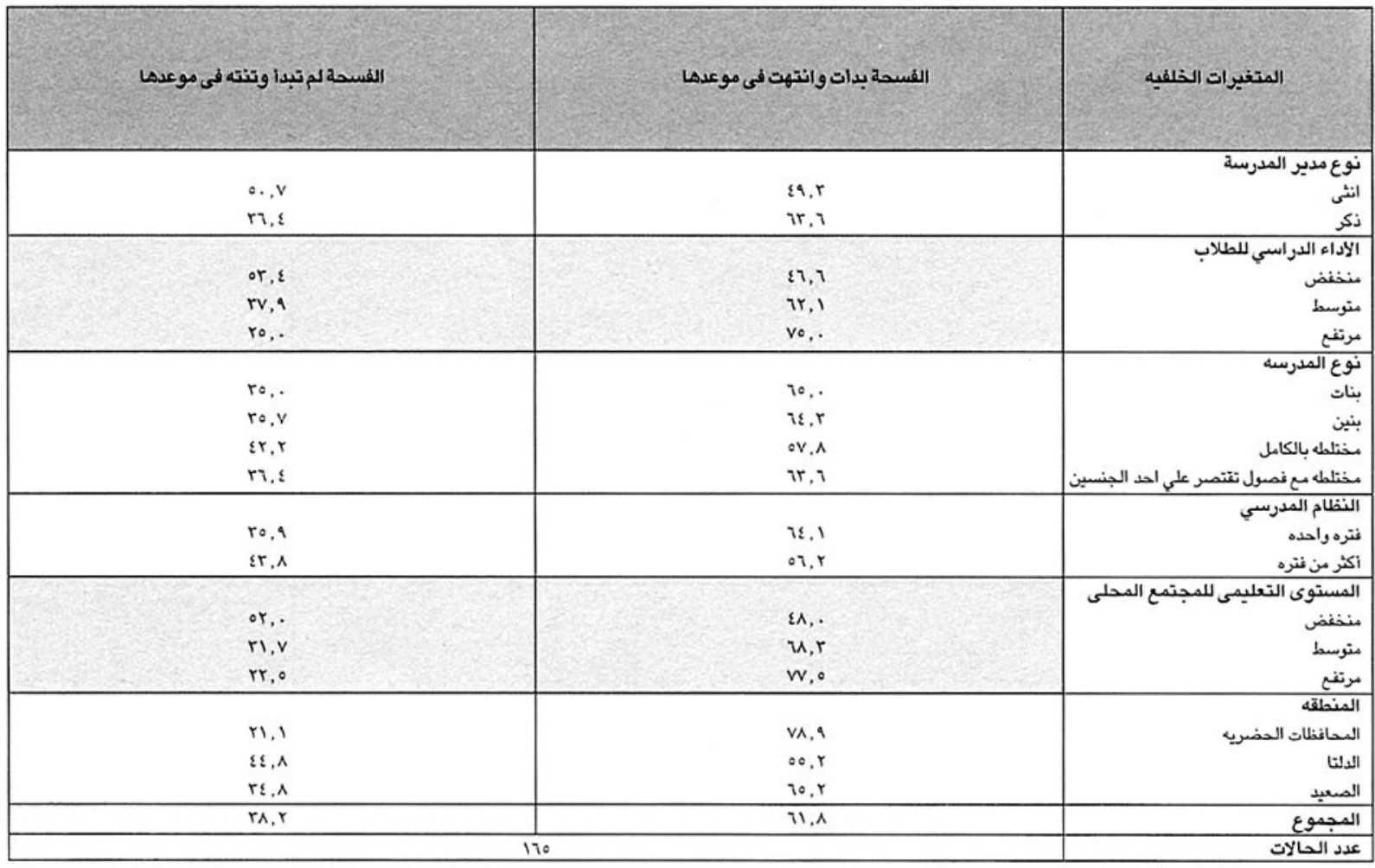




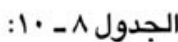

نسب التوزيع المئوية لفترات الراحة التى لم يتم الاشراف عليها، حسب المتغيرات الخلفية الخاصة بمدير المدرسة و الخلفية المدرسية

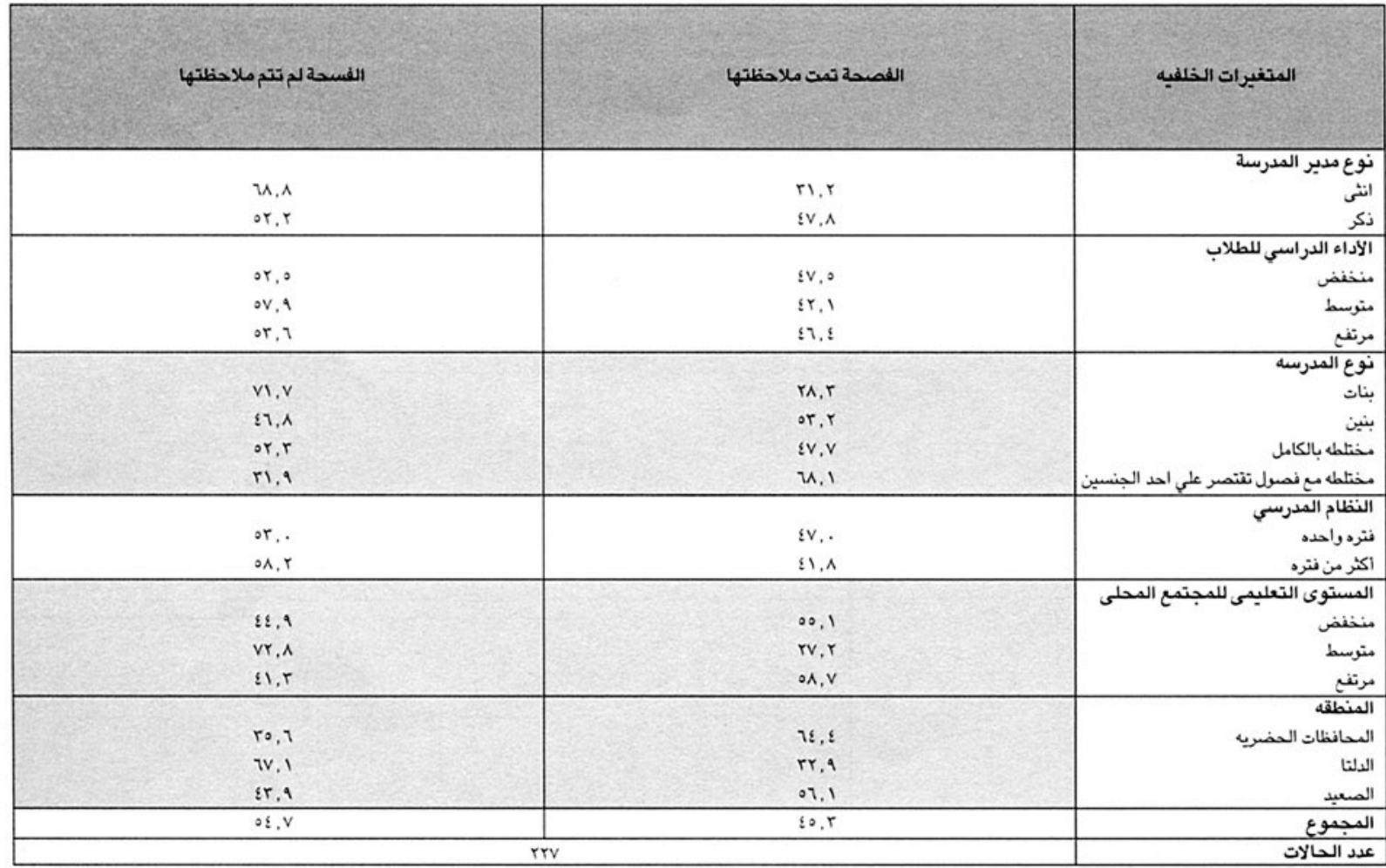

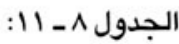

نسب التوزيع المئويـة لمديري المدارس وفق مستوى رضاهم عن كثافة الفصول، حسب المتغيرات الخلفية الفردية والمدرسية

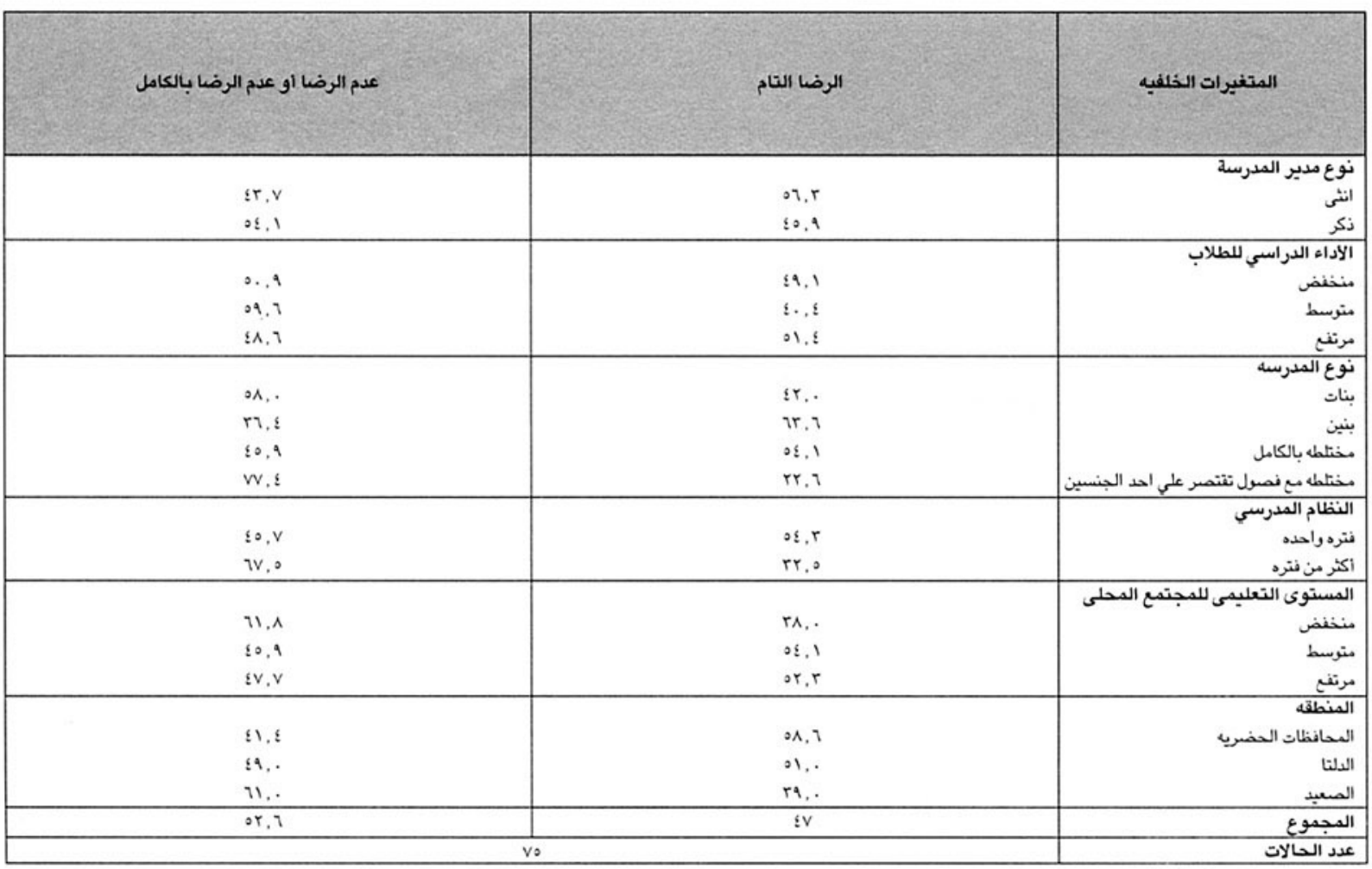




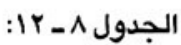

نسب التوزيع المئوية لمديري المدارس وفق مستوي رضاهم عن حالة مرافق المدرسة، حسب المتفيرات الخلفية الفردية والمدرسية

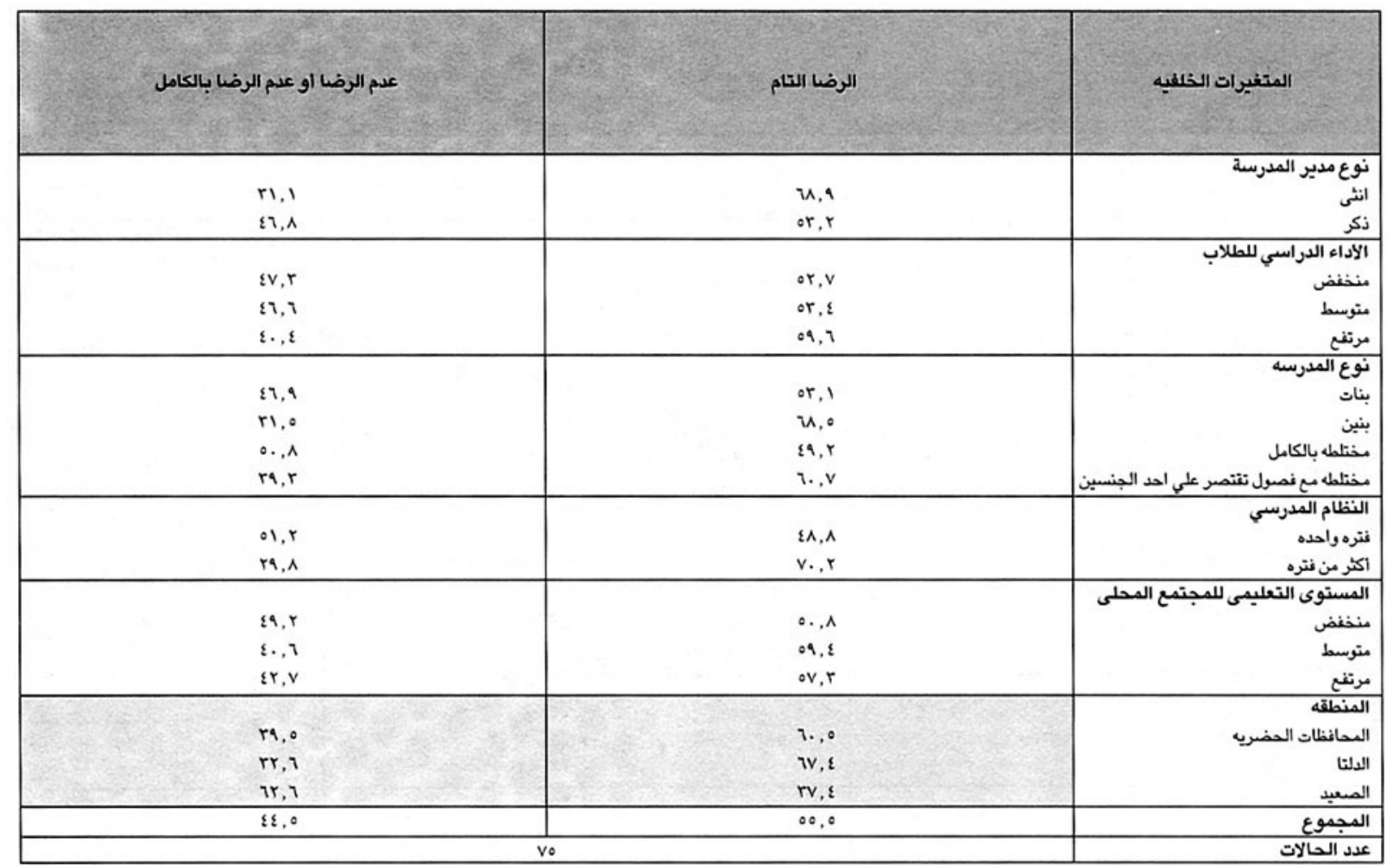

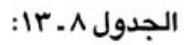
نسب التوزيع المئوية لمديري المدارس وفق مستوي رضاهم عن ساعات عمله، حسب المتغيرات الخلفية الفردية والمدرسية

\begin{tabular}{|c|c|c|}
\hline عدم الرضا او عدم الرضا بالكاهل & الرضا التام & المتغيرات الخلفيه \\
\hline $\begin{array}{l}v, \lambda \\
r, A\end{array}$ & $\begin{array}{l}r a, r \\
r r, .\end{array}$ & انثي \\
\hline $\begin{array}{l}r a, \varepsilon \\
r o, \wedge \\
\varepsilon r, \wedge\end{array}$ & $\begin{array}{l}v,, t \\
v \varepsilon, r \\
o v, r\end{array}$ & 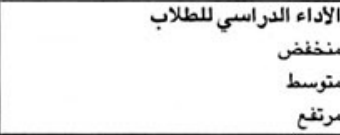 \\
\hline $\begin{array}{l}\varepsilon 0, \varepsilon \\
r, \varepsilon \\
r r, \hat{r} \\
r \varepsilon, r\end{array}$ & 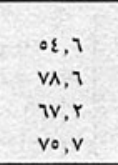 & 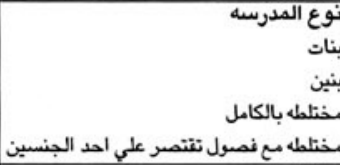 \\
\hline $\begin{array}{l}r q, r \\
r v, 1\end{array}$ & $\begin{array}{l}\text { ir,v } \\
\mathrm{vr}, \mathrm{q}\end{array}$ & اكثر من فنتره \\
\hline $\begin{array}{l}r A, r \\
r r, r \\
r i, \Lambda\end{array}$ & $\begin{array}{l}T, v \\
v r, v \\
i r, r\end{array}$ & مترتفط المستوى التعليمى للمجتمع المحلى \\
\hline $\begin{array}{l}\varepsilon \cdot, r \\
\varepsilon \cdot, q \\
r 1, .\end{array}$ & $\begin{array}{l}09,1 \\
09,1 \\
\mathrm{va,.}\end{array}$ & 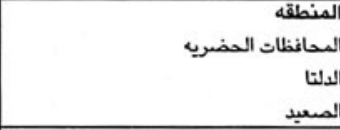 \\
\hline$r r, \varepsilon$ & 11,1 & المجموع \\
\hline \multicolumn{2}{|c|}{$\mathrm{v} \varepsilon$} & 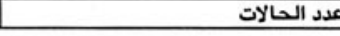 \\
\hline
\end{tabular}




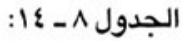
نسب التوزيع المئوية لمديري المدارس وفق مستوى رضاهم عن سلوك الطلاب فيما بينهم، حسب المتغيرات الخلفية الفردية والمدرسية

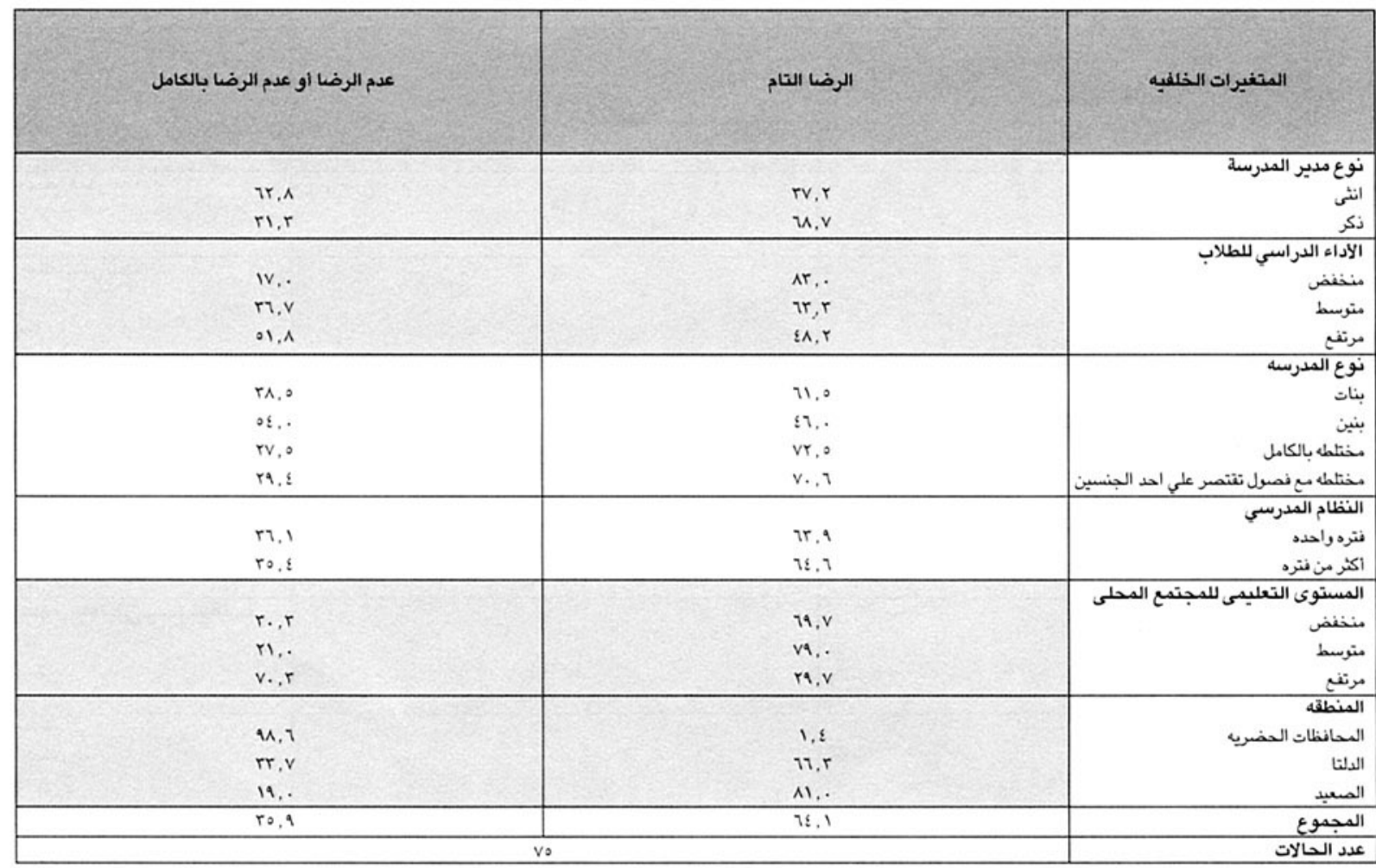

نسب التوزيع المئوية لمديرى المدارس وفق مستوي رضاهم عن التفاعل بين المعلمين و الطلاب،حسب المتغيرات الخلفية الفردية و المدرسية

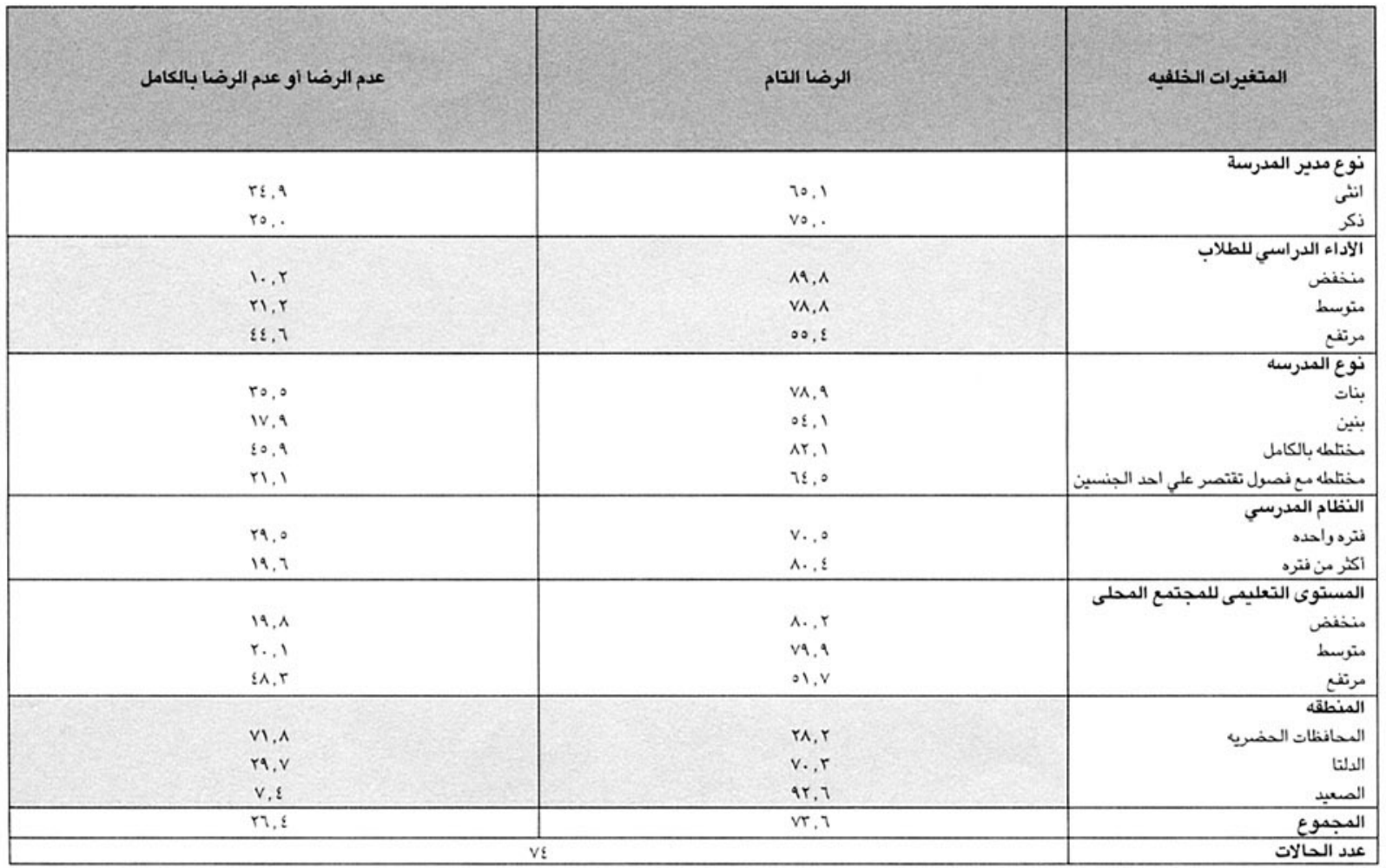




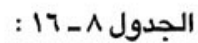

نسب التوزيع المئوية لمديرى المدارس وفق مستويرضاهم عن العلاقة بين المعلمين وادارة المدرسة حسب المتغيرات الخلفية الفردية

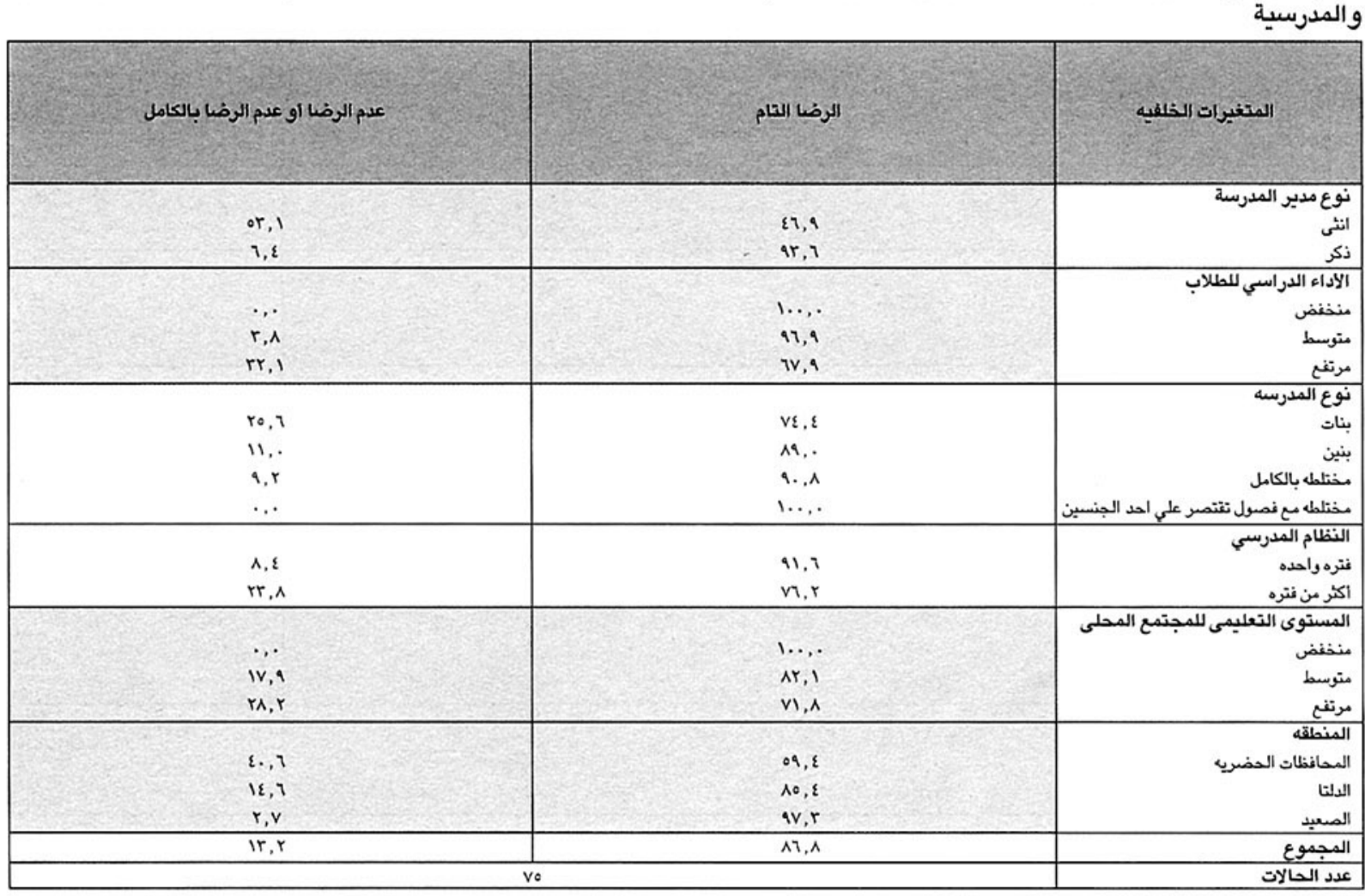

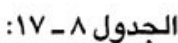

\begin{tabular}{|c|c|c|}
\hline عدم تشبيع مشاركة الوالدين & تشجيع مثاركة الوالدين & المتغيرات الخلفيه \\
\hline $\begin{array}{l}r \varepsilon, . \\
\varepsilon \varepsilon, \varepsilon\end{array}$ & $\begin{array}{l}1 \pi, . \\
00,1\end{array}$ & نونئ ندير المدرسة \\
\hline $\begin{array}{l}v r, q \\
r A, r \\
r v, 1\end{array}$ & $\begin{array}{l}r v, 1 \\
v i, \lambda \\
v r, r\end{array}$ & متزفيط \\
\hline $\begin{array}{l}\llbracket \llbracket, \varepsilon \\
r a, \wedge \\
\llbracket \varepsilon, \wedge \\
r \Lambda, \imath\end{array}$ & $\begin{array}{l}00,1 \\
1 ., r \\
00, r \\
71, \varepsilon\end{array}$ & 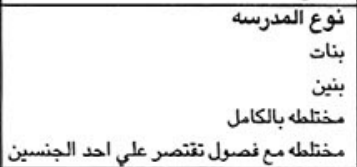 \\
\hline $\begin{array}{l}\varepsilon v, v \\
r r, 0\end{array}$ & $\begin{array}{l}\text { or, } r \\
\text { iv,o }\end{array}$ & 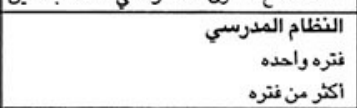 \\
\hline $\begin{array}{l}m, \wedge \\
r \ldots, 0 \\
r r, r\end{array}$ & $\begin{array}{l}r r, r \\
19,0 \\
W, v\end{array}$ & منفغض متوسى التعليمى للمجتمع المحلى \\
\hline $\begin{array}{l}09, \varepsilon \\
r v, . \\
09, v\end{array}$ & $\begin{array}{l}\varepsilon,, \tau \\
v r, . \\
\varepsilon, r\end{array}$ & المالتافنلات الحفنري \\
\hline $8 r, 9$ & ov, I & المجموع \\
\hline \multicolumn{2}{|c|}{ vo } & عدد الحالات \\
\hline
\end{tabular}




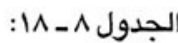

النسبة المئوية للمدارس التى تحصل على مساهمات من المجتمع المحلي، حسب المتغيرات الخلفية الفردية والمدرسية

\begin{tabular}{|c|c|c|}
\hline عدم الحصول علي دساهمات & الحصول علي مساهمات & المتغيرات الخلفيه \\
\hline $\begin{array}{l}r, r \\
09, r\end{array}$ & $\begin{array}{l}\text { ar,v } \\
\varepsilon, v, v\end{array}$ & نوكر ندير المدرسة \\
\hline $\begin{array}{l}07, \varepsilon \\
\text { Iv, } \\
r r, .\end{array}$ & $\begin{array}{l}\varepsilon r, 1 \\
r r, r \\
u, .\end{array}$ & متخفيط \\
\hline $\begin{array}{l}51, \wedge \\
00, r \\
71, q \\
r r, \Lambda\end{array}$ & $\begin{array}{l}\text { or,r } \\
\vdots \leqslant, \wedge \\
r \wedge, 1 \\
\text { ri,r }\end{array}$ & 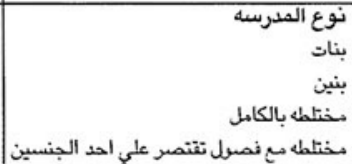 \\
\hline $\begin{array}{l}8 \mathrm{v}, 1 \\
{ }_{\mathrm{A}, \mathrm{A}}\end{array}$ & $\begin{array}{l}\text { or.q } \\
s, r\end{array}$ & 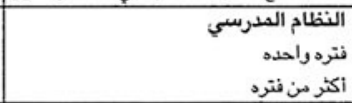 \\
\hline $\begin{array}{l}\varepsilon \varepsilon, v \\
v 1, v \\
r A, 0\end{array}$ & $\begin{array}{l}00, r \\
r A, r \\
V 1,0\end{array}$ & مترتفض المستوى التعليمى للمجتمع المحلى \\
\hline $\begin{array}{l}1 r, v \\
1 \varepsilon, r \\
\varepsilon 1, q\end{array}$ & $\begin{array}{l}\text { Av,r } \\
\text { ro,v } \\
\text { or, }\end{array}$ & الدمافلتات الصنات الحضريد \\
\hline $01 .$. & $\$ 9,$. & المجموع \\
\hline
\end{tabular}

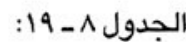

نسب التوزيع المئوية لمديري المدارس وفق مستوي رضاهم عن علاقتهم بالوالدين

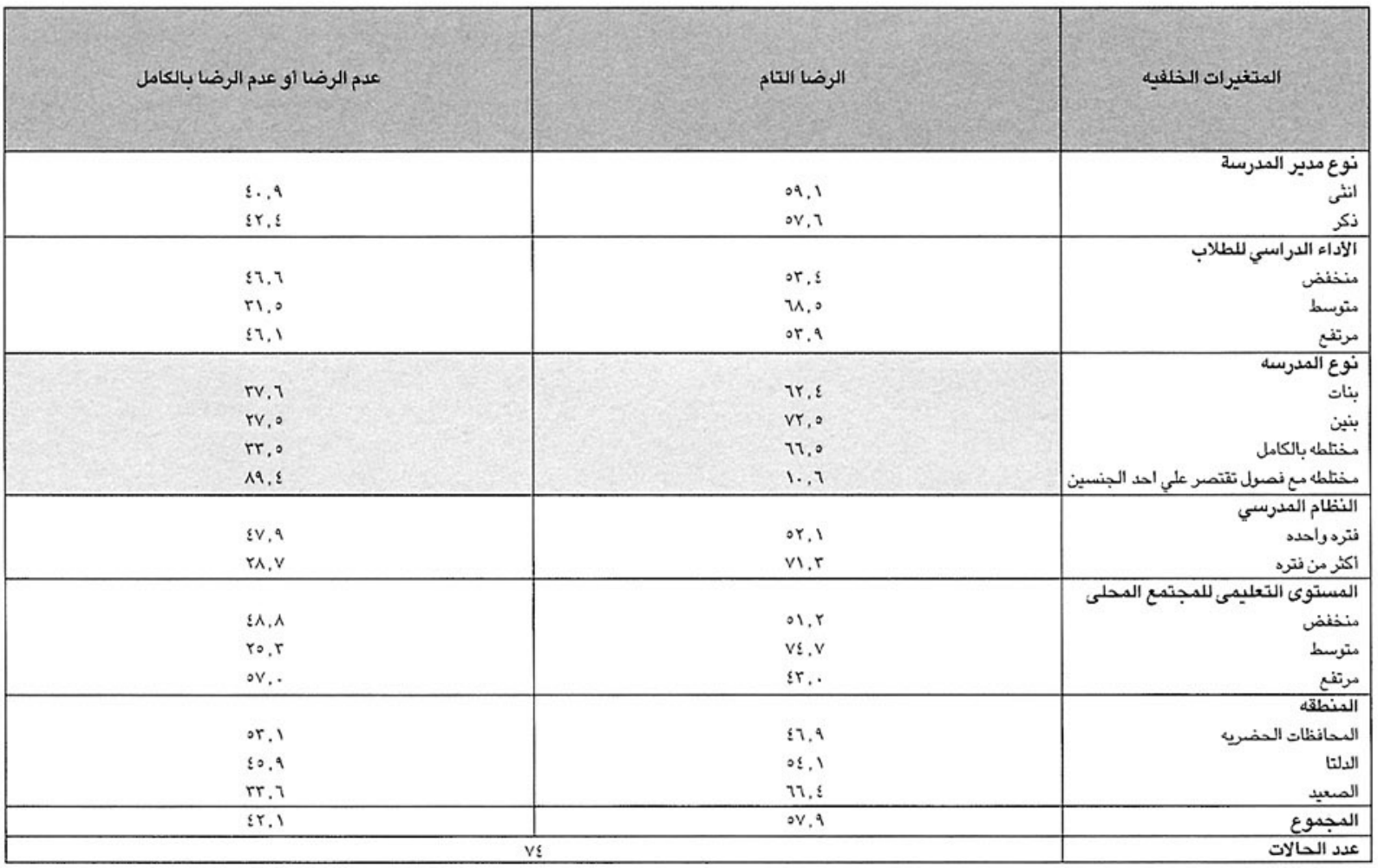


الملحق الثالث 
فريق جمع وإدارة البيانات

$$
\text { ما من من من منال }
$$




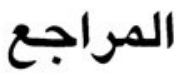

Egyptian Ministry of Education. 1997-1998. Statistics from the Ministry of Education, Arab Republic of Egypt: Department of Information and Computers.

Fergany, Nader. 1999 (April). Estimates of enrolment in basic education: 1990/91 - 1997/98, ALMISHKAT.

1996 (June). Baseline information to plan for universal access to primary education in $\overline{E g y p t}$, Prepared for UNICEF.

1994 (October). Survey of access to primary education and acquisition of basic literacy skills in three governorates in Egypt, Prepared for UNICEF.

Institute for National Planning. 1993 (May). Assessment of Basic Education in Egypt, Arab Republic of Egypt: Institute for National Planning.

Lloyd, CB, BS Mensch, and WH Clark. 2000. "The Effects of Primary School Quality on School Dropout Among Kenyan Girls and Boys.” Comparative Education Review, 44(2): 113-147.

Nandakumar, AK and A Swelam. No date. School Health Insurance: The Experience in Egypt: A Case Study. In Data for Decision Making, A Resource for Managing Health Sector Reform. Boston, MA [USA]: Harvard University, in consortium with Research Triangle Institute.

El-Tawila, S; O El-Gibaly; B Ibrahim; F El-Sahn; S Sallam; SM Lee; BS Mensch; H Wassef; and S Bukhari. 1999. Transitions to Adulthood: A National Survey of Egyptian Adolescence.

Cairo: The Population Council.

Zaytoun, MA. 1991. "Earnings and the Cost of Living: An Analysis of Recent Developments in the Egyptian Economy," in H Handoussa and G Potter (eds.), Employment and Structural Adjustment: Egypt in the 1990s. Cairo: The American University in Cairo Press. 


\section{المؤلفون}

د. سينثيا لويد تعمل مدير بحوث العلوم الاجتماعية بقسم بحوث السياسات في مجلس السكان بنيويورك منذ عام 1919 التركز التركز بحوثها

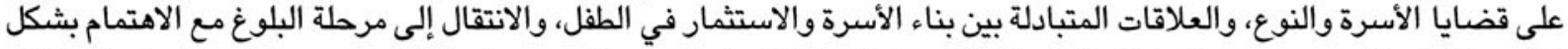

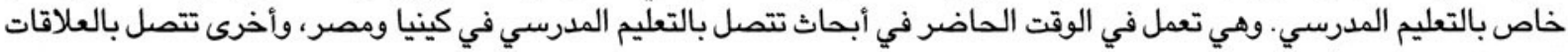

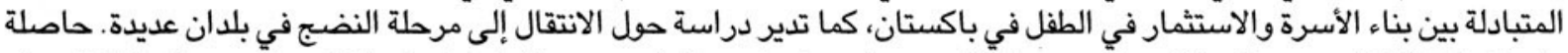

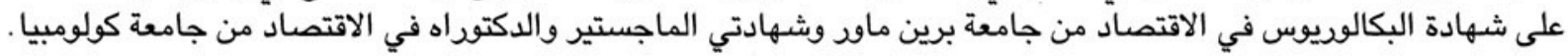

د. باربارا مينش خبير مشارك بقسم بحوث السياسات بالمقر الرئيسي لمجلس السكان بنيويورك. عملت أيضا على مدى السئ السنوات

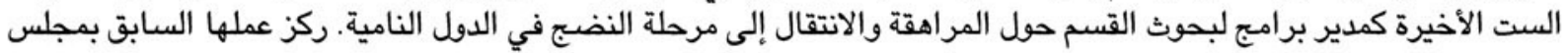

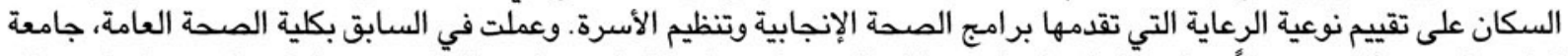

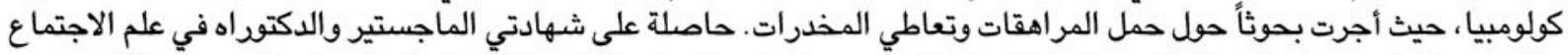

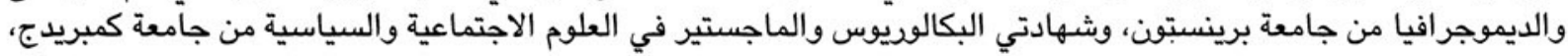
وبكالوريوس في التاريخ من كلية وليسلي.

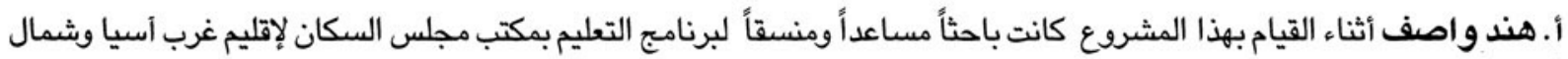

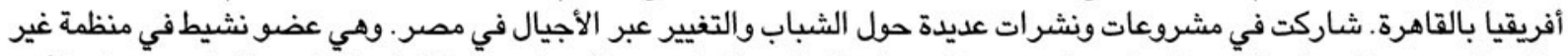

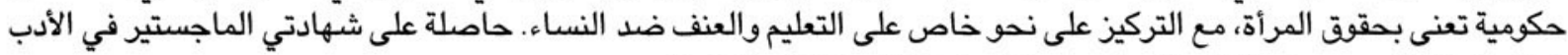
المقارن والبكالوريوس في العلوم السياسية من الجامعة الأمريكية في القاهرة.

د. سحر الطويلة باحث مشارك بمركز البحوث الاجتماعية، الجامعة الأمريكية في القاهرة. حاصلة على شهادتي الدكتوراه والماجستير

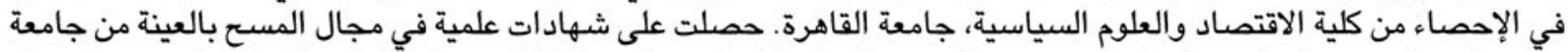

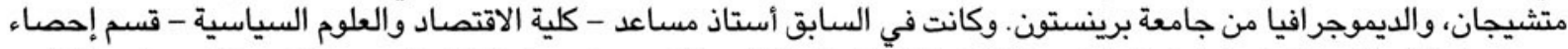
- جامعة القاهرة. وتشمل اهتماماتها البحثية قضايا التنمية والفقر والفرص المتانية المعيشية للشباب مع تركيز خاص على الفي التعليم.

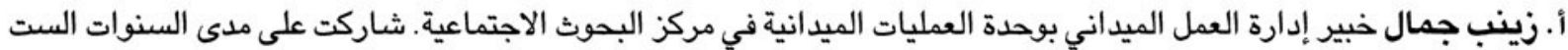

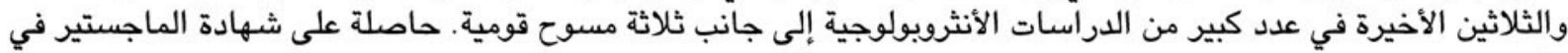

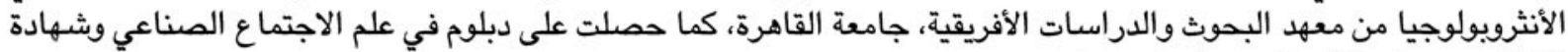

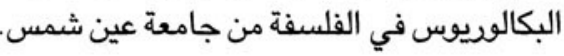

أ. ويسلي كلارك باحث مساعد بقسم بحوث السياسات في مجلس السكان بنيويورك. يعنى بالأطار المفاهيمى للبحث وتصميم ألمات ألاواته

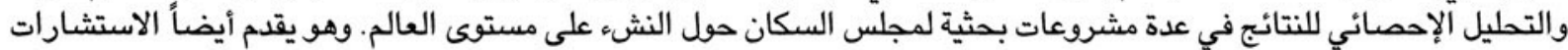

لقسم بحوث السياستات في مجلَس السكان ومنظمات أخرى حول تصميم البحوث وتقييمها.

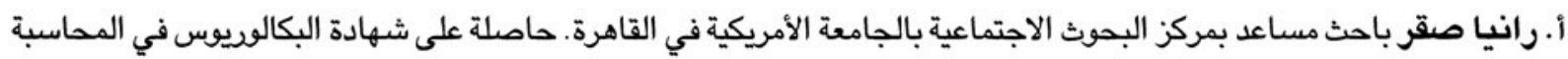

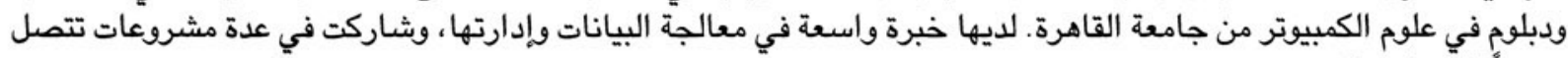

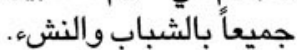


رقم الإيداع : ז^•• 11 11 
الصور الفوتوجرافية:

الأستاذ فكرى عبد الوهاب، مركز البحوث الإجتماعية بالجامعة الأمريكية بالقاهرة

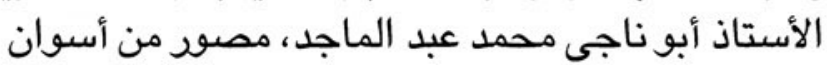

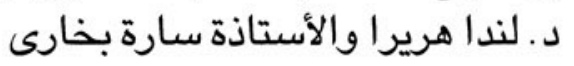

